\title{
Boston Motordom: \\ Automobiles and the Transformation of the City, 1899-1930
}

John Christopher Spelman
New Haven, Connecticut

B. A., Clark University, 1997

M. Des. S., Harvard University Graduate School of Design, 2003

A Dissertation presented to the Graduate Faculty

of the University of Virginia in Candidacy for the Degree of

Doctor of Philosophy

Department of Art and Architectural History

University of Virginia

May, 2014 
CCopyright by

John Christopher Spelman

All Rights Reserved

May 2014 


\section{TABLE OF CONTENTS}

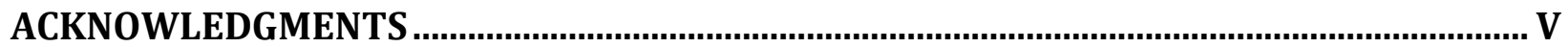

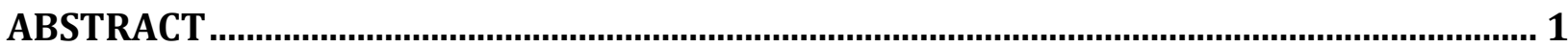

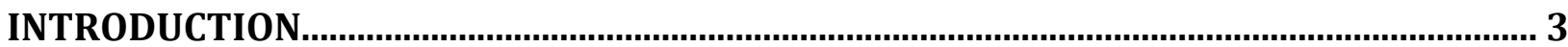

CHAPTER 1 - THE PRE-AUTOMOTIVE TRANSPORTATION LANDSCAPE...........................13

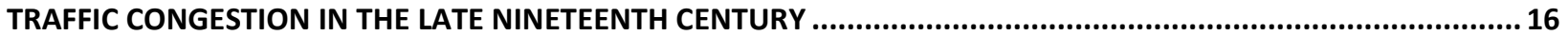

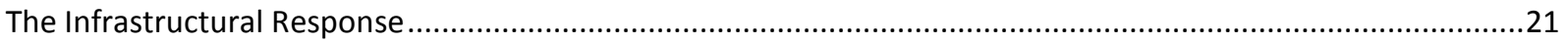

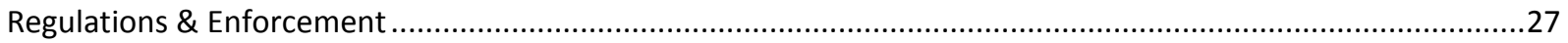

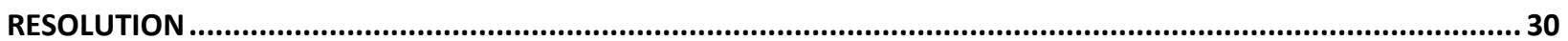

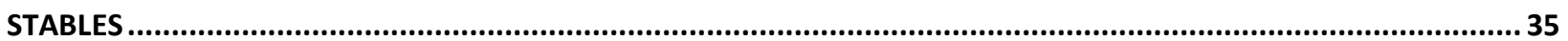

CHAPTER 2 - EARLY AUTOMOBILES: STATUS, STABLES AND BLAZES.............................51

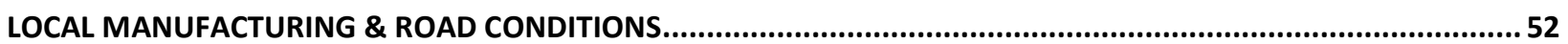

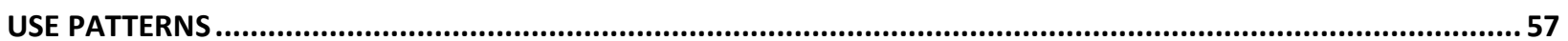

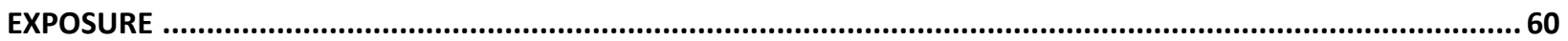

CLUBS

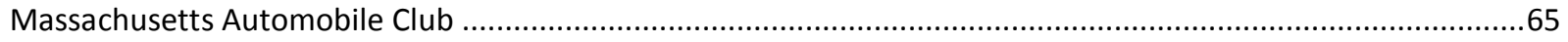

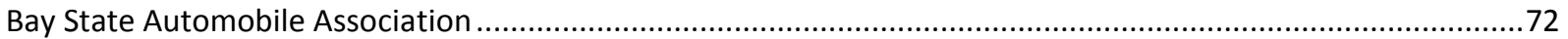

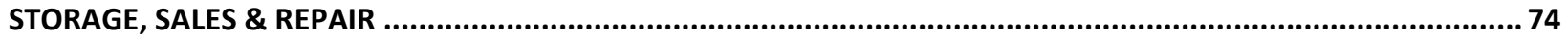

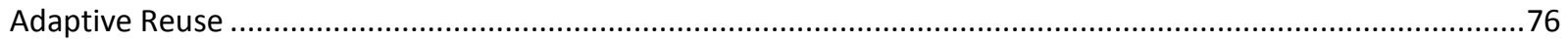

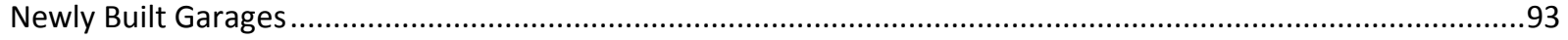

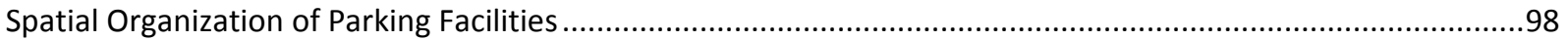

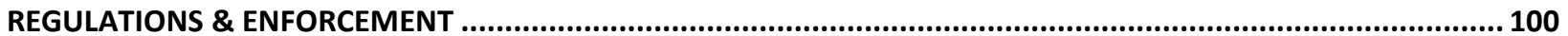

CHAPTER 3 - EARLY MASS USE OF AUTOMOBILES IN CENTRAL BOSTON..................... 107

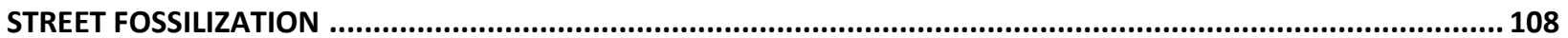

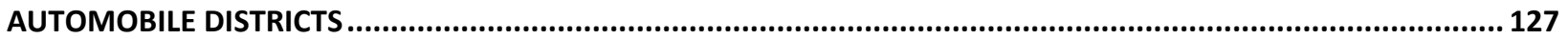

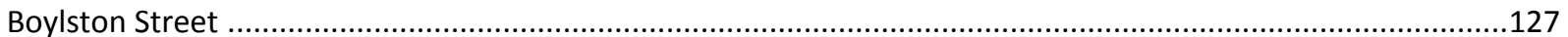

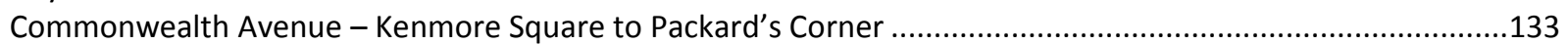

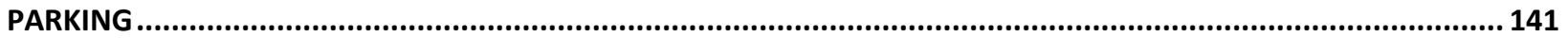

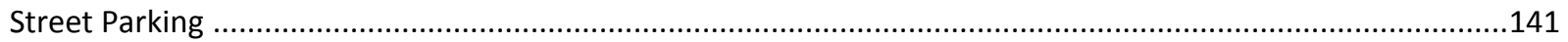

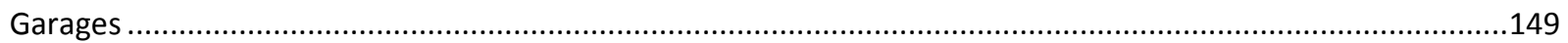




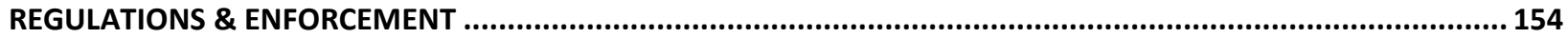

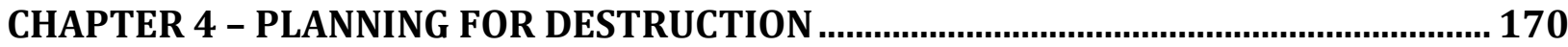

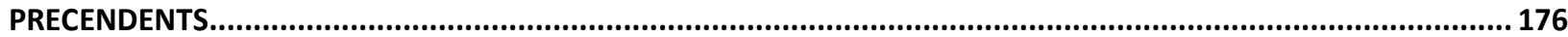

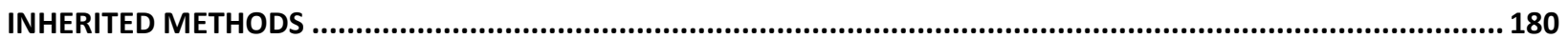

A CHANGING SCALE

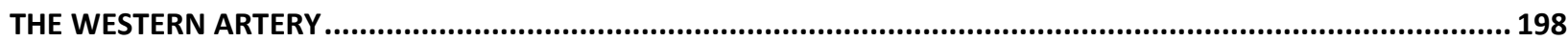

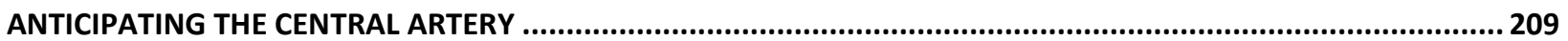

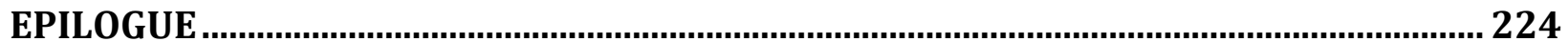

APPENDIX. TRAFFIC REGULATIONS AS THEY APPEARED IN THE 1892 REVISED

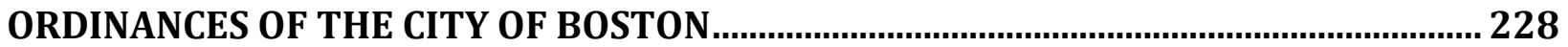

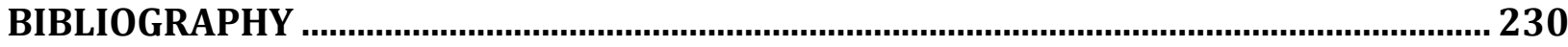




\section{ACKNOWLEDGMENTS}

I am grateful for the critical thoughts and guidance of my dissertation committee:

Daniel Bluestone (Director)

Shiqiao Li

Peter Norton

Richard Guy Wilson

As well as to:

Erik Ghenoiu

Martyn J. Bowden

Michael Gibson

John Morrison

George Gilpatrick

Joseph Lofgren

Dell Upton

Douglas Fordham

Kyle Farley

Jason Fox

Claire Dempsey

Jeff Klee

Matthew Jesse Jackson

Tom Blake

Eve Griffin

Christine Schonhart

Marta Crilly

Ann Kardos

Jeanne Gamble

Lorna Condon

Elizabeth Roscio

The orthopedic surgery team of Yale University

And especially to:

Lisa, Elizabeth and Everett 


\section{ABSTRACT}

This dissertation examines how the city of Boston accommodated automobiles in their first decades of use, from about 1899 to 1930 . The technological advances related to automobiles and their rapid rise in popularity among consumers did not immediately lead to the creation of a city for automobiles, especially in the downtown area and elsewhere in the central business district. Rather, the center city was only remade for automobilists after a protracted period of conflict. This interim period - one that saw a city built largely for pedestrians transformed into one built largely for motorists - was marked by several trends. The earliest accommodation was discrete, with automobilists adaptively reusing the existing public and private landscape. This dissertation discusses that reuse, especially the transformed customs that guided everyday use of the street and the transformation of urban stables into experimental and highly flammable garages. It offers a geography of the automobile landscape that emerged to sell, service and store motor cars, discussing the formation of Boston's two "automobile rows" and the distribution and changing designs of garages and showrooms. It presents an architectural history of important but overlooked buildings, such as a livery stable designed by Peabody \& Stearns, the Massachusetts Automobile Club (first built in 1902), and the Motor Mart (first built in 1905). This dissertation also accounts for the role of planners and other city officials as they worked to undo Boston's fossilized landscape in a series of aggressive campaigns to widen existing roads and to create new boulevards for suburban commuters, beginning around 1917. Though these campaigns consistently failed in their promises to alleviate automobile congestion, Boston's planners undertook increasingly drastic measures to chase this goal, with great repercussions for traditional urban form. 
Though Boston is offered as an arena in which to conduct a vivid reconstruction of early automobile use in a dense urban center, this project is not exclusively about a particular large city. Rather, it is about the impact of a technological paradigm shift on the built landscape and ordinary urban practices. Broadly, this dissertation provides insight into the transformative process of a now-familiar revolution, interrogating our assumptions about the development of the automobile-centric twentieth-century century city. 


\section{INTRODUCTION}

This dissertation examines the responses of the city of Boston to the arrival of motorcars from 1899 to 1930 . It focuses on built and infrastructural changes to Boston's downtown, a landscape that was among the most challenging to adapt to early automobiles due to its density and antiquated street network originally formed to accommodate pedestrians. I focus on the early period of automobile use because it was during this time that the contrast between traditional uses of the city and the needs of the new technology were in sharpest relief. Public and private attempts to accommodate the automobile were highly experimental, and these experiments were often unsuccessful.

My key argument is that the invention and popularization of the automobile did not immediately lead to the formation of an urban environment for automobiles. The process consisted of a long series of public debates and policy accommodations, re-use of the horsebased landscape and building typologies, and tense relationships between various types of private and public transportation modes, including walking. The full story of the growth of the automobile city has not been adequately told. The the evolution of automobile design and the transition of automobiles from playthings for the rich to popular conveyances are inscribed in the urban landscape we inherit from these times. This dissertation examines those traces, especially in their built manifestations.

I investigate infrastructural changes (road construction, street widenings, highway implementation), buildings and spaces designed for the maintenance and storage of automobiles (parking lots, garages, service stations), regulations governing use of the car (traffic lights, speed limits, the separation of pedestrian and vehicular traffic), oppositional practices that worked against such regulations (roadway protests), and the relationship between the changing systems 
of automobility and public transportation. In addition to discussing the form and culture of the downtown automotive landscape, my dissertation positions this changing realm against vital practices and places that were destroyed as part of the process of accommodation. In tracing the history of the car and the central city through a spectrum of creation and destruction, this dissertation uncovers forgotten practices and built forms that were characteristic of earlier periods.

Chapter 1 describes the built landscape that existed when automobiles first appeared on Boston's streets in small numbers around 1899. These earliest automobiles benefitted from Boston's dramatic and expensive decision to create the first subway system in the United States, which freed the downtown area from the excessive streetcar congestion that typified urban travel in the 1880 s and 1890s. New subway tunnels were intended to reinforce and preserve rights of way in the center city as realms for pedestrians and horse-drawn conveyances (mostly delivery wagons), a preservation that would be short lived. I also examine the regulations that governed the use of horse-drawn conveyances in the city, as well as their application, which automobiles later inherited.

Early facilities for automobile sales and storage borrowed heavily from existing urban stables. As Clay McShane and Joel Tarr observe in their influential The Horse in the City, "stables rarely make it into the histories of the built environment, although they occupied a substantial part of that environment."1 Chapter 1 addresses this gap in the scholarly literature, and presents a geography of horse use within the city. It also analyzes the design of large urban stables as horse use reached its peak in the 1890 s.

\footnotetext{
${ }^{1}$ Clay McShane and Joel Tarr, The Horse in the City: Living Machines in the Nineteenth Century (Baltimore: Johns Hopkins University Press, 2007), 125.
} 
In Chapter 2, I account for the built landscape created for the first users of motor cars, from about 1899 to 1909 . This landscape was typified by the adaptive reuse of public streets and of privately-owned buildings. The adaptive reuse of private spaces entailed the conversion of extant buildings (stables, train sheds, bicycle stores) into primitive garages out of which automobiles could be sold, repaired and stored. Early automobiles were easily stolen, open-air and not weather proofed, all of which made it imperative that these machines - many of which cost more than an ordinary suburban home - be stored indoors. The resulting absence of curbside parking and storage within existing buildings belied the impact that early automobiles would soon have upon the city.

The practice of storing and selling automobiles out of facilities originally built for other purposes also proved to be extremely precarious, since the combustion engines of this time were volatile and gasoline and oil were not safely stored. Of the known large central garages that adaptively reused extant structures before 1910, more than half experienced fires. While stables had long been considered a nuisance because of the fire hazards they posed, I show that early garages in Boston were far more dangerous neighbors.

Automobile use in this first decade was fundamentally an elite practice, exemplified by the fact that Boston's first professionally designed garage was also an aristocratic clubhouse. This was the Massachusetts Automobile Club, built in 1902 and expanded in 1904, a building that both encapsulated elite practices but also filled the demand for well-designed storage space, absent before the club's arrival. I analyze this formative building, which still stands on Boylston Street and was for a time Boston's main locus of significant automobile accommodation.

The small number of cars on the road at this time were generally used for recreation and were not yet broadly used for commuting. Cars therefore had a minimal presence in the 
downtown area, and were most actively used outside of the center city in the Back Bay and more peripheral areas. It was only outside of the city center that automobiles could be readily used as the speedy machines they were designed to be, provided a driver could find a road whose surface was in adequate condition. This early period of automobile use was also characterized by an absence of laws that were created to guide motorists. I account for those regulations that existed and approaches to their enforcement, and document the generally lawless conditions of the time.

Chapter 3 discusses the emergence of true mass automobile use, beginning around 1910 and concluding around 1930. This chapter positions the arrival of mass automobile use into what I call a fossilized urban landscape, where the long-held tension between privately owned estates and public rights of way created street networks that were difficult to modify. By the time automobile use was popularized, the streets of the downtown area and surrounding neighborhoods had long been established. Just as automobile technology had adaptively reused extant private buildings for storage in the elite period of use, so too did early users attempt to adaptively reuse existing public rights of way.

The reuse of private estates was far less fraught than the reuse of public streets. While immediate neighbors sometimes objected to the creation of garages because of the threat of fire or concern over the effect that proximate storage facilities might have on property values, Bostonians generally supported their existence. Repurposing streets, however, was contentious, especially those in the downtown area, which were formed around the needs of pedestrians and delivery services and which streetcars had struggled to use. These roads were unable to simultaneously support traditional uses of the street and the widespread adoption of motor cars, especially as cars came to be used for commuting. Chapter 3 discusses the rise of street parking as a form of public storage and a means to assert autoists' perceived right to the road, as well as 
how Boston sought to change the behaviors of pedestrians and motor cars as a means to impose order on traffic.

Chapter 3 continues to discuss the development of the private landscape that supported automobile use. It offers a geography of garage locations, which generally operated outside of the downtown area until the late 1920s. It also presents the changing spatial and architectural strategies used by automobile sellers who began to reorder and decentralize the commercial city for the ease of motor car drivers.

By the early 1920s, motordom was no longer satisfied with the adaptive reuse of public streets and sought to dramatically remake the city. Chapter 4 explains how the city undertook drastic and destructive measures to redesign the city's central streets before it could legitimately claim to understand the traffic problems it was attempting to address. Before Bostonians had come to agree on how automobiles should pass through streets, whether or not cars should be allowed to park at downtown curbs and where to install the city's first traffic light, many had already endorsed plans to significantly widen existing streets and to cut new ones through extant fabric. While the city's form had been previously been defined by its fossilized streets, by 1920 many in Boston were willing to remake the center in service to commuting automobilists, and by 1925 major street widenings and extensions were implemented on Charles Street, Cambridge Street (along with Court Street) and Stuart Street (along with Kneeland Street).

Decisions to create new boulevards were usually guided by the desire to ease congestion and to stimulate private development. New road construction was often encouraged by real estate interests who hoped to profit by anticipated building booms. Boosters earnestly promoted the widening of each of these roads, but the rebuilding that followed rarely fulfilled their 
expectations. Changes were made without much concern for the multitudes who would be displaced along the affected routes, who unsuccessfully protested their creation.

Though the road building campaigns of the 1920s never eased congestion, city officials remained preoccupied with them and continued to pursue increasingly grandiose plans. The Central Artery of the 1950s was born of this context, an early version appearing as a surfacelevel road in a 1923 plan. Though it would take thirty years to build, this monumental superhighway is a testament to the influence held by Boston's planning board, which unwaveringly advocated for the plan (without supplying an alternative) until its adoption was secured.

Many of the changes I explore are to everyday, ordinary practices and are not well documented by official city records. To account for these changes, especially in the years before Boston's Planning Board began its automobile-oriented interventions around 1917, I rely primarily on photographic evidence and newspaper accounts as essential source materials. Additional motion picture evidence is found in Edison's 1906 film, Seeing Boston, which fortuitously captured street life in downtown Boston at a key moment after the construction of subway tunnels and before the arrival of automobiles in significant numbers. Also important are numerous editions of fire insurance atlases produced by the Sanborn Map Company, trade publications such as Horseless Age, court documents, city directories, state and municipal vehicular laws, and popular literature.

This dissertation is a multi-disciplinary effort and draws upon the work of scholars in numerous fields, especially architectural history, geography, urban history and transportation history. While I will not recount all of those who have informed this project, several have outsized influence. These include J. B. Jackson, the intellectual figure behind early cultural 
landscape studies, whose writings in the 1960s and 1970s described with crispness and vitality the condition of everyday American spaces while criticizing architectural discourses for being overly concerned with paper utopias. ${ }^{2}$ Also influential was include contemporary scholarship that addresses ordinary landscapes within more developed theoretical constructs, such as Margaret Crawford's Everyday Urbanism, ${ }^{3}$ Paul Groth and Todd Bessi's Understanding Ordinary Landscapes $^{4}$ and Chris Wilson and Paul Groth's Everyday America: Cultural Landscape Studies after J. B. Jackson. ${ }^{5}$ I am particularly informed by Dell Upton's approach to architectural history, one that moves beyond a preoccupation with "what might be called the 'insider' aspects of architecture ... [that] is most interested in markers' intentions" to a more comprehensive understanding of the built environment and how people lived in it. ${ }^{6}$ I am further informed by Daniel Bluestone's "The Pushcart Evil," which uses debates over the regulation of traditional street hucksters in New York to illustrate the conflict between those who sought to establish a “modern ideal of the street as the exclusive province of smoothly circulating 'traffic' ... [and] earlier social uses of the street for political activity, gregarious socializing, and popular amusements."

Among the many books written on Boston, I am indebted to Nancy Seasholes' Gaining Ground $^{8}$ and to Lawrence W. Kennedy's Planning the City upon a Hill. ${ }^{9}$ Seasholes account of

\footnotetext{
${ }^{2}$ John Brinkerhoff Jackson, Discovering the Vernacular Landscape (New Haven: Yale University Press, 1984); John Brinkerhoff Jackson, A Sense of Place, a Sense of Time (New Haven: Yale University Press, 1994); John Brinkerhoff Jackson with Helen Lefkowitz Horowitz, ed., Landscape in Sight: Looking at America (New Haven: Yale University Press, 1997).

${ }^{3}$ Margaret Crawford, ed., Everyday Urbanism (New York: Monticelli Press, 1999).

${ }^{4}$ Paul Groth and Todd Bessi, eds., Understanding Ordinary Landscapes (New Haven: Yale University Press, 1997).

${ }^{5}$ Chris Wilson and Paul Groth, eds., Everyday America: Cultural Landscape Studies after J.B. Jackson (Berkeley: University of California Press, 2003).

${ }^{6}$ Dell Upton, Another City: Urban Life and Urban Spaces in the New American Republic (New Haven: Yale University Press, 2008), 10.

${ }^{7}$ Daniel Bluestone, "The Pushcart Evil," in Landscapes of Modernity: New York City, 1900-1940, eds. David Ward and Olivier Zunz (Baltimore: Johns Hopkins University Press, 1997), 287.

${ }^{8}$ Nancy S. Seasholes, Gaining Ground: A History of Landmaking in Boston (Cambridge, MA: MIT Press, 2003).
} 
Boston's landmaking practices includes useful framings of nineteenth-century street creation, while Kennedy's work provides a critical history of Boston's planning mechanisms and their execution. Charles Cheape's comparative study of urban transit, Moving the Masses, contextualizes Boston's nineteenth-century transportation landscape and the debates and policy decisions that led to the creation of the subway system. ${ }^{10}$

My work also replies upon the observations of scholars who addressed the formation of downtown spaces. These include Martyn J. Bowden, the avant-garde cultural geographer whose writings on the reconstruction of San Francisco following the earthquake and fire of 1906 directly informed this dissertation's conception of street fossilization, among other themes. ${ }^{11}$ Robert M. Fogelson's Downtown: Its Rise and Fall draws upon the examples of many America cities in its history of the shaping of downtown, among the first books to meaningfully address this topic. ${ }^{12}$ Douglas Rae's extraordinary reconstruction of New Haven at the height of urbanity and its subsequent decline in City: Urbanism and Its End provided both useful thematic framing as well as a model for interdisciplinary urban history. ${ }^{13}$

Several historians writing on traffic and transportation were also influential. Peter Norton's Fighting Traffic: The Dawn of the Motor Age in the American City presents an account of the social reconstruction of public rights of way in American cities as they became the domain of automobilists in the 1920s. His work moves beyond existing explanations for the rise of the

\footnotetext{
${ }^{9}$ Lawrence W. Kennedy, Planning the City upon a Hill: Boston Since 1630 (Amherst: University of Massachusetts Press, 1992).

${ }^{10}$ Charles W. Cheape, Moving the Masses: Urban Public Transit in New York, Boston, and Philadelphia 1880-1912 (Cambridge, MA: Harvard University Press, 1980).

${ }^{11}$ Martyn J. Bowden, "The Dynamics of City Growth: An Historical Geography of the San Francisco Central District. 1850-1931" (PhD diss, University of California, Berkeley, 1967); Martyn J. Bowden "Reconstruction Following Catastrophe: The Laissez-Faire Rebuilding of Downtown San Francisco after the Earthquake and Fire of 1906," Proceedings of the Association of American Geographers 2 (1970): 22-26; Eugene Hass, Robert W. Kates and Martyn J. Bowden (eds.), Reconstruction Following Disaster (Cambridge, MA: MIT Press, 1977); Martyn J. Bowden, "Downtown Through Time: Delimination, Expansion, and Internal Growth," Economic Geography 47, no. 2 (April 1971): 121-135.

${ }^{12}$ Robert M. Fogelson, Downtown: Its Rise and Fall, 1880-1950 (New Haven: Yale University Press, 2001).

${ }^{13}$ Douglas W. Rae, City: Urbanism and Its End (New Haven: Yale University Press, 2003).
} 
automotive city, and importantly discusses the criminalization of traditional pedestrian practices during this formative period. ${ }^{14}$ Clay McShane's Down the Asphalt Path provided a useful framing of automobile trends in American cities, especially in their first decades of use. ${ }^{15}$ McShane also contributed another important text, The Horse and the City, co-authored with Joel Tarr. This title is the first monograph to focus on patterns of urban horse use in the United States, and provides essential information on how the pre-automotive transportation landscape functioned. Finally, recent years have seen numerous titles (many of them deeply flawed) published on the subject of the parking lots and garages, an overlooked topic that is entering scholarly consciousness. Of these works, I would like to cite John A. Jakle and Keith A. Sculle's Lots of Parking: Land Use in a Car Culture. ${ }^{16}$ While this title lacks a critical argument, it has prodded urban historians to consider an unnoticed but ubiquitous part of modern cities.

The scholarship on vernacular landscape still has broad lacunae, oddly often in the same kind of places that early cultural landscape scholars pointed out: aspects too familiar to us for us to notice as objects of study. Many have recognized the oddness of cars parked on streets that were laid out before cars existed, and the use of a circulation space for the massive-scale storage of private conveyances; moreover, we all recognize that a complex tissue of customary practices and legal enforcement makes this phenomenon sustainable. However, we have almost no history of how all this came into existence, of the possibilities and decisions that came to shape the assumptions that still give form to the urban landscape. This dissertation is a contribution to filling this gap in our understanding so that we might not take for granted the results of what

\footnotetext{
${ }^{14}$ Peter D. Norton, Fighting Traffic: The Dawn of the Motor Age in the American City (Cambridge, MA: MIT Press, 2008).

${ }^{15}$ Clay McShane, Down the Asphalt Path: The Automobile and the American City (New York: Columbia University Press, 1994).

${ }^{16}$ John Jakle and Keith A. Sculle, Lots of Parking: Land Use in a Car Culture (Charlottesville: University of Virginia Press, 2005).
} 
were in fact highly politicized and contingent outcomes of debates the stakes of which have elapsed from our memory or understanding. 


\section{CHAPTER 1 - The Pre-Automotive Transportation Landscape}

Boston's transportation landscape in the 1880s and 1890s relied on thousands of horses, fed and housed in large stables that were spread liberally across the city. These horses pulled a ceaseless stream of streetcars along numerous suburban lines into a compact downtown area. The city's many streetcars contended with municipal wagons, thousands of teamsters and hundreds of thousands of pedestrians that traveled to the city center every day. This mixture created a crisis of traffic congestion, brought on by the city's booming population in the late nineteenth century, which spurred several innovations, including the electrification of most of Boston's streetcar lines by 1894 and the inauguration of its first subway in 1897. It was into this landscape - one in which Boston's officials had responded to untenable congestion with mitigating infrastructural developments - that the automobile was first introduced in quantity in the early 1910s.

Understanding how automobiles shaped central Boston requires an understanding of the cultural and built landscapes that existed before their arrival. When automobiles began to be used on Boston's streets in the final years of the nineteenth century, they were both peculiar and extremely rare. These vehicles travelled about an existing landscape following customs that balanced the needs of pedestrians, streetcars and horse-drawn delivery teams in public ways, and where laws had been developed to guide horse use. This was especially true in the most congested areas of the city, where crowded roads made it impossible for automobiles to travel more than a few miles per hour. The first automobiles, as I will show in Chapter 2, were discrete interlopers. Few in number, they drove about at horse-like speeds, did not noticeably contribute to traffic congestion, were sold out of unassuming buildings and were most often stored in stables. In its earliest years, the new automobile technology, which would later so drastically reshape the city, was simply shoe-horned into existing buildings and infrastructure. 
By the time automobiles first appeared on its streets around 1899, Boston, like other large American cities, had intensely centralized. As in other flat-water ports like New Haven, New York, Cleveland, Baltimore and Philadelphia, Boston grew and prospered in part because of the modes of transportation available to industrialized cities. The products of the nineteenth-century industrial landscape could be inexpensively moved only by rail and water, which necessarily concentrated urban activity proximate to railroad stations and wharves. Over time, the residents of these cities were dislocated from downtown areas and central business districts. This dislocation did not push urban dwellers very far, since for most the only practical means to reach the outermost districts of cities was to travel by slow-moving streetcars. Only a select few could afford private carriages.

In Boston, the central city inherited a street network that was originally developed to accommodate pedestrians, with later streets built wider with the turning radius of horse-drawn vehicles in mind. ${ }^{1}$ The original city occupied a small, amoeba-shaped peninsula with three large, steep hills. Boston's irregular coastline and uneven topography contributed to the narrow, angular character of its early street network. As I discuss in Chapter 3, this early network was slowly modified, most often as new acreage was added to the city as Boston undertook landfill projects that incrementally expanded the city into the marshlands, bay, and river that surrounded the original landmass. Such projects included numerous wharf expansions, the filling of the Mill Pond, and the creation of the Beacon Hill Flat, the South End and Back Bay, as well as numerous smaller additions that were made as the early town's rocky banks, marshes and muddy sinks were reclaimed. Streets on the newly added portions of the city were created to connect to existing roads, but also to respond to new demands - related not only to transportation, but also

\footnotetext{
${ }^{1}$ Douglas W. Rae, City: Urbanism and Its End (New Haven: Yale University Press, 2003), 1-11; Clay McShane and Joel Tarr, The Horse in the City: Living Machines in the Nineteenth Century (Baltimore: Johns Hopkins University Press, 2007), 34.
} 
to other concerns, such as for public health. To generalize, the later a street was created, the wider and straighter it was likely to be. As John Reps speculated, Boston's early reclamations of minor topographical variations greatly influenced the formation of the center city's irregular street network, which assumed a shape that continues to plague contemporary automobile drivers. $^{2}$

Like the existing urban fabric that would later be reformed in response to automobile use, the existing fabric of central Boston was reshaped to accommodate the city's expanding reliance on horse power in the nineteenth century. This was manifested in the creation of private buildings, in particular the city's many livery and boarding stables, and in new forms of infrastructure, including the gradual modification of public rights of way.

The most dramatic of these changes occurred in moments of perceived crisis. For Boston, such a crisis emerged in the 1880 s and 1890 s as the city grappled with what was regarded as severe traffic congestion. Hundreds of thousands of people travelled to central destinations to work or otherwise participate in urban life on roadways whose basic shape had been determined during an era when nearly everyone walked and the city was far less populous. In 1790, Boston's population was 18,320 , while by 1890 it had reached $448,477 .{ }^{3}$

The great congestion of the 1890s stemmed from several sources, central among them the immense number of streetcars that travelled on surface roads to cause a daily logjam on Washington Street, Tremont Street and other critical roads that simultaneously accommodated an enormous number of people on foot as well as several thousand teamsters. This crisis spurred

\footnotetext{
2 John W. Reps, The Making of Urban America - A History of City Planning in the United States (Princeton: Princeton University Press, 1965), 140-146.

${ }^{3}$ Department of Commerce and Labor, Bureau of the Census, Head of Families at the First Census of the United States Taken in the Year 1790 Massachusetts (Washington DC: Government Printing Office, 1908), 5; Department of the Interior, Census Office, Report on the Population of the United States at the Eleventh Census: 1890, Part I (Washington DC: Government Printing Office, 1895), lxvii.
} 
Boston to build the first subway system in the United States, as well as an elevated railway, to combat the perceived problem. By the standards of the time, these infrastructural efforts were successful and cleared the roads of central Boston for their "proper use as public ways for teams and foot passengers." The elevation of pedestrians (and delivery vehicles) to their "proper" place would be short-lived, as the space created by the removal of the slow-moving streetcars would soon be assumed by automobiles, which carried far fewer people and which were able to travel at much greater speeds.

\section{TRAFFIC CONGESTION IN THE LATE NINETEENTH CENTURY}

Central Boston contended with significant traffic issues long before the arrival of automobiles. By the 1880s, downtown Boston had begun to reach a state of maturity characterized by large department stores, hotels, theaters and tall office buildings within a very compact district containing less than one percent of the city's land area. ${ }^{5}$ As in other American cities, downtown Boston was the center of trade, communications, business, civic life and cultural activity, and travel to it was an essential daily task for an incredible volume of people.

While the population of the city ballooned enormously $(177,840$ in $1860 ; 250,526$ in $1870 ; 362,839$ in $1880 ; 560,892$ in $1900^{6}$ ), the number of people who lived within Boston's central business district precipitously declined throughout the nineteenth century. By the 1890 s, downtown Boston was virtually free of residential buildings. Neighborhoods such as the Back Bay, Beacon Hill, North End and South End were walkable residential enclaves close to the center, but much of the trend of dislocation was fuelled by the creation and development of streetcar suburbs beginning around 1850, with hundreds of thousands moving to towns like

\footnotetext{
${ }^{4}$ Argument of Mayor Matthews before the Committee on Transit of the Massachusetts Legislature, April 4, 1894 (Boston: Rockwell and Church, City Printers, 1894), 11.

${ }^{5}$ Robert M. Fogelson, Downtown: Its Rise and Fall, 1880-1950 (New Haven: Yale University Press, 2001 ), 14.

${ }^{6}$ Boston Redevelopment Authority, History of Boston's Economy: Growth and Transition, Report 529 (November, 1999), 26.
} 
Brookline, Roxbury, West Roxbury and Dorchester. As the streetcar lines became longer and the cars operating on them moved faster and more efficiently, the effective suburban reaches of the metropolitan area extended ten miles out - as far as Quincy and Lynn. ${ }^{7}$

The separation of residential and commercial life combined with dramatic population increases to create intensive daily traffic patterns typified by congestion as hundreds of thousands of people sought to travel to and within the downtown area each day. In 1891, the city's various steam railroads carried an estimated 51 million passengers into and out of the terminals that lay at the edges of downtown Boston. In the same year, the street railway carried 136 million passengers throughout the metropolitan area. Metropolitan Boston's approximate population in this year was 850,000 , and an estimated 461,000 people commuted to the center each day by streetcar, with many more traveling by foot. ${ }^{8}$

Central Boston's famously angular streets remained quite narrow. In the portion of downtown Boston that lay upon the original peninsula, the average width of a right-of-way at the close of the nineteenth century was approximately 37.5 feet. By comparison, most rights-of-way in downtown San Francisco, a gridded city, were 68 feet, 9 inches wide. ${ }^{9}$

The narrow and irregular streets of Boston were required to accommodate several types of traffic. Though sidewalks were widespread by the 1850 s, custom (and volume) compelled droves of pedestrians into busy streets where they walked amid one of the most extensive and active horse-drawn streetcar networks in the nation. Also competing for space in the streets were thousands of teamsters driving large, heavy wagons often pulled by multiple horses. These

\footnotetext{
${ }^{7}$ Sam Bass Warner, Streetcar Suburbs: The Process of Growth in Boston, 1870-1900 (Cambridge, MA: Harvard University Press, 1978), 153-156.

${ }^{8}$ Rapid Transit Commission, Report of the Rapid Transit Commission to the Massachusetts Legislature, April 5, 1892 (Boston: City Printing Office, 1892), 7.

${ }^{9}$ Some of San Francisco's downtown streets were narrower (Sacramento Street was fifty-nine feet wide) and others broader (Kearny Street was seventy-five feet wide and the boulevard of Market Street was 120 feet wide).
} 
teamsters moved freight from and to the various wharves and railroad terminals, and delivered goods to the hotels, department stores, restaurants, stables, markets, construction sites and other enterprises that depended upon frequent delivery services for success. ${ }^{10}$ Further complicating this traffic landscape were cabs and omnibuses that, along with privately-owned carriages, provided point-to-point transportation options to those who could afford it. Towards the end of the century, a nation-wide bicycling craze added many 'wheelmen' to the fray.

The downtown area was the focal point of the city's extensive streetcar network [Figure 1-1]. Boston's streetcars moved with relative ease outside of the center. But as the many cars traveling on the various lines merged onto fewer and fewer tracks they helped to form a daily blockade in the downtown area [Figure 1-2]. Each streetcar competed for space on narrow downtown roads with other cars, with pedestrians, with bicyclists, with private carriages and with horse-drawn delivery carts and wagons. There were no systematically adopted traffic signals or other mechanisms to establish order. The few regulations that existed were crude and rarely enforced. Steam railroad tracks ran along the surface of Atlantic Avenue and Causeway Street, which freight trains regularly used, creating lengthy, slow-moving barricades. ${ }^{11}$ Targeted road segments were occasionally widened, though this practice failed to speed travel.

Many counterintuitive practices exacerbated traffic. In the years before they were consolidated into the West End Street Railway, seven privately-owned streetcar companies operated on the same publically owned tracks. These companies would often adjust and readjust their schedules so that their cars would arrive just ahead of a competitor's, thus getting more traffic and more revenue. The second-place car would then slow to a crawl hoping that

\footnotetext{
${ }^{10}$ While other animals such as mules were occasionally used to power vehicles, nearly all beasts of burden and carriage were horses.

${ }^{11}$ Rapid Transit Commission, Report to Massachusetts Legislature, 27-28.
} 
passengers from the car behind it would jump off and catch a ride with the leading car. ${ }^{12}$ Teamsters regularly stopped in the middle of the street to unload goods, often at peak travel times. Grocers in the market district regularly backed carts and wagons over the sidewalks. ${ }^{13}$ Carriages and teams sometimes traveled in opposite directions down too-narrow streets that shared space with pedestrians who walked in the roadway, each blocking the other from passage until one yielded. This was time-consuming, as such vehicles moved forward with much greater efficiency and accuracy than they did moving backwards. ${ }^{14}$ The Boston Globe and other newspapers headquartered on Washington Street would often announce the results of boxing matches and other sporting events, and large crowds of enthusiasts would assemble together to share in the event [Figure 1-3].

By the 1890s, Boston's congestion was widely considered to be a crisis by residents and policy makers alike. Because most residents of late nineteenth-century Boston were compelled to travel downtown on a regular basis, nearly everyone was affected by the problem. The residents of the city "complained about traffic congestion endlessly and in flamboyant language." 15 In the 1880 s and 1890 s, the city's major newspapers regularly reported on the problem of congestion and frequently editorialized on the topic in dramatic fashion. Though they catered to different readerships, the editorials written by the Globe, the Post, the Transcript and the Herald all agreed that downtown traffic was one of the major challenges of life in Boston. ${ }^{16}$ In 1894, Mayor Nathan Matthews argued before the Massachusetts State Legislature that traffic congestion, in particular conditions caused by streetcars, was a fundamental urban problem and secured

\footnotetext{
${ }^{12}$ Charles W. Cheape, Moving the Masses: Urban Public Transit in New York, Boston, and Philadelphia 1880-1912 (Cambridge, MA: Harvard University Press, 1980), 112.

13 "Stable Keepers - Legislature Devotes a Day to Talking of Them," Boston Globe, March 19, 1897, 6.

14 "Guardians of Boston's Tangled Traffic," Boston Globe, April 4, 1897, 34.

${ }^{15}$ Asha Weinstein, "Congestion as a Cultural Construct: The 'Congestion Evil' in Boston in the 1890s and 1920s," The Journal of Transport History 27, no. 2 (September 2006): 97.

${ }^{16}$ Weinstein characterizes the Globe and the Post as populist, the Transcript as favoring Brahmin positions and the Herald reflecting the interests of wealthier businessmen.
} 
approval for the city's subway and elevated streetcar system. Aside from the frustrations felt each day by his constituency, Mayor Matthews worried that the problem was growing so severe that it would stifle Boston's economic competitiveness, motivating businesses to migrate elsewhere. ${ }^{17}$ Business owners worried that the difficulty of navigating through the congested area compromised their profits. Testifying before the Joint Special Committee on Transit in 1894, one such businessman asserted:

It is a matter of common knowledge . . certainly within my knowledge, that there are today a great many ladies who will not shop in the congested section; they absolutely refuse to go down in carriages, to be driven about in carriages, and the sidewalks are so crowded that they prefer not to shop in that section, and the number of people who feel that way is growing rapidly day by day. ${ }^{18}$

Concerns about congestion both threatened the success and viability of the downtown area, and also the prospects of further suburban development. Poor traffic conditions made travel times both unpredictable and slow, making it undesirable to live too far from the center, and reducing the incentives for the privately-owned West End Street Railway to build in remote areas. The West End was also concerned about how congestion would affect its profitability, and agreed with Mayor Matthews that an infrastructural response was warranted, though it ultimately advocated only for a network of elevated railways and against the subway. ${ }^{19}$

In the 1890s, the responses to congestion were numerous. These included the development of local ordinances to regulate downtown traffic, the development of a police unit to enforce these regulations, the formulation of civic committees to propose solutions, the study of street widenings, the continuing electrification of streetcar lines and, most far-reaching, the

\footnotetext{
${ }^{17}$ Weinstein, "Congestion as a Cultural Construct," 97.

${ }^{18}$ Joint Special Committee on Transit quoted in Weinstein, "Congestion as a Cultural Construct," 108.

${ }^{19}$ The West End's position on the implementation of rapid transit infrastructure was ever-changing. In the 1880s, when there was no political will, the West End devised grandiose plans for a subway and elevated system. When Mayor Mathews and the Rapid Transit Commission later developed a scheme that had legitimate political and popular support, the West End dissented for unclear reasons even though its transit monopoly was the only logical leasee for the publically owned infrastructure. Cheape, Moving the Masses, 127, 140.
} 
development of the first subway system in the United States. It was only with the implementation of this groundbreaking subway in 1897 that Boston succeeded in significantly mitigating congestion.

\section{The Infrastructural Response}

Local authorities lacked the power and finances to undertake large-scale public works projects throughout most of the nineteenth century. ${ }^{20}$ Most cities, Boston included, left it to private industry to operate utilities and transportation systems. The inefficiencies of this approach to governance were notable. For example,

... no central authority planned new sections of the city or supervised the renewal of older areas. New streets were laid out as private developers saw fit, and streetcar lines extended haphazardly. The city laid water mains, sewers, and paved streets, but trolley, gas, electric, and telephone services were provided by a multiplicity of private firms. It was not uncommon for the municipality to lay water mains and pave a roadway only to have a gas or street railway company tear up everything to install pipes or lay tracks. ${ }^{21}$

Municipal ownership of some public services, though unusual, was not unprecedented in Boston. The city developed land-filled flatlands, built Quincy Market and operated three waterworks as well as a ferry service in East Boston. The city undertook these projects when "private capital would not or could not ... and only the flatlands development and Quincy Market brought a profit." 22

These precedents were emblematic of progressive attitudes that some Bostonians embraced, including many in the (usually defeated) nineteenth-century Democratic party. In 1890, democrat Nathan Mathews was elected mayor, campaigning in part on the problem of

\footnotetext{
${ }^{20}$ Lawrence W. Kennedy, Planning the City upon a Hill: Boston Since 1630 (Amherst: University of Massachusetts Press, 1992); Peter Hall, Cities of Tomorrow: An Intellectual History of Urban Planning and Design in the Twentieth Century (Oxford: Blackwell, 1994); Warner, Streetcar Suburbs.

${ }^{21}$ Robert A. Silverman, "Nathan Matthews: Politics of Reform in Boston, 1890-1910," The New England Quarterly 50, no. 4 (December 1977): 635.

${ }^{22}$ Ibid.
} 
congestion. His administration created new opportunities for publically owned enterprises. In his inaugural address, Mayor Matthews "suggested a new perspective for Boston. The city . . . was now a 'metropolis' with new and complicated functions. Certain public functions, entrusted to private enterprise, must be assumed by the municipal government. ${ }^{, 23}$ He then proposed to create a commission to analyze public transit conditions and to recommend a coordinated solution. ${ }^{24}$

Though Bostonians had complained about congestion in prior decades, by 1890 the problem had grown so acute that numerous efforts where undertaken to control the problem. Prior decades saw much less activity. The West End and other companies, for example, had experimented with streetcar design as they sought to make the cars larger, lighter and capable of carrying more passengers per square foot, but these experiments produced only nominal improvements, which were more than offset by the city's population increases. In 1871, an estimated 34 million streetcar riders were carried within ten miles of Boston. In 1881, these riders increased in number to 68 million. By 1891, the numbers had doubled again to 136 million. ${ }^{25}$ The first comprehensive effort to speed traffic occurred when the West End began to electrify its streetcar network. By eliminating horses from the system, the West End introduced greater reliability and speed while reducing the costs associated with equine care. By 1888, a third of the system had been electrified; by 1892, two thirds were; and, by 1894, over ninety percent. Partially because it was thought to be profitable and partially because it was the

\footnotetext{
23 Ibid.

${ }^{24}$ Mayor Matthews was aided in his efforts to undertake large publically owned projects by virtue of his reputation for being financially stringent, business-minded and unusually honest. Graft had been so commonplace in the 1880s that another Mayor would likely have stoked Bostonians' concerns that the building of the subway would result in lucrative contracts awarded to builders who offered political support to their candidacy. Mayor Matthews, by contrast, was widely viewed as uncorrupted. He also benefited from his work as a respected Democratic lawyer with "an aura of Yankee respectability." Thus, he carried the Irish vote as well as the vote of the Back Bay. Cheape, Moving the Masses, 128.

${ }^{25}$ Rapid Transit Commission, Report to Massachusetts Legislature, 7.
} 
speediest method of collecting fares, free transfers were implemented in 1896, allowing riders to go anywhere on the system for a nickel. ${ }^{26}$

While two-thirds of the system's electrification had been completed by 1892, traffic congestion downtown remained a problem. In order to keep up with ridership demands in the early 1890s, the West End ran as many as 332 cars per hour on Tremont Street, the slightly speedier of the two primary north-south routes in the downtown area. These cars made an average of thirteen stops between Eliot Street and Causeway (seven of them to receive or release passengers, six for other reasons). The great volume of stopping and starting streetcars, combined with other traffic, ensured that speeds were reduced to about one mile per hour, sometimes less. On Washington Street, the other thoroughfare, conditions were worse. Outside of the center, streetcars moved at a much more usable rate of about four miles per hour. ${ }^{27}$

The Rapid Transit Commission was charged in 1891 with the study of this issue and engaged in extensive inquiry into potential solutions. Fifty-one public hearings were given by the commission, and two commission members were dispatched to London, Paris and Berlin, among other cities, to observe their rapid transit schemes. Following their year-long investigation, the commission issued a report that outlined traffic patterns in Boston and provided a comprehensive set of prospective solutions, not all of which were adopted. Among them were suggested improvements to the paths of the steam railways, the modernization of bridges, select street widenings, cutting new streets through the Boston Common and the creation of a tunnel and elevated tracks to remove streetcars from the surface.

This report defined the boundaries of what was termed the "congested district" [Figure 1-4], where the worst traffic prevailed. The perimeter of this area measured just three miles, with

\footnotetext{
${ }^{26}$ Kennedy, Planning the City upon a Hill, 101; First Annual Report of the West End Street Railway Company (Boston: R.H. Blodgett, 1888), 1-12.

${ }^{27}$ Argument of Mayor Matthews, 9.
} 
a length of about one mile and a width of seven hundred feet. The northern and southern extents of this district were wider, while its center contracted around Washington and Tremont Streets, the major downtown commercialized thoroughfares. The commission considered this small area to be the heart of the city that pumped "great arterial streams of humanity . . from the extremities of the city and its suburbs." 28

The 1895 Sanborn fire insurance maps that depict this area show a high volume of industrial, recreational, communicative, municipal and commercial activity. Major department stores, such as Jordan Marsh and R. H. White \& Company, congregated near the intersection of Washington and Temple Streets. Nearby were large-scale suppliers of dry goods (Shepard, Norwell \& Company), clothiers, tailors, music shops, furniture sellers and makers, and photography studios. The congested district contained city hall, the central post office, court houses, police stations, fire stations and the federal customs house. All of the city's newspapers were headquartered there, with presses on-site. There were hundreds of office buildings, various manufacturing enterprises (blacksmiths, soda makers, and a rum distillery), many banks and insurance companies, and a centralized marketing district near Quincy Market and Faneuil Hall. There were several museums, a dozen theaters, an orchestral hall, numerous billiard parlors and bowling allies, restaurants and taverns. While most residential life had left downtown Boston, there were two notable exceptions: multiple hotels and a tenement district populated by Chinese immigrants. Most buildings in the congested district were at least five-stories tall, with larger buildings reaching eight stories. Given the concern over fire after the blaze of 1872, there were

\footnotetext{
${ }^{28}$ Ibid, 10.
} 
very few stables, these concentrated primarily in the Bulfinch Triangle between Haymarket Square (where the city's hay scales had long been located) and North Station. ${ }^{29}$

As Mayor Mathews said in his 1894 argument in favor of the construction of a subway system,

... the facts of the matter simply are that, through no fault of the street-railway company, but in spite of the intelligence displayed by its directors and officers in the management of their cars, the limit of capacity of that system [in the congested area] has long since been reached and passed; that the streets of Boston are no longer highways for public travel, upon which you and I and the rest of the people of the Commonwealth can walk and drive and go in any way we please in freedom and in safety; that they have been diverted from their original and only proper use as public ways into something little better than railway locations; and that, at certain hours of the day, they are simply yards for the storage of cars. ${ }^{30}$

Stating that the streets should be restored "to their proper use as highways for teams and foot passengers," Mayor Mathews and his allies argued that the only possible solution was to remove the cars from the surface of the congested district and build a network of tunnels for them underground. The original scheme sought to build tracks from the corner of Shawmut Avenue and Tremont Street to the northern edge of the Congested District. The benefits, Mayor Mathews stated, were multiple. Cars would no longer have to stop for obstructing teams or other obstacles. They would no longer have to contend with ice, rain or snow. There would be just four fixed stops, rather than the current average of thirteen. Cars could travel at eight miles per hour double the average speed for a West End car traveling on surface streets without "unusual delays, and many times its speed when the road is for any reason blocked." Running the cars underground would allow them to avoid narrow, crooked streets and intersections, which would also many cars to be run in coupled pairs. As many as 512 passenger cars per hour could move

\footnotetext{
${ }^{29}$ This account is based on an analysis of the relevant plates from the Sanborn Map Company's 1895 atlas covering Boston.

${ }^{30}$ Argument of Mayor Matthews, 9.
} 
along the tracks at eight miles per hour. By dropping speeds to six-miles-an-hour, 560 cars could be accommodated. ${ }^{31}$

In addition to the subway, the Rapid Transit Commission sought to build elevated tracks from South Boston to Charlestown and from Roxbury to Cambridge, each track connecting to the others and to either end of the subway at Causeway and Eliot Streets. With the West End refusing to build the tunnel, declaring the project untried and too large a financial risk, the 1894 act that authorized the creation of the subway called for public construction and ownership of the tunnel network. The subway stations and tunnels were designed by the newly formed Boston Transit Commission, who leased the system to the West End for a 20-year term. ${ }^{32}$

After a fraught year of political intrigue where opponents of the subway sough to stymie its implementation with proposals for other transit schemes, construction began on the Tremont Street Subway on March 28, $1895 .{ }^{33}$ The first section, running from the Public Garden to stations at Boylston and Park Street, opened on September 1, 1897. A second tunnel opened in October, running from Boylston Street to Shawmut Avenue. A third tunnel opened on September 3, 1898, running from Park Street to Scollay Square with a branch to Adams Station down Hanover Street, continuing to Haymarket and then North Station. ${ }^{34}$

By virtue of their use of point access, subway stations imposed a new order upon users of mass transit. Streetcars drawn by horses never moved at speeds greater than four miles per hour in the city center, and, even after electrification, traffic congestion and stops at intersections continued to suppress speeds. As a result, streetcar patrons boarded and alighted at will, often

\footnotetext{
${ }^{31}$ Ibid, 13.

${ }^{32}$ In the same year, the Boston Elevated Railroad (BERy) was formed, which took over the West End's operations in 1897, resulting in a bigger monopoly. The BERy founders insisted on a five cent fare fixed for twenty-five years. At first thought to be lucrative, this fare was quickly outpaced by inflation. Architectural Preservation Associates, Massachusetts Bay Transportation Authority Historical Properties Survey Narrative Report vol. 1. (June 1984), 8, 104.

${ }^{33}$ For a full account, see Cheape, Moving the Masses, 126-154.

${ }^{34}$ Architectural Preservation Associates, MBTA Historic Properties Survey, 11-12.
} 
from cars in motion. This chaotic approach to accessing public transit reflected the chaotic use of the street itself (discussed later in this chapter). By moving streetcars below ground and only providing access through defined stations, the formerly chaotic behavior of transit riders was now rigidly structured. When automobile congestion later replaced streetcar congestion, it was never given this degree of discipline.

\section{Regulations \& Enforcement}

Very few regulations existed in nineteenth-century Boston to govern the movement of vehicles (see Appendix for the relevant ordinances). The Rapid Transit Commission observed in 1892 that regulations were so infrequently enforced that there was no deterrent effect for those who violated them. In fact, the commission speculated that enforcement was so rare that many operators of horse-drawn vehicles were not aware that regulations existed at all, or else they understood that regulations existed but that there was no reason to learn what they were. ${ }^{35}$

While moving streetcars underground was the great achievement of the 1890s in terms of the easement of congestion, other efforts were enacted at this time to regulate the thousands of horse-drawn vehicles that travelled in chaotic fashion each day throughout downtown Boston. In 1894, the police department organized a small "street squad" charged with clearing obstructions in the congested district and with enforcing the new regulations [Figure 1-5]. Some of the work of the street squad fell under the jurisdiction of the former "railway squad," which was a minor operation of four men and a sergeant. In 1897, the Boston Globe described the origins of this railway squad, which began its duties eighteen years earlier on January 1, 1879:

It was the inconveniences of travel at the depots that caused the establishment of the original railway squad. In the old days, when there were half a dozen different street railroads lines operating, running over the same set of tracks, the car drivers

\footnotetext{
${ }^{35}$ Rapid Transit Commission, Report to Massachusetts Legislature, 11-12.
} 
fought fiercely for the best places at the depots when the trains were emptying their passengers. The first car that got to the depot held its place and picked up crowded loads of freight, while the cars behind did comparatively nothing. The drivers of the cheated cars swore in vain, and frequently two men wrapped their reins around their brake handles, got off their cars and fought in the street over the enmity that developed out of this system ... It was the custom also in those days for the car drivers to struggle for the best place in front of the theater every night at closing time, and here again were pitched battles between drivers and conductors. $^{36}$

The street squad was larger, with thirty men who watched over thirty separate beats located in or near the congested district. Their shifts all began at 9:00am and ended at 6:15pm, covering the times of the day when traffic was busiest. These men were supervised by a Sergeant. The officers of the street squad were exempted from the routine work of the police department, and focused their attention on encouraging the movement of traffic by settling disputes and enforcing regulations. A Boston Globe reporter shadowed the supervising sergeant on his rounds and recorded in flamboyant detail typical scenarios that the street squad sought to resolve. For example, the reporter observed that some teamsters went into a

saloon to take a drink, and they had another, and they argued and chatted, and the time went by, and a long line of horses champed in contented inactivity, while their drivers indulged in curses loud and deep. Now the teamsters come out and lift themselves heavily to their wagons and lumber on. The long line behind begins to move, but [an officer] has the names of the foolish fellows who loitered when they should be traveling, and lucky are they if they be not called into court for their misconduct. ${ }^{37}$

In another instance, the reporter recounts Officer Doherty's thoughts and actions in response to the discovery of an unmanned horse and cart that blocked a street in violation of three ordinances - it had stood in place longer than twenty minutes, it had been hitched to the wrong side of the road, and it was not parallel with the curb.

\footnotetext{
36 “Guardians of Boston's Tangled Traffic,” Boston Globe, April 4, 1897, 34.

37 Ibid.
} 
What is this vehicle standing in front of a restaurant? The sergeant sees it as soon as he strikes the corner. In must come out. It has stood there half an hour, and Doherty is trying to get the owner out of a lunch house handy. He is a countryman who came to town this morning, without any notion that he couldn't stand his 'gosh blamed ol' hoss whar he'd a mind ter.' He has tied the stupid, barrel-bellied nag to a lamp post and gone 'in ter fee-what d'yer s'pose?'38

The establishment of the street squad represented one of Boston's earliest organized efforts to enforce existing traffic regulations, mostly as they applied to teamsters and cab drivers. As the Boston Globe's account suggests, many operators of horse-drawn vehicles did not have (or professed an ignorance of) the city's statutes. Those who committed the violations reported in this article were not issued summons or citations, typical of this period's approach to traffic regulation. Much of the officers' time was spent tracking down those who had abandoned their teams in the road. At this time, the street squad acted more in an educational capacity, seeking to inform the public about the existence of laws, than in an enforcement capacity.

The laws that existed, though they were intended to spur free-flowing traffic, did not yet privilege maximum efficiency of traffic over other uses of the street, and they specifically protected the rights of moving pedestrians. For example, the city ordinances stated that "no person shall, in a street, willfully obstruct the free passage of foot travelers, nor shall any person in a street saunter or loiter for more than five minutes after being directed by a police officer to move on." ${ }^{39}$ In one case, a socialist advocate - Martha Moore Avery - placed a chair in the junction of Ashland and South streets and proceeded to argue for her political cause before an eventual arrest. At her trial, the central arguments for and against the defendant were astonishingly petty. The arresting officer, George McCausland, testified that Ms. Avery spoke for five minutes and thirty-five seconds after being instructed to move along. A witness for the

\footnotetext{
38 Ibid.

39 The Revised Ordinances of 1892 of the City of Boston, and the Revised Regulations of 1892 of the Board of Aldermen of the City of Boston (Boston: Rockwell and Churchill, City Printers, 1894), 108.
} 
defense asserted that she had only spoken for four minutes and forty-eight seconds after the warning. In finding her guilty, the presiding judge stated that the verdict was not intended to repress free speech, but to ensure that traffic was not inappropriately obstructed. ${ }^{40}$

By contemporary standards, where pedestrians and vehicle operators are expected to respond with immediacy to an officer's instructions, the five-minute allowance granted by this ordinance was quite generous, as was the allowance that a spontaneous protest might occur in the midst of a roadway. While the city's laws sought to balance an interest in vehicular and pedestrian movement against other uses of the street, including the right to assemble, it is plain that the exercising of other rights to the street could easily cripple traffic flow in areas with vehicular congestion. It is also plain that enforcement of this law was extremely time-consuming. The officer needed to respond to the scene, issue a warning, presumably refer to a pocket watch to monitor the time while keeping the peace, and then conduct the arrest.

\section{RESOLUTION}

Weinstein claims that amateurs implemented Boston's built responses to the congestion problems of the 1890s. According to this characterization, those who devised the subway and elevated plans and oversaw their construction gave the projects critical consideration, but their approach was not based on "standardized, formal methods of analysis" and they "had no specific training or shared professional ideology." ${ }^{41}$ Members of the Boston Transit Commission (BTC) were simply prominent male businessmen, politicians and clergymen who happened to have a civic interest in transit.

While many members of this commission may have lacked credentials based on twentieth-century conceptions of urban planning, the project engineer they hired to oversee the

\footnotetext{
40 “Mrs. Avery Fined \$20,” Boston Globe, September 26, 1897, 17.

${ }^{41}$ Weinstein, "Congestion as a Cultural Construct," 112.
} 
construction of the subway approached the task with efficiency and professionalism. Chief Engineer Howard Carlson, a graduate of the Massachusetts Institute of Technology who had overseen the Charles and Mystic River Basin Sewage project, methodically approached the subway project, eventually hiring a staff of engineers, accountants and other experts to scrutinize the work of the contractors who successfully bid on the construction of stations and tunnel segments. The BTC insisted on use of the cut-and-cover technique, pioneered in London, for construction. Excavation was carried out at night to allow surface traffic above to move relatively unhindered by the construction below. The BTC also imposed strict fines when contractors failed to meet the terms of their agreements with the city. As a result of the efforts of Carlson and his team, the BTC completed the ambitious project on time and under budget. Such feats were rarely accomplished by the classes of planning professionals who followed. ${ }^{42}$

The stations and lines planned and operated at the turn of the century were remarkably successful and continue to be used in the twenty-first century (though the tell-tale screech as contemporary cars turn the sharp corner beneath Boylston and Tremont Streets serves as a reminder that the original system did not anticipate faster moving vehicles). Boylston Station remains little changed since it opened in 1897. Its track and platform configuration is unaltered and the entry kiosks at street level, designed by Edmund Wheelright, are still intact [Figure 16]. ${ }^{43}$

After it opened, the subway was widely regarded as a great success, and former critics were muted. Some had argued that the public would decline to use the subway for fear they would contract pneumonia or other illnesses. The fifty million riders who used the tunnel in its

\footnotetext{
${ }^{42}$ Cheape, Moving the Masses, 143-146; Hall, Cities of Tomorrow, 320-341.

43 The Tremont Street subway line was listed on the National List of Historic Places in 1964 and as a National Historic Civic Engineering Landmark in 1978. Architectural Preservation Associates, MBTA Historic Properties Survey, 12-13.
} 
first eleven months of operation disproved such fears, as did tests that demonstrated that the air in the tunnel was at least as pure as that found in schools, churches or other public buildings. Abutters who feared their property values would fall saw them rise. The local newspapers generally gave the subway's performance high marks. The subway also received international attention. Harper's Weekly declared that it "demonstrated at once its value as the key of the rapid-transit problem in [Boston] ... The effect was like that when a barrier is removed from the channel of a clogged up river."44 Photographs of the subway were displayed at the 1900 Exposition Universelle in Paris, and were awarded a Grand Prix. When the British physicist Lord Kelvin visited Boston, "he hurried to the subway before having his dinner and "pronounced it an engineering marvel.",45

The project removed most streetcars from the surface of the congested district (before the subway system expanded and automobile congestion encouraged their removal, some cars continued to run above ground, such as on Washington Street) and greatly improved travel times, achieving the speeds called for in the commission's report. While traffic on surface streets was slow-moving by automotive standards, above-ground movement usually accommodated the pace of the ordinary human gait and horses at a walk. The elimination of most streetcars freed more space for teamsters and municipal workers to maneuver. This relative spatial freedom, combined with the efforts of the street squad, provided the streets of the congested district with workable order.

Thomas Edison's Seeing Boston captured typical traffic conditions and the behavior of street users in select parts of the city after the opening of the first subway and elevated lines. In this six-and-a-half minute film from 1906, a camera was mounted to a moving streetcar and

${ }^{44}$ Cheape, Moving the Masses, 146.

45 Ibid. 
recorded unscripted, ordinary street life. The first segment of this film shows the view from the car as it moved along Tremont Street (beginning near the Eliot Street intersection) towards the Common [Figure 1-7]. The car and camera turned left on Boylston Street and then left on Washington Street, where it ran for seven blocks before terminating at the Old South Meeting House. $^{46}$

Taken at 1:00pm on a sunny workday, the film provides exceptional insight into a typical afternoon on downtown Boston's leading retail thoroughfare, with the streetcar moving unhurriedly past Washburn's Department Store, the Adams House Hotel, Jordan Marsh and numerous other landmarks. Throughout this segment of Seeing Boston, all sidewalks were filled at or near capacity with pedestrians [Figure 1-8]. These pedestrians constantly darted into moving vehicular traffic, which consisted of horse-drawn wagons, horse-drawn passenger conveyances, and streetcars. While it was crowded with pedestrians, all parties moved fluidly in the street. The movement of these pedestrians lacked formal order - there were no crosswalks, signals or police officers to guide them - and at times they surrounded moving vehicles in very close proximity [Figure 1-9]. Since the different vehicle types were unable to move at speeds much greater than four miles per hour, an alert and able-bodied human population could easily intermingle with vehicular traffic. This custom was aided not only by the vehicles' slower speeds, but also by the fact that vehicles moved in predictable ways. Streetcars were fixed to tracks and other carriages and wagons kept to the right side of the road. Not captured by this silent film is speech - pedestrians and drivers could easily communicate with one another, since all vehicles were open-air and since traveling speeds were compatible. ${ }^{47}$

\footnotetext{
46 "Seeing Boston," Earliest Massachusetts Films, DVD (Bucksport, ME: Northeast Historic Film, 2005).

${ }^{47}$ While many carriages were enclosed to protect passengers from weather and to afford them privacy, the drivers were always outside so that they could properly hold reins and so that they could communicate with horses trained to response to voice commands.
} 
The two-and-a-half minute segment featuring Tremont, Boylston and Washington Streets showed approximately fifty horse-powered vehicles and ten streetcars. ${ }^{48}$ All of the streetcars carried full loads of passengers and moved at then reasonable speeds and without significant interruption. ${ }^{49}$ Of the fifty horse-drawn vehicles, most travelling in the roadway were delivery wagons, some of which abruptly broke into tight openings in front of other moving vehicles and in front of the streetcar carrying the camera [Figure 1-10].

Of those vehicles parked along the curb, all were positioned close and parallel. Five of these were carts into which municipal workers shoveled snow from a recent storm. Another four appear to be livery cabs congregating in front of the Boylston Hotel diagonally across from the Common on Tremont Street. The cabs were likely operating out of a sanctioned stand and were probably exempted from the prohibition against parking along the curb for more than twenty minutes. Most of the dozen other vehicles standing along the sidewalk were delivery wagons, some of which entered traffic during the course of the film. Thus, many expanses of curb were vacant, with the general absence of vehicles allowing crowds of pedestrians to easily spill over sidewalk and into the street [Figure 1-11].

One other vehicle was parked on busy Washington Street - a lone automobile, standing in front of the Mechanics Trust Company at the corner of Franklin Street [Figure 1-12]. This motor car sat unmoving with a driver at the wheel. The open-air model was of recent vintage (it had a steering wheel, not a tiller) and was of the Mercedes style (the chassis was very low to the ground), signifying an expensive make. This sole car was the only motor vehicle to appear in the entire film, including a segment where the camera ran along Canal Street and past North Station,

\footnotetext{
${ }^{48}$ Since the camera often panned to one side of the street and did not keep both sides of the road in frame, it is not possible to accurately state the total number of vehicles present at the time of filming.

49 Those producing this film were likely not interested in showing the view from a streetcar stuck in traffic and almost certainly would have arranged to shoot at a time when the streets were free from blockage.
} 
and the final segment where the streetcar ran along Boylston into the Back Bay, turning left to pass the public library in Copley Square and continue down Huntington Avenue.

The evidence captured by this film is substantiated by evidence presented in this dissertation's following chapters. Though automobiles were present in Boston since the late 1890 s, their presence in the city's streets was so limited in the early 1900s that they simply operated in a traffic landscape that followed the customs of a slower-moving age. Edison's film and the many documents that characterize the early subway as a great success show that the automobile was about to enter a built landscape that by many measures had solved the most pressing of the era's perceived problems with congestion. The emergence of the motor car, gradual at first, soon destroyed the harmony achieved by the technological and infrastructural advances made at the end of the horse age.

\section{STABLES}

When automobiles began to infiltrate the urban landscape, their accommodation borrowed many characteristics from those that been developed for horses throughout the nineteenth century as cities increasingly depended upon the various uses of equine power. Just as the earliest automobile users inherited the laws and customs that guided the operators of horse-drawn conveyances, so too did they borrow from existing ideas about stable design and placement. For the first users of motor cars, this was a matter of expediency. New automobile technology was novel and highly experimental, and the sellers and buyers of these machines had not yet devised building forms that responded to their needs. As will be discussed in the following chapters, early automobile users simply took space in existing buildings designed for other purposes. Since all of the earliest cars needed to be stored indoors, the building type most often repurposed for the automobile were the various kinds of stables that existed in the city, especially livery and 
boarding stables, which were functionally the closest thing the nineteenth-century had to a modern parking garage.

Clay McShane and Joel Tarr characterize the nineteenth-century city as "the climax of human exploitation of horse power," pointing out that "humans could not have built or lived in the giant, wealth-generating metropoles that emerged ... without horses." ${ }^{50}$ As American cities grew to support larger and denser populations with increasingly expansive commercial and industrial ambitions, the necessary horse-related systems flourished and evolved. Though steam engines had been used for industrial applications since the 1770s thanks to the inventions of James Watt, horses powered many aspects of the American city for most of the nineteenth century. Transit systems depended on them to haul streetcars. Fire departments could not speedily move heavy equipment into position without horses. Private and livery carriages were powered by horses, as were delivery services. Horses kept roadways clear by dragging rotating street-sweeping devices and hauling away snow. Off the street, many stationary engines were powered by horses on treadmills and other mechanisms.

Since many thousands of horses were needed to power Boston, their housing was a significant concern, as was true for all crowded American cities. The West End Street Railway maintained dozens of large stables for the thousands of horses needed to pull each day's load of passengers (in 1888, the West End maintained 7,684 horses).$^{51}$ Other horse-drawn transportation options, such as cab services and privately-owned carriages, required hundreds of stables throughout the city. Boston's more than 6,000 teamsters kept stables to house their horses and store their carts and large wagons ${ }^{52}$ Fire departments, police departments, street departments and

\footnotetext{
${ }^{50}$ McShane and Tarr, The Horse in the City, 1.

${ }^{51}$ First Annual Report of the West End, 8.

52 "Offer a Scale - Team Drivers Propose a Wage Schedule," Boston Globe, November 25, 1901, 8; "Reject It Master Teamsters So Notify Union,” Boston Globe, January 23, 1904, 1.
} 
other municipal agencies all depended on city-owned horses to fulfill their responsibilities. Each of these entities required specialized stables. They also required a complex horse-service industry. By 1870, there were sixty-two carriage dealers, sixty-one firms making harnesses, twenty-nine hay dealers, and fifteen wheelwrights in Boston. By 1890, their numbers had increased, with 105 carriage dealers, fifty-one hay sellers and thirty wheelwrights. ${ }^{53}$

McShane's and Tarr's analysis of the 1867 Sanborn atlas shows the distribution of stables in central Boston [Figure 1-13]. Approximately one third were located within a block of the waterfront, indicative of the great activity generated by maritime shipping. Many horses were required not only to move cargo by cart and wagon, but also to operate the hoists necessary to position and retrieve freight from the upper decks of ships and from the higher floors of the area's warehouses. Similar concentrations of stables were clustered near the four railroad termini then active in Boston. The majority of the remainder were located "on or close to the four main streets (Tremont, Washington, Beacon and Cambridge), which provided Boston's only links to its hinterland." At this time, roughly one-third of the stables were in back lots and most were concentrated on blocks that included more than one stable. Two thirds were two stories, one fourth were a single story and the remainder were three-stories, with the exception of a single four-story stable. ${ }^{54}$

Regardless of size or placement, all were clearly marked by the Sanborn Company's cartographers, who drew a large $\mathrm{X}$ over each stable, since they were widely known as fire hazards to themselves and to surrounding buildings. In Boston and elsewhere, stables "were built from wood and were full of highly combustible straw and hay, and neither species of occupant was very safety-conscious. On the first floor, stable managers usually stored vehicles and their

\footnotetext{
${ }^{53} \mathrm{McShane}$ and Tarr, The Horse in the City, 32.

${ }^{54}$ Ibid, 105-106.
} 
repair shops, and these contained such highly fire-accelerating materials as paint, varnish, and flammable oils. Contemporary accounts suggested that animals kicking over kerosene lamps caused many fires" [Figure 1-14]. ${ }^{55}$

Such fires were great hazards for large cities. The most disastrous occurred on May 27, 1887 in New York City. During that night, the Belt Line Street Railway's large three-story stable on Tenth Avenue at Fifty-Third Street caught fire and burned rapidly. Of the 1,230 horses stabled at the time of the blaze, 1,185 died. Also lost were the four thousand bales of hay, five thousand bales of straw and twelve thousand bushels of grain that combined with the building's wooden frame, floors and stalls to make it dangerously flammable. This and other fires demonstrated that, while "in theory, horse power was made up of thousands of independent sources not subject to systemic failure, like a twentieth-century power grid," in reality a blaze could disrupt an entire city. ${ }^{56}$

While stables were rightly regarded as significant fire hazards, they also represented other nuisances. Large draft horses produced a significant volume of manure (thirty to fifty pounds every day). For most of the century, it was common practice for urban stable keepers to gather this waste and to store it in large piles, eventually selling it to farmers at select times of the year. While all urban manure had value and was regularly collected and sold (droppings from smooth asphalt streets were more coveted than those collected from other surfaces), stable manure was deemed the purest and therefor was sold at a premium. This practice was so profitable that an owner could recoup the purchase price of a horse in just five years through the sale of its manure. ${ }^{57}$

\footnotetext{
${ }^{55}$ Ibid, 104-105.

${ }^{56} \mathrm{Ibid}, 102-103$.

${ }^{57}$ Ibid, 26-27.
} 
Financially (and environmentally) advantageous as this practice was, the stench produced by the storage of waste was significant. In New York, complaints about stench became increasingly pronounced in the later nineteenth century as horse (and human) populations ballooned, thus exacerbating the problem. By the 1880 s, carts used to transport manure were required to be covered and stables were required to immediately remove storage piles before bad smells were noticeable - a practice which simply moved the problem to large transshipment piles located elsewhere in the city. Urine was sometimes drained from stables into sewers via rudimentary plumbing. Nevertheless, rising fumes from horse urine absorbed into wooden floors and stalls and could become so severe during hot months that they could blister a carriage's paint if stored above the horses..$^{58}$

The stables recorded in the 1885 Sanborn atlas represent the apex of horse use in Boston. These maps predate the West End's electrification efforts, which would soon eliminate horses (and stables) from the streetcar network, and, more significantly, they predate the adoption of the automobile, which would first appear in the city in very small numbers at the end of the 1890s. The 1885 Sanborn atlas showed that central Boston contained "roughly the same number of stables (385) as had been present twenty years earlier ... despite the near tripling of the number of horses in the city." Newly built stables were almost always larger than their predecessors, since there was constant pressure to increase horse capacity. The devastation wrought in Boston by the fire of 1872 provoked city officials to implement and enforce building codes, which affected the construction of new stables and created new prohibitions on where they could be placed. The 1885 Sanborn atlas showed that the former burnt district contained zero small wood stables, and "the number of small back alley stables declined elsewhere. The consolidation of stables reflected not only a more stringent building permit process but also the centralization of

\footnotetext{
${ }^{58}$ Ibid, 26-27, 109.
} 
horse-using businesses, as large firms squeezed independent teamsters out of business. Building regulations that required expensive, modern stables also helped force out the small entrepreneur." 59

An examination of all maps appearing in the 1885 Sanborn atlas shows that the West End located its stables to reflect operational needs and out of concern over the potential for fire. Despite the importance of the West End's services to the vitality of the city (and despite the company's great political and financial clout), not only were there no streetcar stables in the 1872 burn zone, but there were no such stables in the entirety of central Boston. All of them were located outside of the extents of McShane and Tarr's map of stables in 1867. Instead, the West End's forty stable-and-car-house complexes were built at key junctions or along the system's various lines, with many near the ends of these lines in Roxbury, Cambridge, Brookline and Charlestown [Figure 1-15]. This distribution allowed horses to be more easily replaced if they became injured or fatigued (or died on the job). It also greatly reduced the risk that Boston's critical transit infrastructure would be crippled by a single fire.

Of the many kinds of stables that existed in American cities at the end of the nineteenth century, it was livery stables and boarding stables that most directly informed the design of the first large-scale garages that would be soon be built to allow automobiles to function in the city. Indeed, some of these stables would later be converted into early storage facilities for motor cars. These stables were also more centrally located than their transit counterparts.

Livery services afforded those who did not own a horse the opportunity to schedule a ride or to secure one from a cab stand. Livery cabs were frequently in position near the city's major hotels, near the railroad termini and near the opera and other popular entertainment venues. Livery companies kept several kinds of vehicles on hand to meet demand: smaller efficient

\footnotetext{
${ }^{59}$ Ibid, 107.
} 
coupes, larger carriages for bigger groups (often used at funerals), enclosed carriages (offering greater privacy and frequently requested during the spring courting season) and sleighs (which were exceedingly popular during snowy weather).

Those who did own a horse often elected to store them in a boarding stable, thus avoiding the great expense necessary to build and staff a private stable. Boarders could rent stalls and then let the stable keepers feed, groom and exercise their horses, while keeping the stench associated with horse ownership away from their home (and closer to someone else's). By the end of the century, boarding and livery stables were very similar in scale and design. The key differences between them were not in their form, but instead involved operating costs and business models. Operating a livery stable required a more significant capital expense, since the horses were owned by the stable. Large livery stables, such as the Kenney \& Clark enterprise on the corner of Newbury Street and Massachusetts Avenue, sometimes provided boarding services if they had unused space. ${ }^{60}$

Concern over fire hazards and other nuisances created fervent not-in-my-backyard responses where residents sought to prevent stables from being built near their houses or property. In the newly developed Back Bay, a single block (Newbury Street between Hereford Street and Massachusetts Avenue) was set aside for stables, providing many of the neighborhood's elite with a centralized place to store their horses and carriages without being too near them [Figure 1-16].

Elsewhere in the Back Bay, very few private stables were built, nearly all of them at the rear of properties along Back Street, which ran along the Charles River [Figure 1-17]. The stables on Back Street benefitted from the absence of neighbors - these stables were all built at the edge of the property line towards the river and at a moderate distance from human

\footnotetext{
${ }^{60}$ Ibid, 106, 112-114; “For Sale Contents of my Private Stable," Boston Transcript, April 15, 1903, 23.
} 
residences. In total, forty-six private stables were built along Back Street, twenty-eight were built on the Newbury Block and eleven were interspersed along alleys throughout the rest of the neighborhood. ${ }^{61}$

The stables on the Newbury block were all built just before the emergence of the automobile age. Most of the Newbury Street stables were privately-owned, two-story buildings where wealthy neighborhood families would house their collection of horses, store feed and keep several carriages. A groomsman usually lived on the second floor, charged with feeding and caring for the horses and with keeping harnesses and other equipment in good repair. Twentyfour of the twenty-eight stables on the block were of this kind.

Maintaining such stables in the Back Bay was an extremely extravagant enterprise, and despite their modest brick exteriors, these twenty-four private concealed great opulence. Among them was the stable of John Atkins [Figure 1-18],

which all the coachmen and hostlers agree has not its equal in the city, and many even say there is none more elegant in the country. With the exception of upholstered furniture and carpets, the appointments of this stable are hardly less dainty and expensive than the furnishings of a Beacon st residence. The walls of the coach house are ... frescoed in gold leaf and the long glass case, in which the ... harnesses are kept, is painted in white and gold ... The furnishings and adornments of the floor below, where the stalls are situated, are necessarily not so delicate, but they are quite as rich as those of the coach house. Black walnut and brass predominate here. The stalls are all constructed of this dark wood, the ring and the cups of the pillar posts being of solid brass. The manger and the space in front of the horse's face are fresh and unmarred by tooth marks, for the tendency of the horse to gnaw has been provided for by facing it all up with tile. ${ }^{62}$

While Mr. Atkins kept only four horses, the great labor needed to polish the stable's brass and otherwise maintain its excellence required the efforts of three men. When Mr. Atkins moved to New York in 1899, the contents of this "most elegant and perfectly equipped private stable in the

${ }^{61}$ Insurance Maps of Boston Massachusetts, vol. 2 (New York: Sanborn Perris Map Company, 1897).

62 “Some Back Bay Stables - Horses Have Luxury that Men Might Enjoy,” Boston Globe, November 10, $1895,32$. 
country" were auctioned off. These included a covert cart, a vermillion wagon made by Boston's French Carriage Company, a four-wheeled cocking cart, a break built by Chauncey Thomas \& Company of Boston, a Berlin Coach, a cabriolet, a brougham, two phaetons, a Brewster buggy, a speed sleigh and a Skeleton Break, as well as a larger number of silk robes, fur caps, saddles, harnesses and other extravagant equipment. ${ }^{63}$

The two dozen private stables of this block where, by their nature, unable to serve the leisure or transportation needs of very many people. Also located in the Newbury stable district were three large livery stables, two of them operated by the city's most prominent cab companies: Kenney \& Clark and the Boston Cab Company. The Boston Cab Company [Figure 1-19] was organized in 1886 and was intent on providing a "higher grade of service" than was prevalent at the city's other livery enterprises. Thus, the Boston Cab Company enjoyed a reputation for supplying its riders with the newest omnibuses and coupes and avoided lumbering stages that were still in regular use elsewhere. Drivers wore dark-green coachmen's coats and white silk hats, and commanded rates of $\$ 1$ an hour for a one-horse conveyance, $\$ 1.50$ per hour for a two-horse conveyance, $\$ 1$ for a return trip to a theater and fifty cents for each passenger from any railway station to a destination as far as Chester Square. ${ }^{64}$

Since the Boston Cab Company depended on Back Bay ridership and since the location on Newbury Street afforded certain prestige, the stables built here were both convenient and statement-making. The authors of How to See Boston: A Trustworthy Guide-Book were so impressed with the Boston Cab Company and its modern operation that they recommended their

\footnotetext{
${ }^{63}$ Auction Catalog, Mr. John A Atkins' Carriages, Harnesses, Horses, and Stable Outfit, J.E. Conant \& Co of Lowell, as Auctioneers (Lowell: Thompson \& Hill Press, 1899).

${ }^{64}$ Boston Illustrated (Boston: Houghton, Mifflin \& Co, 1891), IX; "Low rates for Easy Rides," Boston Globe, January 27, 1886, 2; National Encampment of the Grand Army of the Republic, How to see Boston: A Trustworthy Guide-book (Boston: Moses King Corporation, 1890), 113-114.
} 
readers to visit it. ${ }^{65}$ The large stable was four-stories tall, with a basement level that opened onto the recessed tracks of the Boston \& Albany railroad [Figure 1-20]. It was well lit, with generous windows on all sides. Horses and vehicles entered through two arched portals on Massachusetts Avenue and through a third entry on Newbury Street. It was topped with the flourish of a Mansard roof.

While the building's walls were brick and the interior was supported by iron posts, the floors and beams followed construction norms typical for stables and were made of wood, in part because wood was much easier on hooves than other surfaces [Figure 1-21]. Photographs suggest that the Boston Cab Company adopted the usual practice of storing carriages and other vehicles on the street level, while horses were kept in sturdy wooden stalls on the floors above. A 1913 photograph shows second-floor stalls arranged in rows oriented along aisles [Figure 1-22], with waste pipes running overhead. An image of the third floor shows a hole centered in the midst of a stall, into which urine drained that was not absorbed into the wooden floor [Figure 123].

The Boston Cab Company was among the larger stables in the city. In 1900, an average of 7.8 horses were housed in each stable in Boston. ${ }^{66}$ By comparison, the Boston Cab company housed over three hundred in 1903. Of course, not all storage on the upper floors was given to horses and stalls, since these three hundred horses consumed two tons of hay every day. ${ }^{67}$ Rides were arranged by a telephone call directly to the stable, or procured at cab stands, which were maintained at clubs such as the Somerset Club and the Algonquin Club, at prominent hotels and restaurants such as the Parker House and Young's and near the opera, symphony and theaters. ${ }^{68}$

\footnotetext{
${ }^{65}$ Grand Army of the Republic, How to See Boston, 113-114.

${ }^{66}$ McShane and Tarr, The Horse in the City, 104.

67 "High Prices - Horse Owners Think They're Squeezed," Boston Globe, June 14, 1903, 4.

${ }^{68}$ Ibid; "Tieup of Service - Cab Drivers on Strike," Boston Globe, December 3, 1903, 1.
} 
Six years after the opening of the Boston Cab Company, Kenney \& Clark, the second prominent livery service, came to the Newbury block. Charles Kenney, one of the proprietors, had previously operated another stable on Charles Street, and, after twenty-one profitable years in Beacon Hill, planned an expansion in the Back Bay with his business partner in 1892, selecting a vacant lot opposite the Boston Cab Company on the corner of Newbury Street and Massachusetts Avenue.

Though Kenney \& Clark sought to build on a block that had been formally designated for stable construction, their efforts to do so were met with organized opposition. After the firm submitted a petition to build their stable, a public hearing held at the Board of Health attracted a crowd of remonstrants who argued against the erection of a new stable. Nearly all of the remonstrants were property owners who lived in the immediate vicinity of the proposed building site and objected to the hazards and nuisances that would accompany the building of another large stable. Aside from these issues, some argued that the construction of a stable would blight the forecasted development of West Chester Park (soon to be renamed Massachusetts Avenue), with one stating that "West Chester Park is bound to become one of the greatest business thoroughfares in the city. It is in an embryonic condition right now and no stable should be allowed because of the character it would give the avenue." In total, there were 191 remonstrants. ${ }^{69}$

An equally engaged group of men (for all of the named petitioners were men) argued on behalf of the stable. Many asserted that the Back Bay needed another carriage service, as the Boston Cab Company was deemed unable to adequately meet demand. Some felt that the caliber of service would also be improved. Others attending the hearing pointed out that it was commonly accepted that this part of Newbury Street was a stable district and that "the number of

69 “That Back Bay Livery Stable,” Boston Evening Transcript, April 4, 1892, 8. 
people who might be affected [by the construction of a new stable was] exceedingly small . . . and that the greatest good to the greatest number was what ought to be looked for." Mr. Kenney argued that the Newbury Street location was not only the most suitable site that could be found in this part of Boston, but that it was the only available lot, since restrictions against new stables were prevalent in the area. He assured the Board of Health that the stables would be "built in the best possible way" and would meet all sanitary requirements. He also sought to mollify objections related to the forecasted business prestige of West Chester Park by pledging to not build an entrance for horses on the side of the stable fronting that street, instead limiting this traffic to openings on Newbury Street. ${ }^{70}$

When the permit to build was eventually granted, Kenney \& Clark erected a stable that responded architecturally to the many concerns about the relationship between the new stable and surrounding properties. Kenney \& Clark not only kept their promise to forgo horse entrances on West Chester Park, but they hired one of Boston's foremost architectural forms, Peabody \& Stearns, to design the building. The result was a stable of unusual elegance [Figure 1-24].

From the street, the five-story building loomed on its corner with understated grandeur. Informed by palazzo types popular in the Renaissance Revival, the stable was not dissimilar to the Palazzo Medici or the Villard Houses. The smooth treatment and exposed brick suggest the influence of trends made popular in the Colonial Revival, an easy sell in Boston. In scale and appearance, the building resembled a department store, with arched entry gates being the only real indicator of the purpose of the building. The carefully symmetrical arrangement of the windows displayed an almost residential concern, and contrasted with those of the Boston Cab Company across the street, which was built without needing to appease neighbors.

${ }^{70}$ Ibid. 
Inside, the large stable was organized according to practical considerations and sought to efficiently provide for the storage and care of the many horse that lived within it. Analysis of the professionally designed interior spaces of the Kenney \& Clark stable illustrates how large urban stables were structured at the nadir of the horse age, a building form that has not been given meaningful consideration by architectural historians.

On the ground floor was an expansive, open carriage room where Kenny \& Clark's numerous conveyances were stored [Figure 1-25]. It provided a generous space to wash these carriages, illuminated by a light well. This floor also contained a large manure pit (approximately twenty-eight feet long by eleven feet wide, with a twelve-foot ceiling) fed by chute that ran to the floors above. This waste pit contained no opening windows and had a large door that opened directly onto Newbury Street to accommodate efficient removal.

Coachmen were unlucky enough to have their changing room and lockers adjoin the manure pit, though Peabody \& Stearns separated the two spaces with a thick wall to withstand pressure from the weight of tons of accumulated horse waste and to mitigate some of the smells that a thinner wall would have allowed. Offices were located off the carriage room further removed from the manure pit and with windows overlooking Newbury Street and Westchester Park. There was also a room for women to wait. Remaining space was given to storage.

In the rear corner, a tightly spiraling ramp and staircase afforded the primary means of horse circulation from one floor to the next. Since horses enjoy a much better turning radius than automobiles (and since they are also narrower), this ramp was much smaller than what would come with commercial automobile garage design in the 1920s.

The second floor was primarily given over to horse storage, with 136 stables organized in rows with troughs at the end of each row [Figure 1-26]. Along the eastern wall was a harness 
room where gear could be stored and cleaned. An interior partition separating the harness room from the rows of stables contained grain chutes to allow delivery of feed from the floors above. Three of four corners of the building contained larger hay chutes. ${ }^{71}$

The third floor mirrored the layout of the second, though many of the stalls appear to have been double-wide, possibly to store larger draft horses [Figure 1-27]. This reduced the number of stalls to seventy, though since the stalls were independent of the building's structural members they could have been easily changed to allow greater capacity. The fourth and fifth floors were given over to storage for the extremely large supply of feed the stable needed to keep on hand. Surplus sleighs and carriages could also be housed on these top floors. A large ten- by eighteen-foot freight elevator provided the means to move feed and conveyances throughout the building.

Neither the stable for the Boston Cab Company nor the stable for Kenney \& Clark would long survive. The end of the Boston Cab Company came as the city sought to extend a subway tunnel underneath the stable. During the tunnel excavation in 1912, one of the stable's walls buckled and the building was eventually condemned after the contactor responsible for the tunnel refused to continue work for fear of the safety of his men. After a brief protest, the stable was torn down in 1913. Though the loss of structural integrity hastened the end of the Boston Cab Company, automobile use had already begun to reach a middle class market, signified by the rapid expansion of auto-related building in Boston around 1910, especially in Park Square and the Back Bay. Competition with automobiles was felt by operators of livery and boarding stables

\footnotetext{
71 Each stall on this floor was three feet wide by ten feet, five inches long, with a ten-and-a-half foot ceiling, yielding 328 cubic feet per horse. Since the horses themselves had a width of approximately two-and-a-half feet, this arrangement would have kept the animals tightly packed and did not align with recommendations that would later be made in The American Architect and Building News, which advocated for far more space per horse as a means to combat the all too typical atmosphere "so impregnated with ammonia and organic impurities that it makes one gasp for breadth and brings tears to the eyes." "Stable and Stable Fittings," The American Architect and Building News (May 16, 1903): 52.
} 
as consumers changed their preferences from horse to motor. Such competition was apparent at the Boston Cab Company, for part of the stable had been leased to the P\&P Tire Company and to the Mass Automobile Clearinghouse before it was condemned. ${ }^{72}$

Kenney \& Clark also failed as automobiles began to achieve popular use. After several years in which Bostonians increasingly favored automobiles for private transportation and for leisure, Kenney \& Clark closed its doors with the death of Mr. Kenney in 1909. A post mortem in the Boston Globe's real estate section reported that the stable "had always been regarded as one of the finest stables in the City, and on account of its very heavy construction is most admirably adapted for an automobile warehouse and garage." ${ }^{, 73}$ The Maxwell-Briscoe Boston Company purchased the building and made "but slight alterations to make it suitable for the automobile business. ${ }^{.74}$

While Kenney \& Clark needed all of the space of the building for its operations, the early automobile trade that came to occupy it did not have the same spatial demands. A principal alteration made to the building was to reorganize the first floor to create five store fronts along the Massachusetts Avenue façade. These small shops and other subdivided spaces within the building were leased to the Hub Automobile Company, the Austin Automobile Company, the J. H. McAlman Company, the Post \& Leser Company, the J. J. Hillman Auto Supply Manufacturing Company, the Boston Auto-Top Company, the Alden-Sampson Manufacturing Company and the Boston Auto School. The main occupant was the Maxwell-Briscoe Company, which maintained its show room and offices on a portion of the first floor and used the upper floors for storage and the top floor as a repair shop. A small garage operated out of the rear of the

\footnotetext{
${ }_{72}^{72}$ Historic New England, photography folder 660.

73 "Real Estate Transactions," Boston Globe, July 27, 1909, 3.

74 "In and about the Agencies," The Automobile 21 (August 12, 1909): 291-292.
} 
first floor and occupied the basement. The entire enterprise relied upon a single freight elevator to move autos from one level to the next. ${ }^{75}$

As will be shown in greater detail in Chapter 2, the practice of repurposing existing stables with what were often makeshift alterations for the automobile trade was a dangerous one. While stables where themselves regarded as significant urban fire hazards, Boston's first makeshift garages were far more likely to erupt in flames (approximately half of the larger makeshift garages in Boston caught fire). For the Maxwell-Briscoe company, such a fire occurred in August, 1910, when a blaze quickly consumed the top floor of the building, destroying forty cars stored in the company's repair shop. Fortunately, prevailing winds and the quick work of the fire department prevented the fire from spreading to surrounding buildings, but all too often early garages menaced their neighbors with a threatening prospect.

75 "Garage Fire Gives Back Bay a Scare - Five-Story Maxwell Building Burned with 40 Cars," Boston Globe, August 11, 1910, 1. 


\section{CHAPTER 2 - Early Automobiles: Status, Stables and Blazes}

Automobiles first appeared in Boston in minute numbers at the close of the nineteenth century and for much of the next decade were primarily used by the city's elite. The first decade of the twentieth century saw new automobile designs proliferate, the first laws to address their use and the development of a few new building forms to service, sell and enjoy them. While a handful of newly designed buildings were created, much of the accommodation made in this period of first use involved the repurposing of existing structures. This period also marked the development of organized strategies of the emerging motoring class to control the resources of the city, especially through the appropriation of streets.

This period of first use was dynamic and the relationship of city dwellers to automobiles in this time was fluid. In the first years of their introduction, very few motor cars were used on Boston's streets and many residents might never have seen one first hand. For much of the first decade of the twentieth century, they were almost exclusively expensive novelties for moneyed people who used them for sport, recreation and display. By the end of this decade, the mass use of the automobile had begun, though true popular adoption would not begin until the 1910s, more or less coinciding with the 1912 introduction of Ford's affordable Model T. ${ }^{1}$ The number of cars registered throughout Massachusetts totaled 600 in 1900, 1880 in 1905 and 31,250 in $1910 .^{2}$ In 1910, there was a ratio of just one registered automobile for every 108 people in

\footnotetext{
1 The Model T was first made available to dealers in October, 1908 , with a price that ranged from $\$ 825$ to $\$ 850$. This machine was built for "the multitudes" and was the most reliable and best performing family car on the market. While the demand for the Model $\mathrm{T}$ was immediate, pricing did not become truly affordable until 1912 when Ford implemented the moving assembly line and the starting price for a runabout dropped to $\$ 575$, the first time the cost of the Model T was below the average annual income in the United States. By 1916, production efficiency allowed the price to drop further, to \$345. James J. Flink, The Automobile Age (Cambridge, MA: MIT Press, 1988), 37-38; James J. Flink, America Adopts the Automobile, 1895-1910 (Cambridge, MA: MIT Press, 1970), 278.

${ }^{2}$ Since Massachusetts (and other states) required non-resident owners to register their cars if they were used locally for more than two weeks in a year, many autos were registered in several states simultaneously. Thus, the registration figures likely exaggerate the number of autos that were regularly used in Massachusetts in these years.
} 
Massachusetts. By 1920, that ratio had ballooned to one registered car per fourteen people. In 1930, the ratio had reached one in five. ${ }^{3}$

The built landscape that existed in the city to support automobiles at the close of the twentieth century's first decade was minimal compared to what soon followed. In the earliest years of automobile use, those that bought and sold motor cars occupied discrete pockets of the city, reflecting a practice that attempted to accommodate these new machines into the existing landscape without significantly changing its character. Boston's handful of early storage facilities usually occupied extant structures, very often former livery and boarding stables, which had (by turn-of-the-century standards) large and relatively open interior spaces. Streets were still shared by pedestrians, horses and others and were not yet considered to be the autoist's domain. The auto industry and drivers themselves more or less stayed out of Boston's downtown core (though some retail businesses in the center slowly began to use motor trucks to deliver goods), instead establishing buildings and use patterns in the Back Bay and other peripheral areas that were not yet fully developed. The use of motor cars was seasonal, and the already minimal presence of automobiles declined further in colder months. Excepting the uncannily prescient, none could imagine the life-altering and destructive implications of urban automobile use.

\section{LOCAL MANUFACTURING \& ROAD CONDITIONS}

Automobiles were built in New England for many years before adequate road systems were developed to allow free and easy movement. According to the United States Census of Manufacturers, there were thirty active automobile makers nationwide in 1899, producing a total of 2,500 cars. Of these manufacturers, ten were in New England (eight in Massachusetts, two in

In 1904, Horseless Age estimated that eleven percent of autos registered in Massachusetts were cars that were reregistered by nonresidents. "Some Automobile Statistics," Horseless Age 14 (September 28, 1904): $303-304$.

${ }^{3}$ Peter J. Hugill, "Good Roads and the Automobile in the United States 1880-1929," Geographical Review 72, no. 3 (July 1982): 340. 
Connecticut), ten were in the Mid-Atlantic and ten were in the Midwest. At this time, the New England firms, led by the Pope Manufacturing Company of Hartford, Connecticut, built more cars than those located elsewhere in the United States. The New England region primarily focused its efforts on building electric and steam-powered cars, while the Midwest was the center of manufacture for gasoline-powered vehicles. As gasoline emerged as the favored fuel type for motor cars, New England lost its position as a center of production. ${ }^{4}$

Aside from the thirty manufacturers listed in the census, there were hundreds of small shops experimenting with automobile design and construction in the United States, with the greatest concentration in the Northeast. These small-scale operators rarely advanced to become actual manufacturing enterprises. Instead, "the goal of most was to produce patentable features of design that could be tested in experimental vehicles," with the hopes that these inventions could be sold at "a high price to an established company or an individual who had the capital to develop them." ${ }^{5}$

Proximity to these early manufacturers helped to encourage and popularize automobiles in Boston and in Massachusetts, and helped to make the region an early adopter of the new technology. Even so, in the first years of their use many wealthy purchasers imported superior cars directly from Germany or France. Another key advantage the region held in supporting early automobile use was the availability of improved smooth-surfaced roads. At the end of the nineteenth century, usable networks of smooth roads existed almost exclusively in the Northeast and California; elsewhere in the United States, road conditions were deplorable. ${ }^{6}$

When they existed, the improved roads of the 1890s were a boon to farmers and others who had the need to travel by horse-drawn vehicle. As useful as improved roads were to farmers,

\footnotetext{
${ }^{4}$ Flink, America Adopts the Automobile, 31.

${ }^{5}$ Ibid.

${ }^{6}$ Hugill, "Good Roads," 331-332.
} 
the greatest voice lobbying for better road conditions were the country's four million bicyclists, among them the League of American Wheelmen, headquartered in Boston, who championed smooth-surfaced roads. The bicyclists' organized efforts raised the political profile of the roads issue through public talks, through their L.A.W. Magazine and through lobbying efforts. This organization "not only agitated for good roads but also published touring maps and guides, erected road signs, and identified inns and hotels that provided appropriate accommodations for middle-class and upper-middle-class urban tourists who were seeking the pleasures of the American countryside." " While the scale of bicycle ownership and the interest in middle-class accommodation suggest a populist agenda, many "middle-class" bicycle owners were far less likely to engage in long distance leisure tours, and multi-day rides away from home were a luxury usually limited to the affluent. In Boston, this elite interest was manifested by the Massachusetts Bicycle Club on Newbury Street [Figure 2-1], whose clubhouse was a logical byproduct of the city's nineteenth-century trend of establishing social clubs in expensive buildings in fashionable parts of town. ${ }^{8}$

The League's organization and emphasis on recreational tours "formed the groundwork for ... automobile owners when the automobile superseded the bicycle as the means to see the United States. Inherent in the elite's approval of the bicycle was a desire to escape the masses as well as the fixed lines and the schedules of the railroad; however, the bicycle required an inordinate amount of work on the part of the operator. The automobile was 'sweat-free' and, because it was more expensive, its ownership was a far better mark of distinction."9

\footnotetext{
${ }^{7}$ Ibid, 328.

${ }^{8}$ Founded in 1879, the Massachusetts Bicycle Club was among the earliest bicycle clubs in the United States. Among its founding members were members of the Pope estate as well as other millionaires. The first bicycle club in the nation, the Boston Bicycle Club of 1878, was also in the city.

${ }^{9}$ Hugill, "Good Roads," 328.
} 
While farmers and granges also argued for good roads since they facilitated transport of horse-drawn goods to market, highway construction in Massachusetts favored the leisure class, first as cyclists and later as automobilists. By 1896, 109 total miles of improved highways had been built throughout Massachusetts. The following year, the Massachusetts Highway Commission devised a cohesive plan for a four-tiered system of macadam roads, which would improve upon routes that were primarily dirt or gravel. This system was comprised of a radial network oriented around Boston, two east-west routes running from the coast to upstate New York, rural service roads serving the major river valleys and a recreational spur that connected Boston to Cape Cod. By 1907, substantial portions of the original plan had been completed and the highway department issued a revised plan that expanded the network [Figure 2-2]. ${ }^{10}$ Of those built, "only one of the four-tiered networks directly benefited farmers. The others benefited the elitist owners of Mercedes-style automobiles ${ }^{11}$ who were able to commute from suburbs to central cities, to make intercity trips, and to tour scenic parts of the state with a hitherto undreamed freedom." 12

While Massachusetts' comparatively generous use of macadam roads in the 1890 s and early 1900s attracted motorists, this type of paving was better suited to horse-drawn and bicycle traffic. Heavy automobiles and trucks easily damaged such roads and their surfaces were soon destroyed when too many cars used them. Further, increased use of automobiles along highways in the early 1900s raised a significant amount of dust on unpaved routes. These conditions led

\footnotetext{
${ }^{10}$ Ibid, 333.

11 Mercedes-influenced automobiles were based on the 1901 Mercedes and featured a body that was low to the ground, which gave them superior performance but required hard, smooth roads. They were unable to navigate rough roads with deep ruts, holes and mud pits. Other car types, such as the buggies and high-wheelers built in this period of experimentation, were derived from carriage design and their bodies were set much higher off the ground. For more on car design before the emergence of normal technology, see Peter J. Hugill, "Technology and Geography in the Emergence of the American Automobile Industry," in Roadside America: the Automobile in Design and Culture, ed. Jan Jennings (Ames: Iowa State University Press, 1990), 29-39.

12 Hugill, "Good Roads," 334.
} 
the Massachusetts Highway Commission to experiment with oil as a treatment on Cape Cod's sand roads. By 1909, the commission, frustrated by the continuous destruction of its roads by the tires of motor vehicles, began to experiment with the use of tar as a means to improve the binding of road surfaces. ${ }^{13}$ Country roads that were appropriately designed to withstand the destructive power of mass automobile use were not laid until 1918, when engineers in Wayne County, Michigan, discovered that concrete pavement between eight and nine inches thick could withstand heavy truck traffic, and meaningful expansion of concrete roadways did not occur until the passage of the Highway Act of 1921. As the Massachusetts Highway Commission's experiments show, road building at the beginning of the century was not adequate to support significant automobile use, and the ease with which roads were destroyed contributed to the unreliability of automobiles as a means of regular transportation. The road networks of Massachusetts were able to increasingly encourage auto use in the first decade of the twentieth century, but they were not yet equipped to allow practicable mass adoption. ${ }^{14}$

While streets in Boston (and in other northeast cities) enjoyed better paving than those in the country and suburbs, urban roads were still fairly rugged. A predominant paving method was to set roughly cut blocks of granite into the roadway. ${ }^{15}$ Installed in these cobbled streets were the many tracks of the streetcar network, which added additional ruts and ridges. Bumpy as it was, this paving type was suitable for horses and teamsters, as well was those riding electrified streetcars gliding over smooth rails. While Boston's cyclists deplored such roads and agitated for

\footnotetext{
${ }^{13}$ American Association of State Highway Officials, Convention and Twenty-Fifth Anniversary (Washington DC: The Association, 1939), 53.

${ }^{14}$ Hugill, "Good Roads," 342.

${ }^{15}$ Stanley K. Shultz, Constructing Urban Culture: American Cities and City Planning, 1800-1920 (Philadelphia: Temple University Press, 1989).
} 
smoother streets in 1900 , early automobiles were able to operate reasonably well on granite blocks. ${ }^{16}$

\section{USE PATTERNS}

Boston was among the first American cities to contend with the automobile, having access to one of the most usable road network in the United States, an active set of local automobile manufacturers and a sizable class of elites who could afford expensive cars and chauffeurs to care for them. Even so, the first years of their use minimally affected the city.

Automobiles were exceedingly expensive until the early 1910s, and their great cost both suppressed sales and kept them out of working-class hands. Throughout this first decade, "it was still possible to think of the automobile as a privilege confined to so small a class of rich people that it would have little impact on urban life." ${ }^{17}$ According to James Flink,

automobility remained a mass movement mainly in sentiment until after $1910 \ldots$ because cars were expensive. Until well after 1910, the initial price of an automobile involved a staggering expenditure for the family of average means. And there is good evidence that prices were not lowered as rapidly as possible. The average selling price of cars produced by the Association of Licensed Automobile Manufacturers (ALAM) went from $\$ 1,170$ in 1903 to an exorbitant $\$ 1,784$ in 1905 . As long as the early luxury market lasted, most automobile manufacturers, who were able to sell all the high-priced cars they could produce, spurned the idea of making lower-priced cars at lower unit profits. ${ }^{18}$

Additional factors also limited automobile ownership to elite circles in this first decade. The early years were a time when automobiles were expected to break down regularly, even those considered to be dependable. In 1904, a parade of 400 automobiles (many of which were autos invited from other cities and towns) was organized to carry Grand Army veterans over a forty-

\footnotetext{
16 "For Smooth Pavements," Boston Globe, July 20, 1900, 10.

${ }^{17}$ Douglas W. Rae, City: Urbanism and Its End (New Haven: Yale University Press, 2003), 223.

${ }^{18}$ James J. Flink, The Car Culture (Cambridge, MA: MIT Press, 1975), 29.
} 
mile round-trip course between Boston and Concord. The Boston Globe enthusiastically reported

that

there were as a matter of fact less than one-half dozen actual break-downs by which cars were put out of the running for any considerable time. During the run out and in the sight of a here and there chauffeur repairing a puncture, inserting a new spark plug, or tarrying for a time to relieve bearings made hot by fast driving and a neglect of lubricating oil was not uncommon, but such things in nowise detract from the automobile, which has now arrived at such a state of perfection as to be absolutely reliable. ${ }^{19}$

These breakdowns were seen as being an unavoidable part of automobile ownership, and early purchasers spent significant time and resources to keep themselves motoring.

During this period, pneumatic tires needed to be inflated to a very high pressure and only lasted for approximately 500 to 2,000 miles of use. ${ }^{20}$ The transmission of the Sears Motor Buggy was advertised to last for only 3,000 to 4,000 miles, indicative of the quality of inexpensive cars. ${ }^{21}$ The batteries of electric cars deteriorated rapidly, and at the turn of the century provided enough power to propel a car just twenty miles before a recharge was required. ${ }^{22}$ The high wheels, solid tires and other mechanical weaknesses of buggies based on carriage designs "cause[d] even the most trustworthy of locking nuts to give way at times" and for parts of these cars to regularly rattle loose. ${ }^{23}$ Electrical starters were not introduced until 1912 when Cadillac began using them, and the hand cranks that preceded them required a great deal of strength and finesse. ${ }^{24}$

\footnotetext{
19 "Splendid Test of the Auto," Boston Globe, August 21, 1904, 29.

${ }^{20}$ Hugill, "Good Roads," 345.

21 Joseph Schroeder and Sheldon Factor (eds.), Sears, Roebuck \& Co. Motor Buggy Catalogue 1909-1912 (Northfield, IL: Digest Books, 1973), 8.

${ }^{22}$ This range improved to about 50 to 80 miles by 1909. Flink, America Adopts the Automobile, 240-242

23 "Motor Buggies and Their Problems," Motor World, 19 (October 22, 1908) in Flink, America Adopts the Automobile, 248.

${ }^{24}$ Hugill, "Good Roads," 345.
} 
In response to the problem of reliability, Tessie Oelrichs, Virginia Fair Vanderbilt and other society women in Newport kept multiple machines on hand which simultaneously allowed them to drive a style of car suited to the motoring occasion (this was reminiscent of the elite's expensive practice of collecting fashionable carriages) and to have multiple backups for those times when the chauffeur was conducting repairs. The practice of owning multiple cars was a nationwide trend among early purchasers. In 1906, Harper's Weekly reported on this trend and estimated that in New York "there are more than 200 persons . . . who have from five to ten cars apiece. John Jacob Astor alone is credited with thirty-two. The string of vehicles owned by an enthusiast of this class will include two or three touring cars, a pair of racers, a couple of broughams, a runabout, a station-car, and a work car." ${ }^{25}$ In addition to the practice of keeping several cars, the earliest owners replaced them frequently to take advantage of the period's great technological advancements, to possess the latest style and simply because early cars did not last long. The trend somewhat diminished the number of registered cars that were in active use. ${ }^{26}$

Since all autos built in these earliest years were not weather-proofed and since passengers rode on open-air seats, use was seasonal. Many car owners stored them for the winter, which minimized their presence on city streets in colder months. The garages of this period regularly offered "dead" storage to clients at cheaper rates. Cars in dead storage were usually covered with a tarp and were parked in less accessible parts of a garage, such as on an upper level reached by a freight elevator. Since cars in dead storage were not actively retrieved, little space was reserved for circulation.

In the first years of auto use, motor cars were largely considered to be objects for sport and leisure. They might sometimes be used to commute to the center of a city, but reliability

\footnotetext{
${ }^{25}$ Henry Jay Case, "The Rise of the Motor Car," Harper's Weekly 50 (January 13, 1906) in Flink, America Adopts the Automobile, 57.

26 “Society’s Automobiles," Boston Globe, August 10, 1902, 34.
} 
issues, a lack of adequate storage, rough road conditions, occurrences of inclement weather and the difficulties of driving in roadways shared by pedestrians, streetcars and horses discouraged motorists from driving downtown.

\section{EXPOSURE}

Written accounts of automobile use reinforced the conception of motor cars as objects of elite fancy. Some of the earliest mentions of motor cars in Boston's newspapers were color pieces describing amusing anecdotes about automobiles in metropolises, such as Paris and New York, where ordinary people viewed the devices with a combination of intrigue, skepticism, disdain and terror. In 1897, for example, the Boston Globe published a comic account of a farmer, portrayed as a practical ignoramus, who went to New York to speak with a seller of horseless carriages about how such a vehicle might be fitted with spiked iron wheels so that his wife could plow their fields in a leisurely manner with their children picnicking in the back. When told the high price, the farmer exclaimed, "Gee whiz! Three thousand dollars for one of them wagons! Not by a durned sight. I thought I could get one for about \$100."27 Booth Tarkington's The Magnificent Ambersons captured this populist sentiment, with the children of the novel ridiculing Eugene Morgan by shouting the epithet "git a hoss!" when they chanced to see him riding his contraption in the years when the aristocratic George Amberson could outrun a motor car in his speedy trotter. ${ }^{28}$

In 1901, a Bostonian's exposure to automobiles was more likely to come from written accounts than from a direct encounter. Nearly all mention of automobiles in Boston's newspapers in this year described the spectacle of races between experimental machines, exhibitions or elite consumption. Readers of the Boston Globe would have learned that William

\footnotetext{
27 “Too High for What He Wanted,” Boston Globe, December 12, 1897, 31.

${ }^{28}$ Booth Tarkington, The Magnificent Ambersons (New York: Doubleday, Page \& Company, 1918 ), 102.
} 
K. Vanderbilt planned to compete against the likes of Foxhall Keene in a 900-mile race between Paris and Vienna. ${ }^{29}$ They would have read of Mr. Vanderbilt's several conquests in races held in Newport, Rhode Island, where "riding like a demon and absolutely fearless in the face of the greatest danger that might be occasioned by the loosening of even the smallest screw in his 'Red Devil,' William K. Vanderbilt Jr. again won the automobile championship of the United States at Aquidneck park today." ${ }^{30}$ The Boston Globe also reported that Louis Deforest, William Sands and Mason Janney (with their attendants) attempted to set a speed record for travel between Boston and Newport using ordinary touring cars. ${ }^{31}$ An illustrated feature announced that Sarah Elizabeth Clark, who recently inherited a fortune, was conducting an automobile trip from New York to Texas, where she planned to view her holdings in the oil region. ${ }^{32}$ The Automobile Club of New England's first annual race was held at the Brookline Country Club in this year, "which was a distinctive novelty in this section of the country [and which] doubtless impressed the 500 or more persons who witnessed it as a weird exhibition of the various things that can happen to automobiles without injuring the riders" ${ }^{" 33}$ [Figure 2-3].

The Boston Globe also accounted for the arrival of automobiles in the wealthy summer resorts of the Berkshires, specifically characterizing them as objects of exclusivity, declaring to its readership that in Lenox "the beginning of the war ... has been declared between millionaire horse owners and millionaire chauffeurs" and that a "controversy" in Lee, Lenox, Stockbridge and Great Barrington led the towns to pass laws that restricted motor cars from operating at speeds greater than eight miles an hour. The Berkshire automobilists were portrayed as chagrined

\footnotetext{
29 "Vanderbilt and Keene in," Boston Globe, November 18, 1901, 5.

30 "Red Devil the Victor," Boston Globe August 31, 1901, 12.

31 "Automobile Run to Boston," Boston Globe July 16, 1901, 7.

32 "New York to Texas on an Automobile," Boston Globe, August 5, 1901, 2.

33 "Automobile Races at Country Club," Boston Globe, June 16, 1901, 5.
} 
roadsters irritated that their preference for country speeding in open-air cars was being unjustly stifled:

'What is the pleasure of hobbling at six miles an hour? That would be going back to babyhood and creeping.' They want to feel the wind howl past them as they cleave the air, and they say that no practical chauffeur feels at home on the seat of a machine unless he has to lean far out of a vehicle as it rounds a corner.

The idea of not leaving a cloud of dust and dirt behind an automobile in operation would be like sending up skyrockets at night that did not explode, say they. Then, too, they claim that the distinctive dress of the chauffeur would be lost. He would be like a man in knickerbockers at a ball if he donned the weather cap, goggles and belted down his coat for a six miles an hour pace. ${ }^{34}$

While the "millionaire chauffeurs" were purported to bemoan the loss of danger that accompanied entirely unregulated driving practices, the reader was meant to find these drivers' (and their horse-riding counterparts') worry over driving laws to be ridiculous, foreign concerns. This kind of characterization prevailed through the first half of the decade, with generous coverage of the Vanderbilts, the Oelrichs and other society people racing, buying new machines, or speeding. ${ }^{35}$

These and other articles underscored the novelty and excitement of new machines while almost universally characterizing them as devices of sport used by people of lavish means. ${ }^{36}$ In the following years, coverage expanded to include more extensive discussion of the future of the automobile and its role in the city, but much of this coverage was speculative. Brick-and-mortar constructions in support of automobiles were rare, with the most significant early construction being the 1902 Massachusetts Automobile Club, a building whose form and social significance

\footnotetext{
34 “To Lock Horns," Boston Globe, August 17, 1901, 3.

35 At this time, the term speeding was not used to describe automobiles driving at rates over an established limit. Rather, speeding was used to simply describe what an automobile was designed to do, namely travel much faster than other conveyances. Peter D. Norton, Fighting Traffic: The Dawn of the Motor Age in the American City (Cambridge, MA: MIT Press, 2008), 30-31.

36 “Automobile Run to Boston," Boston Globe, July 16, 1901, 7; “Automobiles on Exhibition," Boston Globe, November 16, 1901, 5.
} 
encapsulated ways that Boston sought to come to terms with the new technology in its earliest manifestation as an urban fixture.

\section{CLUBS}

An important part of urban life in American cities during the transition into the "horseless age" was the formation of numerous civic organizations through which members participated in their local community. These organizations took many forms, including religious groups associated with particular parishes or congregations, neighborhood and company athletic teams, ethnic organizations, and a wide range of clubs and fraternal organizations. Depending on their nature, the civic organizations active in Boston provided their members opportunities for leisure, to play or watch sports, to advance a cause, or to participate in the local chapter of a national organization. By 1910, hundreds of clubs existed in Boston, their numbers attributed by Douglas Rae to recent improvements for working people, such as the reduction of the average workweek from six to five-and-a-half days, the mechanization of some kinds of labor and new access to an increasingly wide range of popularly priced goods and services. ${ }^{37}$

Among Boston's civic organizations were a handful of upscale, influential and ethnically exclusionary clubs that were created to serve the interests of their mostly male members earlier in the nineteenth century. These clubs, such as the Somerset and the Algonquin Club, were often attached to prominent Boston estates and their members established exclusive clubhouses which contained grandly appointed dining rooms, libraries and sleeping chambers, among other comforts. Depending on their age and fortune, the best of them overlooked either the Common or Commonwealth Avenue [Figures 2-4, 2-5].

\footnotetext{
${ }^{37}$ Rae, City, 142; Robert D. Putnam, Bowling Alone: The Collapse and Revival of American Community (New York: Simon \& Schuster, 2001), 383-394.
} 
Mythologized by Cleveland Amory and others as seats of prestige and vestiges of Brahmin culture, elite clubs played an important role in making decisions that would affect the shape of the city, and this trend continued into the age of the automobile. ${ }^{38}$ The Social Register Association in this period continued to include club memberships as a key attribute in its listings, along with name, university and address. ${ }^{39}$ The clubs became realms of influence, and mayors, governors, and other political figures frequently spoke to members when they sought support for an election, an agenda or a legislative act. Samuel J. Elder, who served as senior counsel for the United States Government before the Hague Tribunal and who was a member of the Massachusetts House of Representatives, frequently spoke at clubs. His addresses included an 1896 speech at the Paint and Oil Club, where he advocated for roads cutting into the Common as part of a street modernization scheme. ${ }^{40}$ In 1909, Mayor John F. Fitzgerald, the executive committee of the Metropolitan Improvement League, and City Councilman James Noyes met at the Puritan Club to discuss a proposal to continue Huntington Avenue through Copley Square to Boylston Street. ${ }^{41}$ The Algonquin Club, in part because it had the largest banquet facilities of any club in the city, played an especially active role in Boston politics. For example, Mayor Thomas Hart and the city's chief engineer spoke at a 1902 meeting of the Merchant's Club held at the Algonquin to discuss metropolitan water consumption and to recommend improvements to Boston's water system. ${ }^{42}$ Various city leaders attended a dinner in 1902 at the Algonquin on the theme of "Boston's Needs," including a representative of Mayor Patrick Collins, the president of

\footnotetext{
${ }^{38}$ Cleveland Amory, The Proper Bostonians (New York: E.P. Dutton \& Company, 1947), 29, 131, 205, 349-350, 355-359.

${ }^{39}$ The Social Register, Boston, 1904 (New York: The Social Register Association, 1903).

40 "Mr. Samuel to Speak on 'The League to Enforce Peace,"” The Harvard Crimson March 31, 1916, n.p.; "Cut up the Common," Boston Globe, April 9, 1896, 6.

41 "Showing the Proposed Improvement of Copley Square," Boston Globe, June 9, 1909, 8.

42 "Boston's Water System," Boston Globe, January 22, 1902, 8.
} 
Boston's Real Estate Exchange, and the chairman of the Metropolitan Park Board. ${ }^{43}$ The Algonquin Club also hosted dinners for political parties, such as one organized for the members of the State Democratic Committee of 1902 and that year's slate of democratic candidates for Congress. ${ }^{44}$

Several automobile clubs were organized in the Boston area in response to rising interest in motor cars. Among them was the Harvard Automobile Club, formed by sporting students who began contemplating intercollegiate meets and races with their peers at Columbia, Princeton, Yale and the University of Chicago as early as 1900. In that year, the Harvard Automobile Club took possession of a horse stable, removed the stalls and used the building to store as many as twenty machines. William Crane was the envy of the school, as he was the only student in 1900 to own a gasoline-powered carriage. ${ }^{45}$

These first automobile clubs reflected contemporary use - they were creations of the elite who perceived motor cars as objects of sport and as a measure of status. Later in the first decade of the twentieth century, the creation of other clubs, such as the Bay State Automobile Association, responded to increasing interest in cars as their use grew into a mass movement.

\section{Massachusetts Automobile Club}

By 1900, automobile use among Boston's most affluent citizens had expanded with such enthusiasm that a prominent social club was formed to support their interests. The Massachusetts Automobile Club (MAC) was founded in October, 1900, following the lead of similar clubs in Chicago (the Chicago Automobile Club) and New York (the Automobile Club of America), both established in 1899 and both embodying the grandeur of late nineteenth-century bourgeois urban

\footnotetext{
43 "For Advance of the City" Boston Globe, February 21, 1902, 1.

44 "Comfort in Northeast," Boston Globe, November 14, 1902, 1.

45 “Automobile Notes," New York Times, October 28, 1900, 11.
} 
culture. The membership of the Automobile Club of America purportedly included more millionaires than any other social club throughout the world. Among them were Alfred G. Vanderbilt, Henry Clay Frick, John W. Gates, A. W. Rossiter, J. F. O'Shaughnessy and Frederick Southtrack. ${ }^{46}$ Motor Age fittingly described the Automobile Club of America as "an ultra-fashionable coterie of millionaires, who have taken up the new and expensive fad of autolocomotion and banded themselves together for its pursuit and the incidental notoriety attributed to all the functions of upper swelldom." ${ }^{47}$

The MAC existed to serve the "upper swelldom" of Boston, and the new club was immediately listed alongside the Algonquin, Somerset, Union and Tennis \& Racquet clubs in the Social Register as defining Boston society [Figure 2-6]. Like its New York predecessor, the MAC's early membership was exclusive and wealthy. The first club officers included Col. James T. Souter (president), Eliot C. Lee, Dr. Joseph C. Stedman, Royal R. Sheldon, Charles J. Glidden, George McQuesten and Newton Crane. Membership in 1902 was limited to 150 men, though the club already had a waiting list. Many members lived in the Back Bay, close enough that they might call the club to have their automobile delivered to their address by a chauffeur within a few minutes [Figure 2-7]. Others lived in select suburban enclaves, especially Brookline. ${ }^{48}$ Members were reported to be "social leaders and solid, substantial business men," and their ranks included many millionaires and old-money Bostonians. Among them were Elliot Cabot Lee, Oakes Ames, Larz Anderson (diplomat), John Silsbee Lawrence (textiles manufacturer and grandson of Amos Lawrence), John C. Philips (prominent wildlife

\footnotetext{
${ }^{46}$ Flink, America Adopts the Automobile, 145.

47 "The Automobile Club of America," Motor Age 2 (June 28, 1900) quoted in Flink, America Adopts the Automobile, 145.

${ }^{48}$ In 1902, there were 138 resident members listed in the Massachusetts Automobile Club's handbook. Of these members, fifty-eight had addresses listed in the 1904 Social Register of Boston. Thirty-four of these fifty-eight members lived in central Boston. Twenty-four lived outside of the city center, with nine in Brookline, two in Jamaica Plain, two in Medford and one each in Cambridge, North Easton, Chestnut Hill, Weston, Needham, Salem, West Newton, Waltham, South Framingham, Newton Center, West Roxbury and Dorchester.
} 
conservationist), Albert A. Pope (of the Pope Manufacturing Company), Quincy A. Shaw and Roger Wolcott (son of the Massachusetts governor). ${ }^{49}$

The club was such an immediate success that the MAC quickly outdid prominent urban auto organizations in other American cities by building a lavish clubhouse and garage for its members at 751 Boylston Street, between Exeter and Fairfield Streets. This clubhouse had "the unique distinction of being the first and only house in this country to be devoted exclusively to the needs of automobile enthusiasts. It marks the beginning of an epoch and Boston with modest pride claims the distinction of being a leader in establishing a clubhouse of this character."50 Others would later follow in Chicago and New York.

The 1902 clubhouse was three stories tall and had a thirty-foot frontage with an approximate depth of 100 feet [Figure 2-8]. As with other clubhouses built by and for the city's elite, social rooms were lavishly appointed. The Boston Globe described these spaces with fanfare, reporting that "the second floor is given over to commodious and inviting reading rooms, reception rooms and a café. The furnishings bespeak comfort on every side. The ceiling finish is massive natural oak, while the wall decorations are of tapestry effect. The whole meets with the approval of the most critical clubman." 51 On the club's inaugural night, "music made the hours merry, and refreshments were served. The enthusiastic members gathered in its spacious parlors or around its roaring fireplace, and, forgetting the bitter cold outside, laughed and prophesied to each other how they would make the dust fly next summer." 52 The excitement of the evening and of the potential camaraderie and adventure that was afforded to these early

\footnotetext{
49 Massachusetts Automobile Club, The Act of Incorporation, Constitution, By-Laws, and House Rules of the Massachusetts Automobile Club with a List of the Officers and Members (Boston: Geo. H. Ellis, Printers, 1902); Sidney Ratner, New Light on the History of Great American Fortunes (New York: Augustus M. Kelly Inc., 1953).

50 "Palace of Comfort," Boston Globe, January 2, 1902, 2.

51 Ibid; “Automobile Club's New Home," Boston Globe, January 2, 1904, 7.

52 "Palace of Comfort," Boston Globe, January 2, 1902, 2.
} 
motorists was evident. When the warmer months did arrive, the club organized tours of New England, races and excursions to seaside resorts.

At the time the club was built, automobiles required a great deal of maintenance and they needed to be stored indoors. Thus, the entirety of the clubhouse's lower two floors were used to store and service members' automobiles. The street level provided ample space for the washing and cleaning of automobiles. The remaining space of the ground floor and the whole of the floor above it were given to storage, with a reported total capacity for about 100 motor cars. ${ }^{53}$ The basement was outfitted for repairs. Each of the automobile floors was connected by elevator, which was how the machines were moved.

Providing these services was a necessity. Since early autos were not weather-proofed, they could not be parked for long in the street even in the warm months. In the winter, cars were stored indoors until the problem of operating an open car in freezing temperatures on snow- and ice-covered streets resolved itself. At the time the 1902 clubhouse was built, public garages were almost nonexistent in Boston and the few in operation had little capacity - the first sizable garage did not open until 1904. A handful of residents in Beacon Hill and the Back Bay had small onestory structures that could serve as private garages or stables behind their homes, but these were very few in number. The clubhouse not only provided social space to converse and daydream about the sport of motoring, but it also provided a centralized place where the hassles of storage, maintenance, cleaning and fueling could all be resolved when other facilities to perform these tasks did not conveniently exist.

Just twenty months after the MAC's clubhouse first opened its doors, the original building was no longer adequate for member needs and a contract to construct a new club was

\footnotetext{
${ }^{53}$ It is doubtful that this many cars could realistically have been stored over two floors given this building's footprint. Those that were stored were packed very tightly and inconveniently.
} 
awarded [Figures 2-9, 2-10]. ${ }^{54}$ This new club incorporated the original building and expanded the street frontage from thirty to eighty-seven feet at an estimated cost of $\$ 280,000 .{ }^{55}$ The Boston Globe advised its readers that "the completed building will be of brick, with terra cotta trimmings, the front being of mottled gray brick to the second story, and above that dark red brick laid Flemish bond.” Besides continuing to afford grand accommodations to a growing pool of members, the MAC significantly expanded its storage and service facilities. The club's garage doubled its reported capacity and could now house more than 200 automobiles. Large central arched entrances permitted two automobiles to enter or exit simultaneously, these covered by a "handsome iron grill." Gasoline pumps were located just outside this entryway, with fuel tanks buried underneath the sidewalk. ${ }^{56}$

The internal program improved upon that of the 1902 clubhouse. The original building was given to social functions, and featured an office, library, kitchen, dining room and billiard room. The first floor of the expanded club contained storage for autos, a "ladies' room" to the left of the entrance and the office of the superintendent to its right. At the rear of this floor was a large washstand that could accommodate four autos simultaneously. The second and third floors were primarily garage space, though the second floor also contained a chauffeur's room with lockers and toilet and the third floor featured a repair shop set under skylights with heavy iron tackles capable of lifting a motor car off the floor. In the basement was more auto storage, plus the heating plant, coal storage and a workshop. Autos that were in frequent use were kept on the first floor; those used occasionally were stored on the floors above. ${ }^{57}$

\footnotetext{
54 “Automobiling," Boston Globe, September 6, 1903, 29.

55 "Motor Cycle Club Acts," New York Times, March 16, 1903, n.p.

56 “Automobile Club's New Home” Boston Globe, January 2, 1904, 7.

57 Ibid.
} 
The walls of each floor were lined with lockers for members to store their belongings, including the goggles, face masks, caps and long coats that equipped the serious motoring enthusiast. These served as effective protection against the dust and debris that were a nuisance to drivers navigating open-air cars on roads that were often unpaved, and a means to avoid identification in the event a motorist was observed driving recklessly [Figures 2-11, 2-12]. As the MAC was concerned about the common problem of automobiles igniting fires in garages, the first floor and basement were granolithic, while the other floors were covered with fireproof paint. An eighteen- by eight-foot elevator ran from the basement to the third floor, as did a fireproof stairway. ${ }^{58}$

When the expanded club opened in December, 1904, the festivities were extravagant and included a dinner, speeches and an orchestra. The occasion warranted the attendance of dignitaries from clubs in other cities. The Automobile Club of America, which sought to promote itself as the leading voice of the emergent automobile movement, sent its president, Harlan W. Whipple, to the inaugural reception, who declared in a speech that the splendid building would inspire the ACA to build such a house for their headquarters in New York. ${ }^{59}$

The architectural tactics used by the builders of the original 1902 Massachusetts Automobile Club were similar to those used by other prominent urban auto clubs. According to Stephen Sennott, the earliest clubhouses built for auto enthusiasts chose forms that resembled grand residential buildings and other established private clubs to convey the prestige and exclusivity that automobiles conferred upon their owners. For example, the Chicago Automobile Club established itself in 1902 in an existing mansion that had been converted into a hotel. It was domestic in appearance, with dormers, a veranda, and a mansard roof. Inside, members enjoyed

\footnotetext{
${ }^{58}$ Ibid; “Auto Club House Open,” Boston Transcript, December 10, 1904, 4.

59 "Clubhouse Dedicated," Boston Globe, December 10, 1904, 4.
} 
access to a billiard room, dining rooms, and bedrooms. A small repair shop and garage to store autos were attached at the back of the club "and indicated the club's initially small number of devotees at a time when cars were still rare and expensive." ${ }^{\prime 0}$ Neither the 1902 clubhouse of the MAC or the Chicago Automobile Club used a built form designed to express an internal program devoted to automobile storage.

When the clubs expanded, however, they used different approaches. In 1906, when the exclusive identity of the Chicago Automobile Club "was more widely recognized, they commissioned [the firm of Marshall \& Fox] to design their own fashionable club" [Figure 213]. ${ }^{61}$ The façade and scale of the new Chicago Automobile Club resembled that of previously built private clubs in the area. Inside, however, the program was very different. There were six floors, each with space for automobile service and storage. At the street level, there were two entrances, one for pedestrians and one for vehicles, as well as storefronts. The second floor featured a lounge with a balcony overlooking the street, a kitchen with men and women's cafes, and sleeping quarters, thus combining garage and social functions in one interior space. Inside the Chicago Automobile Club, "the plan accommodated the automobile; outside, the façade was, like the automobile within, a 'blatant crier of surplus wealth' and expressed the club's restrictive and elite pattern of automobile use" by again taking a form that evoked other clubs. ${ }^{62}$

The Boston club of 1904, on the other hand, departed from typical clubhouse form and sought a design more expressive of the building's purpose, contrasting with Sennott's observations about the Chicago club. The expanded building employed an arrangement with beaux-arts influenced neoclassical row houses on each end, this done to effectively incorporate the original building into the new club's design. The central part of this building sought a grand

\footnotetext{
${ }^{60}$ Stephen Sennott, "Chicago Architects and the Automobile, 1906-26," in Roadside America, ed. Jennings, 159.

${ }^{61}$ Ibid.

${ }^{62}$ Ibid, 160.
} 
expression by using large arches that were explicitly Roman in treatment. It was through these archways that automobilists entered and exited the club, highlighting and celebrating the garage that lay beyond. The scale of these arches and their direct street frontage were almost certainly informed by recent firehouse design, these designs borrowing from an older carriage-house typology. Regardless of the origins of the quotation, the shape and prominence of these arches, as well as the club's location on Boylston Street, did not seek to conceal the storage of cars, but to relish in it.

\section{Bay State Automobile Association}

As automobile use expanded throughout the decade, many prominent urban clubs took an increasingly active role in seeking to influence new legislation to create conditions that favored motorists. In Boston, the Massachusetts Automobile Club at first took part in these efforts, for example by sending a representative to a meeting of a committee on mercantile affairs to argue against garage regulation. ${ }^{63}$ But as it became apparent that automobiles would be used by a broader range of people with utilitarian concerns, the MAC abandoned its efforts to influence legislation. By this time, the organization was "snobbish to the point of neglecting public relations almost entirely, disdained attempting to influence motor vehicle legislation, and rather exclusively emphasized social functions and providing services for a small, select body of members." $" 64$

When the MAC's interest in lobbying shifted with new patterns of motor car use, the Bay State Automobile Association was formed in 1905 as a rival precisely concerned with undertaking such a role, and maintained a legislative committee that sent representatives to all public hearings of held by the highway commissioners "or anywhere else where matters of

\footnotetext{
63 "License for Garage Urged," Boston Globe, March 1, 1907, 4.
}

${ }^{64}$ Flink, America Adopts the Automobile, 151. 
importance [came up] for open discussion." In this decade, limited regulation of automobiles meant that most of their efforts were focused on attempting to limit registration fees and speed laws. In the later 1910s, this organization became far more active as automobile use became more disruptive and widespread. ${ }^{65}$

Like the MAC, the Bay State Automobile Association provided a social outlet to its members by hosting dinners and organizing group excursions. But with 700 members by 1907 and more by the close of the decade, the scale of the organization reflected an interest in the broader public and a different sensibility about the nature of automobile use. While the Bay State Automobile Association sought to maintain a clubhouse, the organization moved regularly in its first years before settling into a suite of rooms at the Hotel Lenox on Exeter Street, a far more modest arrangement than the MAC. Unlike the MAC, the Bay State Automobile Association did not maintain storage facilities for its members, and its members instead made use of the public garages that began to open in the city. ${ }^{66}$

The Bay State Automobile Association was concerned with the everyday adoption of the motor car and sought to attract as many members as possible. The MAC, with its emphasis on extravagant social events and on maintaining a luxurious clubhouse and private garage, failed to see that its model, which depended on "restricted membership and high fees, would cease to attract many motorists once automobile ownership became fairly widespread, motoring came to be considered utilitarian rather than a 'sport,' and the public garage became an established institution. ${ }^{.67}$

\footnotetext{
65 "Bay State Automobile Association Is Growing," Christian Science Monitor, August 2, 1913, 11; "Proposed Changes in Bay State Auto Laws," Christian Science Monitor, April 13, 1912, 16.

66 "Now Has a Membership of 700," Boston Globe, January 8, 1907, 4; "Bay State Auto Association Has Shown Big Growth," Christian Science Monitor, March 6, 1909, 8.

${ }^{67}$ Flink, America Adopts the Automobile, 153.
} 
Reflecting the changing character of the automobile landscape as use became more widespread, the MAC again built a new clubhouse in 1914 on the corner of Stuart and Clarendon Streets [Figure 2-14]. While the house rules published in the MAC's annual yearbook in 1920 implied that club members clung to elite presumptions, the new building's physical form confirmed the end of exclusivity. Seven stories tall and built of concrete, the 1914 clubhouse was far more utilitarian and could house over four hundred automobiles, with significant aisle space reserved for active circulation. Typical of other garages built in this period, the various floors were linked by freight elevator. The new building's only social rooms were confined to a portion of the second floor. Otherwise, the entire structure was given to storage, excepting spaces reserved for repair and maintenance. The glass-filled walls gave the club the appearance of a factory or warehouse. While the 1902 clubhouse appeared to be a residential structure with a garage space hidden inside, the 1914 building appeared to be a garage with an invisible club tucked away. ${ }^{68}$

\section{STORAGE, SALES \& REPAIR}

When the first automobiles were purchased in Boston, their owners faced a dilemma-where to store a very expensive machine that required frequent maintenance and that could not be subjected to standing outside in poor weather. In nearly all cases, the first purchasers were wealthy people buying one or more vehicles for leisurely touring, for sport and for status. Others were aspiring car dealers who bought a number of vehicles from a manufacturer with the hopes of successfully introducing them to the Boston market. Medical doctors who made frequent trips to see patients were also among the earliest buyers. As discussed earlier in this chapter, many of

\footnotetext{
68 "Now Ready for Its Members," Boston Globe, January 15, 1914, 3; Yearbook of the Massachusetts Automobile Club and the Massachusetts Automobile Club Trust (Boston: March, 1920).
} 
these early purchasers were elites living locally who solved the problem of storage by forming the Massachusetts Automobile Club.

While the MAC building was the first to be designed to accommodate the storage and repair of numerous motor cars, by physical and social design it was only able to serve a very limited number of people. Those unable or unwilling to join it were almost always compelled to store their machines in buildings that had been originally designed for other purposes.

One of the first solutions adopted was to convert a family's small private stable into a garage. Even at the apex of horse use, however, few such private stables existed in Boston, and most horse and carriage owners were far more likely to use boarding stables, which had numerous advantages including the concentration of unpleasant odors away from one's home. This preference for boarding meant that only a handful of family stables were available for conversion to garage use. In the residential districts of Boston, these stables-cum-garages existed almost entirely at the rear of lots in Beacon Hill and the Back Bay that abutted the Charles River, most notably on Back Street [Figure 2-15]. The eight private garages shown on this sheet from the 1914 Sanborn atlas all replaced former stables, and constituted the greatest concentration of such garages in the city. Approximately fifty-two personal garages existed throughout central Boston by 1914, and twenty-four of these were located along Back Street and the Charles River Embankment, the great majority of them being former stables ${ }^{69}$ Very few personal garages were newly built in the early years of automobile use, since the row-house and town-house arrangement of old Boston's residential neighborhoods did not leave enough space to accommodate this option. Collectively, central Boston's fifty-two small personal garages had a capacity comparable to the original MAC clubhouse (reported to be approximately 100 vehicles).

\footnotetext{
${ }^{69}$ These counts are based on a systematic review of the various Sanborn plates covering Boston proper.
} 
Long-term street parking was not common as a means of storage, since cars were not suited to standing outside in inclement weather and since custom (and poorly enforced city regulations) did not yet allow vehicles to stand at curbs for extended intervals. On days when a motorist desired to take a car out of a garage, they might park along a curb for a short period of time governed by the same regulations as horse-drawn teams. ${ }^{70}$

\section{Adaptive Reuse}

Given the lack of personal storage and the impracticality of street parking, public "garages," "auto houses," "motor car hotels" and "stables" were needed in order for automobiles to be used in Boston. The first public garage on record in the United States was the Back Bay Cycle and Motor Company of Boston, which began advertising its automobile accommodations in 1899 as "a stable for renting, sale, storage and repair of motor vehicles." ${ }^{, 71}$ While this enterprise is poorly documented, the Back Bay Cycle and Motor Company advertised a commercial model that was replicated by other early garages in the city. At a time when motor cars were rare and little infrastructure existed to support them, this "stable" for motor cars served as a one-stop shop where a car could be viewed, purchased, housed, maintained and repaired. That this enterprise doubled as a bicycle company is not surprising. Manufacturing of early automobiles depended on many advances pioneered a decade earlier by bicycle makers, including cold-rolled steel,

\footnotetext{
${ }^{70}$ According to Peter Hugill's characterization, "despite the effects of standardization, automobile travel in the early 1920s was still an adventure, particularly in inclement weather. The first decade of the twentieth century witnessed the evolution of a reliable automobile; the second decade gave rise to the hard-surfaced road; the third decade saw the refinement of an all-weather automobile," quoted in "Good Roads," 345; The Revised Ordinances of 1898 of the City of Boston and the Revised Regulations of the Board of Alderman of the City of Boston with All the Ordinances and Regulations Passed from the Passage of the Revised Ordinances of 1898 and the Revised Regulations of 1898 to November 1, 1908 (Boston: City of Boston Printing Department, 1908).

${ }^{71}$ While McDonald and others suggest that the Back Bay Cycle and Motor Company was the first public garage on record, an item appearing in the Boston Globe states that the first enterprise where a motor car could be stored, repaired or rented opened in Boston in the spring of 1890. This garage is not named, nor is the street provided, and the date itself is so early that it is probably a reporting error. Shannon Sanders McDonald, The Parking Garage Design and Evolution of an Urban Form (Washington, DC: The Urban Land Institute, 2007), 18; "Did You Know That," Boston Globe, August 11, 1918, 45.
} 
accurately machined gears, ball bearing and pneumatic tires. Many early garages offered to repair both bicycles and automobiles, though this practice was short-lived. Typical of garages that followed, the Back Bay Cycle and Motor Company occupied space in a bicycle store that was not originally envisioned to be a structure in which automobiles would be sold, stored and repaired. ${ }^{72}$

Four years after the Back Bay Cycle and Motor Company began running its advertisement, the Boston Globe presented its readers with a list of "New Words and their Meanings," reproduced from the Typographic Journal, which had lately puzzled editors and proof readers and which were often not found in dictionaries. Among the words listed were grog (a broken brick), savage (a term used by those who frequent races to signify a vicious attack by a dog or horse), racket store (a store, often temporarily open, selling cheap goods) and garage, which "signifies a place where automobile parts are stored, to be assembled, or brought together, when required." In these first years, "garage" was used as a general term to describe almost any building that had a relationship to automobiles. ${ }^{73}$ While Boston was home to what might be the first public garage in North America, automobile storage remained a novel proposition, new enough that the language used to describe automobile use had not yet been codified.

Just as automobiles built during this early period were experimental and rapidly changing, so too were the buildings that housed them. The first decade of the twentieth century witnessed a number of strategies that sought to conveniently and safely protect existing automobiles while simultaneously marketing them to a more widespread pool of consumers. The prevailing strategy was to reuse existing buildings, sometimes without any modification, as spaces to store automobiles. While such storage facilities often repurposed existing boarding and

\footnotetext{
72 Hugill, “Good Roads," 327.

73 “New Words and Their Meanings,” Boston Globe, June 14, 1903, 35.
} 
livery stables (usually these were at least three stories tall, with wooden floors and a freight elevator), those who sold and stored automobiles also sought to reuse other types of existing buildings that had expansive floor plans (such as a railroad's unused freight shed), which allowed automobiles to be moved more easily when inside.

As in other large American cities, Boston's early garages were built outside of the established downtown area. Garages and other businesses catering to automobilists were first concentrated in a small area around Park Square, on Stanhope Street near Columbus Avenue, along Boylston Street near Copley Square and on Newbury Street near Massachusetts Avenue. The selection of these places in or near the Back Bay was deliberate. They were all outside of the congested district, where high real estate prices, existing businesses and traffic difficulties made establishing garages a logistical and economic challenge. Particularly in the case of the Boylston and Stanhope Street areas, these districts were still developing at the turn of the century, making it easier for automobile dealers and sympathetic business to congregate in proximity to one another, a locational strategy that created specialized retail zones similar to others that existed in fin de siècle Boston. ${ }^{74}$ They were conveniently accessible to early car owners, who predominantly lived in the Back Bay, affluent suburbs such as Brookline, or were adventurous inter-city travelers. Routes to these suburbs and to what highways that existed were close at hand. ${ }^{75}$ Also attractive was the proximity of Commonwealth Avenue, which was unique among streets in Boston for being long, straight and wide, and which was very popular with "scorchers"

\footnotetext{
74 David Ward, "The Industrial Revolution and the Emergence of Boston's Central Business District," Economic Geography 42, no. 2 (April 1966): 152-171.

75 Several favored routes were at hand, according to the Automobile Blue Book of 1901. To reach points to the northwest, motorists were advised to take Massachusetts Avenue across the Charles River, drive to Harvard Square and then continue onward to their destination. To reach points to the west, motorists would take Beacon Street through the Back Bay, Longwood, Allston and Brighton to Newton and then onward. To reach points to the south, they would take either Boylston Street to Brookline and then onward, or Tremont Street to Roxbury and then onward. Official Automobile Blue Book, Eastern Edition (New York: Official Automobile Blue Book Company, 1901).
} 
testing the limits of their machines. The absence of garages in downtown Boston also reflected the area's lack of stables, which meant that there was a lack of "appropriate" buildings to adaptively reuse for automobile storage. ${ }^{76}$

In 1897, small, dead-end Stanhope Street occupied land between the tracks of the New York, New Haven \& Hartford and the Boston \& Albany railroads. Its two blocks were home to ten stables serving a variety of interests. Most of them were modest in size and were two stories tall with a basement and narrow street frontage. Two of them were larger - a three-story stable for teamsters and five-story boarding stable with attendant carriage house. The other buildings of the two-block-long street included a wagon shed, two bicycle shops, and two companies that published and printed sheet music. The remainder of the street's lots were vacant. With the exception of the music publishers, the whole of the street was devoted to horses and bicycles.

Within four years, this street would be home to what was briefly considered Boston's "Automobile Headquarters," a newly constituted garage located at 66-68 Stanhope Street [Figure 2-16]. Inspired by a "permanent automobile exhibition" in Berlin and by New York City's recently inaugurated Herald Square Exchange, the new building on Stanhope Street marked the beginning of serious investment in the automobile trade in Boston. Built in 1901, it was five stories tall with a basement, with each floor approximately 5,000 square feet and connected by an elevator capable of lifting an automobile. The basement and first floor appear to have been used for public storage and the repair of automobiles. The second and third floors were rented to the agents of automobile manufacturers, who established showrooms and offices. The top two floors were "elegantly fitted up for club purposes, with reading and lounging rooms, library and offices." Other amenities included private lockers, "well-appointed" waiting rooms,

\footnotetext{
76 "For Auto Racing - Robert Goelet Arrested in the Back Bay," Boston Globe, June 20, 1902, 5.
} 
and conveniences for the entertainment of guests. ${ }^{77}$ Though not itself a club, this early public garage and showroom recognized its clients and understood the need to provide significant space for social connection and leisure.

This building site (previously a vacant lot) appears to have been selected in part because of its proximity to "Cycle Row," a stretch of Columbus Avenue between Ferdinand Street and Clarendon Street that was home to a dense concentration of sympathetic bicycle interests, including multiple salesrooms and the headquarters of the League of American Wheelmen, who famously organized the national Good Roads movement in the 1890s. It was anchored by the Pope Manufacturing Company's Boston branch, a grand edifice designed by Peabody \& Stearns in 1891, which helped to secure Boston's claim as a great American cycling city.

The modest showrooms housed in "Automobile Headquarters" fronted one of the narrowest streets in the Back Bay. Stanhope Street was just thirty feet wide. Depending on the width of the sidewalks, this may have left space for only a single-lane road without room for vehicles to stand along the curb, unless they pulled up onto the sidewalks themselves. Though motor cars were much easier to operate on more spacious streets (elsewhere in the Back Bay, most rights of way were sixty- to 100-feet wide), in these years they were so marginal that those who sought their fortune in the auto trade chose a location on an out-of-the-way tertiary street in a building that closely mimicked the scale and form of Boston's many five-story boarding stables.

As in other American cities, it was Boston's various cycling interests that first brought the automobile trade to the city, beginning with the Back Bay Cycle and Motor Company in 1899, previously discussed. The following year, this affiliation was demonstrated during an annual Cycle Row extravaganza. Each year on the George Washington holiday, the Row's dozen

\footnotetext{
77 “Boston's New Automobile Depot,” Boston Globe, March 10, 1901, 22.
} 
or more cycling shops would open for the season, with festivities, entertainment, complimentary souvenirs, bountiful punch bowls, potted palms, celebrity riders and bunting. In 1900, bicycles remained the star attraction - potential shoppers walked from store to store to inspect the latest models and to ask questions about tandems, tube sizes, coaster brakes and eccentric crank hangers. But visitors to H. N. Shattuck \& Son at 249 Columbus Avenue were to find an unexpected attraction: the Orient Tricycle Automobile on display next to the store's usual lines of Orient, Cleveland and Tribune bicycles. ${ }^{78}$ This curious machine was barely a motor car, but its presence foretold a shifting interest.

One year later in 1901, the stores of Cycle Row again held their seasonal opening with the usual fanfare, promotions and crowds. In this year, however, far more shops went to the effort of displaying motor cars and motor cycles, and "it was remarkable to notice the growing tendency of the cycle trade to get into the motor game . . many of the cycle manufacturers are taking up motor vehicle business as they have the machinery and plant on their hands." In Lon Peck's store, “the largest assortment of [bicycles] ever seen under one roof was on exhibition [with] 60 models of different makes as well as several electric, steam and gasoline motor carriages," these accompanied by a live orchestra. In other stores, "machines of any horse power desired could be found," usually displayed on racks so they could be run in place. ${ }^{79}$

The promotional displays of the bicycle shops soon gave way to Boston's first automobile show, which was held in Stanhope Street's "Automobile Headquarters" in November, 1901. At this time, most motor car dealers and agents had no showrooms in Boston, and the auto show allowed various manufacturers to have a temporary presence in the city, where they displayed fifty or so "carriages." The event was widely publicized, with advertisements and

\footnotetext{
78 “On Cycle Row,” Boston Globe, February 23, 1900, 12.

79 “Cycle Season On,” Boston Globe, February 23, 1901, 7.
} 
coverage in Boston's main newspapers and in journals such as Automobile Topics and Horseless Age. ${ }^{80}$ The event lasted for several days and was among the earliest coordinated opportunities for Bostonians to encounter an automobile firsthand. ${ }^{81}$

When operated by or partnered with a dealer, early garages were sites where aspiring car owners could begin instructional test drives. Since most new car owners had no prior experience behind the steering wheel (or tiller) of a car, this instruction was a vital part of a car sale. In Boston, a typical test drive began with an agent's chauffeur driving the car out of the city to less populated roads, giving the buyer an opportunity to observe the mechanical operation of the car while mitigating the problem of having a novice attempt to navigate busy urban streets.

Robin Damon, who purchased his second automobile from a Boston shop in 1905, chronicled his experience in a telling submission to Horseless Age. His new car, which cost an extravagant $\$ 3,500$ and had thirty-five horse power and four cylinders, must have been a very fine machine at the time. The fact that Mr. Damon was already buying a second car in 1905 implies that he was quite wealthy and that he was an early adopter of motor car technology.

Mr. Damon bought the car when it was on exhibition about two weeks before he first took it out for a drive. His delayed adventure was due to the excessively muddy condition of the highways leading to and from Boston, and he needed a week of pleasant weather to pass so they would dry sufficiently. When he arrived at the dealership, he saw that his new car had sat in a corner since it was purchased and that "the brass became dingy and the paint and upholstering was] covered with dust." An hour of cleaning was needed to get it road-ready. Once properly cleaned, "a husky youth spent considerable effort on the crank without getting a sputter from the

\footnotetext{
80 “Boston's Automobile Show," Horseless Age 8 (November 27, 1901): 764; “An Automobile Trade Exhibition," Automobile Topics 3, no. 1 (October 19, 1901): 24.

81 “Automobiles on Exhibition," Boston Globe, November 16, 1901, 5; Classified Ad, Boston Globe, November 21, $1901,13$.
} 
engine. An expert then advised shifting to the second battery . . . and the engine responded promptly ... The dry cells were in circuit first and were all bad. This was, of course, a minor matter, but it showed [Mr. Damon] that an automobile is still an automobile, even though a couple of extra cylinders be added." Mr. Damon observed that the quart-sized capacity of the oil tank was much less than in his first car, and was concerned that his new machine would only travel seventy-five to 100 miles before a fresh supply needed to be added. Mr. Damon was not complaining about these annoyances, for like most purchasers he considered them an expected part of car ownership, even for such an extremely expensive machine. ${ }^{82}$

Once the car got started, Mr. Damon rode in the front seat with the dealer's "expert." This chauffeur easily slipped into top gear and navigated out of the city. There the machinist handed the car over to Mr. Damon, where he could experiment with driving the car on less crowded streets. Despite his prior experience, Mr. Damon found maneuvering his new car to be challenging: "I got busy at once with both feet, and it seemed to me that I really needed another hand, for there were two levers on the wheel and another for shifting the gears." After a lengthy account of grinding gears, of dreadful lurching, of stalls and of accidentally slipping into neutral, Mr. Damon succeeded in getting the car into the top gear. Once he started moving, he "was advised to keep an eye out for the police, who [were] on the watch for scorchers. [He] was surprised to find how easily the engine was controlled and also what a difference 35 horse power made over 15 in going up grade and on hills. The car could slow down to 3 or 4 miles an hour and pick up to 30 while climbing grades." 83

\footnotetext{
${ }^{82}$ Robin Damon, "Experiences with a New Car and a Word on Gear Changing" Horseless Age 15, no. 14 (April 5, 1905): 418 .

${ }^{83}$ Ibid.
} 
While out in the country, the duo encountered only a few wagons, which gave Damon the chance to open up the throttle to gauge how fast the car could move. When they returned to the city, however, driving conditions became far more dangerous:

I ran the machine back into the city, through the crowded streets to the railroad station, without smashing anything, but narrowly escaped climbing over a man who persisted in standing in the middle of the street. I tooted the horn and yelled at him, but he simply grinned. It did not occur to me to release the clutch and put on the brake, but I slowed down the engine. I certainly would have given the man a bump if he hadn't jumped out of the way. I guess he saw that I was green at the business, for his smile came off and he said some words I paid no attention to. Just before getting to the railroad station a woman started to cross the street some distance ahead of the car and I tooted the horn. Because she was a woman she ran back to the walk, although she was two-thirds of the way across the street. I told her she was foolish, and she saucily replied, "Fudge"-in Boston, too.

Though presented with a storyteller's flourish, Mr. Damon's account underscored the dangerous and lawless driving conditions that prevailed on urban streets. The experience clearly unnerved Mr. Damon and the several pedestrians who were compelled to yield to his unrelenting path, leading him to "wonder how it is that beginners, who never held the wheel of any sort of automobile, have the courage to take the driver's seat in a high powered car and venture forth into the highways." 84

A few months after Mr. Damon's appearance in Horseless Age, three of Boston's thenprominent automobile merchants responded to the problem of selling dangerous machines to novice drivers by acquiring vacant land from the New York, New Haven \& Hartford Railroad on which they built a track for their clients. This track, a third of a mile long and fourteen feet wide, was located between Berkeley and Clarendon Streets and abutted Stanhope Street, where several dealers and repair shops where located [Figures 2-17, 2-18]. The purpose of the track was not

${ }^{84}$ Ibid. 
for racing; rather it provided a space where promoters could demonstrate an auto's virtues and where owners could learn to drive. ${ }^{85}$

At a time when newspaper accounts often portrayed automobiles as dangerous juggernauts, private enterprise created a space for inexperienced drivers to try out a machine, since using them on busy public streets was both difficult and dangerous. As the automobile trade expanded with ownership rates, no additional private tracks were created and new drivers were ultimately compelled to learn to control their machines on pubic ways. The track on Stanhope Street was itself short-lived, and did not last past 1913, when a power station was built for the Edison Illuminating Company.

Among the best examples of early garage experimentation and the adaptive reuse of existing buildings in Boston was the Beacon Garage of 70 Brimmer Street, which began operations as early as 1904. This garage occupied land on the flat of Beacon Hill amid the densest concentration of stables in Boston, which primarily served the well-to-do who lived nearby in the Back Bay or further up the hill. Like other early garages, it was little more than a stable. Two makers of carriages, the Joseph F. Pray Company and Chauncey Thomas \& Company also operated in the area, one of which occupied the floors above the garage [Figure 2-19].

Like the Back Bay Cycle and Motor Company, the Beacon Garage was operated as a place where a vehicle could be purchased, repaired and stored. It was owned by A. R. Bangs, the local agent for the Franklin Manufacturing Company, who purchased cars outright from the manufacturer and then used the garage to store the motor cars he intended to sell to his customers [Figures 2-20, 2-21]. The garage, a humble building located on a back street surrounded by

\footnotetext{
85 James T. Sullivan, "Auto Track in the Heart of the City," Boston Globe, June 11, 1905, 29; James T. Sullivan, "First National Race Meet," Boston Globe, August 20, 1905, 22.
} 
stables, was not considered appropriate for the elegant display of expensive cars, so Mr. Bangs ran a small showroom elsewhere on Boylston Street [Figure 2-22]. This showroom occupied the first floor of a storefront at the corner of Fairfield Street, which was just large enough for a handful of machines to be displayed behind large glass windows but small enough that it was not practical to move a car once it was put in place. Mr. Bang's arrangement, where a manufacturer's agent would operate a show room and sales office that was separate from the garage where inventory was stored, was common practice in this early period.

The Beacon Garage also functioned as a public garage where autos could be repaired, stored and cleaned. It was a modest enterprise, with the capacity to store eighty machines. The garage occupied the lower level of three contiguous buildings (two of them three stories, one of them two stories), while the floors above were occupied by the Joseph Pray Carriage Works and residential apartments. The ground floor of the three buildings connected to one another, creating a single large space. Buried under the sidewalk was 165 -gallon gasoline tank. ${ }^{86}$

Like other early garages, the structures that housed the Beacon Garage were originally built for other purposes and were minimally adapted for the spatial and technical needs of the motor car. Before the arrival of the garage, the spaces where automobiles would be stored had been occupied by the Joseph Pray Carriage Works, who once operated a blacksmith shop and housed carriages on the first floor.

Reused stables and other wood-framed nineteenth-century buildings were not well suited to early automobile use, especially before the perfection of ignition mechanisms, fueling systems and engines in general. The Beacon Garage succumbed to the risks of this adaption and burned to the ground after only a year of use a garage [Figure 2-23]. The combination of wood building

\footnotetext{
${ }^{86}$ Ad, Franklin Motor Car, Boston Globe, June 11, 1904, 2; "Loss of \$70,000 at Beacon Garage," Boston Globe, May 31, 1905, 1, 3.
} 
elements, oil leaks and other hazards present in early garages ensured that any fires would spread quickly and uncontrollably. In the case of the Beacon Garage, "it was while getting one of the machines ready to go to [the races at] Readville that the fire started. An employee was at work heating the apparatus with a torch, which [was] a preliminary to setting the engine in motion. Suddenly there was a blaze on the floor just under the torch which spread with the greatest rapidity, enveloping the whole floor." 87

The entire garage was destroyed, along with the apartments and the carriage works above it. Also destroyed were the approximately forty motor cars stored there, twenty of them Franklins owned by Mr. Bangs. The practice of burying the gasoline supply under the sidewalk proved effective, as the tank survived the blaze despite the fact that the fire started directly above it. Less fortunate than this supply of gasoline were four badly injured firemen, two families whose households were destroyed, and those who lost their livelihoods at the carriage works. ${ }^{88}$

While the Beacon Garage typified early efforts to store and sell automobiles in urban contexts through the repurposing of smaller buildings, the Tremont Garage at 541 Tremont Street signaled the expanding scale of auto use and was advertised as the "world's largest" when it opened in 1904 [Figure 2-24]. Like the Beacon Garage, the Tremont Garage repurposed an existing building, in this case a former cyclorama built in 1884 that had variously been used as a zoo, a pugilist stadium and a combination bicycle store and riding school [Figure 2-25]. In 1902, it was briefly home to the New England Electric Vehicle Transportation Company, who used the building to store taxis and as a power station. ${ }^{89}$

The owners of the Tremont Garage removed the original turreted entry way and replaced it with a two-story rectangular addition with a "double runway" that allowed automobiles to pass

\footnotetext{
${ }^{87}$ Ibid.

88 James T. Sullivan, “Racing Reason Well Under Way,” Boston Globe, June 4, 1905, 31.

89 “'Old Cyclorama Building in New Hands," Boston Globe, August 5, 1902, 9.
} 
from one level to the next. Though the architect Shannon McDonald wrote in The Parking Garage that the earliest ramp recorded in the magazines of this period was used in a garage built for the New York Taxi Company in 1909, according to Horseless Age the Tremont Garage had already been using ramps for at least three and possibly for five years. ${ }^{90}$

The main storage space of the newly converted garage was the great round chamber of the cyclorama, where Paul Philippoteaux's 400-foot-long and fifty-foot-tall panorama of the Battle of Gettysburg had once been hung along the building's walls to be viewed from a raised platform under a 127-foot diameter steel-trussed dome. Eight two-story chambers were built around this circular volume, creating a rectangular building approximately $170-$ long by 135 -feetwide [Figures 2-26, 2-27]. It is likely that the former cyclorama's tall cylindrical space was divided into two floors, allowing the garage's second floor to extend throughout the building and not be confined to the additions. Use of the second floor of the former cyclorama to store automobiles would have been a short-lived practice, since in 1907 this space was altered yet again, this time to create an amphitheater for the Armory A. A., a boxing and wrestling club [Figure 2-28]. ${ }^{91}$

While the Beacon Garage provided capacity for a reported eighty automobiles within a former carriage works, the Tremont Garage was far more expansive, with advertised space for one thousand, which was a great exaggeration. Storing a thousand cars in a two-story building of the modified cyclorama's dimensions would have been impossible. Each floor's total footage equaled approximately 22,950 square feet, for a total of 45,900 square feet. Given the numerous interior walls within the building, the space that was given to its ramp system and the fact that a

\footnotetext{
${ }^{90}$ McDonald, Parking Garage, 29-30; “Tremont Garage, Boston, Mass," Horseless Age 17, no 2 (May 30, 1906): 784-785.

91 Jane Holtz Kay, Lost Boston (Amherst: University of Massachusetts Press, 2006), 205-205; “Armory A.A.'s Big 1600-Seat Arena Now All Ready for Opening Boxing Exhibition,” Boston Globe, January 3, 1908, 4.
} 
portion of the building was reserved for repairs and washing, it is doubtful that the operators of the garage could have fit more than 400 automobiles inside, and these would have been parked with only a few inches separating each vehicle, making it extremely difficult to access those stored more than a few feet from an entryway. Even so, the enterprise dwarfed all other public garages then active in Boston. ${ }^{92}$

As with other rivals created during this period, numerous automobile sellers took space within the Tremont Garage, which they used as a headquarters before seeking to establish more permanent spaces elsewhere in the city, or before going out of business as the auto trade consolidated. Among the manufacturers based out of the Tremont Garage were De Dietrich, the Knox Company, the Atlas Motor Truck Company, and the Buick Automobile Agency. Used cars were also sold out of the building. Since much of the space of this building was given to each seller's stock, the amount left over for public storage would have been further reduced. After the Armory A. A. occupied 12,660 square feet of the second floor for its arena, the storage capacity of the garage shrunk even more. ${ }^{93}$

For a short time, the Tremont Garage, open night and day, was the primary automobile hub in the city. A motorist could have their auto stored in a large space whose generous open plan ostensibly allowed cars to easily maneuver around one another, provided the owners resisted temptation to park too many automobiles inside. There were specialized departments for maintenance, including a room devoted to tire repair and another for painting. The mechanics

\footnotetext{
${ }^{92}$ While early cars came in a range of dimensions, most were approximately six-and-a-half feet wide. Lengths were far more varied. For example, a 1906 Model N Ford (a small two-seater) was just over nine feet long (the wheelbase was eighty-four inches), while a 1910 Buick Model 16 Toy Tonneau (which sat five) was about twelve-and-a-half feet long (the wheelbase was 112 inches). Flink, America Adopts the Automobile, 270-273.

93 Charles W. Restarick, "Real Estate: Suburban Places in Good Demand, Old Cyclorama Building is Leased Again," Boston Globe, May 15, 1904, 18; Ad, "De Dietrich," Boston Herald, April 23, 1905, 15; Ad, "A Tired Horse vs. A Fresh One," Boston Globe, February 5, 1905, 27; Ad, “The New Motor Truck," Boston Globe, June 11, 1905, 29; Ad, “Atlas Motor Truck,” Boston Globe, August 27, 1905, 29.
} 
who worked in house supposedly specialized in both domestic and foreign cars. ${ }^{94}$ Patrons had access to waiting rooms, one hundred lockers in which to store personal motoring gear, and ten showers, important for the removal of grime and dust that resulted from driving open-air cars over dirt and gravel roads. For those who did not own a car, the Tremont Garage kept a supply of fine autos on hand, which could be rented along with a chauffeur. For those that preferred to conduct their own repairs, one of six repair pits on the first floor could be rented for one dollar per day. Concern over the potential fire risks associated with storing such a large number of autos was apparent, as eight fire hydrants were installed throughout the garage. ${ }^{95}$ Each employee who worked at the garage was issued a hand-held fire extinguisher, and barrels of sand were also strategically distributed..$^{96}$

In 1905, the White Sewing Machine Company, a successful manufacturer of steampowered cars, acquired a former livery stable and converted it into a garage. This stable, located at 320 Newbury Street, was three-stories tall with a brick basement. The location was worthy - it was central to the Back Bay and a block removed from Boylston Street and Massachusetts Avenue, both of which were important commercial thoroughfares. Upon conversion, the lower level and basement were used to store motor cars, the second story became a sales offices and the third was used for repairs. ${ }^{97}$ When it opened in April, "the interior of the building [presented] a most attractive appearance, [with] ample space for several hundred cars as well as giving plenty of room for a display of accessories and an additional space for storing duplicate parts of cars"

\footnotetext{
${ }^{94}$ While Boston was home to a leading auto school that began operating out of the YMCA at the close of 1903, there was a lack of qualified mechanics at this time.

95 These fire hydrants are shown on the 1914 Sanborn Map that covers 541 Tremont Street. The previous edition (1897) shows no hydrants.

96 "Tremont Garage, Boston, Mass," Horseless Age 17, no 2 (May 30, 1906): 784-785; Ad, "New Automobile Station," Boston Globe, May 31, 1904, 7; Charles W Restarick, "Real Estate: Suburban Places in Good Demand, Cyclorama Building Leased," Boston Globe, May 15, 1904, 18; "Went Off with Auto," Boston Globe, September 23, 1907, 2.

97 "Real Estate," Boston Globe, January 13, 1905, 9.
} 
and reception rooms for women and men [Figure 2-29]. As with the Tremont Garage, this report exaggerated storage capacity. ${ }^{98}$

Like Boston's other large garages, this converted stable was a fire risk. In its first seven months of operation, the White Garage caught fire three times, including a blaze on November 23, 1905, which was caused by the explosion of a small gasoline tank when it was being filled from a larger 250-gallon tank buried under the street outside. The White Sewing Machine Company was fortunate, as all of these fires were quickly brought under control with minimal damage to building or property. Nonetheless, the danger appears to have encouraged the White Company to build a new garage better able to withstand danger from fire. ${ }^{99}$

This new garage, designed by C. J. Warren, was built in 1907 at 341-343 Newbury Street, on the same block as the original stable [Figures 2-30, 2-31]. ${ }^{100}$ The new garage was built of first-class construction, with a steel frame and concrete walls, and was deemed "absolutely fireproof." In addition to building out of concern for fire, the White Company desired a more modern building better suited to automobile sales and storage. The result was a six-story structure that could accommodate a reported 300 machines, connected by two elevators. To free space for maneuvering, each floor was "virtually without a post." Part of the garage was used as a show room; most of the remainder was given to storage (for the White Company's own inventory and for its customers' autos) and repair services. The building was designed to ease circulation, which integrated basic maintenance:

All cars on entering the garage will be driven on the washstand, where the mud and dust will be removed. Then they will be taken by way of the rear elevator to their respective floors and stalls, where brasses may be polished and the cars otherwise cleaned and oiled ready for immediate use. On leaving the garage the autos will be taken down by the front elevator, driven to the large turntable in the

\footnotetext{
98 James T. Sullivan, "Definition of Amateur Discussed” Boston Globe, April 30, 1905, 31.

99 "Blaze in White Garage," Boston Globe, November 23, 1905, 1.

100 "New White Garage to be Opened in September," Boston Globe, August 25, 1907, 29.
} 
floor center, there be given half a turn and then they will be ready to leave the building. ${ }^{101}$

As with other large garages created at this time, there was a chauffeur's lounge, showers and baths. Also offered were a barber and pool table.

Another garage that occupied an extant building was the Park Square Automobile Station, which repurposed a freight house that had formerly been used by the Boston \& Providence Railroad [Figures 2-32, 2-33]. Like the Tremont Garage, the Park Square Automobile Station reused a building that had been engineered to span a wide space and whose floor plan was not interrupted by columns or other supports that would interfere with the positioning of automobiles. Wide and long, the former freight shed was able to fit many hundreds of cars inside. The Automobile Station operated both as a public storage facility and as a place where dealers' agents and sellers of second-hand cars could store their inventory and establish offices. Among them were the Park Square Auto Company, the Boston Motor Company, the Rambler Motor Company, the Concord Motor Company and the repair shop of the Marmon Company. Like the Beacon Garage, the Tremont Garage, Massachusetts Automobile Club, and the White Garage, the Park Square Automobile Station offered repairs, fuel, washing, and other services. ${ }^{102}$

As with the Beacon Garage, the first White Garage, and the converted Kenney \& Clark livery stable (discussed in Chapter 1) the Park Square Automobile Station illustrated the serious shortcomings associated with storing numerous motor cars in a repurposed building that was not adequately fireproofed. On the night of January 17, 1909, the garage's night watchman, Samuel Kennedy, discovered a fire spreading at an incredible speed. Unable to reach the box to sound an

\footnotetext{
${ }^{101}$ Ibid.

102 "Park Square Station Sold," Boston Globe, March 18, 1906, 15; "Six Garages and 348 Autos Burned," The Hartford Courant, January 18, 1909, 1; “Boston Fire Destroys 400 Autos,” Boston Globe, January 18, $1909,1$.
} 
alarm, Mr. Kennedy was soon trapped by the flames and managed to survive by covering his head with his arms and running through the fire, though he was severely disfigured in the process of this escape. The building soon burned in spectacular fashion, with five alarms pulled in a span of minutes. Soon, fire fighters and apparatus "began pouring into the center of the city from all outlying stations. Even those firemen who came from several miles away knew they had their work cut out for them as they left their houses, for the reflection of the flames on the low lying clouds which were emptying a first-class snowstorm on the city indicated that a great fire was raging." 103 On the scene, the fire fighters observed that "as fast as the rapidly traveling flames reached . . . an automobile the gasoline tanks exploded, throwing the burning fuel far and wide over the machines, and the result was a series of explosions that sounded like a string of gigantic firecrackers, and the flames swept from end to end of the 600 -foot building in incredibly short time." As many as 400 automobiles were destroyed, with an average value of $\$ 2,000$. The fire partially destroyed the old Boston \& Providence Station, which then housed a bicycle track, skating rink and winter garden, and killed six teaming horses who were suffocated in a nearby building. The total loss associated with the blaze approached one million dollars, a staggering sum [Figures 2-34, 2-35].

\section{Newly Built Garages}

Even new structures designed and built specifically for automobile storage were soon destroyed by fire, such as the three-story Taylor-Palmer garage, which was built in 1906 at 169-173 Huntington Avenue. This garage followed the usual business model - it sought to provide storage and repair services to the motoring public, with the remainder of its space given to

103 “Men Run for Life," Boston Globe, January 18, 1909, 1. 
commercial interests. Among them were the Darracq Motor Company and the New England Cab Company, which had taken a ten-year lease.

On the first floor of the garage, two stores with plate-glass fronts flanked each side of a central entryway for automobiles. A repair shop was installed in the basement; elsewhere, chauffeurs were provided a recreation room stocked with the latest trade magazines and outfitted with a shower and tub. On the second floor were offices, a women's recreation room and a room for men outfitted in "bohemian style." The remainder of the space was given to storage, and all floors were linked by a single freight elevator. Though it was supposedly able to house as many as 300 cars, this would have required tremendous effort by the garage attendants and the storing of cars end to end with little space between them. ${ }^{104}$

Despite being built "as fire proof as possible," the garage burned after only a year and a half of use [Figure 2-36]. The cause of the blaze was unknown, though it was "supposed that a spark from an auto that was being placed in position ignited some gasoline, an explosion following and setting the building on fire." ${ }^{105}$ Most of the building was destroyed, along with 120 autos stored inside, and nearby buildings were damaged from the extreme heat. An account of the fire showed that several owners stored multiple cars in the garage, reflecting elite ownership patterns.

By 1905, the Eben Jordan estate recognized that Boston's motor car business had begun to burgeon and that the users and sellers of automobiles desired a new building type that reflected the prestige of ownership and that was customized to the patterns that typified automobile use at the time. The solution they devised was the cutting-edge Motor Mart, Boston's first modern public parking garage, designed by architect Edward T. Barker [Figure 2-37]. The

\footnotetext{
104 “Real Estate," Boston Globe, December 27, 1906, 11.

105 "Ruins of Huntington-Av Garage Destroyed by Fire Sunday Morning," Boston Globe, September 7, $1908,1-2$.
} 
stated intention of the Jordan estate was to make the Motor Mart "the most perfect of any garage in the county." 106

The Motor Mart was built on extremely valuable land at the edge of the congested district and near the Common. The site, which had been considered a potential location for a new city hall, occupied the entirety of a five-sided block bounded by Pleasant Street, Tennyson Street, Church Street, Eliot Street and Columbus Avenue. When it opened in February, 1906, it was the closest garage to the department stores and specialized retail interests located on Tremont Street and Washington Street. At that time, the location of the garage was considered to be unequalled. From the main entrance on Park Square, "streets radiate to all sections of the city and open onto the chosen thoroughfares leading to the suburbs and other cities. It is central, convenient and in every possible way meets the ever-increasing demand for a safe commodious, well-equipped and efficiently managed stable for motor vehicles of every kind and description" ${ }^{\text {"107 }}$ [Figure 2-38].

In plan, the three-story Motor Mart consisted of a large public garage encircled by twenty-one store fronts that faced out to the streets [Figure 2-39]. These store fronts were leased to automobile agents and manufacturers, who used them as offices and showrooms. The architecture of the Motor Mart responded to the needs of these retailers. At the time the Motor Mart was built, even the most successful automobile manufacturer did not sell a large volume of motor cars. While the size and design of buildings devoted to auto sales changed significantly in the 1910s as the market expanded, sellers in the first decade of the twentieth century were limited to operating out of makeshift spaces, as evidenced by the repurposing of bicycle shops, stables, the cyclorama and the Boston \& Providence's train shed. Others achieved a more serious display by establishing shops on the lower floors of more desirable four- and five-story buildings

\footnotetext{
106 "Real Estate," Boston Globe, April 18, 1905, 3.

107 "Boston Has Structure Without Peer Among Buildings Devoted Exclusively to the Automobile Business," Boston Globe, February 26, 1906, 5.
} 
along Boylston Street and Columbus Avenue, where "many houses ... have had the fronts taken out and stores put in, and even new structures [erected], so great has been the demand for space for the various automobiles." ${ }^{108}$ Even so, these newly created retail spaces almost always used a generic form that would accommodate any tenant who might rent the shop space; such store fronts would just as easily accommodate a clothing store or barber shop as they would a tire seller or automobile dealer.

The five-sided block-sized Motor Mart was designed to take advantage of its extensive street frontage. Its twenty-one stores and showrooms faced the various streets that surrounded it. The internal arrangements of these stores were built to order for each firm taking space at the Motor Mart, while the façade itself, by serving twenty-one sellers in a single building, used their combined resources to create a monumental expanse of cutting-edge plate glass, achieving the grandeur and sophistication that automobiles implied, but that sole manufacturers could not yet achieve for themselves. Dealers taking space in the Motor Mart when it opened agreed that "a better situation for a garage would be hard to find" [Figure 2-40]. ${ }^{109}$

The internal garage provided significant space where local residents, suburban dwellers, visitors from other cities and dealers' agents could store their cars, with a total capacity for 300 autos. In an effort to speed the movement of autos from one level to the next, the garage installed two freight elevators, one of which was large enough to carry two autos simultaneously, as well as nine turntables distributed on the three floors [Figure 2-41]. There were two vehicle entries into the garage, one on Tennyson Street and the other at the junction of Columbus and Eliot.

\footnotetext{
108 "Real Estate," Boston Globe, April 18, 1905, 3.

109 “The Boston Motor Mart," Horseless Age 15 (May 10, 1905): 537; "Will Provide Accommodation for 400 Cars," Boston Globe, April 17, 1905, 9.
} 
Chauffeurs had access to lounge rooms and lavatories, while car owners had access to waiting rooms with telephone service. ${ }^{110}$

The repair and service departments were reported to be excellent. The garage featured a devoted fuel room on Tennyson where gas, oil and kerosene were available, as well as tanks mounted on wheels with pumps that could be run to any part of the garage. ${ }^{111}$ Drivers of electric cars could make use of the garage's charging facilities. The repair shop, located on the second floor, swapped out old-fashioned pits for then novel lifts that could raise an auto to ease the work of a mechanic.

Aware of the danger of fire (and of the difficulty of obtaining fire insurance for a building that stored motor cars), the designers of the garage took great care to make the structure as fireproof as possible. It was built of reinforced concrete, which was used for its walls, floors, beams and columns. The garage was divided into three compartments on each of its three floors. Each compartment, as well as the repair department, was separated from the next by a fireproof door, which was supposed to remain closed except when a vehicle passed through. Oil and kerosene were stored in steel tanks surrounded by fireproof partitions, while the supply of gasoline was buried in a battery of tanks. While the Boston Globe eagerly reported that a fire was "practically impossible," it also noted that the multiple elevators and two points of entry would make an evacuation of cars speedier than in a garage with just one entrance and just one elevator. The Jordan estate realized that a raging fire could easily outpace its pair of elevators and also planned to mount several huge cranes on the roof so that an attempt could be made to lower autos from the building in the event of catastrophe, though it is doubtful if these were ever installed and their

\footnotetext{
110 “Boston Motor Mart,” Horseless Age 17 (May 30, 1906): 783-784.

111 Gasoline was stored in a battery of buried 10-barrel tanks.
} 
effectiveness would have been preposterous. The gesture was likely made to ease the nerves of those contemplating storing an auto inside. ${ }^{112}$

\section{Spatial Organization of Parking Facilities}

The early auto trade on Columbus Avenue, Stanhope Street and, especially, in the Motor Mart, was considered by Boston's newspapers to be a boon to the city. The prevailing view was that these businesses were revitalizing an area of the city around Park Square that had entered a state of decline when the Boston \& Providence terminus stopped serving passengers in 1899 , after just twenty-five years of use. Tire shops, parts suppliers and other auto-related businesses competed for space in existing buildings, which drove up their value and encouraged the infill of still empty lots. For those in the immediate vicinity of the Motor Mart, it was expected that their value would be improved not just because of the business that was brought to the area, but also through what was considered to be the building's sheer architectural beauty. ${ }^{113}$

By 1909, few garages existed in central Boston to accommodate public storage, and only a single garage, the Motor Mart, was recommended by the 1911 Automobile Blue Book to its readers. ${ }^{114}$ Some of the city's garages, such as the Beacon Garage, were comparatively modest in size. Others, like the Tremont Garage, were quite large. These garages were essential components of Boston's automobile landscape at this time. Their collective capacity determined, along with the city's handful of private garages (personal garages, select firehouses and police stations), the number of automobiles that could effectively be operated on the city's streets. Interspersed around them were other "garages" that served as showrooms and those that offered

\footnotetext{
112 "Real Estate," Boston Globe, April 18, 1905, 3; "Will Provide Accommodation for 400 Cars," Boston Globe, April 17, 1905, 9; "Boston Has Structure Without Peer Among Buildings Devoted Exclusively to the Automobile Business," Boston Globe, February 26, 1906, 5.

113 "Will Provide Accommodation for 400 Cars," Boston Globe, April 17, 1905, 9.

114 Official Automobile Blue Book, vol. 2, New England and Canada (New York: The Automobile Blue Book Publishing Co., 1911).
} 
repairs and that did not provide meaningful public storage. While quantifying the number of offstreet parking spaces in central Boston is an imprecise task, the total capacity of the city's large garages was less than 2,000 automobiles on the eve of the popular adoption of motor cars.

Mapping the placement of these garages shows that storage facilities operated in proximity to Back Bay [Figure 2-42]. Only one garage, the Corlew-Coughlin Garage on Hawkins Street, was established within the 1892 congested district. Like most other early garages, it repurposed an existing building and occupied the first and second floors of a fivestory structure that previously housed the Hall Carriage Company. This garage began operations in November, 1909, as automobiles became more widespread and marked a turning point in the relationship between Boston's downtown and the automobile. The owners of this modest garage expressly sought to accommodate an emerging category of downtown commuter, and realized "that time counts a great deal in keeping appointments, and that there are times when a man may have an opportunity to run over to Hawkins st when he may not be able to go uptown. Another thing they figure on is that many business men will find an up-to-date garage downtown, something that was needed, for they can drive their machines down there and leave them while they are at work." 115

In 1909, the Sanborn Map Company updated the first volume of their Boston atlas. The extents of the maps in this volume covered most of the original peninsula of the city, which included the North End, Beacon Hill, the West End and the entirety of downtown and the congested district. Only four buildings directly related to automobile use appear in this volume. One of them was the Corlew-Coughlin Garage. The other three (each with a capacity for about two motor vehicles) were a private one-story garage for the Edison Electrical Illuminating Company near Piper's Wharf, a firehouse on Mason Street that contained a steamer and a

115 “New Home Ready,” Boston Globe, November 21, 1909, 38. 
horseless engine and the Chauncey Thomas Company, a carriage builder that began offering automobile repair and storage. By comparison, approximately 150 boarding, livery and other kinds of stables appear on these maps, some of them quite large. In addition to the many buildings still devoted to storing horses, numerous other horse-related functions were accommodated throughout central Boston, such as numerous carriage manufacturers, blacksmith and forge shops, auction houses and storage facilities for grain and hay, emphasizing the comparative importance of the two transportation modes at this time.

\section{REGULATIONS \& ENFORCEMENT}

Laws governing automobile use varied from state to state, and, throughout the country, there was a surprising lack of regulation. The Automobile Blue Book of 1901 summarized Massachusetts road laws by simply reporting that the state had granted its cities and towns the right to impose local speed limits. By contrast, the same edition of the Automobile Blue Book meticulously explained the twenty-two provisions governing the rules of the Gordon Bennett Automobile Cup Race over four pages. ${ }^{116}$

A decade later, states had adopted only a handful of laws, with most requiring cars to be registered, drivers to be licensed, plates to be displayed, cars to have lamps, and speed limits to be followed. In Massachusetts, registration fees and owners' licenses each cost two dollars and were "good for all time." Chauffeurs were required to have their licenses renewed annually for a nominal fee. Plates, provided by the state, were to be displayed at the front and rear of the car. Two lamps were to be displayed on either side of the front of the auto, and these lamps were to

\footnotetext{
${ }^{116}$ Automobile Blue Book, 1901, 11-14, 38.
} 
have the number of the car printed on them. Speed limits in this year were twelve miles per hour in cities, twenty in rural areas and eight around curves and at intersections. ${ }^{117}$

Despite the sensational accounts of automobile misuse that appeared in Boston's newspapers with increasing regularity beginning around 1905, as more and more machines began to be used locally, the city, like others, did not enact any significant laws to control automobile use in its streets other than to impose speed limits. The Ordinances of the City of Boston and the Regulations of the Board of Alderman in effect in 1908 were virtually identical to those that were standing in 1898. These ordinances regulated the use of "vehicles" on the city's streets and sidewalks and made no distinction between beasts of burden, carriages, draughts or motor cars. Automobile operators were understood to be required to follow the rules for "vehicles" or "carriages," and the ordinances did not use the word "automobile" at all, save for a reference to automobiles owned by the city. Motor car operators at the end of this decade were simply meant to follow local regulations developed for horse-drawn traffic, to register their cars, and to drive at the low speeds mandated by the state during this period. ${ }^{118}$

Throughout the decade, the few laws that were devised were poorly publicized and regularly ignored. A city-wide sting set up by the Boston police department in the summer of 1904 revealed the absurd frequency with which early automobilists disregarded the few regulations that existed. The police made unannounced inspections of all automobiles they encountered on a weekday afternoon, stopping a total of 248 machines city-wide. The aim of these inspections was to uncover the extent to which drivers in the city were following Massachusetts law pertaining to licensing and registration. Drivers "were held up without notice,

\footnotetext{
${ }^{117}$ Automobile Blue Book, 1911, xxxix.

118 The Revised Ordinances of 1898 of the City of Boston and the Revised Regulations of the Board of Alderman of the City of Boston with All the Ordinances and Regulations Passed from the Passage of the Revised Ordinances of 1898 and the Revised Regulations of 1898 to November 1, 1908 (Boston: City of Boston Printing Department, 1908).
} 
and they were required to show their certificates entitling them to operate automobiles ... the police also wanted to see the certificates for the machines ... whether the license numbers of the automobiles were properly displayed, and whether the numbers of the machines and their lamps corresponded with the number of the license under which the automobile was being operated." Of the 248 stopped, only 136 were found to be in compliance. In the Back Bay, where the most cars were pulled over, ninety-one cars were examined, with just forty of them compliant. Judge Emmons, who oversaw the case load, took no action other than to state that if any of these motorists were thought to be guilty a second time, then "the board of police would consider it a sufficient cause for hauling them into court." 119

As Judge Emmons' lack of action suggests, the licensing of drivers early in this decade was not considered to be very serious issue. Thus, the Boston Globe was able to marvel over thirteen-year-old Edwin Augustus Challman of Brockton, who in 1905 was both a chauffeur and machinist. Incredibly, Edwin was surpassed in youthful driving by Theron Smith Curtis of North Attleboro, who qualified for his license in 1903 at age ten. This license was granted with some hesitation, though the commissioners overseeing the process were ultimately reassured when they observed that Theron's application stated that he already had a year's experience driving a motor car (as a nine-year-old). The Boston Globe had no qualms in endorsing this practice and was charmed to report that "his skill in crowded thoroughfares and 'tight' places [was] remarkable" and that he was "not averse to making rather long trips. Every good summer day he journeys to Providence, Pawtucket, Attleboro and other surrounding towns and cities and occasionally makes the trip to Boston." The young chap was good enough to "[romp] about with children whose sires [were] obliged to earn their daily bread with the sweat of their brows, despite the fact that his grandfather [was] one of the wealthiest jewelry manufacturers in the

119 “Held up 248,” Boston Globe, July 24, 1904, 3; “Inspection of Autos,” Boston Globe, July 29, 1904, 3. 
country, and his father the head of another big concern." The same article reported that another ten-year-old boy in Brookline received his license in 1905 . $^{120}$

This cavalier approach to licensing was short lived. In 1907, Massachusetts officials saw that its casual practices were creating a public danger and they began to revise the state's policies. Beginning in this year, drivers in the state were required to take road tests to demonstrate their proficiency in operating a motor vehicle. They were also required to take a written examination to prove their understanding of the state's motor vehicle laws. One examiner had an office at the State House in Boston, a second made regular visits to eight other cities. Despite these alterations, regulations at this time remained, on the whole, quite simplistic and did not change significantly until the 1920 s. $^{121}$

Motoring advocates regularly complained about the speed limits enacted during this period. Charles Glidden, who famously circled the world in an automobile in 1902 (and who was an officer of the MAC), argued for an unregulated, "commonsense" approach to driving. In 1905, he editorialized in the Boston Globe that the legislature should "abolish all speed laws, hold owner and driver responsible for damage done to person or property by fast or reckless driving." 122 This sentiment, which favored the discretion of the driver to the creation of regulations, was repeatedly echoed. When describing how racing automobilists such as E. R. Thomas, "the millionaire turfman," avoid being killed in accidents when speeding their machines, the Boston Globe supplied an easy answer: "the men understand their cars thoroughly and they have active brains. It is the inexperienced man who gets in trouble." 123

\footnotetext{
120 "Boy is Chauffeur and Machinist," Boston Globe, April 9, 1905, 11; "Boy Qualified for Motor Car License in His Tenth Year," Boston Globe, March 19, 1905, 5.

${ }^{121}$ Flink, America Adopts the Automobile, 176; "Strict in Bay State," Motor Age 12 (August 1, 1907): 10-11.

122 Charles Glidden, "American Rules Absurd," Boston Globe, August 13, 1905, 30.

${ }^{123}$ Ibid; "Speed Sole Aim of Rich Drivers," Boston Globe, September 24, 1904, 28.
} 
While the speed limits established in this decade were slow, they were an appropriate response to the ways in which urban streets were used. As the Edison film of 1906 demonstrates (discussed in Chapter 1), traffic in Boston, especially in the congested district, was exceedingly chaotic. When automobiles were first introduced on the city's streets, they were a minority among vehicles and remained so for about fifteen years (and they have never outnumbered pedestrians). Though early automobilists complained about being compelled to drive at horselike speeds, this was the prevailing pace of the street and the pace that the pedestrians, cyclists and streetcars who shared this space were accustomed to and able to safely contend with. Only by becoming the dominant users of streets were automobilists later able to change legal driving speeds by removing pedestrians and others from public rights of way. Abram Brown, who assisted with the drafting of the early Massachusetts speed laws, responded to Glidden by reminding the readers of the Boston Globe that "the highways of the state are for the benefit of the whole public, and not for a few, who through overexhileration, ignorance or carelessness, would dash through the country regardless of [safety] ... The auto is here to stay and under proper conditions is a blessing, but it will not supersede the horse . . Hence, the provision for the safety of both horse and driver calls out for [laws] calculated to recognize the rights of the time-honored mode of travel."124

In the earliest years, when only a handful of motorists used the street of Boston, an individual's speeding citation was newsworthy. In 1902, New York's Robert Goelet and his chauffeur were observed "racing" through the Back Bay at speeds ranging from fifteen to twenty miles per hour in a place where the limit was eight. A mounted policeman ran down the car and

\footnotetext{
${ }^{124}$ Abram Brown, “Why Speed Laws Are Just,” Boston Globe, August 13, 1905, 30.
} 
followed usual protocol: Mr. Goelet was arrested and delivered to a precinct station where an account was taken. He was then released, later to appear in court. ${ }^{125}$

Legal driving speeds were often ignored, and the effort to enforce them was quite cumbersome. Policemen were usually on foot, horse or bicycle and were unable to apprehend speeders and other reckless drivers, who regularly ignored orders to stop. In one such event, Mrs. James H. Rhodes, her chauffeur and three other women were in a car that was observed striking and killing a valuable dog while driving in Middleboro. A witness called for the chauffeur to stop, but the car sped off on a primary road leading to Cape Cod. The local police chief was notified, and he in turn called an officer who lived seven miles away, telling him of the facts and describing the car. This officer then waited at a prominent intersection until the offending car arrived. When it did, the officer ordered the chauffeur to stop several times, instructions which were ignored. Having no means to give chase, the officer "finally drew his revolver and threatened to shoot. After the car had come to a stop and he had put his revolver away the chauffeur . . expressed a desire to fight him." 126

By the end of the decade, as more and more motor cars were used in Boston and in the surrounding towns, police began establishing "speed traps" where they would attempt to catch motorists exceeding the limit on key roads. Automobile Topics advised its readers that these were active in Dedham, Concord, Newbury, Lenox, Wayland, Clinton and Williamstown. In Boston itself, the most prevalent speed trap was reported to be on Commonwealth Avenue between Charlesgate East and Massachusetts Avenue. In a typical event elsewhere in the city, a trap was set on the parkway through Jamaica Plain. In one hour, fifteen speeding drivers were held up, their names and addresses were taken, and they were summoned to the municipal court the

\footnotetext{
125 "For Auto Racing," Boston Globe, June 20, 1902, 5.

126 “Drawn Pistol Checks Auto," Boston Globe, August 10, 1909, 14.
} 
following week. Motorists often viewed such police action contemptuously and signaled to one another to draw attention to traps. They would also report the existence of a trap to their garage upon arrival, and then each garage would contact the others so attendants could advise automobilists about the existence of trouble. In an age when very few garages existed and when every driver's destination was usually a garage, it did not take long for this communication to render traps ineffective. ${ }^{127}$

In response to the growing number of traps at the end of the decade, the various automobile interests began lobbying for a state-wide "square deal," which would spare drivers from the irritation and graft they believed speed traps to be. It continued the anti-regulatory approach to automobile use that was characteristic of the period when elites were the sole motorists on the road. In lieu of police enforcement, towns and cities that adopted the squaredeal plan "politely requested [automobilists] to operate their machines agreeably to a reasonable interpretation of the law." Municipalities on the square deal plan posted the following signs where state highways crossed their borders: "Autoists Notice: Please observe the state speed laws through this town." It did not take long for police to observe that these signs were an ineffective deterrent. The creation and passage of functional laws able to protect public safety did not come until the 1920s and these efforts depended upon a redefinition of how public rights of way ought to be used. ${ }^{128}$

\footnotetext{
127 "Many Speed Traps around Boston," Automobile Topics 19 no. 1 (October 9, 1909): 42; "Auto Trap at Jamaica Plain Works Successfully for One Hour," Boston Globe, June 7, 1909, 16.

128 “Ask Square Deal,” Boston Globe, October 3, 1909, 51.
} 


\section{CHAPTER 3 - Early Mass Use of Automobiles in Central Boston}

While the introduction of the automobile to Boston was characterized by the adaptive reuse of existing private buildings and while it was widely assumed that motor cars could be minimally disruptive to existing uses of Boston's public streets, the widespread adoption of automobiles brought new changes to the built landscape. The erection of privately owned buildings to sell, repair and store automobiles began to reorganize newer parts of the city into forms that were deemed advantageous to automobilists. Private land holders demonstrated far greater agility in responding to the needs of automobilists than city officials. Allowing great numbers of motor cars into the city's public streets proved to be a complex undertaking, especially in older parts of the city where existing streets were difficult to alter. This was particularly true downtown and in other central areas where expensive, privately-owned buildings were built tall and often shared walls, creating zones of great density that completely filled the spaces between existing rights of way that were often angular and narrow and essentially locked in place by the estates that surrounded them.

Analysis of the Boston Town Records and the Records of Boston Selectmen shows that, in seventeenth-century Boston, frequently used roads were often only twelve feet wide. By the 1730s, the normal width of a prominent road had increased to about thirty feet, including those that faced the town's all important wharves. By the time Charles Bulfinch contributed to plans for the South End (the first of these was drafted in 1801) and the filling of the Mill Pond (1808), new streets were expected to be forty or fifty feet wide. When the Back Bay was planned in the last half of the nineteenth century, the streets created were sixty to 100 feet wide, not counting Commonwealth Avenue, whose 200-foot breath was the broadest in the entire metropolitan area. 
Since these roads were all planned without any anticipation of the motor car, many of them posed challenges to later automobile use.

In Boston, various arms of the city government, including the police department, the fire department, the Street Commissioners and the planning board, established in 1913, were deeply concerned with the large numbers of automobiles that had appeared in ever-increasing numbers in the 1910s. While a decade earlier it was possible for a relatively intimate number of automobilists to occupy a dozen or so repurposed buildings and to attempt to navigate the central city's angular and narrow roads following long-established speeds and customs, it did not take long for the exponential increase of automobile use in the 1910 s to begin to redefine the city. ${ }^{1}$

This redefinition manifested itself in a variety of ways. Built change was mostly confined to areas outside the downtown area. A new commercial district in and near the Back Bay emerged and grew to service, store and sell ever growing numbers of automobiles to a rapidly increasing pool of customers, many of whom lived outside of the city. Other changes were cultural, with standards for the use of public rights of way emerging that privileged automobile travel over all other uses of the street. New regulations were developed in an effort to standardize circulation of all traffic types, including pedestrians, throughout the city.

\section{STREET FOSSILIZATION}

As discussed in Chapter 2, the first garages and other automobile spaces in Boston benefitted from close proximity to wealthy customers living in relative density in the fashionable Back Bay.

Just as important, however, were the built characteristics of the landscape that hosted these

\footnotetext{
${ }^{1}$ Exact figures for car use in Boston were not systematically recorded. However, registration figures for the State of Massachusetts provide some insight into the rate of change in Boston. State-wide, approximately 38,900 motor cars and trucks were registered in 1911. By 1917, that number had grown to approximately 174,000. By 1919, there were approximately 247,000 motor vehicles registered. By 1926, there were approximately 690,000. "Big Increase in Bay State-Motor Cars and Revenue Make Remarkable Strides," Boston Globe, December 8, 1912, 56; "Big Gains in Registrations," Boston Globe, December 9, 1917, 46; Asha Weinstein, "The Congestion Evil: Perceptions of Traffic Congestion in Boston in the 1890s and 1920s" (PhD diss., University of California, Berkeley, 2002), 73.
} 
enterprises. The gridded Back Bay was equipped with a street network that was far more modern than elsewhere in the city and it was much easier for automobilists to use. Parts of the downtown area and neighborhoods like the North End, by contrast, began to take their form as early as the seventeenth century, and the street network that was developed in Boston in various stages throughout the colonial period proved remarkably resilient. At the beginning of the automobile age, many of the streets of the downtown area had been established approximately 200 years prior. While select widenings occasionally expanded some roads, in general they remained quite narrow. In 1909, downtown streets ranged in width from twenty-five to sixty feet, with a prevailing width of about forty feet. The residential streets of the overcrowded North End, which in 1909 included many tenements, ranged from fifteen to thirty-eight feet, excluding numerous smaller alleys (these ranged from four to eight feet wide) and the Hanover Street commercial corridor (sixty feet wide). ${ }^{2}$

As with the roads that were later designed to enable speedy automobile travel through the metropolitan area, older rights of way were established in response to prevailing ideas about how public ways should be used, which varied greatly depending on time, space and the purpose of the road to be created. As areas of the city were created and buildings constructed around existing rights of way, the value of private property constrained the city's ability to redesign roadways that were adequate when first implemented.

The Blackstone Block provides Boston's clearest and oldest example of these circumstances. Located in the midst of 1892's congested district, most streets of the Blackstone

\footnotetext{
${ }^{2}$ Many of the narrow alleys of the North End were established by 1820 and were created amid a housing shortage. At that time, the North End's housing stock had little changed since the mid eighteenth century, and most buildings were old and wooden. While some landowners tore down antiquated structures and erected larger replacements at this time, many responded the housing shortage by constructing new lanes, alleys and courts and turned former back yards into building sites. John B. Blake, Public Health in the Town of Boston, 1630-1822 (Cambridge, MA: Harvard University Press, 1959), 219-221.
} 
Block took their shape by 1676 , with Union and Hanover Streets possibly dating to 1630, the first year of the settlement [Figures 3-1, 3-2]. By the time automobilists could be found on the city's streets, this block, located in the thick of the downtown area, still had interior streets that were almost unusable by vehicles of any type, including those drawn by horse.

As with other colonial port towns, the most desirable commercial lands in Boston were those tracts that lay closest to mercantile activity supported by the waterfront. These lands formed the base of a distinctive colonial town form, characterized by the geographer Martyn Bowden as the "mercantile triangle." The base of such triangles spread along the waterfront, which was dominated by wharves, warehouses and wholesale markets. Further inland from the waterfront "lay the offices of those engaged in trade, such as merchants . . . and commission agents, as well as financial and commercial intelligence services, such as coffee houses, exchanges [and customs houses] ... Behind these functions lay a zone of retailing sufficiently close to the wharves to allow easy transfer." Near the retailers were lodging houses and taverns "providing hospitality and accommodation for immigrants, mariners, merchants and tradesmen." ${ }^{3}$ Noncommercial functions and residential buildings were pushed outside the boundaries of the triangle, since rents and land values increased prohibitively with proximity to the water [Figure 3-3].

The small area that would eventually become the Blackstone Block lay along the original waterfront and amid the quickly forming mercantile triangle of Boston. In accordance with Bowden's model, the earliest commercial activity of this area occurred on the town's most valuable land. The Blackstone Block's southern edge was formed by the Town Cove (later the

\footnotetext{
${ }^{3}$ Stephen John Hornsby and Michael Hermann, British Atlantic, American Frontier: Spaces of Power in Early Modern British America (Lebanon, NH: University Press of New England, 2005), 186; Diane Shaw, City Building on the Eastern Frontier: Sorting the New Nineteenth-Century City (Baltimore: Johns Hopkins University Press, 2004), 28-29. Another variant of this form is described in Dell Upton, Another City: Urban Life and Urban Spaces in the New American Republic (New Haven: Yale University Press, 2008), 21-25.
} 
site of Faneuil Hall), which supported shipping activity and which was also the site of the town's first market and business center, while its northern edge abutted the Mill Cove. Connecting the two coves was a creek that would be widened in 1643 to make it a navigable canal and to allow the operation of water-powered grist mills. ${ }^{4}$ The marshy land along the Mill Creek was soon developed into the commercial Scottow's Dock in the 1650s, while the most of the streets, paths and lands of the block began to take their shape in the 1640s [Figure 3-4]. ${ }^{5}$

The rights of way created as part of this shaping were not haphazard, despite the persistent and misguided popular myth that the whims of wandering cows determined the layout of the early city's roadways. Rather, these earliest streets were arranged and built at an intentionally human scale. While present in the city (the town forbade riding at a gallop in 1655, citing the danger to children), horses and other beasts of burden were not used in great numbers in the seventeenth and early eighteenth centuries. Those that existed were mostly used to bring wood and provisions from the countryside to the central market, many of these traveling by a highway through Roxbury that was twelve feet wide in 1650. This road was important enough that Petter Oliver was paid $15 £$ per year to keep it in sufficient repair for the passage of horses and carts. ${ }^{6}$ Mercantile activity, such as the unloading of a ship, depended primarily on able-

\footnotetext{
${ }^{4}$ Grist Mills were important in the seventeenth and early eighteen centuries, as grain was not only an essential victual but also was treated as a form of currency. Households routinely made trips to Boston's various mills in order process it for use, making them among the town's most trafficked destinations. Karen Friedmann, "Victualing Colonial Boston," Agricultural History 47, no. 43 (July 1973): 191-193.

${ }^{5}$ Boston Landmarks Commission, Report of the Boston Landmarks Commission on the Potential Designation of the Blackstone Block Street and Sidewalk Network (1983), 17-19.

${ }^{6}$ Rothenberg's review of the 1771 Valuations showed that between twenty and thirty-five percent of farm families in rural communities (thus, excluding Boston, Danvers, Newburyport and Salem) still lacked draught animals, and that in some communities the rate reached forty to forty-eight percent (Ipswich and Hadley). Winifred Rothenberg, "The Market and Massachusetts Farmers, 1750-1855," The Journal of Economic History 41 no. 2 (June 1981): 298. Pruitt's review of the same data finds that fifty-one percent of the nearly 10,000 people owning estates of less than twenty acres had no horse or oxen with which to plow the land. Bettye Pruitt, "Self-Sufficiency and the Agricultural Economy of Eighteenth-Century Massachusetts," William and Mary Quarterly 41, no. 3 (July 1984): 338. For the road to Roxbury and galloping law, see Record Commissioners, Second Report of the Record Commissioners Containing the Boston Town Records, 1634-1660, and the Book of Possessions (Boston: Rockwell and Churchill, City Printers, 1881), 99, 129.
} 
bodied men wielding push-carts and wheelbarrows. The difficulty of this kind of manual labor encouraged dense building and the absence of horse-drawn vehicles did not create a demand for wide streets. In fact, the earliest residents of Boston may have preferred to keep select paths and roads narrow, since devoting less space to rights-of-way allowed more buildings to be constructed closer to the water, which would have reduced the burden of labor. Since the seventeenth-century town's population was relatively small (about 3,000 in 1660) and since beasts of burden were not used in great numbers, public rights of way did not need to be very wide.

The streets of the Blackstone Block responded to these circumstances. The first of them, which formed the perimeter of the block, were built along hard ground and provided connections to other primary roads used to circulate through the town. By 1676, most buildings in the block fronted these streets, and many may have already shared common walls. Lots to the rear were left open, where privies might be located, wood might be stockpiled for fuel and where outbuildings might be placed [Figure 3-5]. Smaller interior streets were formed in short segments as the Mill Creek was shaped and as the marsh was filled in to create the commercial Scottow's Dock (profitably used until about 1711, when the creation of Long Wharf rendered it obsolete) and additional buildable land. ${ }^{7}$

The resulting network was not laid out with an apparent geometric order, but instead was created in response to quickly changing topographical conditions. These crooked interior rights of way were very narrow and retain their original dimensions to this day. Modern Marshall Street is approximately sixteen feet wide at either end. Present-day Creek Square is approximately fourteen feet wide near Marshall Street, widening to twenty-four feet at the Salt Lane

\footnotetext{
${ }^{7}$ Nancy S. Seasholes, Gaining Ground: A History of Landmaking in Boston (Cambridge, MA: MIT Press, 2003), 22-26; Gerald K. Kelso and Mary C. Beaudry, "Pollen Analysis and Urban Land Use: The Environs of Scottow's Dock in 17th, 18th, and Early 19th Century Boston," Historical Archaeology 24, no. 1 (1990): 61-81.
} 
intersection, and then narrowing to sixteen feet at Blackstone Street. Marsh Lane and Public Alley 102 are approximately twelve feet wide, while Salt Lane is approximately eleven feet wide. Scott Alley, the narrowest right of way remaining in the city, is about four feet wide at North Street, widening to sixteen feet. ${ }^{8}$

Outside of the Blackstone Block, other early streets had similar widths. Cambridge Street, laid out in 1647 , was originally twelve feet wide. The lands on either side of Cambridge Street remained agricultural into the eighteenth century with few houses or other buildings erected on the route, making it easier to widen when the Mount Vernon Proprietors later began developing Beacon Hill into a residential neighborhood in $1799 .{ }^{9}$ A “substantial" timber and iron bridge built in 1710 over a creek near Mackrell Lane was also twelve feet wide. Mackrell Lane, near the waterfront and intersecting with Kings Street, was similarly narrow and was widened to become Kilby Street, itself only twenty-eight feet, after the fire of $1760 .{ }^{10}$

By the 1730s, conventional widths for new "highways" had grown to approximately thirty feet, coincident with a rise in population (the population of Boston reached 16,382 in 1743). In 1729, a proposed road near the Common was to be thirty feet in breadth. In 1735 , the "ancient highway" of Sea Street was actually reduced from fifty feet to thirty-five feet in width when the road was judged to have too great a girth. At the time, Sea Street ran along the waterfront from Summer Street to Windmill Point and provided access to Darby Wharf and Bulls Wharf, which implied that it would have been a relatively busy road. ${ }^{11}$

\footnotetext{
${ }^{8}$ Boston Landmarks Commission, Blackstone Block Street Network, 4-7.

${ }^{9}$ Records Commissioners, Boston Town Records, 1634-1660, 115; Walter Muir Whitehill and Lawrence Kennedy, Boston: A Topographical History (Cambridge, MA: Belknap Press of Harvard University Press, 2000), 60-65.

${ }^{10}$ Records Commissioners, A Report of the Record Commissioners of the City Boston Containing the Records of Boston Selectmen, 1701 to 1715 (Boston: Rockwell and Churchill, City Printers, 1884), 105; Records Commissioners, Boston Town Records, 1634-1660, part 2, 100.

${ }^{11}$ For population figures, see Whitehill and Kennedy, Boston: A Topographical History, 37; For street widths, see Records Commissioners, Report of the Record Commissioners of the City of Boston Containing the Boston Records from 1729 to 1742 (Boston: Rockwell and Churchill, City Printers, 1885), 9, 142.
} 
While colonial Boston did not create its streets according to a long-term plan such as the pattern of gridded streets and squares devised by William Penn for Philadelphia [Figure 3-6, 37], its public ways were nonetheless laid out purposefully as the need arose to connect places. $^{12}$ Records from the earliest town meetings show a concern for street design, including those in the Blackstone Block. In one 1636 meeting of the overseers, "it was ordered that from this day, there shall be no house at all built near onto any of the streets or laynes therein, but with the consent of the overseers, for the avoiding disorderly building to the inconvenience of streets and laynes, and for the more comely and commodious ordering of them upon the forfeiture of such sum as the overseers shall see fitting." 13 Other meetings in 1636 document the fact that the widths of ways and roads were already being regulated, and that in the Blackstone Block, "a layne to goe from cove to cove, between Thomas Paynter and Thomas Marshall's, [shall be] one pole and a half between payle and payle."14

When horse-drawn vehicles later became commonplace in the early nineteenth century as a means to move goods, there was a need for wider streets that could accommodate the girth of horses pulling carts and carriages travelling amid increasingly large crowds of pedestrians. Places like the interior of the Blackstone Block were wholly unsuited to the demands of new horse technologies, but high real estate prices, strong property rights and extant building density

\footnotetext{
${ }^{12}$ Penn's 1682 plan called for a gird of streets that were an impressive fifty feet in width, these separated by two axial boulevards (High Street and Board Street) which were 100 feet wide. Penn also called for each house to be built in the middle of its lot. John Reps has speculated that this plan was intended to minimize the risk of future plague or devastating fire, both of which Penn had witnessed firsthand when living in London. Penn's orderly plan also benefitted from his experience laying out two other colonial settlements before establishing Philadelphia. The city's natural geography was far different from Boston's. It occupied a broad, flat expanse elevated between two rivers and there was no need for landmaking. Even so, though Penn's board street network remains, its early development also took the form of a mercantile triangle, with great density near the waterfront and empty lands near the Schuylkill River. The generous blocks within this triangle were soon cut up by additional streets, most of them very narrow, a practice that had begun by 1700 and which converted the idealistic "green country town" into an urbanized area of alleys and row houses. John W. Reps, The Making of Urban America: A History of City Planning in the United States (Princeton: Princeton University Press, 1965): 154-174.

${ }^{13}$ Boston Landmarks Commission, Blackstone Block Street Network, 20.

${ }^{14}$ Ibid. This width equaled approximately twenty-five feet.
} 
effectively fossilized the block, whose interior streets could only be used by pedestrians or as service alleys that provided access to the rear of buildings. This fossilization limited effective horse access, and, much later, automobile access. ${ }^{15}$

By the nineteenth century, commodious city streets were preferred not just because they afforded easier circulation, but because Bostonians desired better access to light and air as the industrializing and increasingly populous city filled with vile odors, especially in warmer months. These were created by various industrial practices (tanning, fat-rendering, etc.), by excess human and animal waste, by piles of rotting food strewn about the market district, among other practices. ${ }^{16}$ As older, narrower streets were populated by greater and greater numbers of people at the close of the eighteenth-century and as some of them became increasingly squalid, many Bostonians began to worry about the growing public health implications. As one wrote in a letter to the Columbian Centinel in 1796:

To know what many suffer, it is only necessary to walk through [the city's] crevices, almost debarred the free air and light of heaven-and then ask yourselves the sober question-How could I live in such a place as this, where the comfort of a refreshing breeze can never come-how can these miserable people bear this stench and filth-what if I should be reduced to the sad necessity of leaving my pleasant, airy, and elegant habitation, and condemned to lie where I can scarcely see to read... Why should not these blessings . . . be more equally diffused to all parts of the town, and the benefits of free air and green and shady walks be enjoyed as easily and cheap by one as another? ${ }^{17}$

Other impulses behind street creation were more philosophical. Wide, gridded streets appealed to what Dell Upton calls the spatial imagination of educated Americans in the late eighteenth and early nineteenth century. Upton describes the creation of such streets as a means

\footnotetext{
15 A similar kind of fossilization occurred with private property. As the city grew, estate owners often desired to build newer and larger buildings to respond to various influences, such as changing ideas about how residential space ought to be organized and the availability of new building technologies. Many of these owners were unable to build as they desired, in part because other structures were frequently in the way and in part because they were often constrained by existing public rights of way.

16 Upton, Another City, 2-15, 41-44, 120-129.

17 John B. Blake, Public Health in Boston, 160.
} 
to provide urban social order based on late-Enlightenment methods of scientific thought and a desire to broadly categorize and systematize space. Also, since streets, which were the primary public spaces available to city dwellers, became more claustrophobic as populations grew, wider streets more easily afforded the genteel the ability to pass through public space without being unduly crowded. ${ }^{18}$ Additionally, wider streets were also regarded as somewhat reducing the odds that an urban fire could grow to disastrous proportions.

While the Blackstone Block provides the oldest example of street fossilization in Boston, many of the pre-horse rights of way built in the colonial period were also locked in place by owners rigidly maintaining their property lines, often by building to the edges of them. Thus, the street network that appeared on the Bonner map of 1722 [Figure 3-8] is still evident on Justin Winsor's 1880 map [Figure 3-9], long after the city industrialized. Wider, straighter streets intended to accommodate greater volumes of bulky, slow-moving horse traffic may be found, selectively, in the altered center, but most zones equipped to provide superior access to horsedrawn vehicles were built on lands reclaimed after horses began to power the city.

Thus, better horse streets can be found on areas created by landmaking projects begun after 1800. This included Commercial Street (sixty-five feet wide), created in response to a 1826 petition to the City Council's request for "a wide commodious street" from Boston's crowded marketing district, which centered around Faneuil Hall and the recently built Quincy Market compound, along a sea wall to prominent Lewis Wharf [Figure 3-10] ${ }^{19}$ As Mayor Josiah Quincy recollected in the early nineteenth century,

on high market days, Union, Elm, Brattle, Washington, and Exchange Streets were often completely obstructed. Farmers, coming from a great distance in the country, were compelled to take their stand along Union Street, as far as

\footnotetext{
${ }^{18}$ Upton, Another City, 86-100.

${ }^{19}$ Seasholes, Gaining Ground, 53.
} 
Marshall's Lane, and in Washington Street, as far as Court Street. They were thus excluded from the space around Faneuil Hall, where their customers chiefly resorted, and where often obliged to sell their goods to forestallers, greatly to their loss and discontent. ${ }^{20}$

Boston's formal market buildings were not able to adequately provision the city and a large, informally organized open-air market of carts and wheelbarrows filled the spaces between the Faneuil Hall, Quincy, North and South Markets while also occupying significant space in the major streets that lead into the area. The newly created Commercial Street was laid out in the hopes of facilitating access to the marketing area from the waterfront, though congestion created by the great volume of vendors who provisioned the growing city persisted in the market district throughout the nineteenth century [Figure 3-11].

When the Mill Pond was filled in to create the Bulfinch Triangle (the filling was begun in 1808 and completed in 1828), the various streets were planned as an easily navigable grid, with most streets having widths of forty or fifty feet. These roads were straighter, longer and wider than the surrounding rights of way, which had been built up long before [Figure 3-12]. ${ }^{21}$ Initially intended to be developed as a lower income residential district for the mechanic classes (and importantly included a canal that served as an extension of the Middlesex Canal and provided access to New Hampshire via the Merrimack River), the area was actually developed as a commercial and industrial center. In 1845, the canal was filled in and replaced with a railroad track, and the north side of Causeway Street was soon lined with the depots of several railroads. ${ }^{22}$ As the 1867 Sanborn atlas demonstrates, the Bulfinch Triangle emerged as the center of Boston's horse trade, and supported a great concentration of stables, auction houses,

\footnotetext{
${ }^{20}$ Josiah Quincy, A Municipal History of the Town and City of Boston during Two Centuries: From September 17, 1630, to September 17, 1830 (Boston: Charles C. Little and James Brown, 1852), 76.

${ }^{21}$ Seasholes, Gaining Ground, 65.

${ }^{22}$ Ibid 73-92; Record Commissioners, A Volume of Records Relating to the Early History of Boston Containing the Minutes of the Selectmen's Meeting, 1799 to, and Including, 1810 (Boston: Municipal Printing Office, 1904), 301, 309, 353, 361, 371, 379.
} 
blacksmiths, carriage works and the city's hay scales, institutions which all benefitted from the wider roads they fronted.

Atlantic Avenue, the widest road on the peninsula with a girth of 100 feet, was proposed in 1868 in response to a very specific circulation problem. Boston's main railroad depots were located about a mile apart from one another (clustered near Kneeland Street in the south and along Causeway Street in the north), and the city desired to build a broad boulevard that would connect the depots while also providing teamsters access to wharfing activity along the waterfront. Atlantic Avenue was a central part of this route, and the greater width of this road was demanded so that surface railroad tracks could be installed in order to transfer freight between the depots. When the road was created, it was laid on infill taken from the contemporaneous excavation of Fort Hill and across significantly truncated wharves (the owners objected but their protests were disregarded by the City Council). Wharf buildings that lay in the way were cut through, forming reduced buildings on either side of the new road. ${ }^{23}$

The Back Bay landmaking project of the mid to late nineteenth century took horse-based neighborhood design to a broader scale. Here, the gridded streets were wider, straighter and longer than any other area in the city [Figure 3-13]. The blocks were also larger, with streets spaced further apart than elsewhere, somewhat reducing traffic interruptions by lessening the number of intersections. Commonwealth Avenue was an amazing 200 feet wide, while most other roads in the area were at least sixty feet wide. ${ }^{24}$

Boston's streetcar network illuminated the shortcomings of the city's central streets [Figure 3-14]. Outside of the downtown area, nearly all tracks were laid on roads that were at least sixty feet wide (and that did not have to accommodate hundreds of thousands of gathered

\footnotetext{
${ }^{23}$ Seasholes, Gaining Ground, 61-71.

${ }^{24}$ Commonwealth Avenue's right of way was 200 feet wide, while buildings on either side of the street where required to be set back an additional 20 feet.
} 
shoppers and commuters). Passing through the South End to destinations in Roxbury and Dorchester, Federal Street, Hamilton Street, Shawmut Avenue and Tremont Street were all sixty feet wide. While narrower than these nearby roads, Washington Street increased in breadth to fifty-five feet south of congested district. In the Back Bay and variously leading to Jamaica Plain, Brookline and Brighton, Beacon Street was seventy feet wide, Columbus Avenue was eighty feet wide, Boylston Street (west of Tremont Street) was eighty feet wide and Huntington Avenue reached a width of 100 feet [Figure 3-15]. Outside of the center, tracks were laid on cross streets like Berkeley Street (eighty feet), Dartmouth Street (100 feet), Broadway (sixty feet), West Chester Park (ninety feet) and East Chester Park (ranging from seventy to ninety-two feet) that were also wider. ${ }^{25}$

These greater street widths terminated at the western edge of the Public Garden and south of Essex Street. In the center city, where most streetcars traveling on suburban streets were bound, tracks operated on the widest available roads (rights of way with widths less than fortyfive feet were avoided), but in general the central streets were far more constrained while carrying much more traffic. The only route that passed through the downtown area meeting the sixty foot standard set by the outlying districts was that formed by Tremont Street and Hanover Street (both sixty-feet wide), which connected to each other in crowded Scollay Square. Otherwise, the only other wide route on the peninsula was the waterfront ring road formed by Atlantic Avenue, Commercial Street and Causeway Street (which ranged from sixty to 100 feet depending on location). While most tracks in the downtown area were laid on streets that were approximately fifty feet in width, occasionally narrower roads were used, though usually in small

\footnotetext{
${ }^{25}$ These figures are taken from the 1885 and 1887 Sanborn atlases covering Boston, which were published near the peak of horse-drawn streetcar use (electrification began in 1889) and before the creation of the subway and elevated system.
} 
segments. ${ }^{26}$ As the Rapid Transit Commission reported in 1892, these central streets with their irregular paths and frequent intersections were unable to adequately allow the passage of the thousands of streetcars that sought to pass through the congested district each hour, which ultimately compelled Boston to create its subway system. These streetcars were far more space efficient than the automobiles that would follow. ${ }^{27}$

The wider, gridded roads of the Back Bay did not take their shape simply to facilitate vehicular movement. The right angles of the street network conformed to established notions about how to divide empty land for sale to speculators and other builders. The neighborhood's greater street widths were meant to appropriately set off the fashionable homes that were soon built upon the created lands, and also to afford a genteel amount of public space to the neighborhood's residents. In part to secure the Back Bay's desired status as an elite residential enclave, Commonwealth Avenue evoked the grandeur of a Parisian boulevard, with Olmsted's broad tree-lined park running in its midst. Underscoring the street's purpose, no streetcars ran on Commonwealth Avenue between the Public Garden and Massachusetts Avenue. Instead, transit lines were installed on the surface of Marlborough Street (sixty feet wide), Boylston Street (eighty feet wide), Clarendon Street (sixty feet wide) and Dartmouth Street (100 feet wide).

Fashionable as they were intended to be, the Back Bay's broader streets with their consistent widths and regular intersections much more easily accommodated horse-drawn vehicles, whether a private carriage, an omnibus, a delivery wagon or a streetcar. They were generous enough to allow vehicles to stop at curbs and to allow multiple "lanes" of traffic. One

\footnotetext{
${ }^{26}$ These were Bedford Street (thirty-five feet), Chardon Street (forty feet), Court Street (thirty-six feet at its narrowest point), Fleet Street (forty feet), Kingston Street (forty feet at its narrowest point), Essex Street (forty feet at its narrowest point), Norman Street (twenty-two feet), Otis Street (forty-five feet) and Washington Street (forty feet at its narrowest point).

${ }^{27}$ Rapid Transit Commission, Report of the Rapid Transit Commission to the Massachusetts Legislature (Boston, 1892).
} 
of the Back Bay's sixty-foot streets (such as Marlborough Street) could provide two ten-foot sidewalks (allowing enough space for three people to walk abreast) and four lanes of traffic (the two lanes running along the curb would have regularly been blocked by standing vehicles or other obstructions). Streetcars on such a road shared space with other vehicles (and pedestrians) in the two active travel lanes [Figure 3-16]. By comparison, a busy forty-foot street in the downtown area needed at least as much sidewalk space to accommodate the greater volume of pedestrians drawn to the area, allowing just two lanes for vehicular traffic (one of which would usually be blocked). If sidewalk widths were reduced, then additional lanes in the road could be created, though more pedestrians would be compelled to walk in the roadway [Figure 3-17]. Given the great crowds of pedestrians and automobilists in the downtown retail district, even sixty-foot roads were unable to grant adequate space to motor car traffic [Figure 3-18, 3-19].

Additional space for deliveries was created by the Back Bay's multiple sixteen-foot-wide service allies, which ran parallel to each major road. The street network was principally a grid, with all rights of way either parallel or at right angles, which eliminated awkward turns. As discussed in Chapter 1, the area even featured an early version of zoning intended to mitigate the nuisances caused by urban horse use, with a single block devoted almost exclusively to stables, which were prohibited from most other lots (exempting the homes of doctors).

As a result of these planning efforts (and because the streets of the Back Bay were comparatively uncrowded with pedestrians and horse-drawn vehicles), streetcars and private conveyances ran far more efficiently in the Back Bay than elsewhere in the city center. Complaints of congestion were almost always directed at the older, denser city, which attracted the greatest share of pedestrians and vehicular traffic. For those who owned or rented private vehicles, Commonwealth Avenue became a celebrated boulevard for carriage riding and, even 
more so, a haven for the popular winter sleighing season, with recreational horse users making regular use of it. In the early years of automobile use when urban motoring was still regarded as an elite sport, wide, straight Commonwealth Avenue emerged as a popular place to run one's car. $^{28}$

Older downtown streets created before the period of mass horse use remained exceedingly difficult to modify, even during large-scale reconstruction following disaster. After the great fire of 1872 destroyed sixty-five acres concentrated around Boston's wholesale district [Figure 3-20], politicians, newspapers, business owners and everyday citizens quickly expressed enthusiasm over the perceived opportunity to re-plan the street network of the burnt district. Like other streets in the downtown area, many of the streets of the burnt district were created before horse use gained prevalence, and were then solidified by the owners of estates protective of their property lines. ${ }^{29}$ The network of streets in the burnt district was representative of the entire downtown area. Streets were narrow (widths ranged from twelve to forty-five feet), crooked and sinuous with many dead-ends. Some were only a block or two long. Many heavily trafficked intersections were awkwardly angular and did not align with the "major" streets that had been used before the fire. ${ }^{30}$

As a result, this area was plagued by traffic congestion, which annoyed pedestrians and seriously delayed streetcars, carriages and delivery teams. Before the area commercialized, the streets, in the historian Christine Myer Rosen's view, were "barely adequate for residential use" and after the wholesalers took over, "they made the area a nightmare for businessmen and coach

\footnotetext{
${ }^{28}$ Asha Weinstein, "Congestion as a Cultural Construct: The 'Congestion Evil' in Boston in the 1890s and 1920s," The Journal of Transport History 27, no. 2 (September 2006): 97-108.

${ }^{29}$ It was not until the 1860s that Boston gained the power to impose betterment assessments on abutters to counterbalance the excessive costs associated with taking buildings and land and then paying damages to property owners. Christine M. Rosen, The Limits of Power: Great Fires and the Process of City Growth in America (New York: Cambridge University Press, 1986), 184-185.

${ }^{30}$ Ibid, 181-183.
} 
and delivery truck drivers, especially those trying to get from the North End or the State Street financial center to the railway terminals. The only direct route between Milk and upper Summer Streets was Hawley Street, which in one place was a mere twelve feet." ${ }^{\prime 31}$

In her examination of the reconstruction that followed the fire of 1872, Rosen shows that early visions for replacing older roads with efficient street networks capable of supporting prevailing traffic patterns were soon abandoned. In the days following the disaster, several proposals were presented to the City Council to fundamentally redesign the streets of the burnt district, such as a plan developed by a Mr. Walling, a city engineer [Figure 3-21]. His scheme was a direct response to early recommendations put forth by the Board of Street Commissioners and the Joint Committee on Streets to take the entire burnt district by eminent domain and reorder the "streets and building lots anew, without reference to the existing lines."

Such a broad application of eminent domain raised financial questions. Many were fearful that the city could not bear the immense cost despite "the city's past success in reselling lands taken under the assessment law for a profit." ${ }^{33}$ The constitutionality of such an expropriation was also questioned, though the City Solicitor concluded that constitutional objections were insufficient to block the use of eminent domain. Many were concerned that the legal, political and practical wrangling associated with rebuilding the district with a wholly new street network would take years, which in turn might have compelled the area's wholesaling enterprises to reestablish themselves in other cities. By far the biggest concern was that such a large acquisition would "threaten a complete redistribution of landholding patterns in the business area ... former landholders might then have been unable to repurchase their old estates or, worse, unable to buy any land at all ... [proposals like Mr. Walling's] would have cut up the

\footnotetext{
${ }^{31}$ Ibid, 182.

${ }^{32}$ Ibid, 187

${ }^{33}$ Ibid, 190.
} 
old plots so thoroughly that even a semblance of a return to the old pattern would have been impossible."34

While most property owners had initially called for dramatic changes in order to create more usable streets, these same owners ferociously sought to preserve their estates and opposed reordering or widening plans that reduced their holdings. Localized strategic efforts, such as an attempt by the Street Commissioners to merge Federal and Congress Streets in order to eliminate a major point of traffic congestion created by the turns on and off Milk Street, were abandoned in the face of protest by wealthy abutters. A plan to widen the stretch of Washington Street that passed through the burnt district was similarly doomed thanks to the efforts of a small group of people who owned land between Summer Street and Central Court. ${ }^{35}$

In the end, rebuilding followed a conservative plan, traffic congestion continued to choke the area and private property continued to prove resilient. The only "completely new additions to the system were the creation of Post Office Square and the extensions of three other streets. Post Office Square was nothing but a small triangle of land, and of the three extensions, only one street, Franklin Street, was lengthened more than one block." While seventeen streets were widened, fifteen of these widenings were very modest and the resulting rights of way ranged between forty and sixty feet in width [Figure 3-22]. ${ }^{36}$

As automobiles were introduced to the city, Boston officials struggled to understand how wide to make new streets and sought to establish guidelines governing the widening of existing roads in response to a growing metropolitan population and to new technologies. Through a directive from the Commonwealth, city commissioners also began to examine the road network of the greater metropolitan area. In the Metropolitan Improvement Commission's 1909 report,

\footnotetext{
${ }^{34}$ Ibid, 190-191.

${ }^{35}$ Ibid, 196-204

${ }^{36} \mathrm{Ibid}, 245$.
} 
Public Improvements for the Metropolitan District, Arthur Shurtleff presented the "Metropolitan Plan" for the Boston area. This plan, in addition to advocating for the development of radial and circumferential thoroughfares that would connect the thirty-nine towns and cities of the metropolitan district, also presented the commission's view on ideal street widths according to the kinds of traffic they should be able to carry.

Though many of the streets in downtown Boston remained very narrow (in the vicinity of the major department stores, West Street was thirty-four feet wide, Winter Street was thirty-six feet wide and Avon Street was thirty-two feet wide), ${ }^{37}$ Shurtleff wrote that a village street, "should have sufficient width to allow vehicles delivering goods or passengers to stand at each side of the traveled way while leaving sufficient gangway between them for a chance moving vehicle to pass, and it should also provide sidewalks for foot passers. Assuming each vehicle to have an over-all width of seven feet (the width of an ordinary express wagon or milk cart), and to be allowed a leeway of eighteen inches on each side, the total width of such a street with narrow sidewalks (six feet wide) becomes thirty-nine feet." ${ }^{38}$ According to the Metropolitan Plan, important side streets in Boston or the main street of a lesser town should be made wide enough to accommodate a set of electric streetcar tracks and to allow space for four lines of teamsters (two unloading at the curb, two moving in the street) as well as a greater volume of pedestrians on ten-foot-wide sidewalks, reaching a width of sixty-one feet. Busier streets were deemed to require additional space, since a street of just sixty-one feet compelled wagons to occupy the same lanes as starting and stopping streetcars. Thus, Shurtleff advised that commercial streets in the city be made eight-four feet wide, with two twelve-foot wide sidewalks, two seven-foot wide

\footnotetext{
37 Sanborn Map Company, Insurance Maps of Boston Massachusetts, vol. 1 (New York: Sanborn Map Company, 1909).

${ }^{38}$ Commission on Metropolitan Improvements, Public Improvements for the Metropolitan District (Boston: Wright \& Potter, 1909), 201.
} 
lanes for narrower wagons, two eight-foot wide lanes for wider wagons, two lanes for streetcars (one of which would share space with delivery teams) and sufficient space between each lane. Artery roads with two lines of streetcars and three lanes (two for traffic, one for stopping) on either side of the tracks should be 112 feet wide, sidewalks included. The suggested width for the largest thoroughfares was 165 feet [Figure 3-23]. With the exception of Atlantic Avenue (which still accommodated freight railroad tracks), the streets of central Boston did not come close to these standards. Most streets of the retail district did not even achieve the width that Shurtleff recommended for a suburban village road.

The Metropolitan Improvements Commission bemoaned the fact that many of the central streets retained widths that created difficulty for horse-drawn teams attempting to make deliveries essential for sustaining the city and its businesses. Throughout the downtown area, an average width of forty feet prevailed, "wholly inadequate ... to carry even a moderate traffic." Court Street was approximately forty feet wide and accommodated three lanes with a pair of sidewalks that were eight feet, four inches wide. Devonshire Street between the Old State House and Adams square reached fifty feet and was deemed to be representative of the wider streets in the downtown area. It was seriously overcrowded "with narrow sidewalks, four lines of vehicles, including a double track for electric cars" [Figure 3-24]. ${ }^{39}$

In 1912, the Metropolitan Plan Commission (established in 1911) issued a report that continued to assert the popular view that Boston's central streets were inadequate to modern demands of traffic. Again, the narrow and angular character of these streets was lamented:

The main thoroughfare of Boston is Washington Street. On it are the great retail stores which serve more than a million and a half of people, yet through its most valuable section the roadway reaches its greatest width at $40 \mathrm{feet}$, and is as narrow

\footnotetext{
39 Though published in 1909, the report was originally due to the state legislature in 1908. Many of the report's conclusions would have been made in 1907. This might explain why the topic of automobile use is largely absent from the report and why Shurtleff's diagrams show only carriages and streetcars, but no motor cars. Ibid, 200.
} 
as 26 feet, while the sidewalks are only 7 to 10 feet in width, and the street is congested by two lines of cars and an immense volume of business teaming. Fifth Avenue in New York, without cars and with no business teaming, is 100 feet wide. The roadway of State Street in Chicago, its main business thoroughfare, is 80 feet wide and has 25-foot sidewalks. Washington Street is only typical of our narrow and discommodious streets. The crowding of our sidewalks, the jamming of our roadway, has cost Boston an incalculable loss in growth. ${ }^{40}$

After Boston's planning board was established in 1913, it devoted much of its efforts to devising ways to dismantle the fossilized landscape that had so persistently survived, even forcing streetcars underground. These efforts, aspirational at first, eventually determined the path of the Central Artery superhighway that would destroy so much of the downtown area a few decades later.

\section{AUTOMOBILE DISTRICTS}

\section{Boylston Street}

As the mass use of automobiles overtook Boston, a large retail zone was quickly established in response to the growing demand for new and used cars. This zone took on a distinct spatial form that differed from the retail and commercial enterprises that had come to occupy Boston's downtown area at the turn of the century. Traditional retailers within the central business district chose locations informed by a variety of determinations, such as rental rates, perceived suitability of building types, proximity to competitors, access to the busiest streetcar lines and availability of space.

While the rationale behind retail site selection in the last half of the nineteenth century was more complex than this crude summation, in general like businesses formed compact nuclei within the confines of the slowly expanding central business district. Thus, horse auctioneers were clustered together near Haymarket Square, department stores were close neighbors, jewelry

\footnotetext{
${ }^{40}$ Metropolitan Plan Commission, Report of the Metropolitan Plan Commission (Boston: Wright and Potter, 1912), 9, quoted in Weinstein, "Perceptions of Traffic Congestion," 177-178.
} 
and watch sellers who depended on high-value, low-volume trade took space next to one another, and sellers of furniture and household goods were similarly grouped. This spatial logic also guided the nucleated form of the market district and the financial district (in 1844, Boston had twenty-five commercial banks, two savings banks and twenty-seven insurance companies, and all but three of these were grouped together on State Street). These nuclei occasionally migrated within the central business district in the face of internal pressure (for example, encroachment of financial institutions into the retail area), but even when dislocated they tended to reform as a new cluster. ${ }^{41}$

Even in its early form, the retailers of automobiles and automobile parts began to occupy far more city space than their forbearers. These enterprises were not organized as a compact nuclei, but instead as an elongated linear form. The first such zone was oriented around Boylston Street, which became the city's original automobile row. By 1910, virtually all commercial activity on this street was devoted to some aspect of the automobile trade. For a short time, the Boylston axis provided the greatest concentration of repair shops, service stations, parts suppliers and tire shops in New England.

While decades later the lots and showrooms of automobile sellers would eventually congregate on state roads and other suburban and exurban thoroughfares, the earliest retail spaces in service to the motor industry were located near the center of the city. Car owners in later periods frequently drove existing automobiles to decentralized showrooms and open lots in order to inspect prospective purchases. In the earliest years of car use, however, many customers

\footnotetext{
${ }^{41}$ Martyn J. Bowden, "Downtown Through Time: Delimination, Expansion, and Internal Growth," Economic Geography 47, no. 2 (April 1971): 121-135; Mona Domosh, "Shaping the Commercial City: Retail Districts in Nineteenth-Century New York and Boston," Annals of the Association of American Geographers 80, no. 2 (1990): 268-284; Bart J. Epstein, "Geography and the Business of Retail Site Evaluation and Selection," Economic Geography 47, no. 2 (April 1971): 192-199; David Ward, "The Industrial Revolution and the Emergence of Boston's Central Business District," Economic Geography 42, no. 2 (April 1966): 152-171.
} 
were first-time buyers still dependent on mass transit and it was far more profitable for dealers to follow standard retailing custom and to locate their facilities close to the city center. Automobile makers only began exhorting their dealers to forgo proximity to urban centers after World War II, when the suburbanized landscape greatly expanded and major commuter highways were established. The 1950s saw the emergence of sprawling dealerships on these commuter highways with large lots and expansive one-story buildings typically housing a showroom, office and service department. ${ }^{42}$

Boylston Street offered many advantages to those who depended up the early automobile trade. The initial luxury car market enjoyed proximity to wealthy customers who lived in the Back Bay and Beacon Hill and was reasonably accessible to the well-to-do in Brookline and other suburbs. The emerging trade catering to a broader mass market relied upon proximity to the garages and other ancillary services that had already been built for elite car owners in the first few years of automobile use. This district was removed from the downtown area, where rents were more expensive, space was hard to come by and streets were ill-suited to mass automobile use. The storefronts along Boylston Street were of modest size (these usually occupied the first floor of a four- or five-story row house), which for a short while made them prudent retail spaces in times when some makers might consider themselves fortunate to sell a handful of cars in a year, and when a wide range of makers of accessories, parts and tires sought to gain a foothold in the emerging market.

The built character of this first automobile row was captured by the activity of the Boston Transit Commission, whose construction of the Boylston Street subway happened to coincide, more or less, with the row's peak years. As part of their efforts to implement the Boylston Street

${ }^{42}$ Chester Liebs, Main Street to Miracle Mile: American Roadside Architecture (Baltimore: Johns Hopkins University Press, 1995), 86-89. 
subway line, the Boston Transit Commission worked with a photographer who sought to document the construction process. In doing so, this photographer systematically photographed each Boylston Street building that fronted the path of the subway line, presumably for insurance purposes. While not all of these photographs survive, a significant portion of the sequence remains intact, providing insight into the scope of the automobile trade on Boylston Street in this year. These seven photographs show the original automobile row as it appeared in 1912 from Exeter Street to Hereford Street [Figures 3-25 to 3-31].

Of the seventeen ground-level storefronts that appear in these photographs whose commercial activities are identifiable, twelve were devoted to automobile sales or servicing: Swinehart Tires, a small showroom, the Fisk Rubber Company, Century Tires, the Fiat showroom, the B. F. Goodrich Company, the Diamond Rubber Company, the American showroom, Hudson Cars, Michelin Tires, the Thomas Motor Car Company and T. A. Quilan Auto Supplies. Additionally, the one empty lot appearing in this set of images contained billboards for automobile jacks and shock absorbers.

The various buildings that appear in these photographs ranged in size from two to seven stories. Some occupied narrow lots while others enjoyed larger footprints. Some addressed the street with bay or bow fronts, while others made use of plate glass. Several of the shops had sunken, cellar-level entries. Others offered entry at the level of the sidewalk. While the Thomas Motor Car company used the entirety of the building that housed it (the ground floor as a show room, the floors above as storage and offices), most of these commercial buildings rented their various floors to different tenants. Thus, a dancing academy operated above the America showroom, a brass parts supplier ran a store above Michelin Tires, a private school was run out of spaces above Century Tire and a photographer kept an office above Swinehart Tires. 
These and other photographs show that the automotive enterprises on Boylston Street simply occupied existing buildings that for the most part were designed as generic retail spaces that could easily accommodate a range of tenants. This proved to be a prudent decision, for Boylston Street did not last long as an automobile district. For example, Swinehart Tires soon left Boylston Street to be replaced by the Atlantic Radio Company in the 1920s [Figure 3-32]. Many of the other tire shops, parts suppliers and showrooms (as well as the original Massachusetts Automobile Club) that operated on this stretch of road did not survive the 1930s. By the time the Sanborn Map Company updated its plates covering this portion of Boylston Street in 1936, no automobile-related industries were recorded, though most of the building footprints and heights remained the same as they appeared in the 1914 atlas. $^{43}$

The shops that formed Boston's first automobile row on Boylston Street were influenced by existing ideas about how retail spaces should engage the street. They did not significantly deviate from retail norms, just as the streets they fronted, designed during the horse age, had been designed according to prevailing norms of street layout. These buildings shared walls, kept a uniform distance from the street, and, for the most part, typified commercial corridors outside of large downtown areas. The Fiat showroom at 839 Boylston Street [Chapter 3, Figure 3-27] sold cars out of a narrow store front (it was just wide enough for a bay window and arched doorway) that had once been a ground-level apartment in 1890s. Even after Fiat began using the newly converted storefront to sell cars, the building maintained a residential appearance (the three floors above continued to be used as apartment flats) and the single car displayed sat under a shady awning in what had once been a living room or parlor. Next door, another four-story row

\footnotetext{
43 Sanborn Map Company, Insurance Maps of Boston Massachusetts, vol. 2 (New York: Sanborn Map Company, 1914).
} 
house with a bow window and arched entry door still maintained a residential apartment on the first floor. ${ }^{44}$

Since a narrow sixteen-foot wide public alley stretched along the length of Boylston Street, inventory was moved in and out of the rear of each shop. Elsewhere, if no such access existed, a large portal was included as part of the composition of the store front. Inside, those shops that stored cars on more than one level made use of freight elevators. Otherwise, "[e]xisting commercial-block design influenced interior organization as well. Many early showrooms were laid out like any large retail shop. The structures had the customary store space behind the shop front. However, instead of being filled with carriages, hardware or dry goods, it now functioned as a salesroom for cars, accessories, clothing, and technical literature. Long a retail-store mainstay for everything from stock storage to restaurant kitchens, the back room was reincarnated as a repair shop with workbenches, lubrication pit, wash rack, and turntable (if the site did not permit sufficient turnaround space)." ${ }^{, 45}$

While the automobile trade did not long thrive in the (mostly) small-scaled and pedestrian-oriented commercial spaces on Boylston Street, the trade did help encourage profitable commercial building in this area. In those years when the automobile was regarded as an item of extravagance, the trade benefitted from the Back Bay's reputation as an emerging and fashionable shopping district, just as the early trade was itself fashionable and helped to build that reputation. A decade later, when much of the trade had migrated to a more mature automobile row on Commonwealth Avenue, Boylston Street boosters sought to capitalize on the street's retailing prospects and fashionable reputation by promoting it as the most cosmopolitan such space in the United States, outshining even Fifth Avenue with its electric brilliance [Figure

\footnotetext{
${ }^{44}$ Liebs, Main Street to Miracle Mile, 76.

${ }^{45}$ Ibid, 76-77.
} 
3-33]. The Boston Herald endorsed these exaggerated claims, and asserted in 1922 that the street "has charm which even [the] great shopping centres of New York, Philadelphia or Paris do not possess. ${ }^{46}$

\section{Commonwealth Avenue - Kenmore Square to Packard's Corner}

The early automobile district that emerged around Park Square and along Boylston Street initially depended on the demands of the numerous small-time automobile interests that operated before Ford's streamlined manufacturing processes compelled other makers to compete with a fundamentally different scale of production. By the early 1910s, automobile sellers began to develop large and grandiose buildings to display and market their cars. The retail spaces on Boylston Street, developed in the 1880 s and 1890 s by landowners who then catered to an automobile trade that was anxious to rent their shops, were soon proven to be of inadequate size. Since there were few remaining vacant lots along the original auto row and since these lots were themselves not large enough for the next generation of sales buildings, the city's most prominent automobile interests began congregating along Commonwealth Avenue between Kenmore Square (originally Governor's Square) and Packard's Corner, more or less following the western trajectory established by the growth along Boylston Street that led away from the city center. ${ }^{47}$

Kenmore Square and the western portion of Commonwealth Avenue were created as part of the Back Bay landmaking project. These roads had been completed in the late 1880s and much of the surrounding area had not yet been developed at the turn of the century. Immediately south of Kenmore Square, the filling of the area that would become the Fens had only begun in 1885 , and was not completed until the 1890s. Many of the prominent institutions that moved to

\footnotetext{
${ }^{46}$ Ad, "Boylston Street and Its Environs to be the Finest Shopping Center in the World," Boston Herald, October 15, 1922, 16; "Boylston Street Now Called Boston's Fifth Avenue," Boston Herald, December 3, 1922, 15.

47 "Boston's Motor Row," Motor Age 21 (February 29, 1912): 5; Patrick Kennedy, "Revisiting Auto Row," Bostonia (Winter-Spring 2012): 24-29.
} 
the Fenway area, such as the New England Conservatory of Music (1902), Simmons College (1904) and the Museum of Fine Arts (1909), were built after motor cars had appeared on the city's streets. ${ }^{48}$ While these large institutions were not positioned on the roadways commercialized by automobile dealers and instead favored more tranquil addresses near the newly completed park lands, the timing of their construction underscores the fact that this area of the city was mostly a spatial void that was developed in coincidence with two trends - the mass adoption of motor cars and the accumulation of astonishing wealth by a select sector of businesses.

The lands of the western Back Bay project were better suited to the new building types and street patterns that favored the automobile. These lands were well removed from the narrow, angular and disrupted streets that typified downtown Boston. They were also removed from the great crowds of pedestrian and vehicular traffic that so complicated movement in the center of the city and that had begun to creep into the Park Square area and down Boylston Street. Thanks to the implementation of electrified streetcar service down Commonwealth Avenue in 1909 and a subway extension to Kenmore Square completed in 1914, western Commonwealth Avenue and Kenmore Square enjoyed access to efficient public transit, allowing dealers operating in this area access to first-time buyers. It was also advantageously positioned to attract suburban drivers. While Commonwealth Avenue from the Public Garden to Massachusetts Avenue was zoned to prohibit commercial development and was envisioned to be a grand and fashionable residential promenade, the extension of Commonwealth Avenue that passed through Kenmore Square lacked commercial prohibitions, yet retained the boulevard's great width. In addition to curbside parking and ample sidewalks, this width allowed four lanes of travel (two eastbound and two westbound). The increased width afforded the earliest motorists space to maneuver around other

\footnotetext{
${ }^{48}$ Seasholes, Gaining Ground, 226-229.
} 
cars at higher speeds. It also allowed them broader sight lines by which they could identify commercial buildings and anticipate approaches to them. Compared to the city's other prominent roads, Commonwealth Avenue was particularly suited to the demands of drivers and was, at first, relatively free of congestion, though by 1920 automobile traffic in Kenmore Square was among the city's most crowded and difficult to navigate.

The commercial buildings developed along Commonwealth Avenue responded to motoring conditions allowed by the wide, undeveloped street. The first and largest of these new buildings was constructed by Alvan Fuller (later governor of Massachusetts), who had secured the privilege of being the Packard Car Company's sole representative in the Boston area. Fuller (who ran a bicycle store before entering the auto trade) had previously occupied space in the 1905 Motor Mart. He soon realized that his small confines and central location in Park Square were about to become obsolete and was the first to recognize the advantages of the Western Back Bay. $^{49}$

The first iteration of the Packard building, completed near the end of 1909, was an enormous, four-story structure of a scale not yet seen in Boston [Figure 3-34]. Part warehouse, part show room and part service station, the original building was 340 feet long and seventy feet wide. It was designed by the famed industrial architect Albert Kahn, who had recently overseen the creation of Packard's manufacturing facility in Detroit and who had designed Packard's first large-scale urban showroom at Broadway and Sixty-First Street in Manhattan in 1907.

The Packard building on Commonwealth Avenue featured a large sales salon occupying a portion of the first floor [Figure 3-35]. Visitors passed through large plate glass doors under an ornate marquise to immediately face "the full sweep of the perfectly lighted sales rooms,

\footnotetext{
49 Fuller did not immediately abandon Packard's space at the Motor Mart. Instead, he retained it to display overhauled secondhand cars.
} 
occupying the full width of the building and extending backward 70 feet." ${ }^{.50}$ Tall, twenty-eightfoot ceilings emphasized the grandeur of the purchasing experience and car ownership, as did a second-story mezzanine reached by a sculptural stairway. A collection of mahogany tables and chairs were provided for prospective buyers to peruse catalogs and view upholstery samples, with walls and floors finished in quarter-sawed oak [Figure 3-36]. ${ }^{51}$

The Boston sales salon was informed by the design of Packard's Manhattan showrooms. Both were expansive - two stories high and extravagantly illuminated. These salons were "designed to appear as grand as a fashionable hotel lobby, [though the] lofty setting was intended to show off cars rather than provide a backdrop for crowds." ${ }^{, 52}$ Elsewhere in these buildings, the "character of the facility changed abruptly (a change not unlike that which a railroad passenger experienced when leaving the sumptuous waiting room of a train station to enter the train shed with its paved platforms and soaring trusses). Here, between massive concrete columns, the company placed the inventory of shiny new cars, plus spare parts and repair shops needed to keep cars running after being purchased." 53

While Fuller used the building as a showroom where one might purchase a new car, most of the building was actually given to the repair and maintenance of Packards that were already sold. The top floor of the building, well lit by large skylights set in the trussed roof and by expansive windows, was entirely devoted to general repairs and had space along the perimeter walls for fifty-six cars to be worked on simultaneously, with more space in the center of the room [Figure 3-37]. Work was specialized: one crew worked on nothing but motors, another was devoted to transmissions, and others were variously assigned to steering, clutches, etc. The

\footnotetext{
50 "Packard Service Depot in Boston," The Packard no. 12 (December 3, 1910): 1-5.

${ }^{51}$ Ibid.

${ }^{52}$ Liebs, Main Street to Miracle Mile, 81.

${ }^{53}$ Ibid.
} 
second floor was devoted primarily to parts supply, and Fuller carried "duplicate parts for Packard cars of both this year's and older models . . . insur[ing] every owner of a Packard car against delay" 54 should a replacement be needed. On the third floor was a paint department with varnishing and finishing rooms, a wheelwright department, a department for accessories (speedometers, clocks, and seat belts were not yet standard), and a "trim shop," where tops might be remodeled and seat covers remade. Elsewhere was dead storage for existing Packard owners, lockers and a cafeteria for the hundreds who worked at the facility, supplies of fuel and oil, warehouses of parts including space bodies, and a substantial accounting department [Figure 338]. If necessary, the building could have accommodated the assembly of complete autos, though that was not intended. ${ }^{55}$

Like most of the public garages that would be built in Boston after this time, Kahn's Packard building was constructed of reinforced concrete, a cutting-edge, fire-proof method that had only recently been perfected. In addition to suppressing the danger of fire that had plagued the city's earliest garages, such buildings were able to support much heavier loads and resisted vibration, making reinforced concrete "an ideal skeletal system for structure designed for the selling and servicing of cars," especially after large numbers of them began to be sold. ${ }^{56}$

Shortly after the Packard building was completed, other prominent makers established large factory branches in Kenmore Square. The Peerless Motor Car Company, Ford and the Auto Car Company occupied three adjoining six-story buildings with wide fronts from 642 to 660 Beacon Street [Figure 3-39]. These three buildings, erected in 1910, 1911 and 1912, were specifically designed for the needs of auto sellers and enjoyed a prominent location at the

\footnotetext{
54 “New Garage Will Represent \$250,000 Investment,” Boston Globe, August 7, 1909, 9.

55 "Packard Service Depot in Boston," The Packard no. 12 (December 3, 1910): 1-5; "Service Plants for Boston Owners," Automobile 28 (March 6, 1913): 578.

${ }^{56}$ Liebs, Main Street to Miracle Mile, 80.
} 
intersection of Commonwealth Avenue, Brookline Avenue and Beacon Streets - three of the main roads to the prominent suburban towns of Brookline, Newtown, Chestnut Hill and Waltham. While all three garaged an ample stock of automobiles for sale on their various floors, these buildings' iconography did not seek a new visual expression but instead drew their influences from established department store façade designs. ${ }^{57}$

By 1913, numerous competitors began to fill the once empty boulevard with a collection of large-scale dealerships. These included recently opened buildings for Kissel Kar, American, Simplex, Locomobile, Winton, Cadillac, Rambler, Oldsmobile, Lozier and Premier, with nearby structures erected for Buick and Studebaker [Figure 3-40]. Other larger buildings were erected for Firestone (established in Kenmore Square in 1912) and U.S. Tire, harbingers of a parts and accessories trade that would soon flourish in the area. Many other interests flocked to the district in the 1910s, with ten new showrooms joining the row in 1919 alone. Anchored by Packard at one end and the dealerships of Kenmore Square at the other, Commonwealth Avenue emerged as the leading automobile row in New England, a reputation it would enjoy until after World War II. $^{58}$

While the collection of dealerships in Kenmore Square created a street presence evocative of department store designs, most other establishments on Commonwealth Avenue, including the 1909 Packard building, brought a different visual and spatial expression to automobile sales. These buildings clearly took forms directly from factory design [Figures 3-41 to 3-43]. All featured large walls filled with windows for ample light. All were narrow and long, allowing the central portion of each building better access to light and ventilation. The elongated

\footnotetext{
57 "Brief Business," Motor Age 21 (February 8, 1912): 42.

58 "Service Plants for Boston Owners," The Automobile 28 (March 6, 1913): 577-579; "Rambler Opens New Sales and Service Station," Horseless Age 30 (October 2, 1912): 509; "News of the Week Condensed," The Automobile (January 11, 1912): 11; "News of the Week Condensed," The Automobile (February 12, 1912): 523; “Announcements,” Motor Age 21 (February 22, 1912): 47; Liebs, Main Street to Miracle Mile, 85.
} 
form of these buildings afforded each dealership greater visual presence on Commonwealth Avenue. Unlike a shop operating out of a thirty-foot store front, no passing motorist could fail to notice these new buildings with their enormous rooftop signs (Boston's iconic Citgo Sign was a later byproduct of this trend; it was first built in 1940 and sits atop 660 Beacon Street, originally home to Peerless).

Boston's modern dealerships shared many formal traits with a famous contemporary, Ford's original Highland Park factory, designed by Kahn in 1908 and completed in 1910. While the Highland Park factory was located in a concentrated industrial zone removed from the city center and surrounded by freight rail facilities [Figure 3-44], Boston's new collection of modern dealerships brought such building forms away from the periphery and into a major boulevard connecting to what was arguably Boston's most prestigious residential street. ${ }^{59}$

The architectural strategies employed by these buildings reflected the changing automobile market and landscape. A decade after the Back Bay Cycle and Motor Company advertised itself as a stable to buy, store and repair automobiles, dealerships "were no longer considered merely places where a fad was merchandised; now they were the point of contact between the public and a rapidly expanding industry, consisting of score of manufacturers. Nagging questions plagued the early-twentieth-century car buyer. 'Should it be a Gray, Dodge, Autocar, Studebaker, Oakland, Regal, Chandler, Gordon, Packard, or Ford?' 'Will the company be around in ten years?' 'Will parts continue to be available?' Producing good cars and convincing advertisements was one way to inspire public confidence. Building impressive and attractive showrooms was another." ${ }^{, 60}$

\footnotetext{
${ }^{59}$ Federico Bucci, Albert Kahn: Architect of Ford (Princeton: Princeton Architectural Press, 2002), 29-36.

${ }^{60}$ Liebs, Main Street to Miracle Mile, 78-79.
} 
In Boston, these proved be pertinent questions. A critical buyer might have observed that the Franklin dealership that had been built at 616 Commonwealth Avenue in 1913 was vacated by that company in 1918 to consolidate its operations near a Beacon Street service station and that Autocar stopped making passenger cars in 1912. Velie's salon at 80 Brookline Avenue boasted a refined and classically influenced design, which graced the pages of the American Architect in 1917 [Figure 3-45]. It would not survive past $1928 .^{61}$

The establishment of grandiose dealerships did more than promote a particular maker to an increasingly broad pool of buyers. The architectural assemblage of automobile row gave the dealers a version of civic credibility. Taken together, the glamorous showrooms persuasively demonstrated through their physicality and scale that automobiles were now a permanent part of the urban experience. Indeed, the appearance of the permanent twice-a-day traffic jam which became a fixture of all large American cities by 1915, Boston included, coincided with the formation of Commonwealth Avenue as Automobile Row. ${ }^{62}$

The location strategies employed by the dealerships on Boylston Street and Commonwealth Avenue demonstrated that even in the earliest years of the twentieth century, automobile use patterns had already begun to refocus and decentralize commercial space. Unlike the nucleated concentrations of similar businesses in the downtown area, the linear automobile district oriented along Boylston Street and Commonwealth Avenue stretched more than three miles from the Motor Mart to Packard's corner in the years when both rows were simultaneously active. By contrast, the downtown retail district was approximately a half mile long by a quarter mile wide.

\footnotetext{
61 "Removals and Trade Changes," Automobile Trade Journal 23, no. 6 (December 1, 1918): 137a; "Store and Office Building, Brookline Avenue, Boston, Mass," The American Architect 112 (August 8, 1917): plate 65.

${ }^{62}$ Clay McShane, Down the Asphalt Path: The Automobile and the American City (New York: Columbia University Press, 1994), 194.
} 


\section{PARKING}

Twice-a-day traffic jams represented a great flow of automobiles into the city from the growing suburbs, with most drivers seeking to reach a destination in or near downtown. While moving automobiles changed the city by coopting street space from peddlers, pedestrians and children, the parking of cars was equally important. It was when automobiles stopped and sat that they become most pronounced in the built landscape. The location and design of parking areas determined how people experienced the city itself by creating new types of structures and interactions.

\section{Street Parking}

With the mass use of automobiles and associated technological improvements came the arrival of extensive street parking along curbs. Parking in the street was allowed during the horse age, but horse-drawn vehicles were never used in numbers that approached those of automobiles after mass adoption. For example, about 820 horse-drawn vehicles used Devonshire Street each day in 1885. In 1913, towards the beginning of mass adoption, approximately 5,400 vehicles could be expected to travel on Devonshire Street each day. ${ }^{63}$ Also, since most horse-drawn vehicles were either delivery teams or livery cabs, they were not inclined to stand at the curb for long intervals (teamsters needed to make the next delivery, cabs were only profitable when moving). Further, horses were living animals that needed regular feedings, waterings, sleep and other forms of care, all of which imposed natural limits on the length of time that a horse could be left at a curb.

The emergence of automobile-driving commuters, shoppers and visitors changed this dynamic. In 1923, an estimated 100,000 motor vehicles came to central Boston each day (a portion of which were motorists simply passing through the congested area en route to other

\footnotetext{
${ }^{63}$ T.W. Howard, "Report by Committee on Traffic on Streets and Roads," Proceedings of the American Society for Municipal Improvements 12 (1913): 146-147.
} 
destinations). By 1927, that number had grown to an estimated 221,000 motor vehicles. The various lots and garages available to these motorists perhaps accommodated 10,000, though many of these were located well outside the city center in places like the Fenway area. ${ }^{64}$

By 1916 nearly every curb throughout the downtown area and elsewhere in central Boston was lined with automobiles as workers and shoppers arrived each morning, reflecting a nationwide trend. Nearly every photograph of a downtown area appearing in American City Magazine in 1915 showed curbs fully lined with automobiles. ${ }^{65}$ By contrast, the Boston Transit Commissions 1912 photographs of Boylston Street show very few motor cars parked at the curb, even though it was a street whose retailing focus likely attracted a disproportionate number of automobiles. Street parking was popular because it was free and also because lucky drivers might find a place to leave their car close to their final destination. Since garages were slow to be built downtown, street parking, in addition to a handful of open lots, was the primary option for those who sought to leave their cars in this area, though the supply of available space represented only a fraction of demand.

In the combined wholesale, retail and office districts, Miller McClintock of Harvard's Albert Russell Erskine Bureau for Street Traffic Research measured the total linear curb space to be 107,837 feet, enough space to park 5,964 vehicles. However, since many streets had various restrictions in place by 1927, the number of legal spaces was 3,233 distributed over 58,182 linear feet of curb. Since Boston's motoring population regularly ignored parking prohibitions, the number of cars actually parked would have been higher than the legal minimum. McClintock estimated that one third of all automobiles standing at the city's curbs were parked improperly,

\footnotetext{
64 "Ingenious and Foolish Excuses from Auto-Parking 'Hogs' Who Have Been 'Tagged' by Police," Boston Globe, July 17, 1923, 3; "What Becomes of the 207,000 Cars Driven into Boston Every Day?" Boston Globe, September $18,1927,2$.

${ }^{65}$ Clay McShane, "The Origins and Globalization of Traffic Control Signals," Journal of Urban History 25, no. 3 (March 1999): 381.
} 
either by parking at the wrong angle, parking too far from the curb, parking in violation of a time limit, parking in a restricted area or being double parked. ${ }^{66}$

Congestion was exacerbated not only because one or two lanes in many streets were given to parking instead of movement, but also because many of the cars clogging the city center were moving only to search for a place to stop. Affluent owners would simply have a chauffeur drive their car around the city's streets while they attended to whatever need brought them downtown. Though city laws through the early 1920s usually prohibited automobiles (and the remaining horse-drawn teams) from parking at a curb for more than twenty minutes, this law was very rarely enforced ${ }^{67}$ As a result, many commuters ignored the rule and parked their vehicles in a single spot all day. The city's newspapers frequently attacked these all-day "Parking Hogs," who were villainized as being a major cause of downtown congestion and for blocking shoppers from finding a space near stores. The Boston Globe editorialized that

parking has become one of the bad habits of this city. About 8 each business morning cars from everywhere, except the harbor, begin to throng the city. The driver of each runs into some area where unrestricted parking is permitted, takes out his key, and goes to his work, appropriating himself a strip of metropolitan real estate. An hour or so later, shoppers or person with brief business errands begin to arrive, hoping for a vacant curb where they may leave their automobiles while they are engaged. Mostly they are disappointed. The good places have been preempted by the all-day crowd. ${ }^{68}$

Though the Boston Globe and others who advocated against these 'hogs' usually accused them of creating congestion in addition to being selfish, the Boston Chamber of Commerce pointed out that compelling all-day parkers to return to their automobiles every twenty, thirty or sixty minutes to move their autos to a new location actually slowed traffic, since this entailed greater

\footnotetext{
${ }^{66}$ Miller McClintock, A Report on the Street Traffic Control Problem of the City of Boston Prepared under the Direction of the Mayor's Street Traffic Advisory Board (Boston: City of Boston Printing Department, 1928), 155163.

${ }^{67}$ On select streets, the twenty-minute limit was relaxed to thirty minutes and sixty minutes in 1923. "Auto Parking Problem Grows," Boston Globe, July 9, 1923, 5.

68 "The City as Garage," Boston Globe, May 16, 1925, 12.
} 
instances of cars interrupting street circulation to be maneuvered against new stretches of curb without providing any additional space. ${ }^{69}$

As traffic volume intensified with each passing year, the city made several efforts to mitigate the often severe congestion that was caused by the use of what might have been active traveling lanes as public automobile storage facilities. One such effort was to forbid parking along strategic stretches of road. In December, 1922, John Noyes, the Chair of Boston's Street Commission, announced one of these early restrictions on street parking. Vehicles were forbidden from stopping on the Common-side of Boylston Street between Tremont and Park Square between 8:00am and midnight, with a similar restriction on the stretch of Boylston between Tremont and Washington Streets. In June, 1923, extreme congestion prompted a ban on all parking along Washington Street's Newspaper Row. By 1925, no passenger vehicles were allowed to park along the following streets between the hours of 7:00am and midnight (delivery vehicles were allowed to stop for a maximum of twenty minutes): Beacon Street between Tremont and Park, Bosworth Street, the eastern side of Bowdoin Street, Carver Street between Boylston and Eliot, Chauncey Street between Summer and Essex, Cross Street between Hanover and Haymarket Square, Devonshire Street between Adams Square and State Street, East Street, Essex Street between South and Atlantic, Exchange Street, Exeter Place, Hanover Street between Court and Washington, Hollis Street, Joy Street between Mt Vernon and Beacon, Kilby Street between Water and State, Kingston Street, the eastern side Massachusetts Avenue between Newbury and Boylston, Merrimac Street between Friend and Haymarket Square, portions of Milk Street, Parkman Street, several roads in Pemberton Square, Prince Street between Hanover and North Square, Richmond Street between North and Hanover, School Street between Chapman Place and Washington, Spruce Street, portions of State Street, the northern side of

69 “Ban on Parking Not a Cure-All," Boston Globe, May 20, 1925, 14. 
Stuart Street between Tremont and Carver, Sudbury Street, part of Summer Street, Temple Street, portions of Tremont Street, Walnut Street, Water Street between Stuart and Haymarket Square and Winter Street [Figure 3-46] ${ }^{70}$

Though not formerly articulated in a 1927 report by Mayor Nichols' Street Traffic Advisory Board that included recommendations on parking bans, a sense of propriety may have guided city officials to forbid parking around prominent buildings. This report advocated for a parking ban on Beacon Street in front of the Massachusetts State House (elsewhere on Beacon Street no such restrictions existed), a ban that is still in place today. Similarly, no parking was allowed along the curbs of Commonwealth Avenue running along Olmstead's elongated park. ${ }^{71}$

The city had already implemented one-way traffic restrictions on some downtown streets that were especially narrow and crooked. It had been the practice to allow parking on one side of these streets, leaving the other curb vacant. Due to the great demand for parking, the curbs of these narrow streets were regularly filled with automobiles, which had proven to be dangerous for the fire department when it needed to respond to an alarm. On multiple occasions, it had been necessary "for firemen to push automobiles down the streets in order to get trucks near enough to buildings to raise the ladders. In some instances, it has been necessary that the big ladders be placed against buildings at dangerous angles because the truck could not be set in proper position." Cars parked in narrow streets also compelled ladder trucks to take position in the middle of the right of way, thus blocking newly arriving fire engines from passing through to

\footnotetext{
70 “Announces New Traffic Rules," Boston Globe, December 3, 1922, 6; "Newspaper Row Parking Forbidden," Boston Globe, June 26, 1923, 3; "City of Boston: Street Traffic Regulations and Rules for Driving," Boston Globe, December 31, 1925, 21.

${ }^{71}$ McClintock, Street Traffic Control Problem, 172.
} 
connect to nearby hydrants. Due to these concerns, parking was forbidden on multiple one-way streets in the downtown area. ${ }^{72}$

By 1923, annoyance with out-of-town residents whose cars occupied free downtown curb space and who did not pay taxes to support the large police force needed to control traffic led to a short-lived plan to ban parking in the downtown area. Congestion was exacerbated not only because potential traffic lanes were instead used for storage, but also because many people were driving into the downtown with the express intention of finding one of these parking spaces. Forbidding storage on streets was expected to effectively widen roadways while also reducing the number of conveyances using them, since many motorists could be expected to park in a peripheral area. With the exception of spaces in Winthrop Square and Post Office Square, a complete ban was called for in the area bounded by Atlantic Avenue and Essex, Boylston, Tremont, Court and State Streets [Figure 3-47].

This proposal, put forth by the Street Commissioners, was endorsed by the Fire Department, the Boston Board of Fire Underwriters, representatives of the Fruit and Produce Exchange, the Team Owners' Association and the Team Drivers' International Union. ${ }^{73}$ Governor Fuller repeatedly argued for the ban, stating that "I have seen automobiles parked in our congested streets day after day and I am perfectly sure that the public would have been better off to have paid the owner of that automobile his daily salary to stay at home rather than to have borne the expense occasioned by the parking of his car in a busy street."74 The following year, Governor Fuller continued to lament the "abusers" who took parking places and left their vehicles for the day. Fuller observed that the rental value of a curbside parking spot far exceeded

\footnotetext{
72 “New Traffic Rules Planned," Boston Globe, November 23, 1922, 13.

73 "Would End Parking in Heart of City," Boston Globe, February 2, 1923, 13; Kerry Segrave, Parking Cars in America, 1910-1945 (Jefferson, NC: McFarland \& Company, 2012), 5-32.

74 “Gov Fuller Attacks Street Curb Parking," Boston Globe, October 5, 1925, 1.
} 
the value of the automobile left there. ${ }^{75}$ However, local business owners complained that parking bans would compel automobile-driving shoppers elsewhere and would ruin the out-of-town trade. For this reason, the Boston Chamber of Commerce regularly opposed attempts to create downtown parking bans, and the concept was debated for only a few years before being abandoned. Organized opposition from retail business owners also undid similar parking bans in downtown Los Angeles, Chicago and Philadelphia. ${ }^{76}$

The Street Commissioners and the police department undertook periodic efforts to publicize parking rules through mass ticketing campaigns which were infrequent enough to be newsworthy. For instance, dozens of motorists who illegally parked on the northern side of Commonwealth Avenue to attend a Braves baseball game were summoned to a nearby police station (they were all given warnings). Fifty court summonses were issued to the owners of cars that were parked for longer than the allowed twenty minutes on Stuart Street on one day in 1923. Another typical roundup was held in April, 1925, when the traffic police sent a detail of six officers out to issue summonses for inappropriate standing along curbs - 160 were distributed. ${ }^{77}$

For the most part, these campaigns to deter illegal parking were ineffective. The police did not have enough personnel to adequately police the city's curbs. Like moving vehicle violations, parking infractions were difficult to enforce, since the legal process was very cumbersome and required officers to make special trips to court. Meters, which would monetize curb parking and greatly change parking habits, would not be created until 1935. Until then, curb

\footnotetext{
75 “Gov Fuller Warns Reckless Motorists," Boston Globe, May 20, 1926, 1.

76 "Boylston-St Merchants Want Parking Allowed," Boston Globe, June 27, 1923, 7; "Ban on Parking Not a CureAll," Boston Globe, May 20, 1925, 14; "Would be a Mistake to Abolish Parking," Boston Globe, August 14, 1926, 1; "Business Men Oppose Ban on Auto Parking," Boston Globe, June 4, 1925, 1; "Oppose Ban on Auto Parking: Merchants Fear Trade Will Go Elsewhere," Boston Globe, June 5, 1925, 13; "Chamber Outlines Policy on Parking," Boston Globe, December 31, 1926, 11.

77 "Many Autos Tagged Near Braves Field," Boston Globe, April 23, 1922, 19; "Tag 50 Cars Left Beyond Time Limit," Boston Globe, June 8, 1923, 7; "Drive on Traffic Violators," Boston Globe, April 11, 1925, 1.
} 
space was free, helping to create an environment where "a motorist paid less for 100 square feet of street space than a streetcar patron paid for $10 .{ }^{, 78}$

By the end of the 1920s, a complex parking landscape had taken shape across Boston. Those seeking to find space in the center were limited to a handful of garages or to curb space that was in very short supply, especially since some streets had parking restrictions on at least one side and nearly all had time limits that did not exceed an hour (though many motorists took their chances, given the lack of enforcement). Other public spaces in addition to the city's rights of way were also entirely given over to automobile storage. Post Office Square became a parking lot for twenty-five cars and was full by the early morning. Winthrop Square was similarly fated. Otherwise, those seeking to park directly in the downtown area could make use of a half dozen vacant lots where buildings had recently been torn down. Among them was a lot located at the corner of Water and Kilby Streets (the cost was fifty cents per day), which was filled to such capacity that there was no space left over for circulation [Figure 3-48]. ${ }^{79}$

The scarcity of parking in the immediate downtown area compelled motorists to attempt to leave their cars at various locations proximate to the downtown area. Park Square was a particularly popular destination, not only because it offered the Eliot Street Garage and the Motor Mart, but also because it held the city's largest taxpayer lot. In such lots, owners could "hold onto land in high price districts indefinitely by turning it into a parking space. The rental is large enough to pay taxes and give the owner some return on his investment." Rumored to be the largest open-air urban parking area east of Chicago, the Park Square lot could hold 900 autos [Figure 3-49] at a cost of thirty-five cents per day. ${ }^{80}$

\footnotetext{
${ }^{78}$ Peter D. Norton, Fighting Traffic: The Dawn of the Motor Age in the American City (Cambridge, MA: MIT Press, 2008), 13.

79 “What Becomes of the 207,000 Cars Driven into Boston Every Day?” Boston Globe, September 18, $1927,2$.

${ }^{80}$ Ibid.
} 
Near Park Square was Boston's favorite free public parking area: Charles Street along the Public Garden and the Common [Figure 3-50]. Each day, a reported 1,400 automobiles were stored here, lining both sides of this stretch of road where parking was allowed with no time limit after 10:00am (before that hour, no stopping was permitted in order to keep the road open for morning travel). Cars did not park parallel, but instead at right angles, thus increasing the number of parking spaces and diminishing the size of the active driving lanes. The centrality of the site and its popularity led to early calls to build a garage under the Common with a Charles Street entry [Figure 3-51], an idea that was later carried out in the $1960 \mathrm{~s}^{81}$

Otherwise, motorists made use of garages further afield. Many thousands took spaces in garages in Kenmore Square, Lansdowne Street, further down Commonwealth Avenue and elsewhere, and then rode public transit to the center. On Dorchester Avenue, beginning near South Station, a mile-long span of automobiles could be found backed against the rail separating the street from the Fort Point Channel. All of these spaces still represented a fraction of the demand, and drivers who attempted to come to Boston might circle the city before eventually driving out to destinations such as Cambridge before finding a space to leave their automobile. ${ }^{82}$

\section{Garages}

By 1922, the Boston Register and Business Directory listed 253 garages operating within city limits. Many of these 253 garages were small facilities that simply offered maintenance services. Many of those that did offer storage could only accommodate a handful of vehicles. Only a few accommodated more than a hundred cars at a time. Even with this caveat, the distribution of these garages shows that automobile storage facilities had spread throughout the metropolitan

\footnotetext{
${ }^{81}$ Ibid; “Auto Parking Problem Grows,” Boston Globe, July 9, 1923, 5.

82 "Adventures of the Poor Auto Parker in Boston: After Two-Hour Search, During Which Car is Tagged, He Has to Go to Cambridge," Boston Globe, September 3, 1926, 13; "What Becomes of the 207,000 Cars Driven into Boston Every Day?" Boston Globe, September 18, 1927, 2.
} 
area. Boston's garages tended to congregate along commercial corridors and arterial roads, as well as on the outskirts of the area's many busy squares. Though garages were widespread throughout the city by 1922, they remained notably absent in residential Back Bay (zoning forbade them) and, more importantly, in the downtown area, the final destination for most motorists. $^{83}$

In 1922, the garages nearest the center were mostly still located outside the boundaries of the 1892 congested district. The two exceptions were the Portland Street Garage [Figure 3-52] and the Eliot Street Garage [Figure 3-53], though these garages were located at the periphery of the old congested district. The Portland Street Garage was a six-story structure built in 1919 at 119 to 121 Portland Street. With reported space for 450 vehicles, this garage was one of the earliest to use ramps to allow cars to move from one level to the next, though it also had three freight elevators (the owners of the Portland Street Garage also operated the Custom House Garage, a five-story facility that opened in 1919, though the Custom House Garage was outside of the original congested district). ${ }^{84}$ The Eliot Street Garage was built in 1920 at 155 Eliot Street near Park Square. The Eliot Garage featured a modern ramp design, with a runway of slight grade running from the basement to the top floor that eliminated the need for elevators and speeded circulation. ${ }^{85}$

With downtown parking space increasingly difficult to find, a handful of automobile parking structures began to penetrate the downtown area. An analysis of the 1929 Sanborn atlas shows that by the end of the decade, five additional garages with capacity for at least one hundred automobiles were created in this area. Three of these garages were clustered between

\footnotetext{
83 Thus, this count does not include garages in Cambridge, Somerville or Brookline. Also, the directory did not distinguish between maintenance garages and garages where one might park an automobile. The Boston Register and Business Directory, 1921 (Boston: Sampson \& Murdock Company, 1921), 549-550.

84 "Many Innovations in New Portland-St Garage," Boston Globe, June 22, 1919, 6.

85 “Autos Can Run up to Sixth Floor in Eliot-St Garage," Boston Globe, May 6, 1920, 2.
} 
Bowdoin and Haymarket Squares on Chardon Street in a district that once held many stables. These were located at 20 Chardon Street (four stories, built in 1922), at 22 to 26 Chardon (five stories and likely a converted stable since it had wooden floors), and at 66 to 84 Chardon (six stories with capacity for 270 cars). Nearby was a five-story garage at 11 to 23 Hawkins that could accommodate 300 automobiles.

By the early 1920s, department stores and other downtown retailers became concerned that they might lose shoppers due to the inconvenience of automobile travel in the city center. Though parking prohibitions and other restrictions would have made streets easier to use, retailers almost always fought such plans because they hoped to attract wealthy automobiledriving customers to curb space near their storefronts. The downtown interests also became worried about competition with new retail districts, in particular along Newbury and Boylston Streets in the Back Bay, that emerged as mass automobile use encouraged commercial decentralization that had previously begun with the implementation of the subway. The Boylston Street Retail Merchants excitedly boasted that "with its wide sidewalks and excellent parking facilities Boylston Street appeals to those who wish to shop with ease and convenience and to avoid the jostle and annoyance inevitable in the more congested parts of the city" and that the district was soon to be "the finest shopping center in the world" [Chapter 3, Figure 3-33]. ${ }^{86}$

Jordan Marsh, a prominent department store on Washington Street, desiring to attract wealthy suburban shoppers and to compete with the emergent Bay Back retail area, built a large, eight-story garage just two blocks away on Beach Street [Figure 3-54]. This garage, with space for 600 automobiles, was erected in 1924 with the intention that it be reserved exclusively for Jordan Marsh customers. Parking was free of charge for a limited number of hours, and, like other large garages of the period, it offered washing services, a filling station and a parts and

\footnotetext{
${ }^{86}$ Ad, “\$40,000,000 to be Expended!” Boston Herald, October 15, 1922, 16.
} 
accessories department. Recognizing that customers desired easy access to their automobiles, the Jordan Marsh garage used the d'Humy ramp system to connect each floor to the next, allowing customers to drive directly to a parking space without having to involve an attendant and an elevator [Figure 3-55]. When it was built, Jordan Marsh made sure to emphasize that cars would be parked just one row deep on all floors. Given the parking shortage in the city, many other garages filled in spaces intended for circulation with surplus automobiles, which made exiting difficult. $^{87}$

Additionally, several large new garages were built just outside the downtown area. In the vicinity of Beacon Hill were the Charles Street Garage [Figure 3-56], built in 1919 at 144-160 Charles Street with space for 200 automobiles (though in 1930 this garage began serving only nearby residents who bought space within it), ${ }^{88}$ and a six-story garage at $248-270$ Cambridge Street with capacity for 250 cars. Nearby, the Bowdoin Square Garage [Figure 3-57] was built in 1920 at 81-93 Cambridge Street and reached seven stories. Its two ramps and deep footprint (it stretched through to Green Street) allowed storage for 780 automobiles. ${ }^{89}$ In the North End, a large three-story garage with capacity for 500 cars was built in the area bounded by Commercial, Prince and Hull Streets. The North End was also served by a five-story garage located at 31-35 Endicott Street.

The most significant of the new structures in the downtown periphery was the 1927 Motor Mart [Figure 3-58], which replaced the original building that opened in January, 1906. The demolition of the original Motor Mart in order to replace it with the 1927 super structure was emblematic of the great changes that had occurred in the automobile landscape in just two

\footnotetext{
87 “Jordan Marsh to Park Autos,” Boston Globe, June 14, 1924, 1.

${ }^{88}$ Moying Li-Marcus, Beacon Hill: The Life \& Times of a Neighborhood (Boston: Northeastern University Press, 2002), 156.

89 “A New Boston Garage,” Boston Globe, May 9, 1926, 69.
} 
decades. Though it was among the most advanced automobile buildings in the world when it was built, the older Motor Mart was already obsolete.

While the original structure housed 300 automobiles on its three floors, the new Motor Mart fit 2,000 on the same footprint. The original Motor Mart relied on elevators and turntables to move cars through the building. Following the trends recently set by other modern garages, the new Motor Mart made use of ramps to allow cars to easily circulate between levels (given its immense size, there were two ramp systems). The new building reached eight stories, and, despite its name, did away with the store fronts that circumscribed the original Motor Mart. In an effort to speed the parking process, customers entered and exited using one of four lanes in a seventy-foot wide entry gate (which was wider than most streets in the city) and collected a tag that was stamped with the arrival time and which told the driver which space to proceed to. After positioning their car, the driver would remove one half of the tag and attach the other to their automobile, allowing the bill to be paid at street level before returning to the car. In an effort to integrate the Motor Mart with the downtown area, free bus service was provided and space was set aside for a dedicated taxi stand. ${ }^{90}$

Despite the building of these large garages in and near the downtown area, Boston's privately owned garages were considered woefully inadequate and did not provide sufficient space to meet demand. In part, this was because new garages remained contentious buildings and many considered them undesirable neighbors. Most efforts to erect new garages were met with protest, and by the late 1920s parking facilities available to the public remained concentrated outside of the downtown area [Figure 3-59]. Additionally, the creation of downtown garages at this time represented an extremely expensive prospect, and most parking entrepreneurs were unwilling to assume the risk of building one. It is notable that the Jordan Marsh garage, the only

90 "Largest Garage in the World," Boston Globe, January 2, 1927, 10. 
garage built in the retail area, was erected not to capitalize on the new opportunity created by the storage needs of motorists, but to protect an older form of commerce. ${ }^{91}$

While in the 1920s there was prevailing public interest in the creation of new garages downtown, there continued to be great demand to confine existing businesses to the same limited acreage. This led to several studies put forth by Miller McClintock that called for new office buildings to be built with subfloors given over to automobile storage, a building form that would allow automobile storage without the loss of traditional commercial activity. But since these studies were published at roughly the same time as the onset of the Great Depression and a cessation of most construction, there was there little opportunity to follow McClintock's advice. The supply of downtown parking, whether on public streets or in private garages, did not meet demand.

\section{REGULATIONS \& ENFORCEMENT}

Though congestion had become an urban fixture by the late 1910s, efforts to combat its effects were halting. In part, this was due to long-established ideas about the role of public streets in daily life. As public spaces, streets before the ubiquity of automobiles were given to myriad uses-they were places to walk, operate streetcars, store building materials, protest and publically congregate (great crowds regularly assembled each day amid Boston's Newspaper Row to hear the latest reports). Among the most important uses of streets was as areas for children to congregate and play.

While all cities experimented with new regulations and street modifications to alleviate congestion, a much larger concern was how to curb a staggering number of automobile-related fatalities, particularly among children, as drivers sought to navigate built landscapes that were

91 “Garage Zone Plan Strikes Opposition,” Boston Globe, January 28, 1927, 15. 
not prepared for their arrival. In New York, for example, more than a thousand children were killed by motorists in the years before World War I. During the four years that followed Armistice Day, "more Americans were killed in automobile accidents than had died in battle in France" a fact that was widely publicized and greeted with shock. ${ }^{92}$ Nationwide, approximately three quarters of motoring victims were pedestrians, most of them children making use of the street as a traditional recreational space..$^{93}$

In Boston, children were frequently killed by automobiles, beginning with their first years of use. Angelo Albenice, aged five, was run over while playing in North Margin Street in $1903 .{ }^{94}$ Marion Holder, aged seven, was killed in 1904 while standing in a crossing with her family [Figure 3-60]. Clearly dying after being struck, Holder was taken to a nearby drug store where the driver, Edward Scribner (a naval officer) paced about nervously and then left to rejoin his party in the car and motor off to Readville before the police arrived (fleeing an accident was not yet considered to be illegal on grounds that a legal compulsion to stay at the scene might lead to self-incrimination in violation of the Fifth Amendment). Later arrested and charged with manslaughter, Scribner argued that the girl was at fault and claimed that she stepped in front of his machine. This defense was enough to earn him an acquittal on the manslaughter charge, though a fine was levied. ${ }^{95}$ In 1905, William Pigot, aged eight, was killed in Mystic Street in Arlington by William Robinson (a wealthy soap manufacturer) while crossing the road. Mr. Robinson, according to a forgiving Boston Globe, "shouted and used every effort in his power to prevent the accident" but "before [he] could apply the brakes" the boy had been crushed to death. Reminiscent of Mr. Damon from this dissertation's preceding chapter, braking for pedestrians

\footnotetext{
${ }^{92}$ Norton, Fighting Traffic, 25.

${ }^{93}$ McShane, Down the Asphalt Path, 175-176.

94 "Killed by an Automobile," Boston Globe, August 24, 1903, 5.

95 "Little Marion Holder Killed by Automobile," Boston Globe, May 31, 1904, 1; "Scribner Discharged," Boston Globe, June 21, 1904, 11; “\$4175 for Child's Death,” Boston Globe, December 10, 1908, 16.
} 
appears to have been an afterthought for Robinson. Both Damon and Robinson preferred to shout at potential victims rather than stop their machines (with pedestrians still regularly walking amid the street, it was sometimes challenging for motorists to distinguish true moments of potential lethal danger). Typical of other such accidents in Boston, no charges were made against Robinson. ${ }^{96}$

These and other stories of automobile-related injuries or fatalities were regular items in Boston's various newspapers beginning in 1903. Even in that year, when relatively few automobiles were operated on the city's streets, a public safety risk had already been established. As the numbers of automobiles increased, so, too, did the numbers of accidents.

Many of the first attempts to regulate city traffic began as efforts to mitigate the safety risks inherent in automobile use and were not designed to mitigate congestion. Peter Norton characterizes the corresponding public response as one that viewed automobiles as, at best, "uninvited guests" in city streets and often regarded them as "unruly intruders," against whom "pedestrians, parents, police and downtown business organizations organized [in order] to preserve streets as they knew them." 97

This safety agenda informed early speeding laws implemented throughout Massachusetts, discussed in Chapter 2, which restricted autos to travel at rates as low as four miles per hour, though eight and twelve miles an hour were more typical. While early speeding laws, rules requiring headlamps and mandatory registration amounted to simplistic responses on behalf of public safety, Boston's automobile clubs almost always organized against regulations that might limit the total freedom of movement (or at least the illusion of it) promised by early motoring.

\footnotetext{
96 “Auto Killed Boy,” Boston Globe, August 13, 1905, 11.

${ }^{97}$ Norton, Fighting Traffic, 1.
} 
During the elite period of automobile use, enforcement of speed rules and other rudimentary laws was completely ineffective. When automobile ownership became an increasingly middle-class phenomenon during the 1910 s, the police sought to more actively enforce existing laws, but the force was greatly outmatched by the huge numbers of motorists that had appeared in Boston. When a police officer did undertake the inefficient process of bringing a motorist to court for a speeding violation, the driver was often found to be not guilty because they could claim their speedometer did not accord with the police account, which had no means to accurately and convincingly measure a car's speed. ${ }^{98}$

The danger associated with expanded automobile use coupled with unregulated or minimally regulated driving practices helped to usher in a change in cultural practice where families were compelled to teach children to avoid streets entirely. The danger of automobiles "forced parents to confine children to the home or subject them to street traffic discipline at an early age." As Clay McShane observed, even toddlers who are not yet toilet trained have long been made to understand that they must never venture into a road. ${ }^{99}$

These changes in custom were initially encouraged by safety councils (sometimes with representatives from motoring groups) who fueled efforts to alter the behavior of children once accustomed to playing in streets. The National Safety Council took great interest in automobile accidents as a matter of public safety, and organized numerous panels on the subject in addition to its interest in workplace safety. ${ }^{100}$ The Massachusetts Safety Council gave special attention to the safety of children, for example by distributing a leaflet called "Ben Hur's Chariot Race and the Automobile" and by issuing a new set of ten commandments for children in public ways to

\footnotetext{
${ }^{98}$ McShane, Down the Asphalt Path, 182.

${ }^{99}$ Ibid, 189-190.

100 “Address of Welcome," Proceedings of the National Safety Council Tenth Annual Conference (1921): 5-7.
} 
obey. ${ }^{101}$ At a public forum held by the Massachusetts Safety Council in 1922, Mrs. James D. Tillinghast gave a session entitled "The Public Street as Playground."102 In the early 1920s, numerous educational efforts continuously sought to teach children about the dangers of the road and aimed to remove them from the street [Figure 3-61]. ${ }^{103}$

In the Boston area, these kinds of educational efforts took time to yield results. During one month in 1924, forty-six children were struck by automobiles in Cambridge. An investigator looking into that city's automobile accidents was alarmed to find more than seventy children playing in a single street on a November afternoon in the same year. In the North End, Cambridge, Somerville and other urban residential districts ringing central Boston, children in the 1920s still made regular use of streets as playgrounds, especially during the late afternoon when they had been released from school, which tragically coincided with the return of commuters traveling from work to home. ${ }^{104}$

In many residential neighborhoods, children did not have ready access to spaces in which to play other than public streets, making it difficult to remove them from the roadways. The danger of the street as playground was underscored by accident statistics, where "nearly half of the children struck down in city streets were on their own block, a fact indicating that unsupervised street play was probably a much bigger risk than journeys to school or stores.”105 This danger worried city planners in the late 1910s and the 1920s, and they began to aggressively pursue the creation of new playgrounds where children could be assured safe places to play.

\footnotetext{
101 "Public Safety Section," Proceedings of the National Safety Council Tenth Annual Conference (1921): 604.

102 "Massachusetts Safety Conference," Safety Engineering 43 (March 1922): 98.

103 Norton, Fighting Traffic, 80-89.

104 "Reckless Pedestrians Outnumber Motorists: Survey Proves Five Percent Afoot Are 'Sleep-Walkers' - Most Accidents on Saturdays," Boston Globe, December 1, 1924, 22.

105 Norton, Fighting Traffic, 83.
} 
In Boston, the City Planning Board's first Annual Report covering 1915 contained a recommendation for a playground to be established in Allston on an empty lot that had already been used informally by children for the previous forty years. Thus, the proposal would have done little to create new play space. Two years later, the City Planning Board more actively pursued playground creation, and recommended land purchases in Mattapan, Forest Hills, the South End, Dorchester and the Mt. Hope district. Throughout the 1920s, playground recommendations formed an important component of nearly every annual report issued by the board. ${ }^{106}$

The playgrounds that were created in this period represented a very practical response to the problem of automobile-related child causalities, at least for those children who lived close enough to use them. However, in facilitating the removal of children from the street and in reducing the casualty rate, the new playgrounds also helped to "limit the claim of a class of pedestrians to street access."

It was not until the mid-1920s that Boston began to comprehensively address safety (and congestion) through the development of expanded traffic ordinances, through the implementation of traffic signals and through the expansion of a police force charged with their oversight. By this time, even Packard's Alvan Fuller plainly saw that automobile accidents had become a persistent challenge to city life. In his inaugural address as the Governor of Massachusetts in 1925, Fuller stated that

The unprecedented and tragic loss of human lives, especially those of little children, by motor vehicles, and whether due to accident or negligence, challenges the sympathetic consideration of all thoughtful citizens and demands

\footnotetext{
${ }^{106}$ Boston City Planning Board, Annual Report of the City Planning Board for the Year Ending January 31, 1915 (Boston: City of Boston Printing Department, 1915), 11-12; Boston City Planning Board, Third Annual Report of the City Planning Board for the Year Ending January 31, 1917 (Boston: City of Boston Printing Department, 1917), 6-14.

${ }^{107}$ Norton, Fighting Traffic, 85.
} 
action on the part of those entrusted with the public safety. The drivers of motor vehicles, the household, the school, the police, pedestrians, and in fact every citizen must devote every energy in a supreme effort to minimize in every way the mounting danger to life and limb. ${ }^{108}$

In this statement, Fuller demanded action from officials who were responsible for public safety and signaled his support for better traffic control. But by demanding that every citizen devote a supreme effort to minimizing automobile accidents, Fuller's address shifted the burden of automobile responsibility to society in general.

For the first two decades of automobile use, Boston's efforts to control traffic consisted simply of traffic officers standing at the busiest intersections and attempting to issue instructions. In 1923, these officers were issued four-sided semaphores directing traffic to "stop" or "go" as they attempted to more clearly broadcast instructions [Figure 3-62], though these semaphores were difficult for drivers in motion to read and were completely ineffective at night. ${ }^{109}$

By 1924, Boston's busiest intersection was the crossing of Massachusetts and Commonwealth Avenues. Approximately 30,000 motor cars passed through this intersection each day, not counting pedestrians, bicycles and horse-drawn vehicles. Movement through this intersection was entirely dependent on common cooperation among the thousands of travelers and on the efforts of the traffic squad overseeing them. ${ }^{110}$

The team of two officers charged with the care of this intersection described it in a 1924 Boston Globe interview. Traffic at this site greatly benefitted from the length, width and straight lines of both intersecting streets, which allowed two lanes of traffic moving in each direction. The officers reported that traffic flows during the weekday were predictable, because most of the motorists passing through were following a regular routine. These motorists were familiar with

\footnotetext{
108 "Full Text of Gov Fuller Inaugural Address," Boston Globe, January 8, 1925, 13.

109 "New Signal Helps Traffic at Boston's Busy Corner," Boston Globe, February 1, 1923, 7.

110 "Interviewing the Men Who Stand in a Whirlpool," Boston Globe, February 3, 1924, 5.
} 
the intersection's prevailing traffic patterns and they were familiar with local traffic laws. They were also familiar with the personal preferences of their regular traffic officers, and could predict the orders that would be issued. Greater difficulty arose on weekends, when out-of-towners drove to the city without a clear understanding of how to proceed through it.

In the opinion of the city's traffic officers, the worst jams were created by motorists who travelled in the right lane and then attempted to make abrupt left turns, thus cutting off other automobiles [Figure 3-63]. The officers lamented that there was no law to prohibit this behavior (one would soon be created). Automobiles at this time did not regularly have turn signals and hand signals were not widely known or effectively used, which exacerbated the problem.

The officers also complained of a lack of power, partially because officers needed to follow a very cumbersome and time-consuming process for even the most straightforward parking infraction or case of speeding, reducing the incentive to follow through on such cases. As officer MacLeod, stationed at Boylston and Tremont Streets put it, "I would like to see the traffic officer empowered to hand a man a summons just as soon as he arrests him, and that if a law were passed so that he could do it, many of our traffic violations would disappear and with them much of our traffic congestion. Now a man must make three trips to the Courthouse to get a summons. First he must apply for it, then he must swear to it, then he must appear against the driver arrested." 111 Since instructions to motorists passing through busy urban roads were only given through the actions of traffic officers, the moment an officer stopped to make an arrest, he lost control over the intersection, further reducing the chances that a law might be enforced.

In a time when basic rules of the road had not yet been codified and when local customs guided a motorist's decisions behind a wheel, many did not hesitate to question the orders of police officers. According to MacLeod, "too many people misunderstand the intentions of the ${ }^{111}$ Ibid. 
traffic cop, and if they don't understand the reason for a signal that sends them in a different direction from the one in which they want to go, they are inclined to stop and argue about it. An argument will stop traffic as quickly as anything else. Drivers and pedestrians should do as they are told. ${ }^{" 112}$ As for pedestrians, many traffic officers saw them as part of the problem. Jaywalkers were common and pedestrians regularly ignored instructions. ${ }^{113}$ William Taylor, stationed at School and Tremont Streets, reported that in his intersection "pedestrian traffic is the most difficult to govern . . . the autoists, as a rule, are very good, but I think that this is the worst corner in Boston in the respect that pedestrians habitually and continually cross diagonally. It hinders the autoists going in both directions, and yet there seems to be no remedy for it."114

These officers were not alone in shifting blame to pedestrians. The Massachusetts Safety Council studied the behavior of pedestrians in 1924, and issued a finding that "more than five percent of our pedestrians are as unconscious as sleepwalkers when they step from the sidewalk into traffic." These "sleepwalkers" failed to heed the instructions of traffic officers and, when there was a moderate break in motor traffic, would "recklessly" leave the sidewalk and dart into the street. The study determined that "careless pedestrians are slightly more numerous than the four percent of reckless motorists known to be on the highway." 115

Interviews with the chief traffic officers in Boston, Chicago, Denver, Minneapolis, New York, Philadelphia, Pittsfield, Portland, San Francisco and Youngstown found a "startling assertion ... that accidents were not chiefly the fault of the driver, as our courts and public opinion have been want to assume, but that the pedestrian is to blame at least 50 percent of the

\footnotetext{
112 Ibid.

${ }^{113}$ For much of the 1920s, most pedestrians who followed their own discretion and crossed a street outside of a designated safety area or without an official signal would have objected to the term "jay walker"-they were simply using the street following long-standing cultural norms. By 1930, most would agree that undertaking such a crossing did amount to jaywalking and was improperly disruptive of traffic. Norton, Fighting Traffic, 5, 71-80.

114 "Interviewing the Men Who Stand in a Whirlpool," Boston Globe, February 3, 1924, 5.

115 “Reckless Pedestrians Outnumber Motorists," Boston Globe, December 1, 1924, 22.
} 
time." These police chiefs collectively argued that "since the pedestrian and driver are equally to blame for accidents, pedestrian traffic in business sections should be regulated as thoroughly as vehicle traffic." 116

Miller McClintock concurred, arguing that:

Thus far the pedestrian has been largely left to follow his own inclination. Such regulations as have been passed have been directed almost exclusively to a restraint against drivers of motor vehicles ... But the time has come when it is imperative that all classes of street users be subjected to moderate and reasonable regulations if motor vehicles are to move faster and with fewer traffic snarls and pedestrians are to secure the maximum of amount of protection ... The Erskine Bureau conducted an intensive study [in downtown Chicago, which] provided proof that the unregulated pedestrian is one of the chief sources of accidents and traffic congestion. ${ }^{117}$

While McClintock's opinion on this matter was almost certainly influenced by the fact that his institute at Harvard was endowed by the Studebaker Corporation, he was still regarded as a leading traffic expert and his recommendations carried weight, which was why he was appointed to Mayor Nichols' Street Traffic Advisory Board in 1926. ${ }^{118}$

Though most officials had come to agree that pedestrians deserved to be held to a much higher standard of accountability when involved in an automobile accident, Governor Fuller offered a compelling counter argument:

I have probably ridden as far in a motor car as almost anyone in the State, and I have been concerned with automobile traffic over a great many years ... I think the responsibility for accident to a pedestrian in the streets by motor vehicles rests primarily and almost always on the individual operator. I have never seen a case - and I have known hundreds - where that was not true. If that is true, then the problem of responsibility rests primarily on the motorists, and the remedy lies in that direction.

There is much that can be said for the jay walkers and the persons who walk across the street. They too have a right to live. They are not informed intimately

\footnotetext{
116 "Abolish Street Parking, Say Traffic Chiefs: Experts of Ten Cities Agree that Pedestrians Are as Much to Blame as Drivers," Boston Globe, June 21, 1925, 60.

117 "Registration Figures," Boston Globe, May 29, 1927, 56.

${ }^{118}$ Weinstein, "Perceptions of Traffic Congestion," 203.
} 
about these modern juggernauts; they do not know about automobiles, have never thought much about this great road locomotive where all a person has to do in order to operate one on the public highways is to have the price to pay for it - or rather the first installment and a license.

The operator may be blind in one eye; he may be half-witted, he may be slow to make up his mind, perhaps he can't hear at all, he may have a bad leg, the automobile may not be in condition to be stopped within a reasonable distance. The only thing this person has to do in order to run this road locomotive is to have the price and the license. ${ }^{119}$

Fuller's eloquence and his reputation as Packard's great automobile man ultimately did little to shape changing opinions about the role of pedestrians in Boston's streets. However, Fuller's concern for pedestrians was manifested in new rules requiring liability insurance. Before the new rule was enacted in 1926, he was "astounded at the number of people who have accidents [involving] motor cars . . . who can get no relief. From records which I have obtained it is reasonable to assume that in accidents last year in Massachusetts in which nearly 26,000 people were killed or injured, it was possible to collect damages in less than 9,000 cases." ${ }^{120}$

It was not until the mid-1920s that the rules governing driving in Boston were updated in meaningful ways. Driving while intoxicated was legal through the 1910s, and when a drunk driving act was finally created in Massachusetts, the penalties associated with it were nominal. In 1925, the act was amended to impose jail sentences upon a second conviction. After postaccident analysis suggested that approximately 66,000 of the 600,000 people licensed to drive in Massachusetts had vision deficiency, the Registrar of Motor Vehicles finally lobbied to have mandatory eye tests become part of the licensing process in 1926. Wipers or other means of clearing rain, snow and debris from windshields were not required in Massachusetts until 1925.

\footnotetext{
119 “Gov Fuller Warns Reckless Motorists,” Boston Globe, May 20, 1926, 1.

${ }^{120}$ Ibid.
} 
Through the mid-1920s, there were no compulsory inspections of cars, and motorists were not required to signal when turning or changing lanes. ${ }^{121}$

In December, 1925, the Street Commissioners issued an update of Boston's traffic regulations, which had been relatively unchanged since 1908. These new regulations more strictly governed vehicles in motion, such as by mandating that vehicles keep to the right except when passing; by mandating that vehicles traveling on roads divided by streetcars, viaducts, or safety zones must keep to the right of the division; that vehicles turning right onto another street must keep as close as possible to the right-hand curb (and thus not cut off a moving car); and that vehicles may not enter a painted crosswalk when pedestrians were within it. Motorists were required to issue a signal by hand or electric light when making turns. The new rule clarified the meaning of signals issued by police (for example, a single whistle blast meant that all vehicular traffic at an intersection should stop, allowing pedestrians to cross). It also restricted vehicles from stopping or standing within fifty feet of the wall of a fire station, within ten feet of a fire hydrant or within twenty feet of a street corner. Children under the age of sixteen were prohibited from operating those motor vehicles required to carry a registration number in public places. Notably, Boston's new traffic rules included directives for pedestrians, who became responsible for understanding what a police officer's whistle blasts signified. Pedestrians were expected to stay on sidewalks, to use designated crossings and to make use of strategically placed safety zones set off by stanchions, painted lines or raised islands. ${ }^{122}$

121 "Changes in Motor Laws Made This Year are Now in Effect," Boston Globe, August 2, 1925, 49; "City of Boston: Street Traffic Regulations and Rules for Driving," Boston Globe, December 31, 1925, 21; "Lack of Signals by Motorists Proving Menace to All Users of Our Highways," Boston Globe, May 17, 1925, 63; "Want Eye Tests for Drivers," Boston Globe, March 27, 1926, 4.

122 "Street Traffic Regulations and Rules for Driving," Boston Globe, December 31, 1925, 21. 
Illuminated traffic signals made their debut in the city on December 7, 1924 at the intersection of Tremont and Boylston. ${ }^{123}$ With an officer operating a control box from the sidewalk, a pole affixed with lights issued a simplified set of instructions [Figure 3-64]. Later in the month, a tower was erected for the officer to stand upon to have a better vantage point to assess the traffic below. Similar to contemporary traffic lights, this early tower relied upon red, green and yellow lamps to issue instructions to vehicles and pedestrians alike. This lighting design was based on a prototypical standard that had been developed at the 1923 International Police Conference. A green light directed vehicular traffic to proceed forward, and green directional arrows allowed easier left-hand turns. A red light was the instruction for vehicular traffic to stop. All red lights flashing on and off rapidly signified the approach of a fire fighting apparatus. Pedestrians were meant to cross when the yellow and red lights were illuminated simultaneously, thereby criminalizing attempts to cross at other times. Since many pedestrians were confused by this dual-light signal, large instructional signs were posted at the base of the light declaring "Foot Traffic Cross on Red, Yellow Lights."

The new traffic light at Tremont and Boylston caused a stir. On the first day of operation, the Boston Globe declared it "a fascinating fine show. All day yesterday and last night, that busy intersection was crowded with people, watching the signal in operation." ${ }^{125}$ Two weeks later, crowds were still gathering to witness the spectacle. Replacing the patrolman with his semaphore, "there has sprouted a slender tower crowned with flashing red, green and yellow

\footnotetext{
${ }^{123}$ The first red/green traffic signal in the United States was used on Euclid Avenue in Cleveland in 1914. The contemporary green/yellow/red system was developed in Detroit in 1920. These early light signals were highly ineffective during daylight, since the lenses were difficult to see. A railway signal design firm (Crouse-Hinds) developed a much more functional lens in the early 1920s, after which traffic lights were soon used throughout the United States. McShane, Down the Asphalt Path, 201.

124 "Signs at Boylston Street to Make Crossing Safer," Boston Globe, December 15, 1924, 1; "Interested Crowds Watch New Traffic Signal Tower" Boston Globe, December 9, 1924, 19; "New Signals Speed up Traffic at Busy Corners," Boston Globe, December 8, 1924, 1.

125 “Interested Crowds Watch New Traffic Signal Tower," Boston Globe, December 9, 1924, 19.
} 
lights. Shrill whistles sound. The lights flutter and change while answering waves of trafficfoot or vehicle, according to the color of the lights—-surge out across the square . . at present the tower is a novelty which holds not only visitors but natives [with] interested watchers at every corner."126 Christmas shoppers diverted from the department stores on Washington Street to witness the new changes at the intersection.

In 1925, additional light signals were erected at key intersections in the city. These new lights were often inspired by City Beautiful ideology, with local businesses sponsoring the erection of sculptural light towers as a form of new civic monument. At the junction of Washington, Summer and Winter Streets, a vice-president of Filene's department store gifted the city an ornate bronze traffic tower with a base of polished black granite in "colonial" design to replace a wooden stand that had previously been located there [Figure 3-65]. The original light fixture in place at Boylston and Tremont Streets was replaced with a more "artistic" tower [Figure 3-66]. The Paine Furniture Company sponsored a marble and bronze, fifteen-foot-tall tower in the intersection of Boylston and Arlington Streets in 1926 [Figure 3-67]. ${ }^{127}$

These new signal towers were erected in the middle of an intersection. An officer sat in a raised booth within the towers and manually operated the lights above with a control. Most towers were four-sided, though some had five, allowing clear views in all directions. Once the public had grown accustomed to their presence, it took less manpower for the police to direct traffic. When four officers had previously been required to control a busy intersection, now only two were needed. However, some of Boston's intersections, such as Governor's Square were so

\footnotetext{
126 "New-Fangled Christmas Tree for Boylston St Corner," Boston Globe, December 21, 1924, 22.

127 “City Accepts Traffic Tower, Gift of Filene's Vice President," Boston Globe, October 26, 1925, 20; "New Traffic Tower at Boylston and Arlington Streets," Boston Globe, March 27, 1926, 6; "Erect Permanent Traffic Signal Tower Tomorrow at Tremont and Boylston Streets," Boston Globe, June 20, 1925, 18.
} 
convoluted that they could not be controlled by a simple traffic tower and these continued to rely upon multiple traffic officers for order [Figure 3-68]. ${ }^{128}$

By 1927, the travelling public in Boston had grown increasingly accustomed to electric traffic signals and the instructions of police officers. This helped to lower the accident rate, just as it helped to allow a greater volume of automobiles to move through the city's streets. However, with the number of motor cars growing every year, it was quickly apparent that while better traffic signals could help to impose order, they could not solve the problem of congestion.

As Boston officials considered expanding the system of traffic signals, James Sullivan, the Boston Globe's regular automobile columnist, urged the city to consider a recent report to the National Auto Chamber of Commerce, which stated "highway engineers and city traffic managers are beginning to learn what railroad authorities discovered some years ago-namely, that signals will work for a certain volume of traffic but cannot handle a peak volume of crosswise traffic satisfactorily. Railroads long ago arranged for separation of grades at busy points, recognizing that the block signal system might serve as a warning, but could not handle the problem of actually moving two lines of traffic crossing each other." ${ }^{29}$

Sullivan believed that "progressive" cities were those that had begun to adopt the separation of grades in places where busy roads crossed, such as East Grand Boulevard and East Jefferson Avenue in Detroit, and used his editorial voice to promote the concept in Boston. Even so, few of Boston's surface streets were modified to include them. Among the earliest of these was the crossing of Massachusetts Avenue and Commonwealth Avenue. An underpass was

\footnotetext{
${ }^{128}$ While the streets leading into and out of Governor Square (such as Commonwealth Avenue) were initially some of the easiest roads to drive on in the early years of automobile use, once commuter traffic was established they also became difficult to use.

129 "Signal Lights Cannot Move Traffic at Peak in Large Cities," Boston Globe, August 14, 1927, 49.
} 
proposed in 1930 and was eventually opened in 1937 [Figure 3-69], but it remained an exception until the arrival of monumental highway building in the 1950s.

While the moving regulations and experiments with standardized signals of the 1920 s did not solve congestion, they did impose order over the traveling public. This new order helped to accommodate somewhat greater numbers of automobiles on Boston's roads, but since the number of cars increased by such large margins in each year, efforts to regulate away congestion were always offset. The real legacy of the regulatory efforts of the 1920s was to codify a new cultural consensus that had been reached about how to appropriately use public rights of way. These vital spaces were now permanently divided, with pedestrians compelled to stay on sidewalks (and other designated safety zones, such as a raised traffic islands) while maintaining a vigilant and self-protecting eye on the motorists who had been legally ceded the center of the road.

Peter Norton contends that this cultural change had been completed in most American cities by the early 1930s, an observation that holds true in Boston. By this time, the city's streets had been "socially reconstructed as places where motorists unquestionably belonged." This social reconstruction not only criminalized the practice of being a pedestrian, who could be fined for walking in inappropriate places, but it also popularized new ideas about how to build future rights of way. During the 1920 s, it became increasingly possible to create new streets whose design was almost exclusively informed by the wants of automobilists, even streets in downtown districts whose existing built forms specifically responded to (and depended upon) the needs of pedestrians and users of mass transit. ${ }^{130}$

\footnotetext{
${ }^{130}$ Norton, Fighting Traffic, 1-18.
} 


\section{CHAPTER 4 - Planning for Destruction}

By the early 1920s, Boston was no longer content with the adaptive reuse of public streets by motorists. Under the direction of a newly established planning board, Boston began to undertake incredibly destructive street creation campaigns in the central city mostly in service to suburban drivers. It did so before the relegation of pedestrians to sidewalks, before it revised its traffic code, before its first systematic traffic count and before it could claim a nuanced undertaking of the automobile challenge. The dismantling of the center city's fossilized streets began long before post-war urban renewal, and by 1925 major street widenings and extensions had been completed. These experimental streets were created with the expectation that they would both ease traffic congestion and encourage real estate development, but these expectations were not fulfilled.

Boston's City Planning Board was established in January, 1914, and was one of fourteen such boards then operating in American cities. The five-member body served only in an advisory capacity with no direct executive power to shape the city. Nevertheless, the board greatly influenced development in the city. The proposals put forth by the board, subject to legislative approval, embodied a singular authority, since no other entity could claim its professional expertise nor its presumed neutrality when it advocated for a project. Business leaders, trade organizations and politicians sometimes promoted plans of their own, usually to fulfill either their own interests or those of a particular constituency. The planning board, by contrast, was meant to act for the betterment of the city in general and ultimately undertook projects that most people in Boston either expected or demanded. ${ }^{1}$

\footnotetext{
${ }^{1}$ The board was originally comprised of Ralph Adams Cram (president of the Boston Society of Architects and a professor of Architecture at MIT), John J. Walsh (an attorney), Emily Greene Bach (professor of economics at Wellesley College), Henry Abrahams (an official of the Central Labor Union) and William C. Ewing (a civil engineer) as well as a secretary, Elisabeth M. Herlihy, to whom Lawrence Kennedy attributes much of the work of
} 
Upon its creation, Boston's planning board provided advice on projects such as the location of high-pressure pumping stations, the maintenance of city-owned buildings and properties, playground construction, the encouragement of housing, the establishment of zoning laws, the creation of public bathrooms and tree plantings. But foremost among their concerns was the question of how to modify the city in response to mass automobile use. During the board's first three years, its actionable responses to this question were tentative, in accordance with the modest practices established as part of nineteenth-century road alternation efforts. But by 1917 , the board began to propose hugely expensive projects that far surpassed historical precedent and sought to bring new order to downtown Boston and its environs.

Since those most disadvantaged by the difficulties of downtown congestion were suburban commuters who did not pay taxes in Boston, it is striking that the city undertook increasingly drastic and expensive measures to create traveling conditions suited to these commuters' needs. Most residents of Boston Proper simply walked to the downtown area or took the subway. City officials, especially those on the planning board, nevertheless privileged the needs of autoists in the 1920s.

In part, the board's great concern for reshaping the city center in order to reduce traffic congestion had to do with the timing of the arrival of mass automobile use, which closely coincided with the emergence of planning as a professional practice in the early twentieth century. ${ }^{2}$ The creation of new roads and the modification of old ones based on traffic counts and other quantifiable metrics directly appealed to the idea that professional planners could apply

the board (the secretary for two decades, she later became a board member and served until her death in 1953). Newspaper coverage of the planning board in the 1910s and 1920s typically portrayed the planning board as judicious and impartial. "City Planning Board," City Record 10, no. 3 (January 19, 1918): 51; Lawrence W. Kennedy, Planning the City Upon a Hill: Boston Since 1630 (Amherst: University of Massachusetts Press, 1992), 125-127.

${ }^{2}$ Harvard's first planning course was taught in 1909 and the first National Conference on City Planning was held in that year. Stanley K. Schultz, Constructing Urban Culture: American Cities and City Planning, 1800-1920 (Philadelphia: Temple University Press, 1989), 191. 
rational methods to remedy urban problems. Like the implementation of zoning, these rational responses were uniquely suited to the new profession's conception of itself.

Moreover, the creation of a network of roads that would increasingly connect the center city to suburban districts appealed to an ideological position that Peter Hall argues was central to the new profession. Many among the first class of planners sought to intellectually and professionally respond to the evils of the nineteenth-century city, especially excessive overcrowding in residential districts and poor sanitary conditions. ${ }^{3}$ To this end, easing entry to suburban areas was broadly viewed as means to facilitate access to what was considered to be suitable housing well removed from the filth, noise and overpopulation created by the industrial city. ${ }^{4}$ The Boston 1915 movement, with its early concern for the establishment of a politically unified metropolitan area and the coordinated construction of radial and circumferential highways throughout the metropolitan area, was in part motivated by this logic. 5

In her investigation into the stance of Bostonians toward congestion in the 1920s, Asha Weinstein situates the city's response in terms of a phenomenon described by the historian Paul Barrett in his writing on Chicago's municipal transportation policy. Barrett emphasized the importance of "policy definitions" defined "as assumptions about the nature of a problem that underlie and shape all polices, and which are so fundamental that they are often left unexamined." In Urban Transit Policy, David Jones similarly discussed the "routines, traditions and working agreements of an industry' that guide explicit policy, even though they are never

\footnotetext{
${ }^{3}$ Widenings of Morton Street (originally eleven feet wide) and Stillman Street in the North End were undertaken not to facilitate traffic, but to provide humane access to light and air for those who lived in squalid tenement buildings that surrounded these two narrow streets. Boston City Planning Board, Fourth Annual Report of the City Planning Board for the Year Ending January 31, 1918 (Boston: City of Boston Printing Department, 1918), 6.

${ }^{4}$ Peter Hall, Cities of Tomorrow: An Intellectual History of Urban Planning and Design in the Twentieth Century (Oxford: Blackwell Publishers, 1994): 7.

${ }^{5}$ Frederick Law Olmsted, "A Suburban Town Built on Business Principles," New Boston (January 1911): 395-399; "Syllabi of Boston-1915 Conferences," New Boston (January 1911): 399; William Baile, "Town Planning and Garden Cities," New Boston (July 1911): 87-88; Frederic C. Howe, "The American City of Tomorrow," New Boston (July 1911): 106-107; Earl F. Gates, “Boston’s Need for a City Plan,” New Boston (July 1911): 108-110.
} 
formally stated." ${ }^{\prime 6}$ In Boston, this phenomenon of shared underlying assumptions was typified by the city's surprising lack of official discussion as to why traffic congestion was such a great concern for planners, politicians and citizens alike.

Weinstein found near unanimous agreement among the editors of the Boston Globe, the Boston Herald, the Boston Post and the Boston Transcript that automobile congestion in the 1920s was a menace warranting intervention, implying that the reading constituencies of these papers held similar views. Mayor Curley (numerous terms served in 1914-1918, 1922-1926, 1930-1934 and 1946-1950) Mayor Peters (1918-1922) and Mayor Nichols (1926-1930) all railed against congestion, as did the City Planning Board, members of the city council and various trade organizations, best represented by the Chamber of Commerce. While passionate, Weinstein found that these voices typically described the problems of congestion in vague terms.

While few of these speakers on the subject of automobile congestion bothered to offer a detailed rationale for why the matter deserved costly public intervention, four broad categories of thought on the matter prevailed. For many, redesigning the city to ease congestion was a means to make the city safer and to reduce traffic accidents. Some argued that congestion damaged the economy of the city and were concerned that congestion caused Boston to lose economic competiveness against rival cities with easier driving conditions. Many were specifically worried about the difficulties faced by trucking and teaming concerns, who were unable to efficiently make deliveries in the downtown area, especially to and from the retail district, the market district and the wholesale district [Figure 4-1]. As a letter published in the Transcript fretted "How is Boston to compete with other cities ... when her waterfront and market district by its impossible congestion impedes import and delivery by teams or truck of goods, especially goods

\footnotetext{
${ }^{6}$ Asha Weinstein, "Congestion as a Cultural Construct: The 'Congestion Evil' in Boston in the 1890s and 1920s," The Journal of Transport History 27, no. 2 (September 2006): 99.
} 
which are perishable?"7 Similarly, a merchant appeared in 1894 before the Joint Special Commission on Transit to complain that "the trucking facilities of Boston are badly hampered by [congestion]" and offered several examples of the problems faced by many concerns:

The Boston and Maine ... have moved their freight houses away over to Rutherford Ave., and orders that come in to the thousand and one business houses in Boston by mail and telegraph oftentimes have to be left over until another day because the trucks get in line, and they get detained on their way in jams, so that that truck load has either got to come back to the warehouse and be unloaded, or it has got to go to the truckman's stable and take the risk of fire and all that sort of thing over night, and go to the freight house the next day. This fact can be demonstrated by many merchants who lose trade by this congested condition, in my judgment." 8

Other figures, such as a chairman of the Massachusetts Real Estate Exchange, "contend[ed] that the increased costs of doing business due to congestion were passed directly on to consumers, thus raising the cost of living." Weinstein further argued that a "growing emphasis on congestion and the cost of living was most likely a political effort to convince the larger population that congestion-generated delay was a problem for them, too, even if they didn't directly experience it as auto drivers. Once the subway eliminated the congestion-induced delay experienced by people travelling downtown on the streetcars, proponents of expensive and controversial congestion relief projects ... needed a new argument to convince the general public that they should support these policies, and the cost-of-living argument filled that role." 10

Additionally, prominent retailers, such as Jordan Marsh, were deeply concerned that downtown congestion would become so bothersome that its customers would be compelled to shop elsewhere. Other merchants agreed, especially those in the immediate vicinity of crowded

\footnotetext{
${ }^{7}$ Ibid, 107.

${ }^{8}$ Ibid, 108-109.

${ }^{9}$ Ibid, 109.

${ }^{10}$ Ibid, 111-112.
} 
Washington Street. ${ }^{11}$ Louis F. Kirstein, vice-president of Filene's and member of the Chamber of Commerce's traffic committee, claimed that congestion was a great threat to his department store's profitable business and also that the streets of the city must be made accessible to motor traffic since "the automobile is the new method of transportation." 12 John Shepard of the Shepard Stores was similarly concerned with the difficulties his customers faced on account of congestion, and speculated that "pretty soon the stores along Washington st will have to supply their employees with gas masks and station them near the doors to care for the customers and others who are overcome by [fumes]."13

By the late 1920s, the Boston Globe celebrated the city's recent investment in wider streets and enthusiastically reported that more buildings had been deliberately razed to modernize the central street network in the prior ten years than had been destroyed in the fire of 1872. The newspaper's editors felt that this newly emerging road network was helping to expand the city and to encourage dense commercial building in new realms outside of the downtown area in Park Square, the Back Bay and in the vicinity of the Fenway. At the same time, the editors saw the new streets as contributing to the commercial success of the central area (their evidence was simply that some new buildings had been erected downtown). As a headline proudly proclaimed, the "New City Pushes Its Way into Surrounding Country." While the city center was contained between Park Square and the waterfront at the dawn of the motor age, by 1928 it was seen to be encroaching upon other cities. These editors were unable to understand that they were witnessing the beginning of a contrary trend that conflicted with their assessment

\footnotetext{
${ }^{11}$ Loop Hearing Speakers Are Entirely in Favor of Project" Boston Globe, March 31, 1925, 23; "Speakers Differ as to Ban on Parking," Boston Globe, August 16, 1923, 4.

12 "Loop Hearing Speakers Are Entirely in Favor of Project" Boston Globe, March 31, 1925, 23; "Business Heads Urge Highway," Boston Globe, November 25, 1924, 10; "Speakers Differ as to Ban on Parking," Boston Globe, August 16, 1923, 4.

13 "Tremont as One-Way Street Still Seriously Considered," Boston Globe, August 3, 1929, 12.
} 
of a strengthening and expanding commercial core: the end of traditional urbanization and the entrenchment of commercial decentralization. In reality, it was the surrounding towns and cities that had begun to encroach upon Boston, not vice versa. ${ }^{14}$

\section{PRECENDENTS}

The schemes developed by the City Planning Board in response to automobile use significantly departed from prior efforts to redesign the city's fabric to the needs of horse-drawn conveyances and to those of great crowds of moving pedestrians. City engineers in the late nineteenth century relied on occasional widenings to make piecemeal alterations to the street network in an effort to improve pedestrian and horse-drawn traffic as well as to allow the passage of streetcars. But ultimately street widenings in the center were modest and infrequent, even in the aftermath of the fire of 1872 .

Since the central city itself was a densely built urban form that specifically responded to the physical needs of pedestrians (manifested by department stores, tall office towers, wholesale districts and busy stream railroad termini), there was less urgency for nineteenth-century officials to contemplate large widening projects. ${ }^{15}$ Though many citizens, newspapers, officials and trade organizations complained about congestion in downtown Boston and about the difficulty of navigating the city's crooked streets in the late nineteenth century, significant street widenings

\footnotetext{
14 “City Pushes Its Way into Country," Boston Globe, January 1, 1928, 35.

15 On this urban form, see Robert M. Fogelson, Downtown: Its Rise and Fall, 1880-1950 (New Haven: Yale University Press, 2001); Douglas W. Rae, City: Urbanism and Its End (New Haven: Yale University Press, 2003); Richard Longstreth, The American Department Store Transformed, 1920-1960 (New Haven: Yale University Press, 2010); Alison Isenburg, Downtown America: A History of the Place and the People Who Made It (Chicago: University of Chicago Press, 2004); James Vance, The Continuing City: Urban Morphology in Western Civilization (Baltimore: Johns Hopkins University Press, 1990).
} 
were not considered feasible, and when the problem was eventually regarded as a crisis it was largely solved by the creation of the subway system. ${ }^{16}$

Significantly, the major transformations to the city's fabric in the late nineteenth century were the continuation of landmaking programs (expensive undertakings that created more buildable acreage in proximity to the downtown area) and the construction of the subway. The subway, though it increased the usability of streetcars which then made nearby suburbs more convenient and thus encouraged some decentralization, ${ }^{17}$ also helped to make the streets of the downtown area easier for pedestrians to use by removing streetcars from most surface roads, diminishing the need for downtown widenings. Of course, by building the subway underground, the new mass transit system helped to preserve Boston's walkability by creating a new type of transit experience that purposefully sought to avoid changes above the surface level of the city.

Widenings to existing streets in the city center were infrequently undertaken throughout the nineteenth century and in the beginning of the twentieth century. From 1820 to the fire of 1872, the most substantial such widening was made to Devonshire Street in the late 1850s, when the road's width was expanded to forty-eight feet and was extended to create a long-desired link between State and Summer Streets. Though this development required the alteration or demolition of several buildings that lined the sides of the road, this destruction was not (for the most part) adversarial, as the city "undertook the extension and widening of Devonshire Street,

\footnotetext{
${ }^{16}$ For a detailed account of the many hundreds of formal and informal complaints against traffic congestion by Boston's elected officials, newspapers, business leaders and the public in general, see Weinstein, "Congestion as a Cultural Construct," 97-115; Asha Weinstein, "Curing Congestion: Competing Plans for a Loop Highway and Parking Regulations in Boston in the 1920s," Journal of Planning History (2004): 292-311; Asha Weinstein, "The Congestion Evil: Perceptions of Traffic Congestion in Boston in the 1890s and 1920s" (PhD diss., University of California, Berkeley, 2002).

${ }^{17}$ Sam Bass Warner, Streetcar Suburbs: the Process of Growth in Boston (1870-1900) (Cambridge, MA: Harvard University Press, 1978); Charles W Cheape, Moving the Masses: Urban Public Transit in New York, Boston, and Philadelphia - 1880-1912 (Cambridge, MA: Harvard University Press, 1980).
} 
which was then an upper class residential street, specifically at the request of improvementminded property owners in order to help them redevelop it for business." 18

With the exception of the modest reorganization of the wholesale district following the fire of 1872 (see Chapter 3) and alterations made to Fort Hill beginning in 1866, other occurrences of street widenings in the center were uncommon and modest in scope. At the close of the nineteenth century, for example, widenings in the center sometimes involved the taking of only a few square feet at a time, such as the 4.12 square feet of land taken at the junction of Tremont and Boylston to improve that intersection in 1897 and the fifty-nine square feet of land added to Boylston Street near Park Square in $1898 .{ }^{19}$

According to Christine Rosen's account of Boston's nineteenth-century street widening practices, the Street Commissioners would give those who sought to redevelop their properties notice advising them what "grade and width the city planned to establish as the standard on their streets, in the hope that the property holders would then build in compliance with the standard of their own accord." In the absence of voluntary compliance, the Street Commissioners would wait until they knew an owner intended to demolish a valuable property in order to pay smaller damages to that owner when private property was taken by eminent domain. In many instances, this haphazard approach intensified problems by creating uneven streets and bottlenecks, many of which survived into the automobile age. Moreover, it also "antagonized those property owners

\footnotetext{
${ }^{18}$ Christine M. Rosen, The Limits of Power: Great Fires and the Process of City Growth in America (New York: Cambridge University Press, 1986), 83; "City Document No. 60: Report of a Majority of the Committee on the Extension of Devonshire Street, From Franklin to Summer Street," Documents of the City of Boston for the Years 1857 vol. II (Boston: Geo. C. Rand \& Avery, City Printers, 1858), 3-12.

19 These small adjustments to the scope of Boylston Street were likely made as a byproduct of infrastructural changes, such as the excavations for the new subway system. Street Laying-Out Department, Annual Report of the Street Laying-Out Department for the Year 1897 (Boston: Municipal Printing Office, 1898), 7; Street Laying-Out Department, Annual Report of the Street Laying-Out Department for the Year 1899 (Boston: Municipal Printing Office, 1900), 8.
} 
who had . . . built stores and warehouses to conform to contemplated street grades and widths, who then had to wait years before their buildings could be properly used."20

This is not to suggest that many Bostonians and city officials did not desire wider, more modern downtown roads during the late nineteenth century. Before the subway removed most streetcars from the surface of the congested district, numerous downtown widenings were proposed by various civic leaders to create space for pedestrians, mass transit services and delivery teams. For example, in 1892, the Rapid Transit Commission called for the widening of Tremont Street (to at least eighty feet from an original prevailing width of sixty feet), Eliot Street (from fifty to 100 feet) and Charles Street (from fifty-five to eighty feet), as well as the extension and widening of several existing roads to create a broad circumferential circuit for teams running from Charles Street to North Station, thence to the already wide Commercial Street (eighty feet in width) and Atlantic Avenue (which ranged from eighty to 100 feet in width). ${ }^{21}$

The desire for efficient delivery was still a prominent concern at the time that mass automobile use began to emerge in the 1910s. As the authors of a 1914 report sponsored by the Chamber of Commerce declared

the concentration of the principal retail activities of the city [in a small downtown area] attracts thousands of shoppers and also makes it necessary to deliver great quantities of merchandise to the stores, and from the stores to their customers. Large numbers of teams move through the district, most noticeably in the afternoon, between two and six o'clock. The presence of the many teams, electric cars and pedestrians causes serious congestion throughout the district, especially between four and six in the afternoon, when all the streets are taxed to their utmost by the pedestrians bound either for subway stations on Tremont Street, or down Summer Street to South Station. In Winter Street every afternoon about the

\footnotetext{
${ }^{20}$ Rosen, The Limits of Power, 185.

21 Though Commercial Street and Atlantic Avenue were among Boston's widest roads, they were significantly congested in the late nineteenth century. Not only were they heavily used by teamsters who needed access to shipping facilities and wharves along the waterfront, but also because a surface rail operated on these streets to provide a means to move freight from South Station to North Station. Rapid Transit Commission, Report of the Rapid Transit Commission to the Massachusetts Legislature, April 5, 1892 (Boston: City Printing Office, 1892), 4663.
} 
time the stores close delivery teams line both curbs solidly, leaving space in the street wide enough only for the passage of a single row of vehicles, and even this is frequently blocked by hand trucks and men passing to and from the various teams. As foot traffic is also heaviest at this hour, the narrow sidewalks are crowded until movement becomes almost impossible, and the teams prevent the use of the street to relieve the overloaded sidewalks. ${ }^{22}$

\section{INHERITED METHODS}

After it was created, the City Planning Board's efforts to modify the heart of the city often took the form of targeted street widenings, a continuation of established nineteenth-century practice. What distinguished the board from their predecessors was the scale and scope of the widenings that were proposed and then enacted. The board also sought to make changes to existing downtown fabric (and eventually to the metropolitan area in general) through the creation of new, broad boulevards.

As it considered widenings in the 1910s, the board's initial logic was grounded in the belief that the streets of central Boston were not appropriately modern. The board felt that the central street network was "deplorably narrow and crooked ... which could and should have been widened a generation ago [and] now [was] so fully built up as to make the cost of widening prohibitive. ${ }^{23}$ With the downtown street network deemed to be grossly inadequate for the traffic of the mid 1910s, the City Planning Board at first favored the widening of select streets within the downtown area itself, but not of major streets that provided direct connection to the district. Tactically, the board appears to have been initially guided by the idea that it might first repair key streets in the center as opportunities arose to undertake a widening.

\footnotetext{
${ }^{22}$ Boston Chamber of Commerce, Street Traffic in the City of Boston (Boston: E.L. Grimes, Printers, 1914), 26.

${ }^{23}$ Boston City Planning Board, Annual Report of the City Planning Board for the Year Ending January 31, 1915 (Boston: City of Boston Printing Department, 1915), 4.
} 
Along these lines, one of the first acts of the City Planning Board was to recommend an exacting topographical survey of the central business district so that it might make proposals for future street development. It was specifically interested in conducting this survey "as a preliminary to a wise planning of future thoroughfares" which the board hoped would be created in the downtown area when later events occurred to make takings more affordable. ${ }^{24}$ The board desired to take advantage of future disasters akin to the fire of 1872 (or as individual buildings were demolished either by small-scale conflagration or as their owners saw need to rebuild them). The board reasoned that, should a sanctioned plan already be in place, it would be far easier to implement it in expeditious fashion following such opportunities. ${ }^{25}$

While surveys were being conducted, the board continued to advocate for widenings in the piecemeal fashion of the late-nineteenth century. In 1915, the board encouraged the Street Commissioners to consider the modest widening of a block of Beacon Street between Tremont and Bowdoin Streets as well as Somerset Street between Beacon Street and Pemberton Square with the intention of "improv[ing] facilities for vehicular traffic." This proposal "would include the laying down of a building restriction line through the present City Club property, the widening to be made whenever the present building is demolished." In this way, the board sought to craft a street it considered to be suitable when fate allowed this to be done cheaply, an

\footnotetext{
${ }^{24}$ Boston City Planning Board, Annual Report for 1915, 3.

${ }^{25}$ This was an unlikely prospect. Daniel Burnham's 1905 Plan for San Francisco, which proposed the creation of a modernized street network (albeit one informed by a City Beautiful framework), was almost entirely disregarded after the earthquake and fire of 1906. Reconstruction after disaster eschewed such plans and sought familiar spatial order. See Martyn J. Bowden, "The Dynamics of City Growth: An Historical Geography of the San Francisco Central District. 1850-1931" (PhD diss, University of California, Berkeley, 1967); Martyn J. Bowden "Reconstruction Following Catastrophe: The Laissez-Faire Rebuilding of Downtown San Francisco after the Earthquake and Fire of 1906," Proceedings of the Association of American Geographers 2 (1970): 22-26; Eugene Hass, Robert W. Kates and Martyn J. Bowden (eds.), Reconstruction Following Disaster (Cambridge, MA: MIT Press, 1977); Daniel H. Burnham, Report on a Plan for San Francisco (San Francisco: Sunset Press, 1905).
} 
approach that often came with unpredictable and long delays before implementation was achieved. ${ }^{26}$

The following year the board advocated for a widening of State Street using identical tactics. Though State Street was not then an important thoroughfare (given its narrow character, this would have been an impossibility), the board predicted that it might become one in the future (a prospect that would certainly be encouraged with a widening). At the time, State Street was fifty feet wide in most places, though in a twelve-foot stretch just east of Chatham Row the right-of-way narrowed to thirty-five feet (and just twenty feet between curbs) [Figure 4-2]. This was wide enough for only two vehicles to stand abreast. If an automobile or a team stopped, just one lane of traffic remained for cars moving in both directions. If a conveyance did not park parallel or if other obstructions were created in the road, the street became impassable.

The board advocated for a widening based on grounds of aesthetics, public safety and efficiency of travel and opined that "the narrow place is unsightly in a big, dignified, and historic street; it is a cause of delay to present travel, and forms a dangerous place for fire apparatus to pass in case of necessity." 27 In determining how to best conduct a future widening, the board's guidance was preoccupied primarily by financial concerns:

On the south side of the narrow point there is now a modern office building, assessed at $\$ 649,600$, while on the north side there is a block of smaller buildings, between Chatham row and Commercial street, assessed at but $\$ 56,500$, some of which will doubtless be replaced in the future. From these facts it is evident that a widening on the north side, even though it involved more land-taking, would be more practicable and reasonable in cost, and would also make the best street line. Realizing that to make the entire widening at this time would involve [presently unwanted expense, the board] recommended that steps be taken at once, before

\footnotetext{
${ }^{26}$ Boston City Planning Board, Annual Report for 1915, 6.

${ }^{27}$ Boston City Planning Board, Second Annual Report of the City Planning Board for the Year Ending January 31 , 1916 (Boston: City of Boston Printing Department, 1916), 6.
} 
new buildings were erected, to place a restriction line across the block . . . in order to provide for widening in the future. ${ }^{28}$

\section{A CHANGING SCALE}

It was soon apparent to the city that piecemeal widening campaigns would do little to solve the city's rapidly intensifying problem with automobile congestion. By 1920, city officials began to undertake a series of modifications to central streets that drastically expanded Boston's widening efforts. This expansion of widening as a practice to facilitate the circulation of ever-growing numbers of automobiles coincided with a recommendation made at the National Conference on City Planning in 1920 that advocated for continued growth in street widths as a means to accommodate automobiles. Based on information from traffic counts that had been conducted in various cities, it was thought that "one vehicle per foot of width of roadway per minute" was the maximum that a street could accommodate. By this calculation (which was made before the widespread use of traffic lights and other control mechanisms), a forty-foot road with two tenfoot wide sidewalks and two ten-foot wide traffic lanes could accommodate twenty vehicles per minute and 1,200 per hour. If one of the two traffic lanes were used for parking, then just 600 vehicles could be accommodated, unless the sidewalks were narrowed, which they often were. ${ }^{29}$

Boston's aggressive program of widenings on behalf of automobile users began with changes that were made to Charles Street in 1920. This street, originally fifty-three to fifty-five feet wide, was widened ten feet to sixty-five feet for four full blocks between Revere Street and Beacon Street, with every estate along the western side Charles Street compelled to undergo some form of city-mandated destruction [Figure 4-3].

\footnotetext{
28 Ibid.

${ }^{29}$ Kerry Segrave, Parking Cars in America (Jefferson, NC: McFarland \& Company, 2012), 45.
} 
Originally created by the Mount Vernon Proprietors in 1805 to connect the Common to the West Boston (now Longfellow) Bridge, Charles Street was mostly built of infill along the original bank of the Charles River. At the time of its creation, the physical characteristics of Charles Street distinguished it from other streets in Beacon Hill, which were narrow and often very steep. Not counting the neighborhood's small alleys and courts, these ranged from twentyfour to forty feet wide, with the prevailing width being approximately thirty feet. Charles Street was wider with no discernable grade changes. In time, it emerged as the commercial corridor of Beacon Hill and the neighborhood's most populated road (horses, particularly those carrying heavy loads, could not easily walk up the steep slopes of the hill). At the turn of the century, it served as a dividing line between the aristocratic rises of the hill and a community of poorer residents who lived amid the stable district on the Beacon Hill flats.

Though wider than many other roads in Boston when it was created (and wider than many of the downtown streets that carried streetcars), Charles Street's fifty-three to fifty-five foot width frustrated city officials when they sought to engineer away the traffic congestion that came with mass automobile use. ${ }^{30}$ The street had become particularly attractive to motorists, since it was the only road that provided convenient access to the Longfellow Bridge without passing through the congested district. It also led to the city's most popular public parking area, which was Charles Street itself between the Common and the Public Garden [Chapter 3, Figure 3-50].

Those who advocated for the widening of Charles Street supposed the project would accomplish several goals. It was presumed that a broader Charles Street would allow through traffic a means to avoid the downtown area, thereby reducing traffic in the congested district

\footnotetext{
30 These measurements are from the 1909 Sanborn atlas and apply to the portion of Charles Street between Cambridge Street and Beacon Street.
} 
while providing a speedy road for those travelling on the west side of the peninsula. The new road was also expected to invigorate commercial business development on Charles Street, presumably because the road would attract more motorists who might stop to shop in the area. ${ }^{31}$

This expectation prompted many Beacon Hill business interests and property owners to support the plan. These included William C. Codman, a realtor who in 1910 had formed the West End Associates, a trust that sought to acquire houses on select streets (for example Myrtle, Pinckney and Revere) in order to ensure that they were not, in the trust's view, ruined by developers who might rebuild the properties in manner inconsistent with the existing scale and stylistic character of Beacon Hill. After acquiring properties, the trust would then sell them only to like-minded buyers who could assist in the Associates' plan to establish the area as a homogenous historic district and increase real estate values in the process. Codman also formed the Beacon Hill Associates in 1917, an organization that actively sought to reinvigorate the North Slope (fronting Cambridge Street, this was a working-class, low-rent area with the largest African-American population in the city) and the West Slope (the flat of the hill, which contained many stables and additional working-class housing) "so that both slopes would be known as neighborhoods of first class homes." As part of these efforts, Codman and his partners "realized early on the significance for the new Beacon Hill of its main promenade ... As Charles Street went, they believed, so too would the whole neighborhood." ${ }^{32}$ So motivated, the Beacon Hill Associates not only bought up at least sixty-four buildings, some of them on the affected waterside of Charles Street, but it also encouraged the widening of the road. ${ }^{33}$

\footnotetext{
31 "Would Develop Charles Street," Boston Herald, October 18, 1919, n.p.

${ }^{32}$ Moying Li-Marcus, Beacon Hill: The Life and Times of a Neighborhood (Boston: Northeastern University Press, 2002), 45 .

${ }^{33}$ It is unclear whether or not Codman and the BHA bought properties on the affected area of Charles Street before or after the widening occurred. The three properties known to be purchased in the affected area of Charles Street were the "Studio Building" located at the corner of Chestnut Street, the Lincolnshire Hotel located at number 20 and a commercial building located at number 30 out of which Codman operated his real estate offices.
} 
With the anticipation of free-flowing automobile traffic and profitable real estate development, in 1920 each building on the river side of Charles Street had approximately ten feet chopped off its front in order to widen the right of way to sixty-five feet [Figure 4-4, 4-5]. The only exception was the Charles Street Meetinghouse, built in 1807 according to an Asher Benjamin design, which was moved ten feet to the west to spare it from destruction [Figure 4-6]. This meetinghouse, originally home to the Third Baptist Church (who likely took advantage of the proximity of the river for its rituals), was later used by the African Methodist Episcopal Church beginning in 1876. Numerous antislavery speakers had occupied its pulpit, including Frederick Douglas and Harriet Tubman. At the time of the widening, it was the largest of Boston's five black churches and the only one in Beacon Hill. ${ }^{34}$

When the widening proposal was put forth, the planning board expressed concern for the preservation of the meetinghouse, which like all other buildings on the riverside of Charles Street, was initially slated to have its frontage destroyed by a demolition crew. ${ }^{35}$ The planning board judged the building worthy of consideration using vague terms "on the grounds that it was picturesque and interesting, and by restoration could be made a distinct architectural ornament to the city." The Street Commissioners took a different view, and felt that "the building could not be classed as an historical relic inasmuch as no important historical events were connected with

\footnotetext{
${ }^{34}$ Michael Southworth and Susan Southworth, AIA Guide to Boston (Guildford: Globe Pequot Press, 2008), 13-14; Robert C. Hayden, Faith, Culture and Leadership: A History of the Black Church in Boston (Boston: Boston Branch of the NAACP, 1983); Kathryn Grover and Janine da Silva, Historic Resource Study: Boston African American National Historic Site, National Park Service (December 2002): 118; Robert Campbell and Peter Vanderwarker, "Cityscapes - Charles Street," Boston Globe, March 21, 1993, 9.

${ }^{35}$ There was also discussion of a plan to arcade the eastern side of the church to accommodate the Charles Street sidewalk, but the city could not legally mandate this and there were concerns that this arcading might have endangered the structural soundness of the church.
} 
it, and that, so far as its architecture was concerned, many better types were to be seen elsewhere in the city." ${ }^{36}$

Reverend Hayes of the AME Church was concerned with matters graver than picturesqueness or design grandeur when he appeared before the Street Commissioners to plea for his congregation, who he feared would be forced to move elsewhere in the city if the 112year-old building were condemned. Others attending the hearing countered the pleas of Reverend Hayes and justified the structural risks associated with modifying the building because the black population of Beacon Hill had lately been moving away and the neighborhood "will doubtless eventually have to be abandoned by the clored [sic] people soon." Still, these voices desired the physical retention of the meetinghouse (should it survive alteration) and recognized that the building's "architectural value" warranted reflection and hoped it might soon be repurposed as a community center akin to Faneuil Hall. ${ }^{37}$

Reverend Hayes and his congregation demonstrated fierce attachment to their house of worship and raised funds to pay to move the entire building ten feet west. This maneuver saved the façade and interior spaces of the church when the widening of Beacon Street began in 1920, but it was an expensive enterprise. Along with other difficulties, it has been suggested that the cost of the move helped to bankrupt the congregation, who ultimately were forced to sell the building in the process of relocating to Dorchester in 1935. Thus, a decade and a half after the widening began, this remnant of a previously-thriving African American community was evicted from the neighborhood. ${ }^{38}$

\footnotetext{
${ }^{36}$ Boston City Planning Board, Fifth Annual Report of the City Planning Board for the Year Ending January 31, 1919 (Boston: City of Boston Printing Department, 1919), 33-34.

37 "Fears for Ancient Charles-St Church," Boston Globe, November 27, 1919, 4.

${ }^{38}$ Hayden, Faith Culture Leadership.
} 
The AME Church was not alone in protesting the widening of Charles Street. Thomas Kelly, whose mother owned and lived in the house at 11 Charles Street (which was not on the side where takings occurred), also objected to the widening at the Street Commissioners' hearing. He asked "Who, that lives in Charles Street, is behind the widening proposal? All those who have indorsed the widening proposal live either up on Beacon Hill or in such interior thoroughfares as Lyme and Brimmer Streets." 39

Likely Mr. Kelly's neighbors on Charles Street shared his point of view. Though their dissent was not officially recorded or articulated, many of the families who lived on the water side of Charles Street indirectly voiced their dissatisfaction with the city by refusing to vacate their homes or to alter them per city order. ${ }^{40}$ This led Mayor Peters to assert "that if the families persist in staying, they will be asked to move all their effects to kitchens and back rooms of the houses" while the facades were demolished. ${ }^{41}$

Otherwise, little else formally documents the grievances of those who opposed the project, either in newspaper accounts or in official city records. In these years, the concerns of individuals were not given much credence unless they had the backing of a recognized organization. Appearances before the Street Commissioners were an opportunity to argue against a widening plan, but such arguments by individual citizens rarely yielded results when a widening could be accomplished without great cost to the city (in the case of Charles Street, whose existing buildings were mostly three-stories tall, the damages amounted to $\$ 350,000$ ) and there was a perceived need to create a traffic artery. Since individual dissent at a public hearing was almost always a fruitless effort, most did not bother to voice it. Moreover, most Bostonians elsewhere in the city appeared to have supported the project.

\footnotetext{
39 "Fears for Ancient Charles-St Church," Boston Globe, November 27, 1919, 4.

40 "To Send Ultimatum to Charles-St Residents," Boston Globe, July 10, 1920, 6.

41 "Ouster Move to Drive out Tenants," Boston Globe, July 7, 1920, 5.
} 
Thus, the original Kenney \& Clarke stable (near Beacon Street) was demolished. Also lost were the memories and spaces of dozens of houses, including that of James Field at 148 Charles Street, ${ }^{42}$ of which Henry James had written:

Here, behind the effaced anonymous door, was the little ark of the modern deluge, here still the long-drawing room that looks over the water and towards the sunset, with a seat for every visiting shade, from far-away Thackeray down, and relics and tokens so thick on its walls as to make it positively, in all the town, the votive temple to memory. Ah, if it hadn't been for that small patch of common ground, with its kept echo of the very accent of the past, the revisiting spirit, at the bottom of the hill, could have but muffled his head, or but have stifled his heart, and turned away for ever. Let me even say that-always now at the bottom of the hill-it was in this practical guise he afterwards, at the best, found himself roaming. It is from about that point southward that the new splendours of Boston spread, and will clearly continue to spread. ${ }^{43}$

James' votive temple to memory was destroyed when the widening of Charles Street claimed the library [Figure 4-7] and other rooms of James Field. ${ }^{44}$ But in addition to such personal and privately owned spaces, the widening also claimed something from the public. In James' view, Charles Street as a public right-of-way was enlivened as a spatial nexus from which the splendors of fin-de-siècle Boston emerged. This public space embodied a kind of sacredness, evidenced in the way that the damaged estates of Charles Street often sought to rebuild with facades that were sympathetic to the original demolished fronts. It was also evidenced in the Beacon Hill Civic Association's repeated efforts beginning in 1922 to block the city from repaving the neighborhood's antiquated sidewalks with a material other than brick (though ironically the historicist BHCA did support widening efforts).

\footnotetext{
42 "Charles Street Widening Approved by Mayor," Boston Globe, February 14, 1920, 6; "City Goes Through form of Auctioning Houses," Boston Globe, July 23, 1920, 3; Jane Holtz Kay, Lost Boston (Amherst: University of Massachusetts Press, 2006), 135.

${ }^{43}$ Henry James, Collected Travel Writings Great Britain and America: English Hours, The American Scene, Other Travels (New York: Library of America: 2003), 556.

${ }^{44}$ Rachel Cohen, A Chance Meeting: Intertwined Lives of American Writers and Artists, 1854-1967 (New York: Random House, 2004), 113-114.
} 
William C. Codman had often asserted that “Back Bay is man's land, but Beacon Hill is God's land, and by God they will come back to His land." ${ }^{45}$ This assurance turned out to be doubly prophetic. While the residential neighborhood in the 1920 s did enjoy the kind of elite rebirth that Codman had desired, many thousands more came to (or through) Beacon Hill every day on Charles Street as automobilists. After just eight years, the Beacon Hill Associates sought to protect the neighborhood from the great volume of traffic that had been brought into their midst on the very road that they helped to create. Codman argued that Boston's best residential neighborhood now harbored the city's worst traffic. Many of his neighbors concurred, including one who complained in the Boston Transcript that Charles Street was now "an impassable roaring river of traffic. Beacon Hill residents would like to walk to the Esplanade. I do not dare to risk the crossing. The shock of dodging the 'engines of death' is too great."46 By 1928, Codman and the Beacon Hill Associates petitioned Mayor Nichols to divert heavy trucking away from Charles Street and towards the downtown area, an idea that confounded the original purpose of the road as a means to reduce downtown congestion.

By 1930, Beacon Hill residents had begun to fight the accommodation of automobiles rather than promote it. In that year, automobile travel on seven streets was restricted to one direction, an effective practice which was intended to discourage non-residents from using the neighborhood's side streets as alternate routes. Residential parking restrictions along curbs were argued for (but not yet implemented). Beacon Hill's largest parking facility, the Charles Street Garage, was bought by a stock company formed by twenty neighbors who then sold parking spaces to nearby residents to prevent outsiders from using them. ${ }^{47}$

\footnotetext{
${ }^{45}$ Li-Marcus, Beacon Hill, 45.

46 Ibid, 64.

${ }^{47}$ Ibid, 69 and footnote 39 on page 156.
} 
There were other ways to create ten feet of additional traffic space that did not destroy property, community and memory. As the City Engineer of New Bedford pointed out, "the removal of standing cars widens a roadway 18 feet without expense. Compare this with the cost of widening a street in a business district." ${ }^{\prime 48}$ Along the stretch of Charles Street from Revere Street to Beacon Street was enough linear feet to legally park a mere forty cars along each curb. If the city had implemented a strict ban on parking on just one side of the road, it would have effectively widened Charles Street enough to retain its buildings intact.

Automobile-driven appetites for space also began to affect places that had been deemed sacred and historically protected by popular public sentiment. The Common itself faced the prospect of assault as city officials puzzled over how to accommodate automobiles. Though great public concern compelled the builders of the Boylston Street subway line to carefully preserve the southern and eastern edges of the Common after the tunnels had been built (see Michael Holleran's Boston's Changeful Times for a full account), calls had been made to build a 3,000 car garage under the Common and to build an automobile parkway across it and the Public Garden. By 1920, automobile congestion prompted the Street Commissioners (against the strenuous objection of the Planning Board) to slice off long stretches of the Common to widen Tremont Street four-and-a-half feet and to widen Boylston Street ten-feet, with overwhelming support of Boston's voters. This followed upon an earlier widening of Boylston Street at the expense of the Public Garden, which occurred in 1913. At that time, Boylston Street between Arlington Street and Charles Street was widened from eighty to 120 feet. $^{49}$

\footnotetext{
48 “Gov Fuller Attacks Street Curb Parking," Boston Globe, October 5, 1925, 1.

${ }^{49}$ In the referendum, 23,414 voted for widening Tremont Street while 16,101 voted against it. As for Boylston Street, 23,300 were in favor of that widening, while 16,101 were against it. "Ford, Brickley and Watson Win; Common to be Sliced," Boston Globe, December 17, 1919, 1; "Would Finish up Western Artery," Boston Globe, October 31, 1919, 3; "Park Cars in Cave Under the Common," Boston Globe, January 21, 1923, 46; Michael Holleran, Boston's Changeful Times: Origins of Preservation and Planning in America (Baltimore: John Hopkins University Press, 1998), 115-122; Boston City Planning Board, Annual Report for 1915, 5-6; Boston City Planning
} 
Still, public sentiment ultimately protected the Common and the Public Garden from fundamental change. No automobile roads were ever built across them, and the city long resisted calls to sell off parts of these public lands in order to allow the retail district to expand. ${ }^{50}$ After the automobile age alterations had been completed, the fifty-acre Common lost approximately 17,500 square feet to accommodate the widenings of Tremont Street and Boylston Street, about 0.8 percent of its area. The Public Garden fared worse, losing about 3.3 percent of its area as approximately 34,500 square feet were given to Boylston Street. ${ }^{51}$

As with the regulations that were discussed (and sometimes implemented) in the 1910s and 1920s, street widening efforts were often informed by guess work. The vast number of cars that increasingly occupied city streets demanded a response from Boston's planners, who had little experience designing for automobiles since the problems they faced had only existed for a short time. Simultaneously, the rapidly-changing automobile context made it difficult for the planning board to authoritatively craft long-term solutions that could effectively respond to everevolving circumstances.

The City Planning Board's earliest decisions about which widening efforts to support and which to oppose appear to be guided partially by whim. For example, in the case of prospective widenings of Tremont and Boylston Streets in 1920, the board argued that bigger roads would simply attract additional cars that would compound downtown congestion. However, other widening campaigns, which very obviously would have similar consequences for traffic in the

Board, Sixth Annual Report of the City Planning Board for the Year Ending January 31, 1920 (Boston: City of Boston Printing Department, 1920), 41-42.

${ }^{50}$ Mona Domosh, "Shaping the Commercial City: Retail Districts in Nineteenth-Century New York and Boston," Annals of the Association of American Geographers 80, no. 2 (1990): 268-284; Holleran, Boston's Changeful Times, $115-122$.

51 "All Ready to Take Hack at Common," Boston Globe, January 10, 1920, 10. 
downtown area, were endorsed, such as the widening of Cambridge Street (enlarged to a width of 100 to 110 feet from an original width that ranged from forty-two to fifty feet).

The widening of Cambridge Street was an early concern for the board, with the desirability of this widening mentioned in 1914 and the first formal proposal put forth in December, 1920, shortly after the widening of Charles Street had gotten underway. Along with the Board of Street Commissioners, the City Planning Board "consider[ed] the widening of Cambridge Street one of the most necessary features in the development of the city." ${ }^{52}$ The board felt that the widened road, which would create a broad, straight boulevard connecting Bowdoin and Scollay Square to the Longfellow Bridge (and Cambridge beyond) and to the newly widened Charles Street (where one could then connect to Beacon Street and travel through the Back Bay to points west), “will possess many attractive possibilities as a convenient means of entrance to and from the down-town section of the city. Automobile traffic from many of the outlying suburbs would doubtless make use of the widened thoroughfare; heaving teaming and trucking will be only too anxious to utilize its advantages." 53

Private real estate promoters also encouraged the widening of Cambridge Street into a vehicular boulevard, and made grand claims about how the new road would lead to a building boom along the length of Cambridge Street from the bridge into Bowdoin Square [Figure 4-8]. Led by John Riley (a real estate man) and George Crocker (an attorney), the boosters asserted that estates along this path had stagnated in value, with their assessed values in 1920 generally being less than they were in 1900. The transformation of Cambridge Street into an easy-to-use boulevard would "rejuvenate the entire district, revive values of realty" and elevate the commercial prospects of Bowdoin Square so that they would be commensurate with "Scollay

\footnotetext{
${ }^{52}$ Boston City Planning Board, Seventh Annual Report of the City Planning Board for the Year Ending January 31, 1921 (Boston: City of Boston Printing Department, 1921), 20.

${ }^{53}$ Ibid, 23.
} 
Square (only three hundred yards away) ... where every foot of land is worth seven to ten times more than it is in Bowdoin Square." 54 City officials were similarly optimistic, and John Noyes (chairman of the Street Commission) declared that "it is the hope of the Mayor, the Board of Street Commissioners and all persons interested in city planning that the owners of real estate on the boulevard will appreciate what has been done and will not mutilate this fine roadway with cheap, ugly structures." 55

Leslie Jones, a Boston Herald photographer who documented many of Boston's infrastructural changes in the early twentieth century, captured the widening of Cambridge Street in a pair of photographs [Figure 4-9 and 4-10]. These images show the path of the original roadway, which had a slight curvature, as it extended from Bowdoin Square to the Longfellow Bridge. Before the widening, there was space for three lines of automobiles, which shared the right of way with a single set of discontinued streetcar tracks. But since curbside parking was allowed and building supplies and other obstacles were stored in the roadway, the space left over for active driving was reduced, unpredictable and frequently interrupted.

The new road was far wider than its predecessor. Once the regulatory and cultural changes of the 1920s had been resolved and the roadway between the curbs was completely given over to automobile use (discussed in Chapter 3), enough space had been created to allow six automobile lanes (the two lanes along the curb given to parking, the other four lanes given to active travel), effectively quadrupling the usual capacity for moving vehicles from one to four lanes.

Jones's images show that estates were taken and demolished on either side of the road. Closer to Bowdoin Square, takings were mostly conducted on the south side of Cambridge

\footnotetext{
54 Ad, "Bowdoin Square Building Revival," Boston Herald, November 28, 1920, 8; “Organization Will Boom Cambridge St," Boston Globe, December 7, 1925, 15.

55 “Mayor Signs Papers for Street Widening," Boston Globe, August 21, 1924, 1.
} 
Street. As the road approached the Longfellow Bridge, taking were concentrated on the north side of the road. In this way, the city was able to both straighten the boulevard while simultaneously reducing the number of damaged properties. Given the significant width of the widening (the girth of the road more than doubled), properties were also taken from side streets that did not front the old road but lay within the path of the new one. Unlike Charles Street, nearly all of the affected buildings were completely destroyed.

A comparison of the relevant plates from the 1909 and 1929 Sanborn atlases shows the state of Cambridge Street approximately ten years before and after John Riley and George Crocker predicted that a new boulevard would lead to a building boom. In general, the structures erected after the creation of the boulevard were far more modestly sized than they had been at the turn of the century. For example, the south side of Cambridge Street between Joy Street and Bowdoin Street had buildings with prevailing heights of four- and five-stories in 1909 [Figure 411]. After these buildings were taken and razed, they were replaced with commercial structures whose prevailing heights were only one-story and two-stories [Figure 4-12]. On those blocks closer to the Longfellow Bridge, the formerly dense fabric of three- and four-story buildings with store fronts was demolished and replaced primarily by automobile service stations (three dispensing gasoline, one for lubrication). The fueling stations each consisted of an open-air lot with a free-standing pump and a small free-standing kiosk at the rear where the attendant kept a limited stock of supplies; the lubricating station used similar spatial arrangement [Figure 4-13].

Cambridge Street before the transformation embodied a form characteristic of traditional urban commercial corridors. Located outside of the downtown retail core, which attracted customers from the entire metropolitan area, many of the commercial functions located on Cambridge Street served Bostonians who lived and worked nearby. Here were modest tailors, 
markets, laundries, bowling allies and other enterprises frequented by those who lived locally in the working-class West End or on the North Slope of Beacon Hill. Closer to Bowdoin Square, the commercial character of the street gave way to several small hotels.

Though their protests are not well documented, it is clear that many of those who lived and worked on Cambridge Street strongly opposed the widening. Proprietors of seventy-five stores that occupied space within buildings slated to be razed petitioned Mayor Curley for further consideration. Among these businesses was the MacArthur Bakery of 40 Cambridge Street, a beloved purveyor of baked beans and brown bread that was forced to close after seventy-five years. Others were the Hotel Bowdoin, the Hotel de Vincenzi, the Revere House Hotel and several lodging houses. At least 150 families who were evicted by the city also protested. ${ }^{56}$

After the widening, the low-density rebuilding of privately-owned lands failed to fulfill the boosters' expectations. The boosters had hoped to rebuild with grand structures possessing values comparable to Scollay Square, a lively commercial district located within the downtown area. The boosters' advertisement in the Boston Herald suggested that they envisioned a new street lined with expensive buildings taking traditional urban forms with shared walls and greater heights (i.e., adopting designs that traditionally took advantage of people passing by on foot). However, the new Cambridge Street emerged as a hybrid that was divided between its former role as the main commercial street of surrounding residential neighborhoods and as a heavily trafficked road where entrepreneurs established business that served the needs of automobilists, most of whom where commuters. Thus, the collection of service stations gave parts of the street a gap-toothed appearance, and the only privately-owned buildings of great size built after the

\footnotetext{
56 “To Raze Old-Time Bakery in Cambridge-St Widening," Boston Globe, December 6, 1924, 10; "150 Families Must Get Out," Boston Globe, August 22, 1924, 11; "Fronts of Many Historic Buildings Will Be Sliced off to Widen Court and Cambridge Streets," Boston Globe, September 28, 1924, 24.
} 
widening were two garages (the larger of them was the Bowdoin Square Garage, discussed in Chapter 3).

The expectation that a free-flowing Cambridge Street would become "a convenient and attractive means of entrance to and from the downtown sections of the city" ${ }^{97}$ was soon proven to be misguided. Within just three years, the planning board complained about congestion on both Cambridge Street and Charles Street, observing that

the widening . . . accomplished under the provisions . . of the Acts of 1923, has been followed by a largely increased volume of traffic passing from the heart of the city to points west and even indirectly to points on the north and south, until at the present time congestion at the intersection of Cambridge and Charles streets has reached such proportions as to occasion a serious loss of time on the part of vehicular traffic as well as constituting an actually dangerous situation for pedestrians, drivers and both horse-drawn and motor vehicles. ${ }^{58}$

This congestion, encouraged by the existence the newly widened roads, prompted the board to escalate their road design efforts in the area by proposing a large new rotary for the exchange between the Longfellow Bridge, Cambridge Street, Charles Street and Embankment Road [Figure 4-14]. The board also responded to this congestion by using it as justification to seek an additional widening of Charles Street at it extended north through the West End [Figure 4-15]. In discussing this new road as part of a coordinated thoroughfare plan for the Boston area, the board made one of its saddest predictions by suggesting that this kind of comprehensive roadmaking effort "would be to the benefit of the people in . . . the entire West End district," a neighborhood that was infamously bulldozed as part of the mid-century urban renewal movement. ${ }^{59}$

\footnotetext{
${ }^{57}$ Boston City Planning Board, Ninth Annual Report of the City Planning Board for the Year Ending January 31, 1923 (Boston: City of Boston Printing Department, 1923), 41.

${ }^{58}$ Boston City Planning Board, Thirteenth Annual Report of the City Planning Board for the Year Ending December 31, 1926 (Boston: City of Boston Printing Department, 1927), 27.

${ }^{59}$ Ibid, 26.
} 


\section{THE WESTERN ARTERY}

By 1917 (which closely followed the arrival of the twice-a-day commuter traffic jam), the board had become so concerned with downtown congestion that it advocated for a wholly new scale of destruction in its Plan for a Western Artery to Boston Central District. This plan discussed the reasons for congestion in the center of the city, citing heavy traffic of all types and the area's great concentration of business. Several prospective solutions were given nominal attention, including the creation of a network of underground passages and overhead sidewalks for pedestrians. But whether or not such measures of pedestrian accommodation were adopted, it was deemed that the removal of Boston's heavy foot traffic from key streets had "no bearing upon the need for a better arterial thoroughfare," 60 since the volume of private automobiles entering the center was overwhelming regardless of the existence of other modes of travel. Guided by this assessment, the planning board proposed the creation of a broad thoroughfare specifically to accommodate the daily rush of automobile traffic to the downtown area.

This thoroughfare, the so-called "Western Artery," was intended to run from Huntington Avenue to Phillips Square, and the original plan required an astonishing scope of demolition, since hundreds of existing buildings lay directly in the path of the new road [Figure 4-16]. The planners argued that the central district was restricted with no space for expansion and it "is congested because the internal thoroughfares are narrow and are not well connected with the surrounding approaches." Two sides of the central business district were flanked by water, while the others were cut off by Beacon Hill, the Common and the Boston \& Albany freight yards. Around the Common and Copley Square, business was seen to be rapidly developing, thus

\footnotetext{
${ }^{60}$ Boston City Planning Board, Fourth Annual Report, 2.
} 
increasing traffic congestion in those areas, which exacerbated the difficulty of travelling from the Back Bay to the downtown retail and wholesale areas. ${ }^{61}$

Contradicting their assessment that internal thoroughfares were too narrow, the authors of the report declared that many of the streets in Boston's central district served the "various requirements" of vehicular traffic "reasonably well."62 They felt that the suburban lands surrounding Boston were well equipped with many radiating and connecting thoroughfares, which afforded a generous amount of space for travel. The chief problem facing the city, it was thought, was a "conspicuous lack of adequate connections" between this network of comparatively generous thoroughfares in service to the suburbs and the main streets of the downtown area. ${ }^{63}$

The Western Artery was perceived to accomplish several goals. It would allow traffic from the Back Bay and the western suburbs a means to travel along the southern edge of the congested district before penetrating into it without having to pass through the intersection of Tremont Street and Boylston Street, which the board then considered to be worst in the city. It would also create an orderly connection between the Back Bay and Summer Street, a principal downtown right-of-way favored for its direct access to South Station, Atlantic Avenue and Dorchester Avenue, all of which were important for commuters and teamsters. The board asserted that this connection would allow some traffic to entirely bypass the downtown area, which it speculated would reduce vehicular congestion. The board also felt that the kind of physical connection provided by the Western Artery would also more easily allow the central

\footnotetext{
${ }^{61}$ Boston City Planning Board, Third Annual Report of the City Planning Board for the Year Ending January 31, 1917 (Boston: City of Boston Printing Department, 1917), 15-16

${ }^{62}$ This also contradicted the view the board expressed in their first report, published just two years prior, when they declared the downtown street network to be deplorably crooked and in dire need of systemic widenings that they felt should have been conducted "a generation ago."

${ }^{63}$ Boston City Planning Board, Third Annual Report, 16.
} 
business district to extend into the Back Bay and the South End, though the reasoning behind this assertion was not explained. Not yet aware that the ever expanding use of automobiles would be a fundamental component of the end of centralized urban development in America (Douglas Rae convincingly dates this terminus to the early 1920s), the planners wrote that other "centers and subcenters [of concentrated business] exist on all sides, some of considerable importance, but the primary center remains and certainly will continue." ${ }^{\prime 64}$

The planners desired for the Western Artery to be exceptionally wide (though a precise number was not given, they felt that a width that was "much more than 100 feet" was warranted). Since building to such a scale would "involve serious inconveniences to business" the board ultimately sought a right-of-way that was 100 feet in width, which would allow for two fifteenfoot sidewalks, two lines of vehicles standing at curbs, two lines of streetcars and two lines of motor vehicles. The planners advised building a subway beneath the road, to capitalize on the fact that the area would already be so disrupted by demolition and construction.

At its western and eastern ends, the wide and straight Western Artery was originally meant to be serviced by additional radiating streets of sixty to eighty feet in width, which the board felt would be sufficient to allow traffic to be dispersed amid secondary roads. Creating these roads would require the taking of approximately 500,000 square feet of land at an estimated cost of $\$ 19,343,625$ (the construction of the Western Artery and widened access roads was estimated to cost $\$ 221,000) .{ }^{65}$ The number of affected businesses and estates was vast. In the path of the artery itself or the widened radiating streets were scores of commercial buildings, numerous wholesaling operations, four hotels, several furniture stores, two movie houses, a bowling alley, the Scotch Presbyterian Church, an undertaker, the Boston News Boys Club, the

\footnotetext{
${ }^{64}$ Rae, City, 7-22; Boston City Planning Board, Third Annual Report, 17.

${ }^{65}$ Boston City Planning Board, Third Annual Report, 23.
} 
Young Women's Christian Association, two stables, a large gas storage tank, approximately 150 residential buildings, Hope Chapel, the Abraham Lincoln School, a boarding house, the Ames Building on Bedford Street (not to be confused with the fourteen-story tower of the same name by Shepley, Rutan \& Coolidge), the Jordon Building, the Shubert Theater (added to the National Register of Historic Places in 1980), and the Church Green Building (designated a Boston landmark in 1979), among other enterprises. ${ }^{66}$

Despite the recent example of extreme streetcar congestion that had been judged to be solvable only by removing public transit from the surface level and putting it into subway tunnels, Boston's planners embraced an unproven idea that automobile congestion could be significantly mitigated simply by establishing major pathways that passed through the most trafficked parts of the city at surface level. The city officials believed, incorrectly and without evidence, that the creation of a wide road which connected to extant "thoroughfares" of similar width would allow large numbers of commuters and other travelers speedy access to downtown quarters. The Western Artery plan did not address where automobiles would be stored once they arrived downtown, or how automobiles would circulate on downtown streets once they left the artery. It did not address how the very predicable congestion that would be created on these downtown streets would affect travel conditions on the artery itself. It did not discuss potential reform of Boston's frequently ignored parking and driving regulations, the absence of which significantly contributed to the congestion the Western Artery was meant to address. It did not discuss effective ways to allow traffic on cross streets to pass through the artery, other than to suggest that the curbs and buildings at the corners of these intersections be cut back in a manner reminiscent of the chamfered street corners in Barcelona's Eixample to allow for easier turns. ${ }^{67}$

\footnotetext{
${ }^{66}$ This tally is based on an analysis of the relevant plates from the 1909 and 1914 Sanborn atlases.

${ }^{67}$ Boston City Planning Board, Third Annual Report, 22.
} 
The planning board repeated and enthusiastically endorsed the roadway in its annual reports, and urged Mayor Peters to bold action, asserting that

the great trouble with municipal improvements everywhere is that they are in nature of minor rather than major operations; they do not go far enough. The problem confronting the City of Boston at the present time is one which calls for fundamental action, and this the City Planning Board feels it has accomplished in presenting for your consideration its plan for the so-called "Western Artery," based as it is upon a study of the rapid transit system, the main thoroughfares approaching the central district, the interior street system, the division of the central area into special kinds of uses demanding special kinds of vehicular traffic, and the relative assessed values of land and of land and buildings combined. ${ }^{68}$

Though the original plan to connect Huntington Avenue with Summer Street was never realized ${ }^{69}$ arguments from the original proposal were successfully used to support a revised plan to widen and extend Stuart Street (the width of the new road was seventy feet) from Huntington Avenue to the intersection of Washington and Eliot Streets, where it then continued as Kneeland Street. Largely as a cost-saving measure, this revised plan did not include the widening of radiating approach streets or chamfered intersections and, though destructive to the existing city fabric (approximately 550 feet was entirely new roadway), was less damaging than the original route.

When the Stuart Street project began in September, 1921, the board optimistically considered this work the first step in achieving the goals embodied by the Western Artery proposal, though the new road followed a different path and never reached Summer Street. ${ }^{70}$ Instead, through-traffic on Stuart Street continued along Kneeland Street (which was itself widened to eighty feet from a width that ranged from forty feet to sixty-five feet in 1925 to

\footnotetext{
${ }^{68}$ Boston City Planning Board, Sixth Annual Report, 42.

${ }^{69}$ The City Council deliberated for several years over the original plan, during which time an expensive new eightstory telecommunications structure planned by the New England Telephone and Telegraph Company sprouted amid the intended route. These and other cost concerns led the city to pursue the creation of a less expensive road.

${ }^{70}$ Boston City Planning Board, Eighth Annual Report of the City Planning Board for the Year Ending January 31, 1922 (Boston: City of Boston Printing Department, 1922), 35.
} 
accommodate this flow) and finally to Atlantic Avenue. This new route ran at the southern edge of the 1892 congested district, but, despite the board's earnest aspirations, did not successfully penetrate denser portions of downtown area. Notably, no subway was built under the widened road and no streetcar tracks were installed on the surface, though both of these transit components were part of the original plan.

The course of the new Stuart Street began at Huntington Avenue and moved east. For its first block, between Huntington and Dartmouth Streets, the road was a wholly new extension built amid existing structures, which required the demolition of the Hotel Oxford and several four-story apartment buildings and the displacement of the Copley Theater, which was moved to a nearby location. ${ }^{71}$ Between Dartmouth Street and Trinity Place, the existing Stuart Street was widened from sixty-five to seventy feet by taking land from an empty lot at the rear of the Copley Plaza Hotel. The old Stuart Street then terminated at Trinity Place before resuming again at Clarendon Street, requiring the creation of another new road segment and the demolition of existing buildings that lay in the way, in this case the former engineering buildings of the Massachusetts Institute of Technology. Between Clarendon and Berkeley Streets, the original Stuart Street was already seventy feet wide, so no alterations were made. Between Berkeley and Arlington Streets, much of the original road was already seventy feet wide, with the exception of three commercial structures (four- and five-stories tall) that extended into the roadway for part of the block, creating a bottleneck that narrowed the right of way to about thirty-five feet. These were demolished.

From Arlington Street to Tremont Street, the new Stuart Street passed through dense, existing fabric. The entirety of the block once bounded by Columbus Avenue, Tennyson Street, Church Street, and Greenville Place was razed, as was the block bounded by Tennyson Street,

\footnotetext{
71 "Begin Work on Stuart St," Boston Globe, May 11, 1921, 20.
} 
Pleasant Street, Shawmut Avenue and Church Street. The new road then cut through existing buildings that once stood along Pleasant, Carver, and Warrenton Streets before continuing along the path of Eliot Street (widened from forty-eight feet to seventy feet) between Tremont Street and Washington Street.

The city government presumed that the project enjoyed widespread support. But before the widening got underway, unexpectedly strong opposition arose at hearings held by the Street Commissioners. Prominent real estate interests objected, including a trustee of Park Square's Motor Mart who asserted that the new road "would involve a large expenditure for the results [expected, and that he] could see no improvement that the change would bring to Trinity Court or to the Motor Mart" itself. ${ }^{72}$ Representatives of the Copley Square Trust stated that its affiliation of abutters did not want the project and considered it "more of a damage than a benefit." Representatives of the Copley Plaza Hotel agreed and felt that the new road would disadvantage the hotel. So, too, did the Hotel Oxford, which was eventually demolished to make way for the road. James Rollins, representing owners of several residential structures, submitted a petition with 400 names of those who firmly opposed the project - these included those who would be evicted as their homes were destroyed as well as others who did not want alterations made to their neighborhood. City Councilor James Watson and some of his peers characterized the new road as an opportunity for speculators and politicians with ties to real estate holdings in the area to make money at the expense of taxpayers. ${ }^{73}$

\footnotetext{
72 "Wide Objection to Stuart-St Plan," Boston Globe, April 29, 1921, 19; "Wider Stuart Street Opposed," Boston Globe, July 28, 1921, 4.

73 "Stuart-St Project Faces Opposition," Boston Globe, January 13, 1920, 10.
} 
Many who retained properties along the route or in its vicinity were alarmed that they were expected to pay betterments ${ }^{74}$ to support the building of the road (when ground broke on the project, takings were estimated to cost $\$ 2,391,065$ and $\$ 2,369,938$ of this was to come from betterments). ${ }^{75}$ The owners of more than 200 parcels were enraged that the city planned to route a large volume of automobile traffic past their properties on a new artery road and then sought reimbursement for an unwanted change to the landscape. Large properties, such as the Copley Plaza Hotel and the John Hancock Insurance Company also objected (the insurance company's betterment was the largest at $\$ 243,000$ ). The Pastorellis of Carver Street, the Qualeys of Shawmut Street and other families owning smaller estates, "given over to private dwellings or lodging houses, put in a spirited debate, claiming that the betterments [assessed] were all out of proportion to ... the values of their properties." ${ }^{.76}$ At a hearing of the Street Commissioners, representatives of some of the larger parcels stated unreservedly "that the improvement would not benefit their properties" and were angered to learn that city intended to exact payment from them. Other objectors were the Trinity Church, the owners of a Turkish bath, and the YMCA. ${ }^{77}$

Most support for the road came from real estate developers and from those who coveted the tremendous tax contributions that the potential construction of new and large commercial buildings would contribute to the city's coffers. Few established businesses vocally advocated

\footnotetext{
${ }^{74}$ Betterment assessments were the primary method used by the city to raise money to pay for new roads. A state highway fund was created in 1925, first financed by motor car registration fees and in 1929 by a two-cent tax on gasoline. While Boston's streets served approximately thirty percent of the state's automobiles, from 1925 to 1937 it received only 2.5 percent of Massachusetts' total highway expenditures. Yanni Tsipis, "Central Corridor Highway Planning in Boston, 1900-1950: The Long Road to the Central Artery," Civil Engineering Practice (Fall/Winter 2003): 44.

${ }^{75}$ With the total cost of takings and construction initially estimated to be $\$ 2,741,068$ and the amount recovered through betterments estimated to be $\$ 2,369,938$, proponents calculated the net cost of the new road to be $\$ 371,131$, which they felt would easily be covered by the high taxable values of the new buildings it was anticipated would be built in the vicinity of the route. "Mayor Signs Stuart Street Act," Boston Globe, September 10, 1921, 2; "Mayor Uses Spade on Stuart Street," Boston Globe, November 18, 1921, 15.

76 "Oppose Betterment Levies as Too High," Boston Globe, February 28, 1924, 14; "Stuart-St Levy Starts Battle," Boston Globe, February 12, 1924, 3; "Woes of Stuart Street Dwellers," Boston Globe, February 28, 1924, 13.

77 "Begin Work on Stuart St," Boston Globe, May 11, 1921, 20.
} 
for the project. Among those that did was the Prime Furniture Company, which had the good fortune of finding itself blessed with a newly created corner location (at Washington and Stuart Streets) when the new road demolished its neighbor (prior to the widening, the furniture company's frontage was only on Washington Street) [Figure 4-17]. The Prime Furniture Company was remodeled to add windows and display galleys to its Stuart Street wall, and the president of the company expressed great satisfaction over the building's new prospects on a prominent intersection. ${ }^{78}$

As with the widenings of Cambridge and Charles Street, those who supported the Stuart Street project were motivated by several concerns. As the planning board articulated in its arguments for the Western Artery, one of these goals was to ease traffic congestion through the creation of a wider road that would connect the waterfront to the broader roads of the Back Bay. It was expected that this new road would siphon congestion away from the downtown area. The project was also meant to encourage real estate development along Stuart Street and in nearby Park Square, which were widely regarded as business areas into which the downtown might geographically extend. ${ }^{79}$

A supportive Boston Globe reported that the new street would efficiently modernize a section of the city whose fifty-year-old fabric it considered to be both dated and of insufficient scale. The newspaper took pride in the fact that the new Stuart Street "amputate[d] a good portion of what used to be the liveliest section of old 'Kerry Village,"' an Irish enclave of apartments, lodging houses and tenements. In the name of progress the site of "John Lewis' famous little smoke shop, where the sages and wits of the village used to gather nightly to ponder the affairs of this mad world ... [was] now only a hole in the ground." Also gone was the Hotel

\footnotetext{
78 "Remodeled Store of the Prime Furniture Co Opened," Boston Globe, April 17, 1923, 5.

79 "Mayor Uses Spade on Stuart Street," Boston Globe, November 18, 1921, 15.
} 
Oxford, "scene of many a gay revel a half century ago." Altogether, approximately 100 buildings were cleared. ${ }^{80}$

Mayor Peters felt that, along with the completion of the Arlington Street subway station, the widened Stuart Street would stimulate development and had "no doubt that [after] the expansion of the retail business into this district, Boston will have one of the finest business sections of any city in the country." 81 The Boston Herald editors wrote that the road "will undoubtedly stimulate ... real estate development." ${ }^{~} 22$ Those at the Boston Globe concurred that a widened Stuart Street would bring new commercial towers to the area, and indeed, it was able to report that "the steel worker's riveter is now singing its merry ditty upon ... costly structures that are springing up on or close to the brand new highway." The newspaper congratulated "the courageous pioneers [blazing] the trail on this new uptown commercial line [who] must eventually collect handsomely on their vision, when the full tide of travel begins to flow through this broad new channel." ${ }^{\prime 3}$ While the Boston Globe credited the new Stuart Street with creating the physical conditions needed to secure this and other building projects, the Park Square area and the Boylston Street commercial corridor in the Back Bay had already arisen as worthy targets for real estate speculators, and other large buildings had been erected in the area before the road had been proposed (for example, the Paine Furniture building of 1913 and the Hotel Touraine of 1898 , both ten-stories tall), a reminder that investment in this area of the city was already underway independent of the creation of the boulevard.

\footnotetext{
80 "Clearing Away 100 Buildings to Make Room for the New Stuart Street Nearly Complete," Boston Globe, August $18,1922,7$.

81 "Mayor Wants to Go on With Stuart St," Boston Globe, February 4, 1921, 5.

82 "Stuart Street," Boston Herald, October 13, 1922, 22.

83 "Clearing Away 100 Buildings to Make Room for the New Stuart Street Nearly Complete," Boston Globe, August $18,1922,7$.
} 
Several expensive new office towers were completed contemporaneously with the new road, several of them built for prominent insurance companies. These new buildings were grouped together in the vicinity of Copley Square and Park Square and included the Park Square Building of 1922, the eleven-story tower of the Prudential Insurance Company (it occupied the block bounded by St. James Avenue, Arlington, Berkeley and Providence Streets), as well as the original John Hancock Building (built in 1921) [Figure 4-18] diagonally opposite the Park Square Building. Other large additions were the triangular fourteen-story Statler Hotel, built in 1927 (it occupied the block bounded by Columbus Avenue, Providence and Arlington Streets), the thirteen-story YWCA Building of 1927 at the corner of Clarendon and Stuart Streets, and the eight-story Motor Mart of 1926 (whose trustees had objected to the new road).

After the widenings of Stuart and Kneeland Streets were completed, rebuilding along the boulevard was intermittently successful, if judged by the creation of large buildings generating ample taxes for the city. Along Kneeland Street from Albany Street to Washington Avenue, many of the takings had occurred on the south side of the road. This portion of the road was lined with several new towers, such as the fourteen-story Kneeland Building (15-19 Kneeland Street, built 1924), the eleven-story Traders Building (25-43 Kneeland Street, built 1922) and the fourteen-story Hudson Building (69-81 Kneeland Street, built 1928). While these taller buildings replaced an older fabric composed of two- to four-story row buildings, most of them were under construction before the widening of Kneeland Street was approved.

On Stuart Street, development along the newly created road took a different form. Here, too, were tall towers, most notably a new grouping of commercial buildings housing insurance companies. But also created along the road were a number of vacant lots and low one- and twostory buildings that replaced a denser fabric of four- and five-story buildings with first floor 
storefronts. This new fabric was similar to that created along Cambridge Street. Other new additions to the landscape were several enormous parking lots, often adjacent to the area's largest office towers and used by suburban commuters who worked inside of them [Figure 419].

\section{ANTICIPATING THE CENTRAL ARTERY}

A second major road project was proposed by the City Planning Board in 1923, the so-called Intermediate Thoroughfare (also known the Loop Highway), that would have required far greater destruction than even the Western Artery proposal of 1917. This surface-level boulevard was never realized and reflected the bold aspirations of the early planning board. It also reflected the board's increasing willingness to make drastic and experimental changes to the city center to combat a problem that was not yet practically understood. The planners and their allies believed that the Intermediate Thoroughfare would solve traffic congestion in the most affected parts of central Boston.

The board observed that the city center already had two existing "thoroughfares" - wider concentric surface roads that were the easiest for automobilists to navigate (though in other reports the board complained about traffic conditions on both of these routes). The first of these they labeled the "Inner Thoroughfare," which was a loop of Boylston, Tremont, Court and Cambridge Streets that wrapped around the Common, passed through one of the two main retailing streets of the downtown area and then proceeded west over the Longfellow Bridge to the city of Cambridge. Most of the streets of this inner loop had been recently modified by street 
widening campaigns (Cambridge Street had been widened in 1923, Boylston Street underwent widenings in 1913 and 1920, and Tremont Street was widened in 1920). ${ }^{84}$

The second extant boulevard was the "outer thoroughfare," which ran from Huntington Avenue along Stuart and Kneeland Streets to the waterfront ring road (formed by Atlantic Avenue, Commercial Street and Causeway Street) and then the Charles River Dam via Leverett Street. These two "thoroughfares" mostly followed routes that had been favored by teamsters for at least 30 years.

The Intermediate Thoroughfare was intended to create a third circumferential road that would run between the existing routes and provide cross connections between them (the creation of these cross connections entailed the widening of numerous additional streets). ${ }^{85}$ The proposed route ran as an arch from the intersection of Washington and Kneeland Streets through Church Green, Fort Hill Square, Mercantile Street, Cross Street, Haymarket Square, Merrimac Street, Wall Street and Leverett Street to Charles Street at the Charles River Dam. The new boulevard was meant to be 100 feet wide (two twelve-foot sidewalks and a seventy-six foot roadway) that could accommodate cars parked parallel along both curbs, as well as three lanes of traffic moving in both directions. Streetcars were not to be permitted to operate on its surface [Figure 4-20]. ${ }^{86}$

\footnotetext{
${ }^{84}$ Boston City Planning Board, Annual Report for 1915, 5-6; Boston City Planning Board, Sixth Annual Report, 4142; Boston City Planning Board, Thirteenth Annual Report, 27.

${ }^{85}$ In the original proposal, Tremont Street, from Arlington Square to Stuart Street, was to be widened to at least eighty feet. Albany Street between Broadway and Kneeland Street was to be approximately 120 feet wide, while the stretch of Albany between Kneeland and Beach was to be at least eighty feet wide. Kingston Street, from Beach Street to the Intermediate Thoroughfare, was to be no less than eighty feet wide. Broad Street, from Wharf Street to India Square, was to be "widened to an extent sufficient to afford a uniform width throughout the entire length of the street." Beverly Street was to be widened to eighty feet and also extended to the intersection of Cross and Endicott Streets. Staniford Street, from the new thoroughfare to Green Street, was to be approximately 120 feet. Green Street, from Bowdoin Square to Chambers Street, was to be widened to eighty feet and also extended to the intersection of Blossom and Cambridge Streets. Boston City Planning Board, Progress Report on Proposed Intermediate Thoroughfare (December, 1925), 10.

${ }^{86}$ For example, Tremont Street (from Arlington Square to Stuart Street) and Kneeland Street (from Washington to Atlantic Avenue) were to be widened to not less than 80 feet. Albany Street (from Broadway to Kneeland) and
} 
While the route of the intermediate thoroughfare was determined in part by perceived need, the great cost associated with takings was given significant attention in the planning board's report, which stated that "the exact location for the proposed thoroughfare was determined only after an intensive study of property values throughout the entire district, with the result that one third of the proposed takings were of land valued at $\$ 20$ a square foot or less and only thirteen of the parcels exceeded a value of $\$ 45$ a square foot. In a district where land values closely approximate an average of $\$ 100$ a square foot this feature of the study is in itself convincing." In order to recoup a greater share of the project's cost through betterments, the board deemed it essential that the boulevard cut through low-value property to the greatest possible extent [Figure 4-21]. ${ }^{87}$

The board felt that "through traffic should be led around, not through, the present most congested district; that, when possible, present streets should be widened but that existing blocks should be cut through freely when street lines do not offer satisfactory routes." The scale of this project would have required a massive program of takings. The combined cost of the road construction and property takings was estimated to be nearly thirty-three million dollars, a huge sum. The total proposed length of new boulevard was 13,000 feet. $^{88}$

As with most of the planning reports produced by the board, there was no discussion of the businesses, residences or civic activities that were hosted by the buildings and spaces that lay in the path of the Intermediate Thoroughfare. The proposed scheme was based upon a relatively simple metric whereby low property value determined the route. Owners of expensive holdings

Staniford Street (from the proposed intermediate thoroughfare to Green Street) were to be widened to 120 feet. Other street widenings included segments of Beverly Street, Broad Street, Green Street, Kingston Street and Stuart Street. Boston City Planning Board, Tenth Annual Report of the City Planning Board for the Year Ending January 31, 1924 (Boston: City of Boston Printing Department, 1924), 29-30; Boston City Planning Board, Progress Report on Proposed Intermediate Thoroughfare, 10-12.

${ }^{87}$ Boston City Planning Board, Tenth Annual Report, 28; Boston City Planning Board, Progress Report on Proposed Intermediate Thoroughfare, 7.

${ }^{88}$ Boston City Planning Board, Progress Report on Proposed Intermediate Thoroughfare, 7, 34. 
were protected de facto (the city depended upon the outsized taxes these buildings generated), since high value properties tended to be clustered together and thus insulated their neighbors against the kind of mass takings needed to create new roadways. (Simplistic financial calculations were also partly responsible for determining the path of the Stuart Street extension and other widenings.)

Many parties in the city were initially supportive of the new project. According to the board's self-assessment "practically every civic organization" endorsed early versions of the plan, such as Boston Central Labor Union, Boston Chamber of Commerce, Boston Fruit and Produce Exchange, Boston Motor Truck Club, Boston Real Estate Exchange and the Boston Society of Architects. ${ }^{89}$ So, too, did the Board of Street Commissioners. ${ }^{90}$

Though Mayor Curley had supported the plan (he was attracted by the large number of construction jobs that would have been created), Republican Mayor Nichols, who took office in 1926, opposed the plan in his first year of office. Mayor Nichols objected to the Intermediate Thoroughfare principally by criticizing the great cost of the new roadway. He was joined in this criticism by Henry Shattuck, a republican leader in the State House of Representatives and the chairman of the Ways and Means Committee, who regularly attacked the loop highway for its excessive price tag. Shattuck also questioned whether the new road would meaningfully reduce congestion. The combined opposition of the Mayor and the chair of a House committee that oversaw the government's budget postponed serious consideration of the project, though the

${ }^{89}$ Others who endorsed a 1925 version of the plan were the Advisory Committee on Public Improvements, Affiliated Technical Societies of Boston, Boston Society of Landscape Architects, Expressmen's League, Massachusetts Real Estate Exchange, Master Builders' Association, Retail Trade Board, Team Owners' Association, United Improvement Association, Women's Municipal League, as well as various financial, shipping and warehouse interests. Boston City Planning Board, Progress Report on Proposed Intermediate Thoroughfare, 27. 90 Amy Finstein, "Lofty Visions: The Architectural Intentions and Contrary Realities of Elevated Urban Highways in America, 1900-1959” (Ph.D. diss, University of Virginia, 2002), 257. 
planning board continued to advocate for revised versions of the plan and the merits of the road received regular coverage in Boston's newspapers throughout the 1920s. ${ }^{91}$

As Yanni Tsipis observed, the Intermediate Thoroughfare plan (whose funding was considered by the State Legislature in 1925 and 1926) failed in part because both the planning board and the special commission who advanced the loop highway pitched the new road as a means to rehabilitate the downtown area and to improve the commercial prospects of stakeholders in the central retail district. While this pitch greatly appealed to downtown business interests, little evidence was presented to explain how constituencies in outlying districts would benefit from the plan and "the General Court received . . reports with interest, but decidedly took no action to permit funds for the plans implementation." 92

Both Nichols and Shattuck favored an approach that would first alter parking and traffic regulations as a means to ease congestion, a very inexpensive and obvious strategy that Boston, surprisingly, did not seriously pursue before the planning board and other arms of the city government began their early attempts to significantly alter existing city fabric. The loop highway plan was first put forth a year before Boston began using its first traffic light in 1924, a full decade after Cleveland introduced the United States' first illuminated traffic signal in $1914 .^{93}$ In his concern for regulatory reform, Mayor Nichols formed the Street Traffic Advisory Board in 1926, which sought to accurately measure the scope of Boston's traffic woes and to devise rules for the various types of traffic in the city. Miller McClintock and his colleagues at the Albert Russel Erskine Bureau were appointed by Mayor Nichols and the City Council to direct this effort. Under McClintock’s supervision, the Street Traffic Advisory Board conducted

\footnotetext{
${ }^{91}$ Weinstein, "Perceptions of Traffic Congestion," 157-158.

92 Tsipis, "Central Highway Planning in Boston," 39.

93 McShane, Down the Asphalt Path, 200-202; "New Signals Speed up Traffic at Busy Corners," Boston Globe, December 8, 1924, 1 .
} 
a comprehensive traffic count and sought to connect this count to driving patterns, thereby giving the board relatively accurate insight to the routes of traffic flows into and through the city.

This study positioned the city center within larger "metropolitan" and "automotive" regions, the latter being defined as "the area between which and the city proper there is exchanged daily a substantial flow of motor traffic" [Figure 4-22]. ${ }^{94}$ The metropolitan region consisted of forty cities and towns, including Boston itself. At the time of the report, the metropolitan area had a total population of $1,808,845$ people (780,000 of whom lived in Boston) with a total of 307,127 automobile registrations (approximately 100,000 of these registrations were issued to Bostonians). On a typical work day, the Traffic Advisory Board estimated that more than 125,000 vehicles entered the city using one of forty-five main gateways [Figure 423]. These tabulations did not factor "the tremendous number of intra-district [vehicular] movements during a normal business day." 95

Automobiles traveling through the central city favored particular routes, which the Street Traffic Advisory Board represented with a map showing thick, black lines threateningly layered over the city's street network [Figure 4-24], with wider lines representing greater daily traffic flows. ${ }^{96}$ The Advisory Board also calculated average vehicle speeds throughout the downtown area [Figure 4-25], and found that, on many of the major inbound/outbound roads in the Back

\footnotetext{
${ }^{94}$ Miller McClintock, A Report on the Street Traffic Control Problem of the City of Boston Prepared under the Direction of the Mayor's Street Traffic Advisory Board (Boston: City of Boston Printing Department, 1928),40.

${ }^{95} \mathrm{Ibid}, 76$. Other reports on traffic for 1927 suggested higher numbers of vehicles passing into and out of the center on a given day. The Report on a Thoroughfare Plan for Boston cited 164,218 such vehicles (page 40) in the same ten-hour period, while the Boston Globe suggested the number might be 221,000. See "What Becomes of the 207,000 Cars Driven into Boston Every Day?” Boston Globe, September 18, 1927, 2.

${ }^{96}$ Nearly all of the maps appearing in McClintock's report where drawn with a threatening appearance. This would have suited McClintock in his role as a paid consultant to Boston. His disturbing maps emphatically portrayed traffic congestion as an acute problem, a design tactic that may have encouraged the city to continue to engage his expertise in crafting additional reports. Indeed, one of McClintock's findings was that the work of the Traffic Advisory Board be extended into the future. McClintock, Street Traffic Control Problem, 297.
} 
Bay and South End, travel speeds reached as high as twenty-five miles per hour. In the downtown area, many streets were limited to rates of less than five miles per hour.

On the basis of volume, Massachusetts Avenue was the only boulevard that provided significant traffic flow across the peninsula, and it experienced the greatest delays at the intersections of Albany Street and Beacon Street. Commonwealth Avenue and Beacon Street were the most heavily used inbound roads. Beacon Street traffic was seriously delayed at Governor Square, Massachusetts Avenue and Charles Street before reaching the central area of the city. Commonwealth Avenue traffic was complicated by its abrupt end at Arlington Street and the Public Garden, though the Bay Back's numerous gridded cross streets allowed traffic to navigate over to the inbound stream on Boylston Street, where it then reached a near impasse at Tremont Street. Other dominant roads were Dorchester Avenue, Albany Avenue and Cambridge Street.

The intersection of Tremont and Boylston Streets received the greatest concentration of vehicular traffic in the retail district. In the ten hours between 8:00am and 6:00pm, 22,726 vehicles were recorded passing through these roads, an average exceeding 2,000 per hour. Heavy vehicular traffic here and elsewhere in the retail district was complicated by competition with huge numbers of pedestrians. On Washington Street, for example, 164,358 pedestrian movements were recorded between 8:00am and 6:00pm. During this period, 26,630 people were forced from the sidewalk into the road because the spaces reserved for pedestrians were too overcrowded for normal use [Figures 4-26, 4-27]. This spillage then interrupted the flow of vehicular traffic [Figure 4-28].

The Advisory Board proposed a series of small modifications to the city's existing regulations, such as clearly mandating that public employees must obey traffic rules, forbidding 
the display of signs imitating those erected by the city, and defining the ways in which pedestrians must use crosswalks. The board made recommendations against practices that created obstructions in roadways, such as the storage of building supplies needed to repairs streets. It sought to create more safety zones for pedestrians, particularly at congested intersections and in the midst of the city's numerous squares. Citing overcrowding, the board proposed to restrict the amount of space given to vehicles on Washington Street in order to provide pedestrians a greater share of the right of way. The board recommended a more comprehensive use of traffic lights, and expanded use of standardized signs and automation where possible. It suggested a reorganization of the police force and the impounding of cars that flagrantly ignored parking restrictions. It sought to expand the number of one-way streets in the downtown area. ${ }^{97}$

Informed by the methodical traffic counts of the Traffic Advisory Board and a belief in the great utility of the Loop Highway, the Planning Board expanded its aspirational roadbuilding agenda to devise the Report on a Thoroughfare Plan for Boston published in 1930 under the consultation of Robert Whitten (president of the American City Planning Institute). This plan sought to create a comprehensive express road network covering the entire metropolitan area, which would then, it was hoped, provide seamless connections to major highways leading elsewhere in New England. This highway network was meant to meet present traffic needs while at the same time building expansively and aggressively enough to provide for the next twenty-

\footnotetext{
${ }^{97}$ While the Advisory Board felt that anti-jaywalking rules were desirable under normal conditions, it also felt that Boston had special reasons for continuing to allow pedestrians the right to cross mid-block (provided they granted the right-of-way to moving vehicles). Because many sidewalks, especially in the retail area, were so overcrowded and inadequately narrow, the Advisory Board reasoned that if all pedestrians were compelled to cross only at marked intersections, there simply would not be sufficient space to allow passage. The Advisory Board further reasoned that the narrowness of the streets themselves made this less risky than in other cities, since the pedestrians would only have to dodge two lines of moving cars. McClintock, Street Traffic Control Problem, 1-4, 8-10, 212219.
} 
five years of anticipated automobile growth [Figure 4-29]. The most important component of this plan was a revised version of the loop highway, now termed the Central Artery. ${ }^{98}$

In the report's self-assessment, its meticulous study of the metropolitan area's traffic landscape, based on data from the Mayor's street traffic survey as well as on the board's own research, "included the determination of the origin and destination, volume and distribution of traffic and a forecast of traffic growth. It furnishes what is probably the most complete factual basis for the design of highway improvements that has ever been secured for any great city."99 The board used its exclusive claim to a scientific understanding of the city's automobile problem to put forth a convincing plan whose presumed effectiveness was difficult to contest.

The route of Central Artery proposed in the 1930 Thoroughfare Plan was little changed from the original version proposed in 1923. However, the board now advocated for an entirely new kind of roadway, based on the design of New York's West Side Highway. The Central Artery of 1930 was to be a one-and-a-half-mile long two-level roadway running from Nashua Street near North Station to Kneeland Street and then south to Albany Street and onward to the proposed Blue Hills Radial [Figure 4-30]. The right-of-way was to be a minimum width of 100 feet. Local traffic was intended to use a lower road at the surface level, while through traffic was to use a limited-access upper level fifty-four feet in width. The raised deck was meant to carry

\footnotetext{
${ }^{98}$ Ten major projects were proposed in the report: the East Boston Tunnel (twin two-lane tunnels from East Boston to the proposed Central Artery); the Central Artery (a two-level express road running through the downtown area); the Blue Hills Radial (an express road connecting the Central Artery to Blue Hill Avenue); the North Shore Radial (an express road from Revere to the East Boston Tunnel); the Roxbury Crosstown (an express road from Old Colony Parkway to Bay State Road); the Charles River Parkway (an express parkway from the Longfellow Bridge to the Cottage Farm Bridge); the development of North Beacon Street in Brighton (to create an express road from Union Square to the Charles River); the Canterbury and Clarendon Hills Parkways (to provide connection from the proposed Blue Hills Radial to the proposed Neponset River Parkway with a branch connection to the West Roxbury Parkway; the Neponset River Parkway (to run from Readville to Quincy Shore Drive with a branch to the Southern Artery; the B\&A Highway (an elevated road that would run over the tracks from the Cottage Farm Bridge to Arlington Square). Additionally, the plan called for fifty-six smaller projects, including many street widenings in the central district. Robert Whitten and the Boston City Planning Board, Report on a Thoroughfare Plan for Boston (Boston: 1930), 8-9.

${ }^{99}$ Ibid, 4.
} 
six lanes of traffic (three in each direction), with a total capacity from four to six times that of an ordinary city street at 60,000 vehicles each day. ${ }^{100}$

The use of this viaduct was meant to eliminate congestion caused by streets crossing at grade. Access ramps were to be installed at Kneeland Street and Broadway, at Congress and Federal Streets, at Fort Hill Square, and at Market and Commercial Streets, though the design of these ramps differed from the curving banks typically used in later freeway construction and the utility of these short, direct runways was questionable [Figures 4-31, 4-32]. Also complicating this version of the elevated road was an obstacle presented by the Boston Elevated Railway, whose raised infrastructure blocked the route the vicinity of Beach Street, forcing the raised portion of the artery to briefly join the surface roads before rising again by ramp, thus breaking the continuity of the upper level. ${ }^{101}$

As with the widenings of Cambridge Street and Stuart Street, the proponents of the central artery presented the new road as a mechanism to stimulate new building along the path of the highway. The idealized illustrations of the elevated road from the Thoroughfare Plan show the new central artery closely flanked by uninterrupted rows of towers at least eleven stories in height, with larger stepped-back edifices looming in the distance. These illustrations ignored Cambridge Street's recent example, where building densities along the newly widened road significantly declined. It also ignored the example of Stuart Street's redevelopment, where large towers were erected (many of them built before the road was created) but were often separated from one another by expansive parking lots. (Depicting the Central Artery amid a collection of open lots and lesser buildings would not have been convincing rhetoric.)

\footnotetext{
${ }^{100}$ Ibid, 12, 80.

${ }^{101}$ Ibid, 81-82.
} 
Once built, the board expressed confidence that a key transportation component would be implemented as the metropolitan area advanced towards the goal of an integrated highway system. They argued that the "present thoroughfare layout is defective in its radial access to central Boston from the northeast and from the south ... In thirty minutes one can travel about two times as far to the west via Beacon Street or to the northwest via the Northern Artery, as toward Chelsea, East Boston and the North Shore; and about one and three-fourths times as far as towards Roxbury, Dorchester and the south." To remedy this defect, "a central feature of the Thoroughfare Plan is a great north-south express road extending from the northerly city line bordering Revere to the southerly city line at Readville, a distance of 13.7 miles." This new thoroughfare would connect to the existing state highway system and to a newly proposed highway to Providence. It was expected that this new north-south express road would "greatly facilitate access to Central Boston.” Travel speeds on this new highway were projected to be thirty miles an hour, which was two-and-a-half times the average speed of twelve miles per hour for those traveling the same distance along existing roads. ${ }^{102}$

The planners highlighted the enormous economic savings they estimated would be afforded to those using motor vehicles and expected material reductions in costs for those who transported goods. The board estimated that motorists in the metropolitan area spent approximately $\$ 180,000,000$ each year on the operation, maintenance and replacement of automobiles and trucks, and, concerned that these motorists see a return for their investment, desired to systemically adjust the road network. Seeking to highlight potential financial advantages against potential criticism of the plans huge price tag, the board asserted that "[e]ven

102 Ibid, 9. 
a 10 per cent average increase in efficiency due to the improvements proposed by the Thoroughfare Plan will be worth $\$ 18,000,000$ annually to motor vehicle users." ${ }^{\prime 103}$

Aware that the Central Artery and other major changes proposed to the downtown area represented the most disruptive, expensive and contentious elements of the Thoroughfare Plan, the planners sought to forestall criticism by asserting in their introduction that an "attempt has been made to so locate and plan the new facilities that they will harmonize with the existing appropriate development. In the proposal for Boston Proper particular pains have been taken to avoid injury to the historic interest or charm of the crooked streets of Old Boston."104

This concern appears to have been, at best, superficial. In no place did the report refer to its devotion to older fabric, to an assessment of community spaces, or to visual charm, and the board never identified a crooked street that it favored. In fact, the only real discussion of fabric retention was in connection to places like the Washington Street retail corridor, which the planners felt should not be widened on account of the great financial cost that would be incurred by taking the city's largest and most expensive estates. The report does not describe "the particular pains" that were purportedly taken to avoid injuring the city, though whatever assessment might have occurred as part of that endeavor certainly was less systematic and timeconsuming than the effort to tally motor cars entering the city, whose driving patterns were carefully examined and plotted on a dozen carefully drawn maps.

Recognizing that the public had a distaste for elevated transportation structures, ${ }^{105}$ the board sought to mollify potential criticism of the new road:

As a matter of first impression the erection of additional elevated structures in Downtown Boston is very objectionable. The comparison of course is with the present noisy and ugly elevated railway structures. It must be remembered,

\footnotetext{
${ }^{103}$ Ibid, 14.

${ }^{104}$ Ibid, 1.

${ }^{105}$ Finstein, "Lofty Visions," 253-254.
} 
however, that the proposed upper level roadway will occupy the central portion only of a broad avenue; that it will be but two thirds the height of the elevated structure in Atlantic Avenue; that great care will be taken in its design to make it attractive and to reduce noise and vibration; that it will be used by motor vehicles and not by railroad trains. ${ }^{106}$

After its publication in 1930, most of the recorded criticism of the plan targeted the huge cost associated with each of the major projects. ${ }^{107}$ For the Central Artery, that cost remained approximately $\$ 30,000,000$ according to the planning board's estimates, though some suggested a more accurate figure was $\$ 60,000,000$. By comparison, the city's entire annual budget was approximately $\$ 33,658,000$ in 1929 and $\$ 36,189,000$ in $1930 .{ }^{108}$

Mayor Curley, after his election in 1930, could never muster enough political influence to see ground broken on the project, despite the support it had from numerous trade and professional organizations and major businesses (these included the Boston Society of Architects, the United Improvement Association, the Retail Trade Board, the Boston Chamber of Commerce, the Dorchester Savings Bank, the Massachusetts Real Estate Exchange, the Boston Central Labor Union, the Expressmen's League and many automobile interests), and despite the fact that the construction of the Central Artery would have created many needed jobs. ${ }^{109}$

A hearing before of the Legislative Committee on Municipal Finance typified the main objections to the Central Artery. While most of those who appeared at the hearing endorsed the bill, several legislators put forth winning counter arguments. These legislators, including

\footnotetext{
${ }^{106}$ Whitten, Report on a Thoroughfare Plan, 82.

${ }^{107}$ This is not to suggest that objections were exclusively about the project's cost. In 1929, a worried citizen warned their fellow Bostonians not to ascribe "all wisdom and foresight to city planners and street commissioners," because each year, "structures with priceless associations are destroyed by the hands of progress; streets endeared by their very narrow crookedness are made wide and straight for a generation in a hurry." Even so, without an active and organized preservation movement, such sentiments might have been popular, but they were often unable to gain traction. Kennedy, Planning the City upon a Hill, 137.

${ }^{108}$ Reports of Proceedings of the City Council of Boston for the Year Commencing January 6, 1930 and Ending December 29, 1930 (Boston: City of Boston Printing Department, 1930), 106.

109 "Architects Approve Thoroughfare Plan," Boston Globe, December 3, 1930, 6; "Favor Two-Level Downtown Artery," Boston Globe, December 4, 1930, 10; "Urges Action on Central Artery," Boston Globe, November 16, 1930, 23.
} 
Representative Bernard Finkelstein of Dorchester and former Representative Martin Lomasney, suggested that the City Planning Board and Mayor Curley were willfully underestimating the already large cost of the project in order to secure passage of needed bills. They complained of corruption, asserting that Mayor Curley desired to distribute construction work as political patronage. They accused Curley's bill of being supported by "several slick little jokers" who desired to profit by selling land they owned in the vicinity of Haymarket Square and near the path of the highway. ${ }^{110}$

Complaints of corruption against Curley (governor of Massachusetts from 1934 to 1936 in addition to his numerous terms as mayor of Boston) were long-standing, and the Republicancontrolled City Council were highly critical of infrastructural projects implemented under his administration, denouncing him as a "Santa Claus" who bought votes with publically financed jobs. His well-documented Tammany-Hall style approach to governance and his reputation for malfeasance exacerbated the already fractious relationship between the Massachusetts legislature and the municipal government, which curtailed Curley's ability to secure approval for expensive public work projects. Additionally, Mayor Nichols had already committed $\$ 16,000,000$ to the construction of the widely supported East Boston Tunnel (now Sumner Tunnel) in 1929, a vast sum that stymied that city's ability to undertake another giant infrastructural project. ${ }^{111}$

Curley's reputation for corruption was also cited as a reason why Boston did not receive as much Federal largesse as might have been expected under the Public Works Administration (PWA), even though he was an early supporter of Franklin Delano Roosevelt. ${ }^{112}$ Harold Ickes, director of the PWA, was disdainful of both Massachusetts and Boston, portraying them as

\footnotetext{
110 “Central Artery Plan Indorsed,” Boston Globe, March 5, 1931, 7.

111 Tsipis, "Central Highway Planning in Boston," 42.

112 Kennedy, Planning the City upon a Hill, 143-147.
} 
fiefdoms of "Byzantine intrigue," 113 and "not until 1935 would the city see a penny from the PWA, by which time the city's finances were in such strained disarray that it proved impossible to raise matching municipal funds necessary undertake a project on the scale of the proposed Central Artery." $" 114$ In that year, the city received a mere $\$ 679,504 .{ }^{115}$

Within this context of cost and corruption, the fundamental changes that would have been required to implement the proposed Central Artery were a political impossibility, especially in the economic context of the Great Depression. Boston instead pursued other federally-funded building projects that were less contentious. By 1943, these had included a $\$ 5,000,000$ court house for Suffolk County in 1936, the \$7,000,000 Huntington Avenue subway completed in 1941, hundreds of miles of street repairs and upgraded sewer lines. ${ }^{116}$

Though the Central Artery was rejected in its first iteration as the Intermediate Thoroughfare and then later rejected following the publication of the Thoroughfare Plan, the route originally suggested in 1923 proved to be remarkably resilient. When the Central Artery of the 1950s was later installed as a monstrous 400-foot-wide elevated expressway, the path it followed coincided closely with the original. First crafted at a time when mass automobile use was still novel and poorly understood (and two years before Boston had its first traffic light), this highway demonstrated that the City Planning Board, though it did not have direct power and relied upon other branches of government to implement its agenda, had great influence because it was the only entity that could meaningfully present such ideas to the city. When the board had conviction and remained devoted to a plan, its long-term stamina was very powerful in the context of a city government that was structurally unable to produce other options.

\footnotetext{
${ }_{113}$ Charles H. Trout, Boston, the Great Depression, and the New Deal (New York: Oxford University Press, 1977), 151.

114 Tsipis, "Central Highway Planning in Boston," 43.

115 Trout, Boston and the New Deal, 149.

116 Trout, Boston and the New Deal, 152, 170.
} 


\section{EPILOGUE}

Throughout the first decades of automobile accommodation, proponents of the new form of transportation consistently operated under the illusion that a traffic-free urban landscape was possible. After lengthy experiments with new motor laws, the cooption of the street from pedestrians and other users, the creation of new vehicular boulevards, and attempts to standardize and regulate movement and parking in the downtown area, it became clear that this goal was unobtainable in the built landscape of traditional center cities.

The architecture of the new sales buildings that emerged on Commonwealth Avenue reflected the divide between illusion and reality. The glamorous and lofty salons located at the front of these structures displayed automobiles in idealized settings that promised freedom, excitement and luxury (themes that were replicated in the marketing materials readily available for customers to review). Behind the sales salons and occupying far more space within these buildings were vast utilitarian expanses given to repair, maintenance and storage. In the city, most car owners only encountered glamour when viewing an unmoving car that they might purchase. After the purchase, nearly all spaces created for automobiles in the traditional center city, whether public or private, were mundane.

In the first decade of use, when popular media still characterized motor cars as elite curiosities, driving was ultimately a monotonous practice even on long-distance journeys. In The Automobile Girls at Newport (1910), the novelist Laura Dent Crane sought to portray the summertime adventures of three brave girls and their chaperone as they travelled from the town of Kingsbridge (a fictive village a day's drive from New York City) to the gilded splendor of Newport, Rhode Island. This book and the five others in the Automobile Girls series pledged to 
tell "the adventure[s] of the natural and charming girls in their automobile."1 Though the title of the series and the promised content was precisely about the wonder of automobiles, and though it was written at a time when the prospect of driving was still a fantasy for most people, the actual text of the book was unable to describe ordinary driving in exciting terms. The novel instead focused on the destinations that their automobile allowed the girls to visit. Thus, it described a stay at the Waldorf in New York, a ball attended at Yale, a visit to a former governor's yacht in New London and eventually a month spent in Newport. The only excitement the automobile afforded the girls was the experience of becoming stuck in a ditch (thus compelling the theft of a farmer's horse to get help) and pursuit by thieves who also has a car (hardly a typical motoring event). Once the girls arrived in Newport, the girls participated in an automobile parade (again, not typical) and took a single drive along Ocean Boulevard. But otherwise their car is never mentioned again. Instead, the girls' month by the sea is a story of tennis, sailing, walks along the cliff, parties and fairs. Unsurprisingly, Crane did not bother describing the trip home.

The experience of driving a car in the traditional center city more emphatically reflected the divide between the promise of excitement and daily utility. Much of the visceral pleasure of automobile use was felt in the experience of acceleration and speed (and also danger, though this last attribute was one that most had come to agree had no place in the urban use of motor cars). Conditions that allowed easy acceleration and high speed could only be found in the countryside. In the city, even outside of the highly congested center, the experience of car use was defined by routine drudgery and frustration, especially by commuters. From their first years of use, automobiles in the center city always moved at slow speeds with frequent stops. Due to the presence of many other users in roadways (whether pedestrians or rival motor cars), they were often stuck in thick congestion. The composition of this congestion changed over the decades,

\footnotetext{
${ }^{1}$ Laura Dent Crane, The Automobile Girls at Newport (Philadelphia: Henry Altemus Company), 254.
} 
but it was always present. Early car users may have experienced greater utility as they sought to move throughout the city, but this utility was not marked by promised exhilaration.

As early plans for the Central Artery indicate, by 1930 Boston officials and other prominent figures began to embrace a vision of city order which sacrificed traditional urban form to make way for massive infrastructural projects that, they hoped, would allow automobiles to reach speeds that previously only existed as an illusion. When a later version of the Central Artery was eventually built in the 1950s as a product of Governor Bradford's 1948 Master Highway Plan, the limited-access elevated freeway had expanded in scale. While the main portion of the freeway was six lanes across, the project also include numerous access ramps which essentially doubled the width of the right-of-way to an astonishing 400 feet. The construction of the road ravaged the neighborhoods of the North End and Chinatown and obliterated dozens of acres of extant fabric as it demonstrated the incompatibility of the traditional city and automobiles [Figures E-1, E-2].

The roadbed of the new Central Artery was raised fifty feet above the surface of the city. At select times of the day, the experience of speeding on this lofty expressway as it wound cinematically through the heart of the old city aligned with early promises of urban driving pleasure. However, these times were indeed select - when the new artery opened in 1959, it was already nearly obsolete. During commuting hours, use of the road was marked by traffic jams even in its first year of use.

Other post-war projects typified the expanded sacrifice of the traditional city. In the 1920s, the creation of garages in the downtown area was rare. The only large garage in the retail district was erected by Jordan Marsh, which built the structure to protect its existing trade interests. Otherwise, garage entrepreneurs avoided the downtown area as too risky a place in 
which to invest. Real estate prices were so high that many feared an inadequate financial return. As urban decentralization expanded with increased automobile use, central real estate prices dropped, eventually making garage construction less costly. In time, the downtown area was remade to feature numerous large garages as automotive spaces more aggressively consumed traditional fabric. In this context, the most significant structure erected as part of Ed Logue's 1964 plan to replace Scollay Square with the Government Center was not the monumental City Hall or Boston's famously vast City Hall Plaza, but the Government Center Garage [Figure E3], the largest building in the new compound.

The vast plazas of Government Center under the master plan of I. M. Pei and the characteristically pedestrian-only landscapes of Victor Gruen's Charles River Park embraced the visual absence of automobiles that made their existence possible, and for which so much infrastructural investment had been made. At Government Center Garage, Kallman, McKinnell \& Knowles carried out an exercise in brutalist architecture freer and more aggressive than their better-known City Hall, in some ways the most deliberately monumental gesture tied to the Central Artery, over which it dramatically loomed. By the time the garage was finished in 1970, this willingness to embrace the automobile's presence at the city center had already eroded in the face of preservation and historic fabric-oriented attitudes ushered into the popular discourse by writers like Jane Jacobs. The 2013 decision of the Boston Redevelopment Authority to replace the Government Center Garage is typical of the present state of this turn not only in Boston but around the globe: the recreation of the street character and building massing of major downtowns of around 1900, an almost subconscious urge to reset the urban fabric back to the state it took just before the arrival of the automobile. 


\section{APPENDIX. Traffic regulations as they appeared in the 1892 Revised Ordinances of the City of Boston. ${ }^{2}$}

Section 1. No person having charge of any vehicle in a street shall not stop his vehicle abreast of another vehicle, not so as to obstruct a street or any sidewalk or crossing of a street, nor shall any person snap a whip while is horse or beast is stopping in a street.

Sect. 2. No owner or driver of an omnibus shall drive it, or permit it to be driven, in a street other than that designated therefor by the board of aldermen.

Sect. 3. No person having charge of an omnibus shall stop it in a street, unless to take or leave a passenger, and then only for such a time as it is sufficient to enable the passenger to take his seat or to leave the omnibus.

Sect. 4. No person having charge of a truck, cart, wagon, sled, or a dray with an animal attached thereto to draw the same, shall in any street drive said animal attached thereto at other than a moderate foot pace, nor shall any such person, when riding, cease holding the reins in his hands to guide and restrain such animal, nor, when not riding, cease from walking by the head of the shaft or wheel animal, either holding, or keeping within reach of, the bridle or halter thereof.

Sect. 5. No person shall in any street use any truck or dray the length whereof, from the end of the shaft to the extreme end of the side, shall be greater than twenty-four feet and six inches.

Sect. 6. No person shall carry, or cause to be carried, on any vehicle in any street, a load the weight whereof exceeds three tons, unless the load consists of an article that cannot be divided.

Sect. 7. No person having the charge of a vehicle in any street shall neglect or refuse to stop the same, or to place the same when stopped, as directed by a police officer.

Sect 8. No person having the charge of any vehicle shall allow the same, without an animal harnessed thereto, to remain in a street except as provided in section fourteen.

Sect. 9. No person having in any street the charge of a vehicle, with an animal attached thereto to draw the same, shall allow such animal at a crossing of a street to come within ten feet of any vehicle in front of him.

Sect. 10. No person shall in any street at one time drive, guide, or have the care of, two animals harnessed respectively to different animals.

Sect. 11. No person having the charge of a vehicle with an animal attached thereto to draw the same, shall drive, or allow such animal to round a corner of a street at a gait faster than a walk.

\footnotetext{
${ }^{2}$ The Revised Ordinances of 1892 of the City of Boston, and the Revised Regulations of 1892, of the Board of Aldermen of the City of Boston. Boston: Rockwell and Churchill, City Printers. 1895.
} 
Sect. 12. No person shall in any street ride upon the steps of an omnibus or other vehicle, without the permission of person in charge thereof.

Sect. 13. No person having the charge of a vehicle with an animal attached thereto to draw the same, shall drive, or allow such an animal to go over a drawbridge, at a gait faster than a walk.

Sect. 14. No person having the charge of a vehicle, with or without an animal harnessed thereto, shall suffer the same to remain in a street for more than five minutes, without some proper person to take care of the same, unless hitched to a post or to a sufficient weight, nor for more than twenty minutes in any case; but no person shall be deemed to have violated this provision who shall satisfy the court that he was a physician visiting the sick, or a market or provision man standing for the purpose of selling provisions, until eleven o'clock in the forenoon at places in the city designated therefor.

Sect. 15. No person shall drive an animal drawing a vehicle in a street during any time that snow or ice is upon or covers the streets, unless there are three or more bells attached to the shaft or pole of the vehicle, or to the animal, or to some part of the harness thereof.

Sect. 16. No person having charge of a vehicle shall so place the same in a street as to prevent the passing of other vehicles, unless it is for a reasonable time, not exceeding six minutes, for the unloading or unloading of coal, wood or lumber, brick or stone, or heavy articles the weight of which in any one parcel or package is not less than six hundred pounds.

Sect. 17. No person with, or having the care of any cart, barrow, hand-cart, wagon, or other vehicle shall, except in accordance with an order of the board of aldermen, stop and stand, for the purpose of hawking, peddling, or selling any goods, wares, or merchandise, fruit or other articles, between the hours of eight o'clock A.M. and half-past six o'clock P.M., in, or occupy any part of, any of the following streets, ways, and squares, namely: Haymarket square, Sudbury street, Court street from Sudbury street to Scollay square, Scollay square, Tremont street from Scollay square to Eliot street, Eliot street from Tremont street to Washington street, Washington street from Eliot street to Franklin street, Franklin street from Washington street to Devonshire street, Devonshire street from Franklin street to Milk street, Milk street from Devonshire street to Pearl street, Post Office square, Water street from Congress street to Devonshire street, Devonshire street from Water street to Washington street, State street between Merchants row and Devonshire street, and Washington street from Adams square to Haymarket square, or any of the streets, ways, or squares included within the territory bounded as above described.

Sect. 18. No person having charge of a vehicle shall otherwise, unless directed by a police officer, stop the same in any street, otherwise than lengthwise with the street close to the sidewalk, and on the same side of the street with any other vehicle already stopping, if the street is not more than thirty feet in width.

Sect. 31. Whoever violates any provision of this chapter shall be punished by a fine not exceeding twenty dollars for each offence, and not only the person actually doing the prohibited thing, but also his employer and every person concerned in so doing, shall be punished by the said fine. 


\section{BIBLIOGRAPHY}

"Address of Welcome." Proceedings of the National Safety Council Tenth Annual Conference (1921): 5-7.

American Association of State Highway Officials. Convention and Twenty-Fifth Anniversary. Washington, DC: The Association, 1939.

Amory, Cleveland. The Proper Bostonians. New York: E.P. Dutton \& Company, 1947.

“Announcements." Motor Age 21 (February 22, 1912): 47.

Architectural Preservation Associates. Massachusetts Bay Transportation Authority Historical Properties Survey Narrative Report. Vol. 1. June 1984.

Argument of Mayor Matthews before the Committee on Transit of the Massachusetts Legislature, April 4, 1894. Boston: Rockwell and Church, City Printers, 1894.

“An Automobile Trade Exhibition.” Automobile Topics 3, no. 1 (October 19, 1901): 24.

Baile, William. “Town Planning and Garden Cities.” New Boston (July 1911): 87-88.

Barrett, Paul. The Automobile and Urban Transit: The Formation of Public Policy in Chicago, 1900-1930. Philadelphia: Temple University Press, 1983.

Blake, John B. Public Health in the Town of Boston, 1630-1822. Cambridge, MA: Harvard University Press, 1959.

Bluestone, Daniel. “The Pushcart Evil.” In Landscapes of Modernity: New York City, 1900-1940, edited by David Ward and Olivier Zunz. Baltimore: Johns Hopkins University Press, 1997.

Borden, Iain. Drive: Journeys through Film, Cities and Landscapes. London: Reaktion Books, 2013.

Boston Chamber of Commerce. Street Traffic in the City of Boston. Boston: E. L. Grimes, Printers, 1914.

Boston City Planning Board. Annual Report of the City Planning Board for the Year Ending January 31, 1915. Boston: City of Boston Printing Department, 1915.

- Second Annual Report of the City Planning Board for the Year Ending January 31, 1916. Boston: City of Boston Printing Department, 1916.

- Third Annual Report of the City Planning Board for the Year Ending January 31, 1917. Boston: City of Boston Printing Department, 1917. 
- Fourth Annual Report of the City Planning Board for the Year Ending January 31, 1918. Boston: City of Boston Printing Department, 1918.

—. Fifth Annual Report of the City Planning Board for the Year Ending January 31, 1919. Boston: City of Boston Printing Department, 1919.

—. Sixth Annual Report of the City Planning Board for the Year Ending January 31, 1920. Boston: City of Boston Printing Department, 1920.

- Seventh Annual Report of the City Planning Board for the Year Ending January 31, 1921. Boston: City of Boston Printing Department, 1921.

- Eighth Annual Report of the City Planning Board for the Year Ending January 31, 1922. Boston: City of Boston Printing Department, 1922.

—. Ninth Annual Report of the City Planning Board for the Year Ending January 31, 1923. Boston: City of Boston Printing Department, 1923.

—. Tenth Annual Report of the City Planning Board for the Year Ending January 31, 1924. Boston: City of Boston Printing Department, 1924.

- Thirteenth Annual Report of the City Planning Board for the Year Ending December 31, 1926. Boston: City of Boston Printing Department, 1927.

—. Progress Report on Proposed Intermediate Thoroughfare. December, 1925.

—_. A Parking Program for the Central Business Area: a Summary of Findings. 1954.

Boston Illustrated. Boston: Houghton, Mifflin \& Co., 1891.

Boston Landmarks Commission. Report of the Boston Landmarks Commission on the Potential Designation of the Blackstone Block Street and Sidewalk Network. 1983.

“The Boston Motor Mart.” Horseless Age 15 (May 10, 1905): 537.

“Boston Motor Mart," Horseless Age 17 (May 30, 1906): 783-784.

Boston Redevelopment Authority. History of Boston's Economy: Growth and Transition. Report 529. November 1999.

The Boston Register and Business Directory, 1921. Boston: Sampson \& Murdock Company, 1921.

“Boston’s Automobile Show.” Horseless Age 8 (November 27, 1901): 764.

“Boston's Motor Row.” Motor Age 21 (February 29, 1912): 5. 
Bottles, Scott L. Los Angeles and the Automobile: The Making of the Modern City. Berkeley: University of California Press, 1987.

Bowden, Martyn J. "Downtown through Time: Delimination, Expansion, and Internal Growth." Economic Geography 47, no. 2 (April 1971): 121-135.

-. "The Dynamics of City Growth: An Historical Geography of the San Francisco Central District, 1850-1931.” PhD diss., University of California, Berkeley, 1967.

-. "Reconstruction Following Catastrophe: The Laissez-Faire Rebuilding of Downtown San Francisco after the Earthquake and Fire of 1906," Proceedings of the Association of American Geographers 2 (1970): 22-26.

“Brief Business.” Motor Age 21 (February 8, 1912): 42.

Bucci, Federico. Albert Kahn: Architect of Ford. Princeton: Princeton Architectural Press, 2002.

Bunting, Bainbridge. Houses of Boston's Back Bay. Cambridge, MA: Belknap Press of Harvard University Press, 1982.

Burnham, Daniel H. Report on a Plan for San Francisco. San Francisco: Sunset Press, 1905.

Cheape, Charles W. Moving the Masses: Urban Public Transit in New York, Boston, and Philadelphia 1880-1912. Cambridge, MA: Harvard University Press, 1980.

"City Document No. 60: Report of a Majority of the Committee on the Extension of Devonshire Street, From Franklin to Summer Street" in Documents of the City of Boston for the Years 1857. Vol. 2. Boston: Geo. C. Rand \& Avery, City Printers, 1858.

“City Planning Board," City Record 10, no. 3 (January 19, 1918): 51.

Cohen, Rachel. A Chance Meeting: Intertwined Lives of American Writers and Artists, 18541967. New York: Random House, 2004.

Commission on Metropolitan Improvements. Public Improvements for the Metropolitan District. Boston: Wright \& Potter, 1909.

Crane, Laura Dent. The Automobile Girls at Newport. Philadelphia: Henry Altemus Company, 1910.

"A Chronicle of the Boston Transit System." Unpublished paper, April, 1981. State Transportation Library of Massachusetts.

Damon, Robin. "Experiences with a New Car and a Word on Gear Changing." Horseless Age 15, no. 14 (April 5, 1905): 418. 
Department of Commerce and Labor, Bureau of the Census. Head of Families at the First Census of the United States Taken in the Year 1790 Massachusetts. Washington, DC: Government Printing Office, 1908.

Department of the Interior, Census Office. Report on the Population of the United States at the Eleventh Census: 1890, Part I. Washington, DC: Government Printing Office, 1895.

Domosh, Mona. Invented Cities: The Creation of Landscape in Nineteenth-Century New York and Boston. New Haven: Yale University Press, 1996.

- "Shaping the Commercial City: Retail Districts in Nineteenth-Century New York and Boston." Annals of the Association of American Geographers 80, no. 2 (1990): 268-284.

Epstein, Bart J. "Geography and the Business of Retail Site Evaluation and Selection." Economic Geography 47, no. 2 (April, 1971): 192-199.

Finstein, Amy. "Lofty Visions: The Architectural Intentions and Contrary Realities of Elevated Urban Highways in America, 1900-1959.” Ph.D. diss., University of Virginia, 2002.

Flink, James J. America Adopts the Automobile, 1895-1910. Cambridge, MA: MIT Press, 1970.

—. The Automobile Age. Cambridge, MA: MIT Press, 1988.

—. The Car Culture. Cambridge, MA: MIT Press, 1975.

Fogelson, Robert M. Downtown: Its Rise and Fall, 1880-1950. New Haven: Yale University Press, 2001.

Foster, Mark. From Streetcar to Superhighway: American City Planner and Urban Transportation, 1900-1940. Philadelphia: Temple University Press, 1981.

Friedmann, Karen. "Victualing Colonial Boston." Agricultural History 47, no. 43 (July 1973): 189-205.

Gans, Herbert J. The Urban Villagers. New York: The Free Press, 1962.

Gates, Earl F. “Boston’s Need for a City Plan.” New Boston (July 1911): 108-110.

Groth, Paul and Todd Bessi, eds. Understanding Ordinary Landscapes. New Haven: Yale University Press, 1997.

Grover, Kathryn and Janine da Silva. Historic Resource Study: Boston African American National Historic Site. National Park Service. December, 2002. 
Hall, Peter. Cities of Tomorrow: An Intellectual History of Urban Planning and Design in the Twentieth Century. Oxford: Blackwell, 1994.

Hass, J. Eugene, Robert W. Kates and Martyn J. Bowden (eds.), Reconstruction Following Disaster. Cambridge, MA: MIT Press, 1977.

Hayden, Robert C. Faith, Culture and Leadership: A History of the Black Church in Boston. Boston: Boston Branch of the NAACP, 1983.

Holleran, Michael. Boston's Changeful Times: Origins of Preservation and Planning in America. Baltimore: Johns Hopkins University Press, 1998.

Hornsby, Stephen John and Michael Hermann. British Atlantic, American Frontier: Spaces of Power in Early Modern British America. Lebanon, NH: University Press of New England, 2005.

Howard, T. W. "Report by Committee on Traffic on Streets and Roads." Proceedings of the American Society for Municipal Improvements 12 (1913): 137-149.

Howe, Frederic C. “The American City of Tomorrow.” New Boston (July 1911): 106-107.

Hugill, Peter J. "Good Roads and the Automobile in the United States 1880-1929." Geographical Review 72, no. 3 (July 1982): 327-349.

- "Technology and Geography in the Emergence of the American Automobile Industry." In Roadside America: the Automobile in Design and Culture, edited by Jan Jennings, 29-39. Ames: Iowa State University Press, 1990.

“In and about the Agencies.” The Automobile 21 (August 12, 1909): 291-292.

Isenburg, Alison. Downtown America: A History of the Place and the People Who Made It. Chicago: University of Chicago Press, 2004.

Jackson, John Brinkerhoff. Discovering the Vernacular Landscape. New Haven: Yale University Press, 1984.

—. A Sense of Place, a Sense of Time. New Haven: Yale University Press, 1994

— with Helen Lefkowitz Horowitz, ed., Landscape in Sight: Looking at America. New Haven: Yale University Press, 1997.

Jacobs, Jane. The Death and Life of Great American Cities. New York: The Modern Library, 1969.

Jakle, John and Keith A. Sculle. Lots of Parking: Land Use in a Car Culture. Charlottesville: University of Virginia Press, 2005. 
James, Henry. Collected Travel Writings Great Britain and America: English Hours, The American Scene, Other Travels. New York: Library of America: 2003.

J. E. Conant \& Co of Lowell, Auctioneers. Mr. John A Atkins' Carriages, Harnesses, Horses, and Stable Outfit. Lowell: Thompson \& Hill Press, 1899.

Kay, Jane Holtz. Lost Boston. Amherst: University of Massachusetts Press, 2006.

Kelso, Gerald K. and Mary C. Beaudry. "Pollen Analysis and Urban Land Use: The Environs of Scottow's Dock in $17^{\text {th }}, 18^{\text {th }}$, and Early $19^{\text {th }}$ Century Boston." Historical Archaeology 24, no. 1 (1990): 61-81.

Kennedy, Lawrence W. Planning the City upon a Hill: Boston Since 1630. Amherst: University of Massachusetts Press, 1992.

Kennedy, Patrick. "Revisiting Auto Row.” Bostonia (Winter-Spring 2012): 24-29.

Klee, Jeffery. "Civic Order on Beacon Hill.” Buildings \& Landscapes: Journal of the Vernacular Architecture Forum 15 (Fall 2008): 43-57.

Krieger, Alex and David Cobbs with Amy Turner. Mapping Boston. Cambridge, MA: MIT Press, 1999.

Leahy, William and the Boston City Planning Board. A Compendium of Reports and Studies Relating to the Commerce and Industries of Boston. Boston: City of Boston Printing Department, 1924.

Li-Marcus, Moying. Beacon Hill: The Life \& Times of a Neighborhood. Boston: Northeastern University Press, 2002.

Liebs, Chester. Main Street to Miracle Mile: American Roadside Architecture. Baltimore: Johns Hopkins University Press, 1995.

Longstreth, Richard. The American Department Store Transformed, 1920-1960. New Haven: Yale University Press, 2010.

- The Drive-in, the Supermarket, and the Transformation of Commercial Space in Los Angeles, 1914-1941. Cambridge, MA: MIT Press, 1999.

“Many Speed Traps around Boston.” Automobile Topics 19, no. 1 (October 9, 1909): 42.

Massachusetts Automobile Club. The Act of Incorporation, Constitution, By-Laws, and House Rules of the Massachusetts Automobile Club with a List of the Officers and Members. Boston: Geo. H. Ellis, Printers, 1902. 
- Yearbook of the Massachusetts Automobile Club and the Massachusetts Automobile Club Trust. Boston: March, 1920.

“Massachusetts Safety Conference.” Safety Engineering 43 (March 1922): 98.

McClintock, Miller. A Report on the Street Traffic Control Problem of the City of Boston Prepared under the Direction of the Mayor's Street Traffic Advisory Board. Boston: City of Boston Printing Department, 1928.

McDonald, Shannon Sanders. The Parking Garage - Design and Evolution of an Urban Form. Washington, DC: The Urban Land Institute, 2007.

McShane, Clay. Down the Asphalt Path: The Automobile and the American City. New York: Columbia University Press, 1994.

- "The Origins and Globalization of Traffic Control Signals." Journal of Urban History 25, no. 3 (March 1999): 379-404.

and Joel Tarr. The Horse in the City: Living Machines in the Nineteenth Century. Baltimore: Johns Hopkins University Press, 2007.

Metropolitan Plan Commission. Report of the Metropolitan Plan Commission. Boston: Wright and Potter, 1912.

Mumford, Lewis. The Highway and the City. New York: Harcourt Brace Jovanovich, 1963.

National Encampment of the Grand Army of the Republic. How to see Boston: A Trustworthy Guide-book. Boston: Moses King Corporation, 1890.

"News of the Week Condensed." The Automobile (January 11, 1912): 11.

"News of the Week Condensed." The Automobile (February 12, 1912): 523.

Norton, Peter D. Fighting Traffic: The Dawn of the Motor Age in the American City. Cambridge, MA: MIT Press, 2008.

Official Automobile Blue Book, Eastern Edition. New York: Official Automobile Blue Book Company, 1901.

Official Automobile Blue Book, New England and Canada. Vol. 2. New York: The Automobile Blue Book Publishing Company, 1911.

Olmsted, Frederick Law. "A Suburban Town Built on Business Principles." New Boston (January 1911): 395-399.

“Packard Service Depot in Boston.” The Packard no. 12 (December 3, 1910): 1-5. 
Pruitt, Bettye. "Self-Sufficiency and the Agricultural Economy of Eighteenth-Century Massachusetts." William and Mary Quarterly 41, no. 3 (July 1984): 333-364.

"Public Safety Section." Proceedings of the National Safety Council Tenth Annual Conference (1921): 604.

Putnam, Robert D. Bowling Alone: The Collapse and Revival of American Community. New York: Simon \& Schuster, 2001.

Quincy, Josiah. A Municipal History of the Town and City of Boston during Two Centuries: From September 17, 1630, to September 17, 1830. Boston: Charles C. Little and James Brown, 1852.

Rae, Douglas W. City: Urbanism and Its End. New Haven: Yale University Press, 2003.

Rae, John B. The Road and the Car in American Life. Cambridge, MA: MIT Press, 1971.

“Rambler Opens New Sales and Service Station." Horseless Age 30 (October 2, 1912): 509. Rapid Transit Commission. Report of the Rapid Transit Commission to the Massachusetts Legislature, April 5, 1892. Boston: City Printing Office, 1892.

Ratner, Sidney. New Light on the History of Great American Fortunes. New York: Augustus M Kelly Inc., 1953.

Record Commissioners. Second Report of the Record Commissioners Containing the Boston Town Records, 1634-1660, and the Book of Possessions. Boston: Rockwell and Churchill, City Printers, 1881.

- A Report of the Record Commissioners of the City Boston Containing the Records of Boston Selectmen, 1701 to 1715. Boston: Rockwell and Churchill, City Printers, 1884.

Report of the Record Commissioners of the City of Boston Containing the Boston Records from 1729 to 1742. Boston: Rockwell and Churchill, City Printers, 1885.

- A Volume of Records Relating to the Early History of Boston Containing the Minutes of the Selectmen's Meeting, 1799 to, and Including, 1810. Boston: Municipal Printing Office, 1904.

“Removals and Trade Changes.” Automobile Trade Journal 23, no. 6 (December 1, 1918): 137a.

Reports of Proceedings of the City Council of Boston for the Year Commencing January 6, 1930 and Ending December 29, 1930. Boston: City of Boston Printing Department, 1930.

Reps, John W. The Making of Urban America - A History of City Planning in the United States. Princeton: Princeton University Press, 1965. 
The Revised Ordinances of 1892 of the City of Boston, and the Revised Regulations of 1892 of the Board of Aldermen of the City of Boston. Boston: Rockwell and Churchill, City Printers, 1894.

The Revised Ordinances of 1898 of the City of Boston and the Revised Regulations of the Board of Alderman of the City of Boston with All the Ordinances and Regulations Passed from the Passage of the Revised Ordinances of 1898 and the Revised Regulations of 1898 to November 1, 1908. Boston: City of Boston Printing Department, 1908.

The Revised Ordinances of 1914 of the City of Boston Being the Thirteenth Revision with Tables Showing the Disposition of Prior Ordinances and Regulations. Boston: City of Boston Printing Department, 1915.

The Revised Ordinances of 1925 of the City of Boston Being the Fourteenth Revision with Tables Showing the Disposition of Prior Ordinances. Boston: City of Boston Printing Department, 1925.

Rosen, Christine M. The Limits of Power: Great Fires and the Process of City Growth in America. New York: Cambridge University Press, 1986.

Rothenberg, Winifred. “The Market and Massachusetts Farmers, 1750-1855." The Journal of Economic History 41, no. 2 (June 1981): 283-314.

Rubenstein, James M. The Changing US Auto Industry: a Geographical Analysis. New York: Routledge, 1992.

- Making and Selling Cars: Innovation and Change in the US Automotive Industry. Baltimore: Johns Hopkins University Press, 2001.

Rutman, Darrett B. Winthrop's Boston: A Portrait of a Puritan Town, 1630-1649. New York: W. W. Norton \& Company, Inc., 1972.

Sanborn Map Company. Insurance Map of Boston. Vol. 1. New York: D. A. Sanborn, 1867.

- Insurance Maps of Boston Massachusetts. 6 vols. New York: Sanborn Map Publishing Co., 1885-1888.

1895-1897.

-. Insurance Maps of Boston Massachusetts. 6 vols. New York: Sanborn Map Company, 1909-1925.

- Insurance Maps of Boston Massachusetts. 2 vols. New York: Sanborn Map Company, 1929-1938. 
—. Insurance Maps of Brookline Massachusetts. New York: Sanborn Map Company, 1925.

- Insurance Maps of San Francisco California. Vol. 1. New York: Sanborn Map \& Publishing Co., 1887.

Schroeder, Joseph and Sheldon Factor (eds.). Sears, Roebuck \& Co. Motor Buggy Catalogue 1909-1912. Northfield, IL: Digest Books, 1973.

Seasholes, Nancy S. Gaining Ground: A History of Landmaking in Boston. Cambridge, MA: MIT Press, 2003.

"Seeing Boston." Earliest Massachusetts Films, DVD. Bucksport, ME: Northeast Historic Film, 2005.

Segrave, Kerry. Parking Cars in America, 1910-1945. Jefferson, NC: McFarland \& Company, 2012.

“Service Plants for Boston Owners.” The Automobile 28 (March 6, 1913): 577-579.

Shaw, Diane. City Building on the Eastern Frontier: Sorting the New Nineteenth-Century City. Baltimore: Johns Hopkins University Press, 2004.

Shultz, Stanley K. Constructing Urban Culture: American Cities and City Planning, 1800-1920. Philadelphia: Temple University Press, 1989.

Shoup, Donald. The High Cost of Free Parking. Chicago: American Planning Associate, 2005.

Silverman, Robert A. "Nathan Matthews: Politics of Reform in Boston, 1890-1910." The New England Quarterly 50, no. 4 (December 1977): 626-43.

The Social Register, Boston, 1904. New York: The Social Register Association, 1903.

“Some Automobile Statistics.” Horseless Age 14 (September 28, 1904): 303-304.

Southworth, Michael and Susan Southworth. AIA Guide to Boston. Guildford, CT: Globe Pequot Press, 2008.

"Stable and Stable Fittings," The American Architect and Building News (May 16, 1903): 52.

"Store and Office Building, Brookline Avenue, Boston, Mass," The American Architect 112 (August 8, 1917): plate 65.

Street Laying-Out Department. Annual Report of the Street Laying-Out Department for the Year 1897. Boston: Municipal Printing Office, 1898. 
- Annual Report of the Street Laying-Out Department for the Year 1899. Boston: Municipal Printing Office, 1900.

“Strict in Bay State." Motor Age 12 (August 1, 1907): 10-11.

“Syllabi of Boston-1915 Conferences.” New Boston (January 1911): 399.

Tarkington, Booth. The Magnificent Ambersons. New York: Doubleday, Page \& Company, 1918.

“Tremont Garage, Boston, Mass.” Horseless Age 17, no 2 (30 May 30, 1906): 784-785.

Trout, Charles H. Boston, the Great Depression, and the New Deal. New York: Oxford University Press, 1977.

Tsipis, Yanni. "Central Corridor Highway Planning in Boston, 1900-1950: The Long Road to the Central Artery." Civil Engineering Practice (Fall/Winter 2003): 33-52.

Tucci, Douglas Shand. Built in Boston: City and Suburb 1800-1950. Boston: New Graphic Society, 1978.

Upton, Dell. Another City: Urban Life and Urban Spaces in the New American Republic. New Haven: Yale University Press, 2008.

Vance, James. The Continuing City: Urban Morphology in Western Civilization. Baltimore: Johns Hopkins University Press, 1990.

Vanderwarker, Peter. Boston Then and Now. New York: Dover Publications, 1892.

Ward, David. "The Industrial Revolution and the Emergence of Boston's Central Business District.” Economic Geography 42, no. 2 (April 1966): 152-171.

Warner, Sam Bass. Streetcar Suburbs: The Process of Growth in Boston, 1870-1900. Cambridge: Harvard University Press, 1978.

West End Street Railway. First Annual Report of the West End Street Railway Company. Boston: R.H. Blodgett, 1888.

“The West End Street Railway Company.” Street Railway Journal 11 (April, 1895): 208-225.

Weinstein, Asha. "Congestion as a Cultural Construct: The 'Congestion Evil' in Boston in the 1890s and 1920s.” The Journal of Transport History 27, no. 2 (September 2006): 97-115.

- "The Congestion Evil: Perceptions of Traffic Congestion in Boston in the 1890s and 1920s.” PhD diss., University of California, Berkeley, 2002. 
- "Curing Congestion: Competing Plans for a Loop Highway and Parking Regulations in Boston in the 1920s." Journal of Planning History (2004): 292-311.

Whitehill, Walter Muir and Lawrence Kennedy. Boston a Topographical History. Cambridge, MA: Belknap Press of Harvard University Press, 2000.

Whitten, Robert and the Boston City Planning Board. Report on a Thoroughfare Plan for Boston. Boston: 1930.

Wilson, Chris and Paul Groth, eds. Everyday America: Cultural Landscape Studies after J. B. Jackson. Berkeley: University of California Press, 2003. 


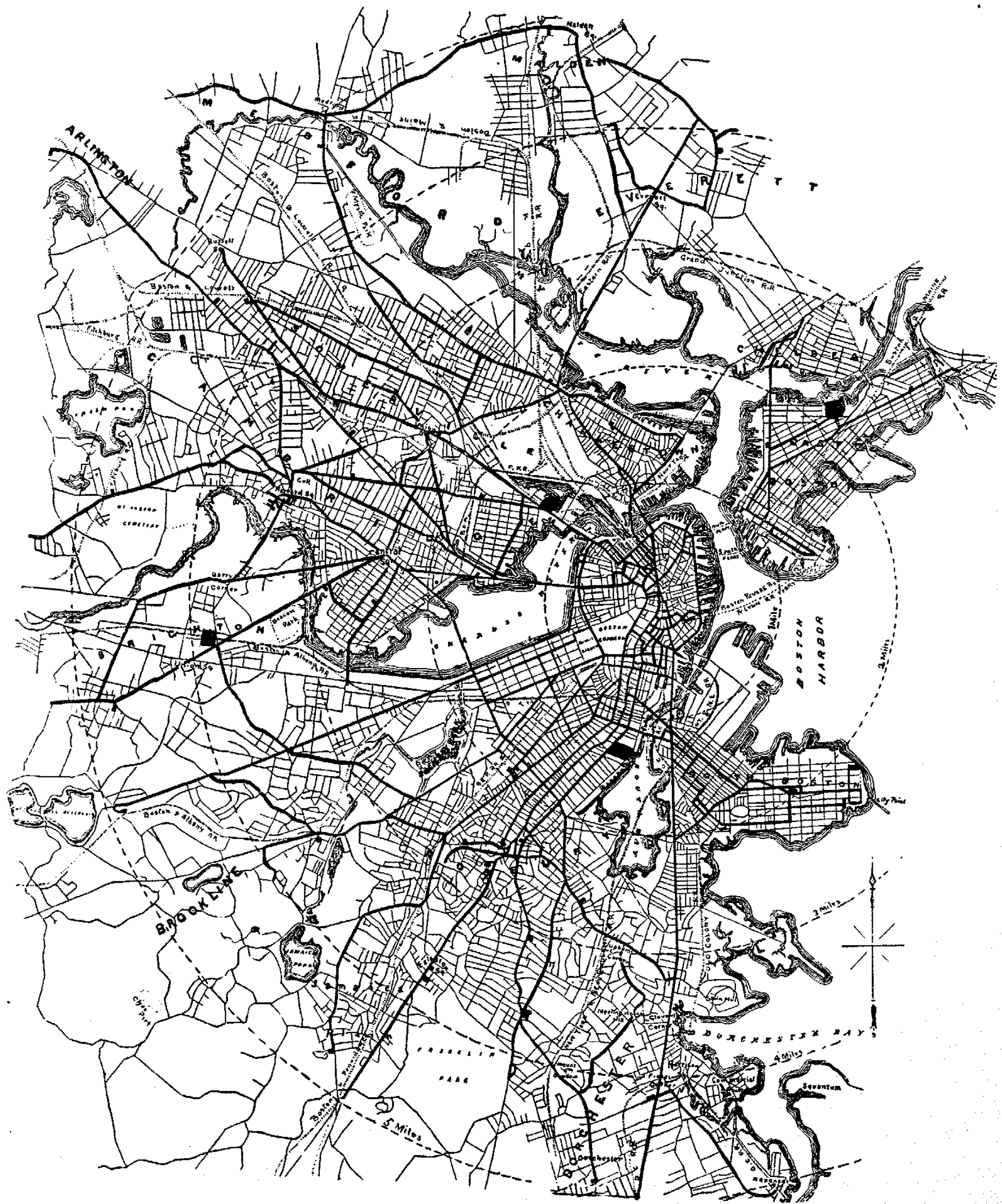

Figure 1-1. Map of the West End Street Railway network in 1895. Streetcar routes are marked by thicker lines. Street Railway Journal 11 (April 1895), 209. 


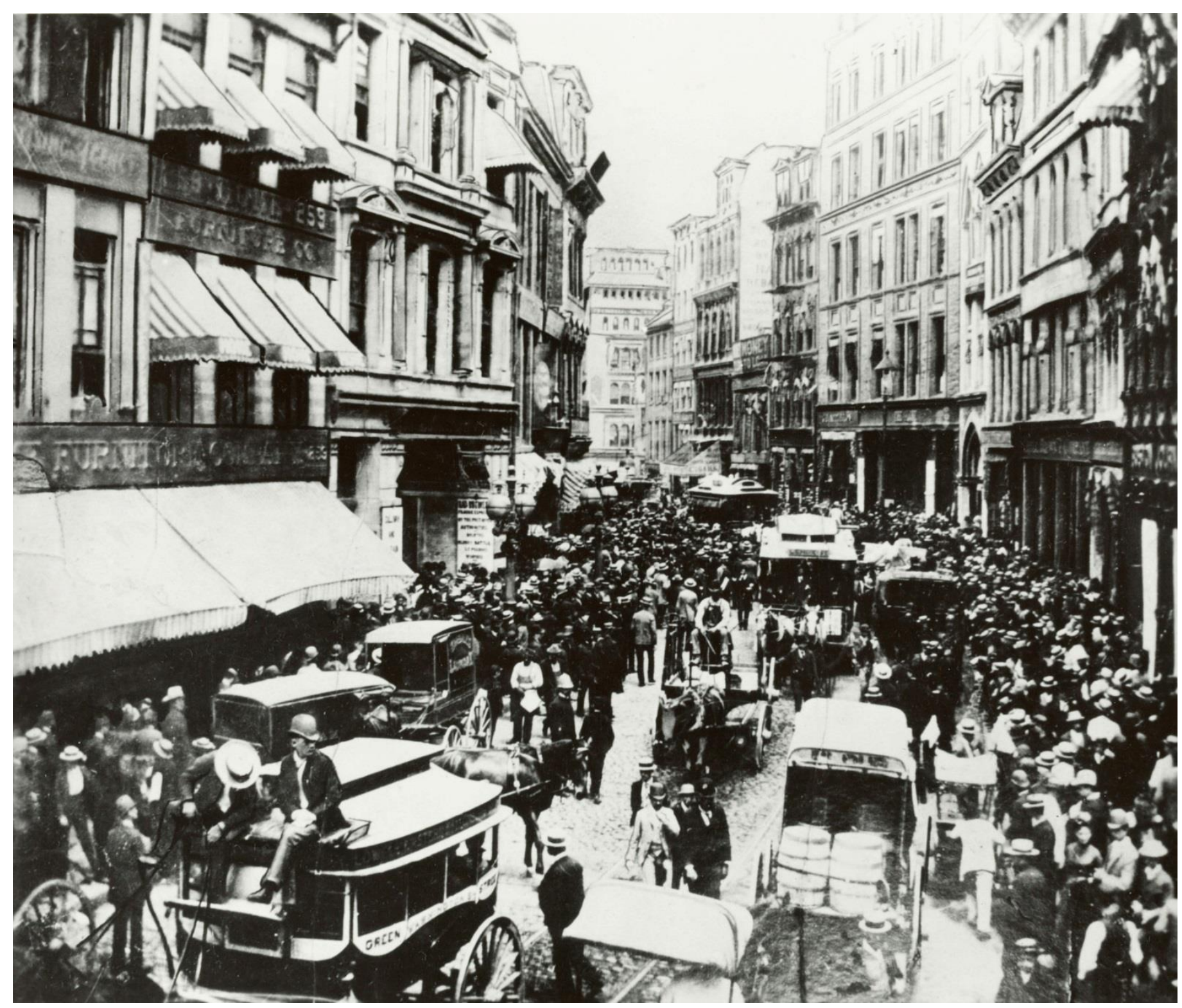

Figure 1-3. Crowds gather on Washington Street for news of the Sullivan-Kilrain fight on July 8, 1889. Courtesy of Historic New England. 


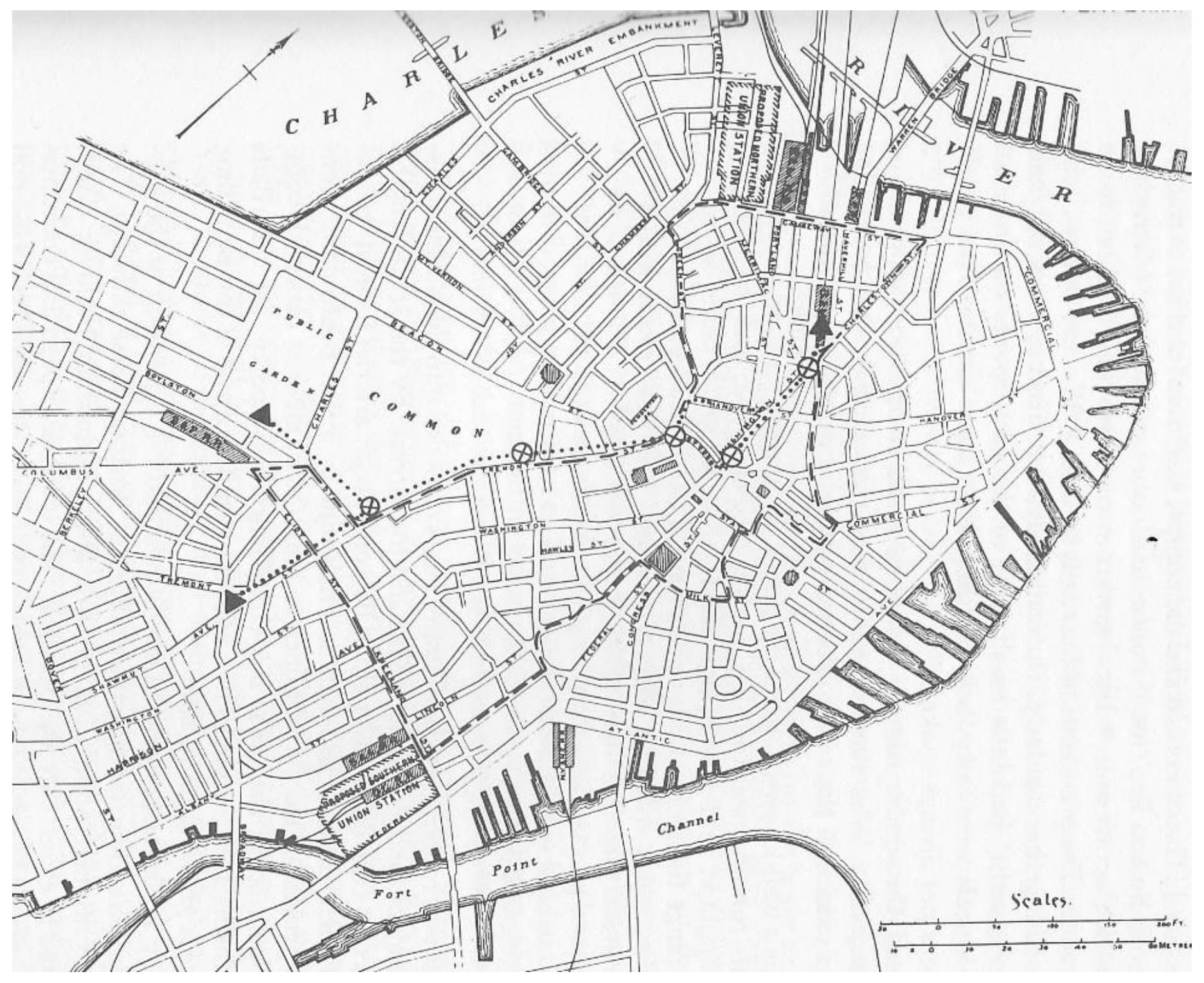

Figure 1-4. Downtown Boston's subway system in 1898. The congested district is marked with a dashed line and the subway with dotted lines. Crossed circles mark the location of stations, while triangles show inclines into the tunnels. Boston Transit Commission, Fourth Annual Report as reproduced in Cheape, Moving the Masses, 111. 


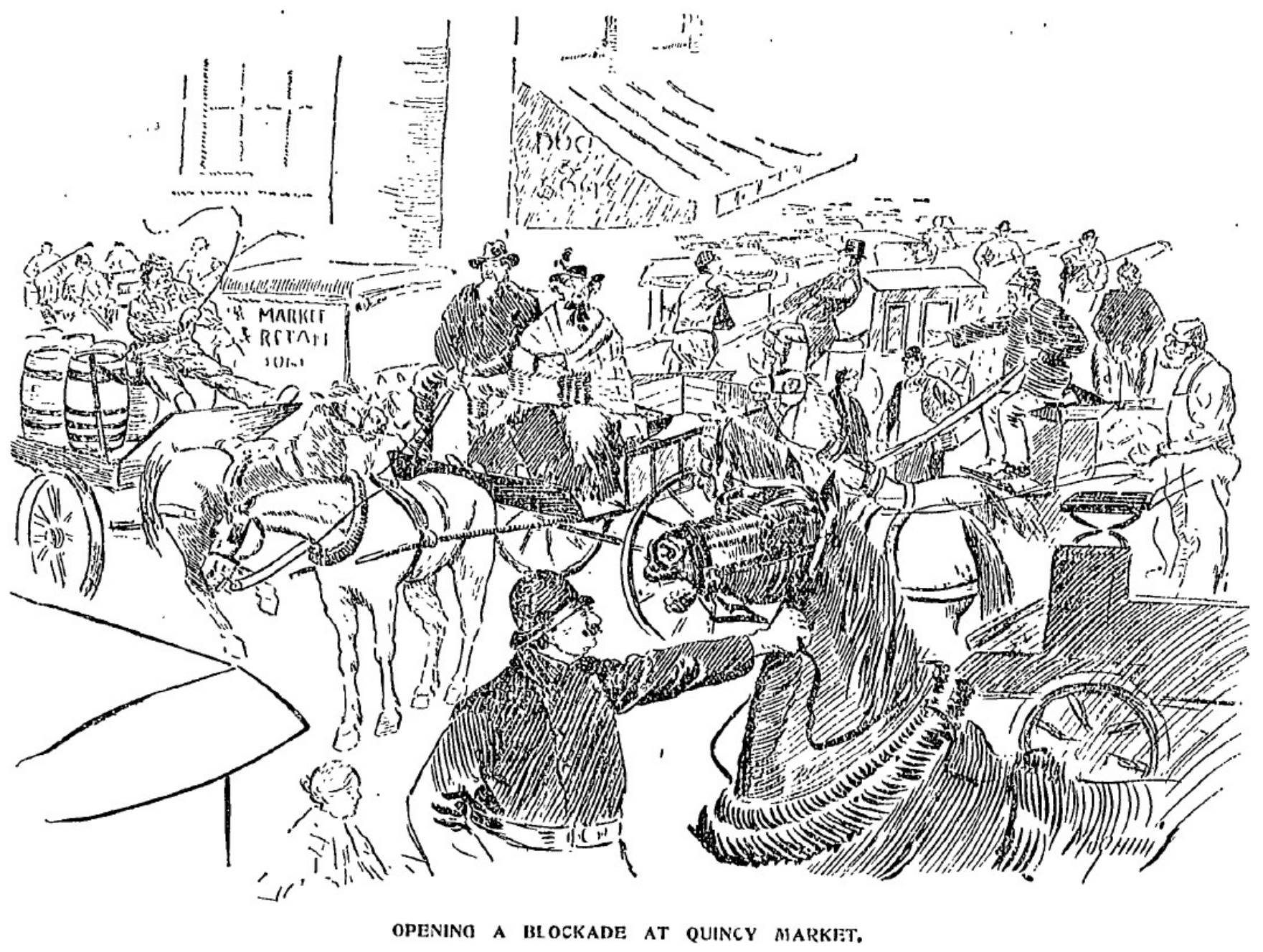

Figure 1-5. An illustration of a member of the "street squad" in action. Boston Globe, April 4, 1897, 34. 


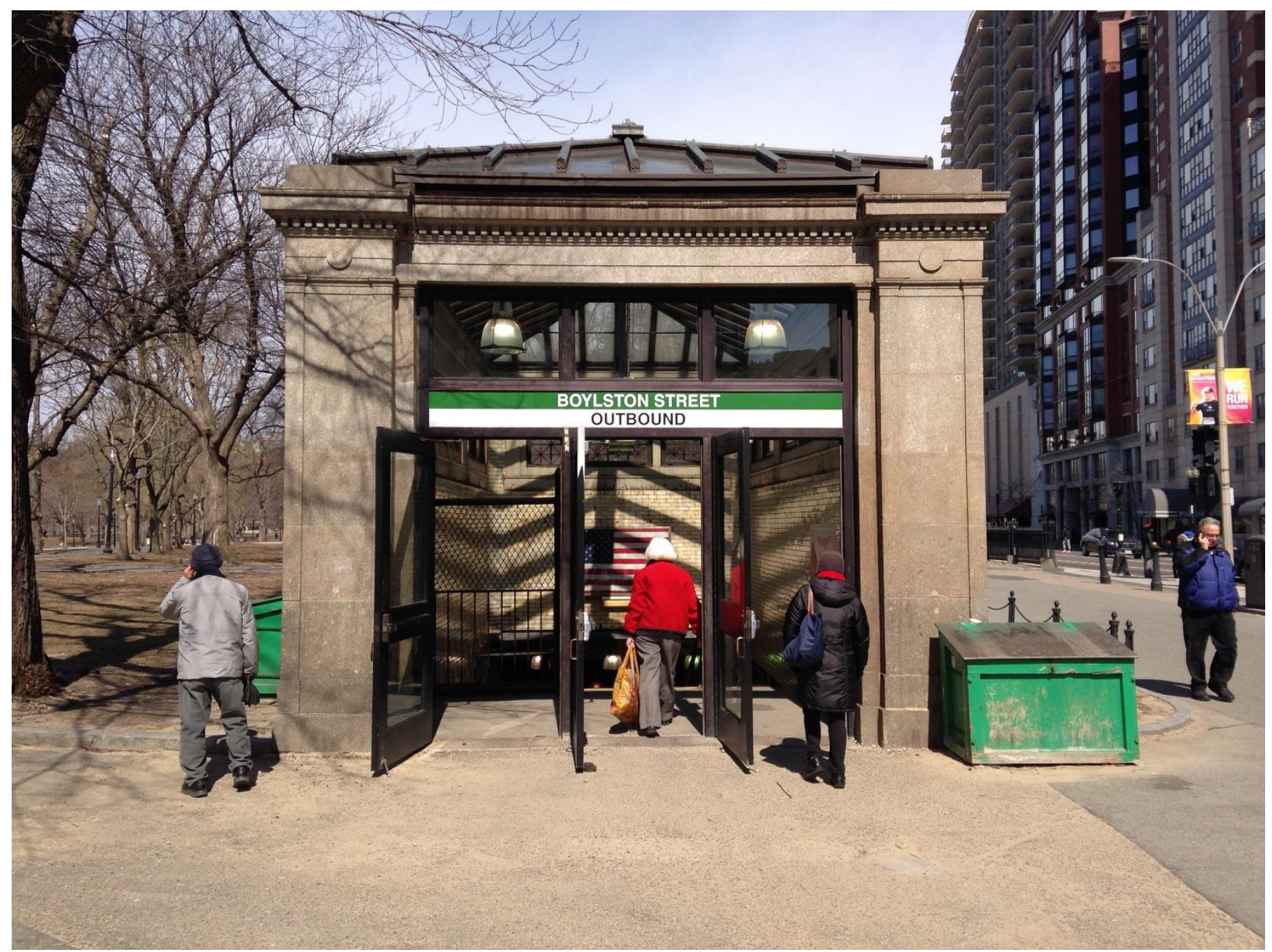

Figure 1-6. Boylston subway entry kiosk. Designed by Edmund Wheelwright, 1897. Author photograph. 


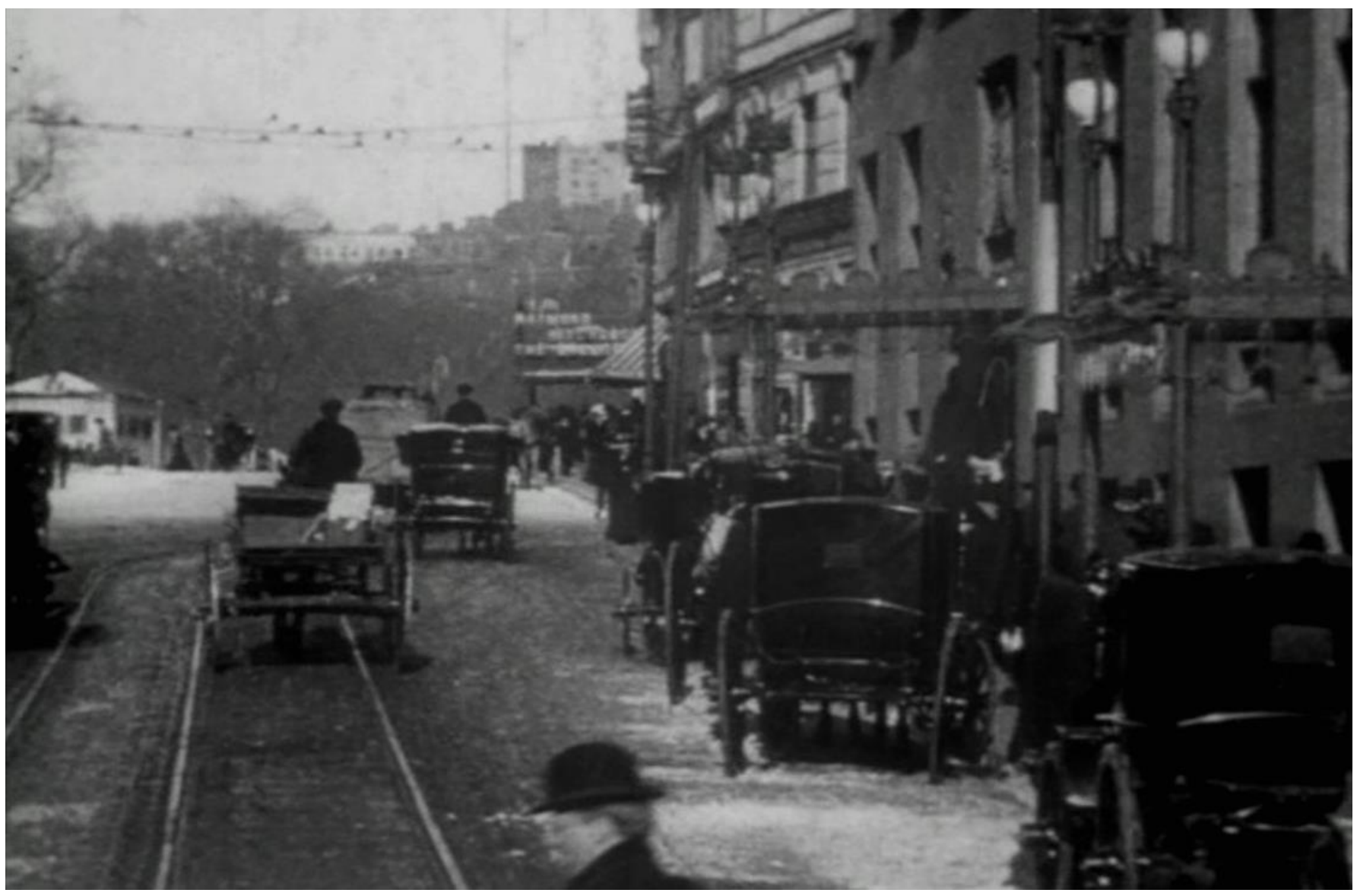

Figure 1-7. Image from Seeing Boston, 1906. The camera is moving north on Tremont Street. A livery cab stand in front of the Boylston Hotel appears to the right. The Boylston station entry kiosk appears on the left in the background. 


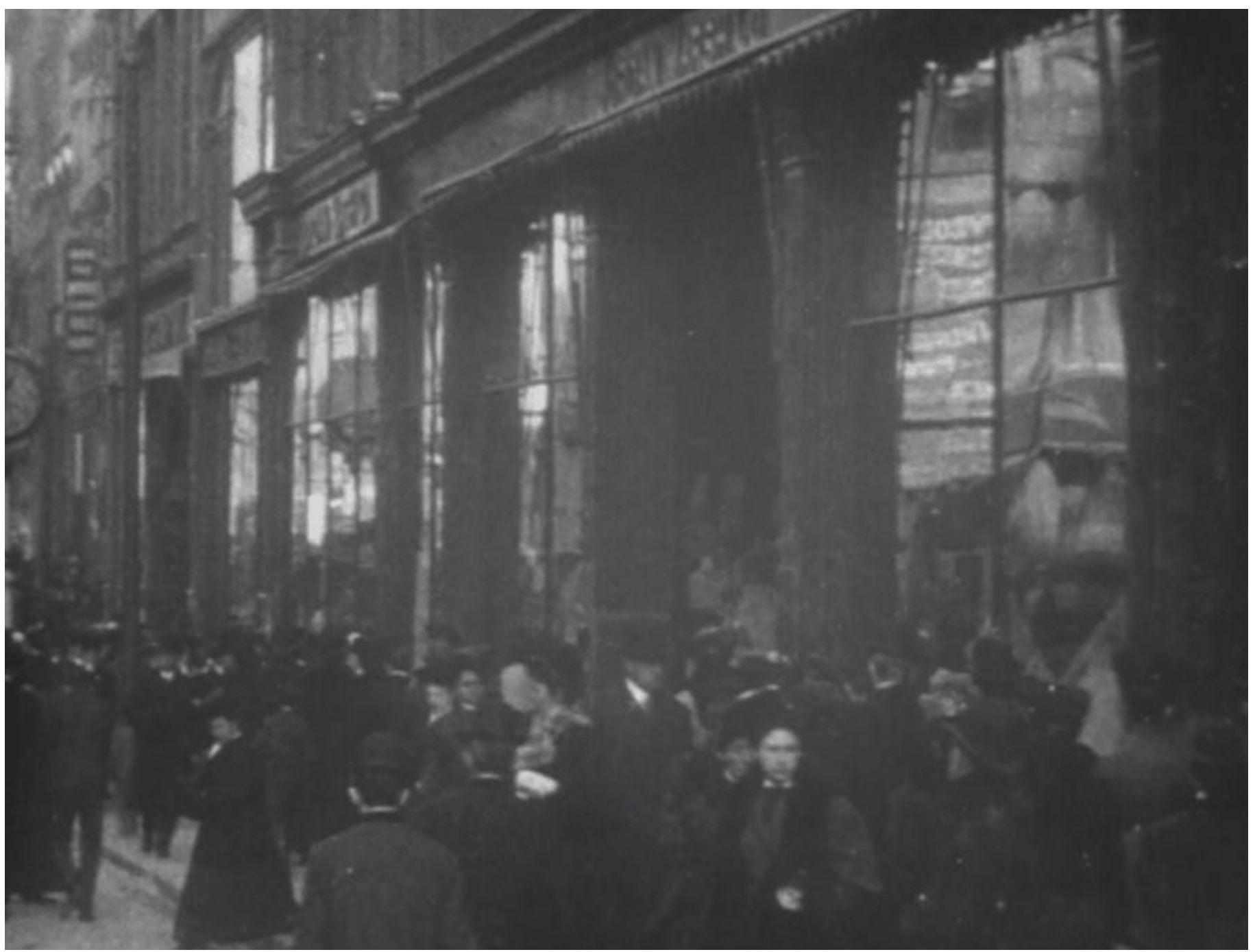

Figure 1-8. Sidewalk crowds on Washington Street. Image from Seeing Boston, 1906. 


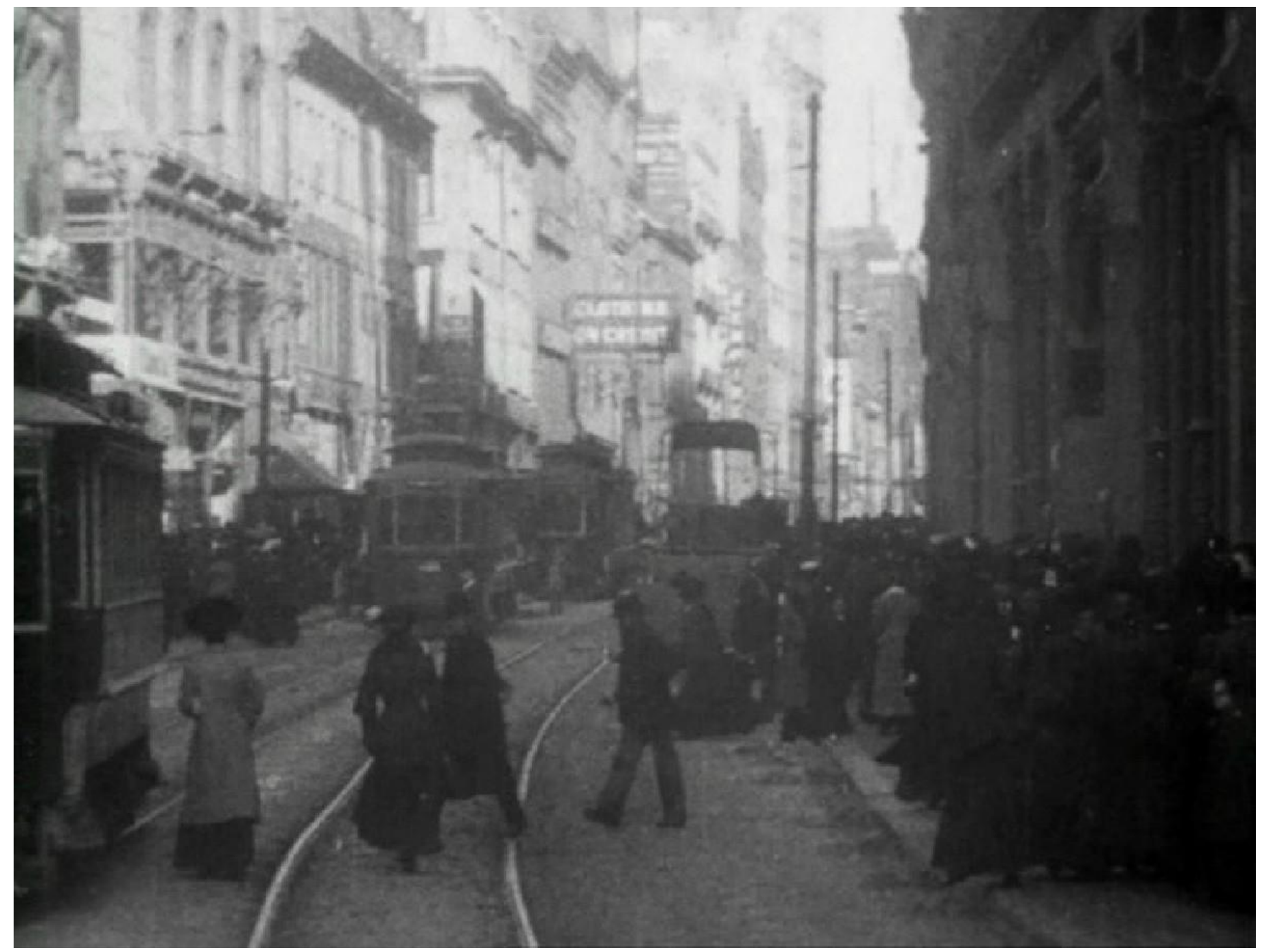

Figure 1-9. Pedestrians amid vehicular traffic on Washington Street. Image from Seeing Boston, 1906. 


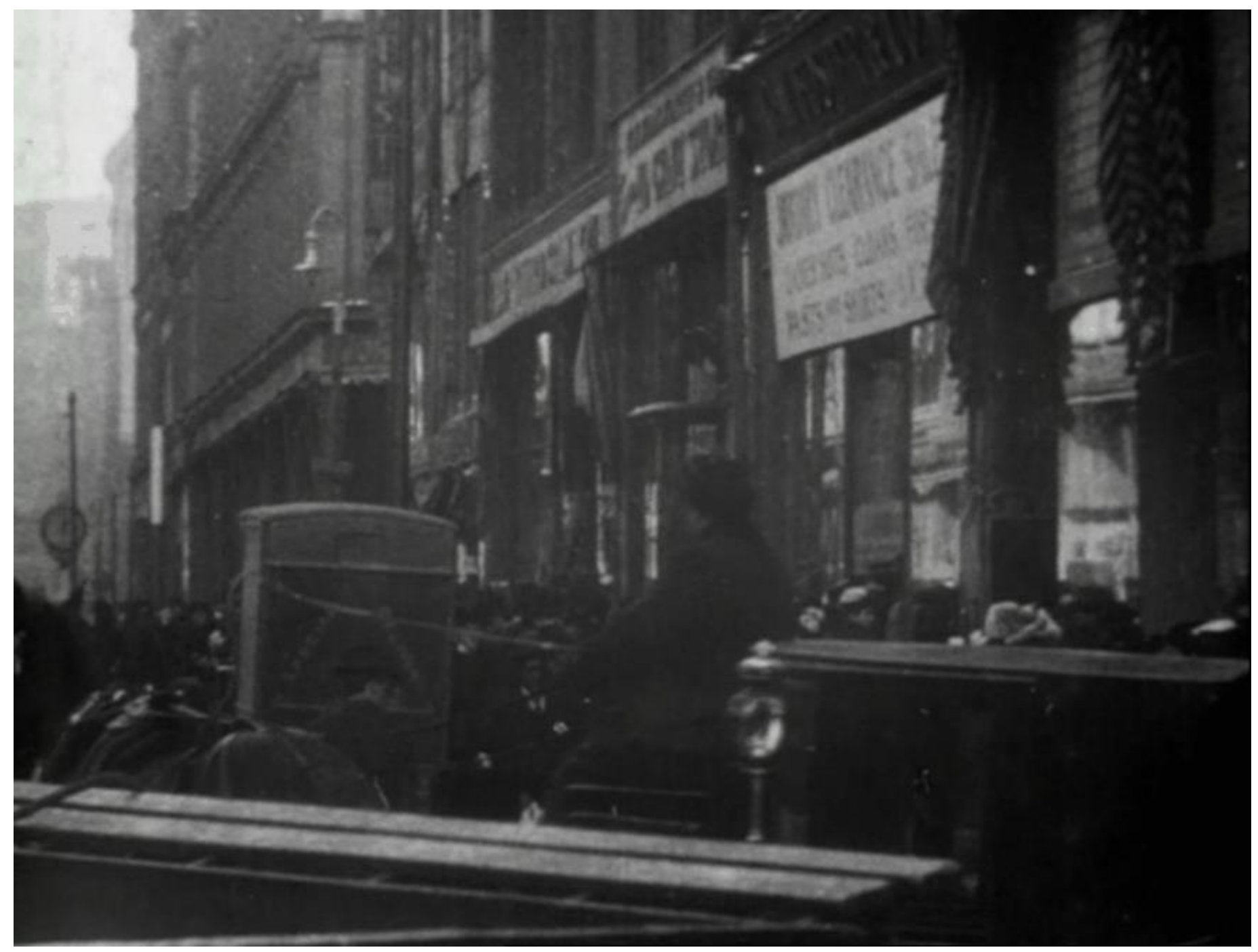

Figure 1-10. Moving vehicles in close quarters. Image from Seeing Boston, 1906. 


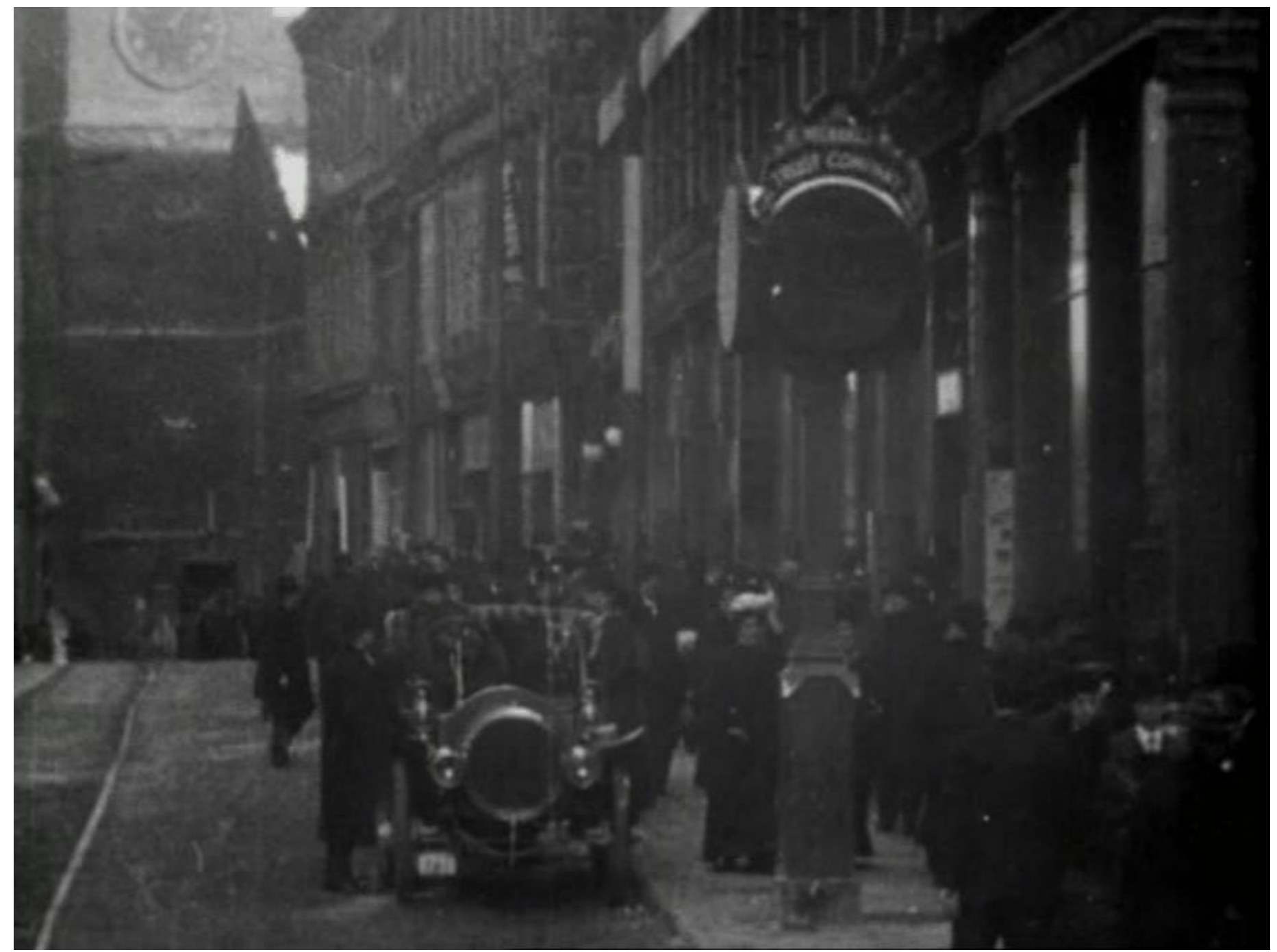

Figure 1-12. Automobile on Washington Street. Image from Seeing Boston, 1906. 


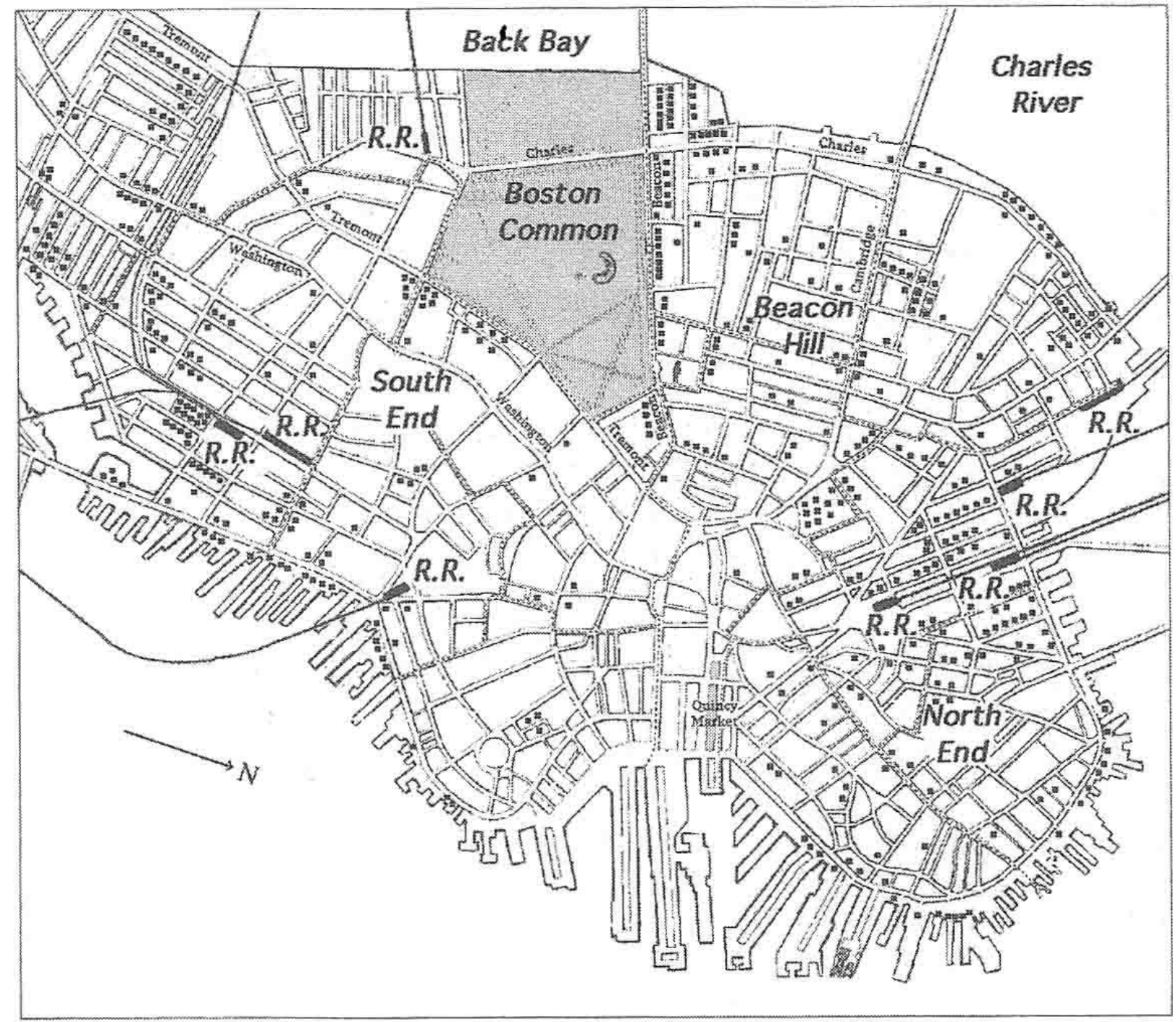

Figure 1-13. Location of Boston's stables in 1867. McShane and Tarr, The Horse in the City, 105. 


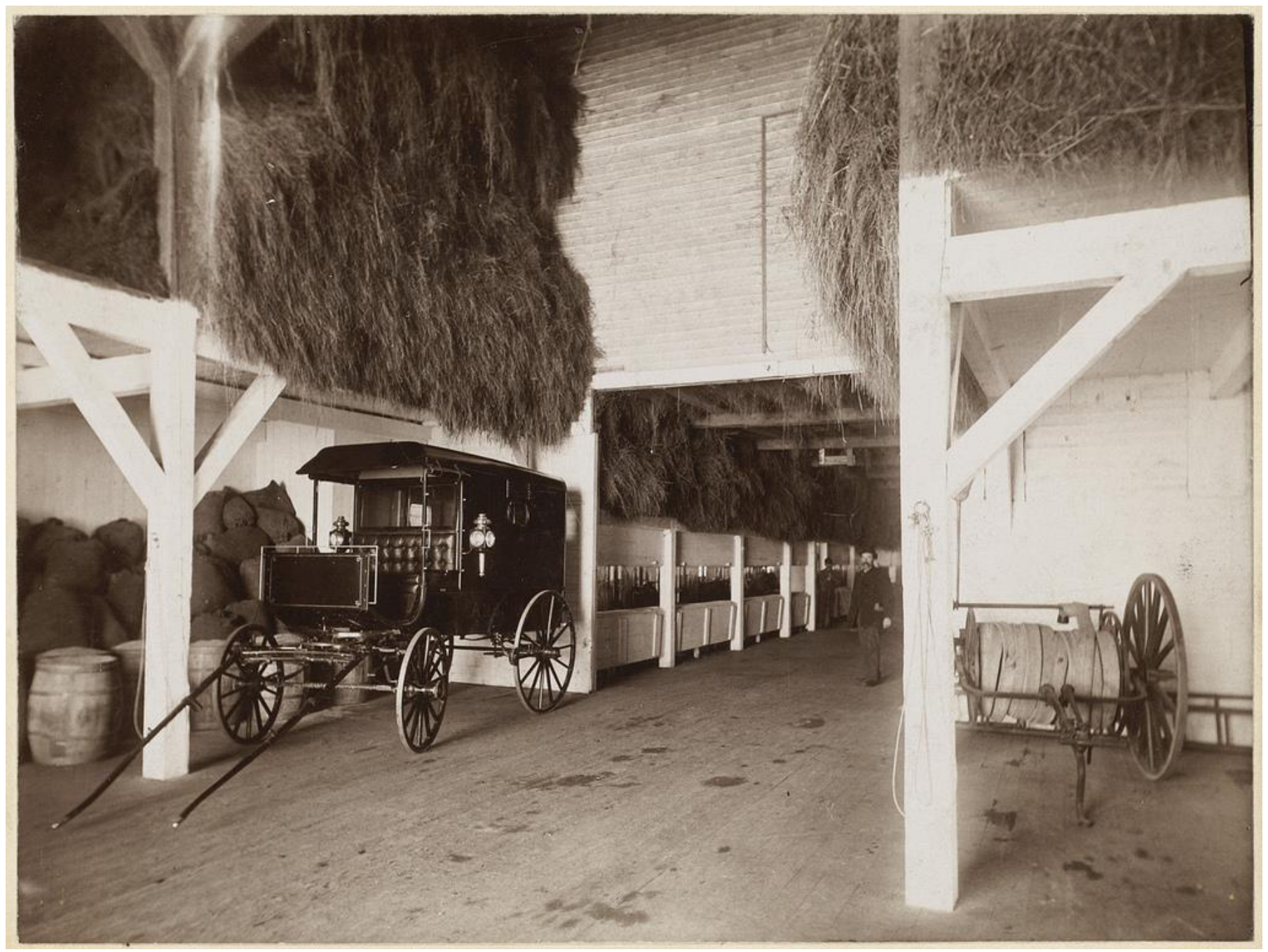

Figure 1-14. Unidentified stable in Boston. Undated photo taken by Baldwin Coolidge. While the spooled fire hose to the right could be moved to an external water supply, the great volume of dried hay and other grains would likely outmatch any efforts to combat a fire should one have arisen. Courtesy of the Boston Public Library. 


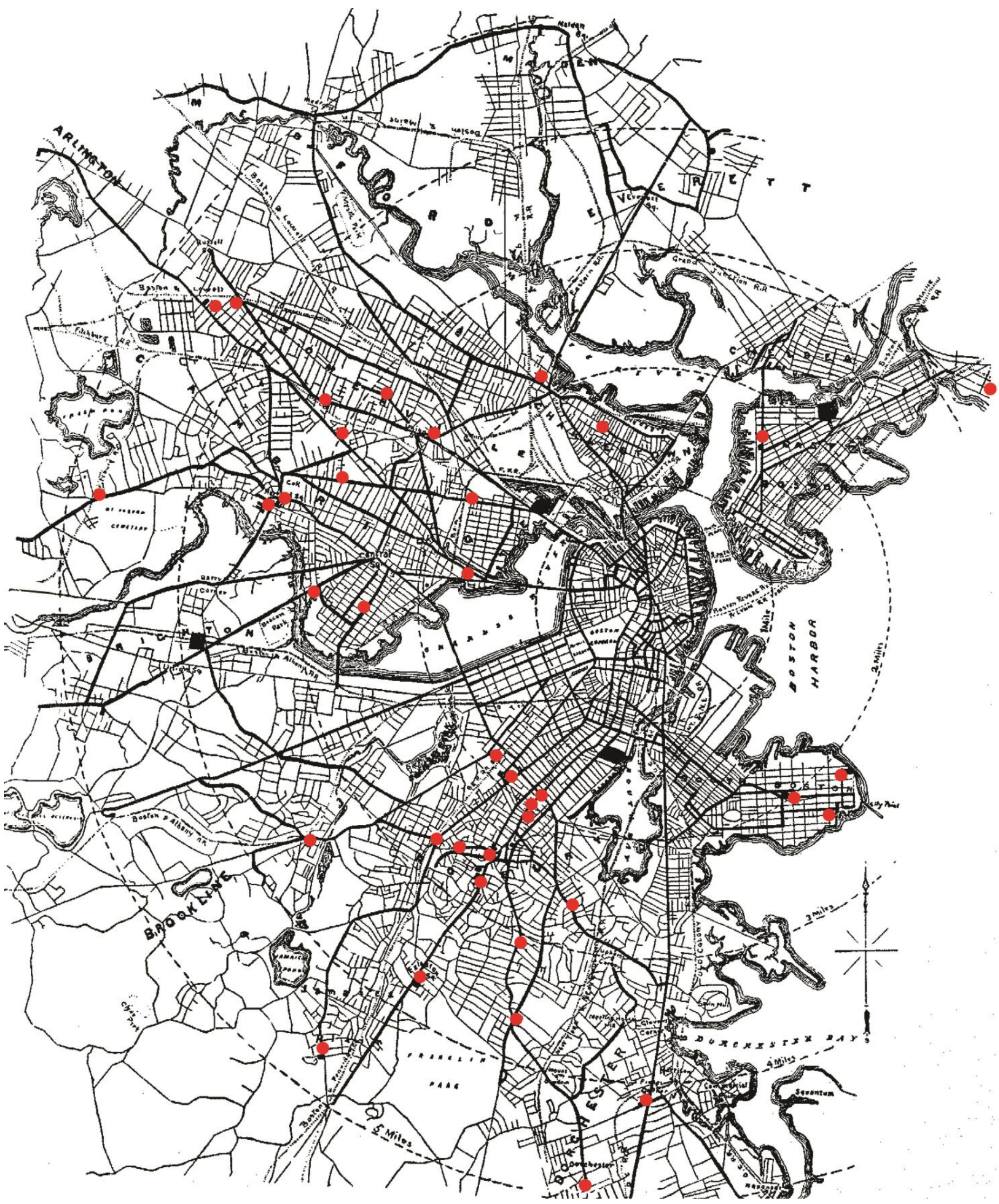

Figure 1-15. Map showing the distribution of Boston forty street railway stables. These locations were determined from review of the 219 sheets of the 1885 Sanborn Atlas. The basemap shows the West End's system in 1895, with streetcar tracks marked by thicker lines. 


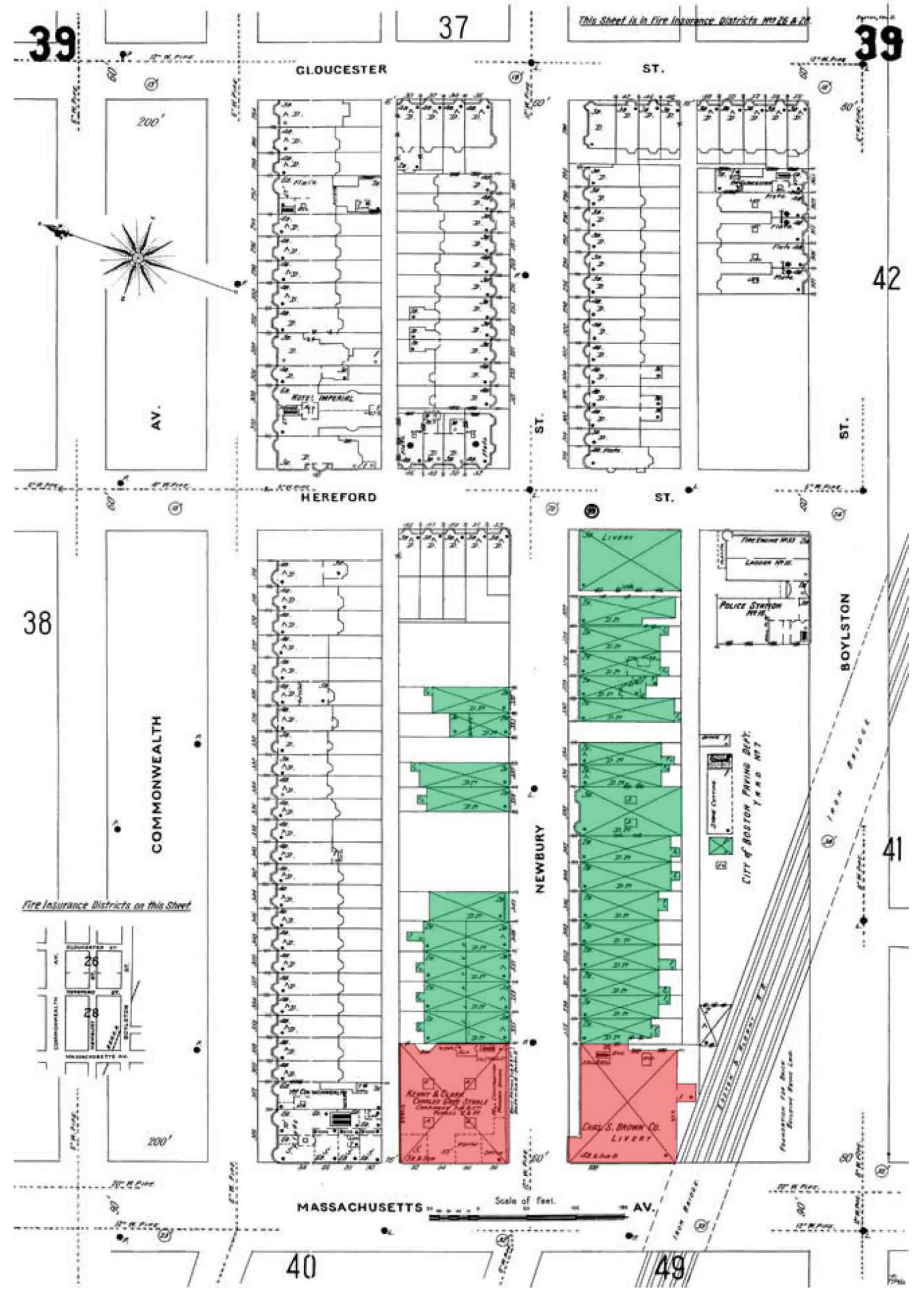

Figure 1-16. The Newbury Street stable district. The Kenney \& Clark and Boston Cab Company stables are highlighted red. All other stables are highlighted green. Sanborn Atlas, 1897, sheet 39. 


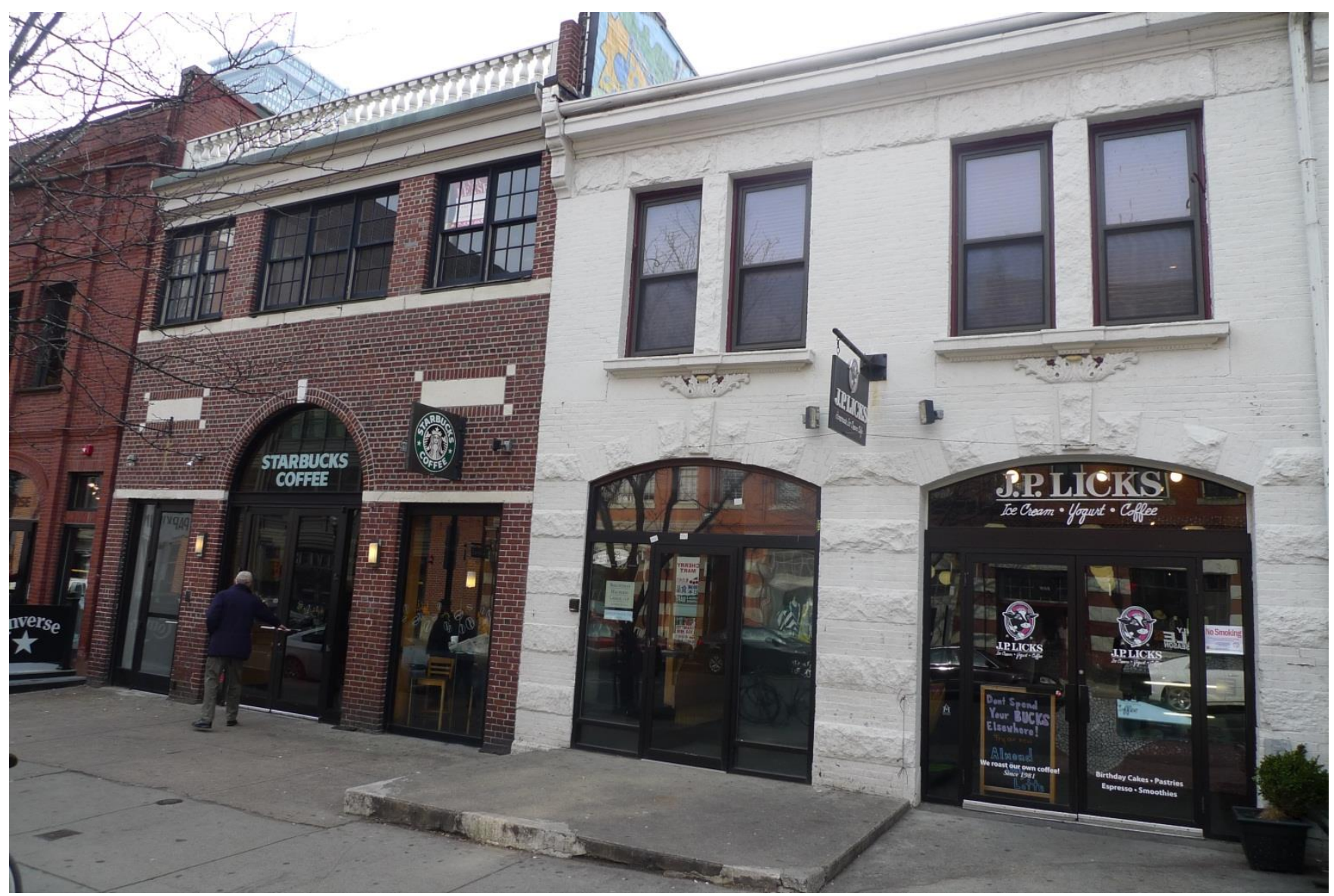

Figure 1-18. The former stable of John Atkins at 350 Newbury Street, now a Starbucks Coffee. Author photograph. 


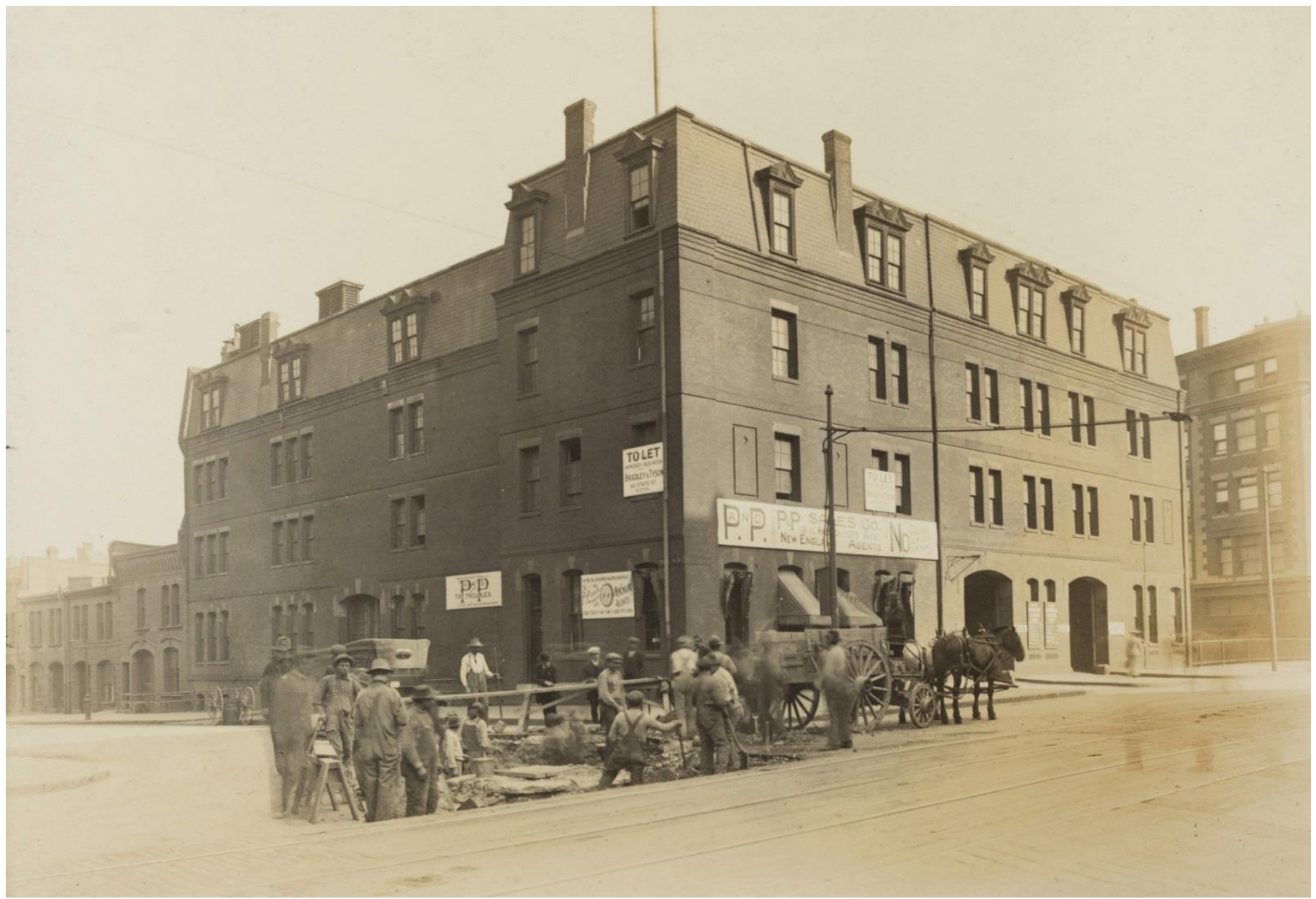

Figure 1-19. The Boston Cab Company, corner of Massachusetts Avenue and Newbury Street. Photo taken 1912, Boston Transit Commission. Courtesy of Historic New England. 


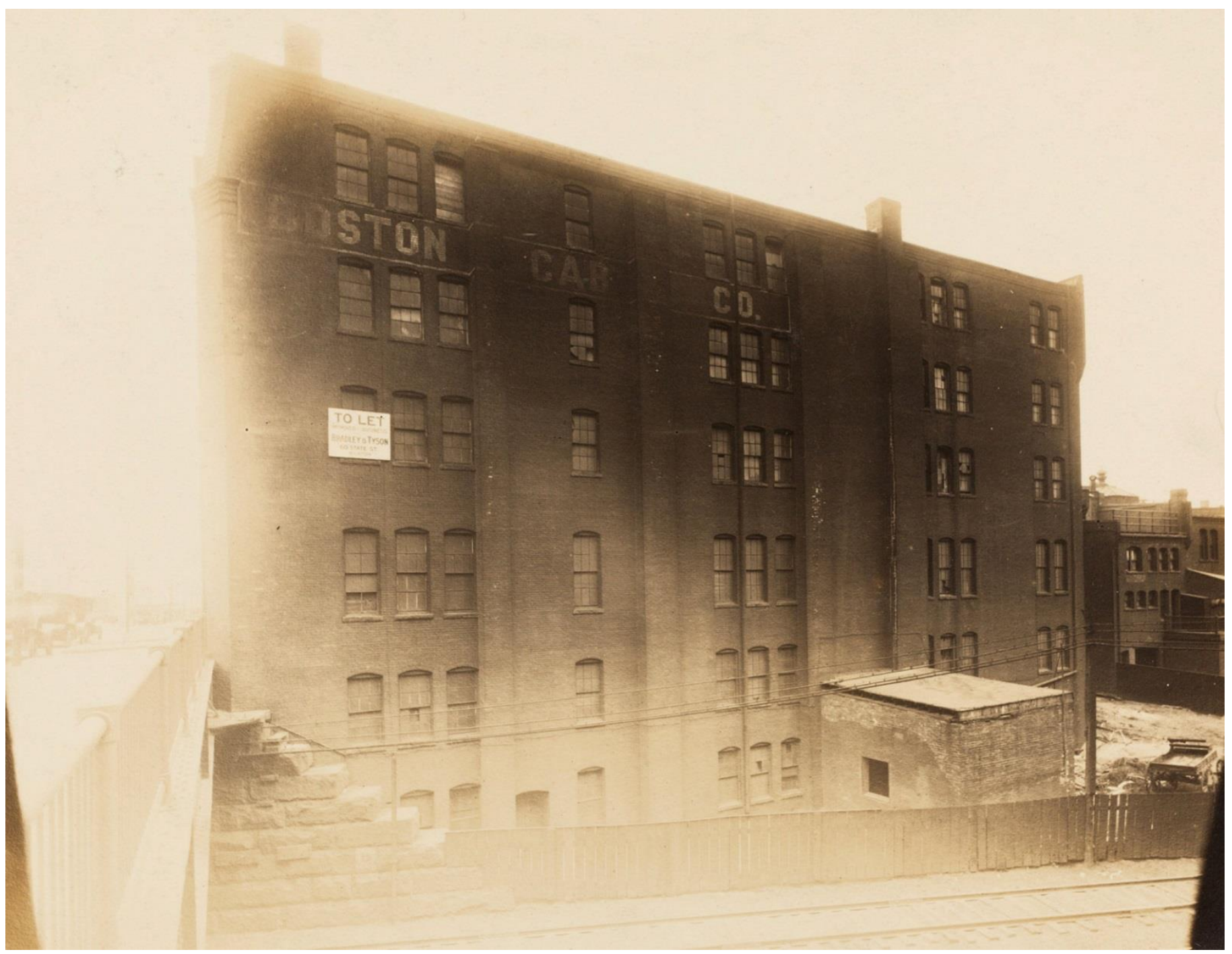

Figure 1-20. The Boston Cab Company fronting the tracks of the Boston \& Albany railroad. Photo taken 1912, Boston Transit Commission. Courtesy of Historic New England. 


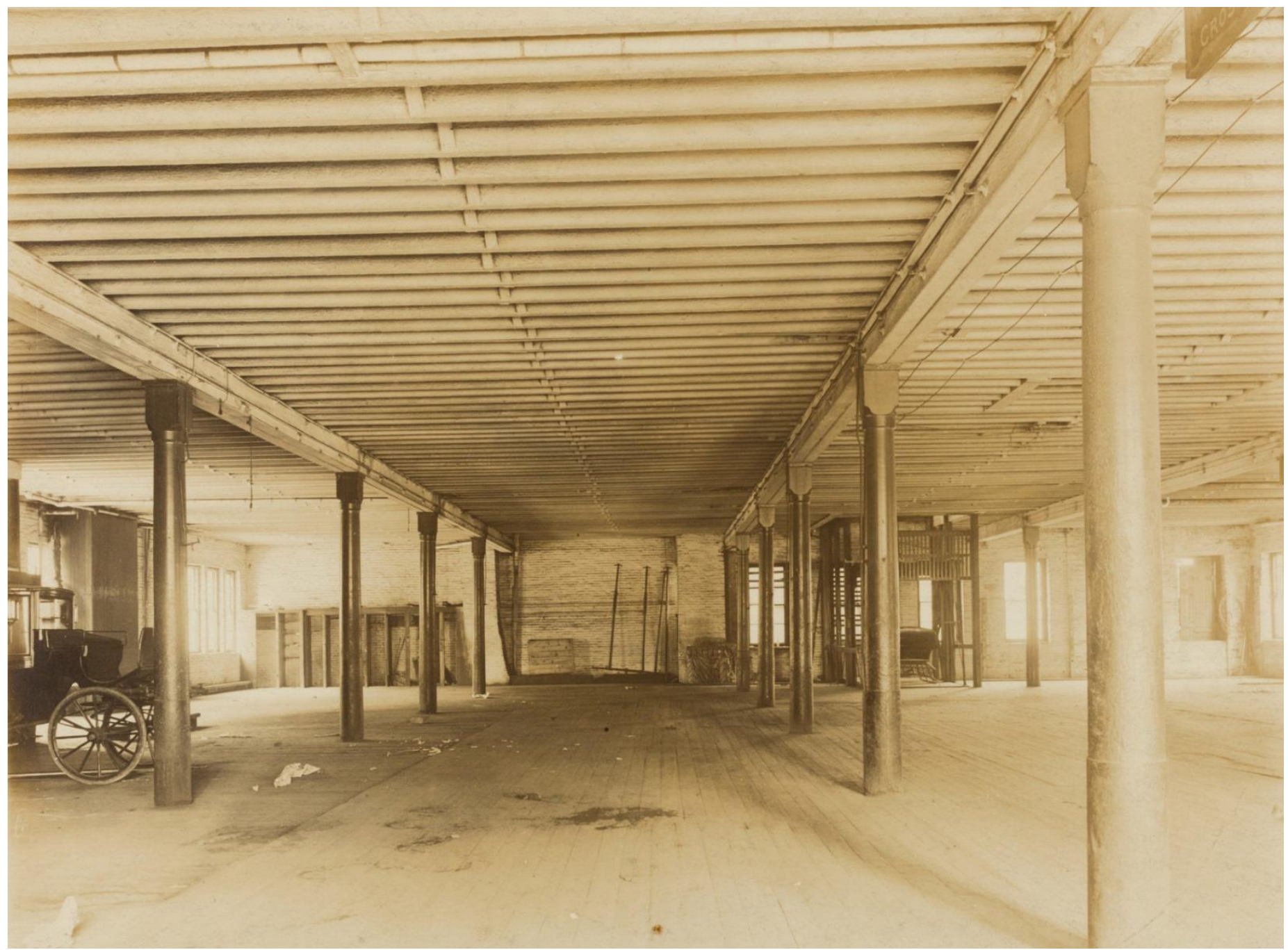

Figure 1-21. Street level interior of the Boston Cab Company. Photo taken 1912, Boston Transit Commission. Courtesy of Historic New England. 


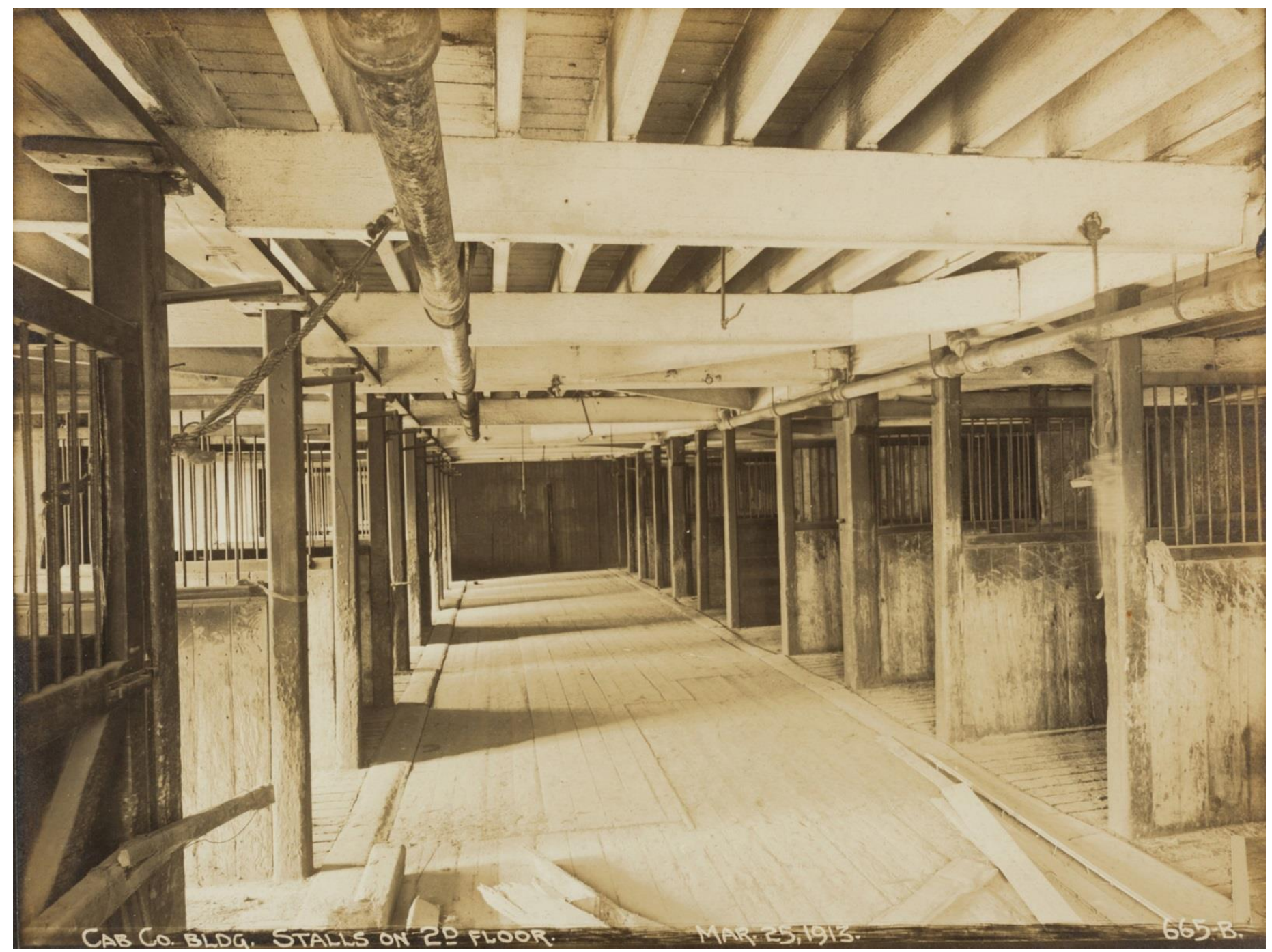

Figure 1-22. Arrangement of horse stalls on the second floor of the Boston Cab Company. Photo taken 1913, Boston Transit Commission. Courtesy of Historic New England. 


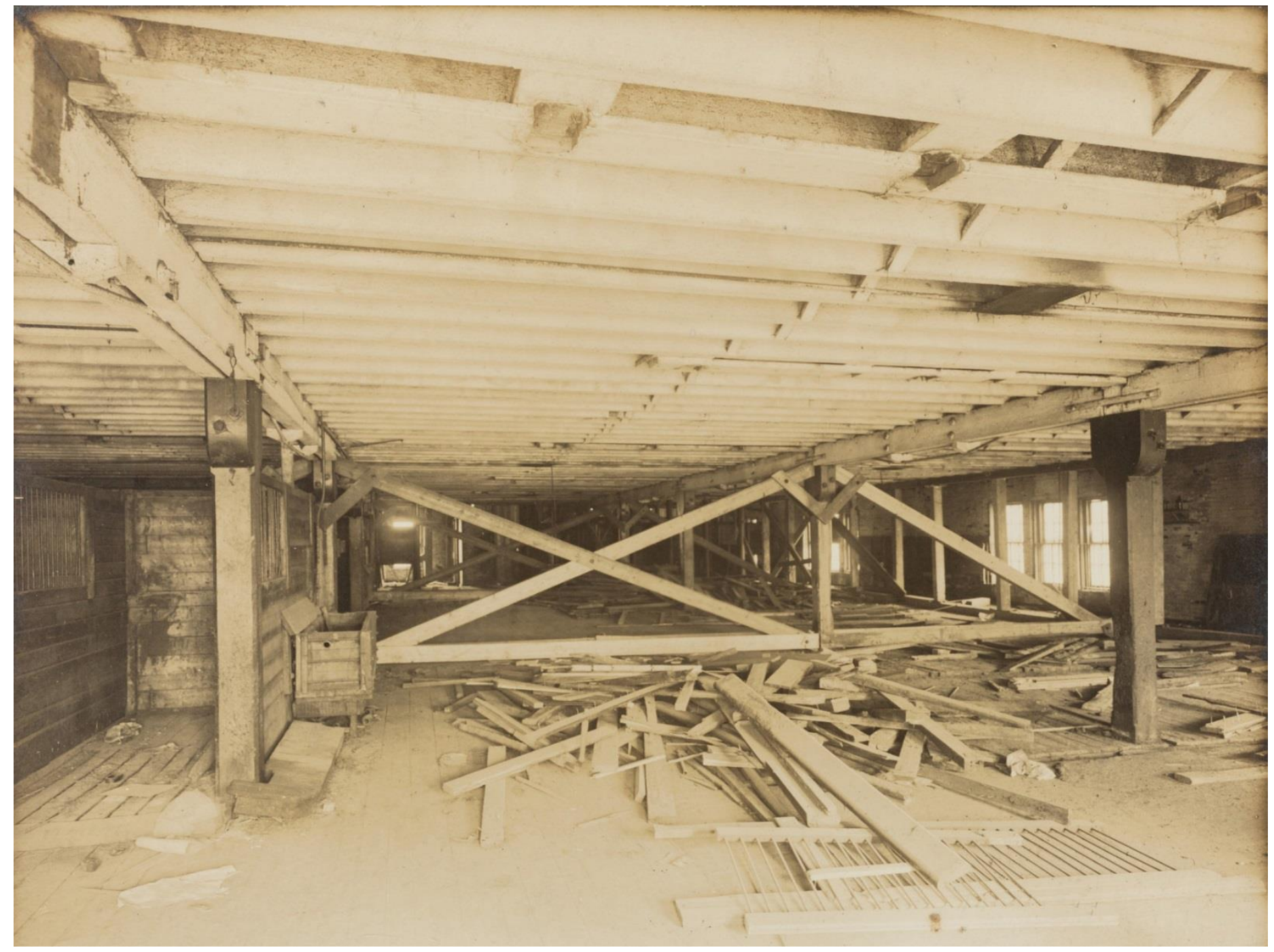

Figure 1-23. Third floor of the Boston Cab Company. The stall to the left has a drain pipe centered in the floor to collect horse urine. Photo taken 1913, Boston Transit Commission. Courtesy Historic New England. 


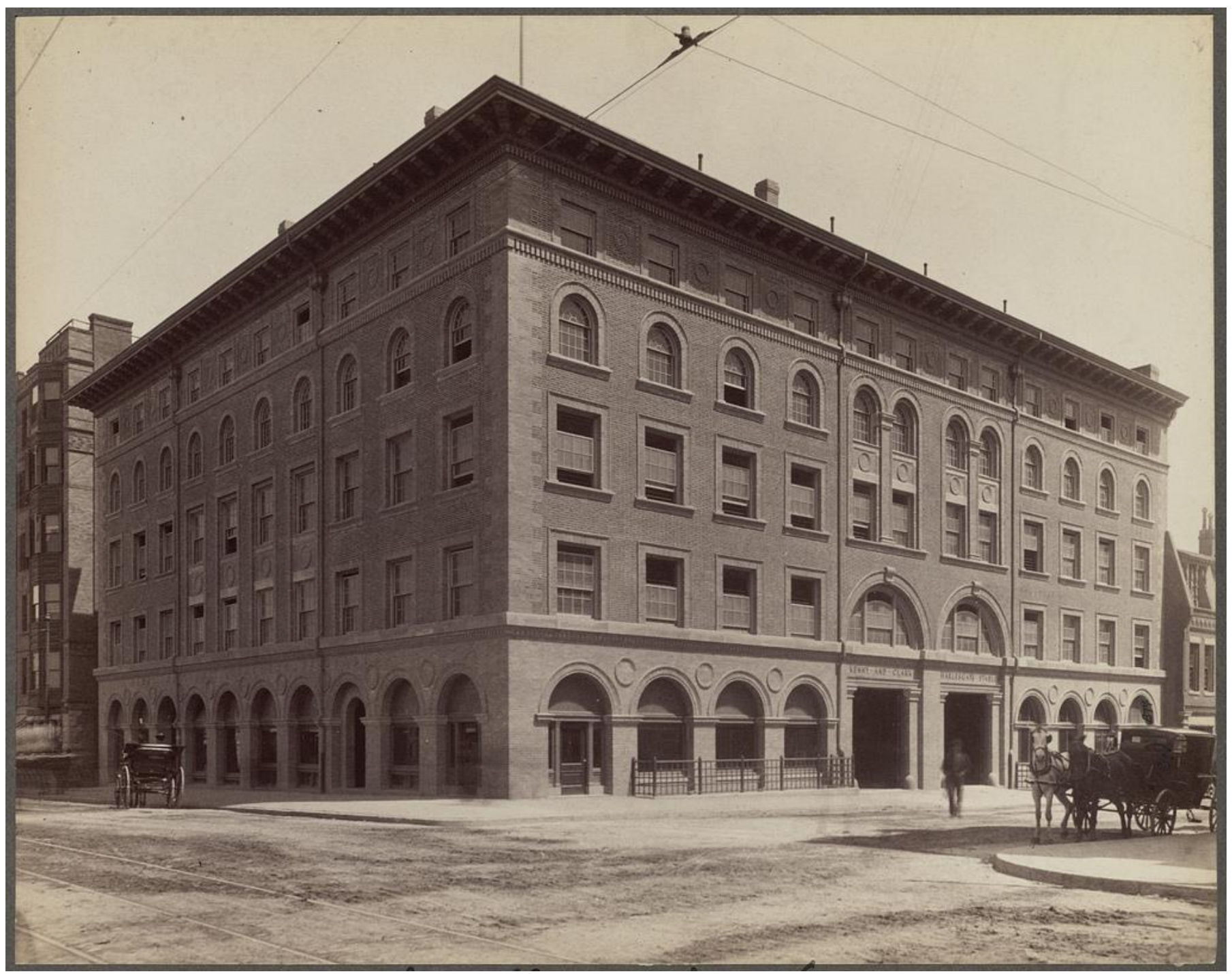

Figure 1-24. Charlesgate Stables, corner of Massachusetts Avenue and Newbury Street. Designed by Peabody \& Stearns for Kenney \& Clark, 1893. Courtesy Boston Public Library. 


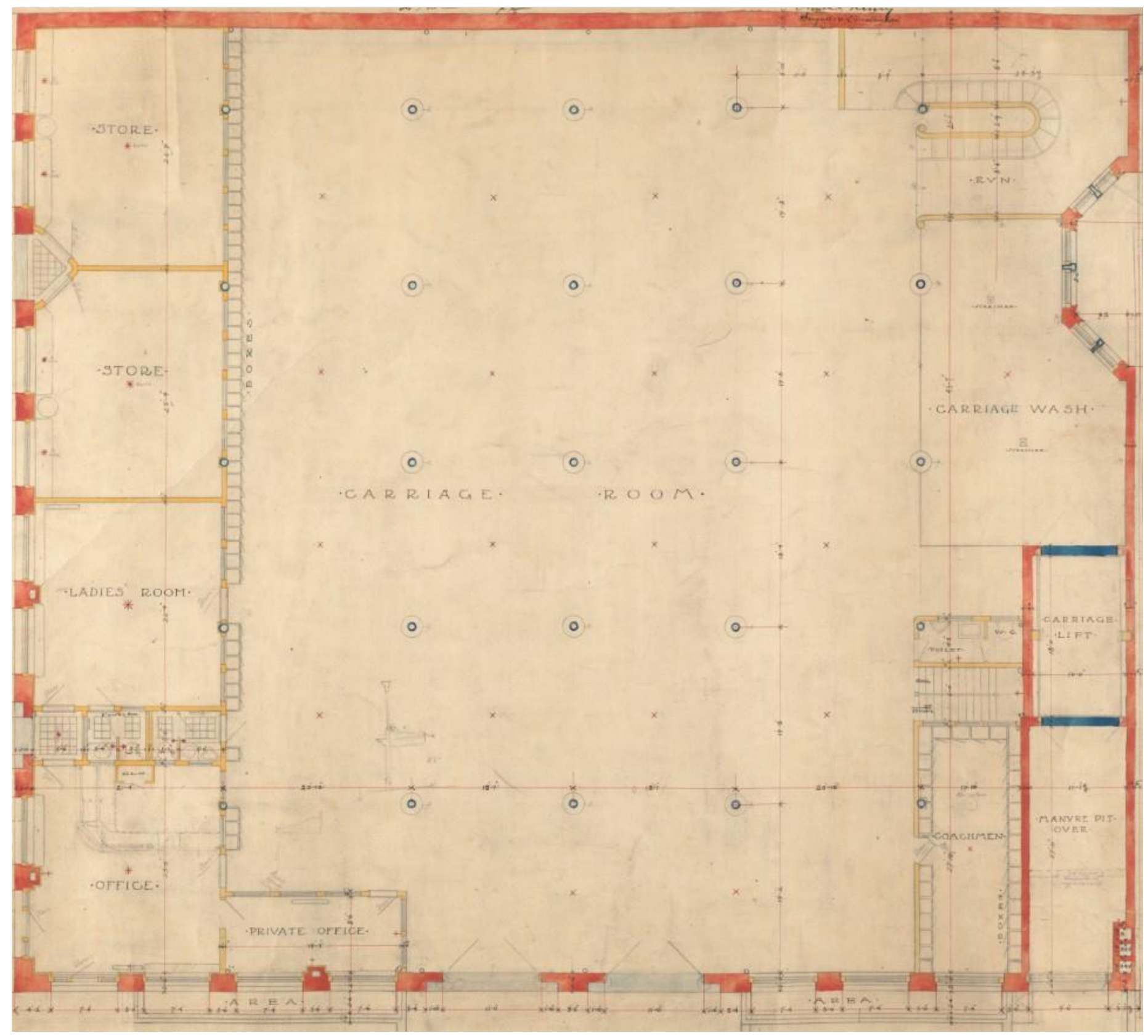

Figure 1-25. Plan for the ground floor of the Charlesgate Stables, Peabody \& Stearns, 1893. 


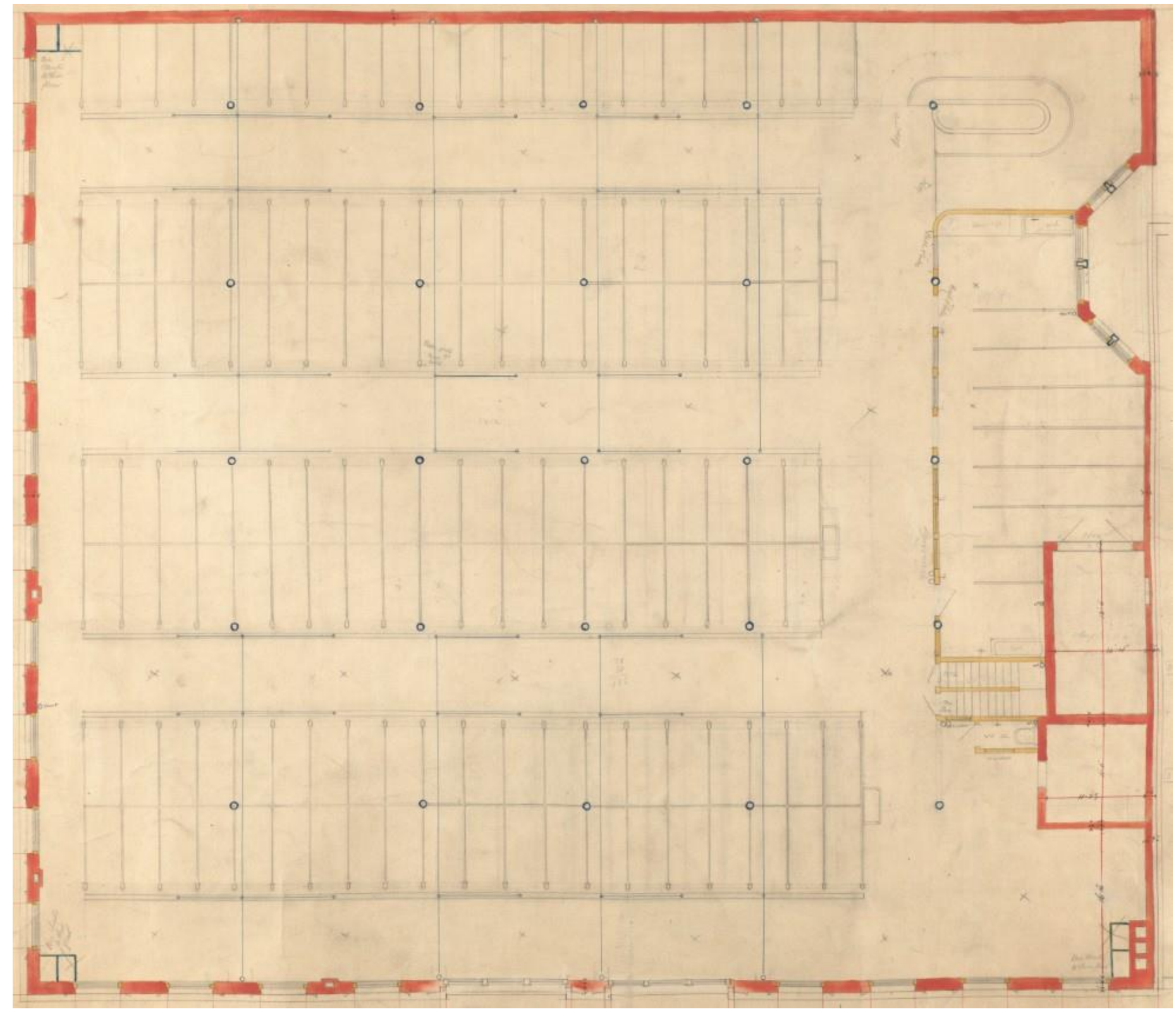

Figure 1-26. Plan for the second floor of the Charlesgate Stables, Peabody \& Stearns, 1893. 


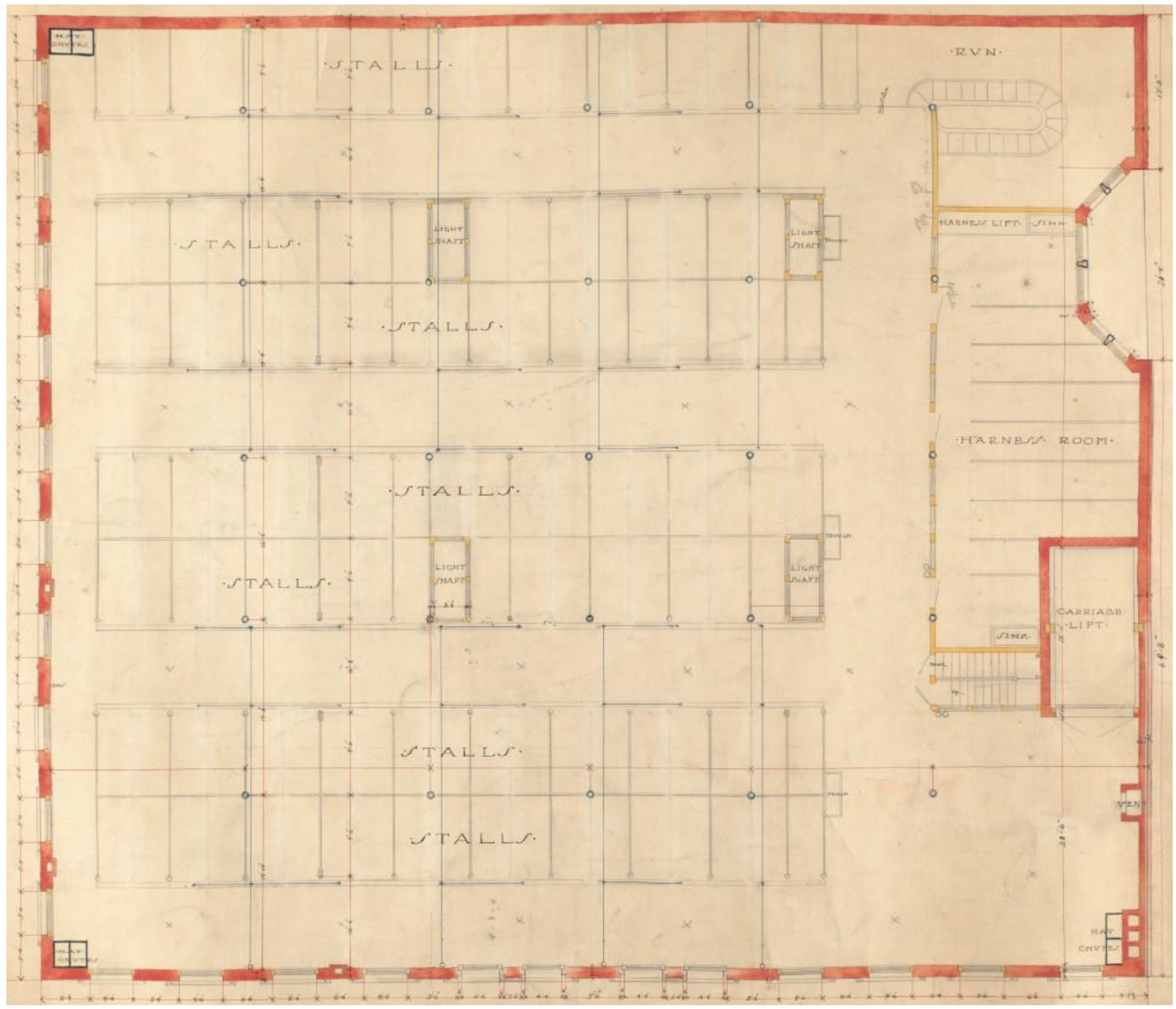

Figure 1-27. Plan for the third floor of the Charlesgate Stables, Peabody \& Stearns, 1893. 


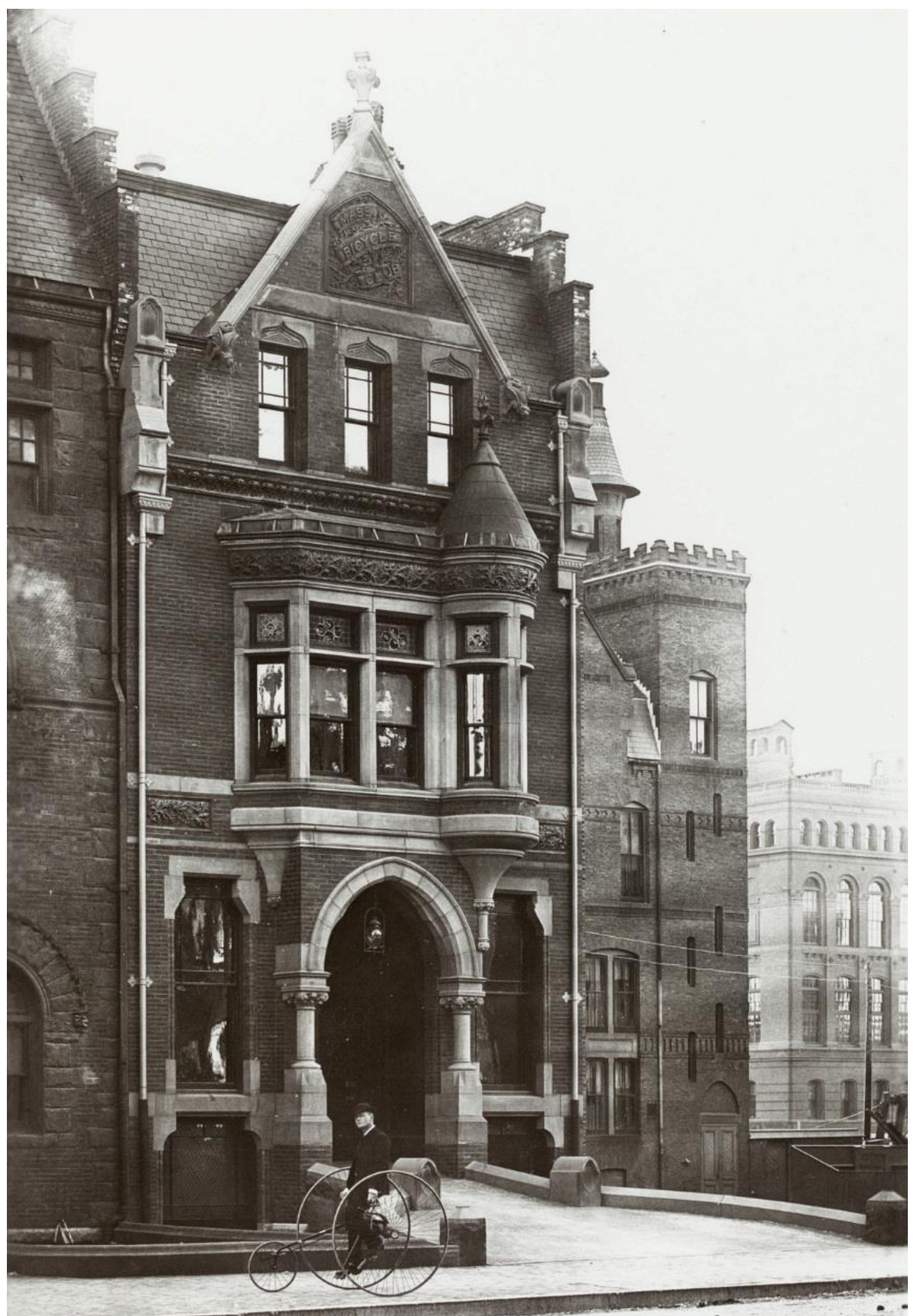

Figure 2-1. Massachusetts Bicycle Club, 152 Newbury Street. Designed by George Meacham, 1884. Courtesy of Historic New England. 

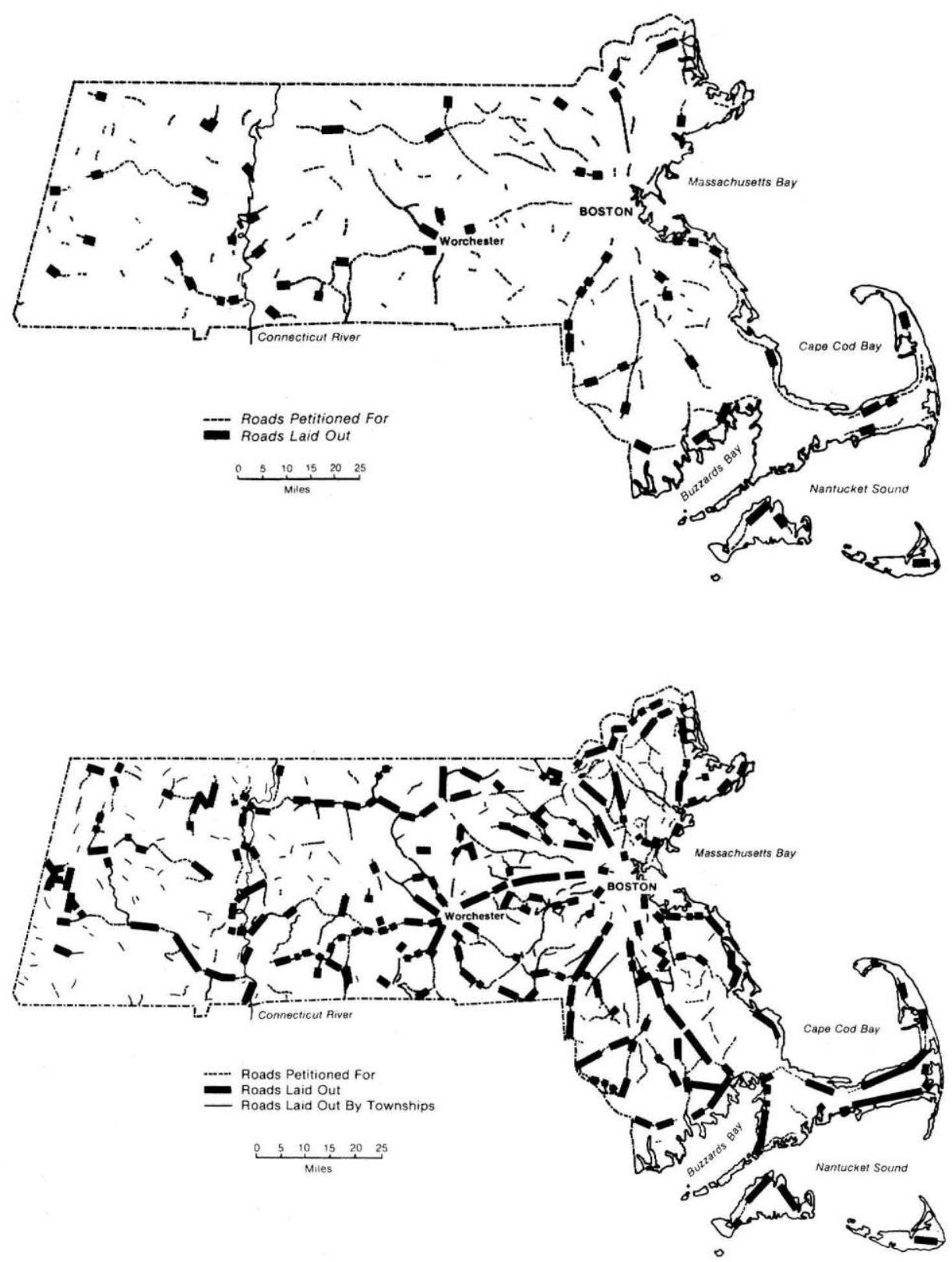

Figure 2-2. Good-Road network in Massachusetts in 1897 (top) and 1907 (bottom). Hugill, "Good Roads and the Automobile in the United States 1880-1929," 333. 


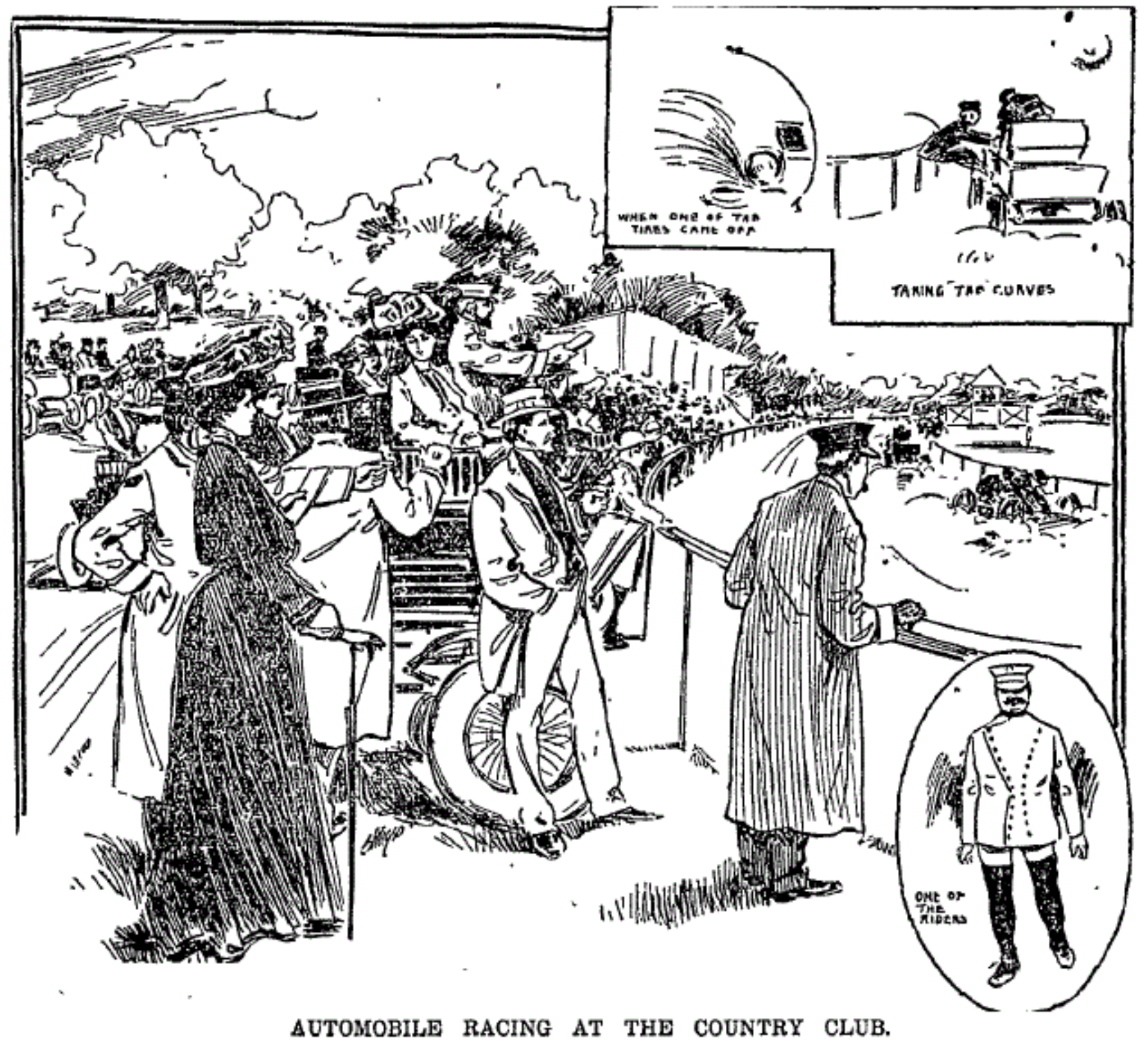

Figure 2-3. Illustration of the Automobile Club of New England's first automobile race, held at the Brookline Country Club in 1901. Boston Globe, June 16, 1901, 5. 
CI.UB ARBREVIATIONS.

A............................

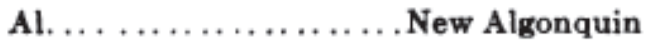

At $\ldots \ldots \ldots \ldots \ldots \ldots \ldots \ldots$ Athletic

Au.................. Automobile

Cy........................ Country

Ec............ Essex County Country

Ex.................... Exchange

Ey.........................

Hn............... Harvard of N Y

My....................... Myopia
Myf.... A. ...............Msyflower Nh.................... Norfolk Hunt Ok................ Oakley Country P. .......................Puritan Sb...................... Botolph Sm...................... Somerset Tr................. Tennis \& Racquet Tv. ........................ Tavern Un. ...................... Union Uv. ................. University

Aht' Br' Cl' Dth' H' P' Wms' Y' respectively indicate the college, and, when the date follows, the graduating class.

The first club following a name indicates where letters may be sert.

Club atbreviation; rot included in the above list, refer to Nerr York, Washington, Philadelphia, Chicago, St. Louis, Battimoye Ptisburgh, Buffalo or Southern Cities Clubs, to distinguish which is added respectively the letters, $n, w, p, c h$, si, bl, pt, bj or so.

Figure 2-6. Key to the abbreviations used by the 1904 Boston Social Register to indicate club memberships. 


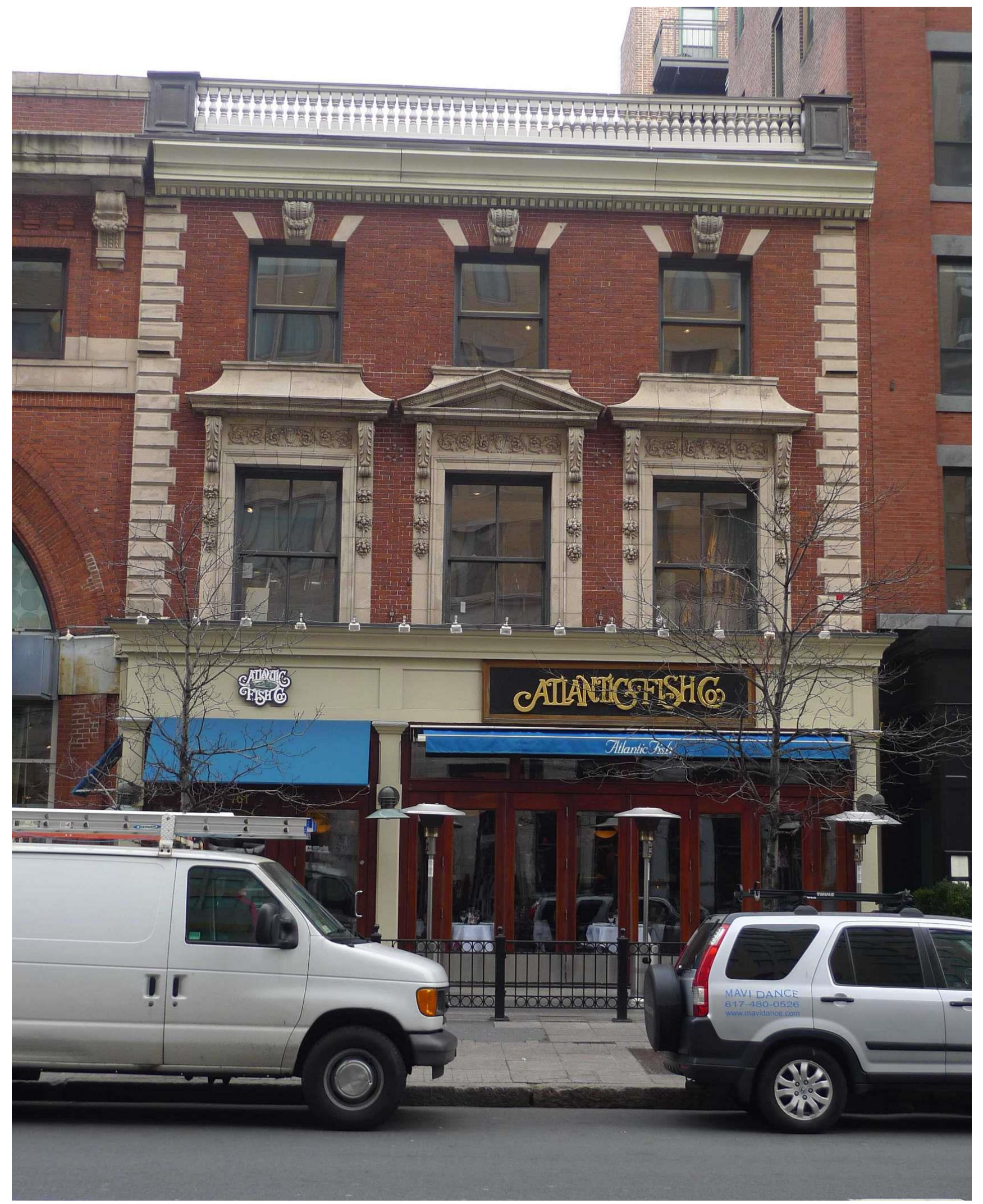

Figure 2-8. The former Massachusetts Automobile Club, 1902, 761 Boylston Street. Author photograph. 


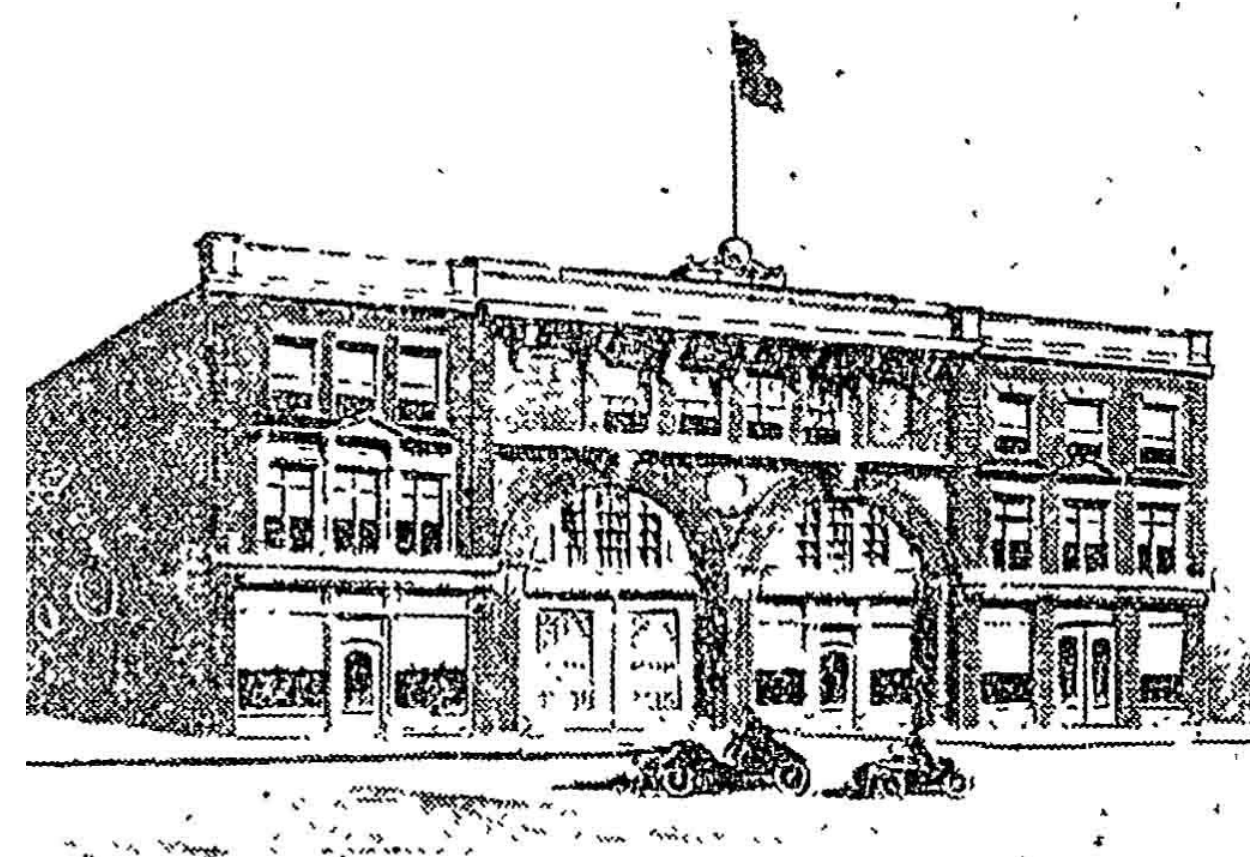

Figure 2-9. Illustration of the Massachusetts Automobile Club. "Automobile Club's

New Home," Boston Globe, January 2, 1904, 7.

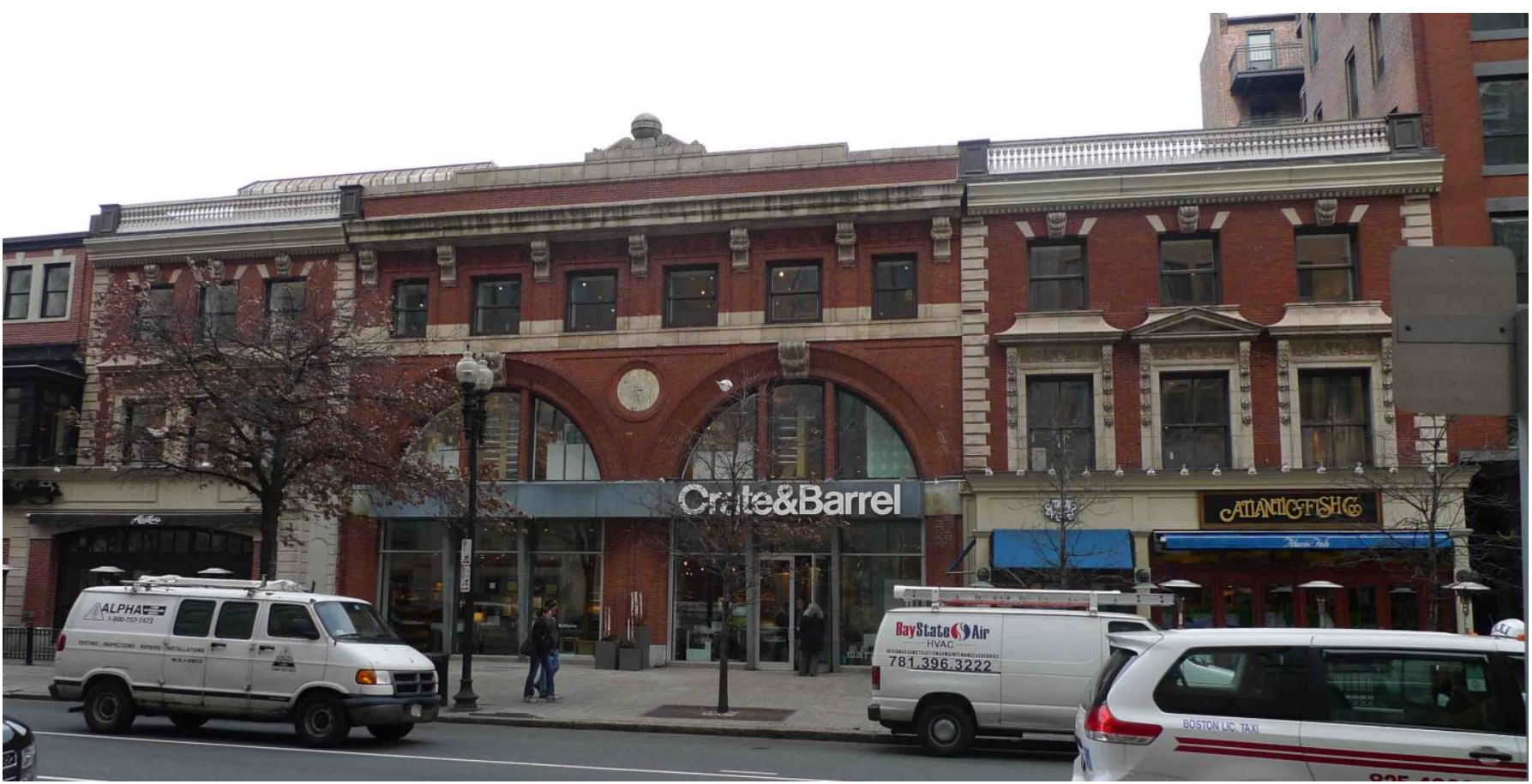

Figure 2-10. The former Massachusetts Automobile Club after it was expanded in 1904, 761-791 Boylston Street. The Atlantic Fish Company occupies what was the original 1902 clubhouse. Author photograph. 

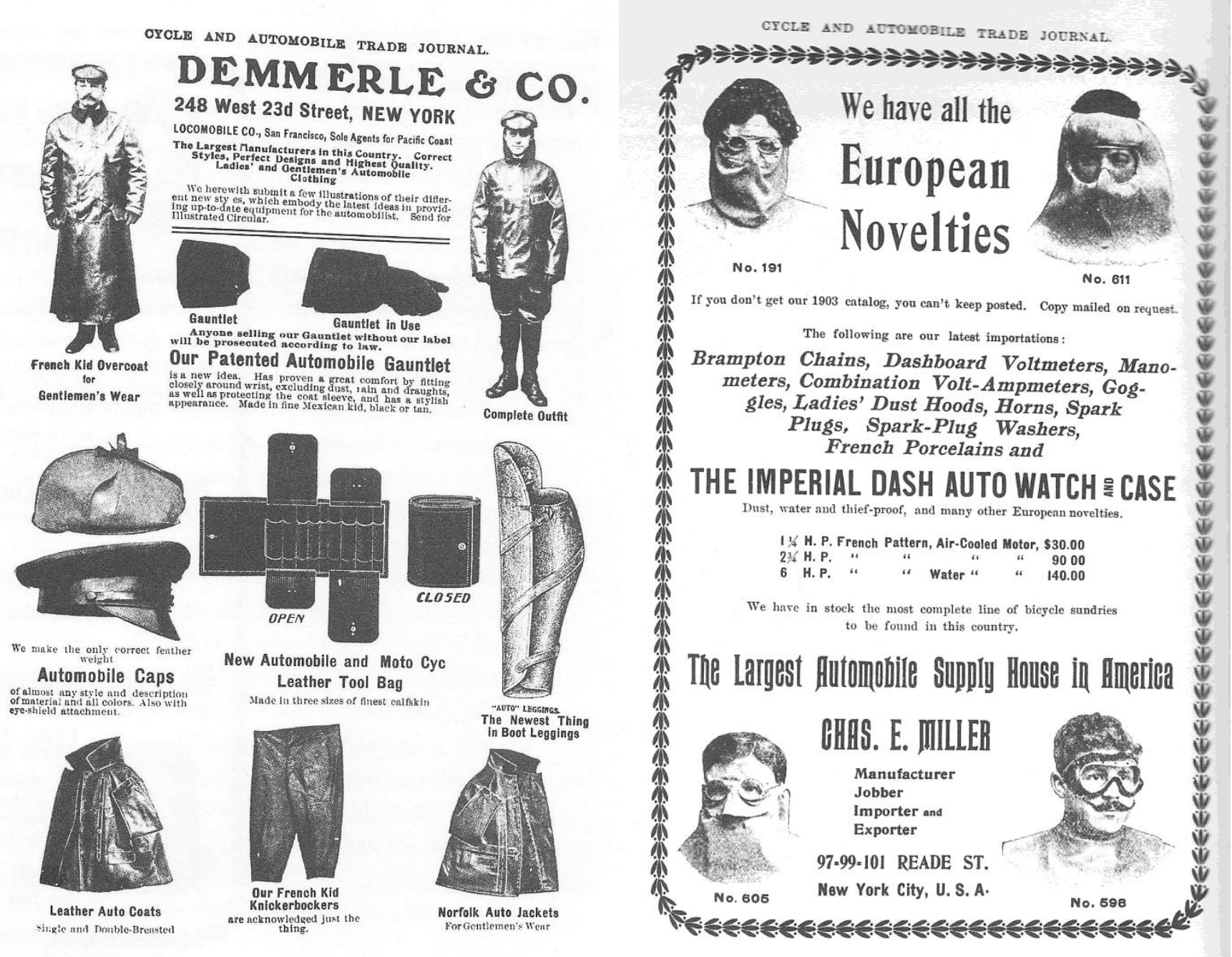

Figures 2-11, 2-12. Advertisements for automobilists' clothing from 1903. Flink, America Adopts the Automobile, plates 25 and 26 . 


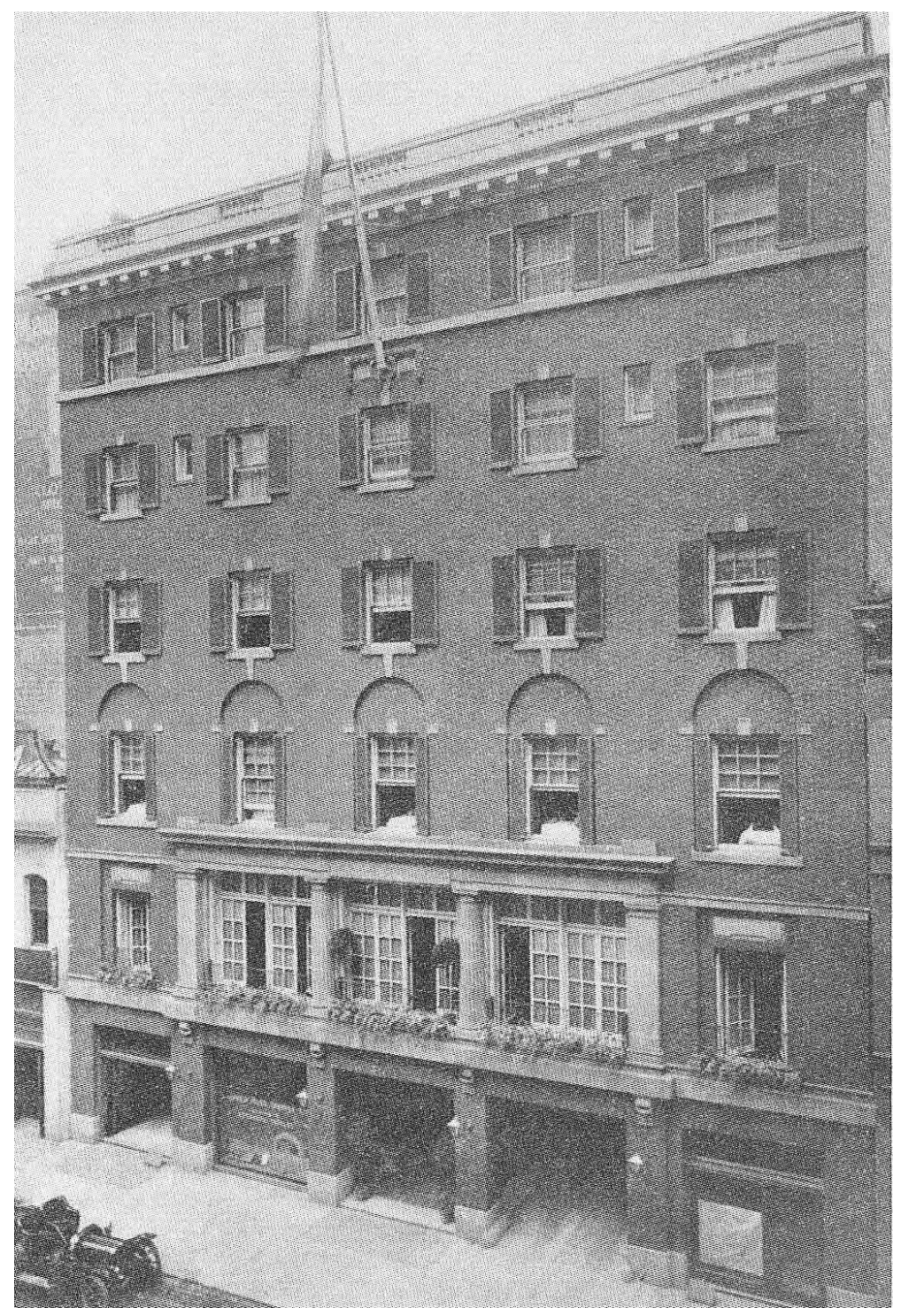

Figure 2-13. Chicago Automobile Club built in 1907, Marshall and Fox, 321 Plymouth Court, Chicago. Sennott in Jennings (ed.), Roadside America: the Automobile in Design and Culture, 160. 


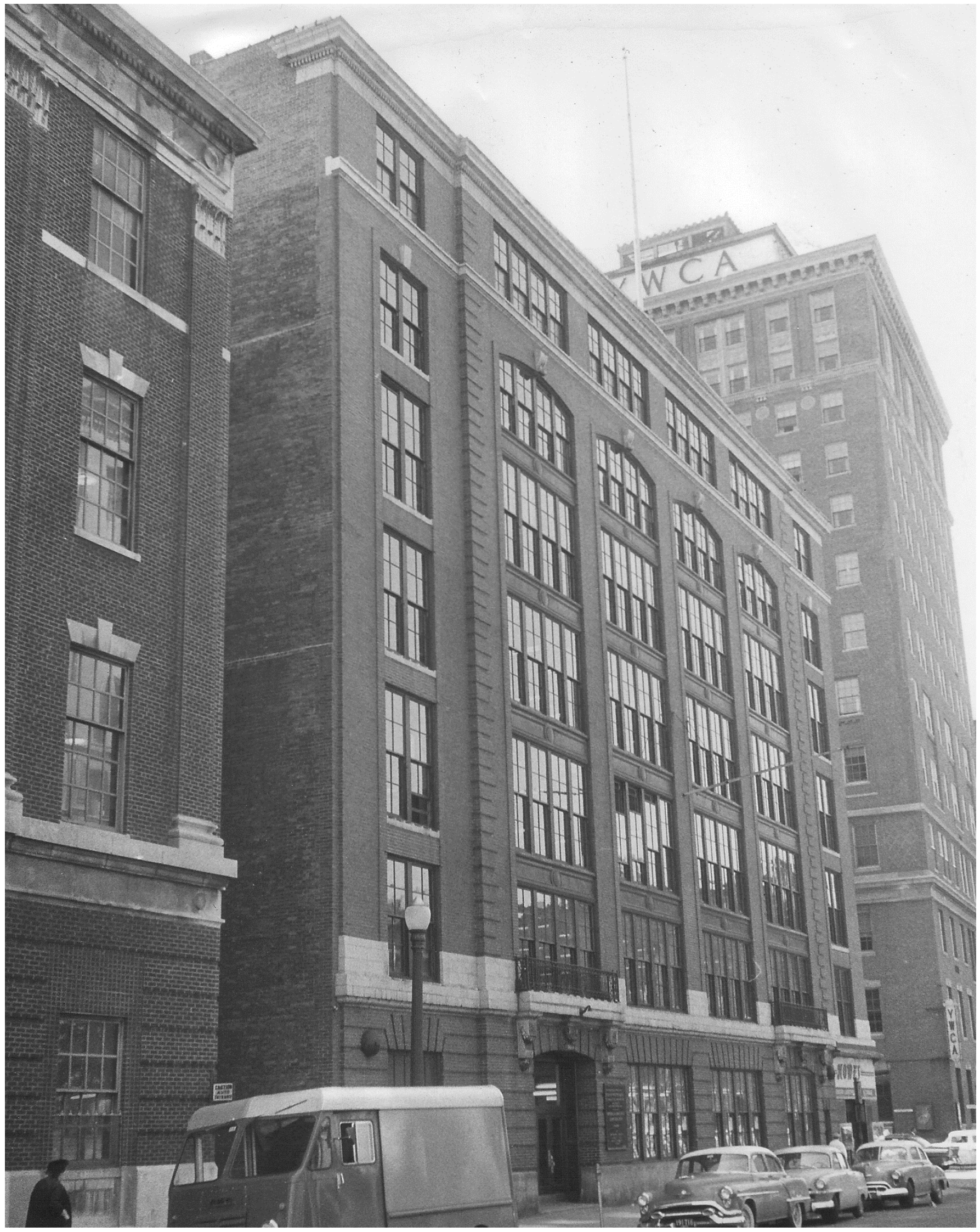

Figure 2-14. The 1914 Massachusetts Automobile Club at the corner of Stuart and Clarendon Streets. Courtesy of the Bostonian Society. 


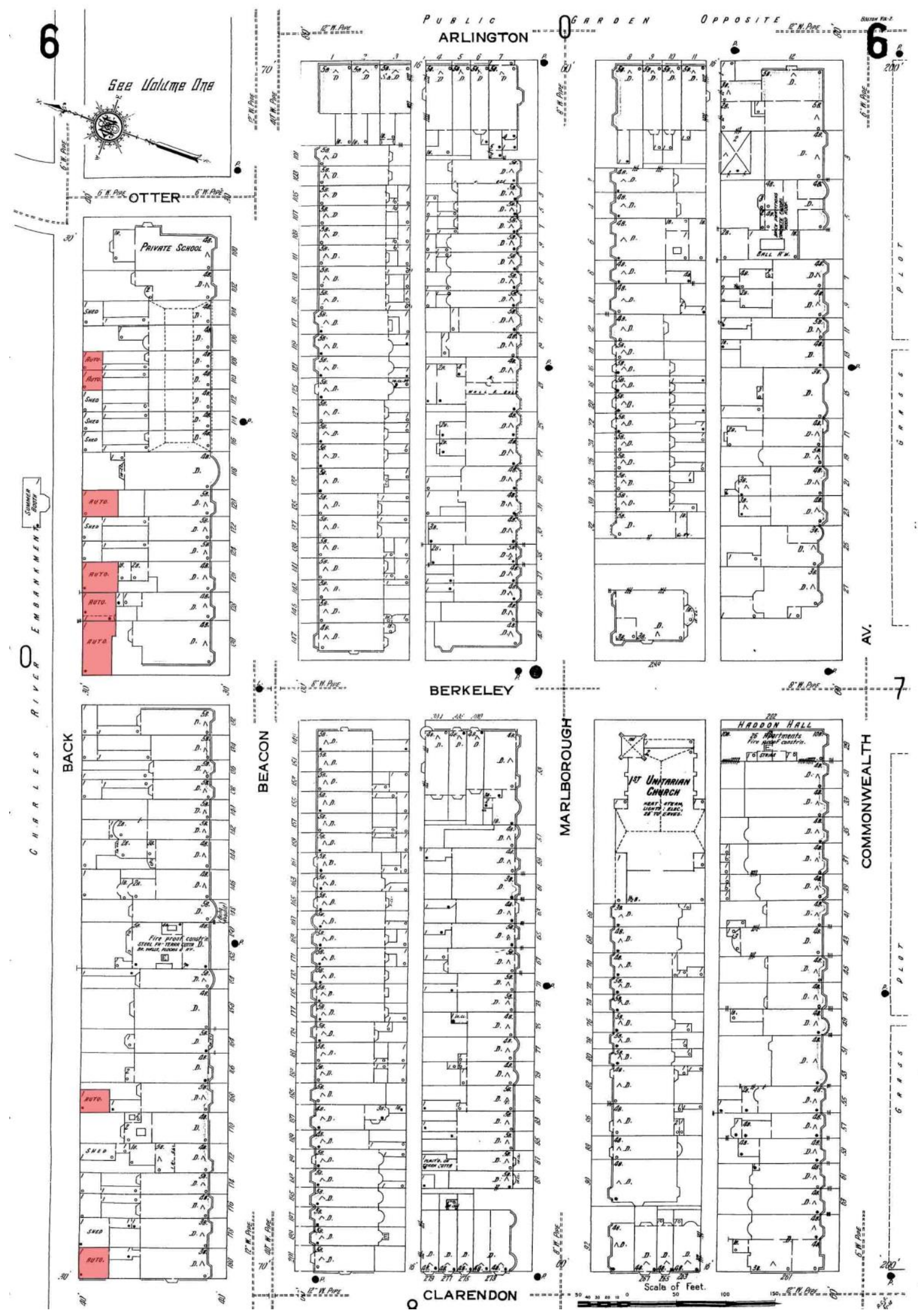

Figure 2-15. Sanborn Fire Insurance Map, Boston, 1914, volume 2, sheet 6 . This six garages highlighted on this map represent the greatest density of private garages in Boston. 


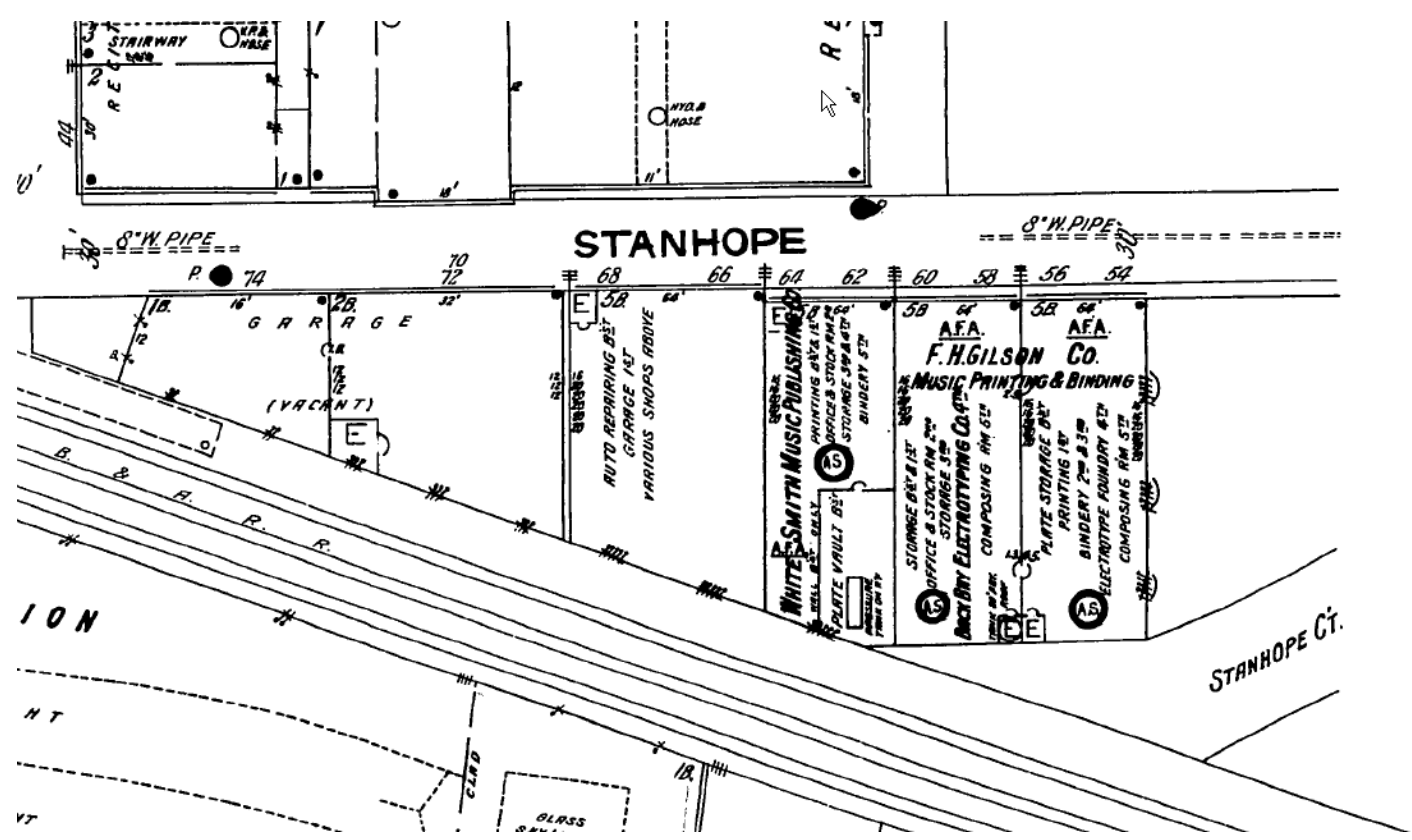

Figure 2-16. Detail of 1914 Sanborn Fire Insurance plate showing location of "Automobile Headquarters" at 66-68 Stanhope Street.

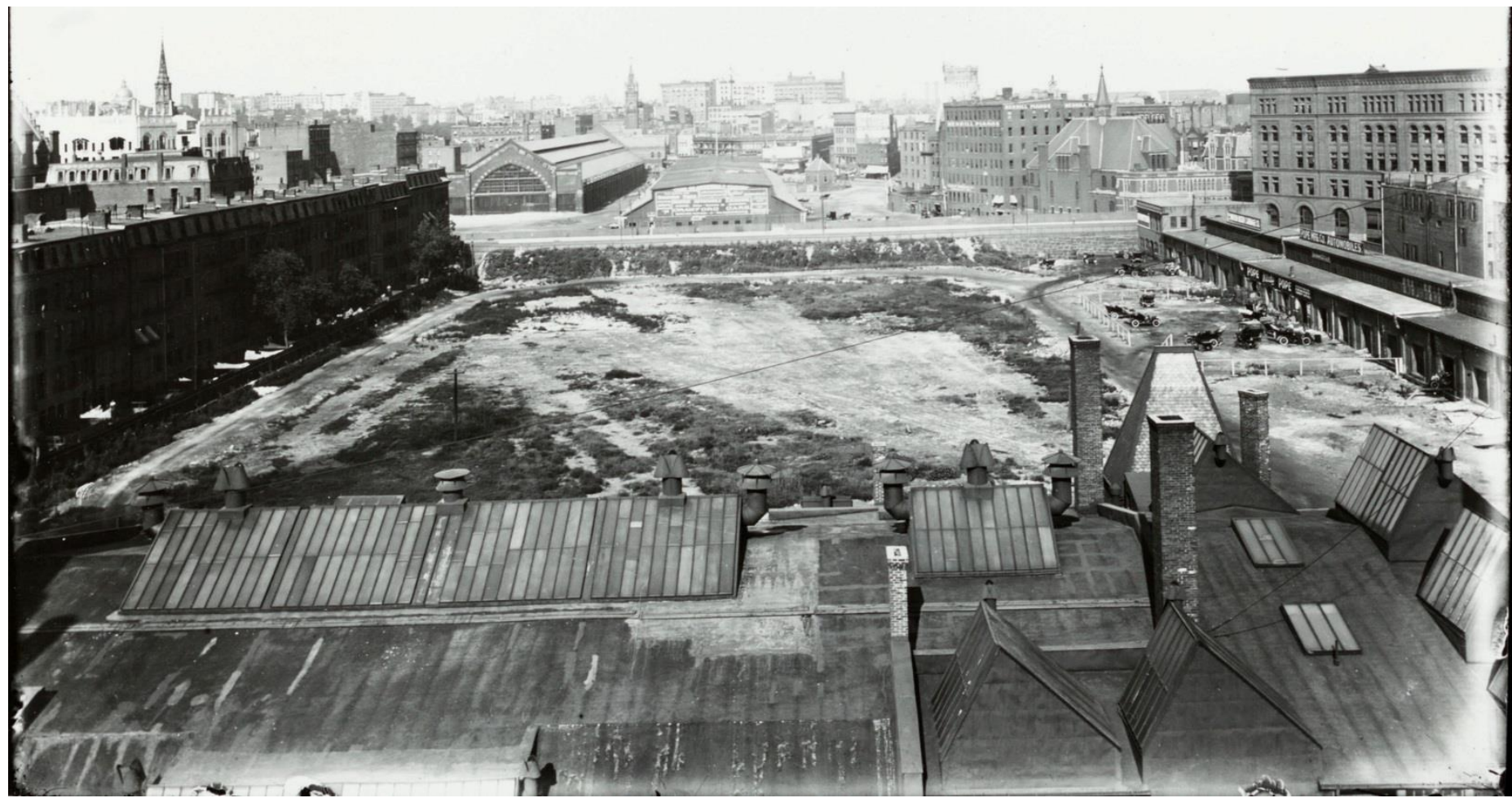

Figure 2-17. Image of the automobile track located between Berkeley Street, Clarendon Street, Stanhope Street and St James Avenue. Some of the automobile businesses located on Stanhope Street are visible on the right side of the image. Previously unidentified photograph, courtesy of Historic New England. 


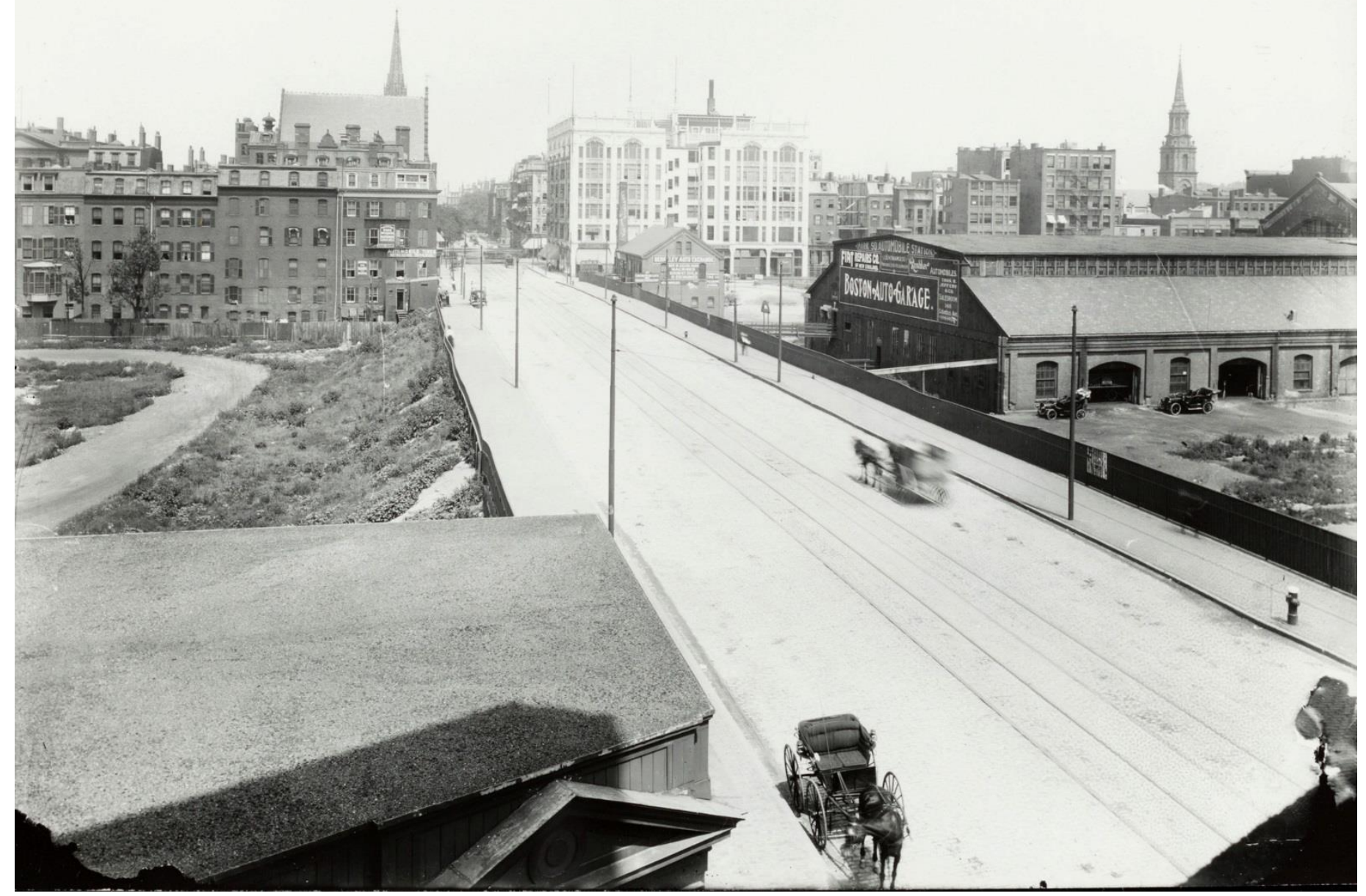

Figure 2-18. Partial view of the automobile track located between Berkeley Street, Clarendon Street, Stanhope Street and St James Avenue. The Park Square Automobile Station, a former freight shed for the Boston \& Providence Railroad, appears to the right. Previously unidentified photograph, courtesy of Historic New England. 


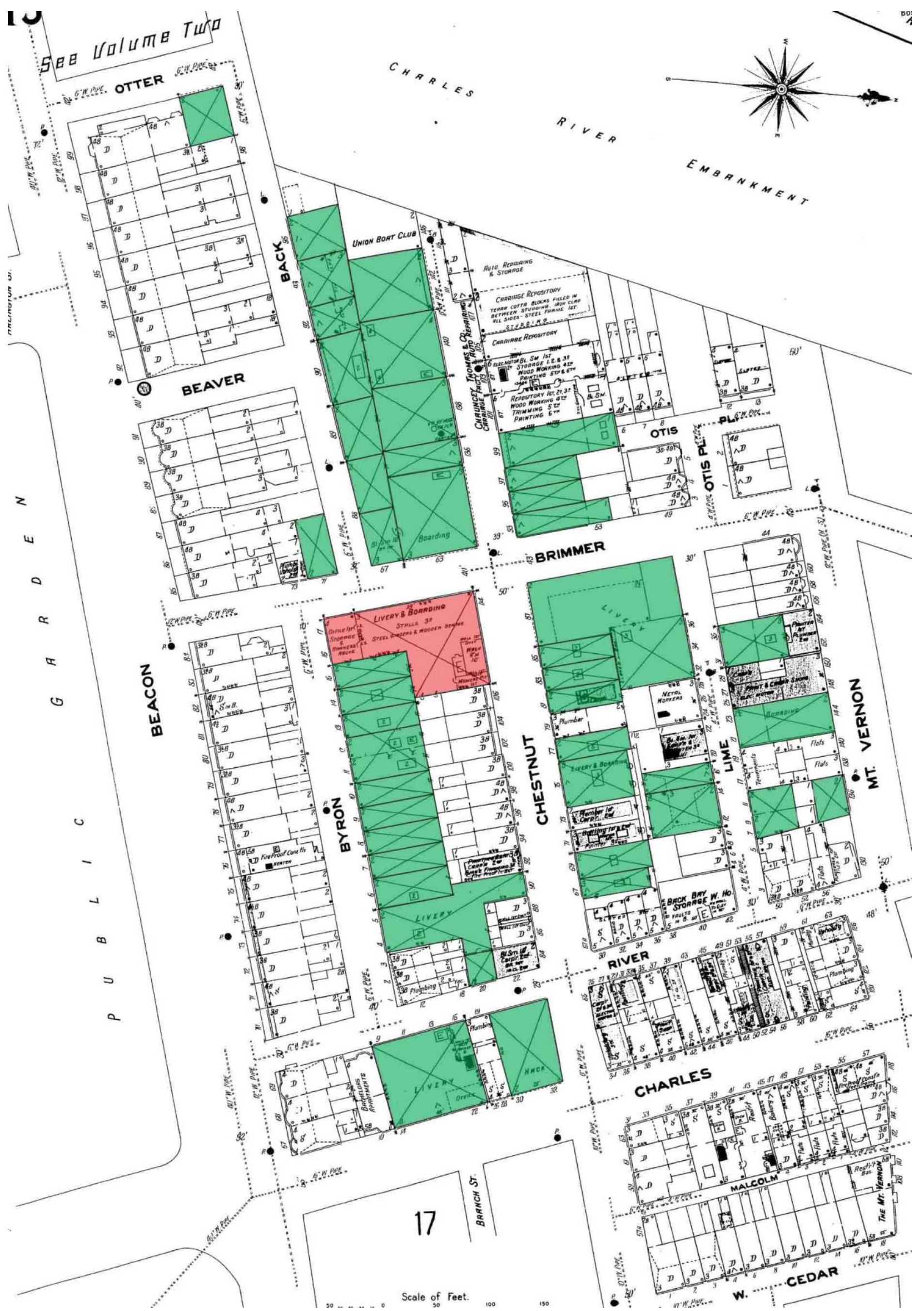

Figure 2-19. Plate 13 from the 1909 Sanborn Fire Insurance Atlas. Buildings highlighted in green are stables. The extents of the Beacon Garage are highlighted in red. 


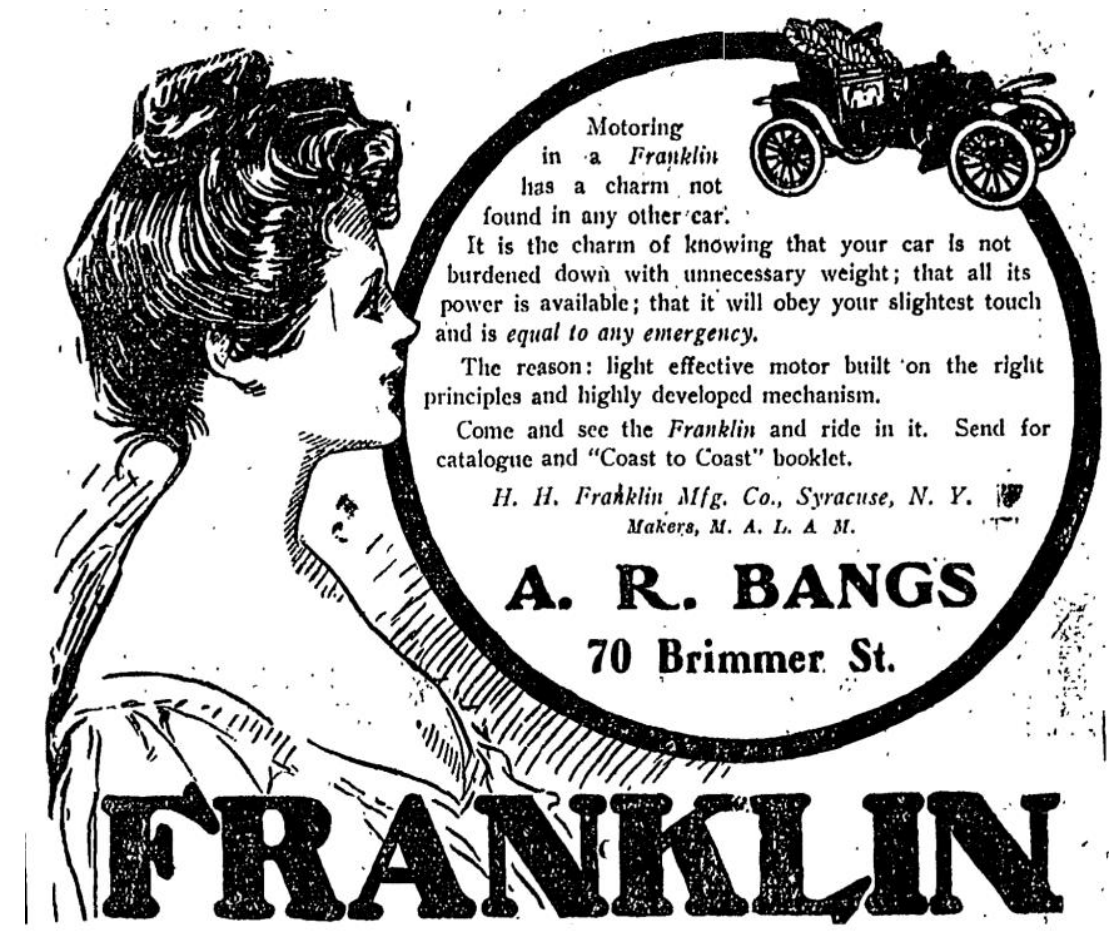

Figure 2-20. Ad for Franklin Cars sold at the Beacon Garage. Boston Globe, March 9, 1905, 3.

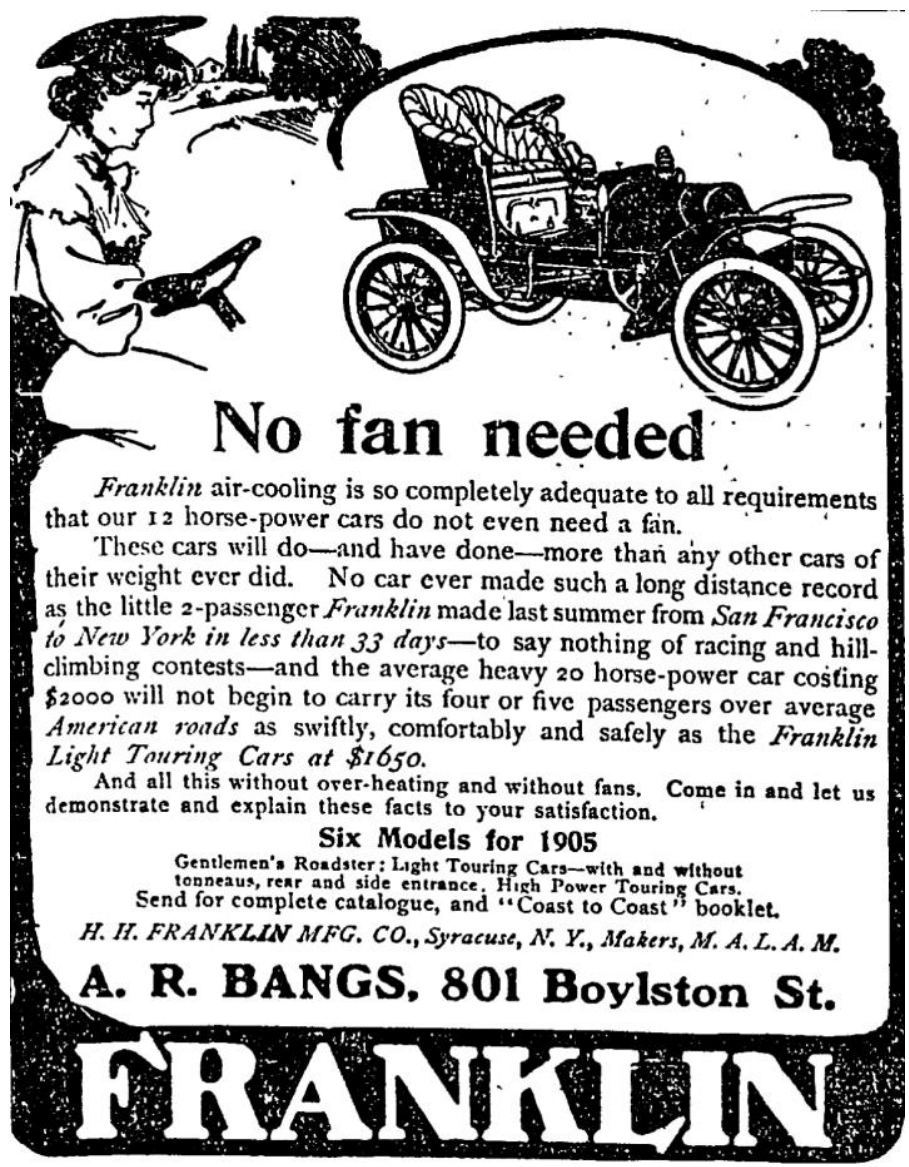

Figure 2-21. Ad for the showroom of Franklin cars, located at 801 Boylston Street. Boston Globe, May 18, 1905, 3. 


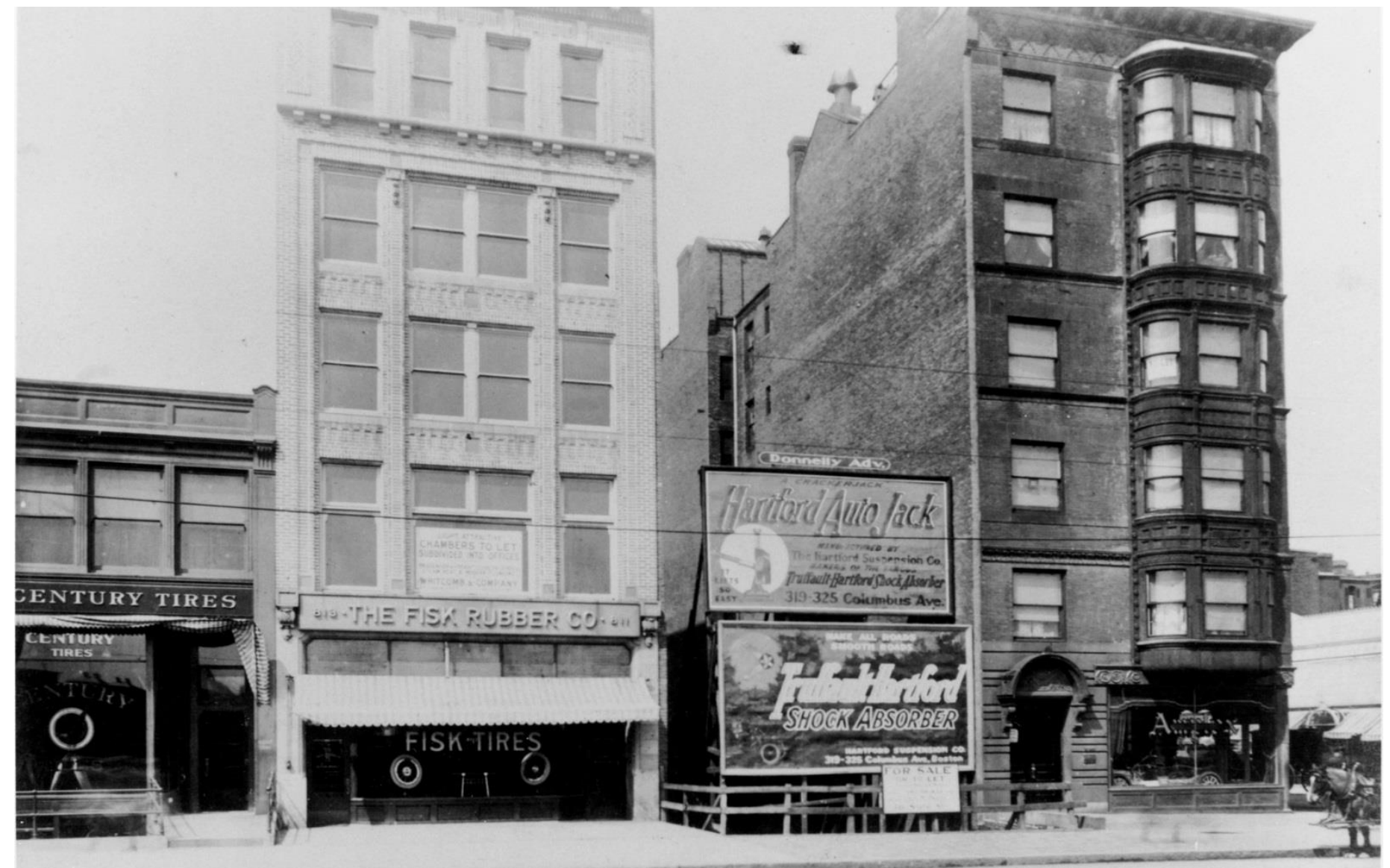

*233-3. *815-*801 BorL5TOM ST. APR.5.1912.

Figure 2-22. Image of 801-815 Boylston Street. Photo taken 1912, Boston Transit Commission. The rightmost building is 801 Boylston Street, which had been used as a showroom by A. R. Bangs, the agent of Franklin cars, until shortly after the 1905 fire that destroyed the Beacon Garage. Courtesy of Historic New England. 


\section{RUINS OF THE BEACON GARAGE HEROINE AND TOTS SHE SAVED}

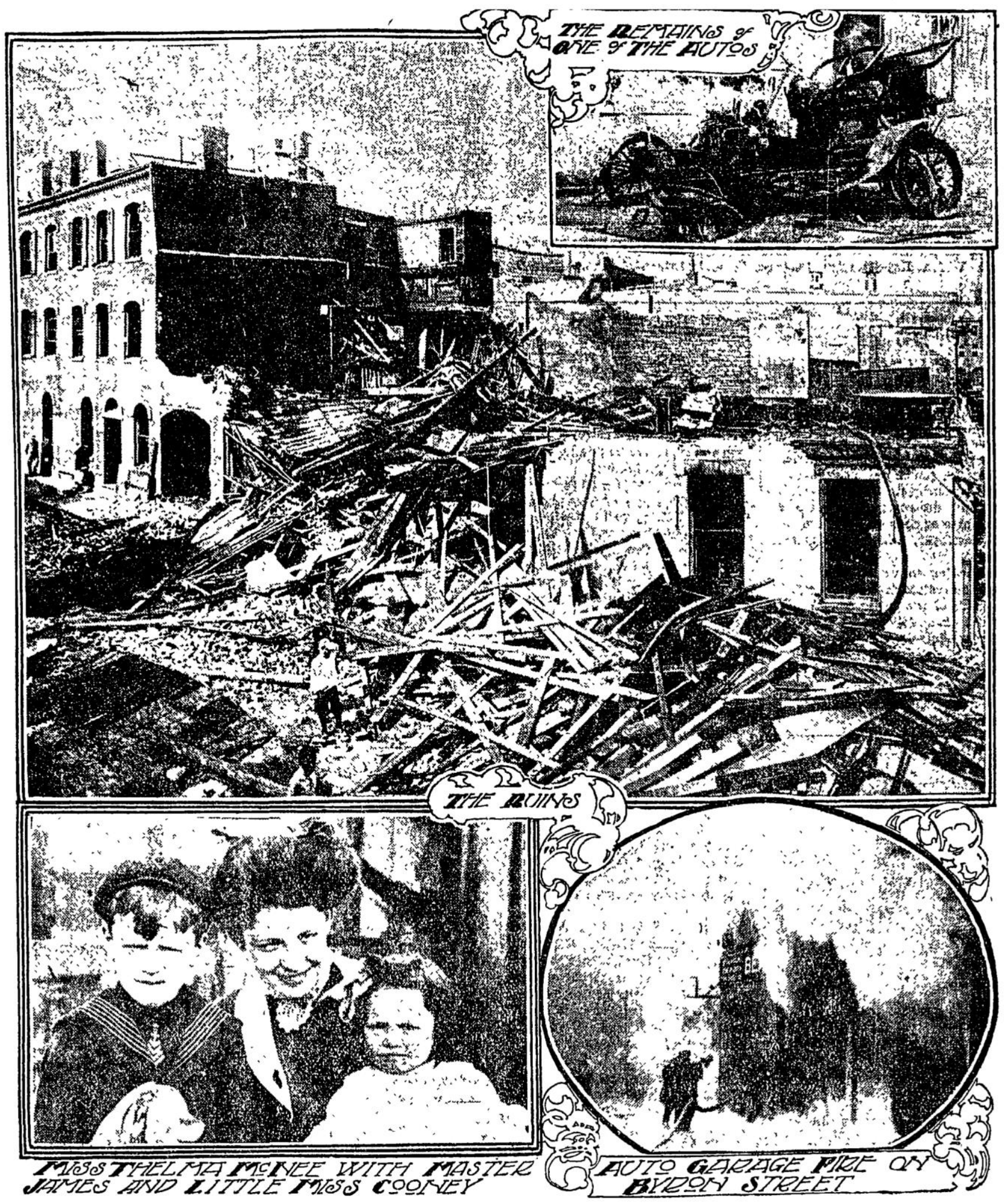

Figure 2-23. The Beacon Garage after the 1905 fire. Boston Globe, May 31, 1905, 1. 


\section{NEW TREMONT GARAGE, LARGEST IN THE WORLD.",}

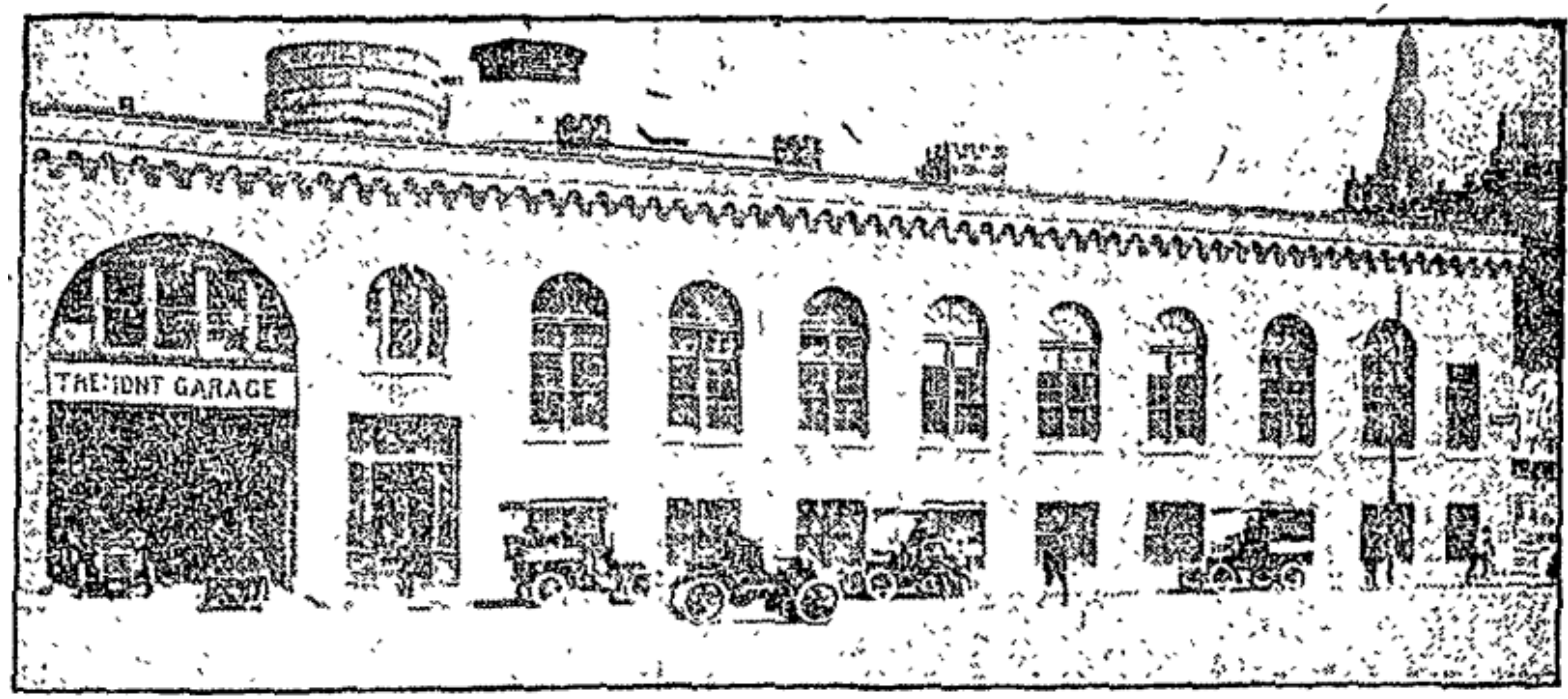

Figure 2-24. Ad showing the entrance to the Tremont Garage. Boston Globe, May 29, 1904, 20.

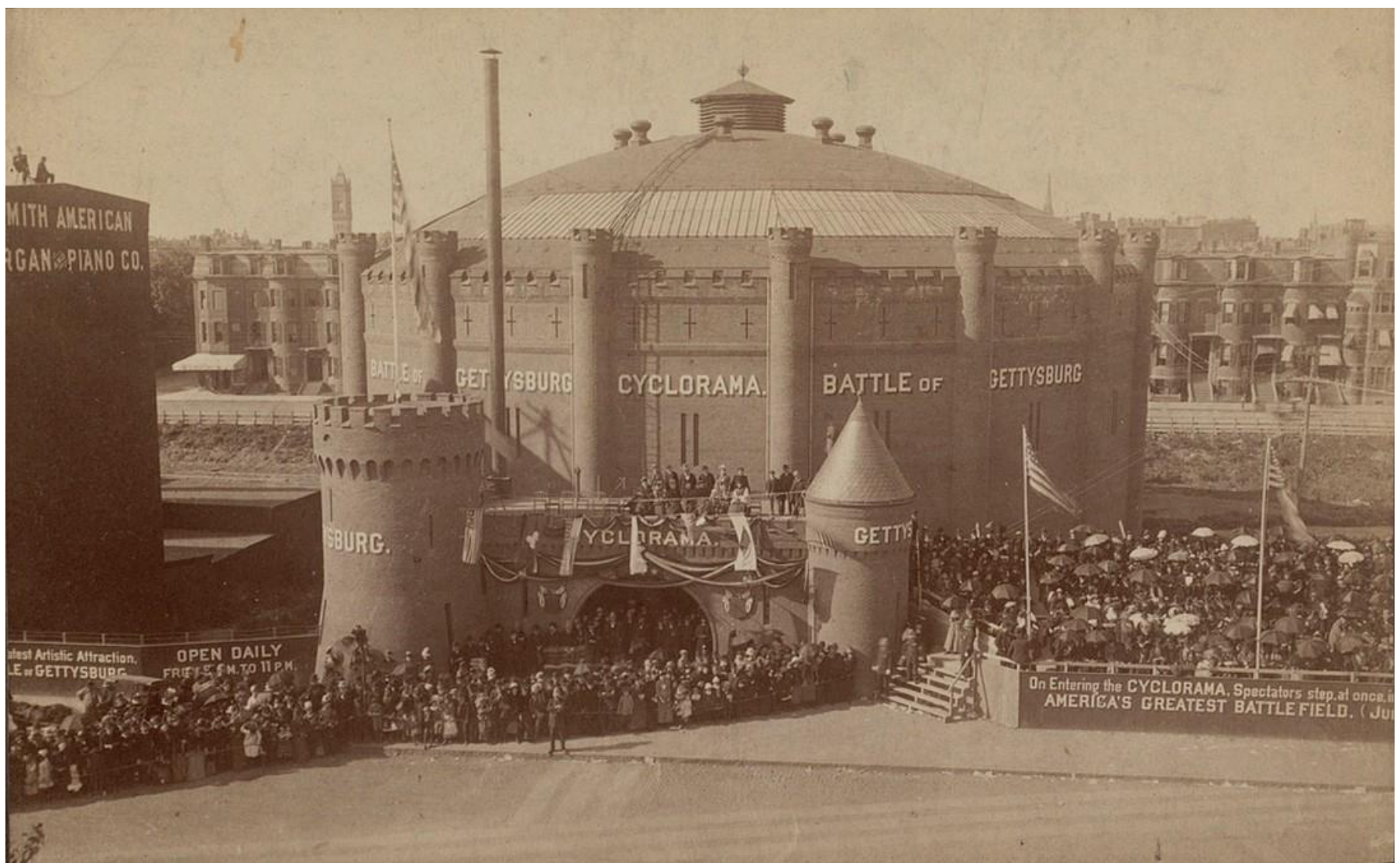

Figure 2-25. The Cyclorama located at 541 Tremont Street in Boston. Designed by Willard Sears, 1884. Courtesy of the Boston Public Library. 


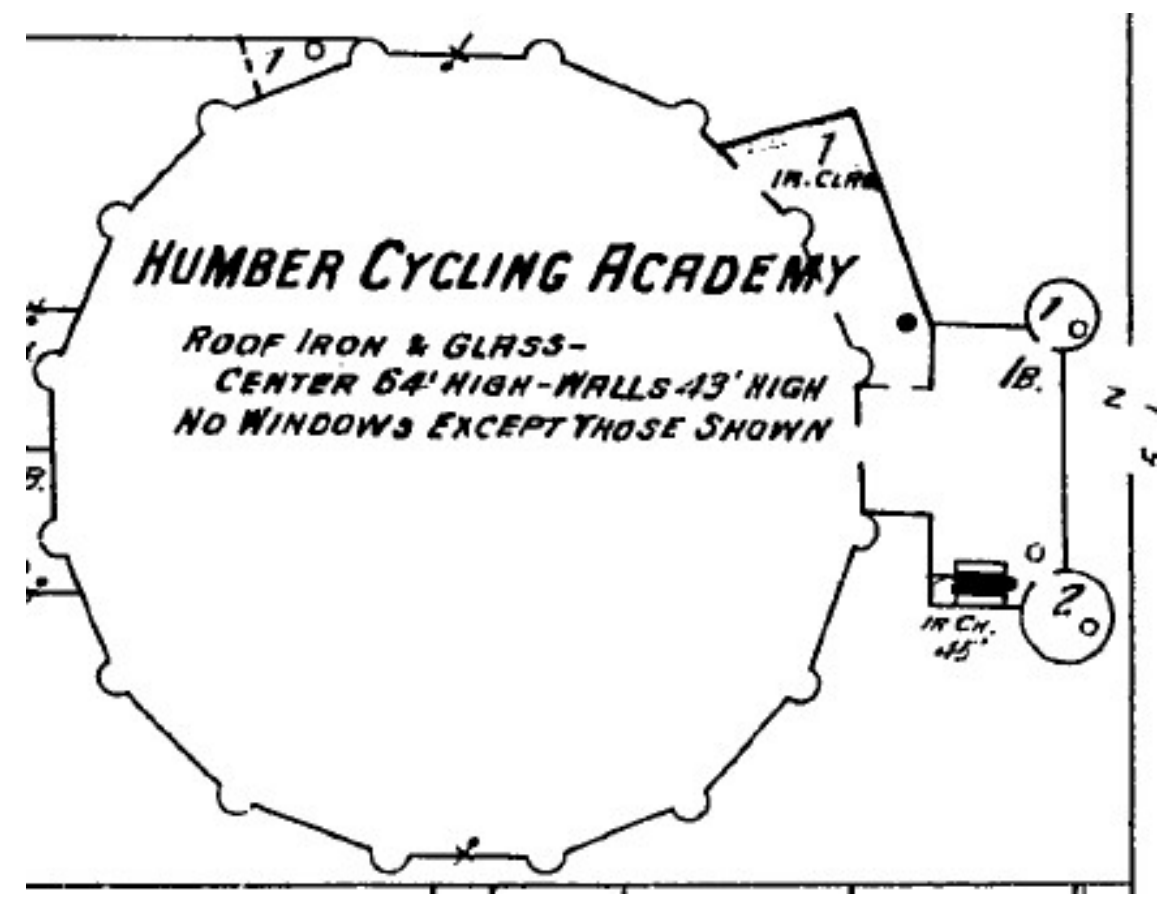

Figure 2-26. Detail from a 1897 Sanborn Fire Insurance plate showing the plan of the Cyclorama in its incarnation as a bicycle shop and school.

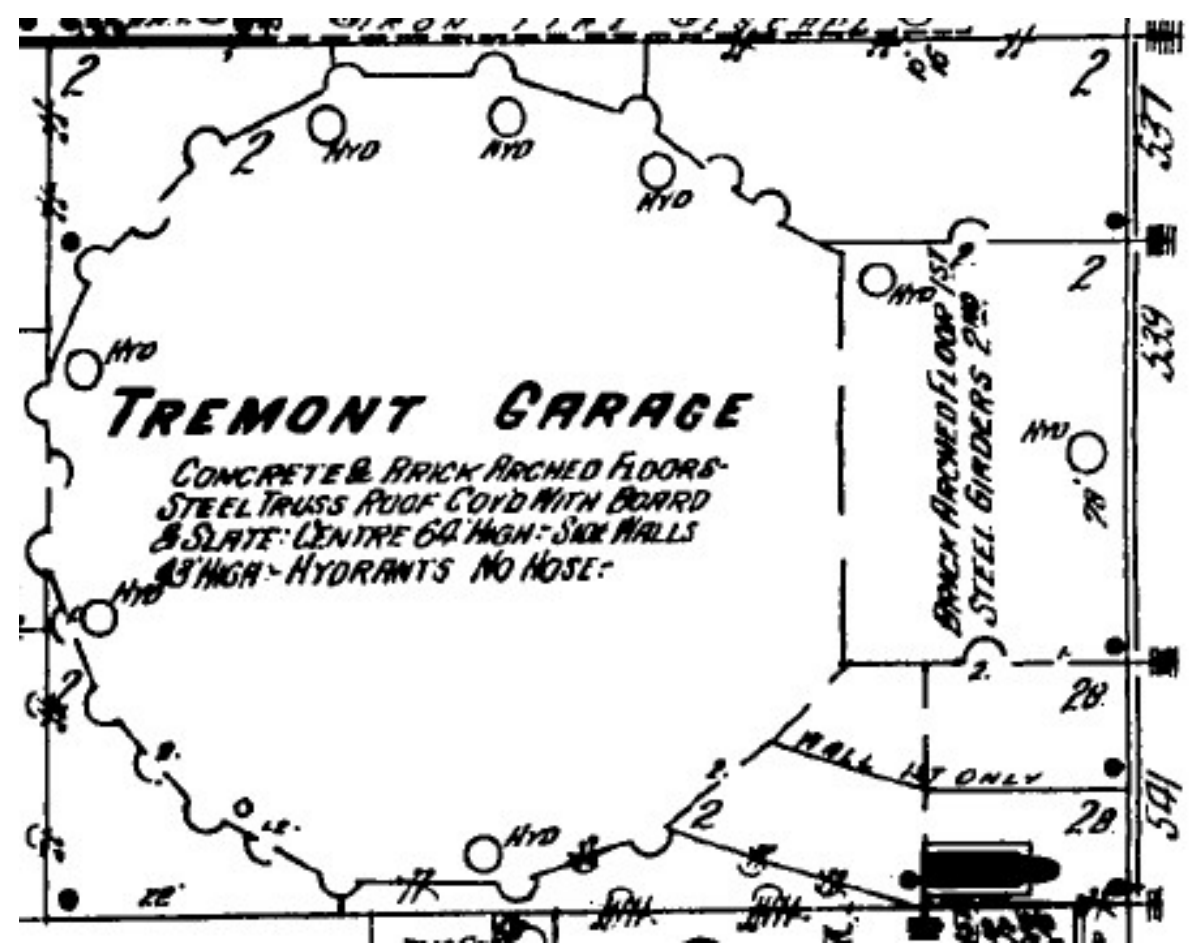

Figure 2-27. Detail from a 1914 Sanborn Fire Insurance plate showing the plan of the Cyclorama in its incarnation as the Tremont Garage. The turreted entry has been removed and multiple chambers have been added to the original cylinder. 


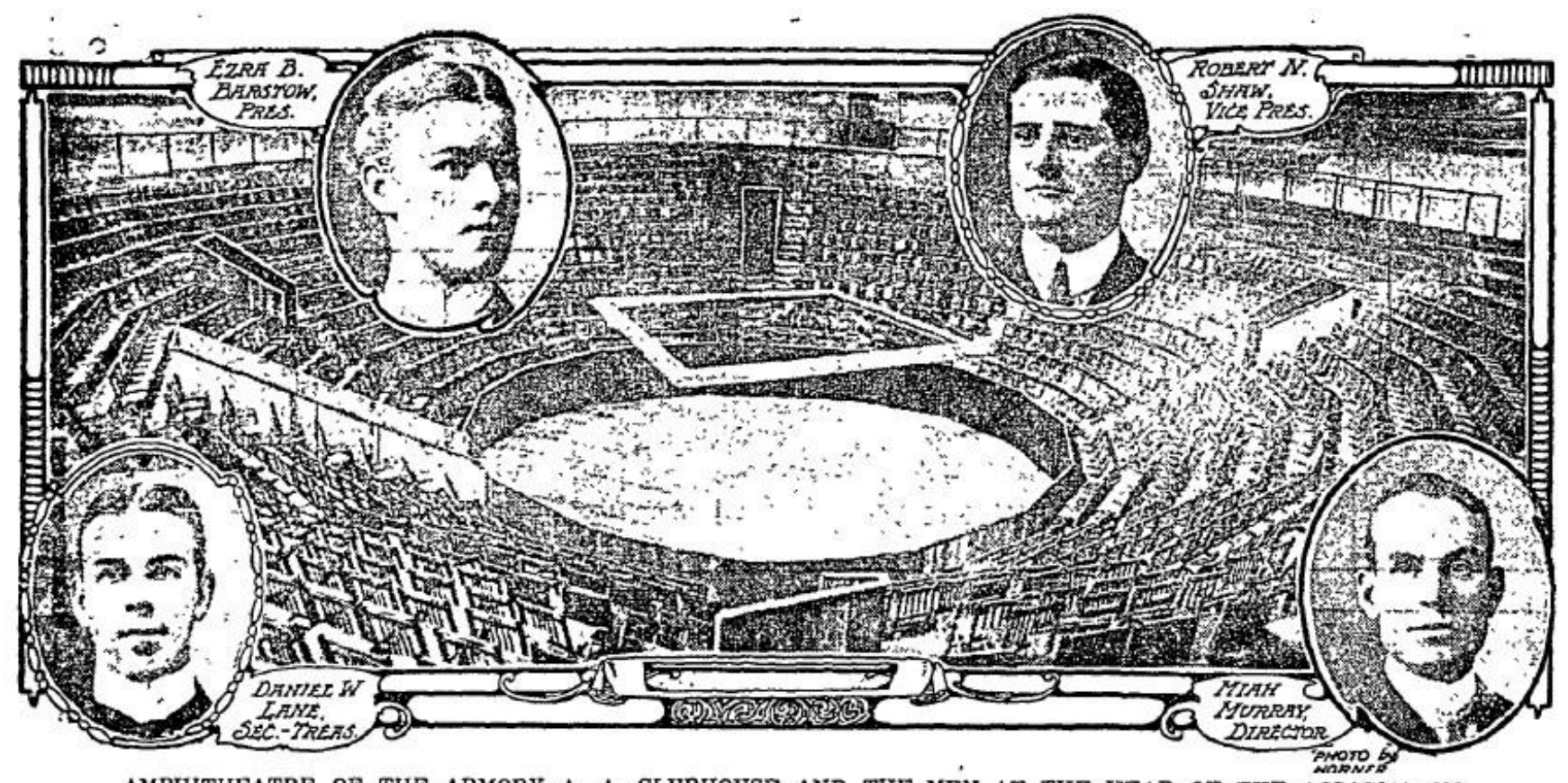

AMPHITHEATRE OF THE ARMORY A. A. ClUBHOUSE AND THE MEN AT THE hEAD OF THE ASSOCIATION.

Figure 2-28. Illustration of the arena built on the second floor of the former Cyclorama in 1907 and opened in 1908. Boston Globe, January 3, 1908, 4.

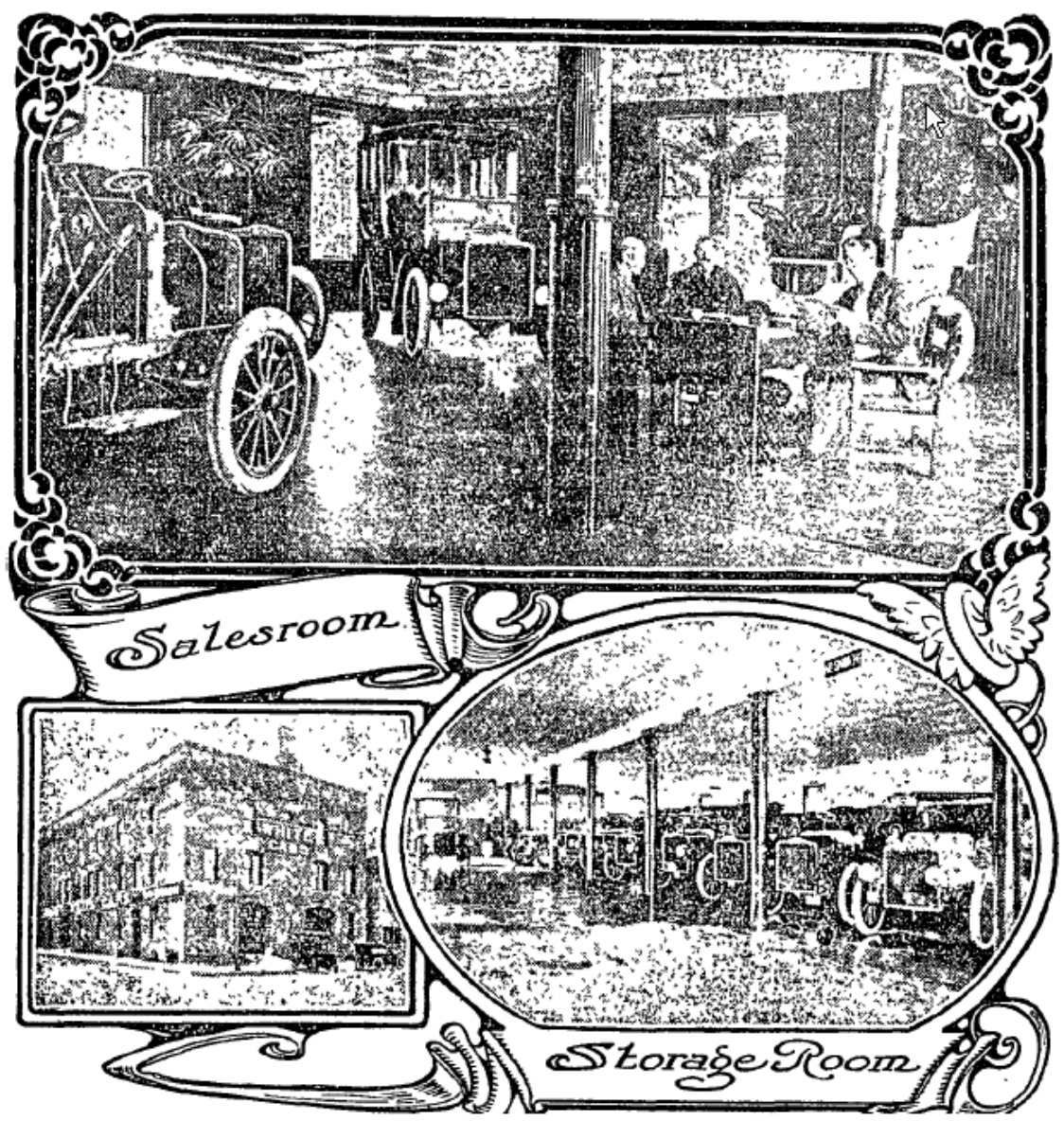

Figure 2-29. Illustration of the converted three-story stable used by the White Sewing Machine Company before multiple fires compelled construction of a new garage. Boston Globe, April 30, 1905, 31. 


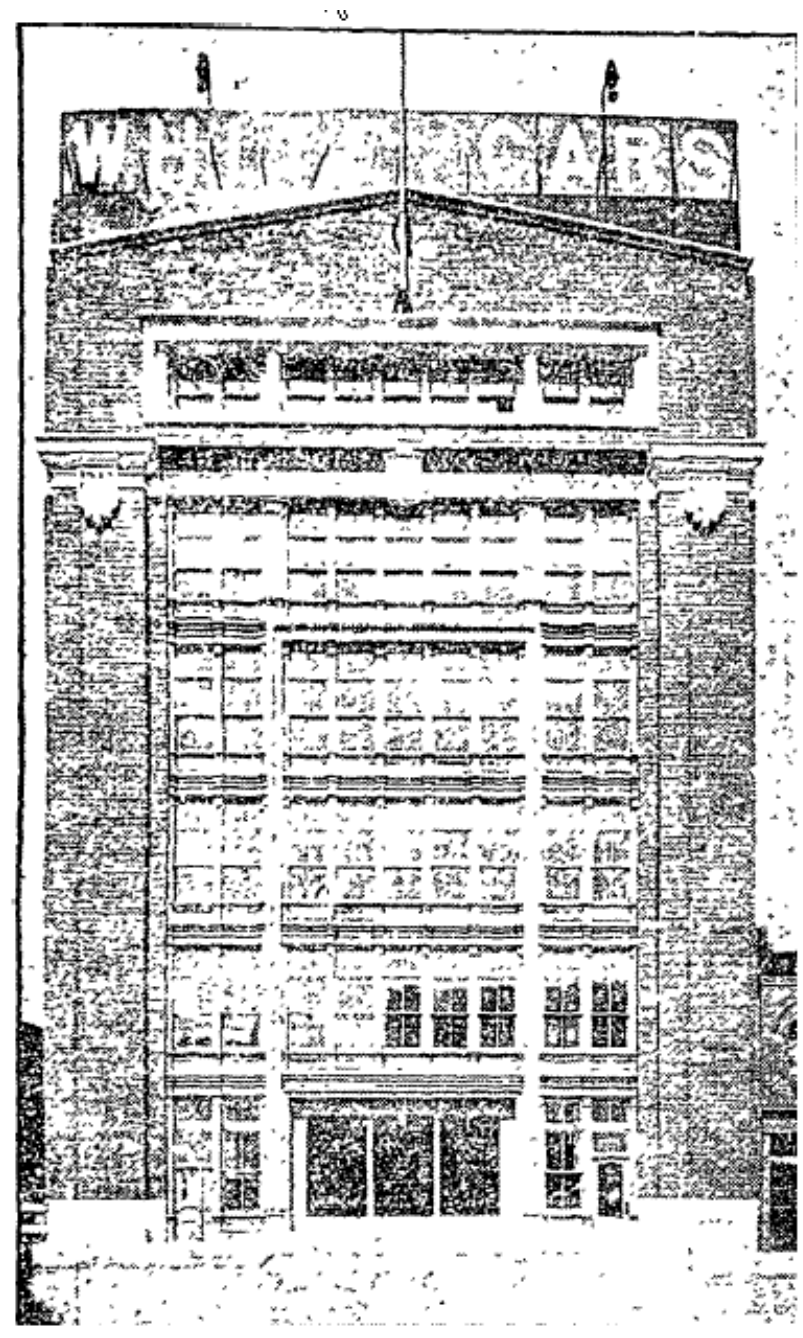

NEW WHITE GARAGE ON NEWBURY ST.

Figure 2-30. Illustration of the White Garage at 341-343 Newbury Street. Designed by C. J.

Warren, 1907. Boston Globe, August 25, 1907, 29.

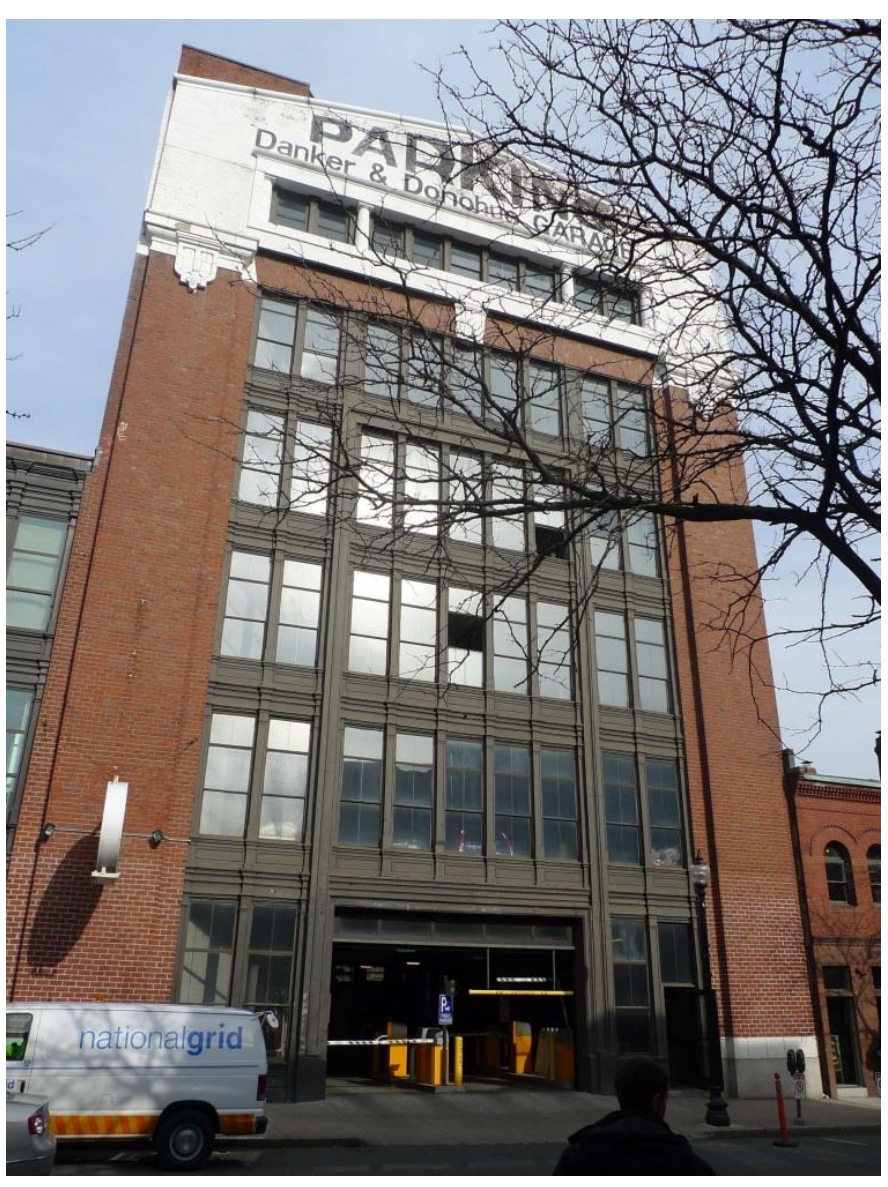

Figure 2-31. The White Garage at 341-343 Newbury Street. Designed by C. J. Warren, 1907. Author photograph. 


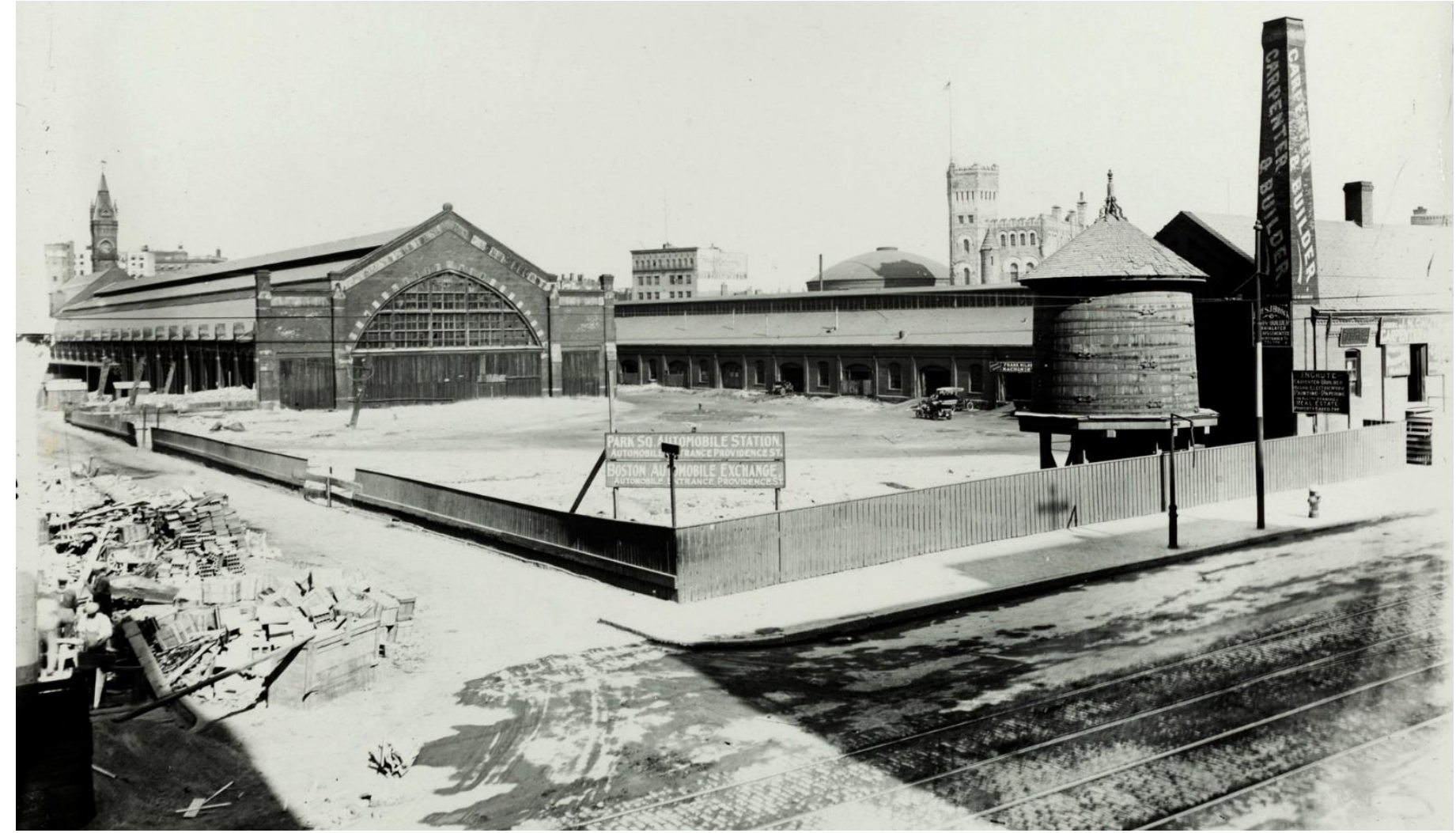

Figure 2-32. Park Square Automobile Station. Courtesy of Historic New England.

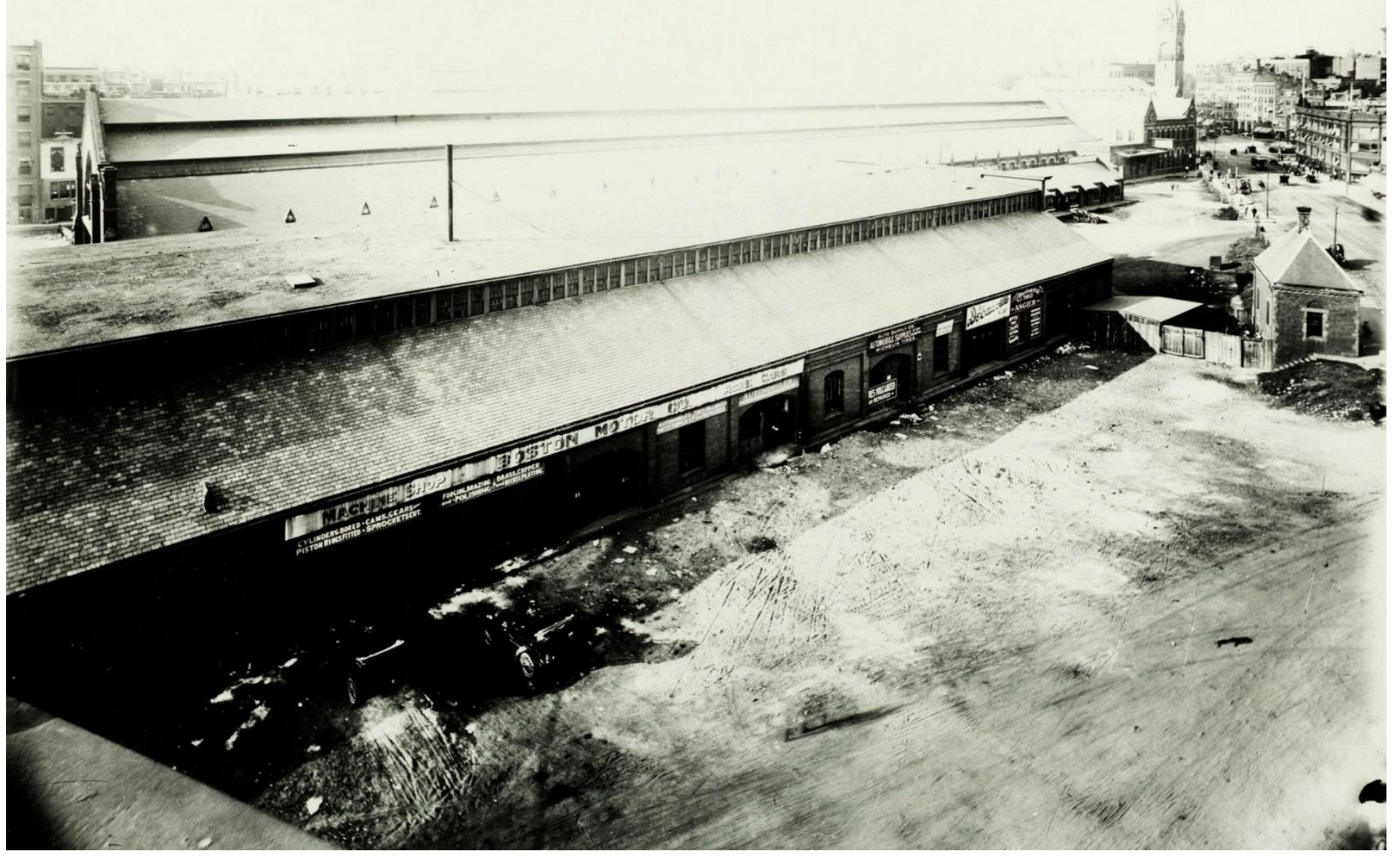

Figure 2-33. Park Square Automobile Station. Courtesy of Historic New England. 
Figure 2-34. The Park Square Automobile Station after its destruction by fire. Courtesy of Historic New England.

\section{DIAGRAM SHOWING LOCATION OF THE BUILDINGS BURNED OR THREATENED}

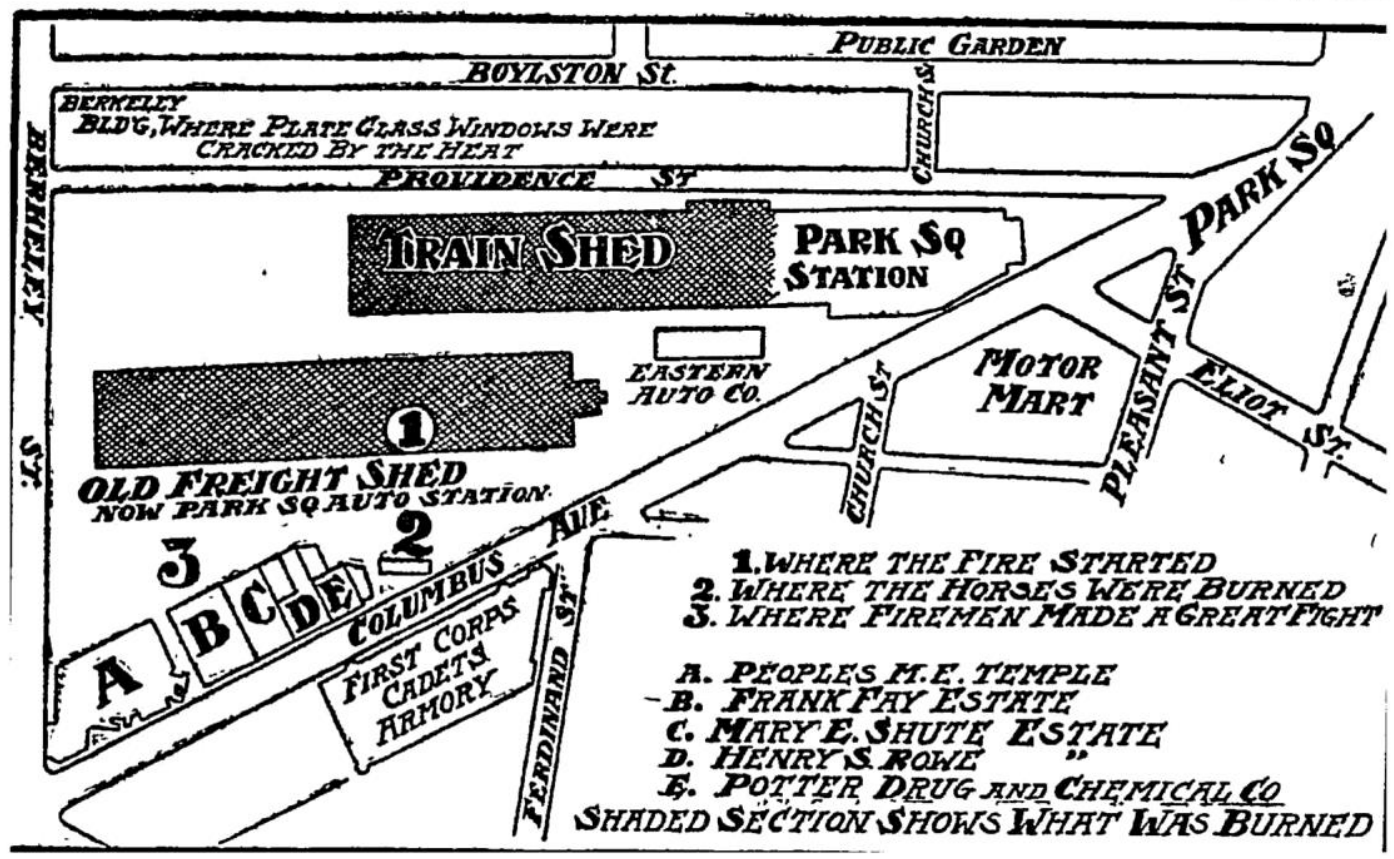

Figure 2-35. Illustration of the Park Square Automobile Station fire. Boston Globe, January 18, 1909, 1 


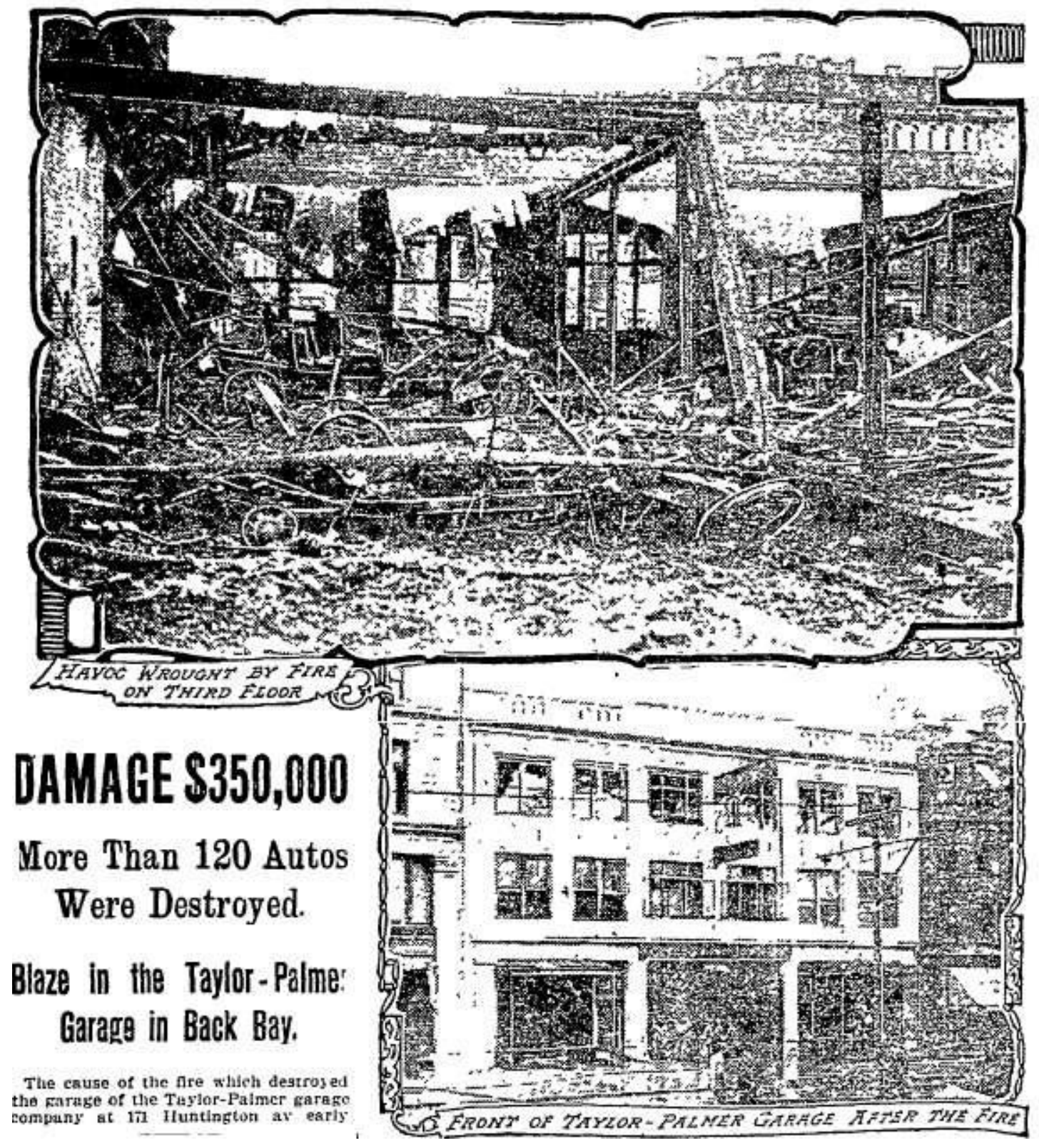

Figure 2-36. Images of fire damage at the Taylor-Palmer Garage in 1908. Boston Globe, September 7, 1908, 1. 


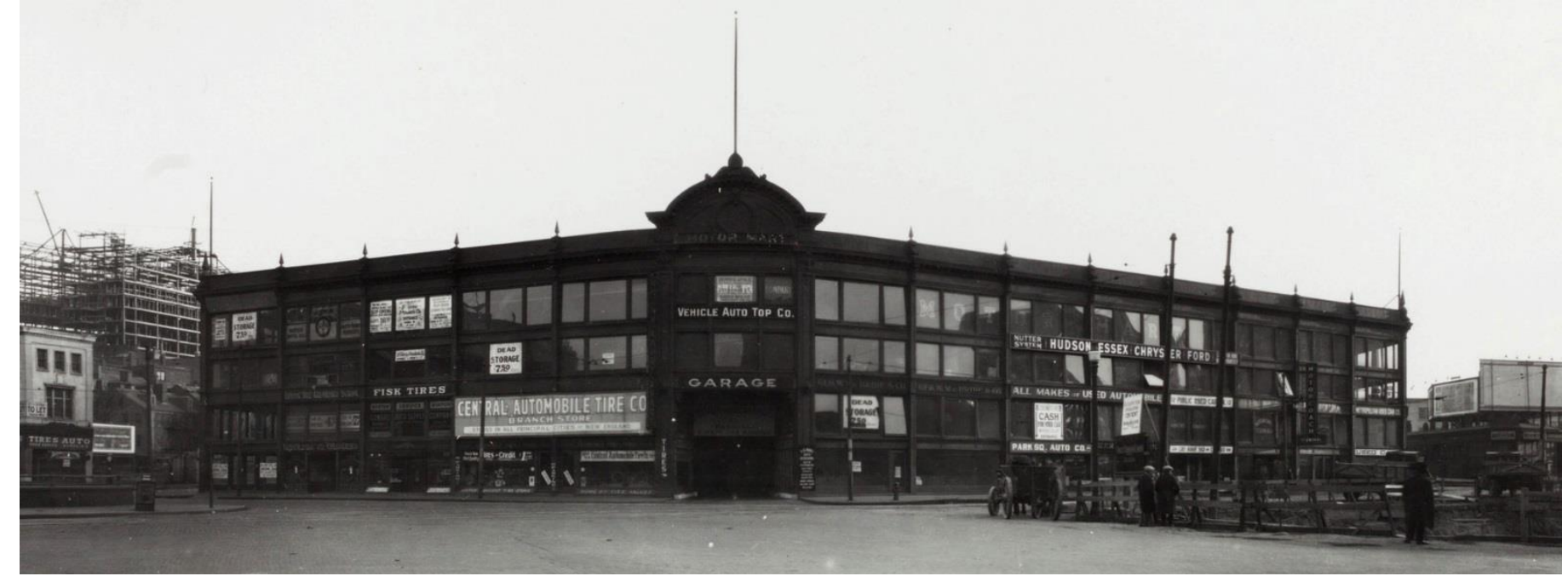

Figure 2-37. Motor Mart Garage, Park Square. Designed by Edward T. Barker, 1905. Courtesy of Historic New England.

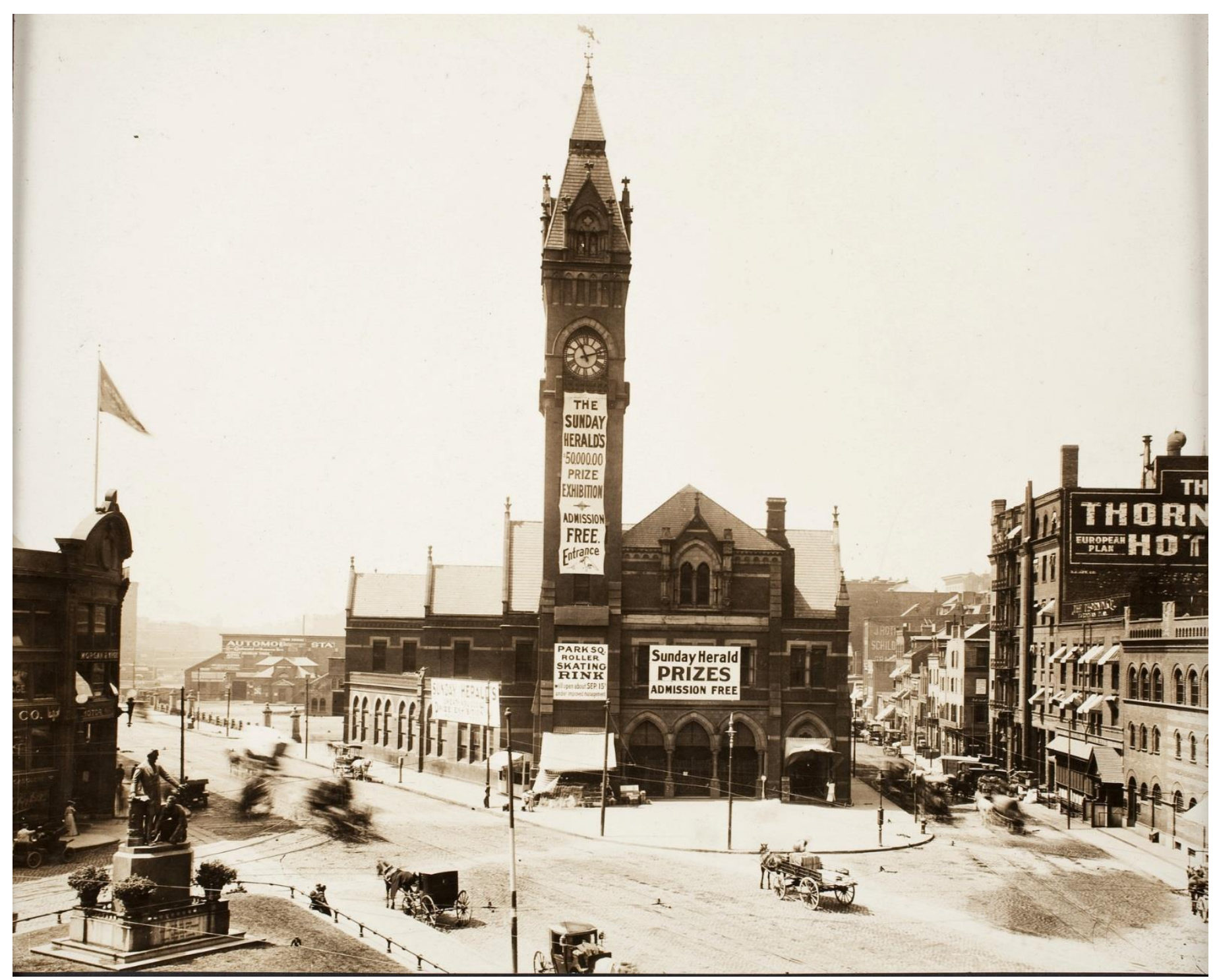

Figure 2-38. Image of Park Square with the Motor Mart Garage to the left and the Automobile Station in the distance. Courtesy of Historic New England. 


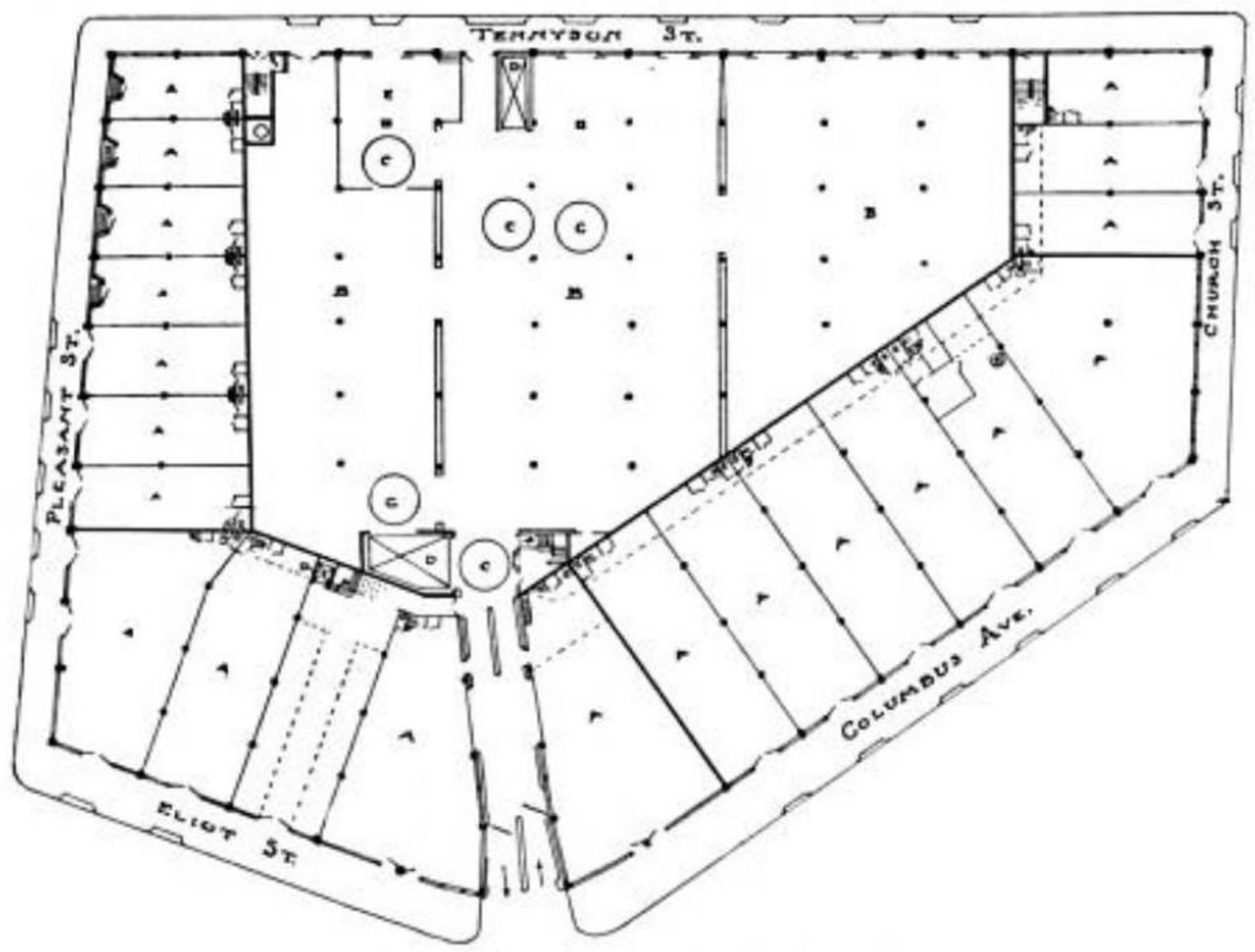

Plan of the Motor Mart, Boston.

Figure 2-39. Plan of the 1905 Motor Mart Garage. Horseless Age (May 30, 1906): 783. 


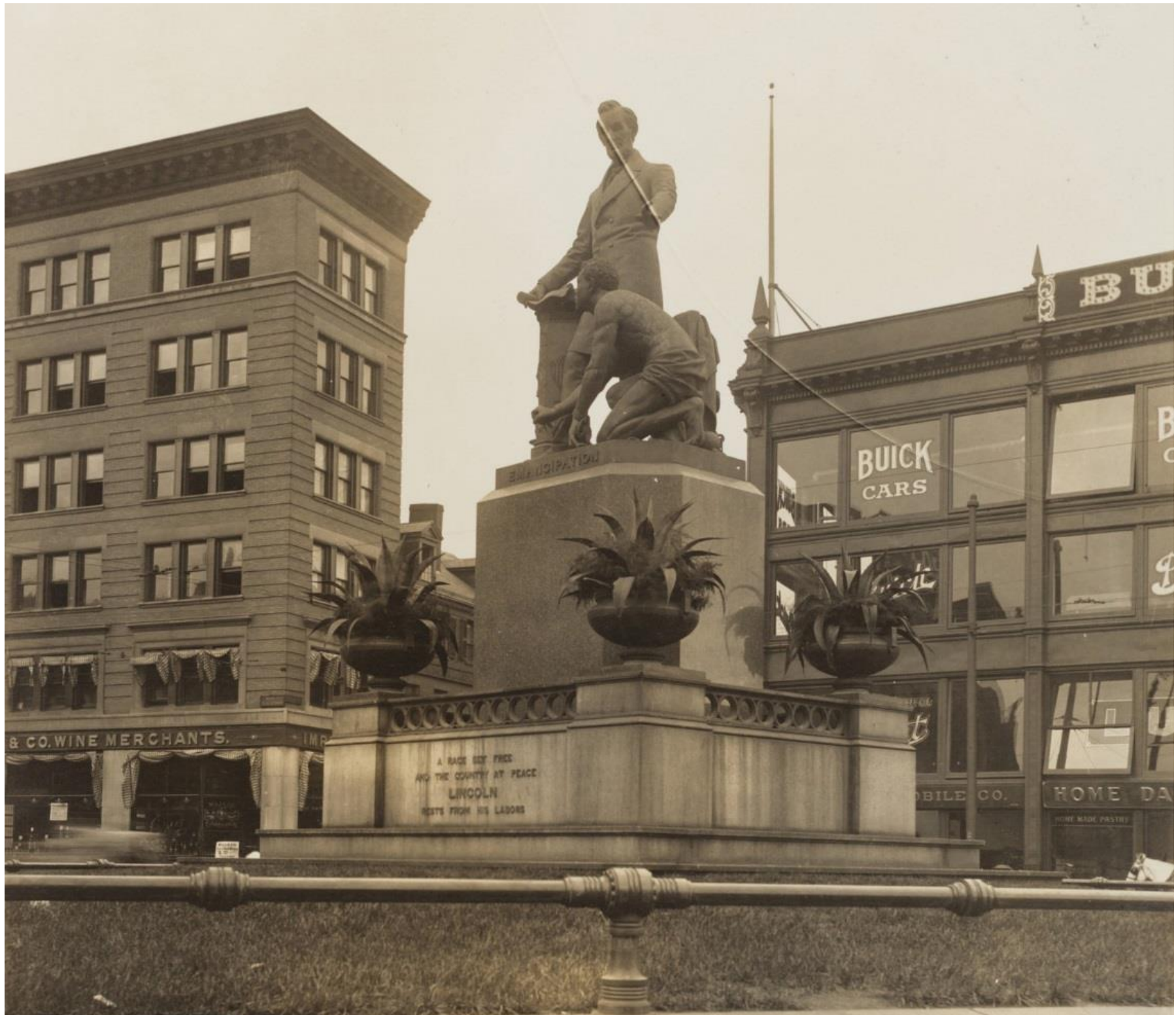

BALDWIN COOLIDCE, Phot. I 3312

Figure 2-40. Partial view of Buick's showroom at the Motor Mart Garage. Photo by Baldwin Coolidge in September, 1910. Courtesy of Historic New England. 


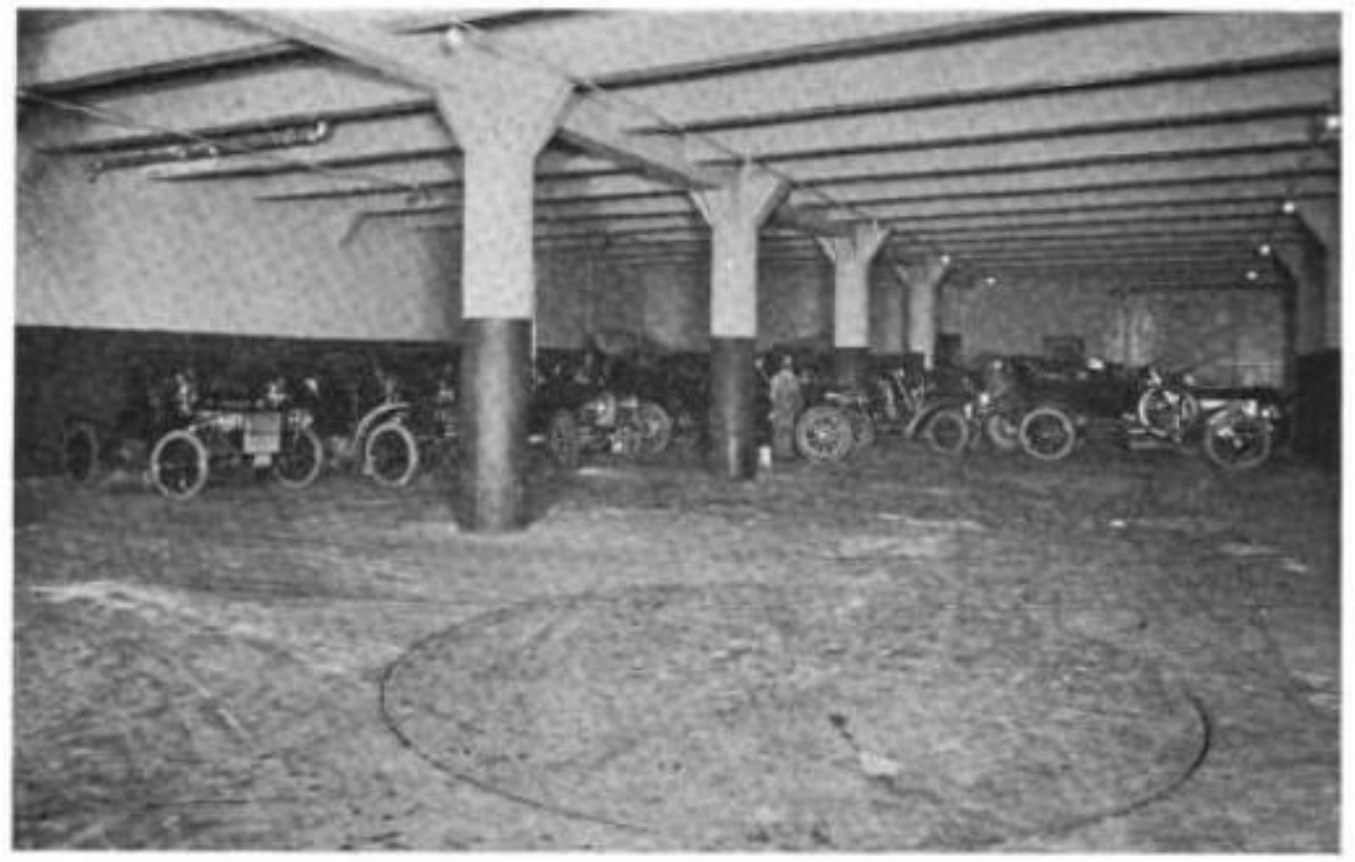

INTERLoR VieW OF THE Motor MAKT

(Showing corrucated iron turntable, conerete covered beams and pillars).

Figure 2-41. Interior of the 1905 Motor Mart Garage with turntable in foreground. Horseless Age (May 30, 1906): 784 


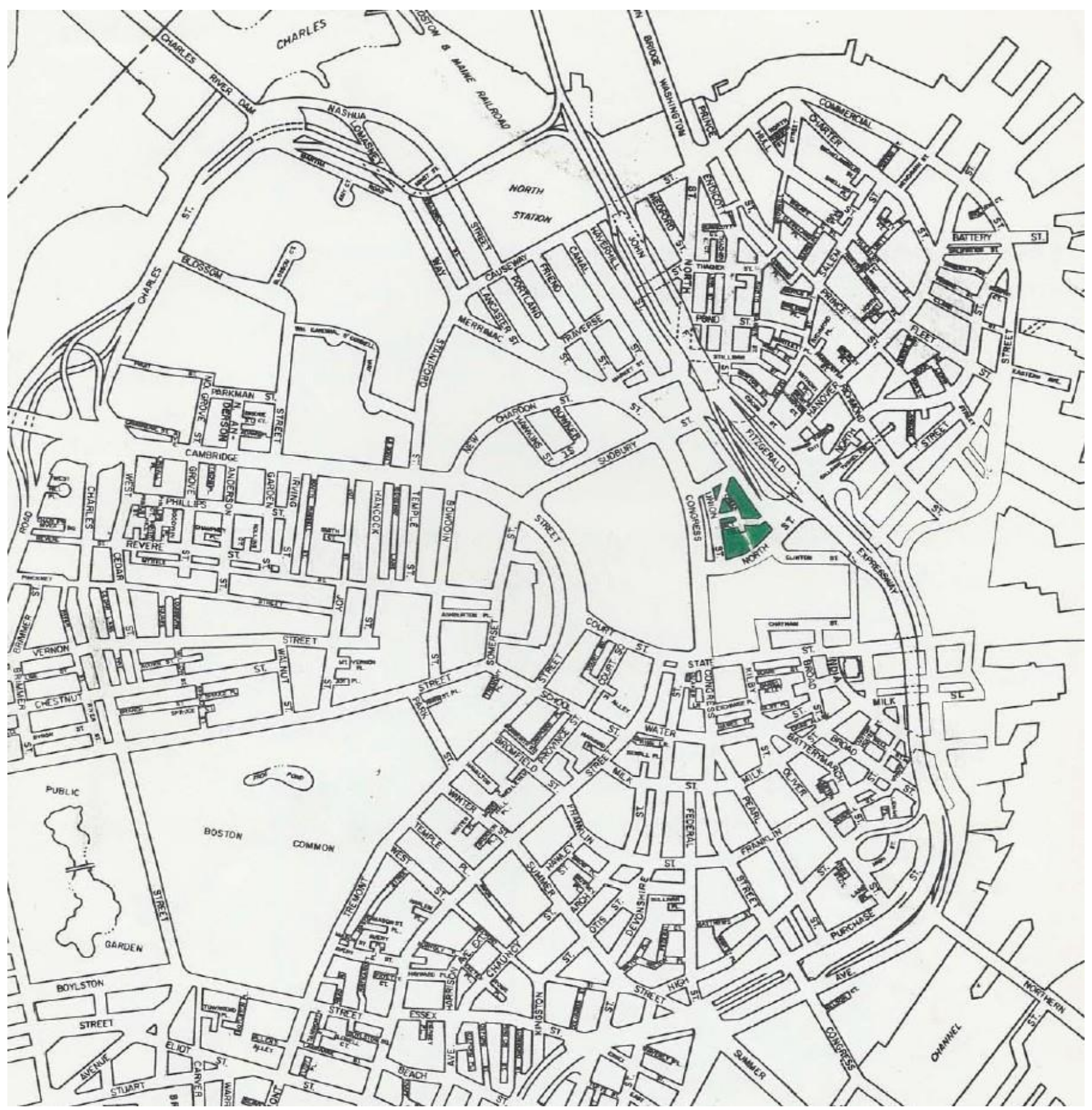

Figure 3-1. The area of the Blackstone Block is highlighted in green. Boston Landmarks Commission, Blackstone Block Street Network, 2. 


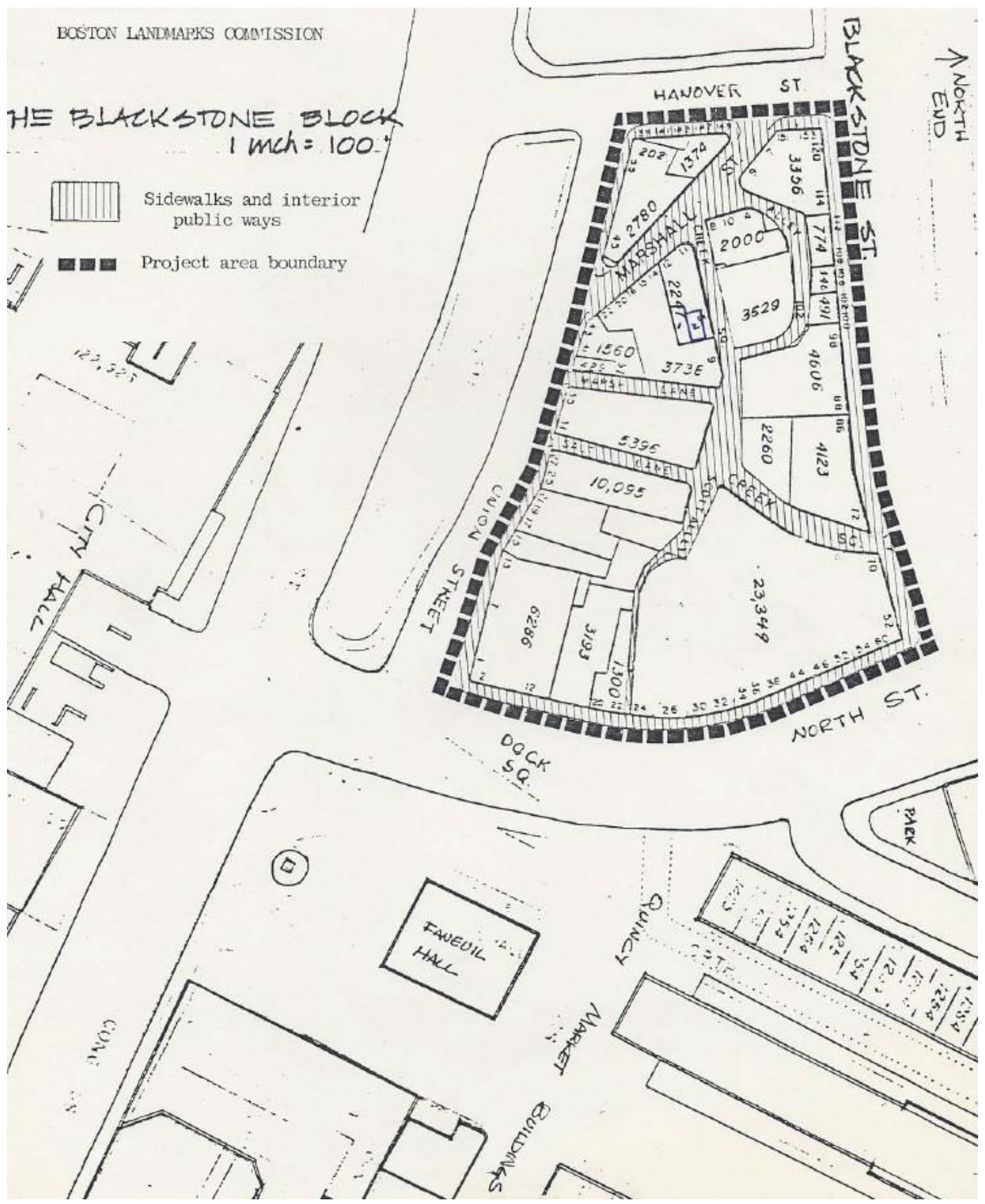

Figure 3-2. Detail of Blackstone Block. Boston Landmarks Commission, Blackstone Block Street Network, 3. 


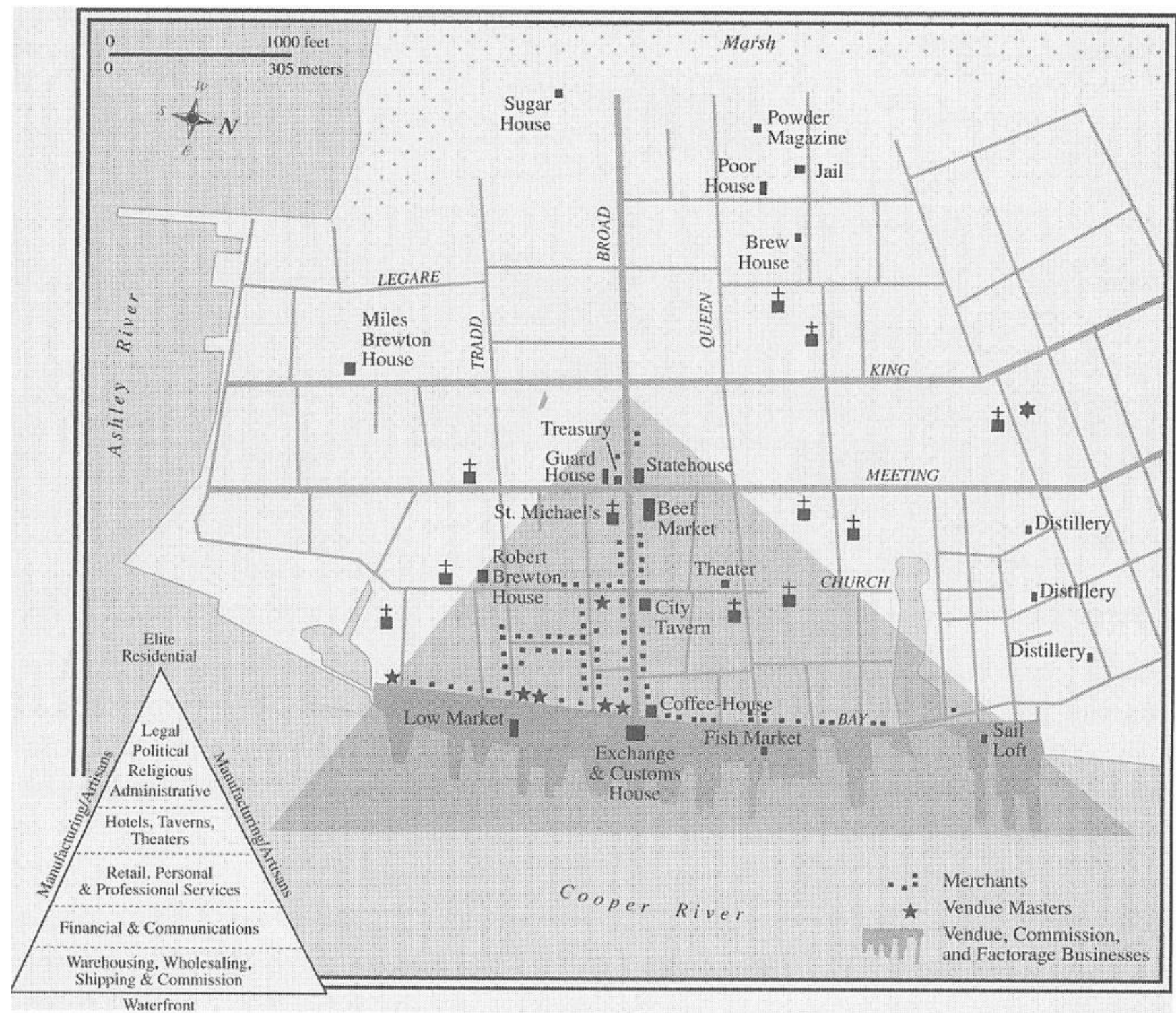

Figure 3-3. The Mercantile Triangle as exemplified by Charleston, S.C. Stephen Hornsby, British Atlantic, American Frontier: Spaces of Power in Early Modern British America, 186. 


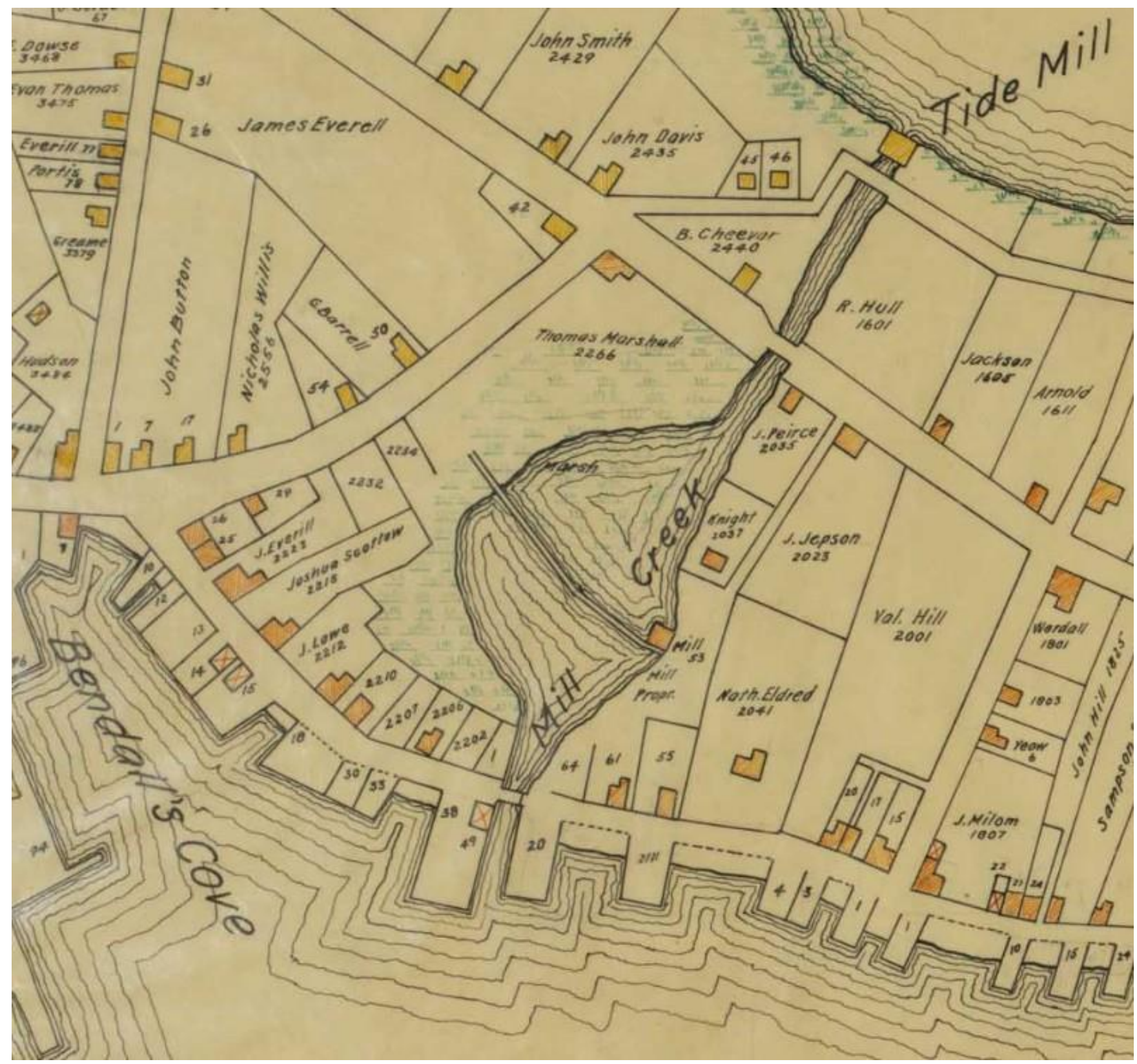

Figure 3-4. Detail of the Blackstone Block and vicinity as it appeared in 1640 taken from a map drawn by Samuel Chester Clough in 1919. Massachusetts Historical Society. 


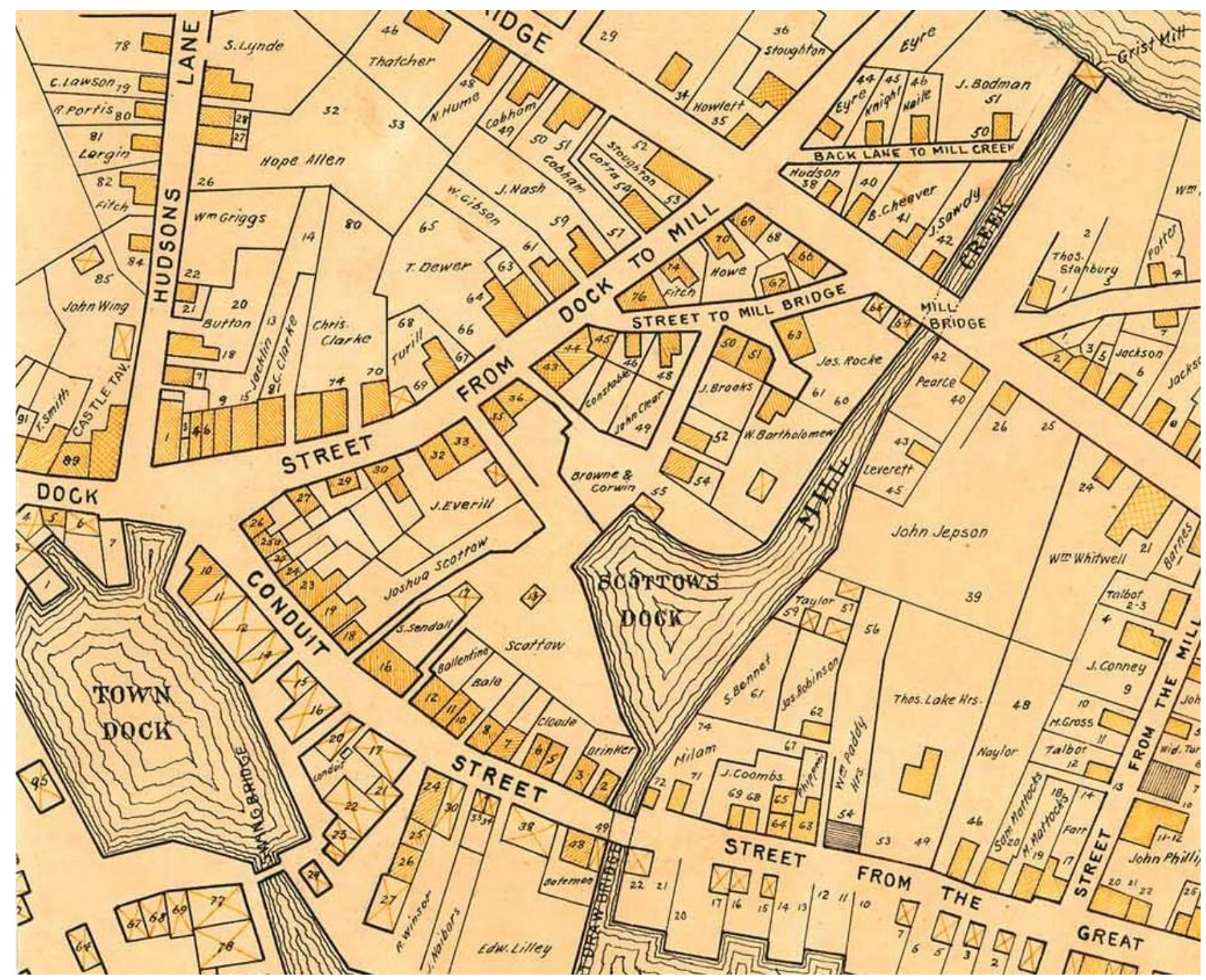

Figure 3-5. Detail of the Blackstone Block and vicinity as it appeared in 1676 taken from a map drawn by Samuel Chester Clough in 1920. Massachusetts Historical Society. 


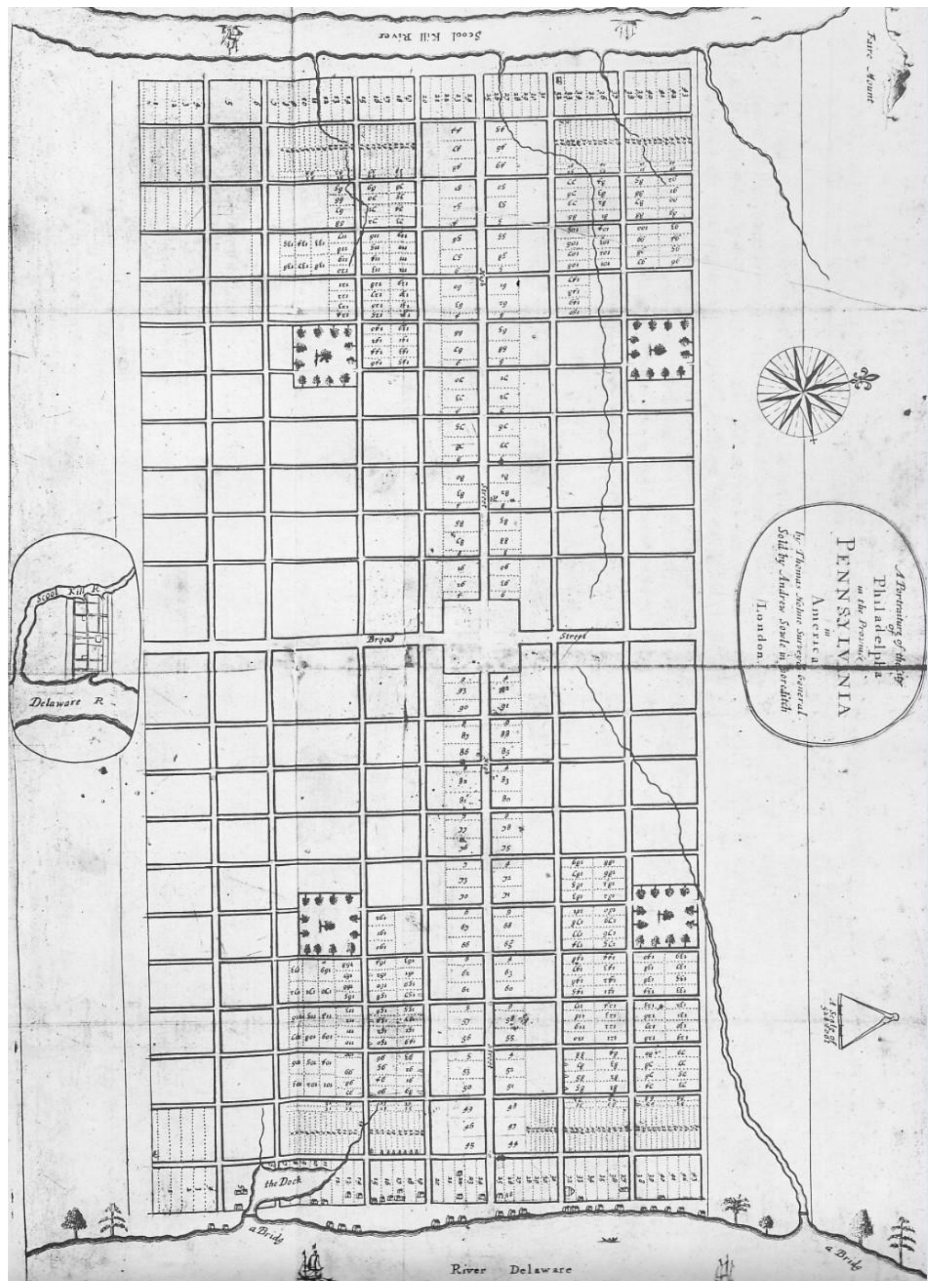

Figure 3-6. William Penn's Plan for Philadelphia, 1682. Reprinted in Reps, The Making of Urban America, 162. 


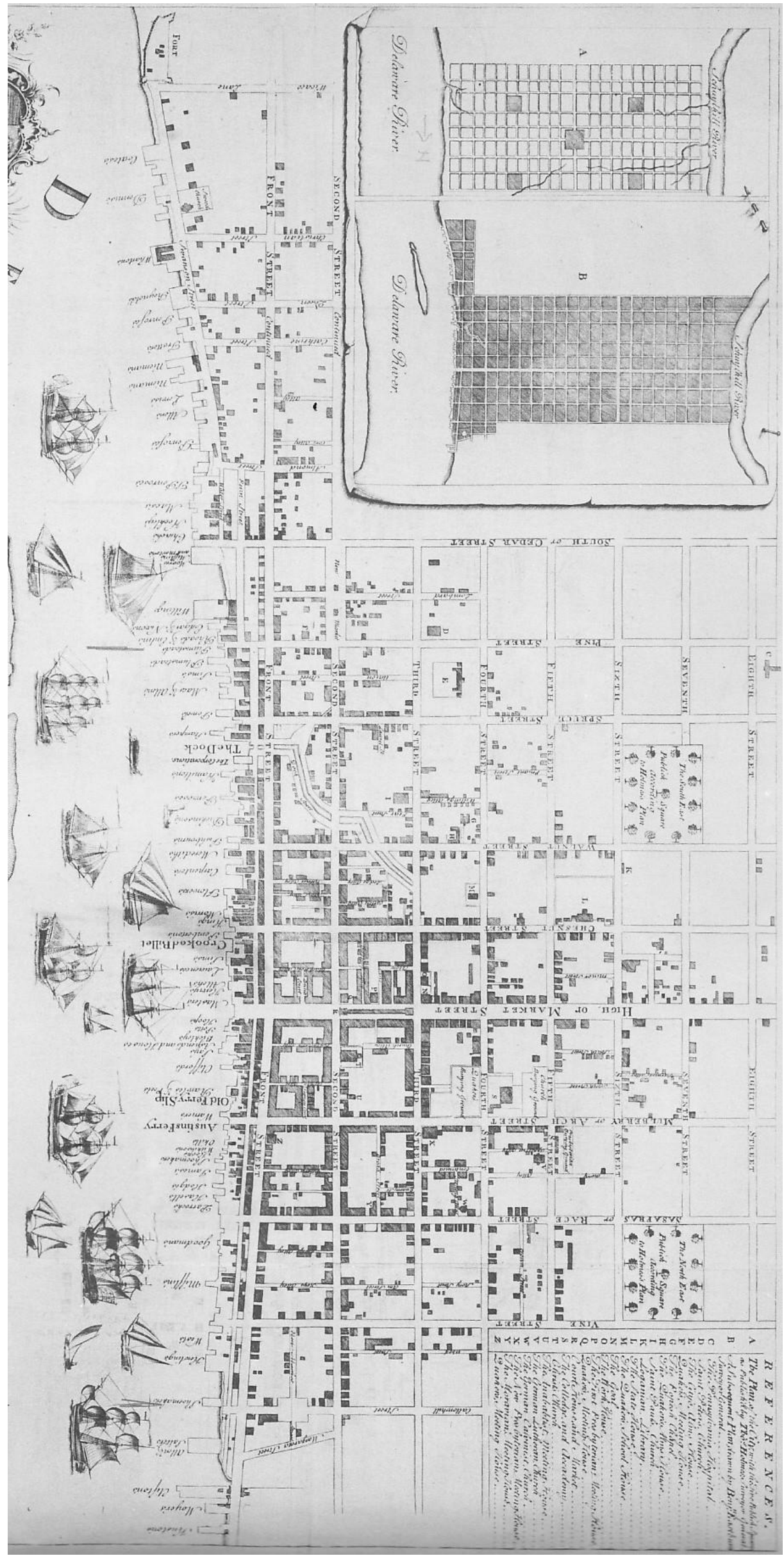

Figure 3-7. Plan of Philadelphia, 1762. Reprinted in Reps, The Making of Urban America, 167. 


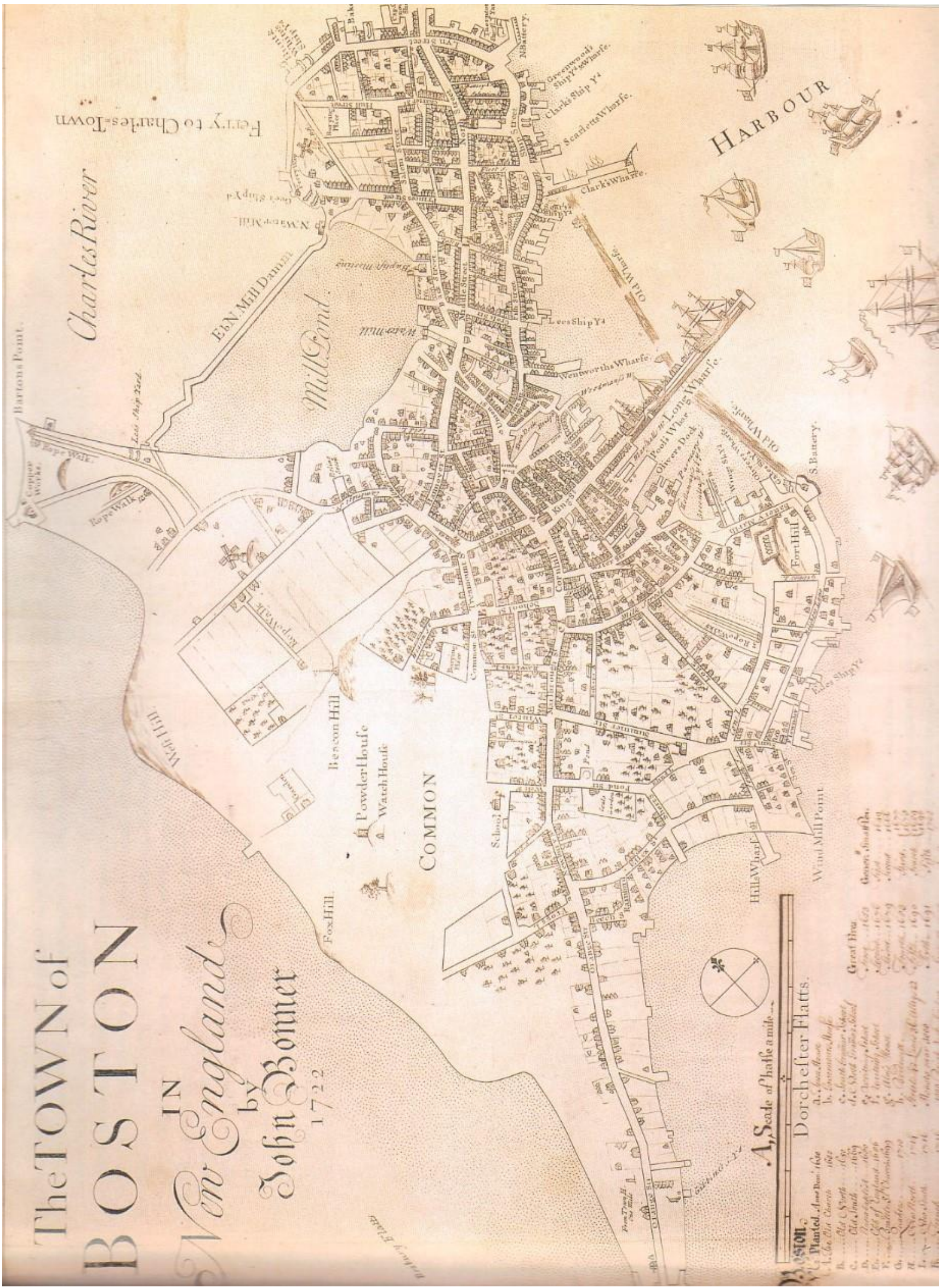

Figure 3-8. John Bonner's 1722 Map of Boston. Reprinted in Alex Krieger, Mapping Boston, 175. 


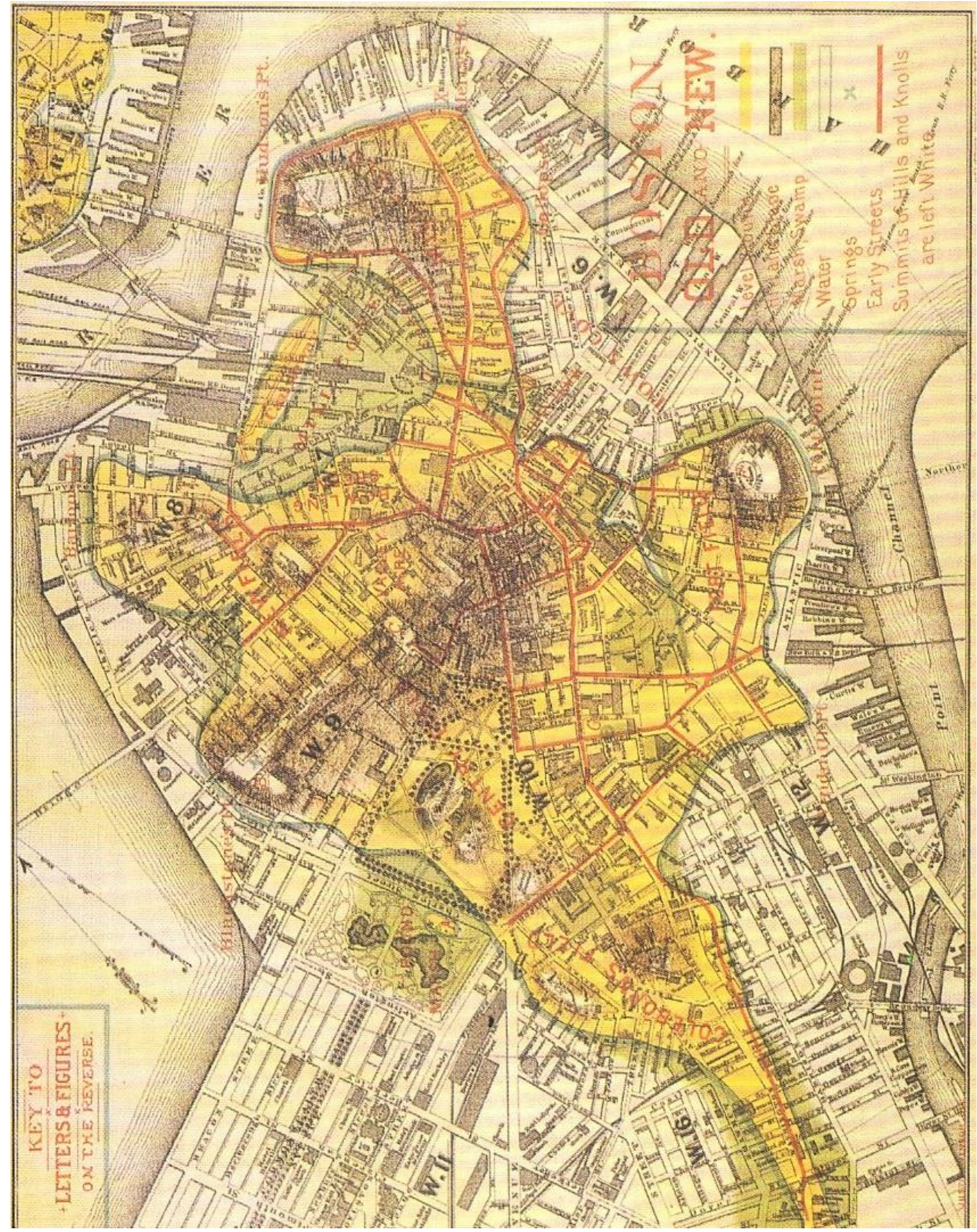

Figure 3-9. This map originally appeared as the frontispiece for Justin Winsor's Memorial History of Boston, including Suffolk County, Massachusetts, published in 1882. Reprinted in Krieger, Mapping Boston, 174. 


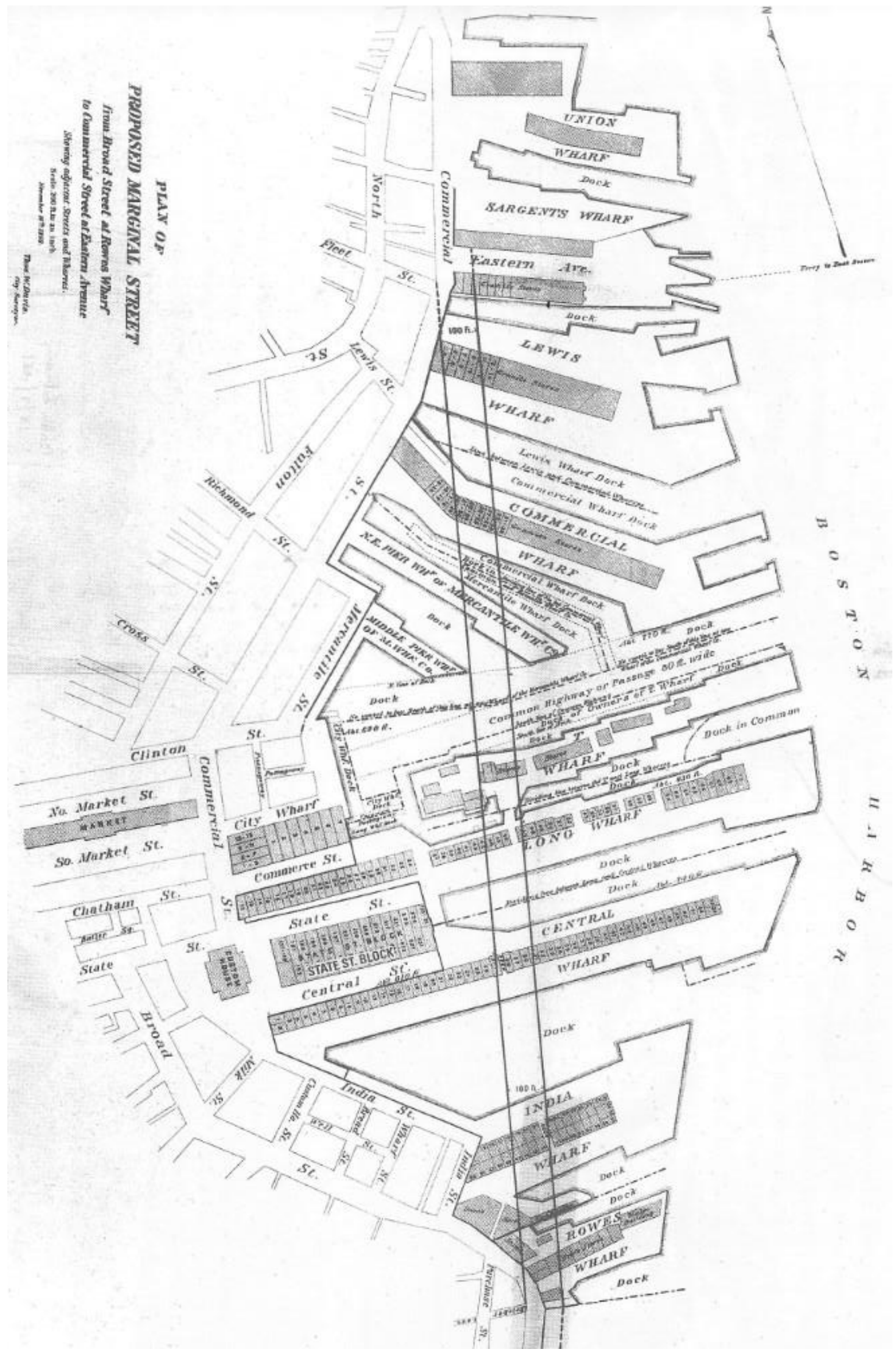

Figure 3-10. 1868 plan of the proposal Marginal Street (later Atlantic Avenue). Reprinted in Seasholes, Gaining Ground, 65. 


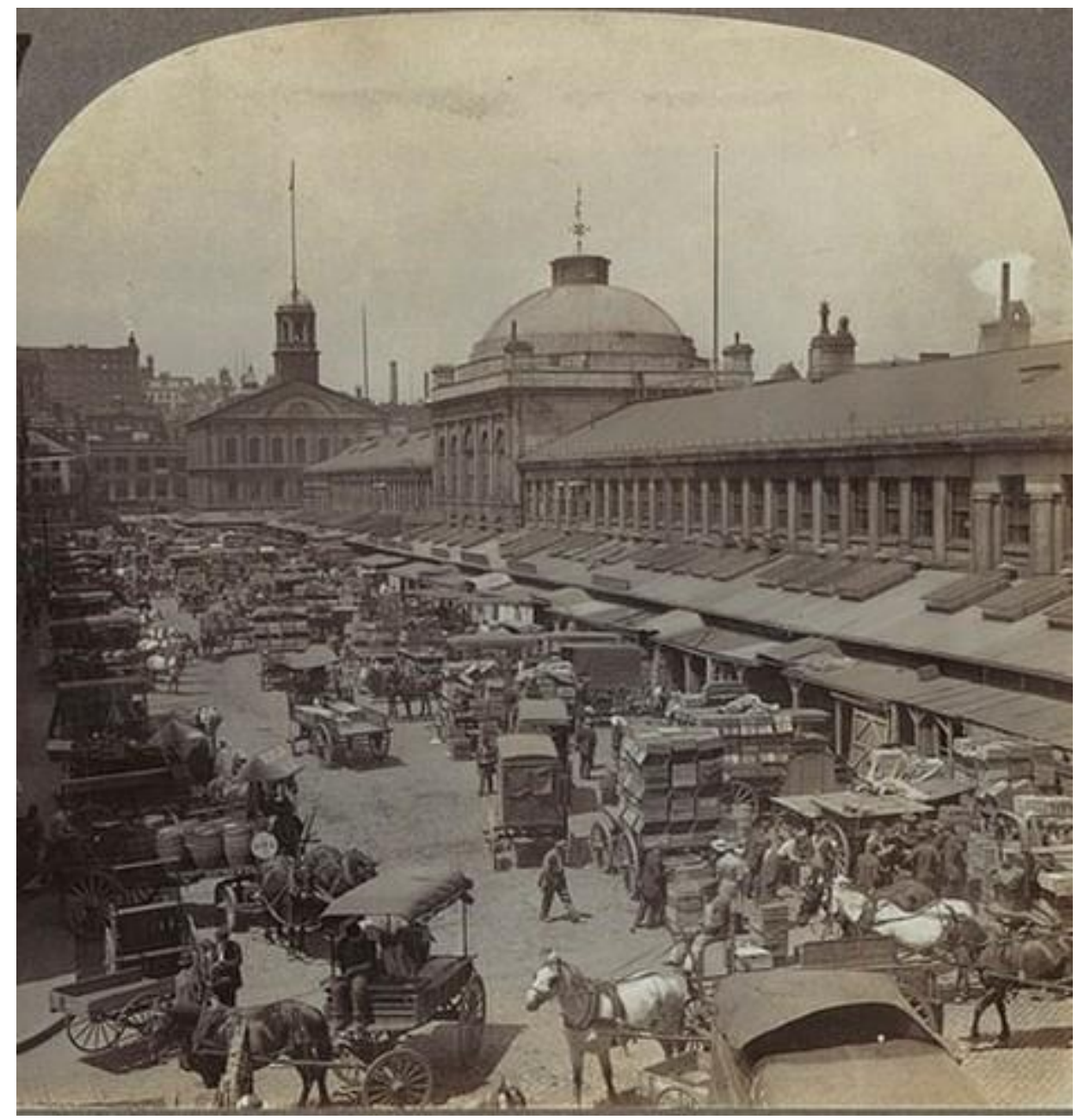

Figure 3-11. Frame from a stereoscopic slide showing Quincy Market and Faneuil Hall circa 1890. Courtesy of the Boston Public Library. 


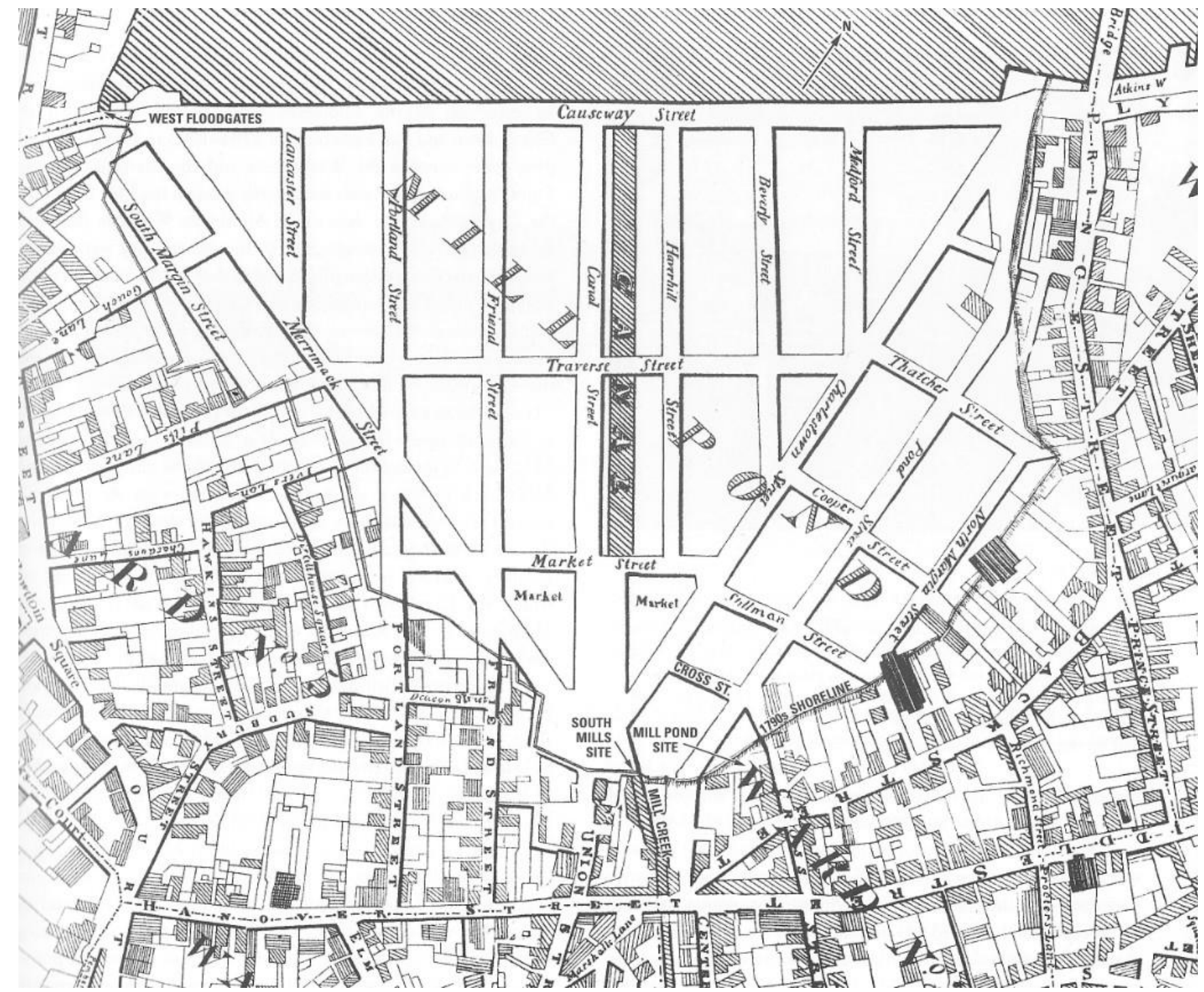

Figure 3-12. Detail from John G Hale's 1814 Map of Boston. Reprinted in Seasholes, Gaining Ground, 87. 


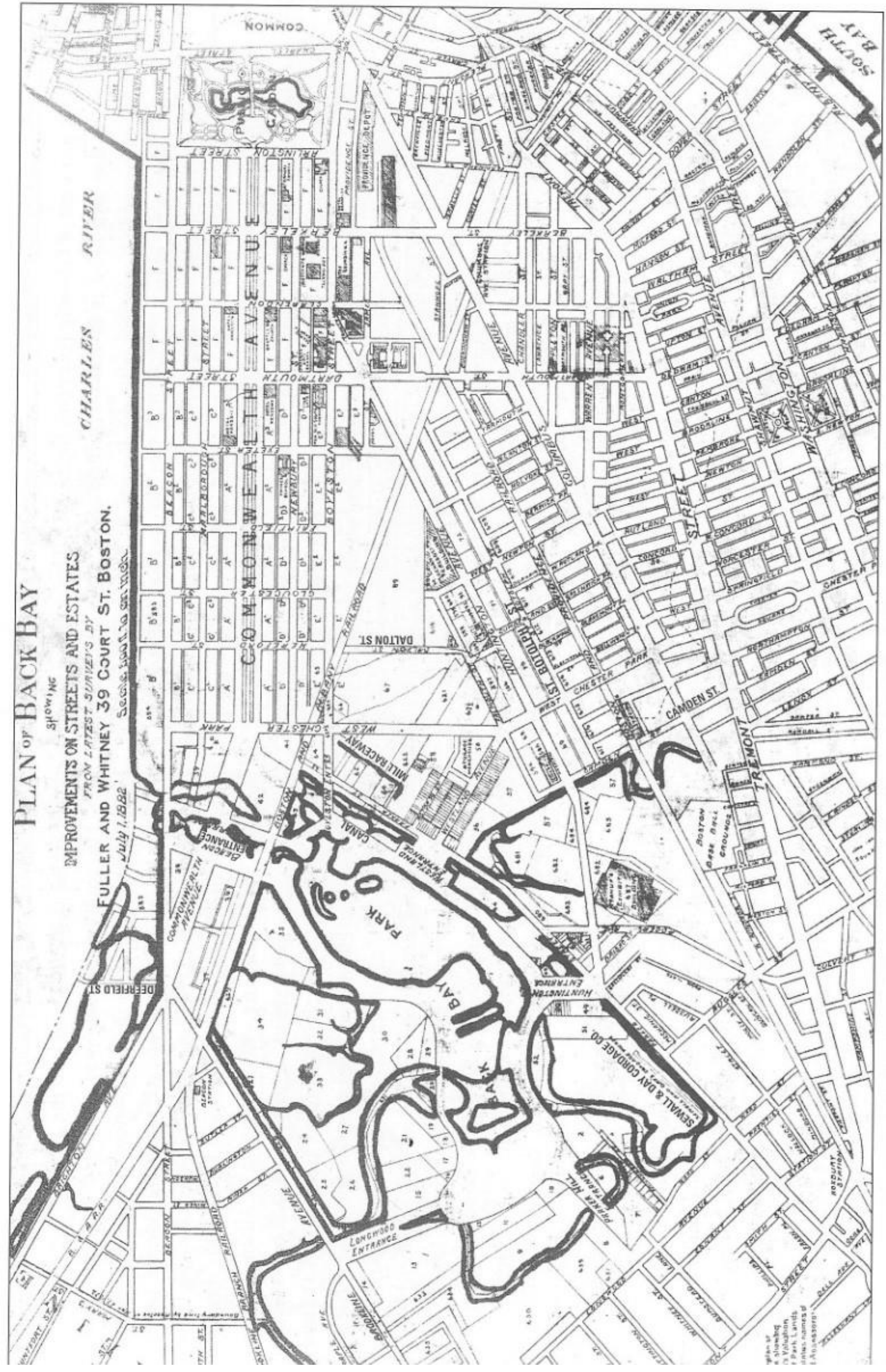

Figure 3-13. Survey of the Back Bay in 1882. Reprinted in Nancy Seasholes, Gaining Ground, 225. 


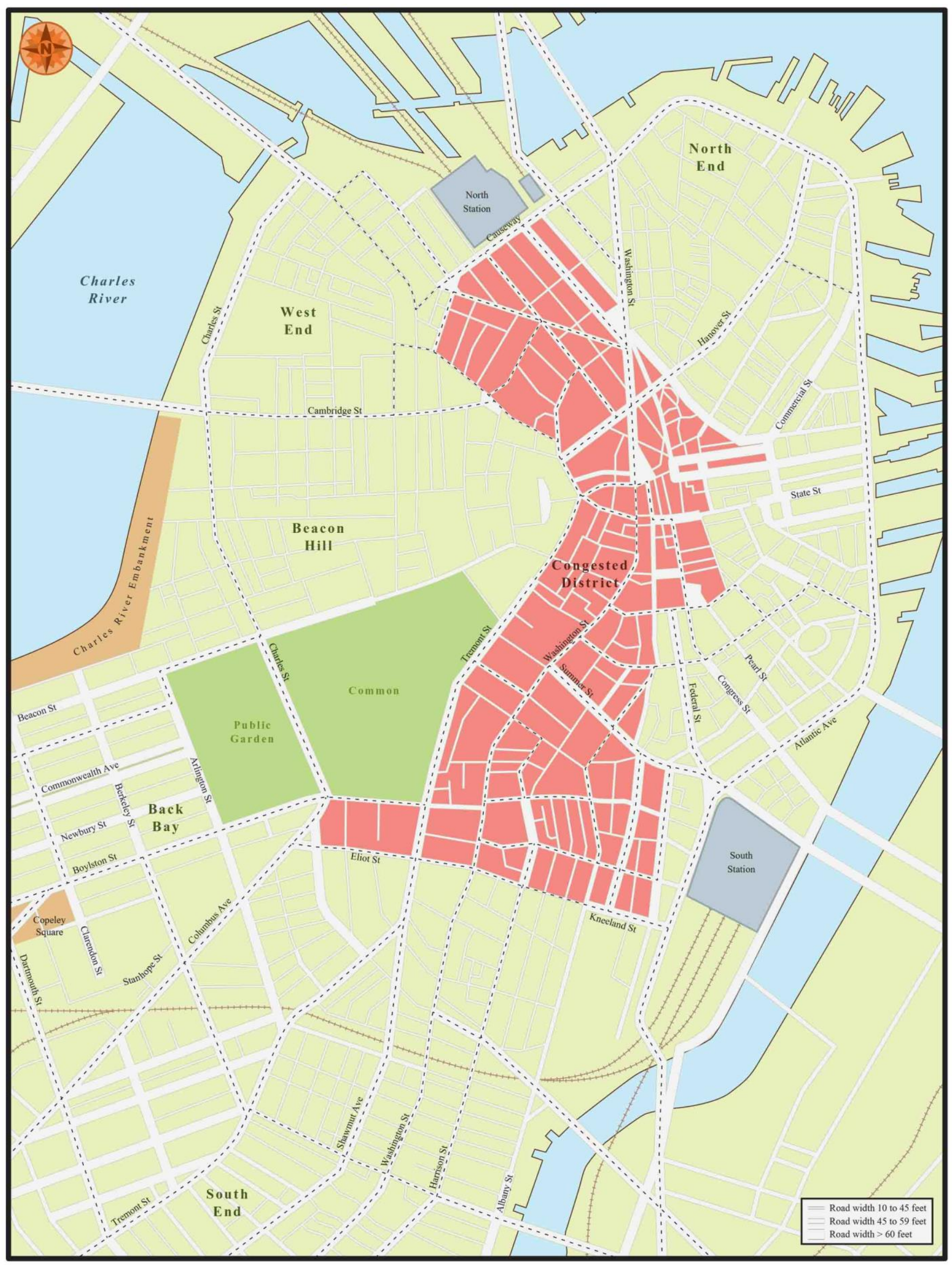

Figure 3-14. Map showing the width of central Boston's streets and the location of streetcar tracks around 1900. Drawn by author. 


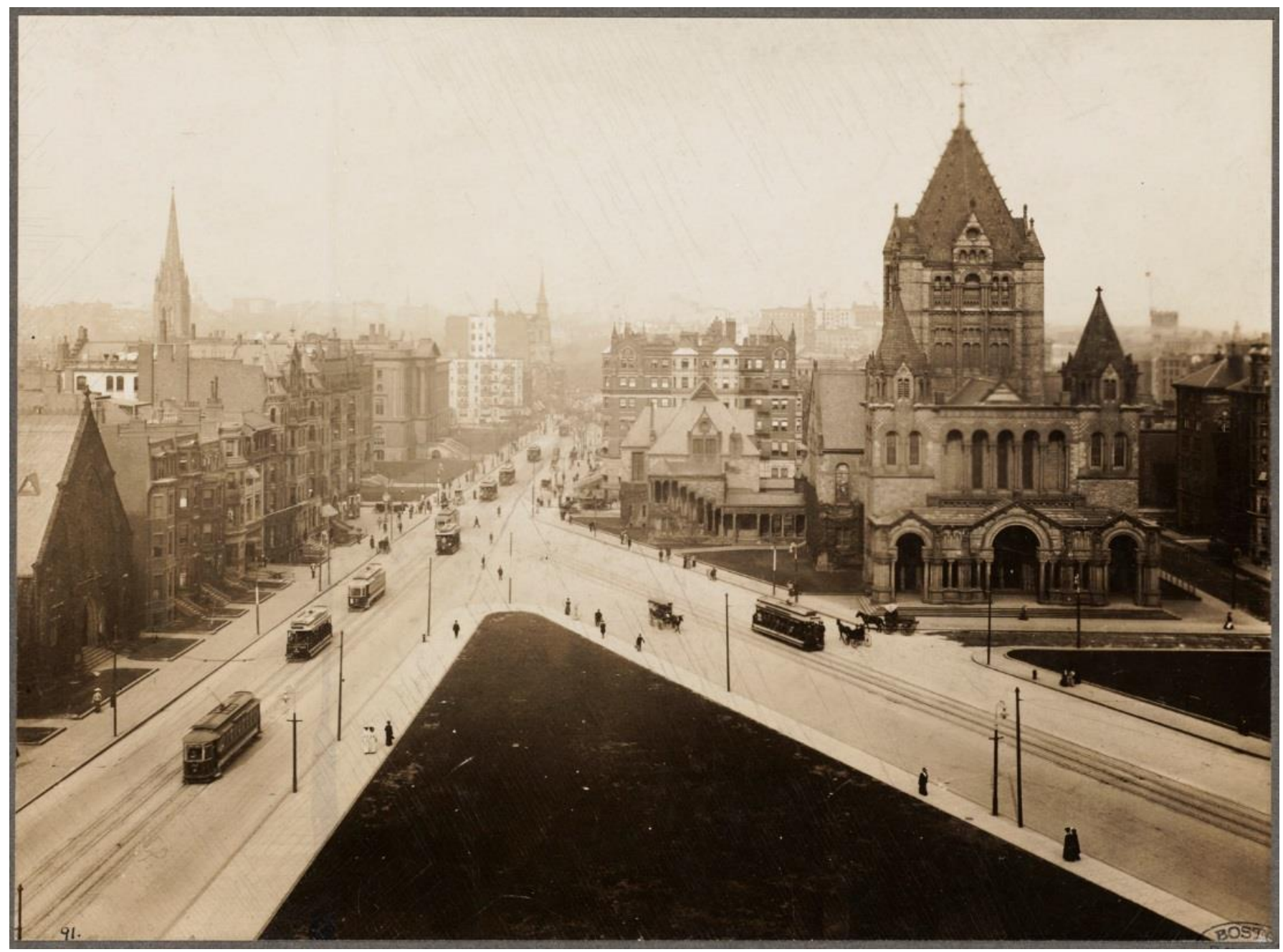

Figure 3-15. Intersection of Boylston Street and Huntington Avenue in Copley Square taken after the electrification of the streetcar lines. Courtesy of the Boston Public Library. 


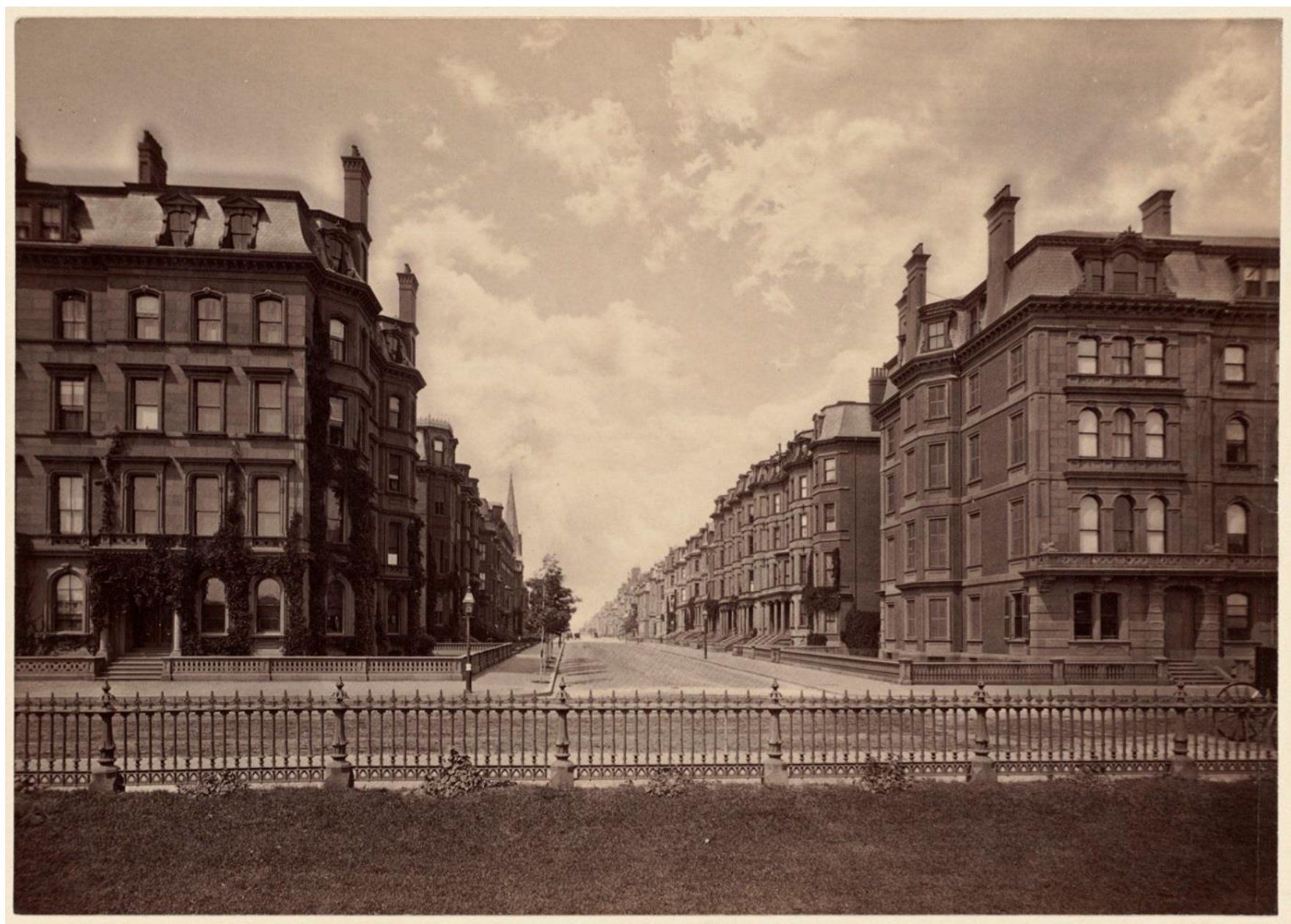

Figure 3-16. A view down Marlborough Street from Arlington Street in 1890. Courtesy of the Boston Public Library. 


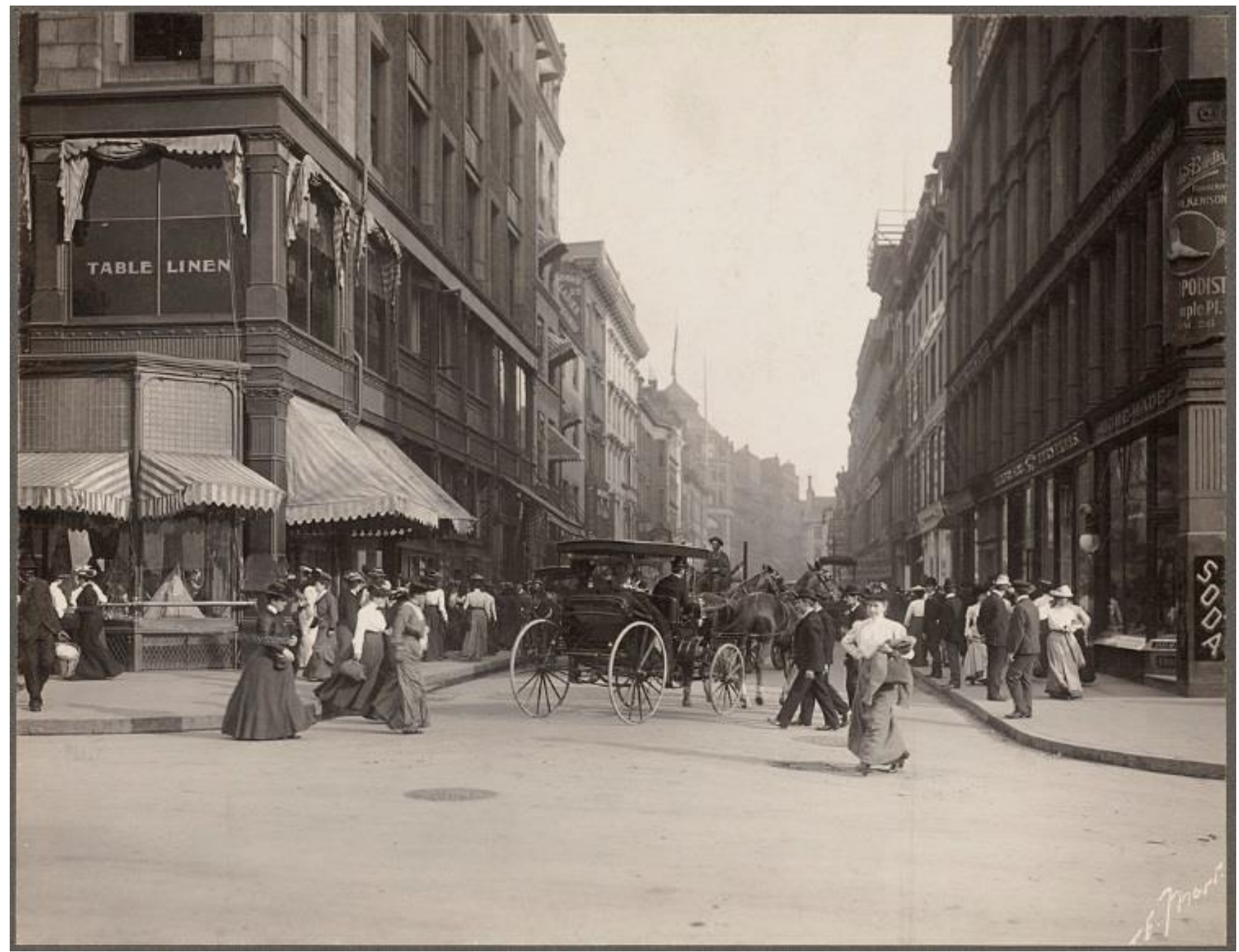

Figure 3-17. Image of Temple Place in 1900, a forty-foot wide right of way in downtown Boston. Courtesy of the Boston Public Library. 


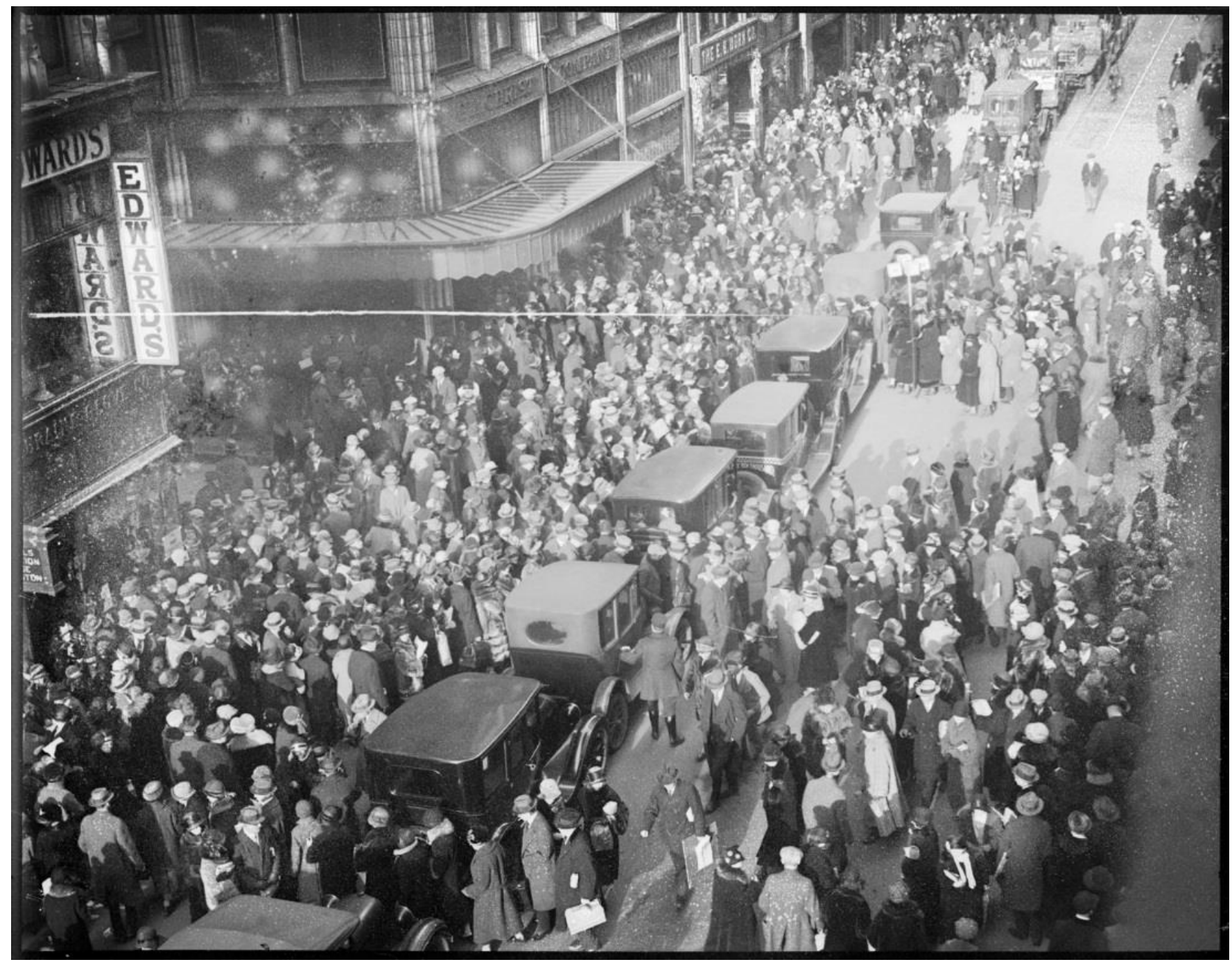

Figure 3-18. Washington Street at the intersection of Winter Street looking north. Winter Street, on the left side of the image, was thirty-six feet wide. This block of Washington Street was sixty feet across, though this width was not consistent and narrowed to forty feet in the vicinity of Court and School Streets and to fifty feet on most other blocks. A police officer with semaphore ineffectively attempts to guide traffic. Photograph taken by Leslie Jones in the early 1920s. Courtesy of the Boston Public Library. 


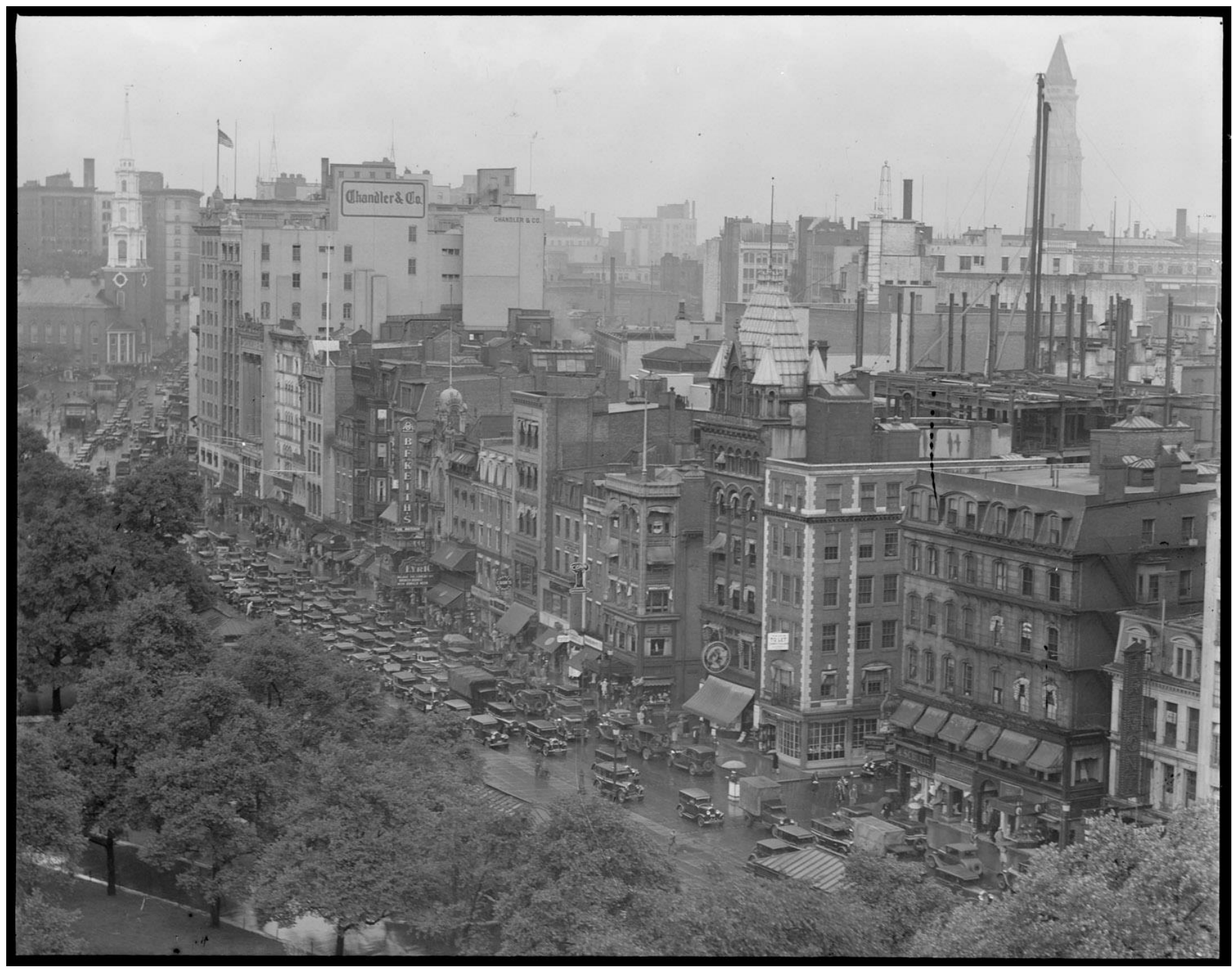

Figure 3-19. Photograph of Tremont Street along the Boston Common taken by Leslie Jones in the mid 1920s. While this right-of-way was sixty feet across, it was effectively wider since pedestrians could make use of additional space by walking along the edge of the Common itself. Even with a greater portion of the roadway given to automobile use, congestion was still significant along Tremont Street, among the widest roads in the downtown area. A police officer gave instruction from a white stand in the midst of the roadway. Courtesy of the Boston Public Library. 


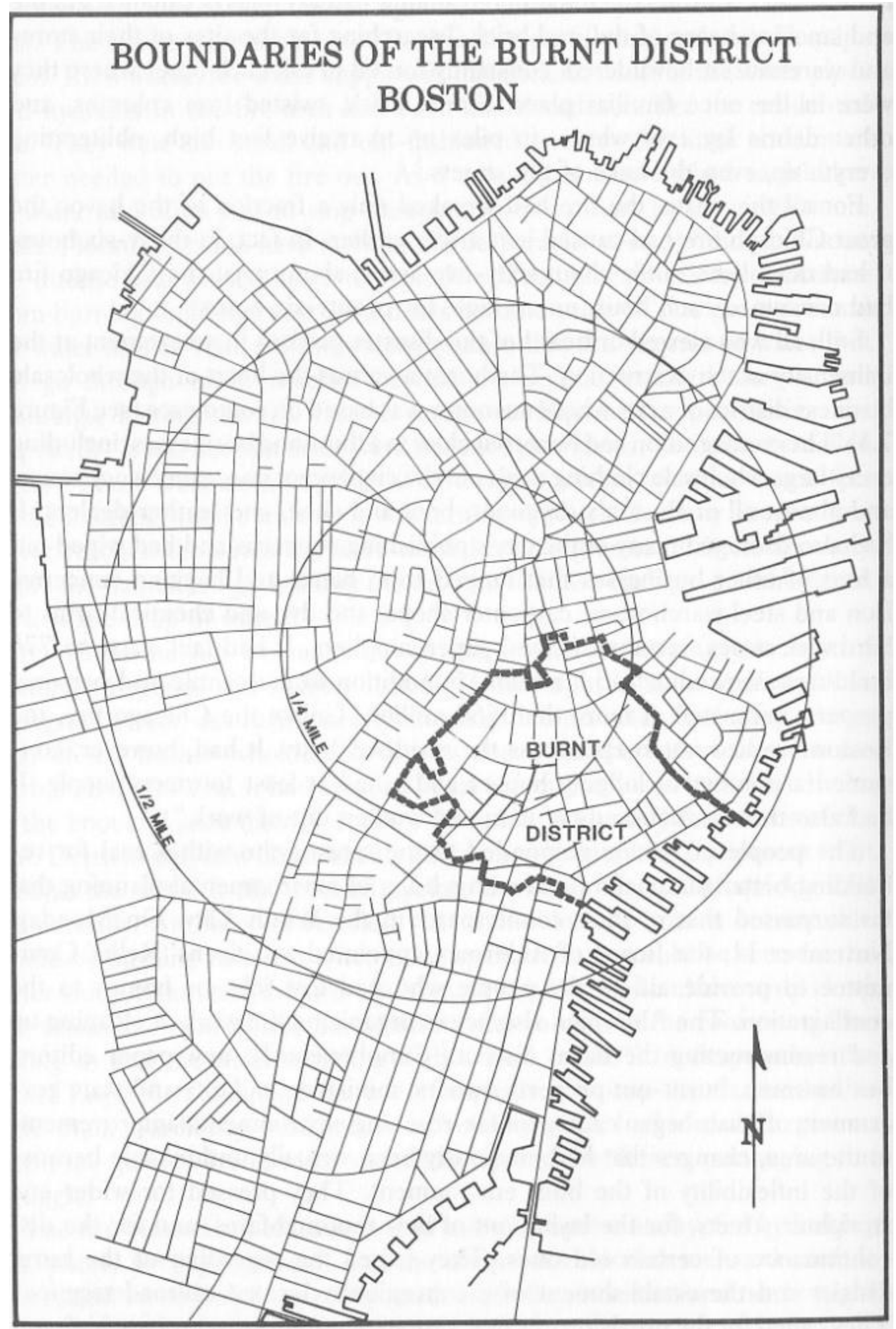

Figure 3-20. Map of the 1876 burnt district. Rosen, The Limits of Power, 180. 


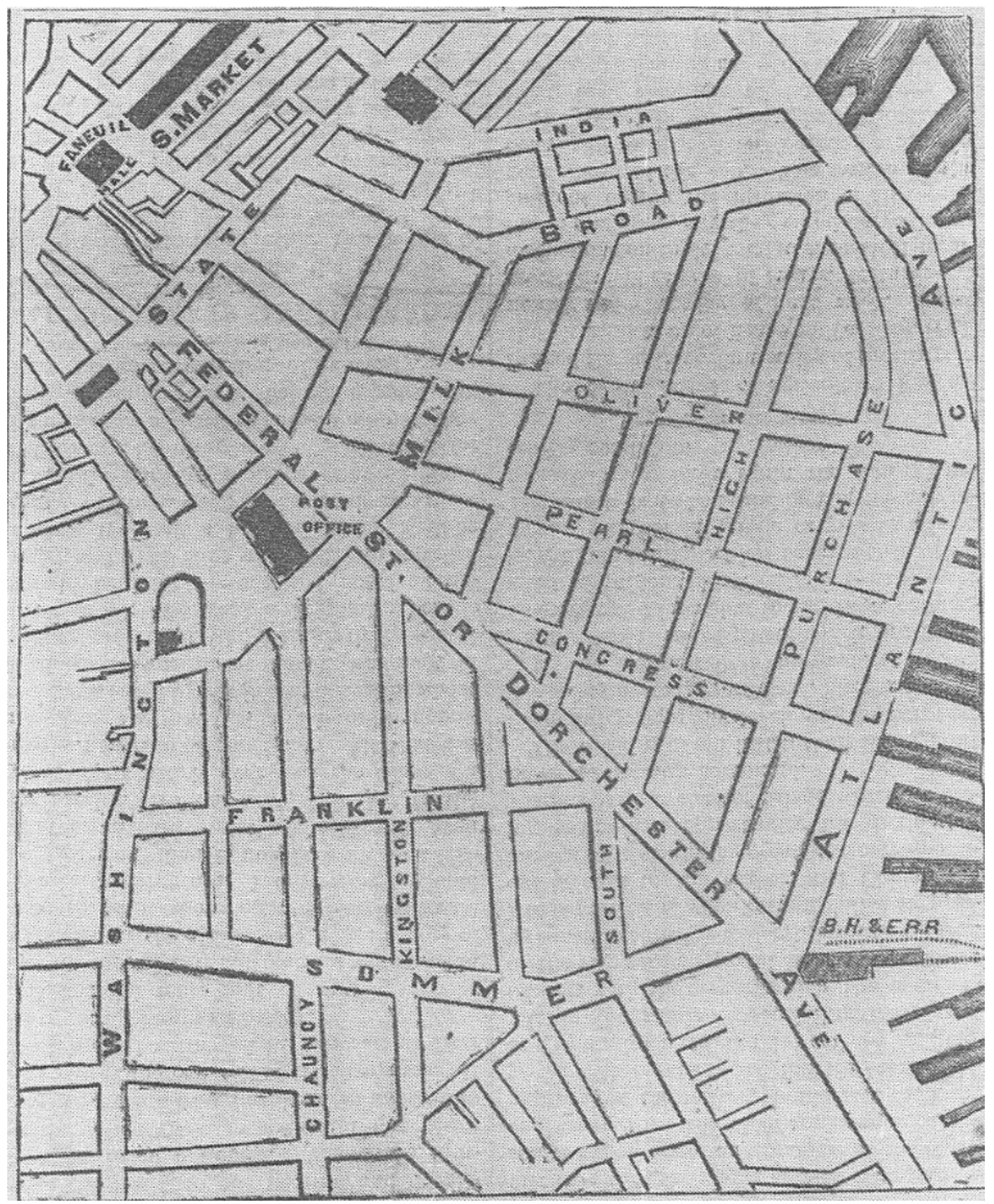

Figure 3-21. Walling's plan for a new street network within Boston's burnt district. Reprinted in Rosen, The Limits of Power, 189. 


\section{BURNT DISTRICT STREET IMPROVEMENTS}

\section{AS FINALLY INSTITUTED BOSTON}

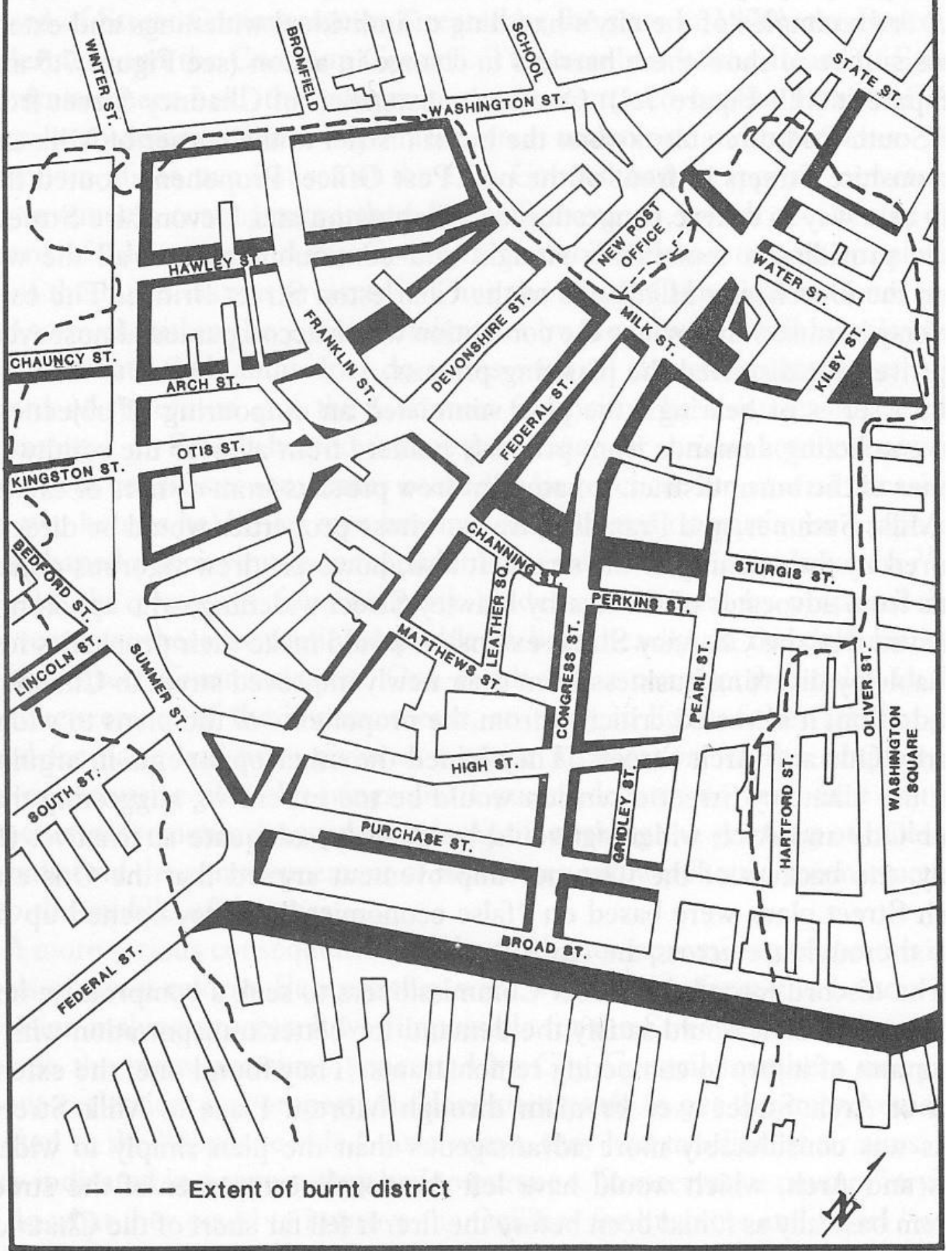

Figure 3-22. Rosen, The Limits of Power, 198. 


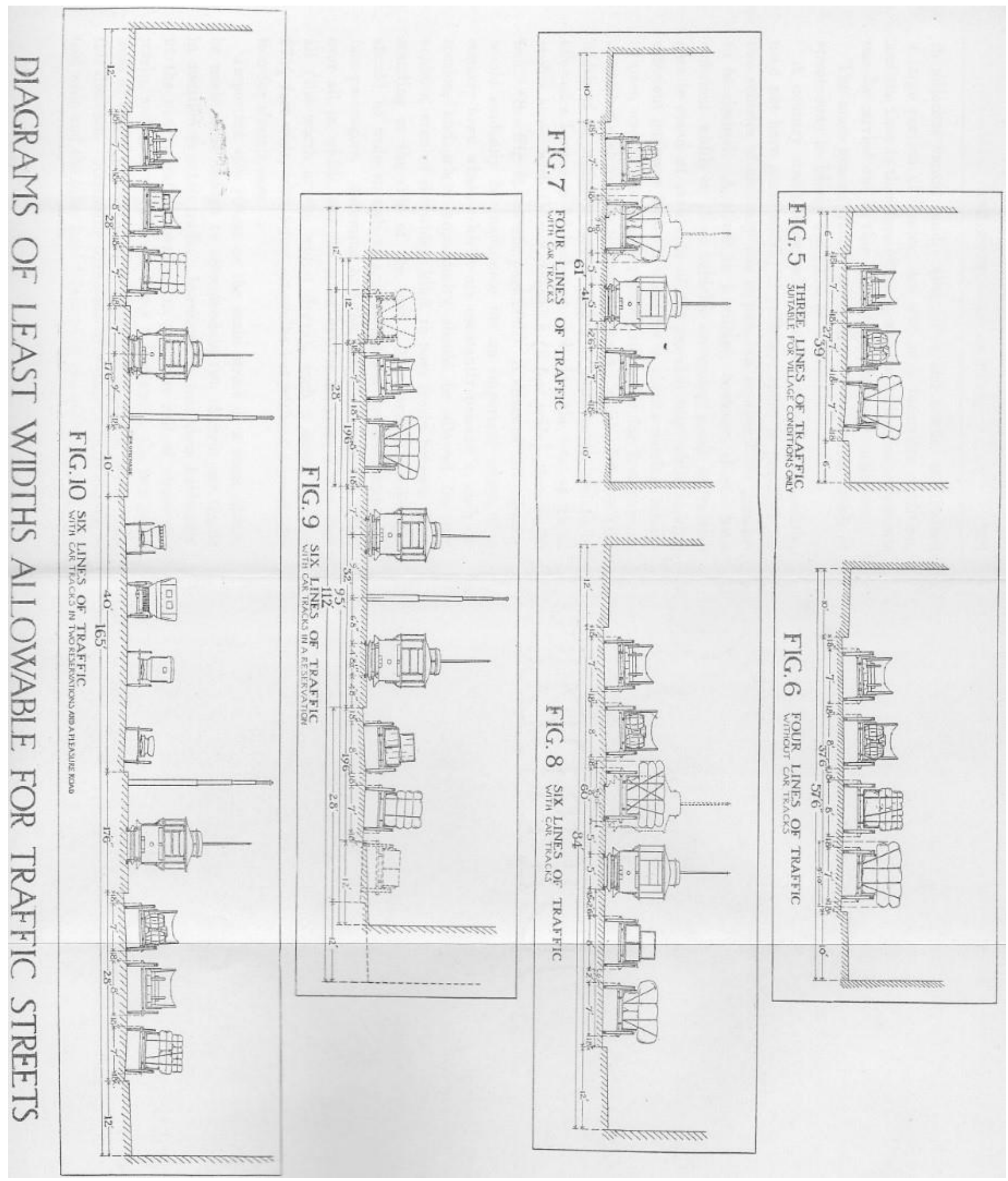

Figure 3-23. Diagram showing preferred street widths by road type. Metropolitan Improvements Commission, Public Improvements for Metropolitan District, opposite page 200. 

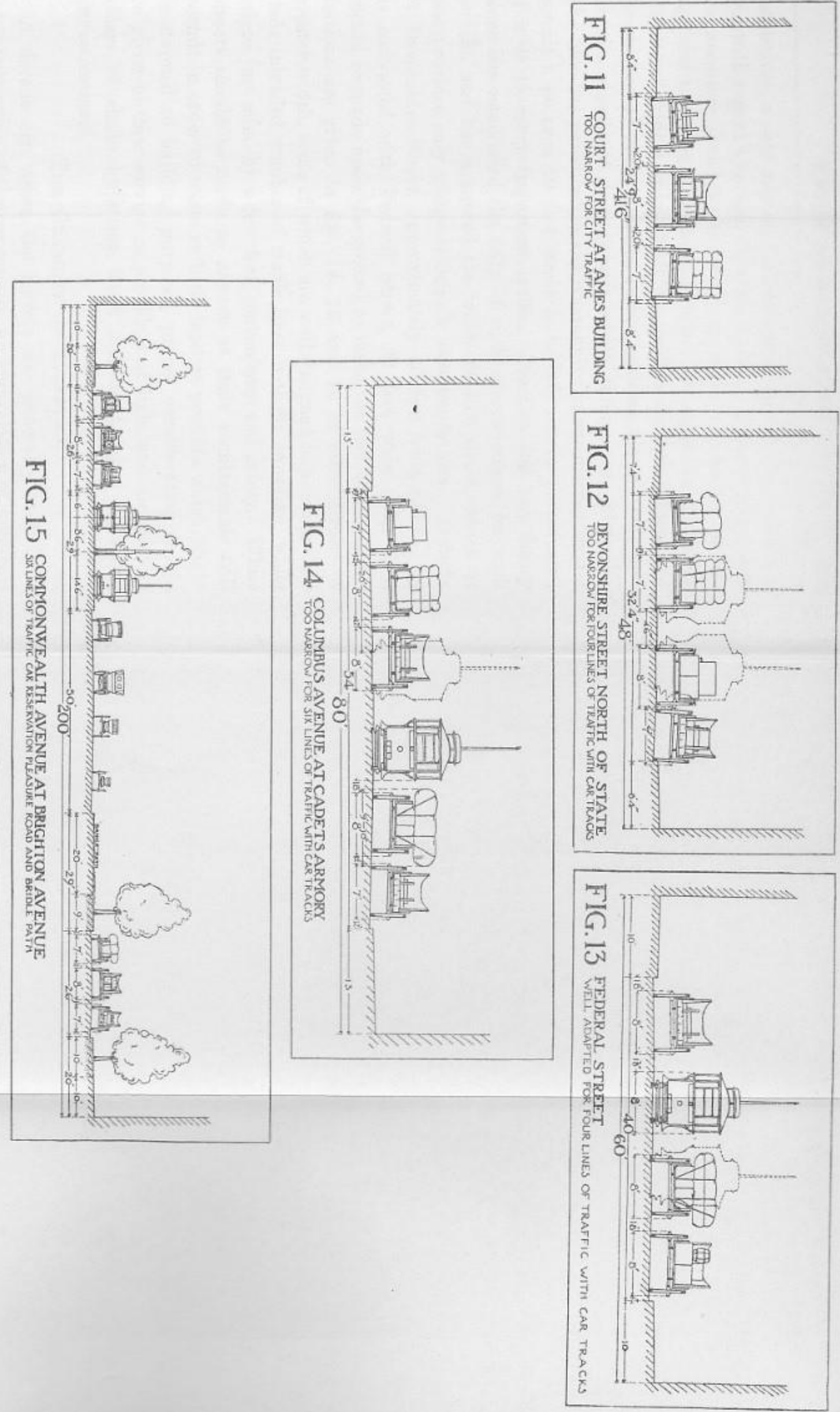

Figure 3-24. Diagram showing actual street widths. Metropolitan Improvements Commission, Public Improvements for Metropolitan District, opposite page 202. 


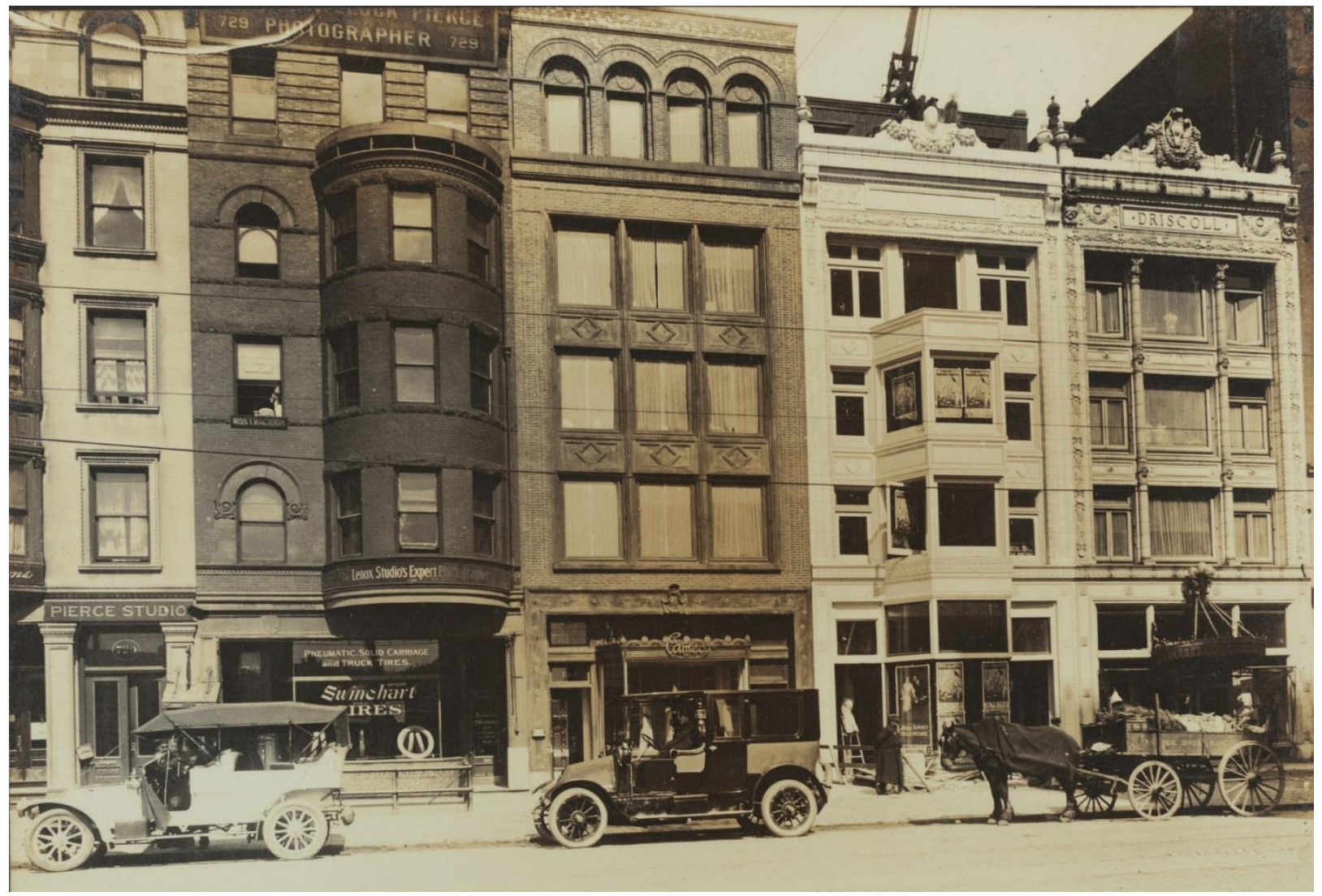

Figure 3-25. 715-729 Boylston Street. Photo taken April 1912, Boston Transit Commission. Courtesy of Historic New England.

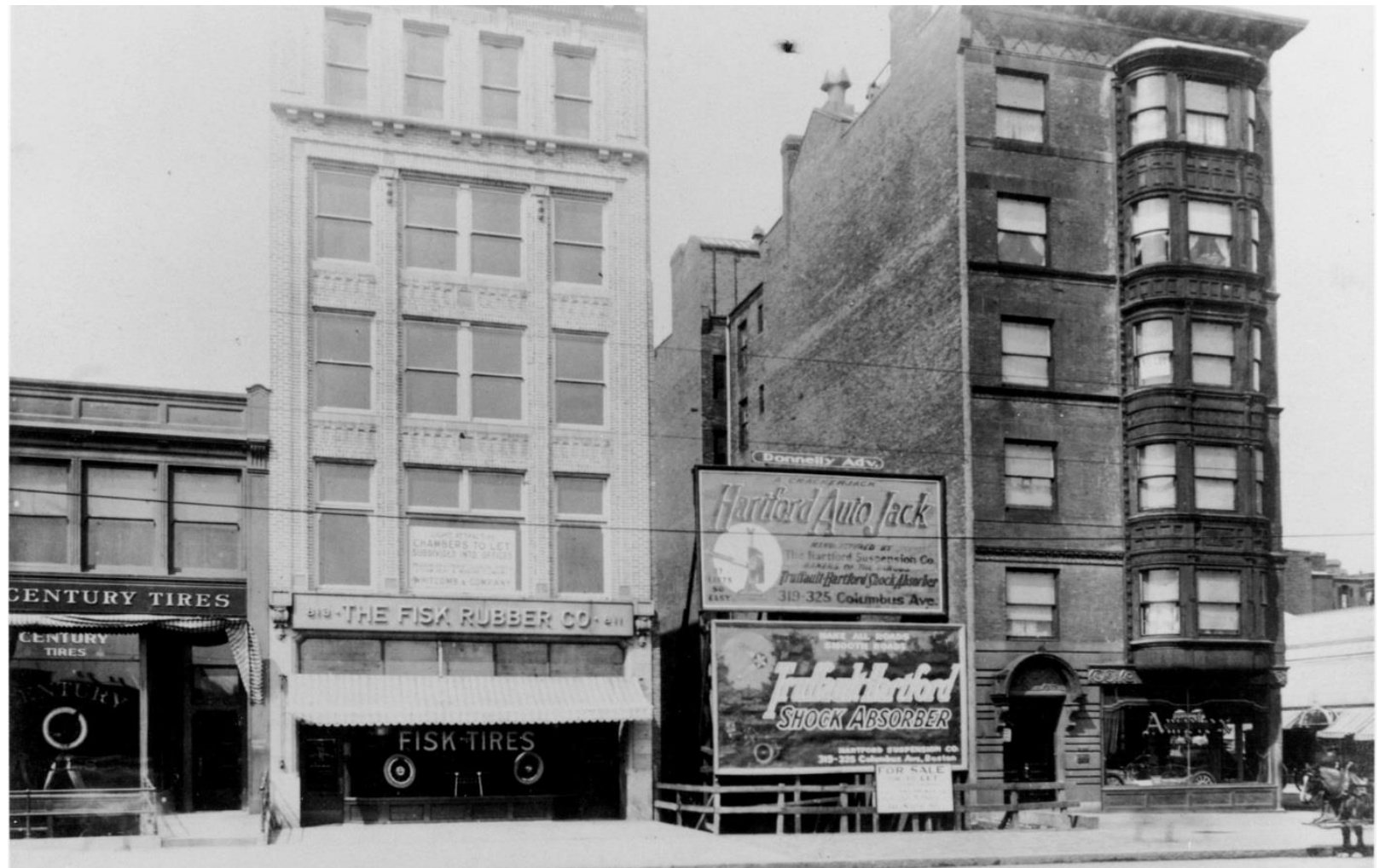




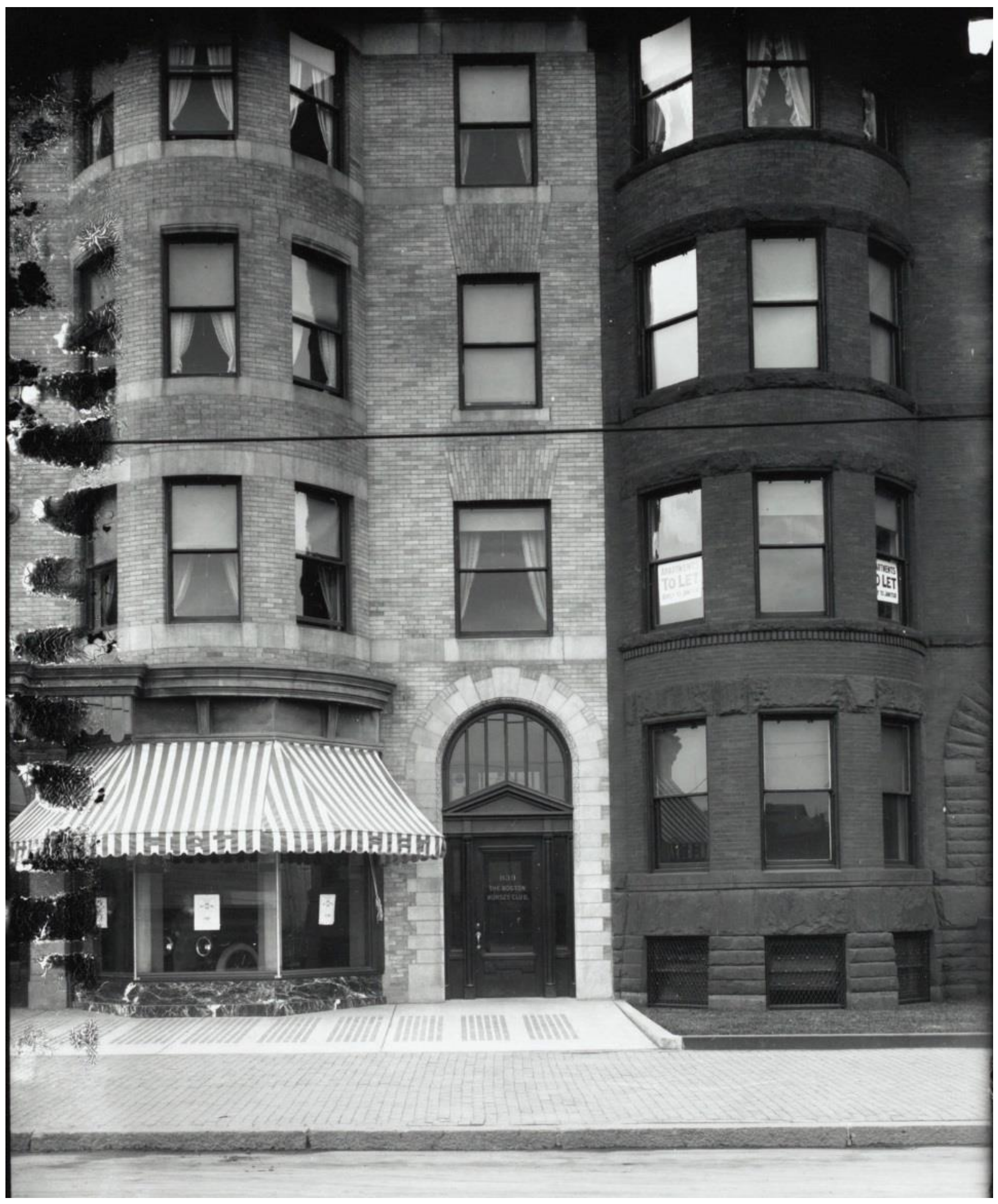

Figure 3-27. 839 Boylston Street. Photo taken 1912, Boston Transit Commission. Courtesy of Historic New England. 


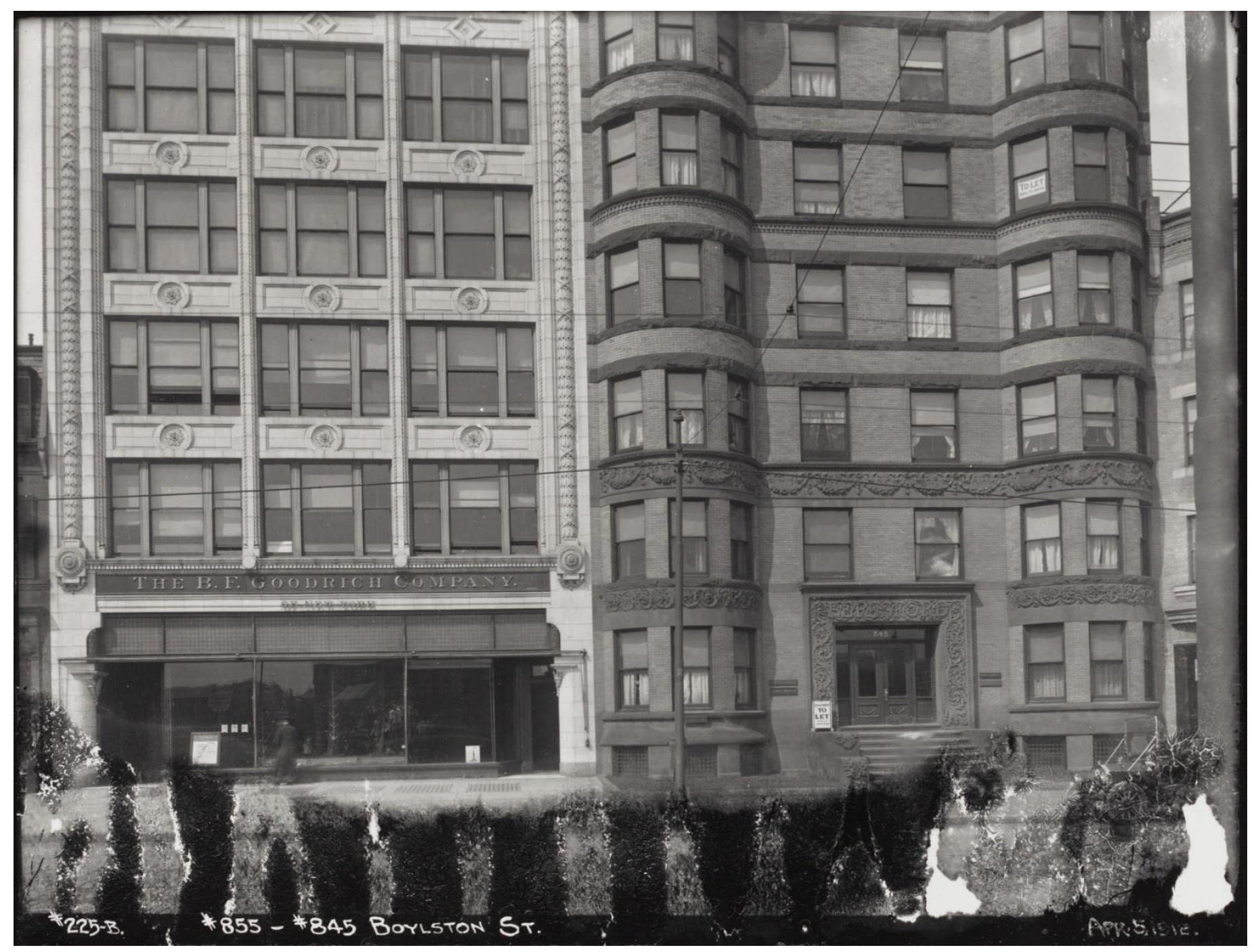

Figure 3-28. 845-855 Boylston Street. Photo taken 1912, Boston Transit Commission. Courtesy of Historic New England. 


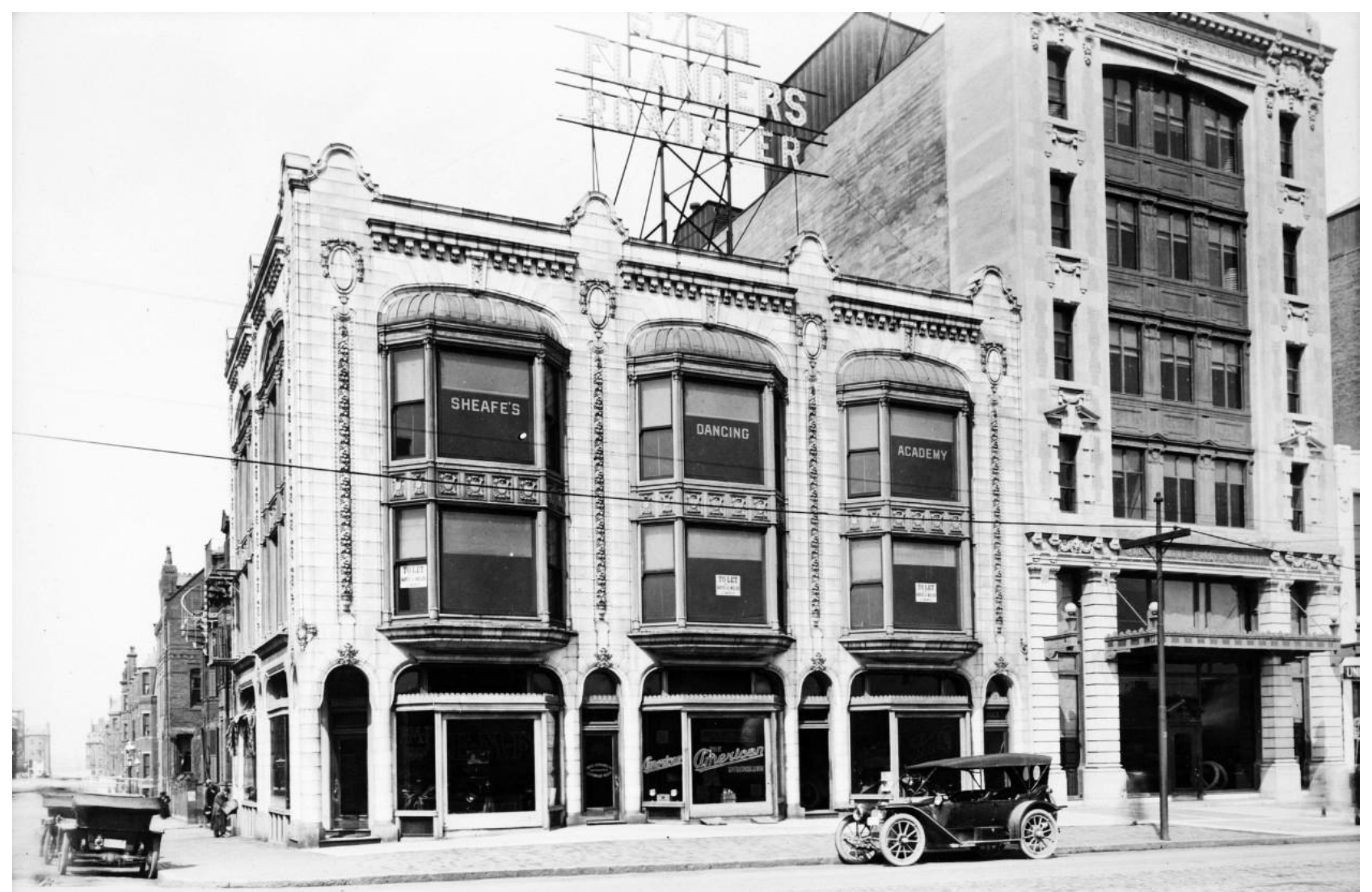

Figure 3-29. 867 Boylston Street to the corner of Gloucester Street. Photo taken 1912, Boston Transit Commission. Courtesy of Historic New England.

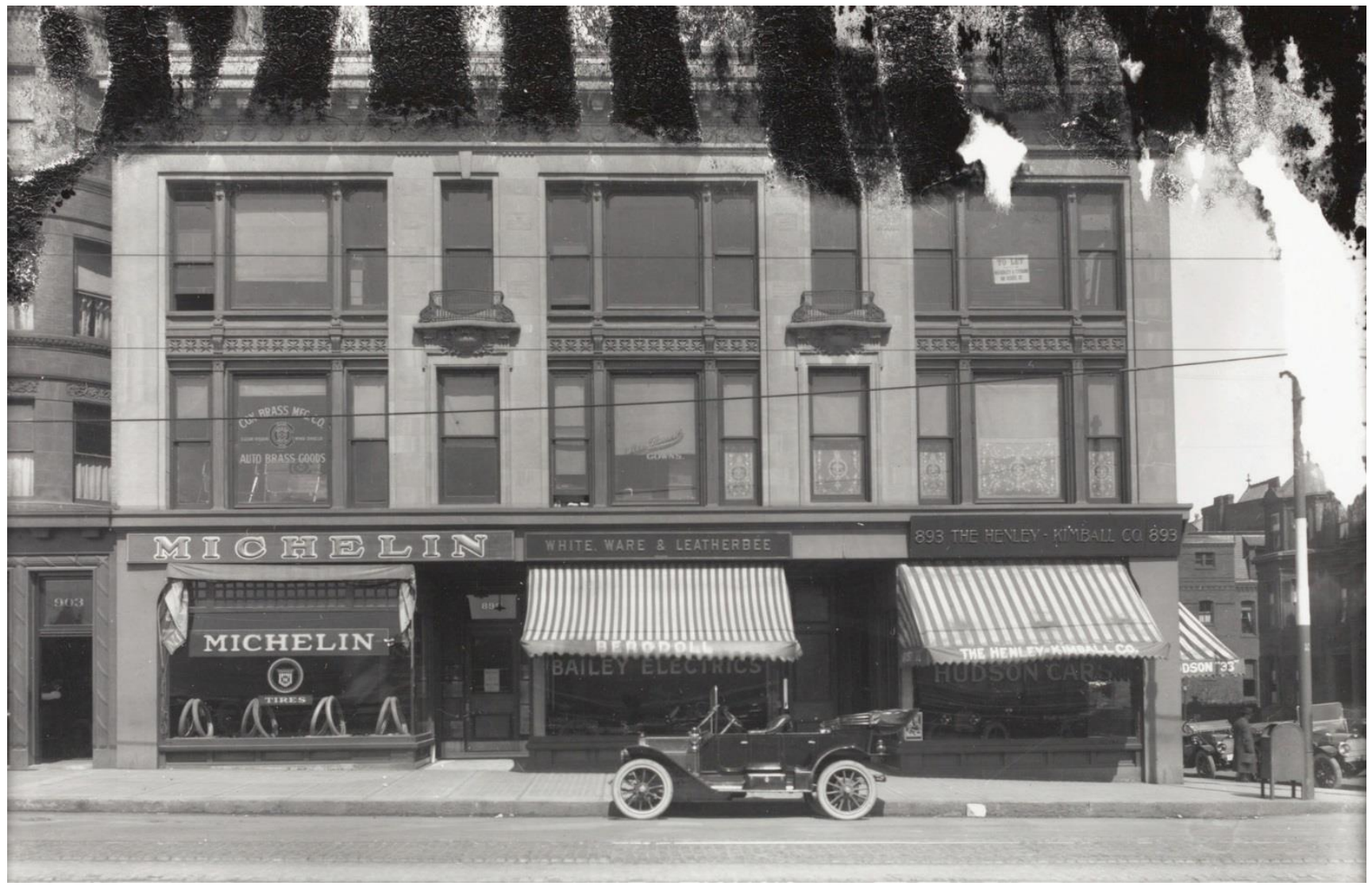




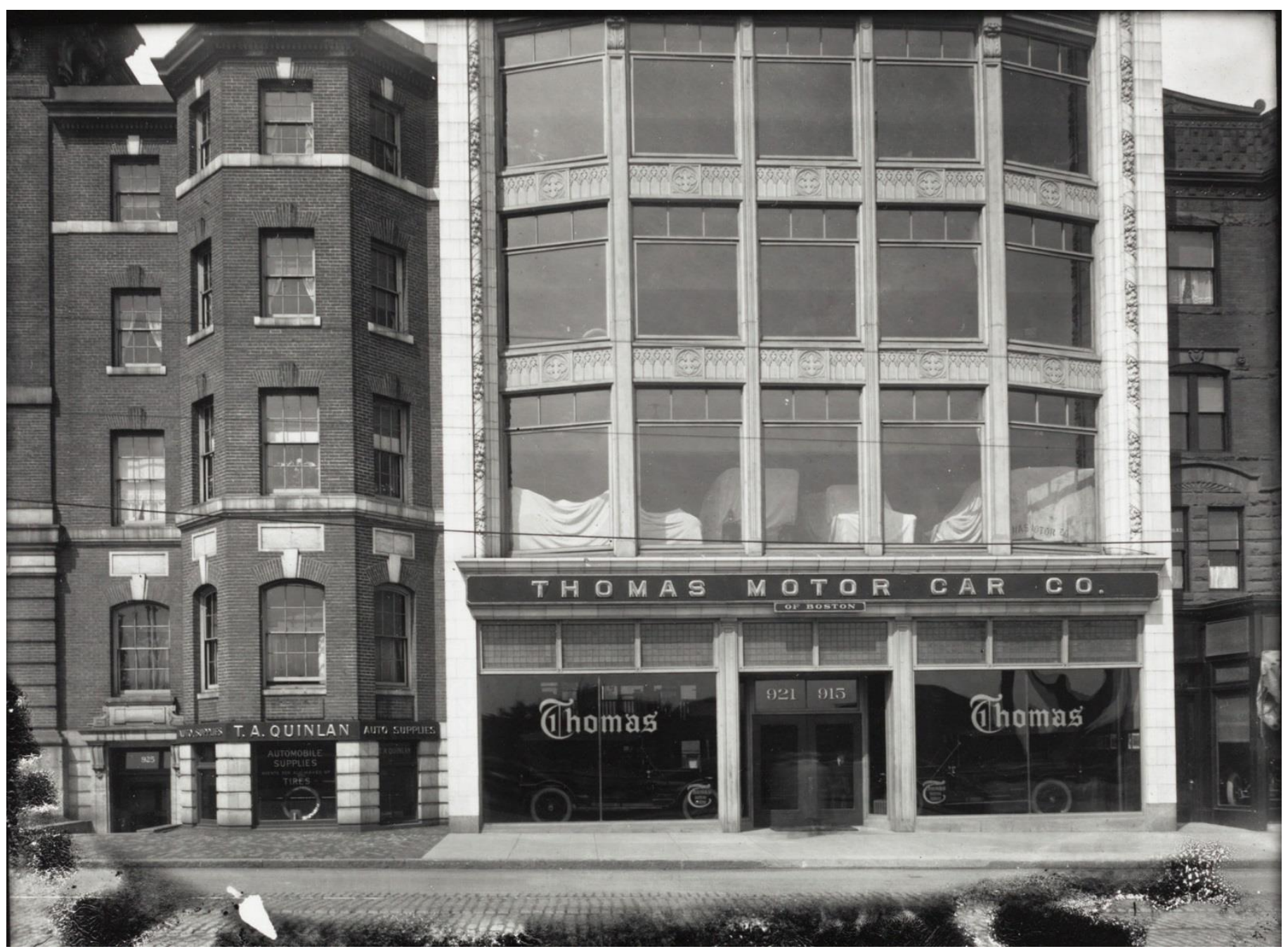

Figure 3-31. 915-925 Boylston Street. Photo taken 1912, Boston Transit Commission. Courtesy of Historic New England. 


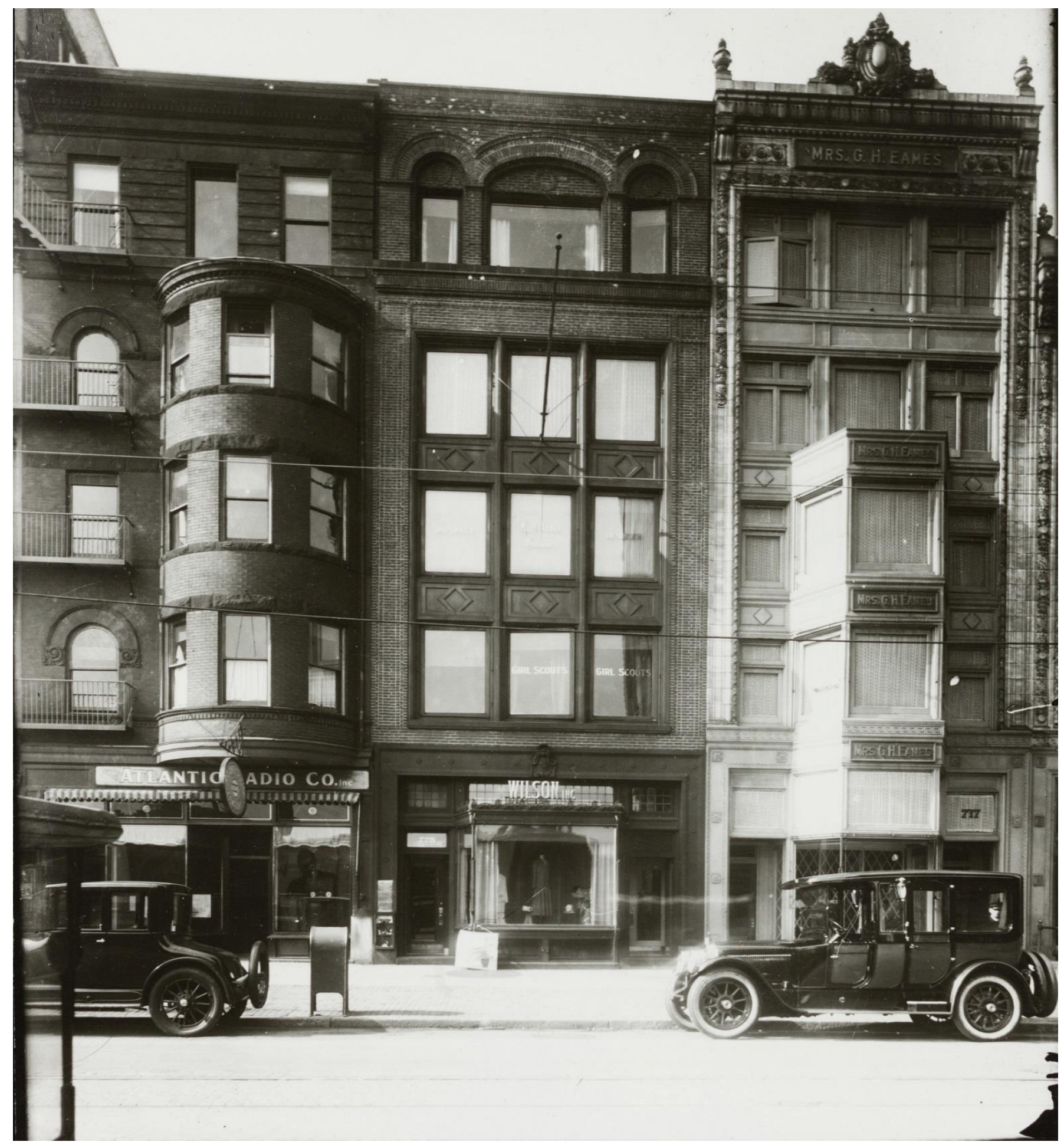

Figure 3-32. 723 Boylston Street and neighboring properties in the 1920s (compare to Figure 3-16). Courtesy of Historic New England. 


\section{$\$ 40,000,000$ TO BE EXPENDED!}

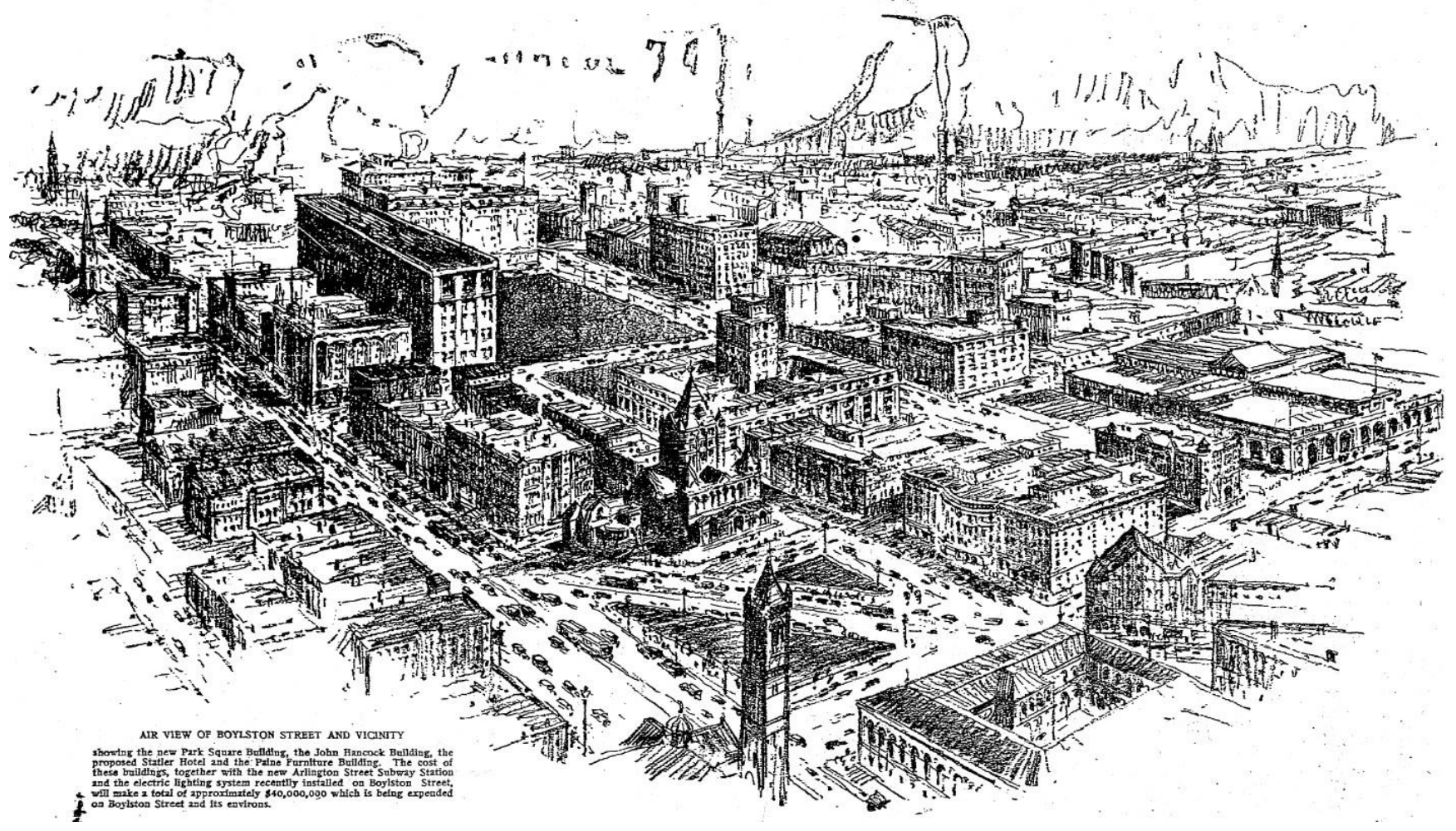

Figure 3-33. Part of an advertisement portraying Boylston Street and environs as the finest shopping district in the world. Boston Herald, October 15, 1922, 16.

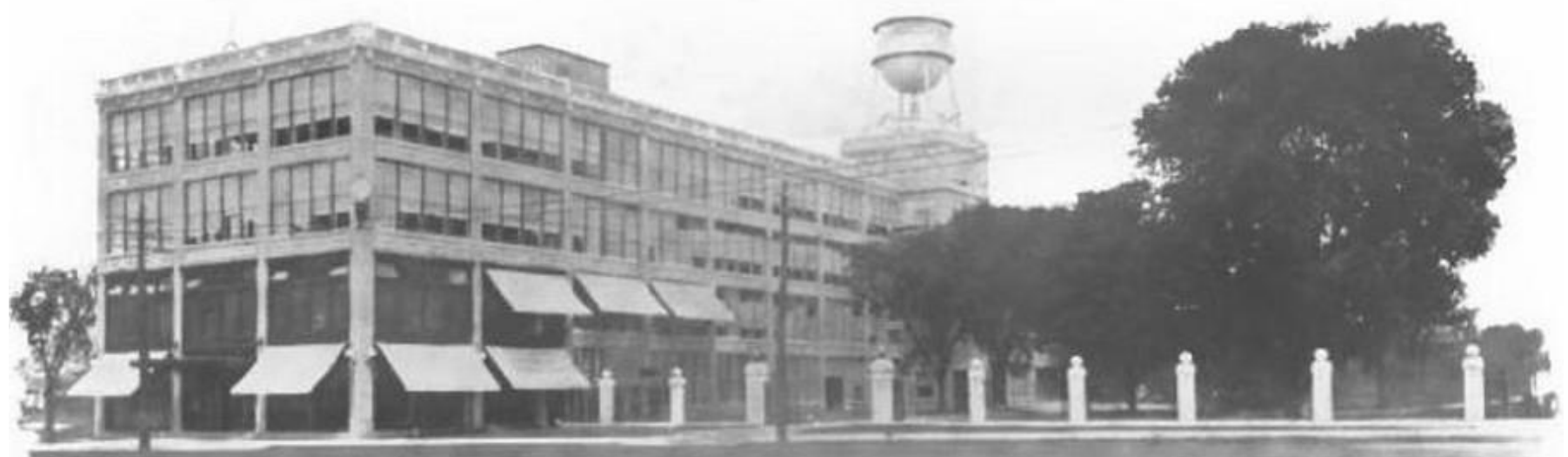

Figure 3-34. Image of the 1909 Packard Building. Packard 12 (December 3, 1910): 1. 


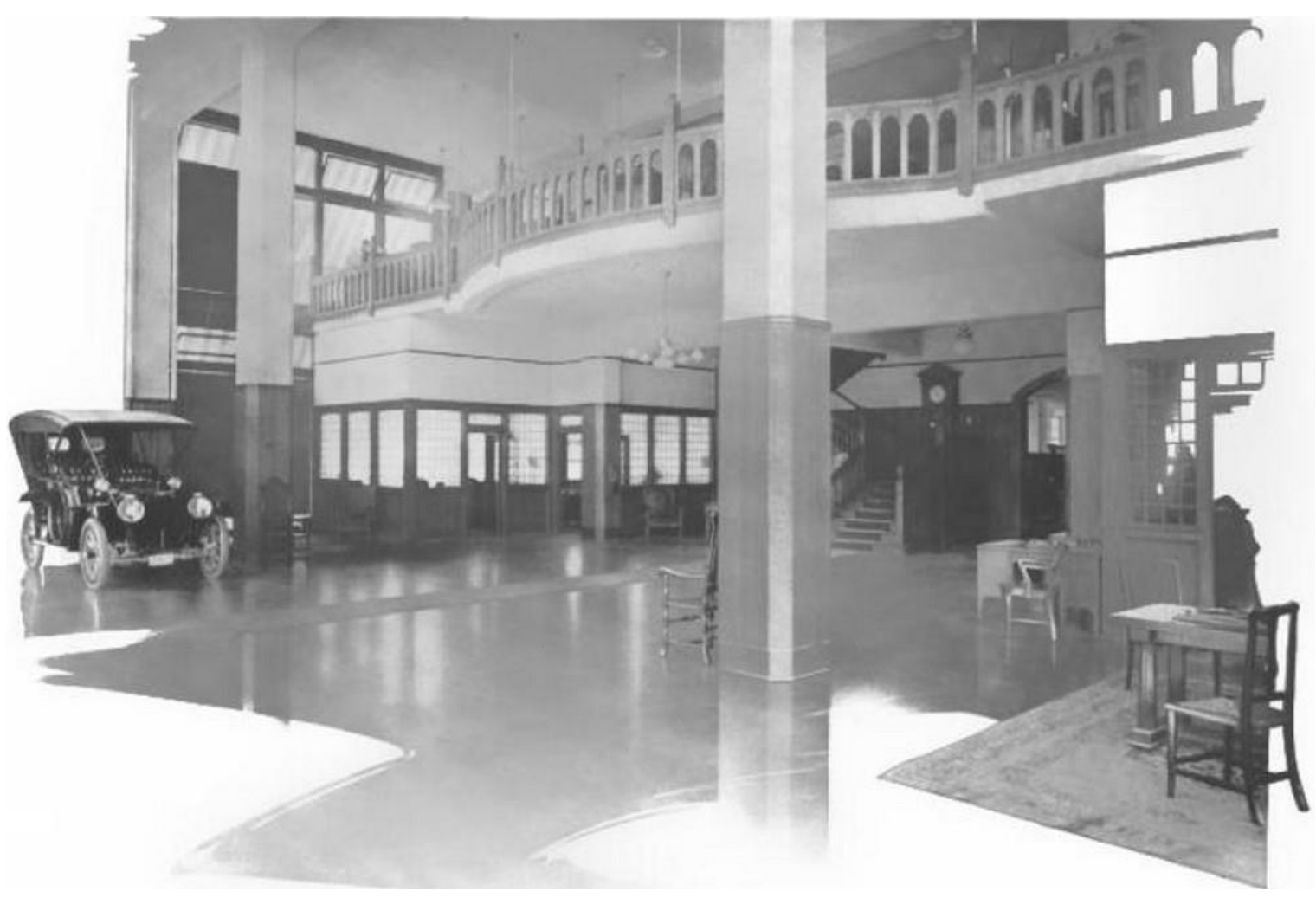

Figure 3-35. Image of the 1909 Packard Building's sales salon. Packard 12 (December 3, 1910): 2.

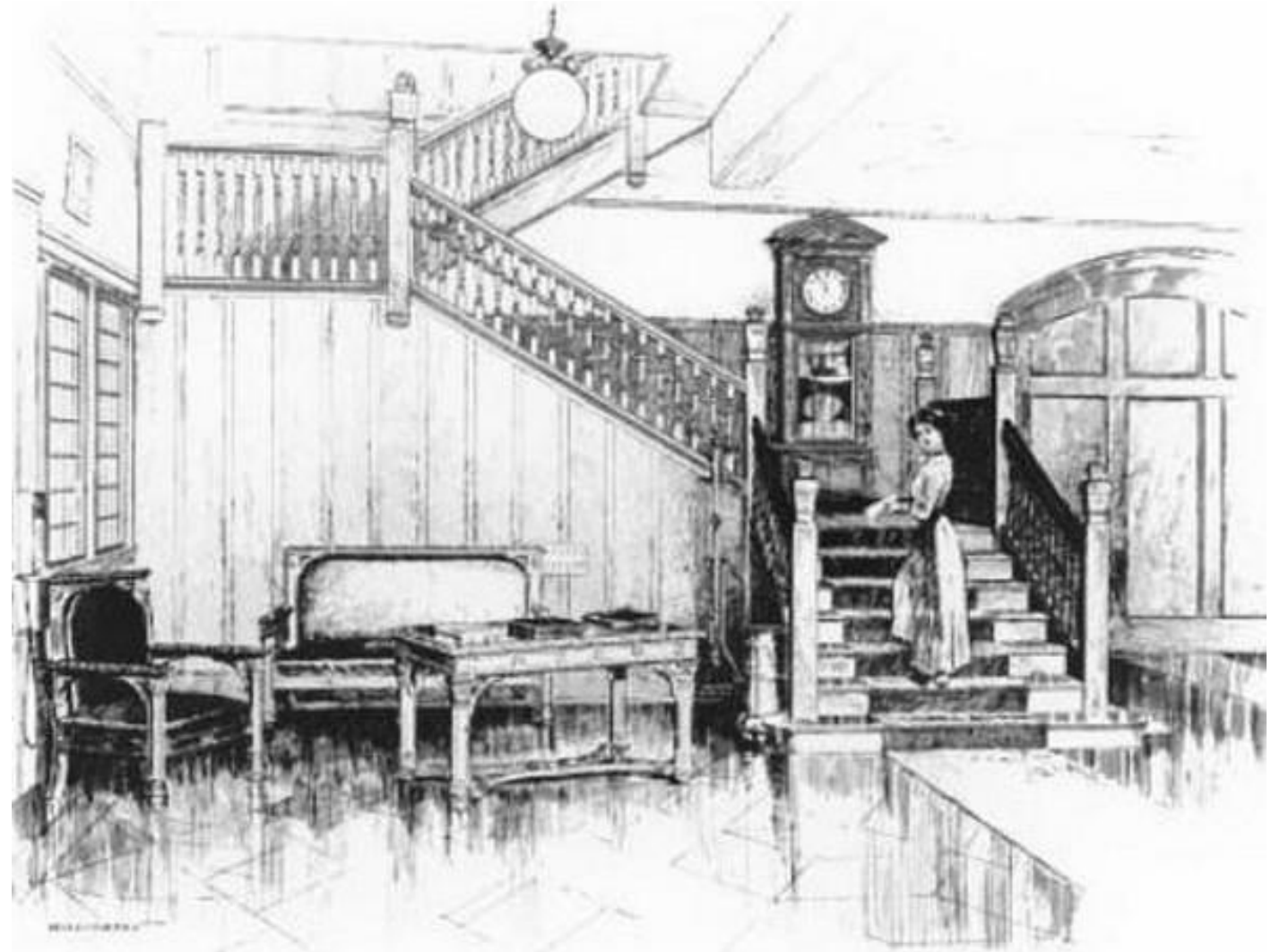

Figure 3-36. Detail of lounge area and stair within the 1909 Packard Building's sales salon. Packard 12 (December 3, 1910): 3. 


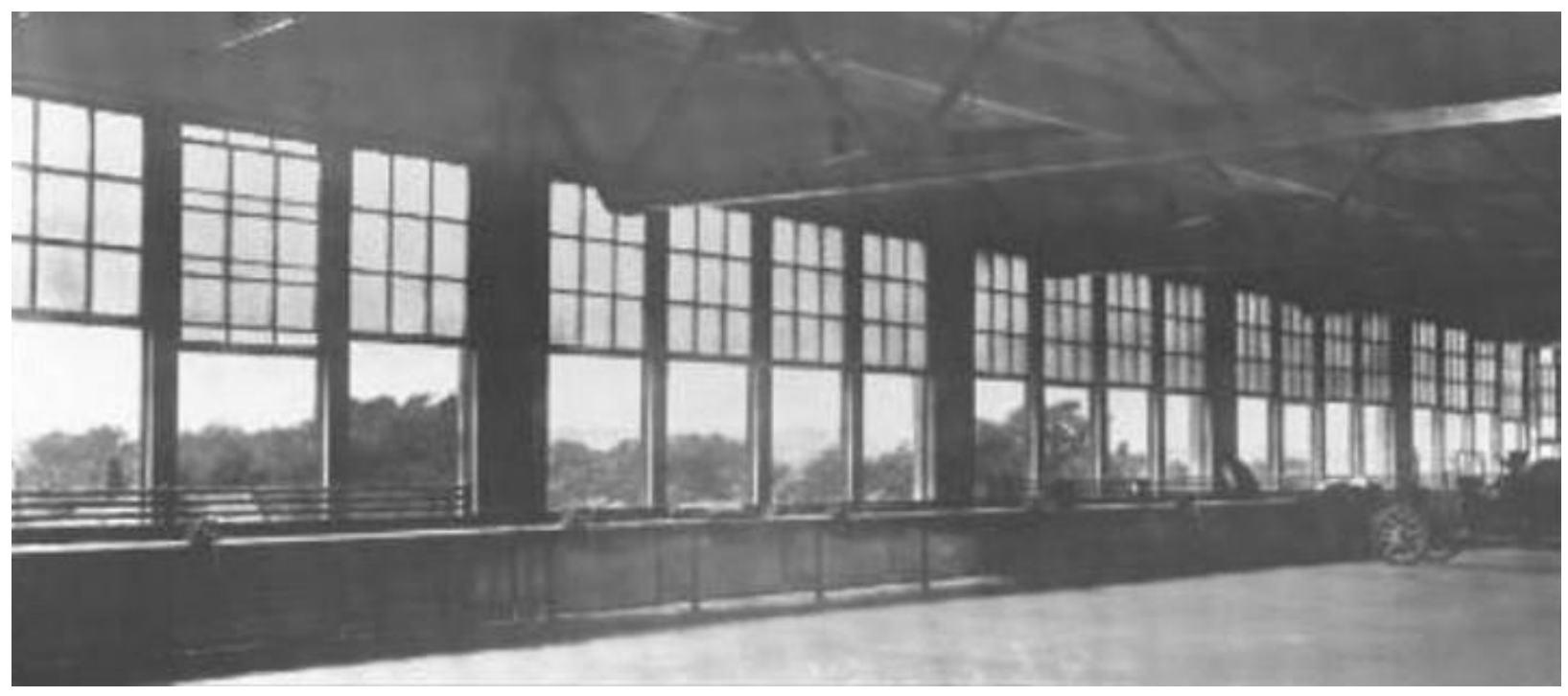

Figure 3-37. Image of the 1909 Packard Building's top floor. Packard 12 (December 3, 1910): 5.

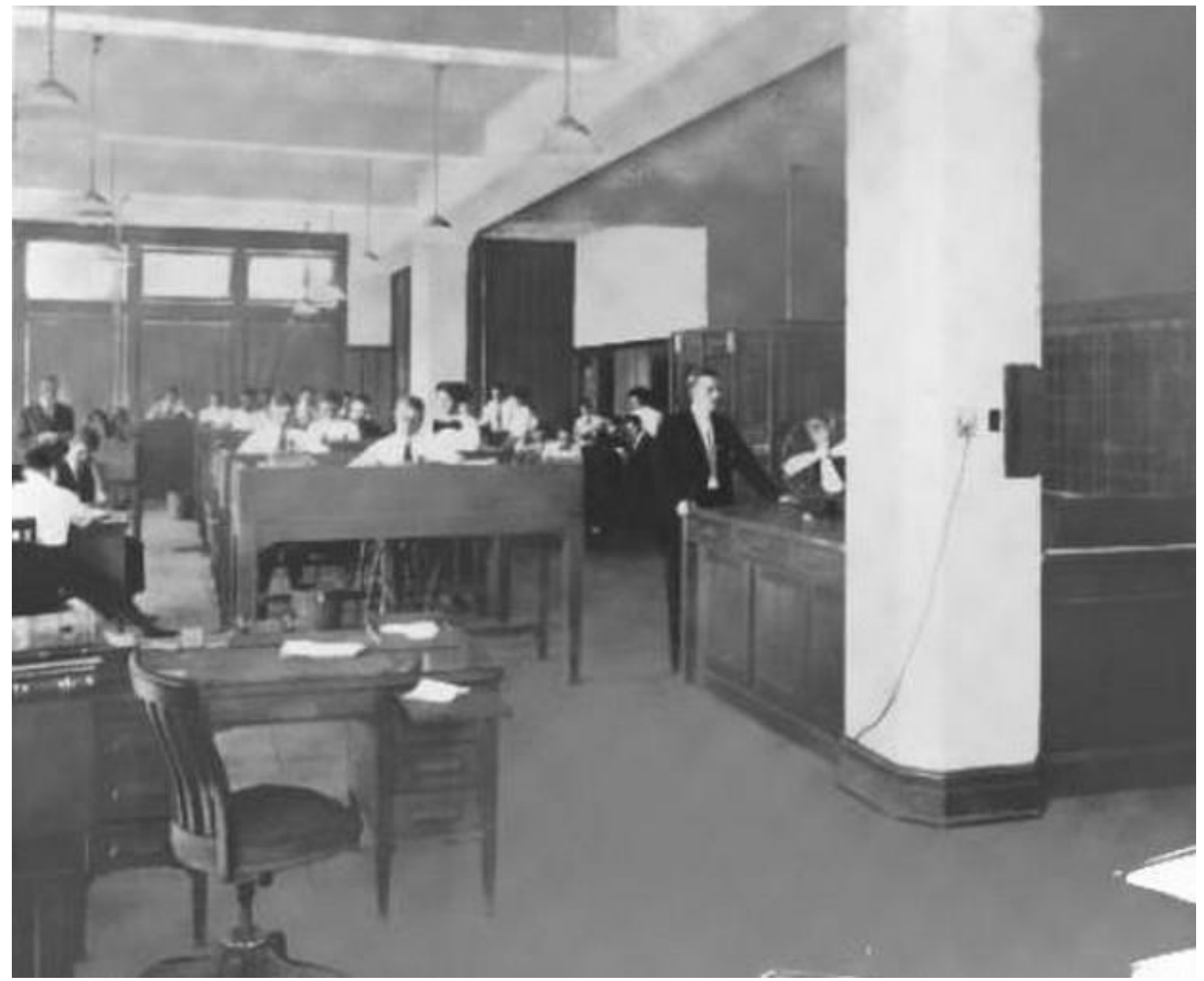

Figure 3-38. Image of the general offices of the 1909 Packard Building. Packard 12 (December 3, 1910): 3. 


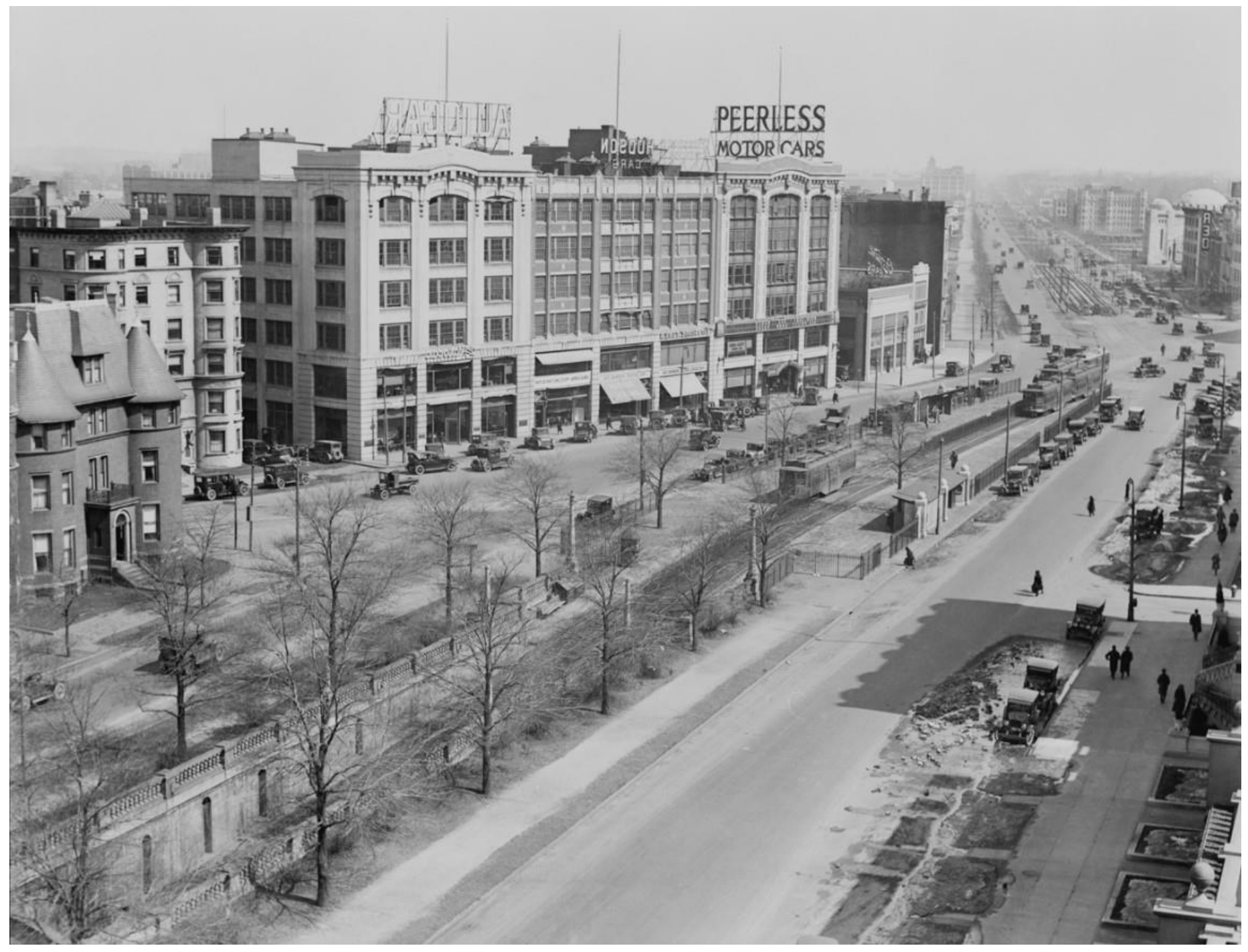

Figure 3-39. The Peerless, Ford (now Hudson in this image) and Auto Car buildings located at 642-660 Commonwealth Avenue in Kenmore Square. Courtesy of the Boston Public Library. 


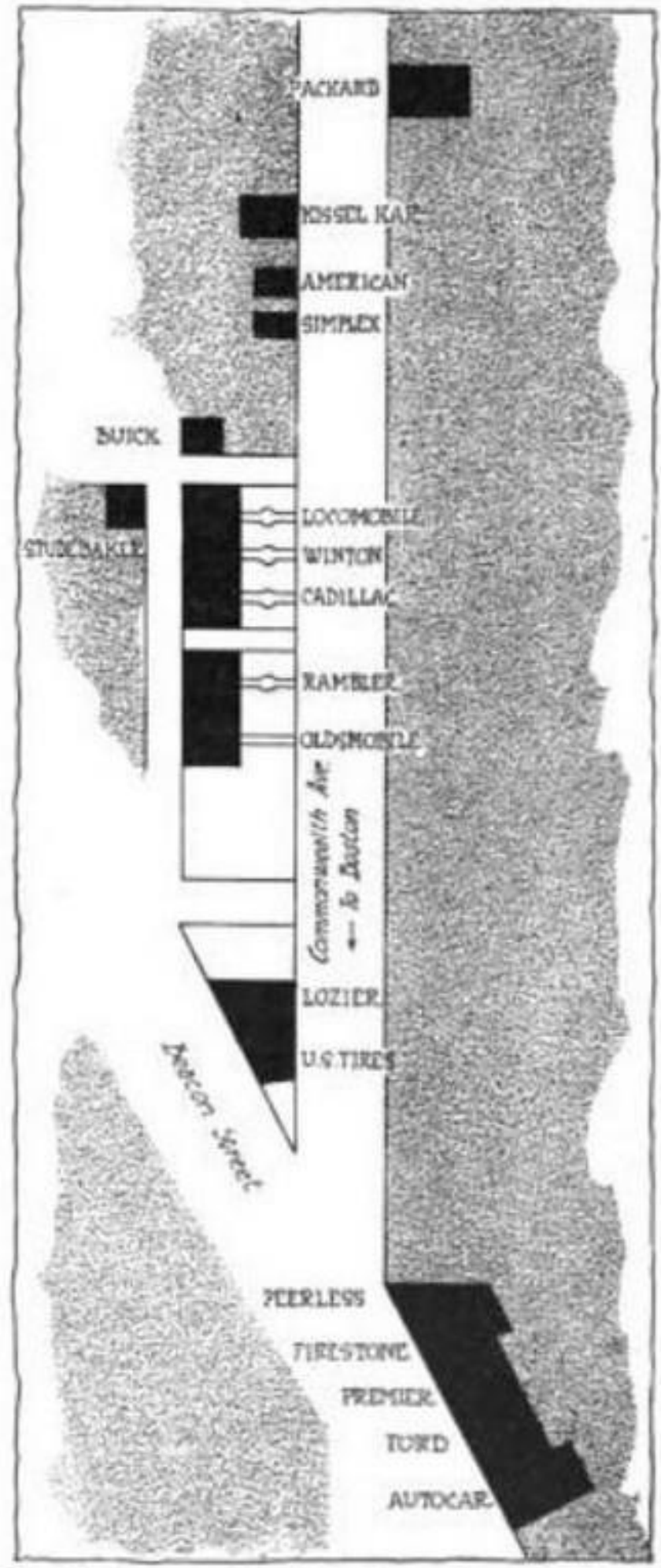

Figure 3-40. Diagram of Boston's Commonwealth Avenue Automobile Row in 1913. Automobile 28 (March 6, 1913): 577. the Fenway district of Boston 


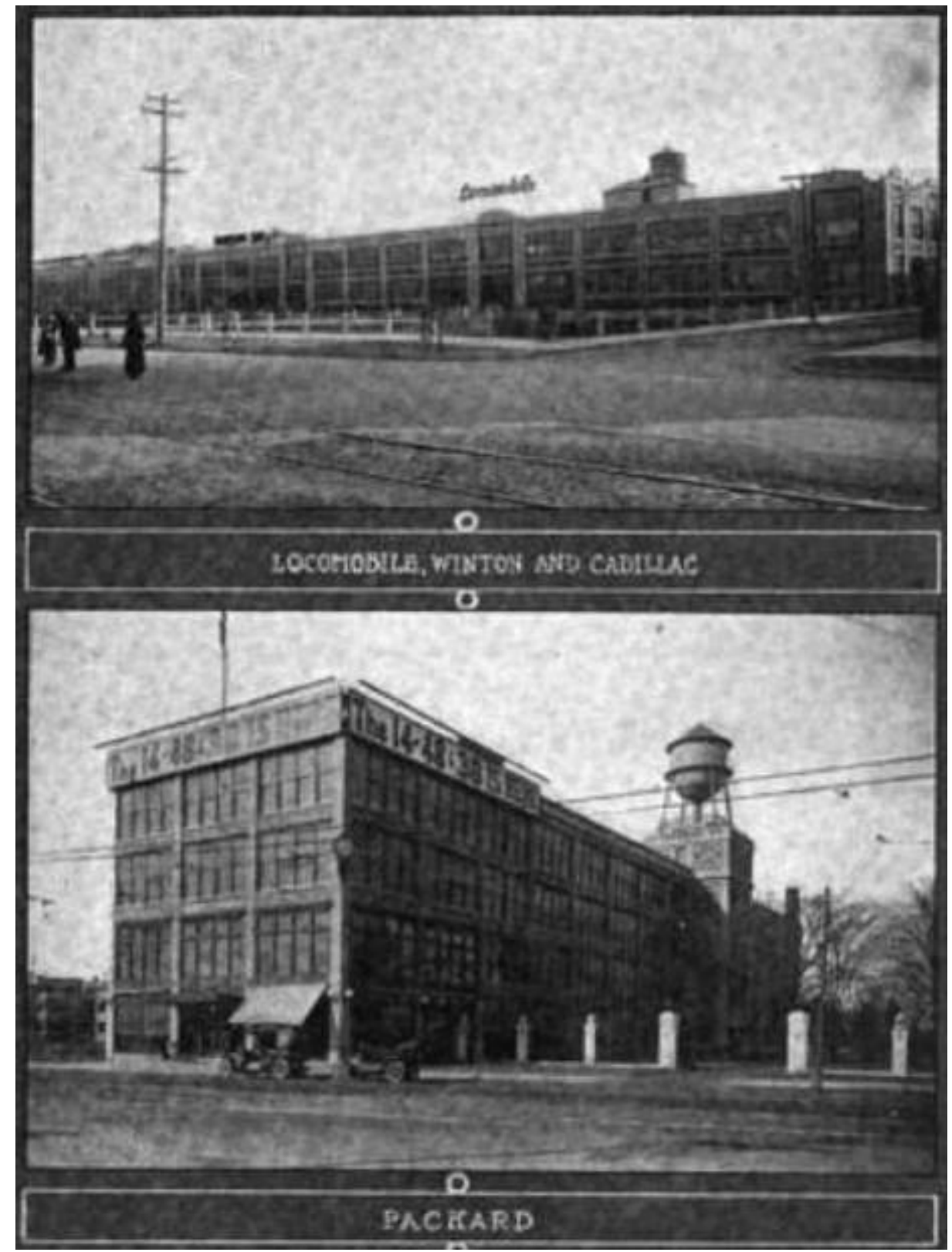

Figure 3-41. Photographs of the Packard, Locomobile, Winton and Cadillac facilities on Commonwealth Avenue in 1913. Automobile 28 (March 6, 1913): 578. 


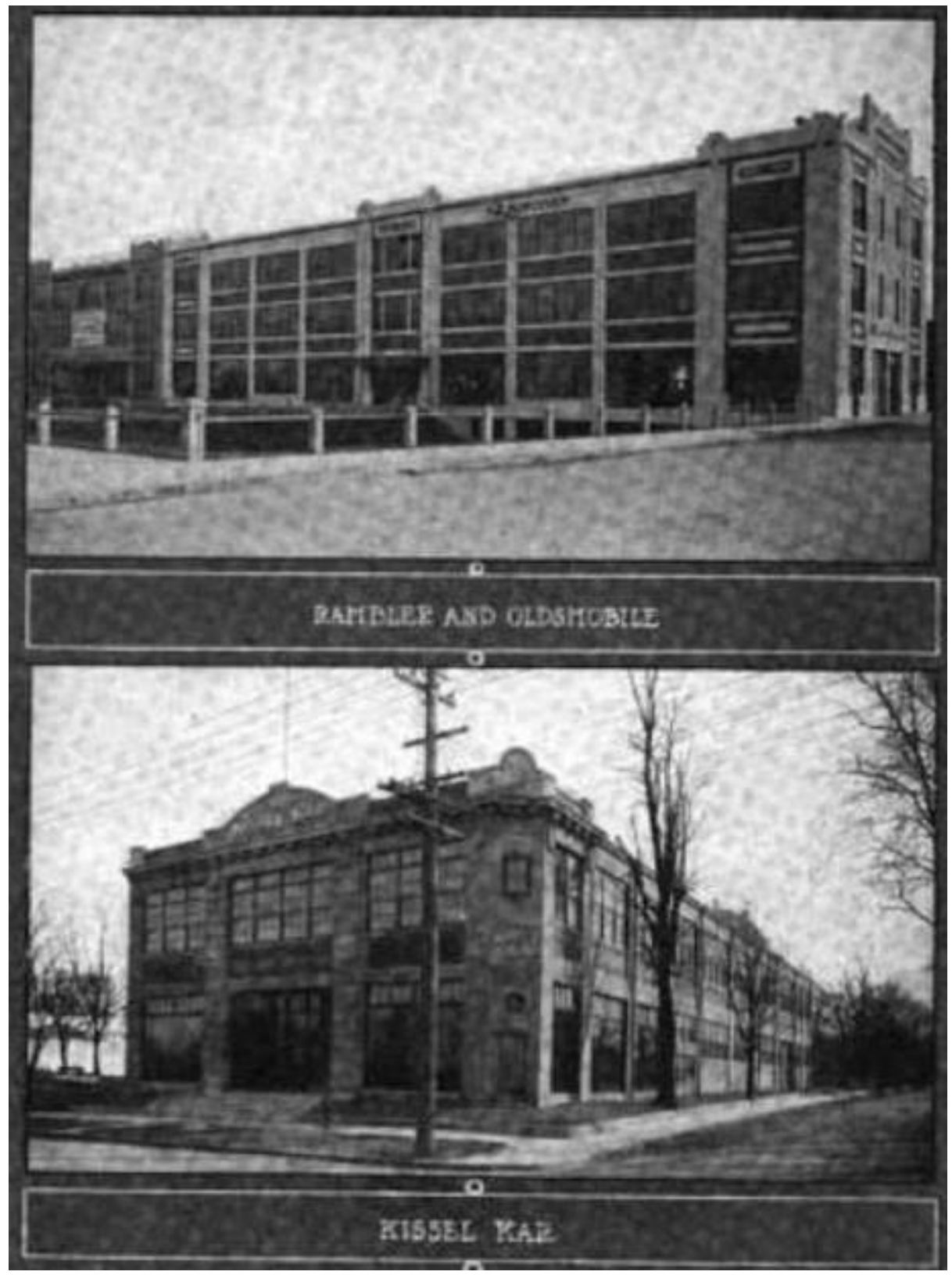

Figure 3-42. Photographs of the Rambler, Oldsmobile and Kissel Kar facilities on Commonwealth Avenue in 1913. Automobile 28 (March 6, 1913): 579. 


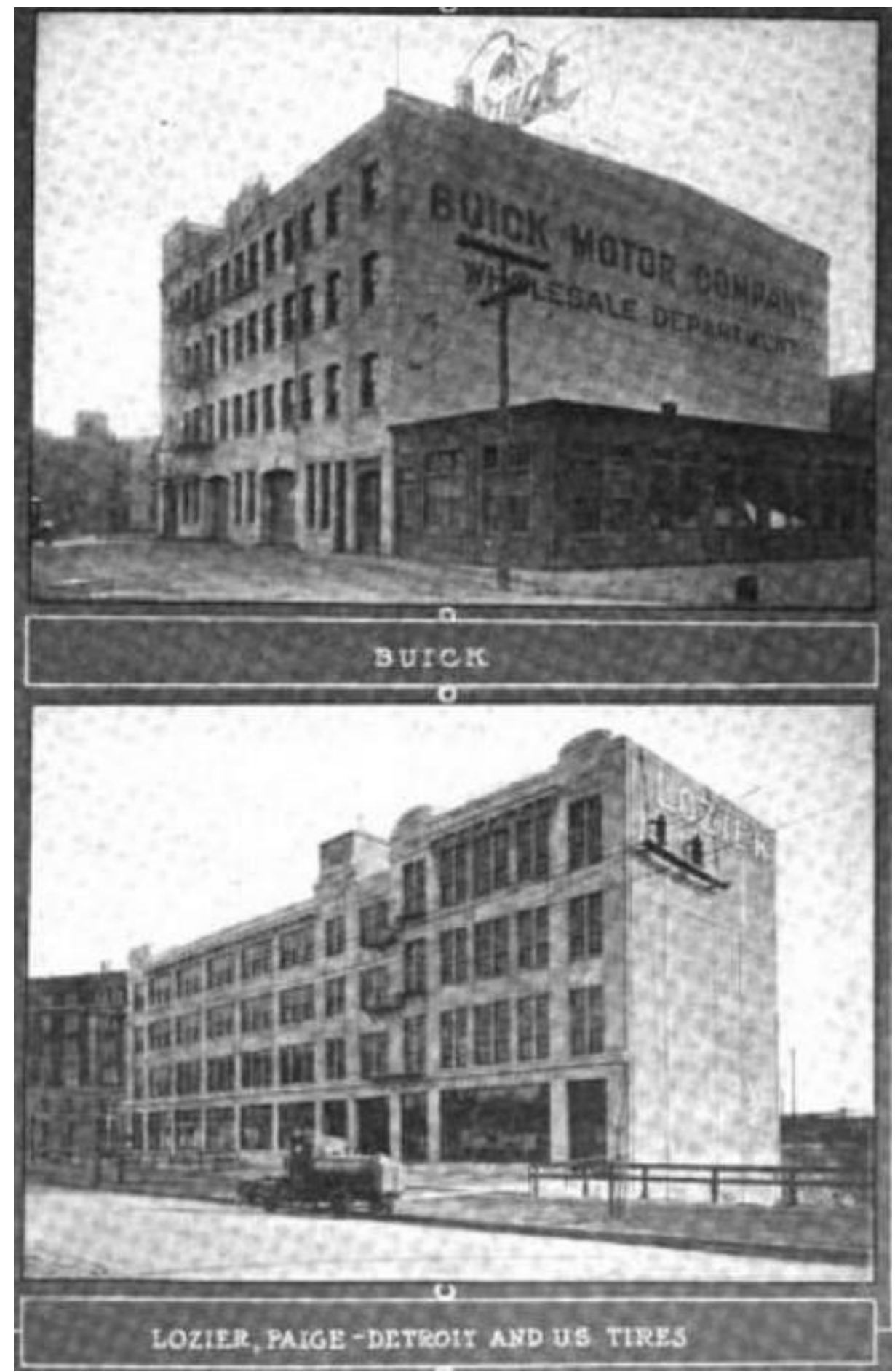

Figure 3-43. Photographs of the Buick, Lozier, Paige-Detroit and U.S. Tires facilities on Commonwealth Avenue in 1913. Automobile 28 (March 6, 1913): 577. 


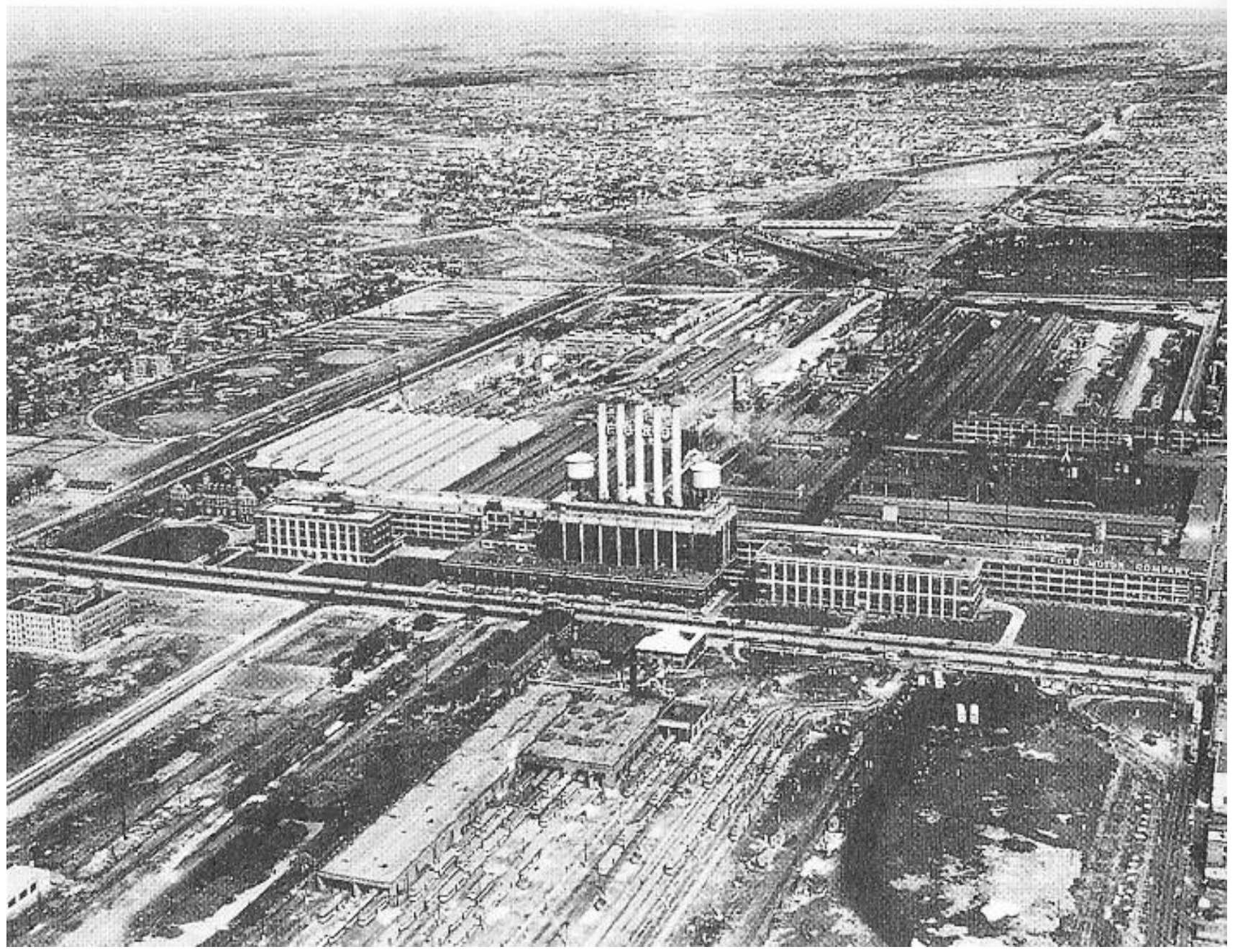

Figure 3-44. Aerial view of Highland Park in 1915. Federico Bucci, Albert Kahn: Architect of Ford, 42. 


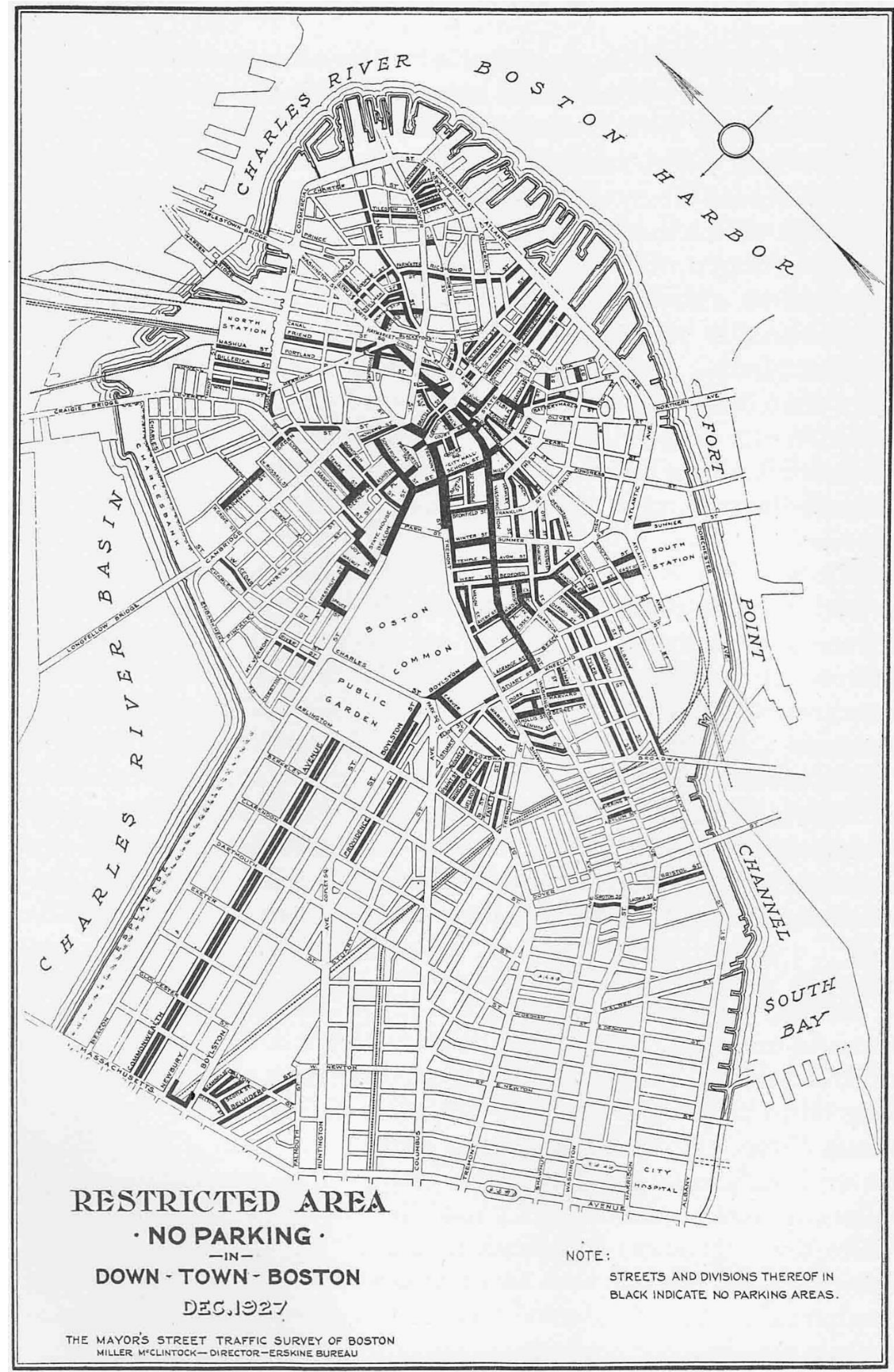

Figure 3-46. Streets with no parking in downtown Boston. McClintock, Report on the Street Traffic Control Problem, 172. 


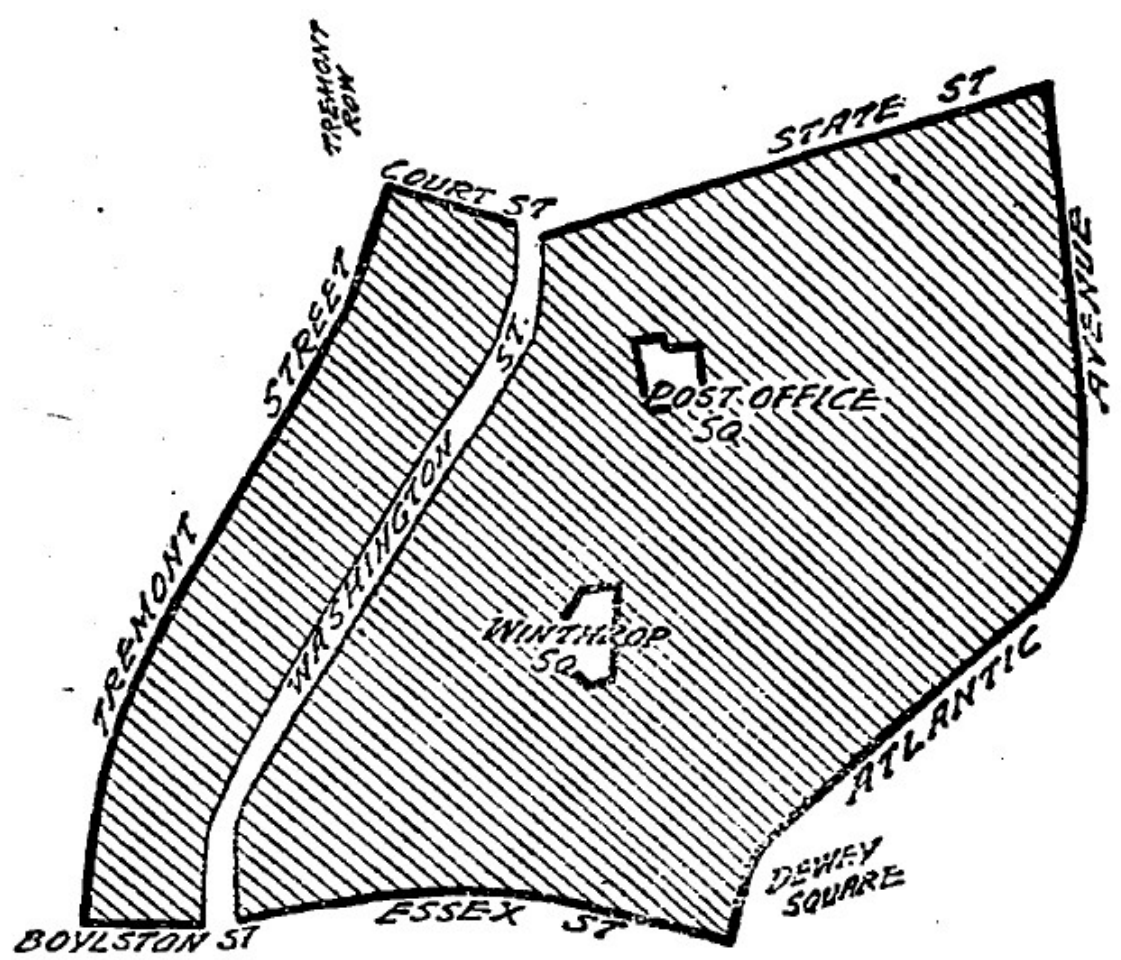

Figure 3-47. The 1923 proposed ban on street parking. "Would End Parking in the Heart of the City," Boston Globe, February 2, 1923, 13.

SHADED AREA SHOWS SECTION IN WHICH PARKING OF AUTOS IN STREETS WOULD BE PROHIBITED.

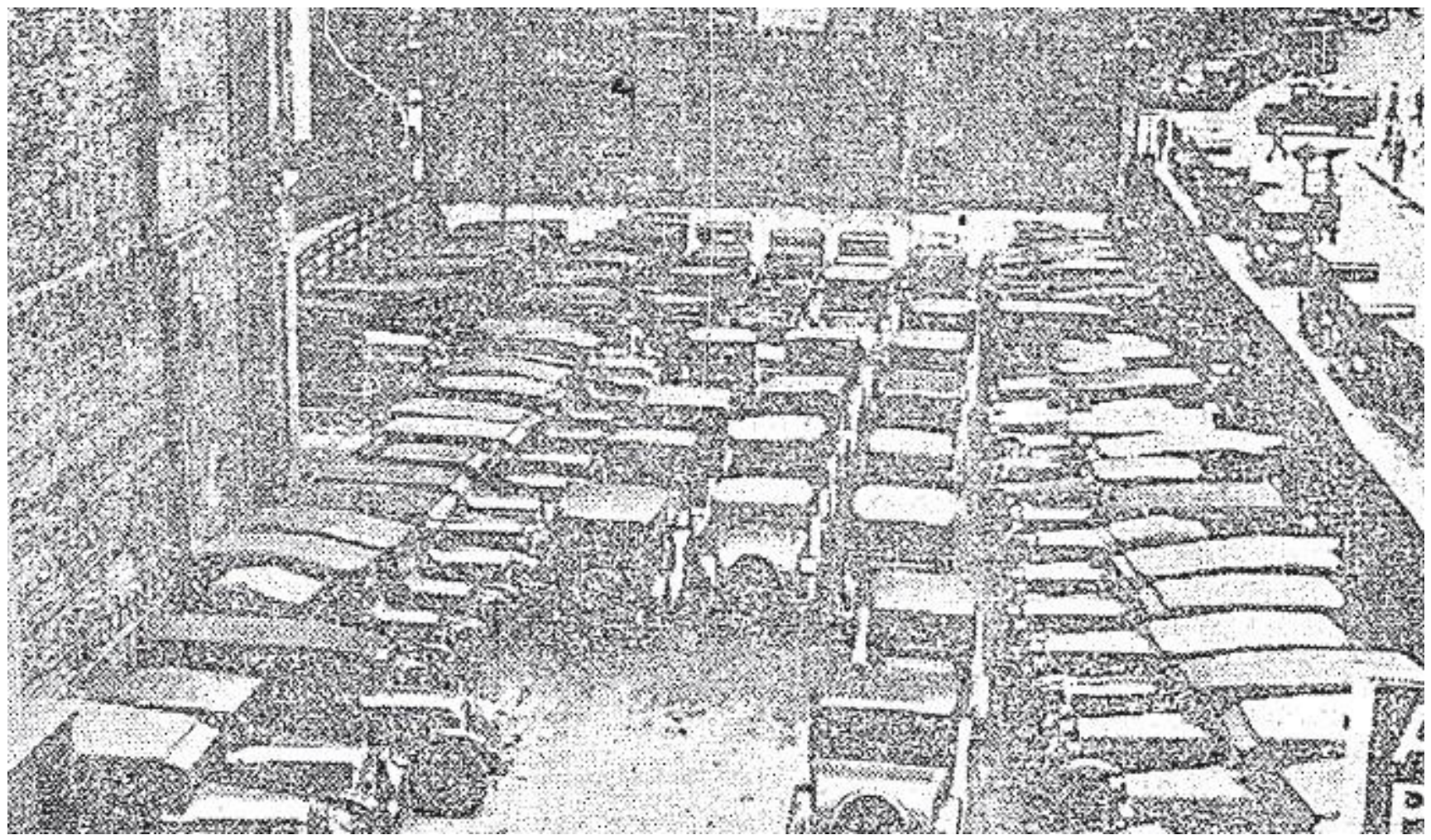

Figure 3-48. Open-air parking lot at the corner of Water and Kilby Streets. "What Becomes of the 207,000 Cars Driven into Boston Every Day?" Boston Globe, Sep 18, 1927, 2. 


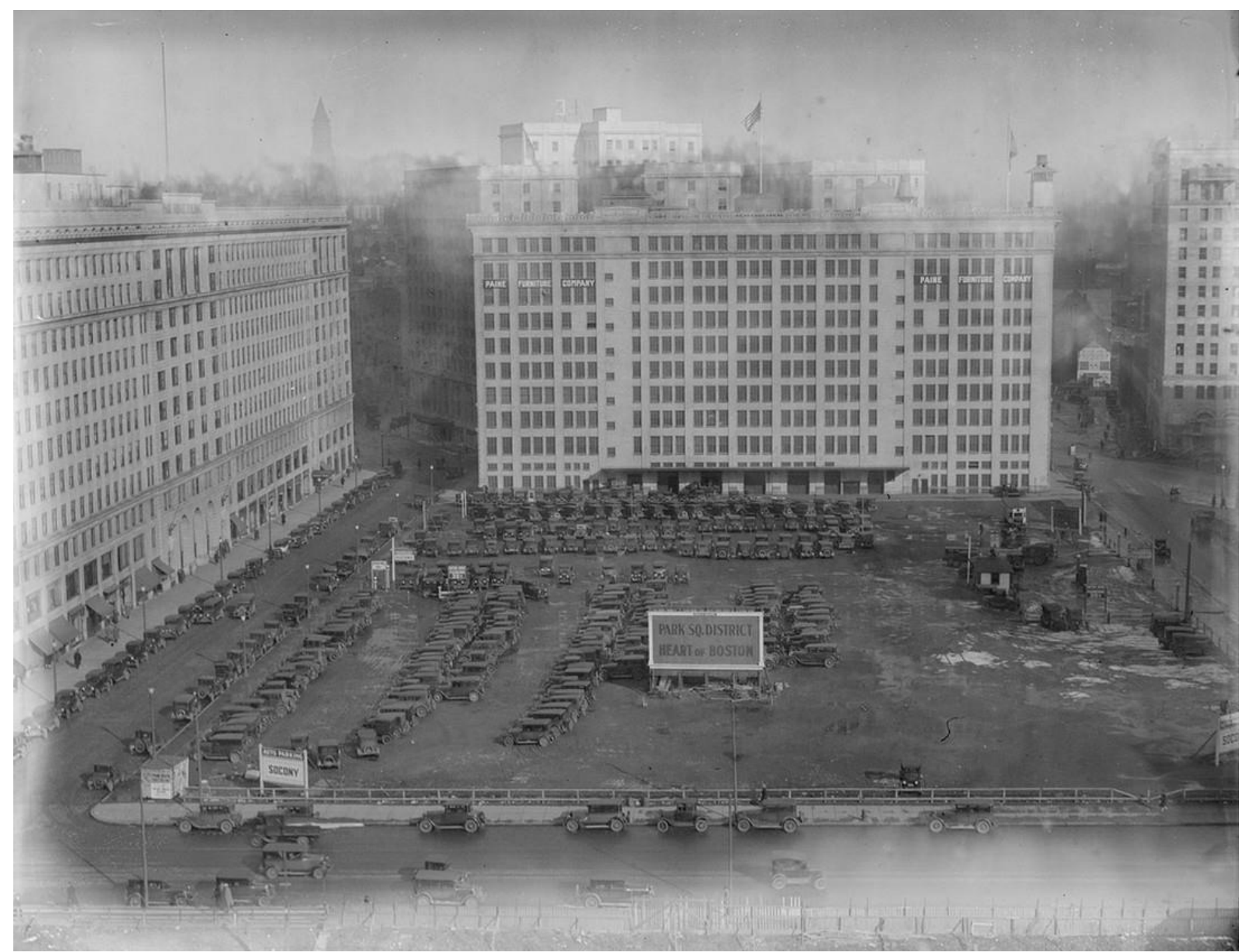

Figure 3-49. Boston's largest parking lot in the 1920s and the "Heart of Boston." Courtesy of the Boston Public Library. 
Figure 3-50. Parking on Beacon Street between the Public Garden and the Boston Common. Photo by Leslie Jones. In Li-Marcus, Beacon Hill: The Life and Times of a Neighborhood, 68.
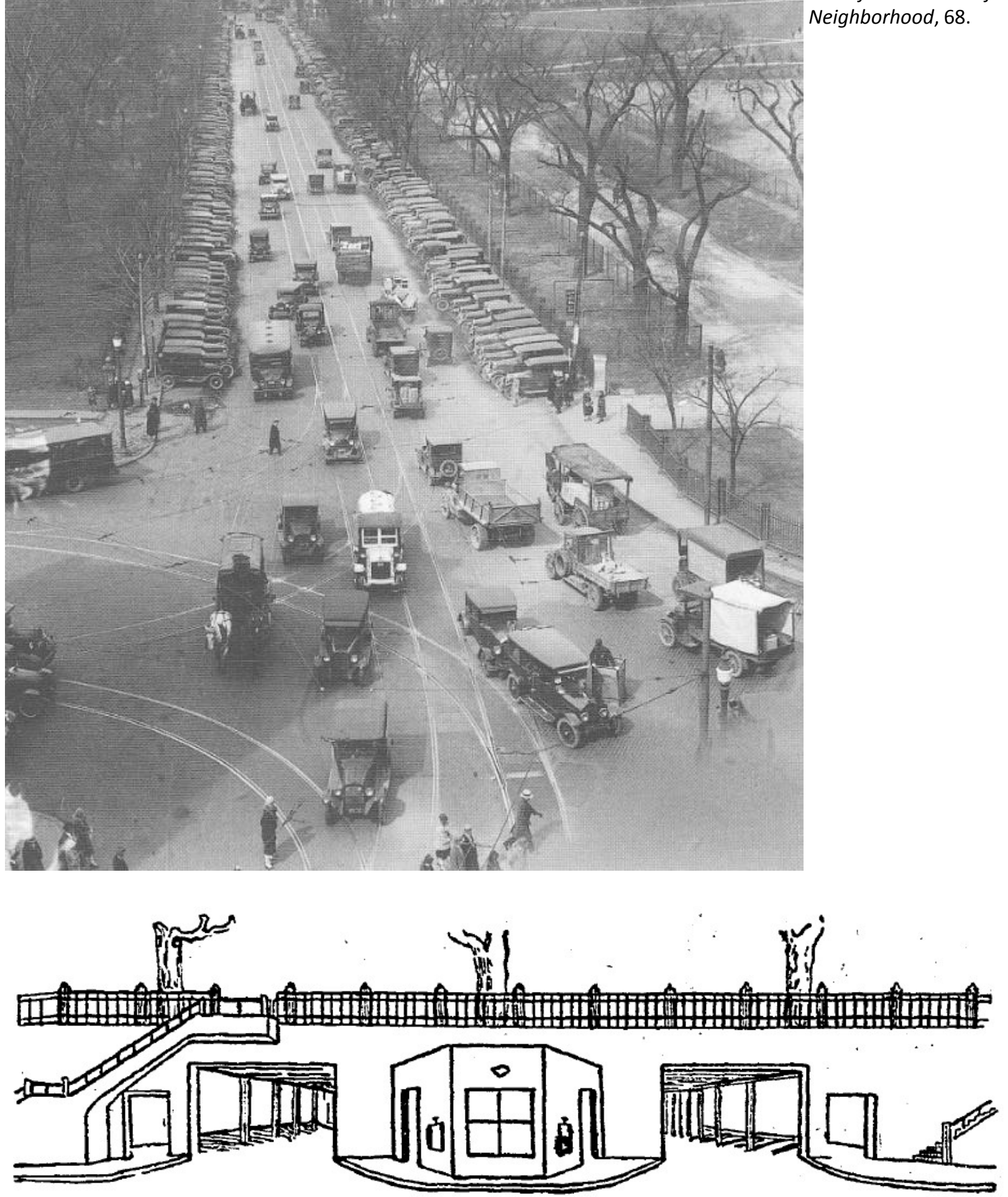

FRONT VIEW OF MOTOR CAVE PROPOSED FOR CHARLESST SIDE OF THE COMMON

Figure 3-51. Illustration of an early proposal to build a garage under the Boston Common. "Park Cars in Cave under the Common," Boston Globe, January 21, 1923, 46. 


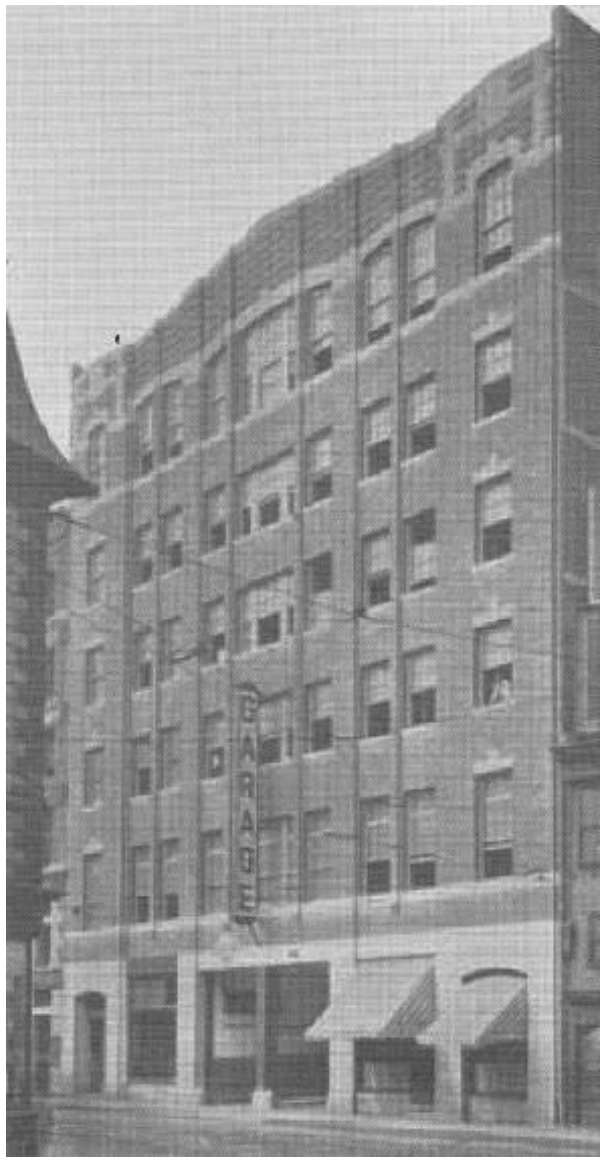

Figure 3-52. Portland Street Garage. McDonald, The Parking Garage, 29.

Figure 3-53. Eliot Street Garage. Courtesy of the Boston Public Library.

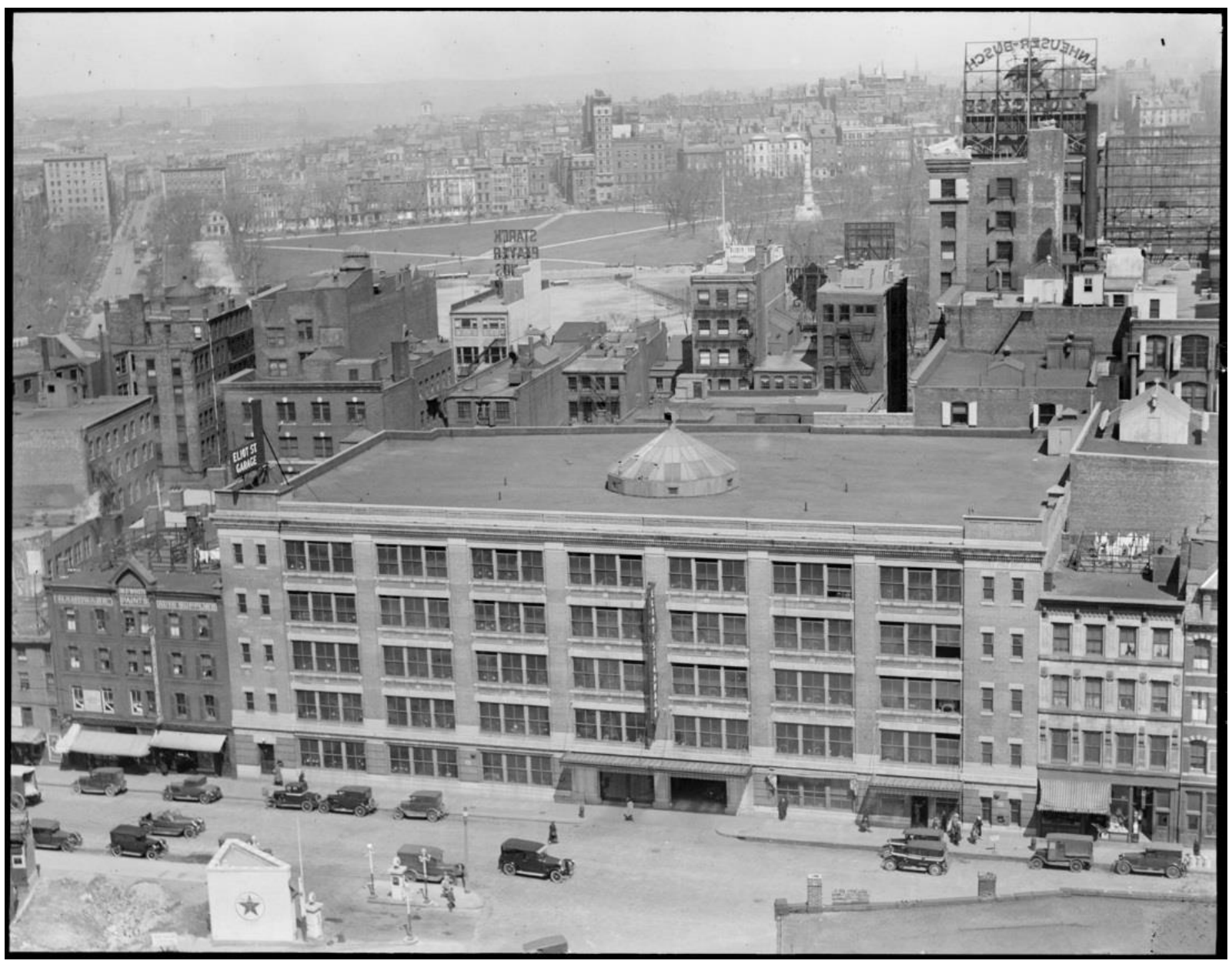




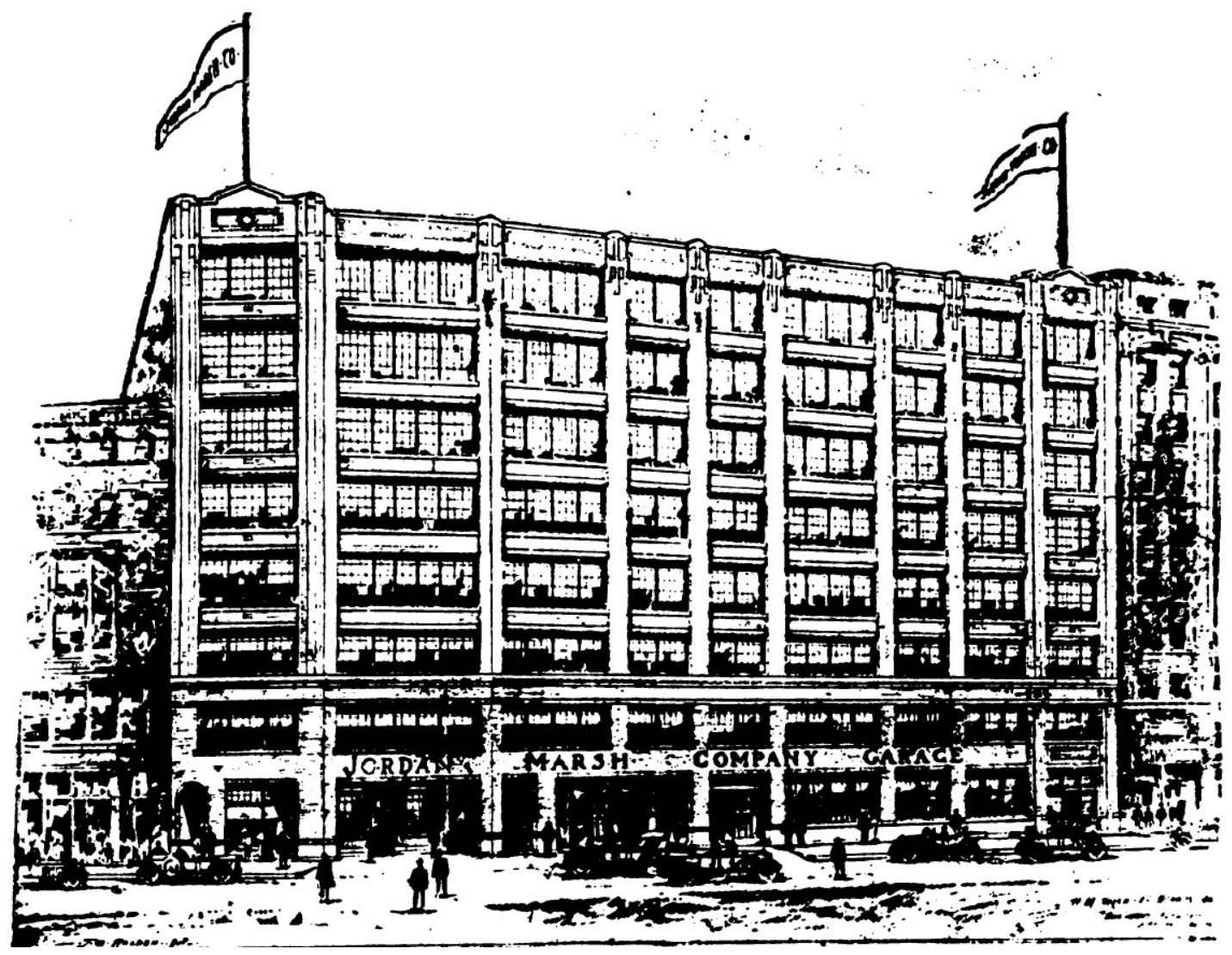

Figure 3-54. Illustration of the Jordan Marsh Garage on Beach Street. "Jordan Marsh to Park Autos, Boston Globe," June 24, 1924, 1.

\section{SLOPING INCLINES TO SPEED HANDLING OF AUTO PARKING}

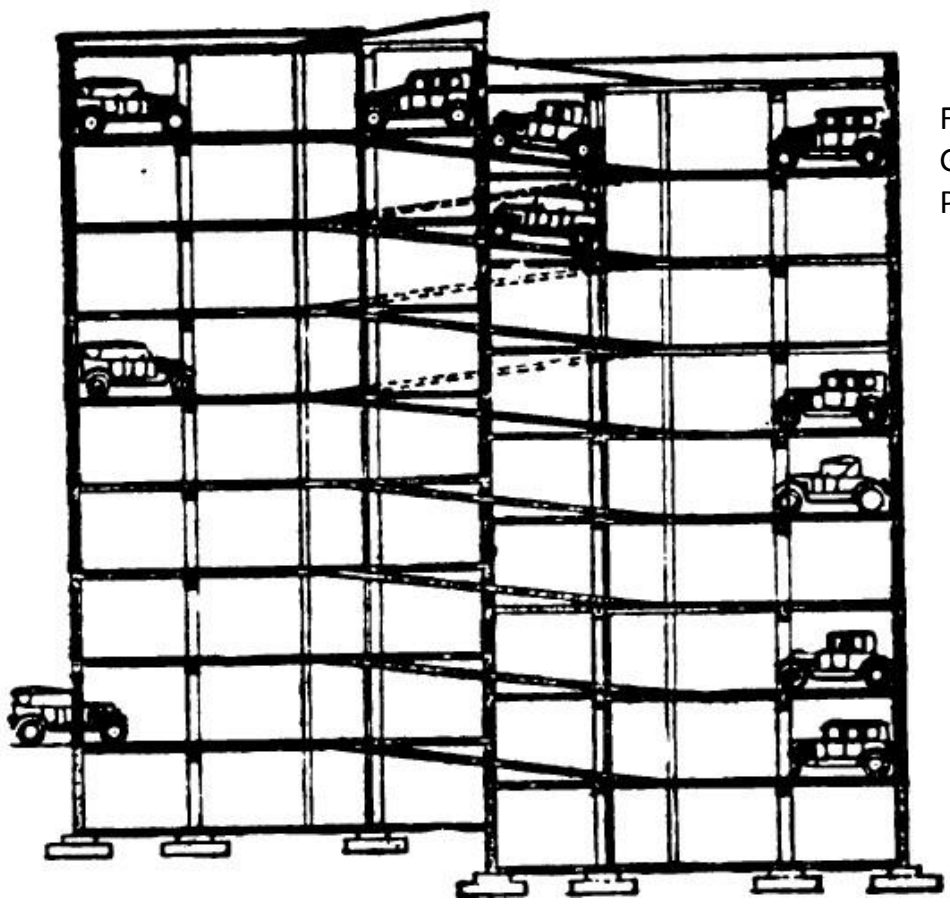

Figure 3-55. Section of the Jordan Marsh Garage on Beach Street. "Jordan Marsh to Park Autos," Boston Globe, June 24, 1924, 1. 


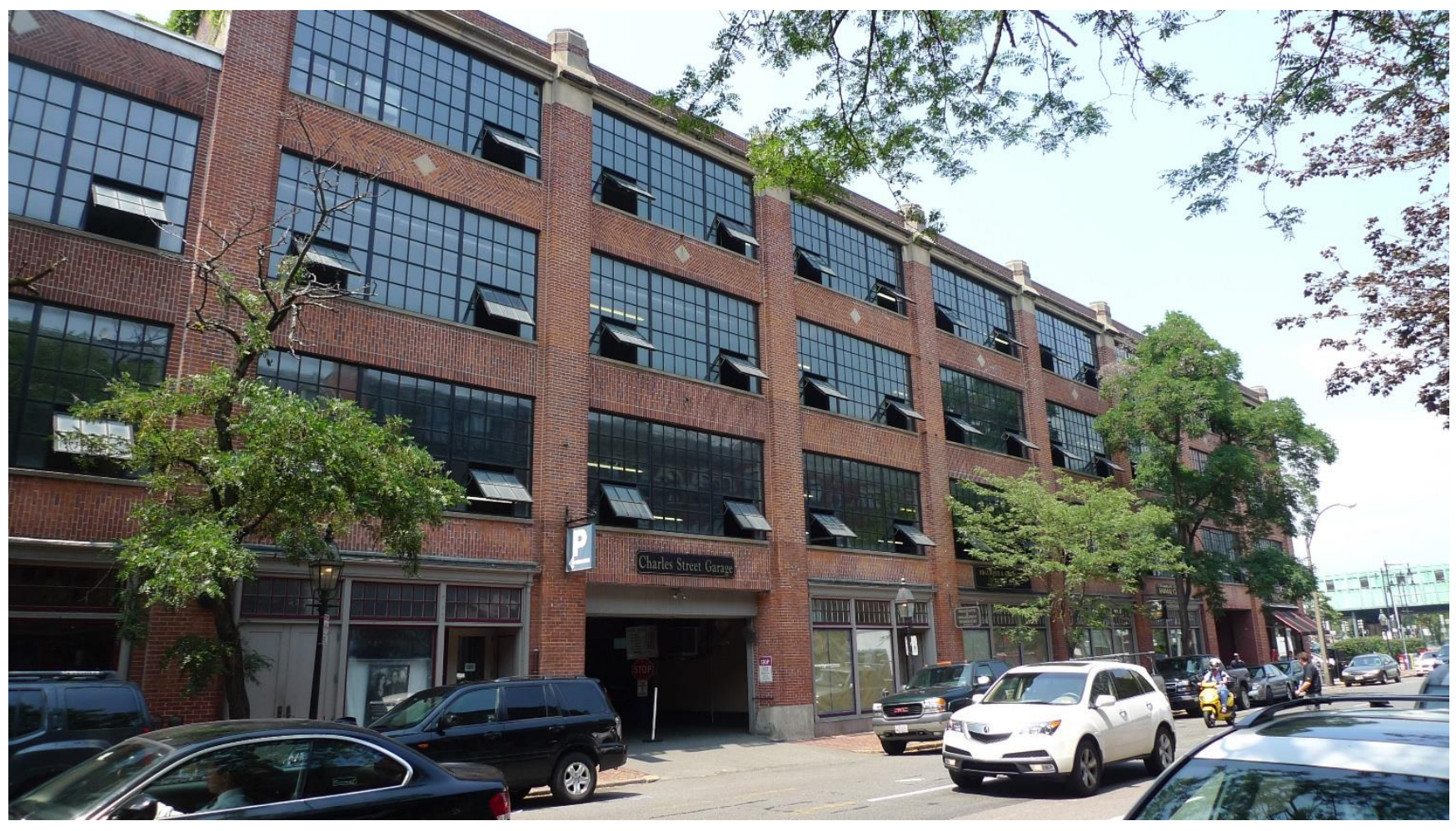

Figure 3-56. The Charles Street Garage at 144-160 Charles Street. Author photograph.

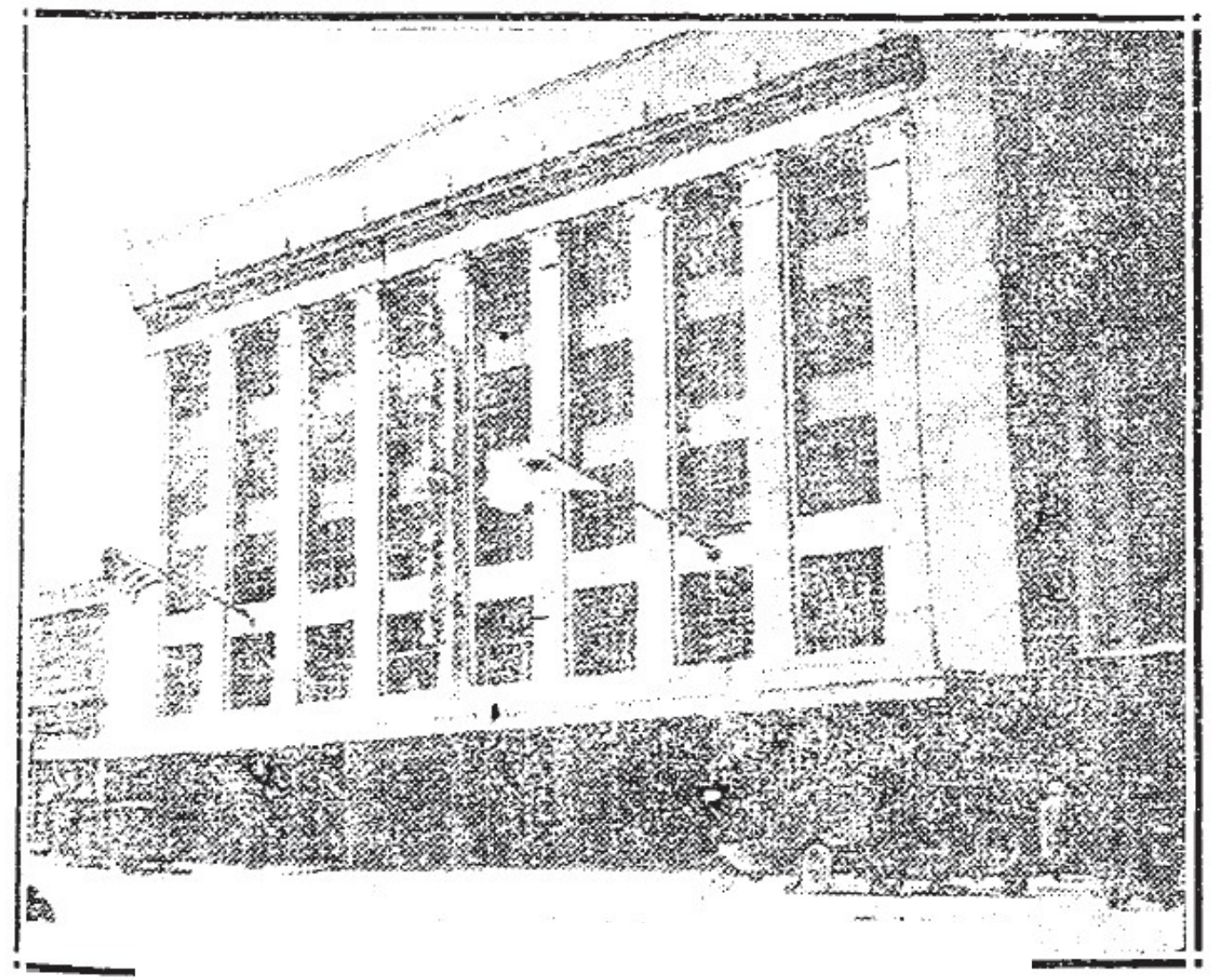

Figure 3-57. The Bowdoin Square Garage at 81-93 Cambridge Street. "A New Boston Garage," Boston Globe, May 9, 1926, 69. 


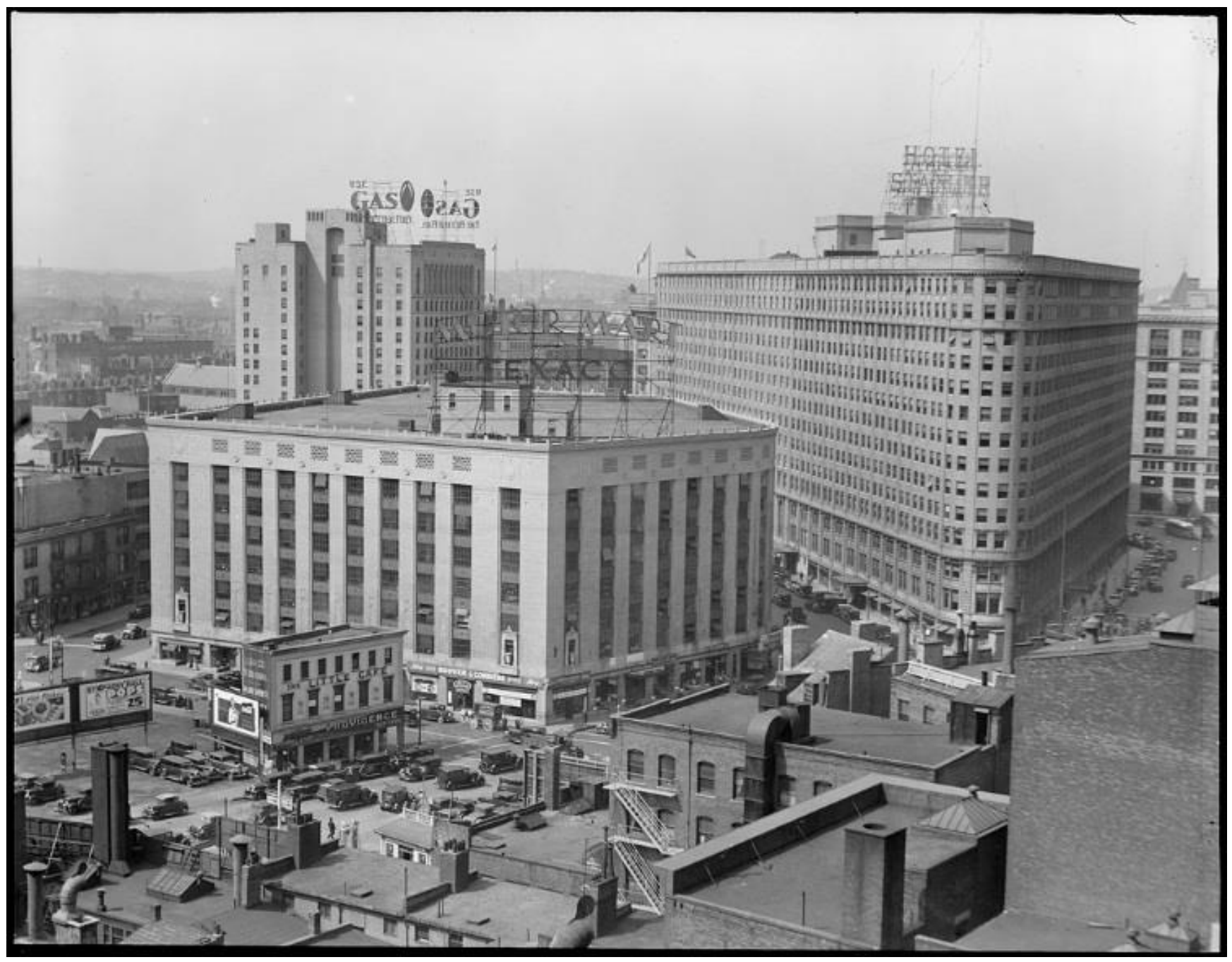

Figure 3-58. The Motor Mart Garage (five-sided with rooftop Texaco sign). Designed by Ralph Harrington Doane, 1927. Courtesy of the Boston Public Library. 


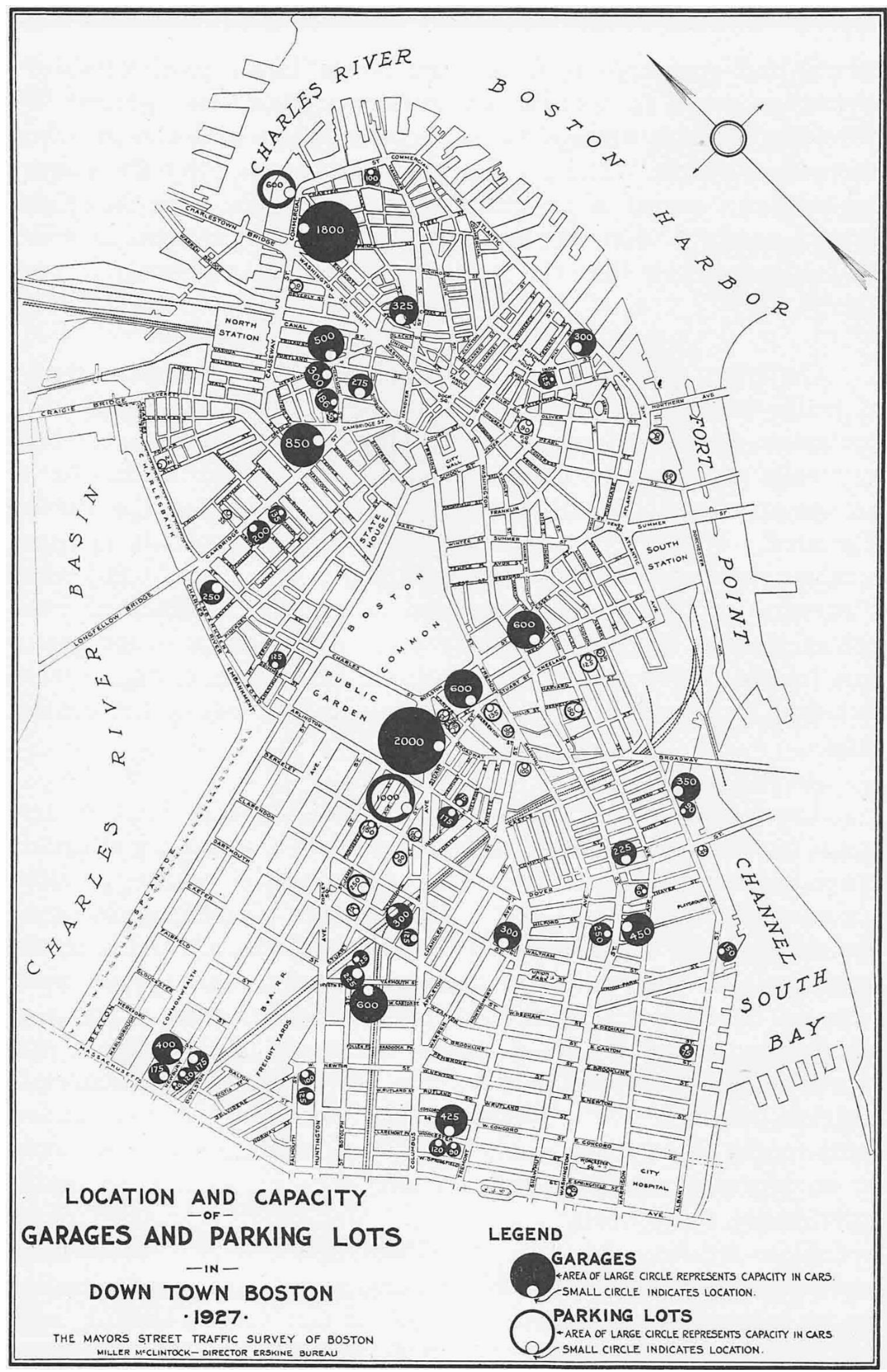

Figure 3-59. Locations of garages and parking lots in Boston. McClintock, Street Traffic Control Problem, 172. 


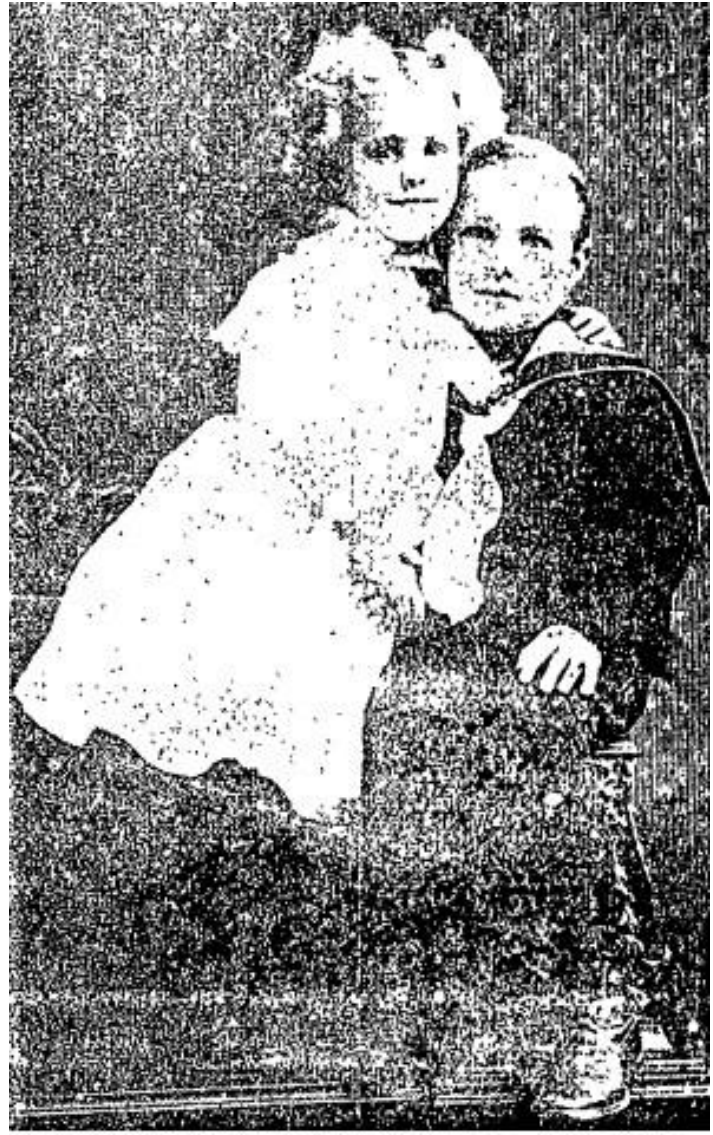

LITTLE MARION HOLDER, WHO WAS KILLED. AND HER BROTHER HERBERT.

Figure 3-60. Marion Holder. "Little Marion Holder Killed by Automobile, " Boston Globe, May 31, 1904, 1.

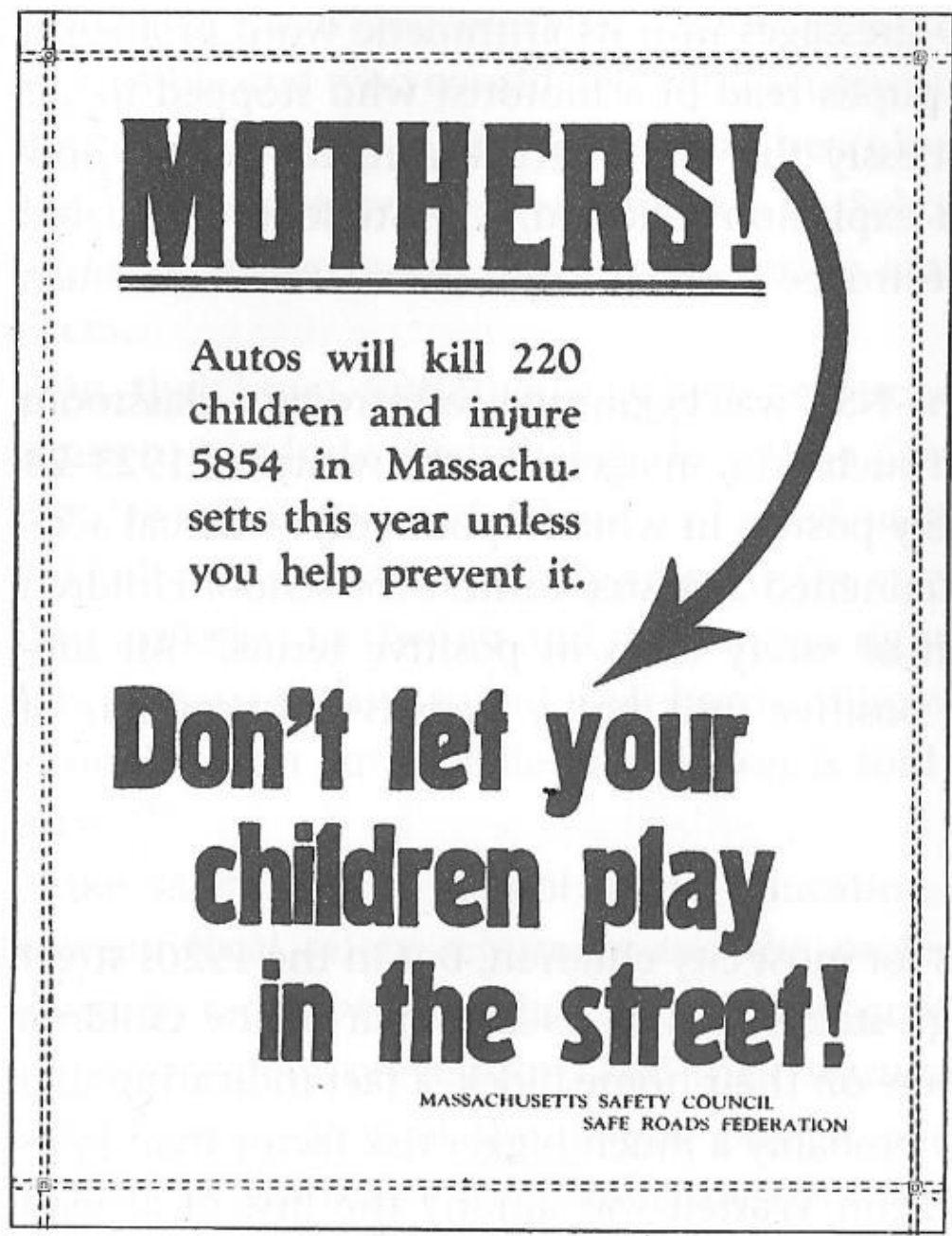

Figure 3-61. Poster by the Massachusetts Safety Council as it appeared in Lewis E. MacBrayne, "Saving the Massachusetts Child," National Safety News, July 1923, page 36. Reprinted in Norton, Fighting Traffic, 84. 


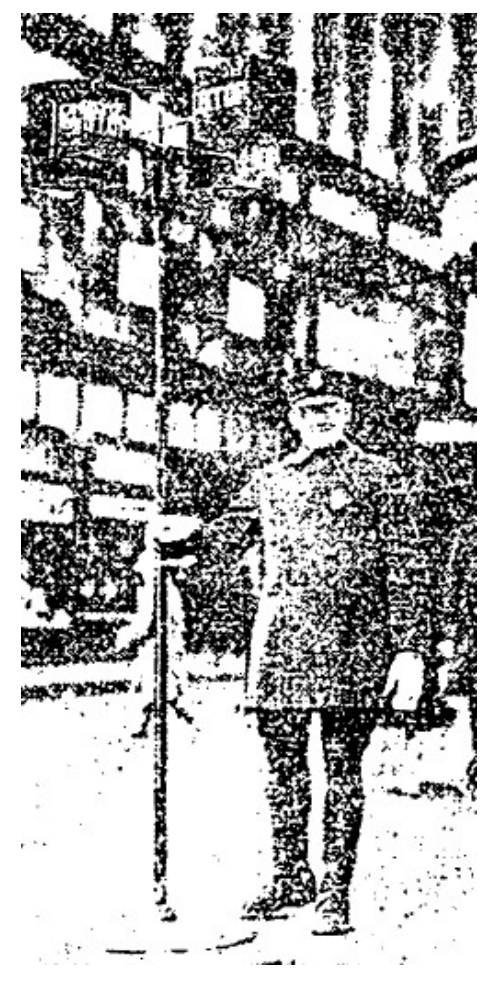

Figure 3-62. Police officer with semaphore in 1923. "New Traffic Signal Helps at Boston's Busy Street Corner," Boston Globe, February 1, 1923, 7.

\section{What the Traffic Officer Thinks}

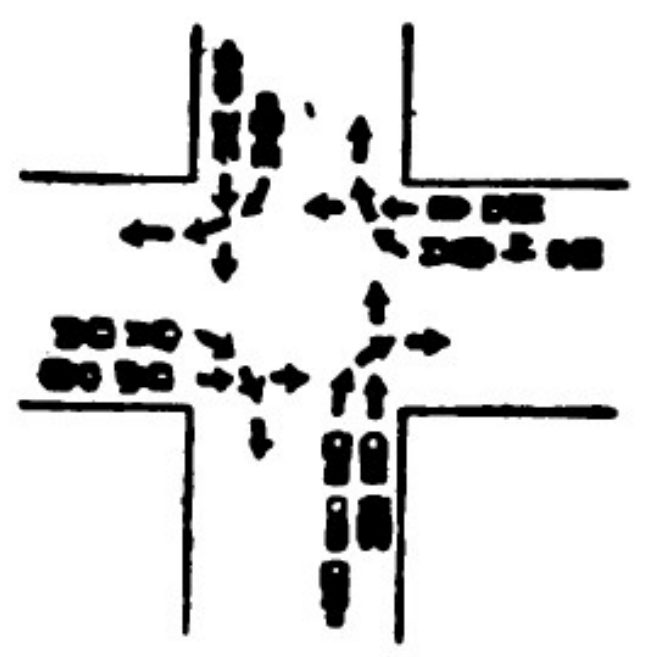

THIS CaUszs comerstion

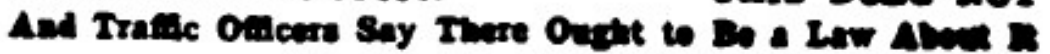

Figure 3-63. Diagram of a common and problematic turning practice. "Interviewing the Men who Stand In a Whirlpool," Boston Globe, February 3, 1924, 5. 


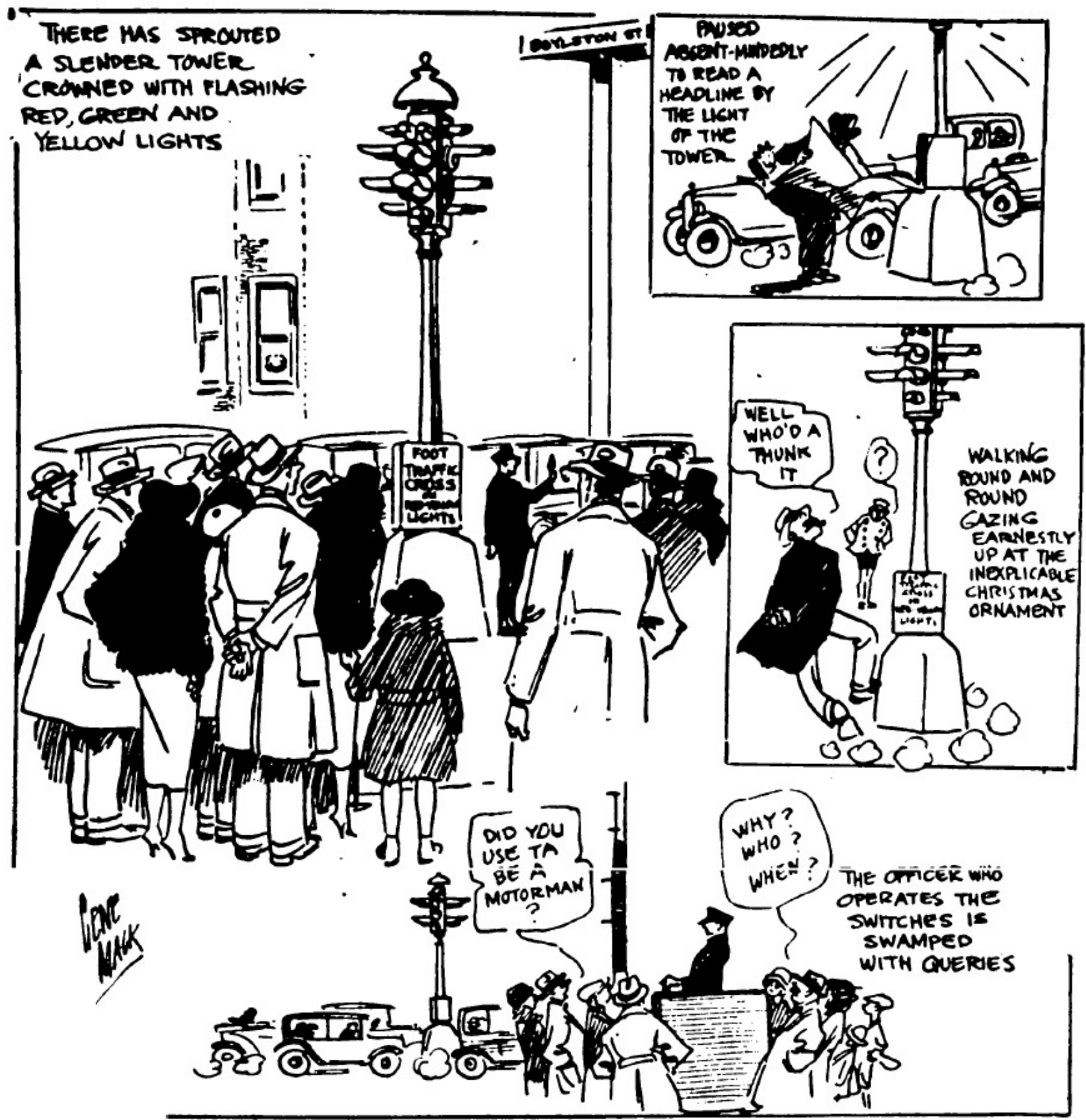

Figure 3-64. Illustration expressing Boston's fascination with its first traffic light. "New-Fangled Christmas Tree for Boylston St Corner," Boston Globe, December 21, 1924, 22. 


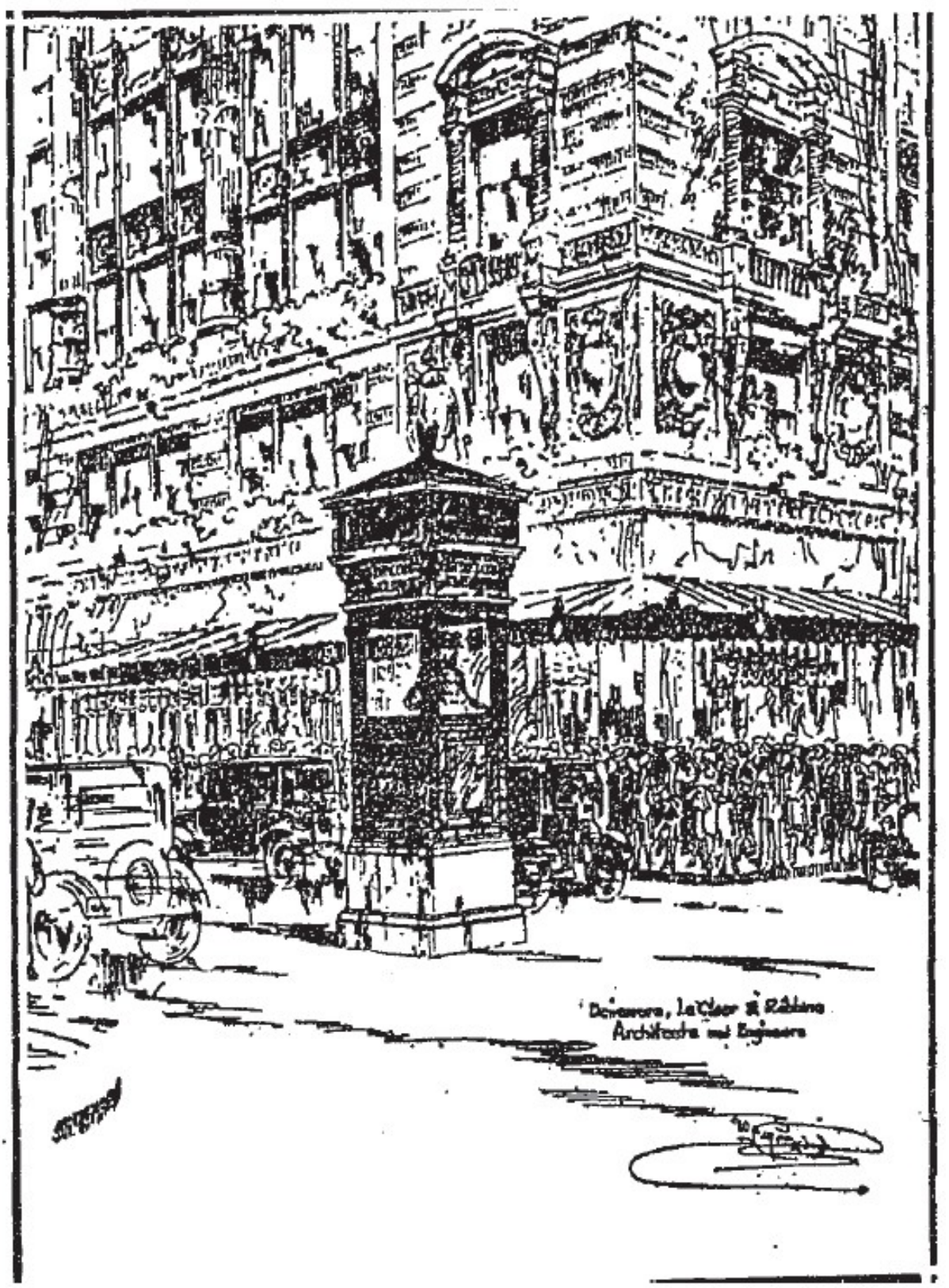

Figure 3-65. Traffic tower at Summer, Winter and Washington Streets. "City Accepts Traffic Tower, Gift of Filene's Vice President," Boston Globe, October 26, 1925, 20. 


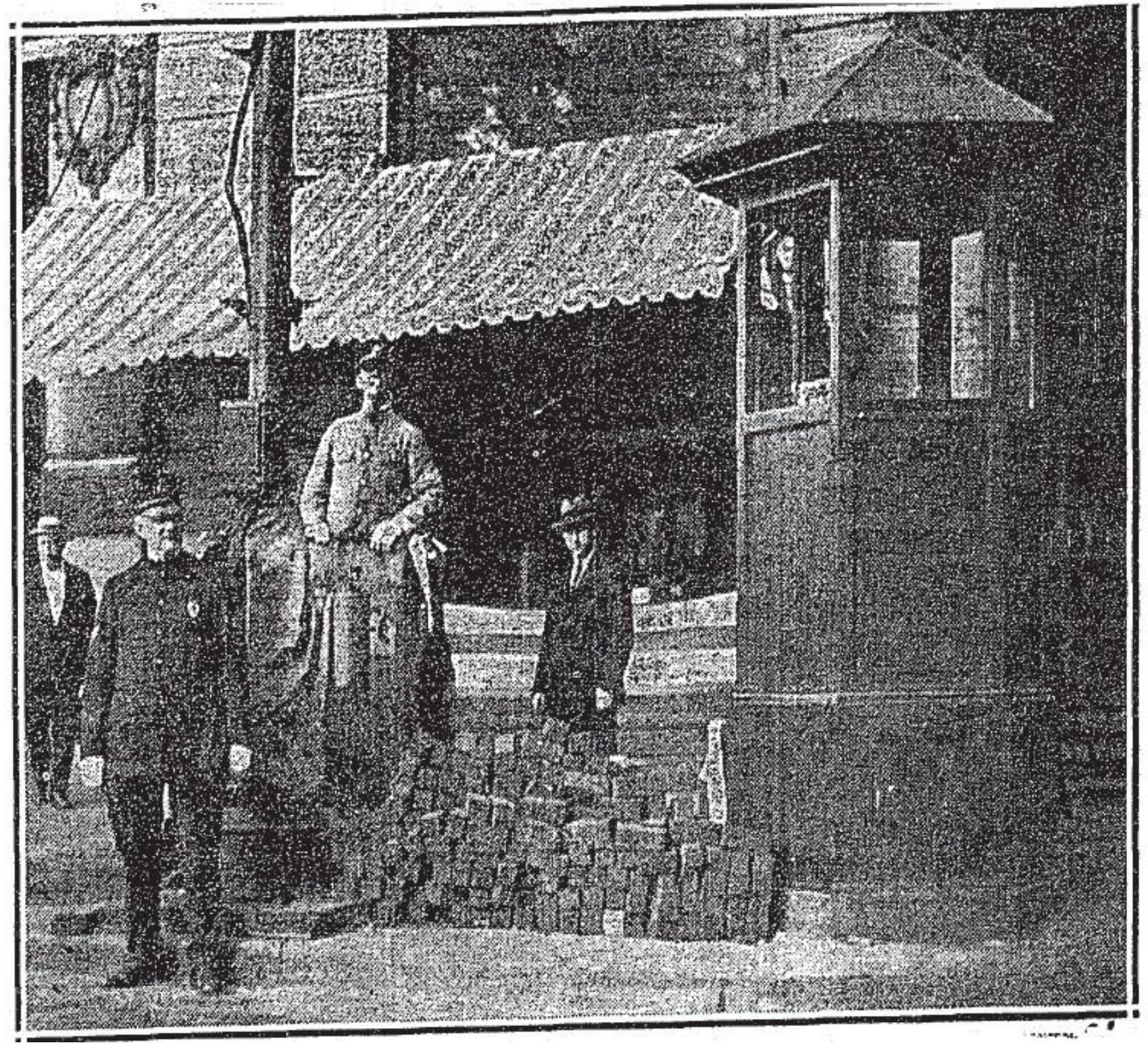

Figure 3-66. "Artistic" traffic tower at Boylston and Tremont Streets. "Erect Permanent Traffic Signal Tower Tomorrow at Tremont and Boylston Streets," Boston Globe, June 20, 1925, 18. 


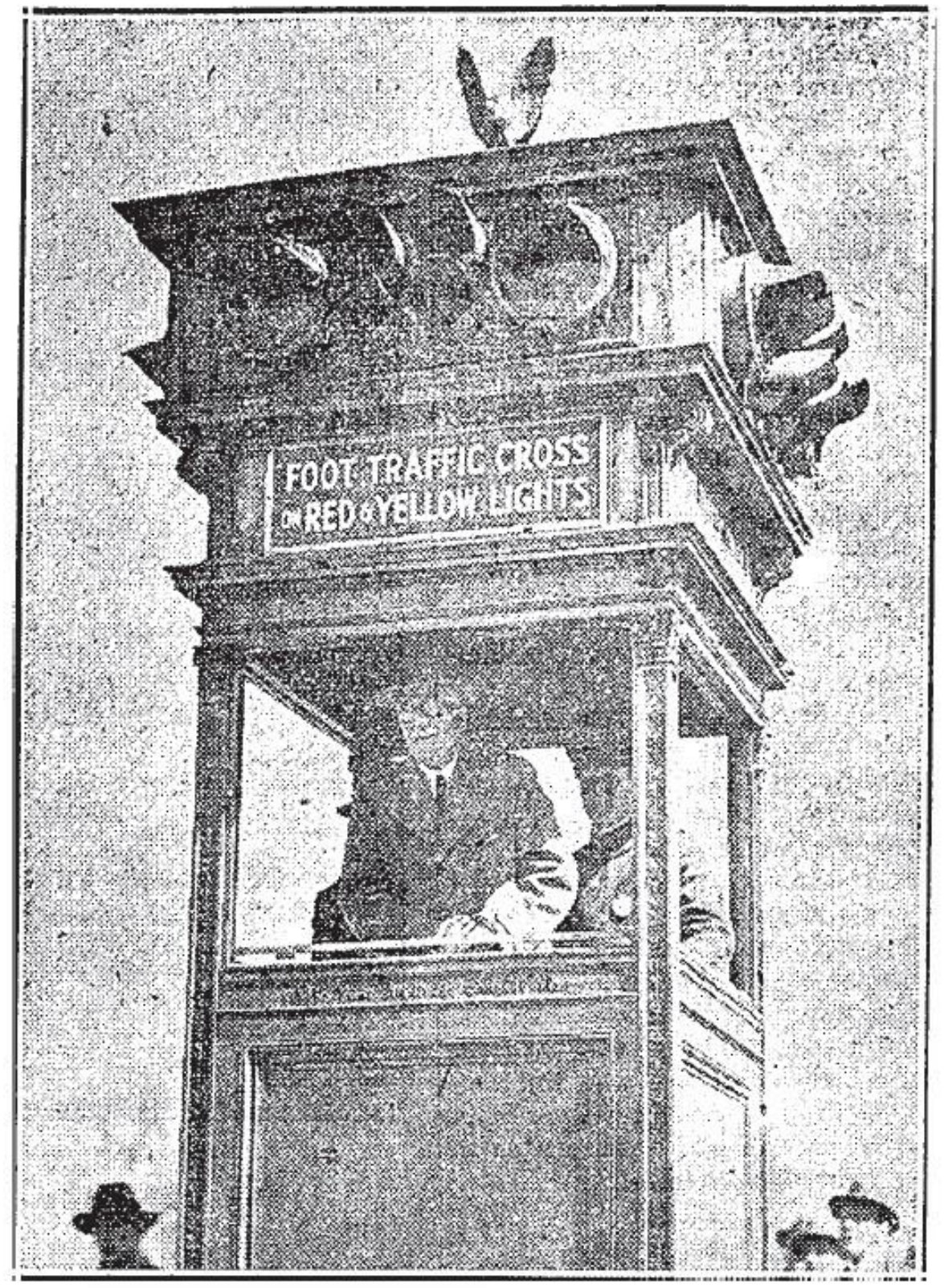

Figure 3-67. The traffic tower sponsored by Paine Furniture at Boylston and Arlington Streets. "New Traffic Tower at Boylston and Arlington Streets," Boston Globe, March 27, 1926, 6. 


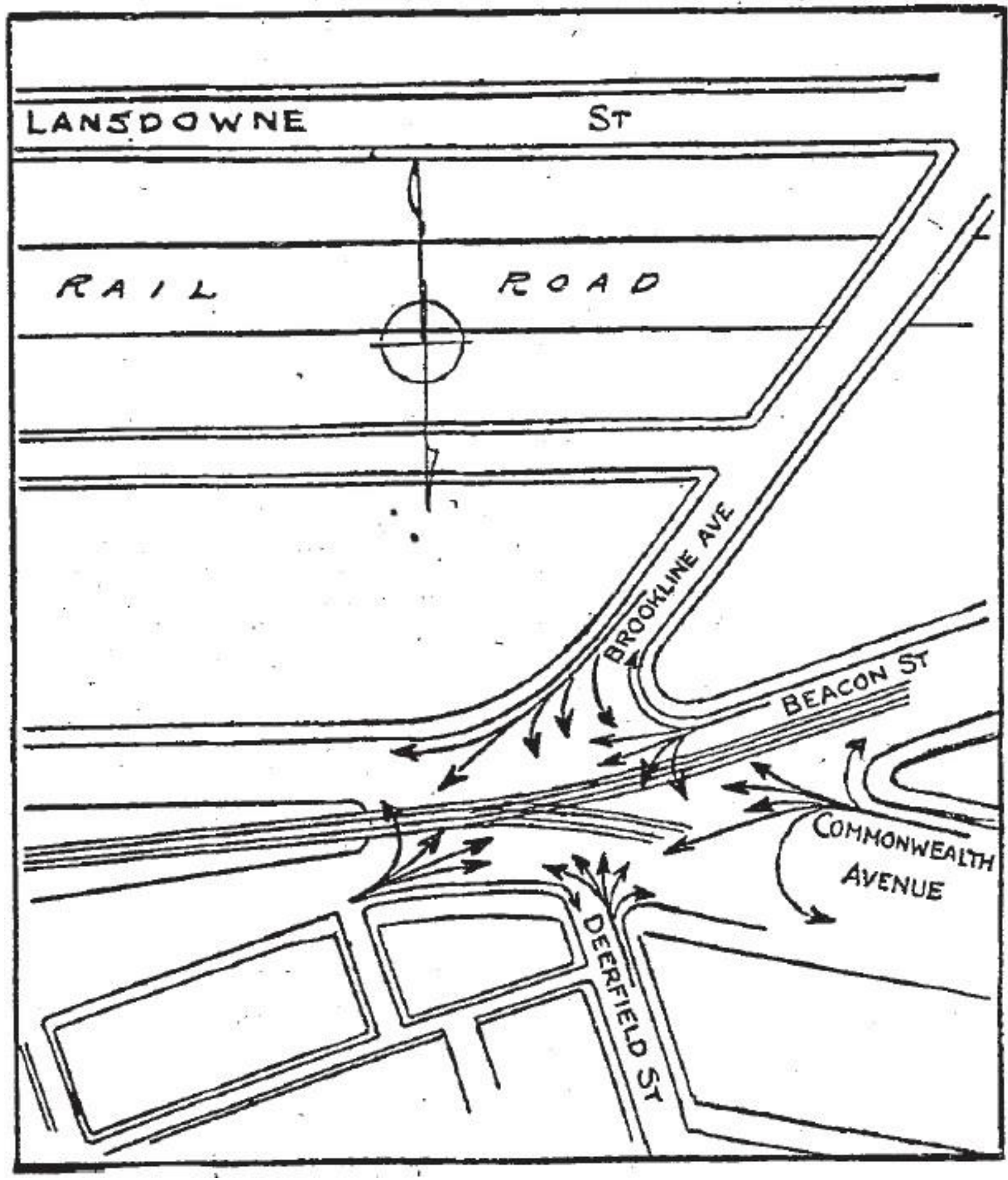

Figure 3-68. Diagram showing the 26 possible turns that vehicular traffic could make in Kenmore Square (Governors Square). “Governors Sq. Tangle No Nearer Solution,” Boston Globe, July 3, 1927, 15. 


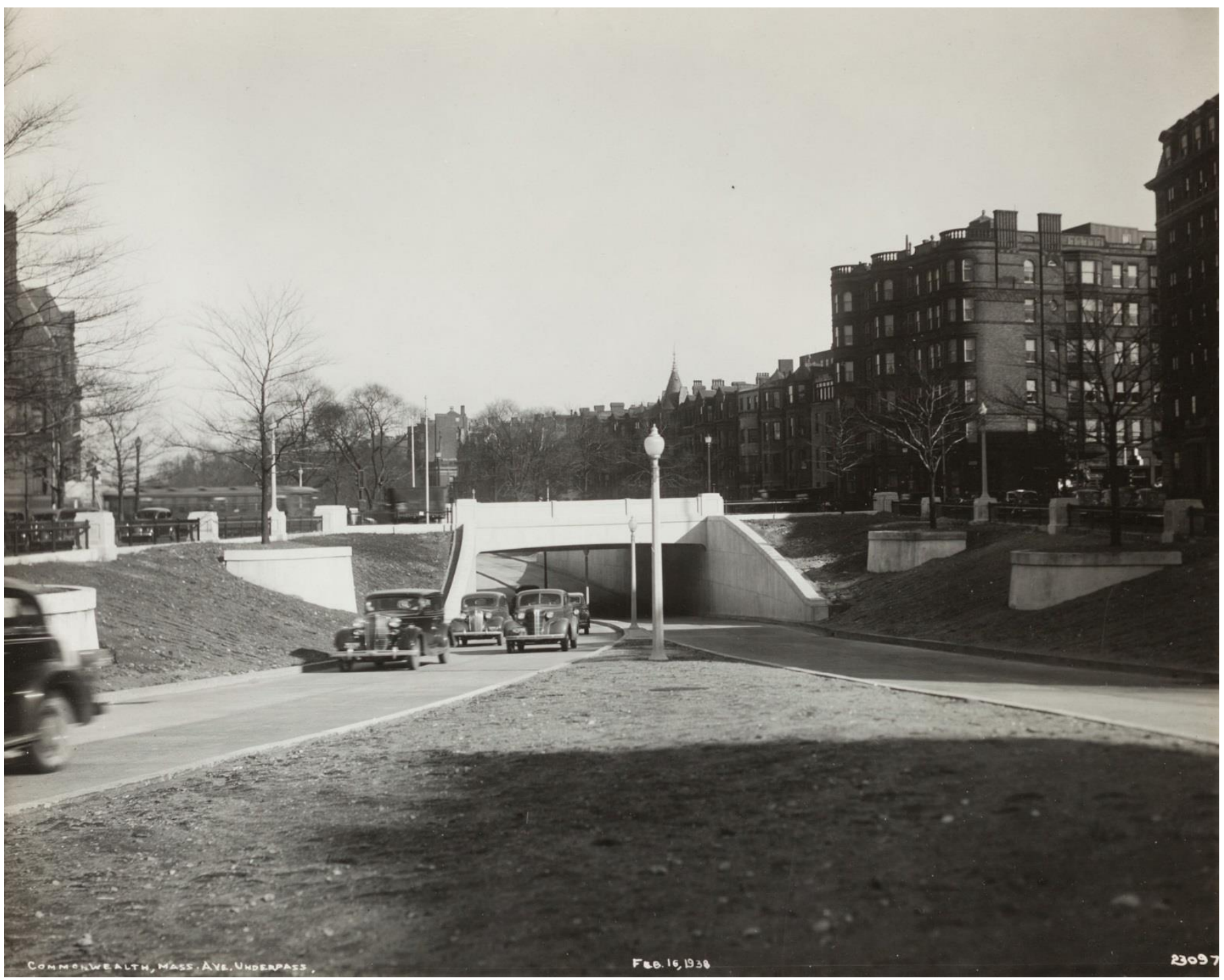

Figure 3-69. Commonwealth Avenue underpass at Massachusetts Avenue in 1938. Courtesy of Historic New England. 


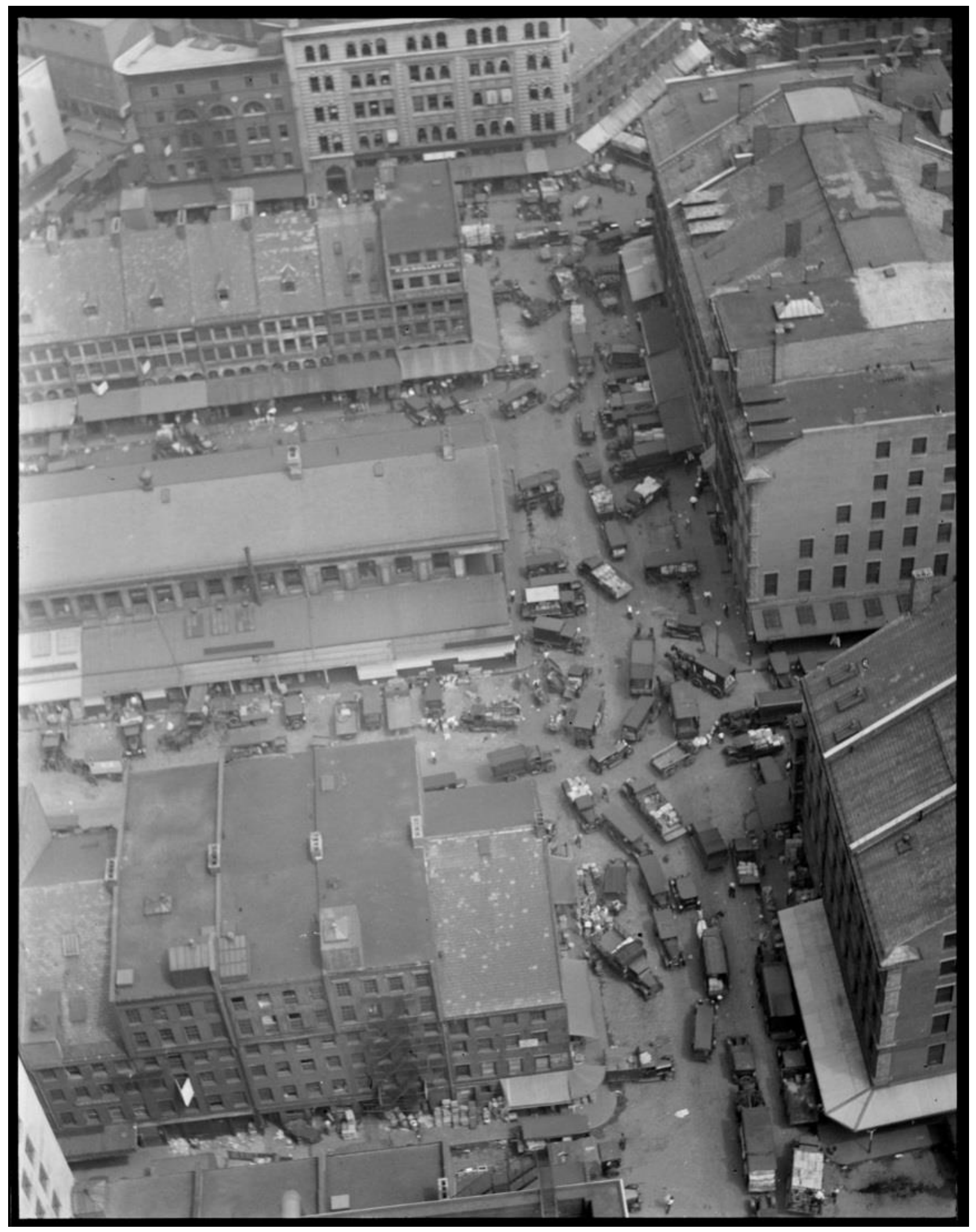

Figure 4-1. Congestion in the market district as seen from the tower of the Custom House. Photograph by Leslie Jones, 1928. Courtesy of the Boston Public Library. 


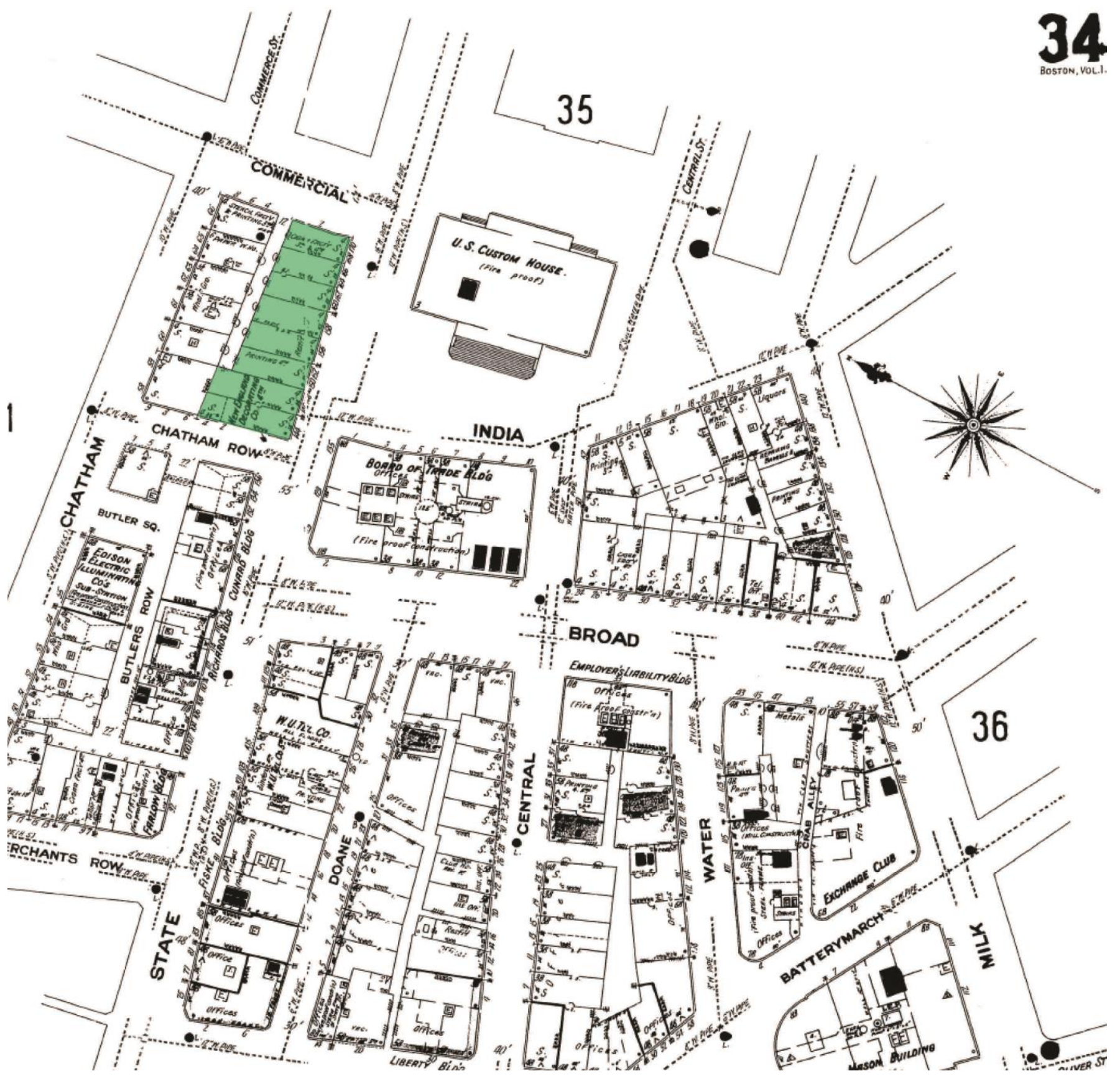

Figure 4-2. Plate from the 1909 Sanborn Atlas showing the section of State Street proposed to be widened in 1916. The buildings suggested for taking are highlighted in green. 


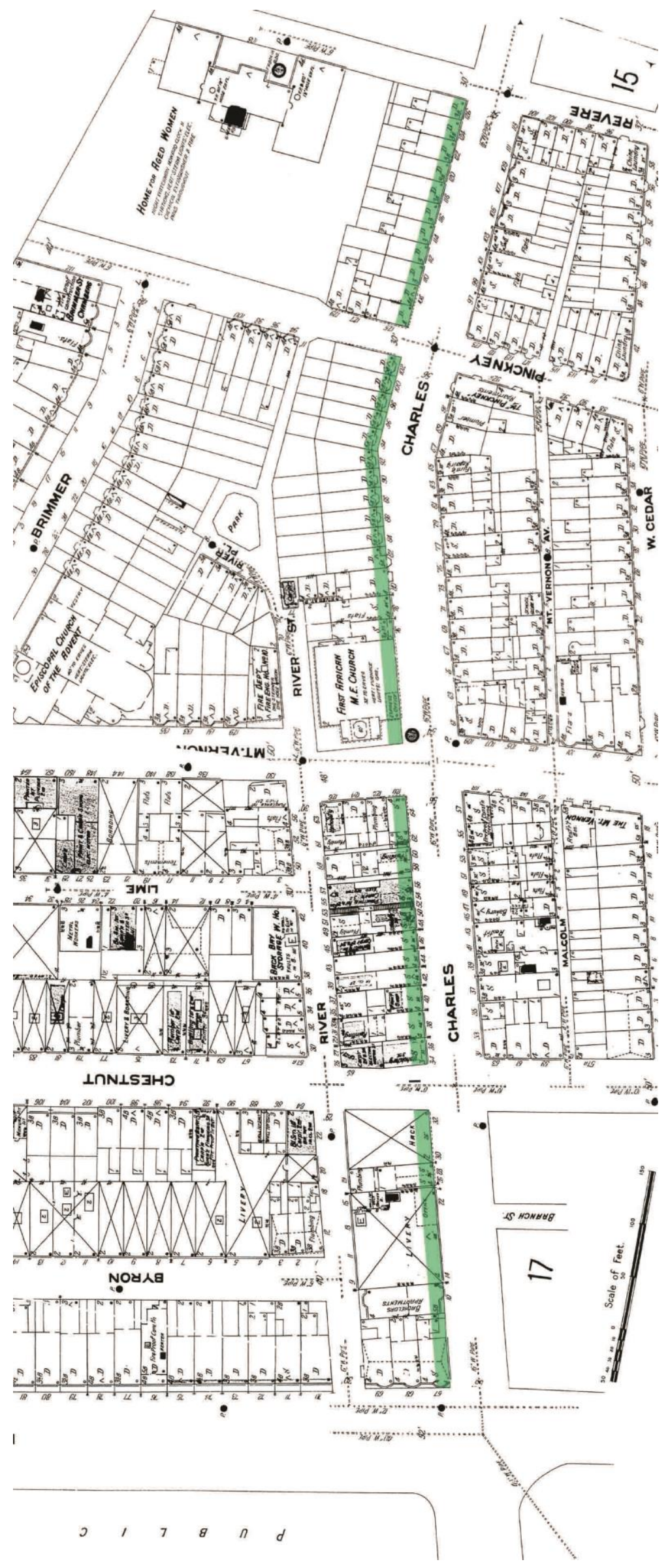

Figure 4-3. Composite image taken from plates 13 and 14 of the 1909 Sanborn Atlas. The ten-foot widening along Charles Street from Revere Street to Beacon Street is shown in green. 


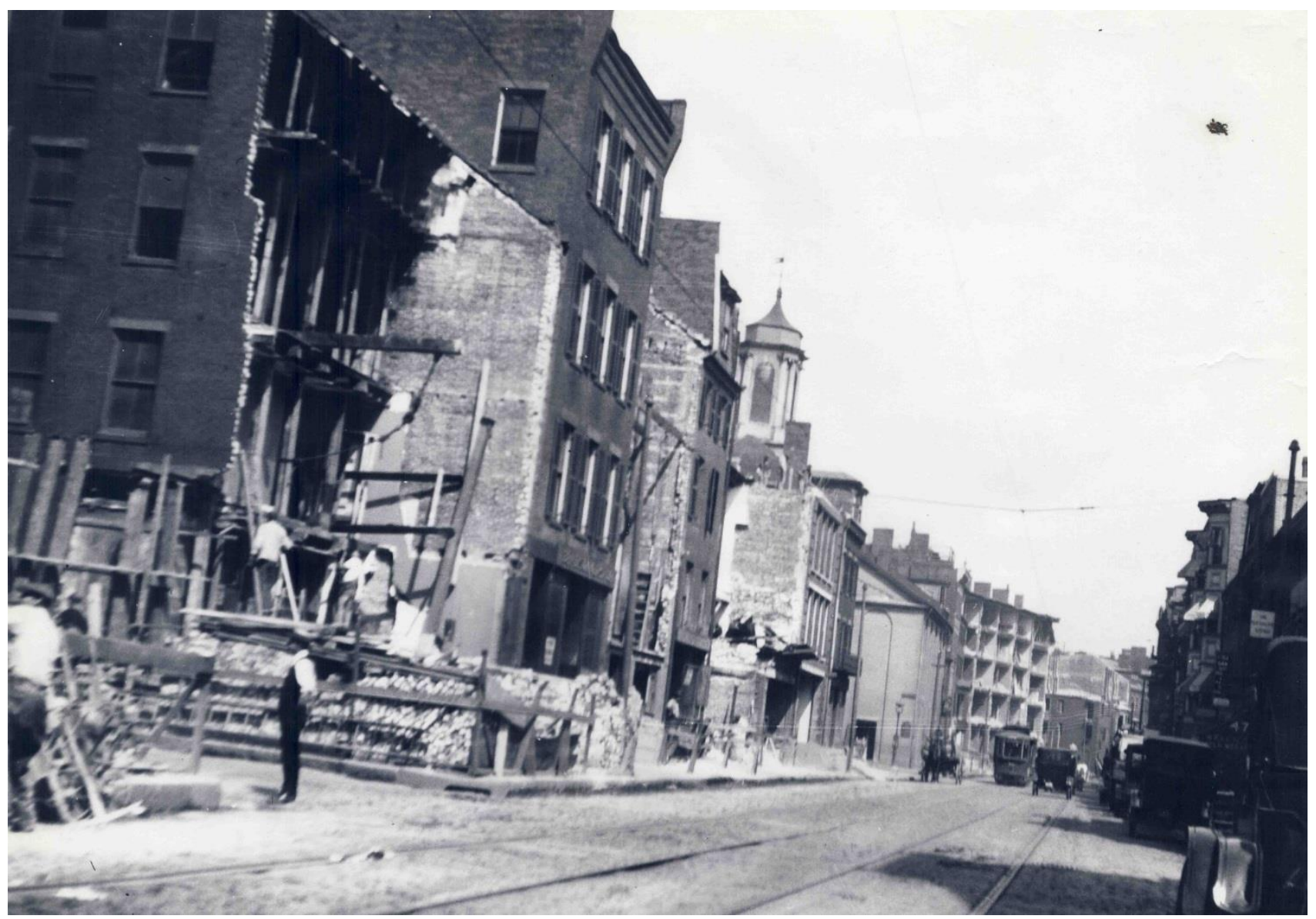

Figure 4-4. Widening of Charles Street in 1920. Courtesy of the Boston Public Library.

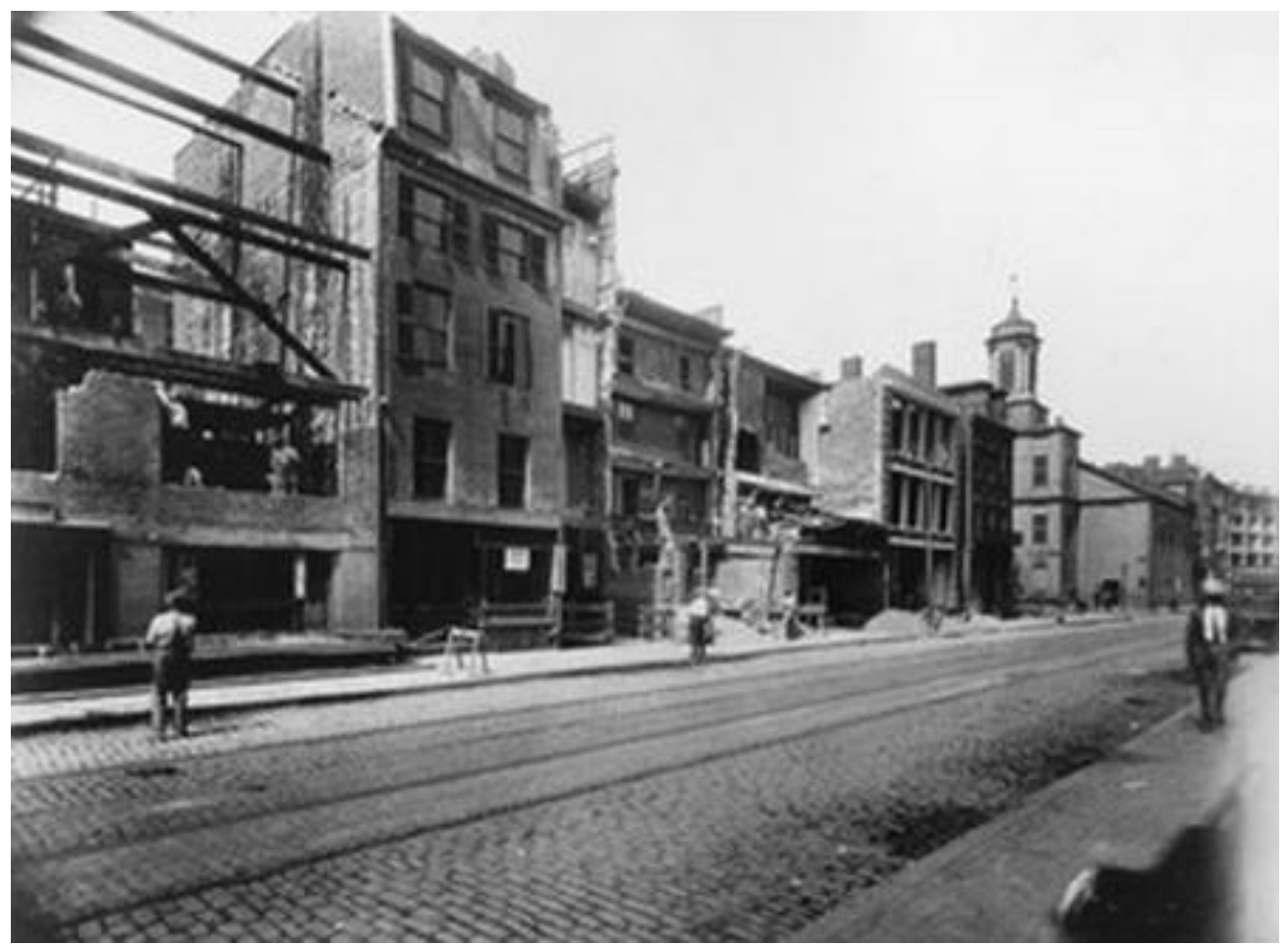

Figure 4-5. Widening of Charles Street in 1920. Courtesy of Historic New England. 


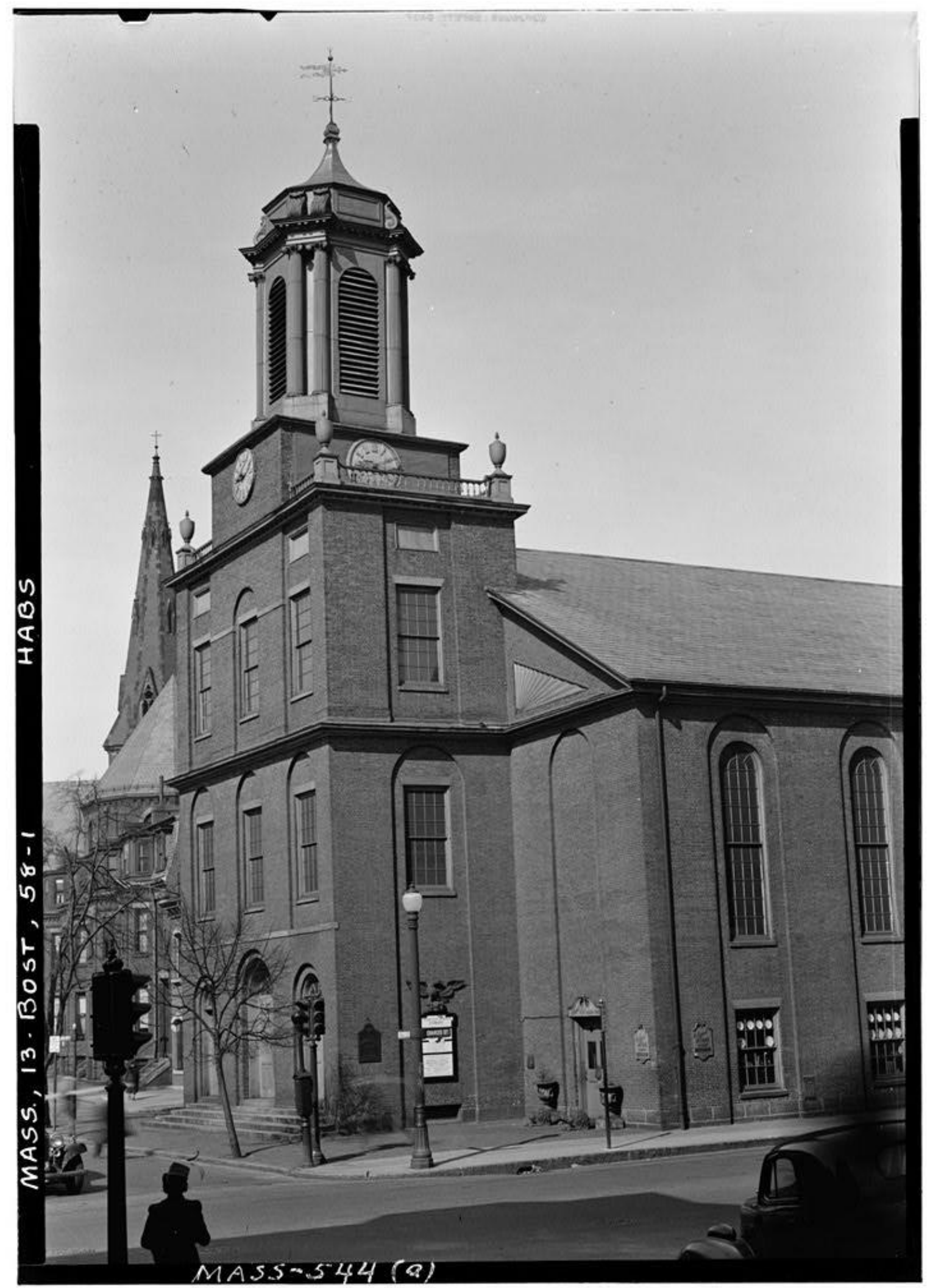

Figure 4-6. Image of the Charles Street Meeting House. Historic American Buildings Survey, 1941. 


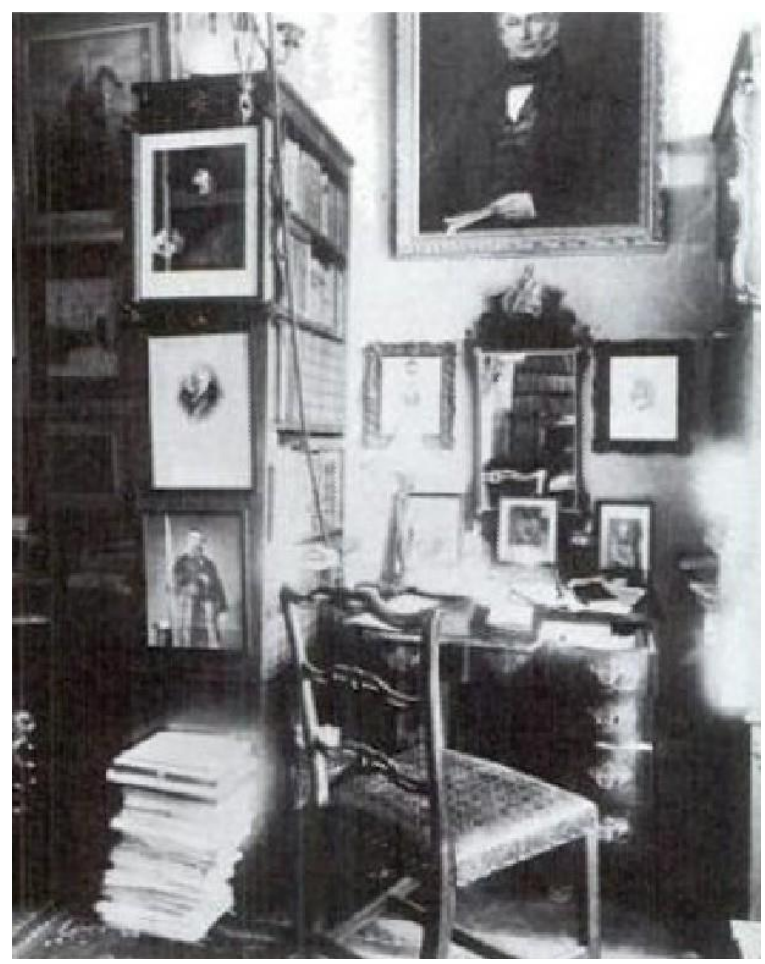

Figure 4-7. The library of James Field. Cohen, A Chance Meeting, 113. 


\section{BOWDOIN SQUARE BUILDING REVIVAL}

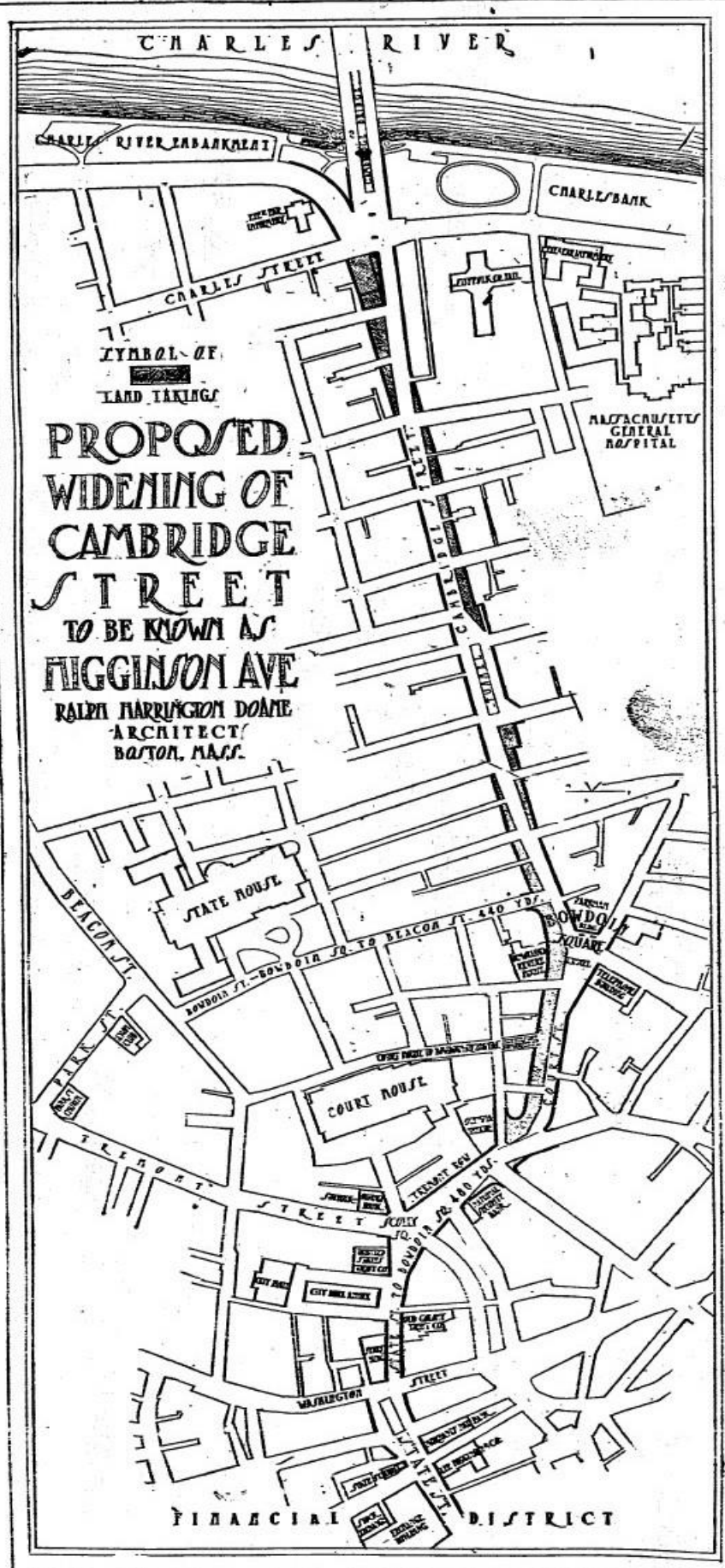

GEORGE U. CROCKER

50 Congress St., Boston
The properties on Court Street from the junction of Howard Street, the properties in Bowdoin Square and on Cambridge Street from the Square to Charles Street, and practically all the property on side streets, nearby, have suffered during the past twenty years from yearly depre. ciation more than any other district in downtown Boston. Yet Bswdoin Square is convenient to State Street, Ciiy $\mathrm{Hall}$ and the retail centre; why property heresbouts has depreciated to the extent it has, has been difficult to understand. But whatever the causes, they are not sound from a realty standpoint and can be easily remedied.

$1 \mathrm{si}$-Bowdoin Sotare is within 400 yards of State Street

End-It conned with all subways, tunnels and efevated railisads, haying a physical connextion with the Bowdoin Square station of the East Boston tunnel extension.

3rd- and is assessed and worth at present less than it was 20 years ago and can be bought for one-fourth of what land is sold for in the wholesale district around Fort'Hill Square.

4th-Vehicle traffic congestion on Tremont and Washington Streets will soon compel the City Governiment to find means of relief. The natural way to do so would be to develop a new exit out of the City. Court Street from Scollay Square to Bowdoin Square, thence through Cambridge Street to Charles Street and the Esplanade woild furnish this exit. It would mean the widening of Court Street from Howard Street, and the widening, of Cambridge Street from Bowdoin Square to the River and Charles Street, and this can be done for a most reasonable sum as the buildings to be demolished are mosty obsolete. Such an improvement is so compelling that it is bound to come to pass and will do more. to rejuvenate the entire district, revive values of realty and tie up Bowdoin Square to Scollay. Square (only 300 yards away) and where every foot of land is worth seven to ten times more thanit is at Bowdoin Square si h an abnormal meruality in valuations betesen two squares caninot last.

5 th-There are taking placéat Bowdoi fe which the neople

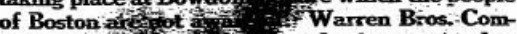
pany, roaif lak, iose business stretches from the A.ticitic To the Pacific, have leased for ten years for their home office, the entire upper floors of the Parkman Building on the corner of Bowdoin Square, Green and Cambridge Streets. The New England Tel. \& Tel Co. are demolishing the old Tabernacle Church preparatory to erecting a new building for offices and the Haymarket Exchange. The old Revere House has been demolished, thereby. leaving about 22,009 square feet of land (the largest unimproved plot in downtown Boston) for development.

6th-The nearness of Bowdoin Square to the financial and retail districts, its physical connection with the subways, the coming of Warren Bros. Cỏmpany to Bowdoin Square, the new telephone building, the inanguration of prohibition which changes the entire atmosphere of the district, and the prospective widening which is sure to come in order to remedy the. vehicle congestion in the City proper, should appeal to all business men, institutions or corporations who want permanent offices or workshops in downtown Boston and who are mable to stand the recent inflation of rents in other parts of the City.

The Bowdoin Square Realty Association, composed of many of the property owners in this vicinity, in order to facilitate the proper development of this district, invite inquiries from infivisaals and corporations desiring to lease or purchase properties for their own occupancy-

\section{JOHN C. KILEY}

18 Tremont St, Boston

Figure 4-8. Promotional ad for the widening of Cambridge and Court Streets. Boston Herald,

November 28, 1920, 8. 


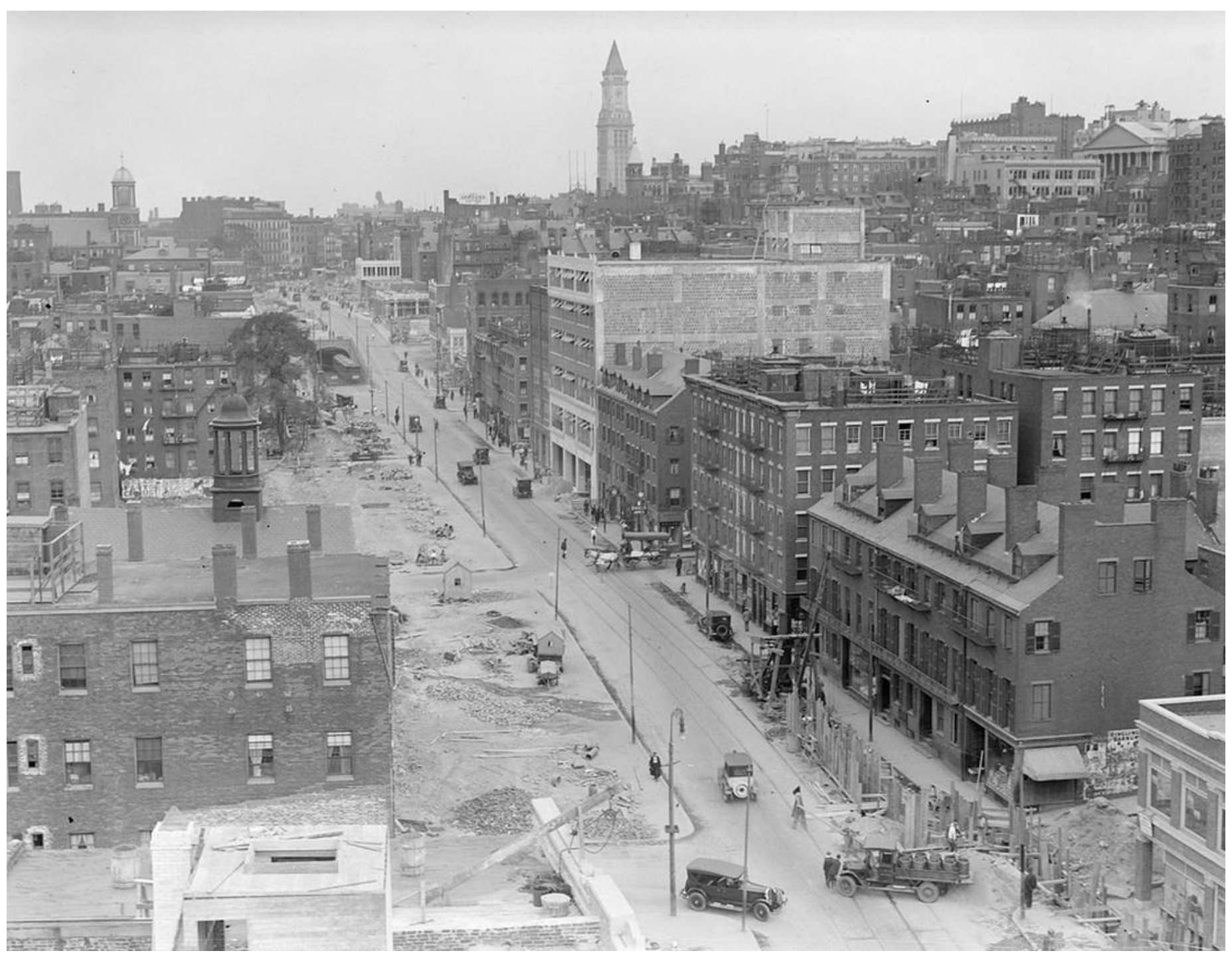

Figure 4-9. Cambridge Street widening, looking east. Photograph by Leslie Jones. Courtesy of the Boston Public Library. 


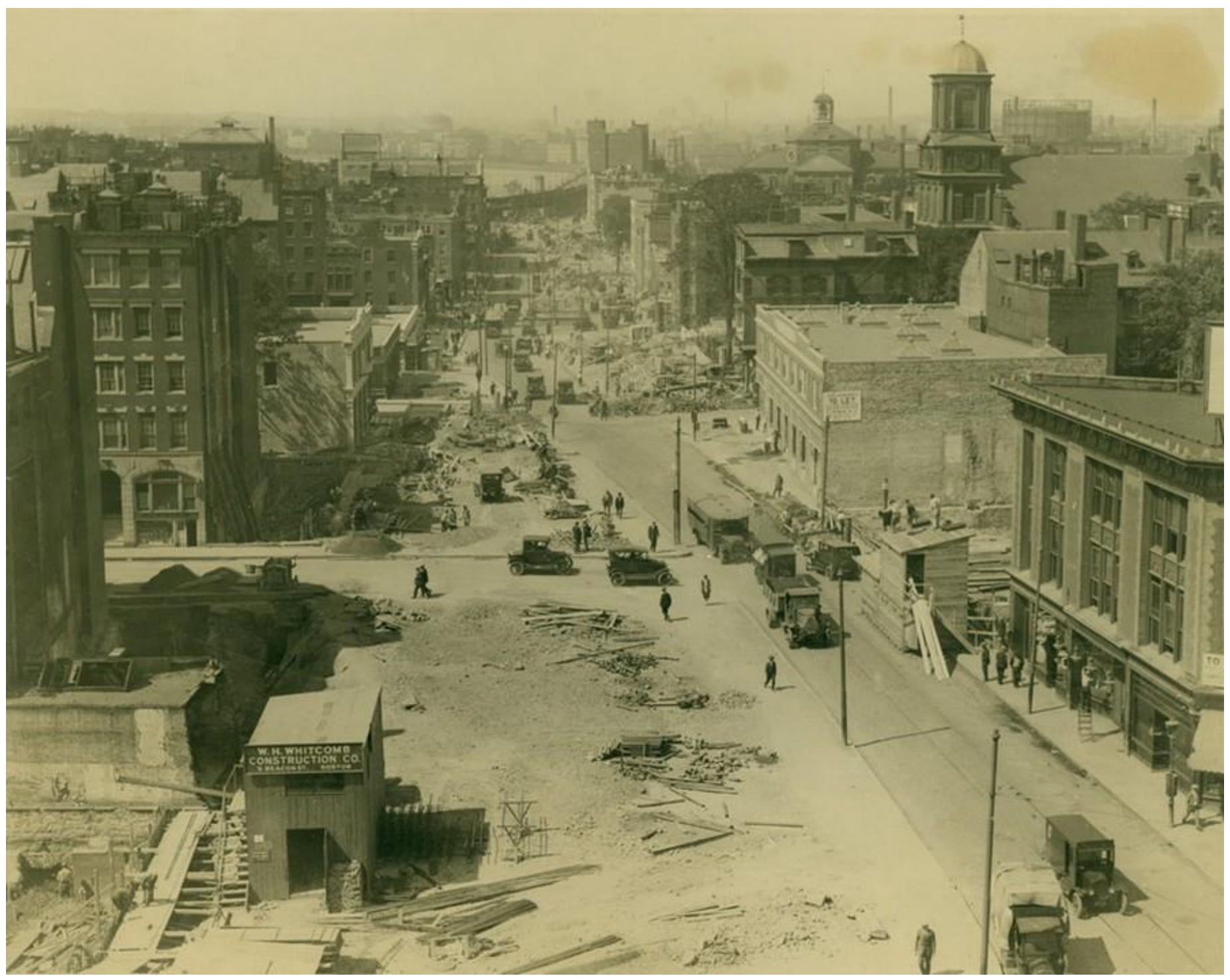

Figure 4-10. Cambridge Street widening, looking west. Photograph by Leslie Jones. Courtesy of Historic New England. 


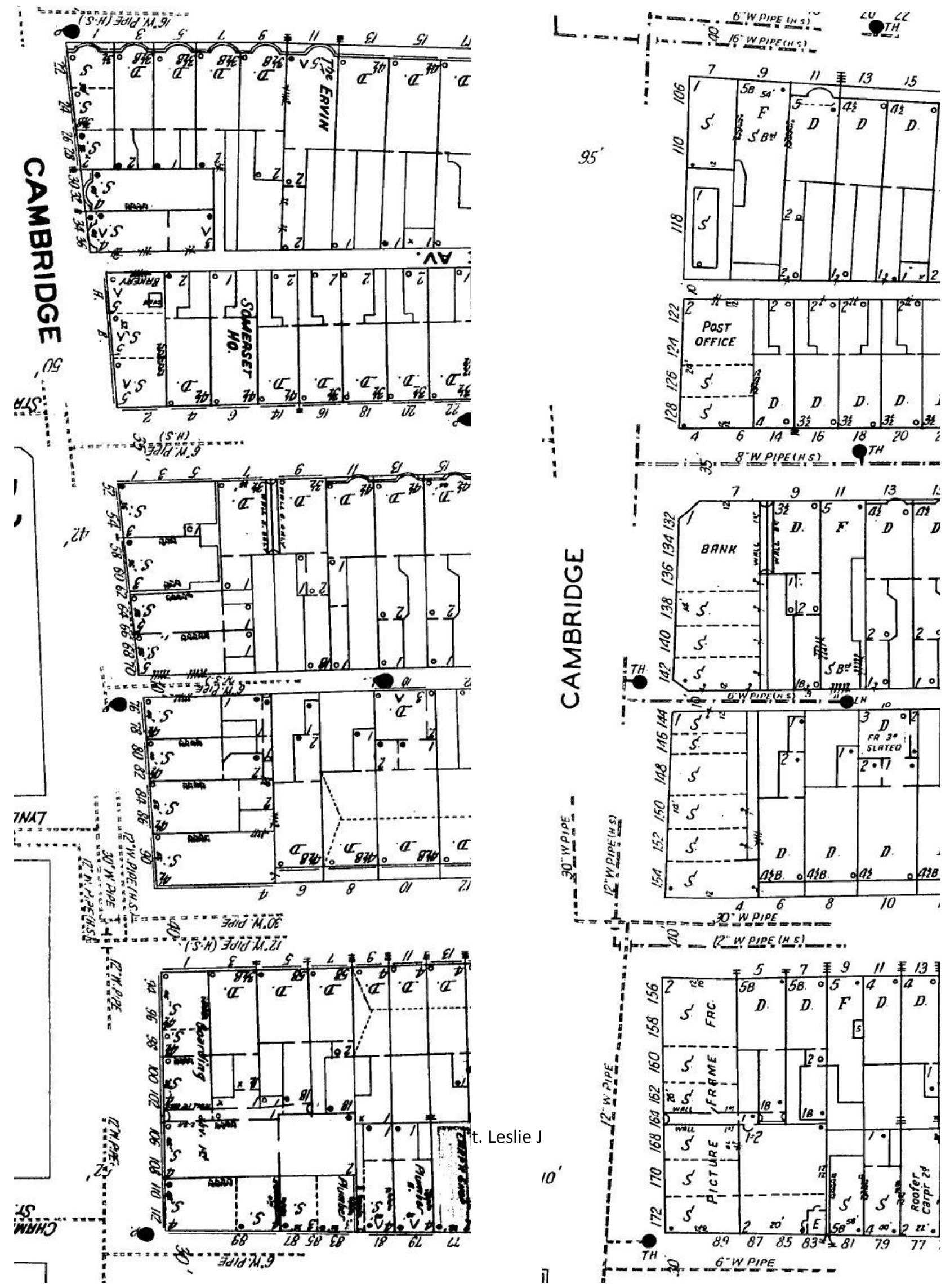

Figure 4-11. South side of Cambridge Street from Joy to Bowdoin Street in 1909. Sanborn Fire Insurance Company.

Figure 4-12. South side of Cambridge Street from Joy to Bowdoin Street in 1929. Sanborn Fire Insurance Company. 


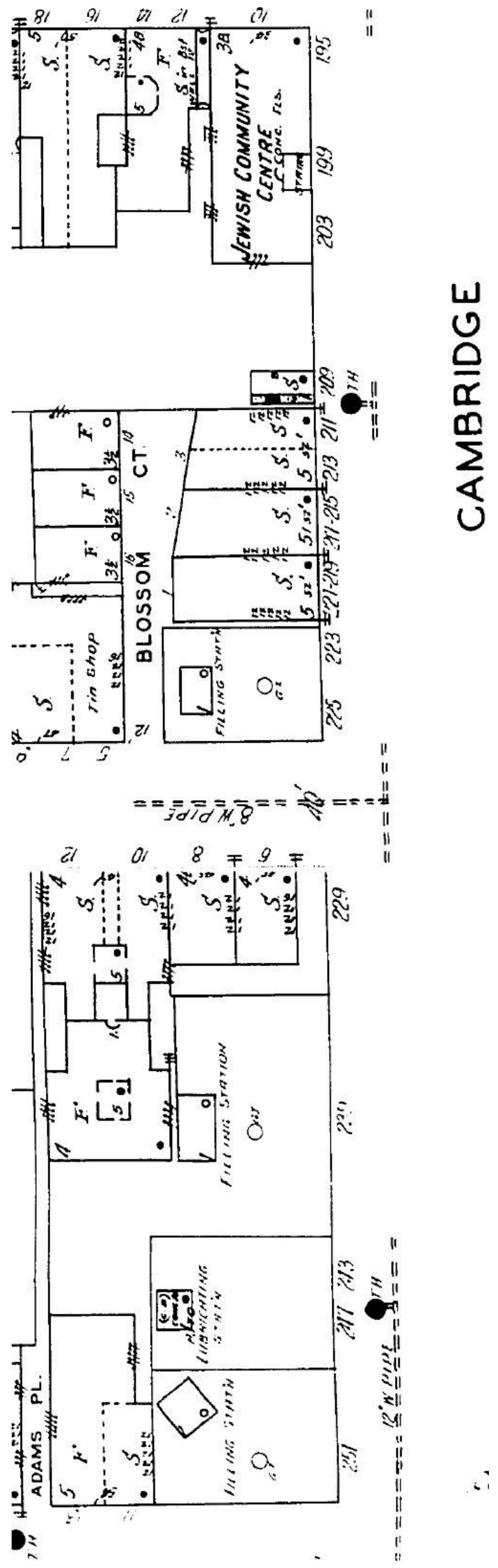

Figure 4-13. North side of Cambridge Street from North Anderson Street to North Russell Street in 1929, showing three gas stations, a facility for oil changing and a vacant lot. Sanborn Fire Insurance Company. 


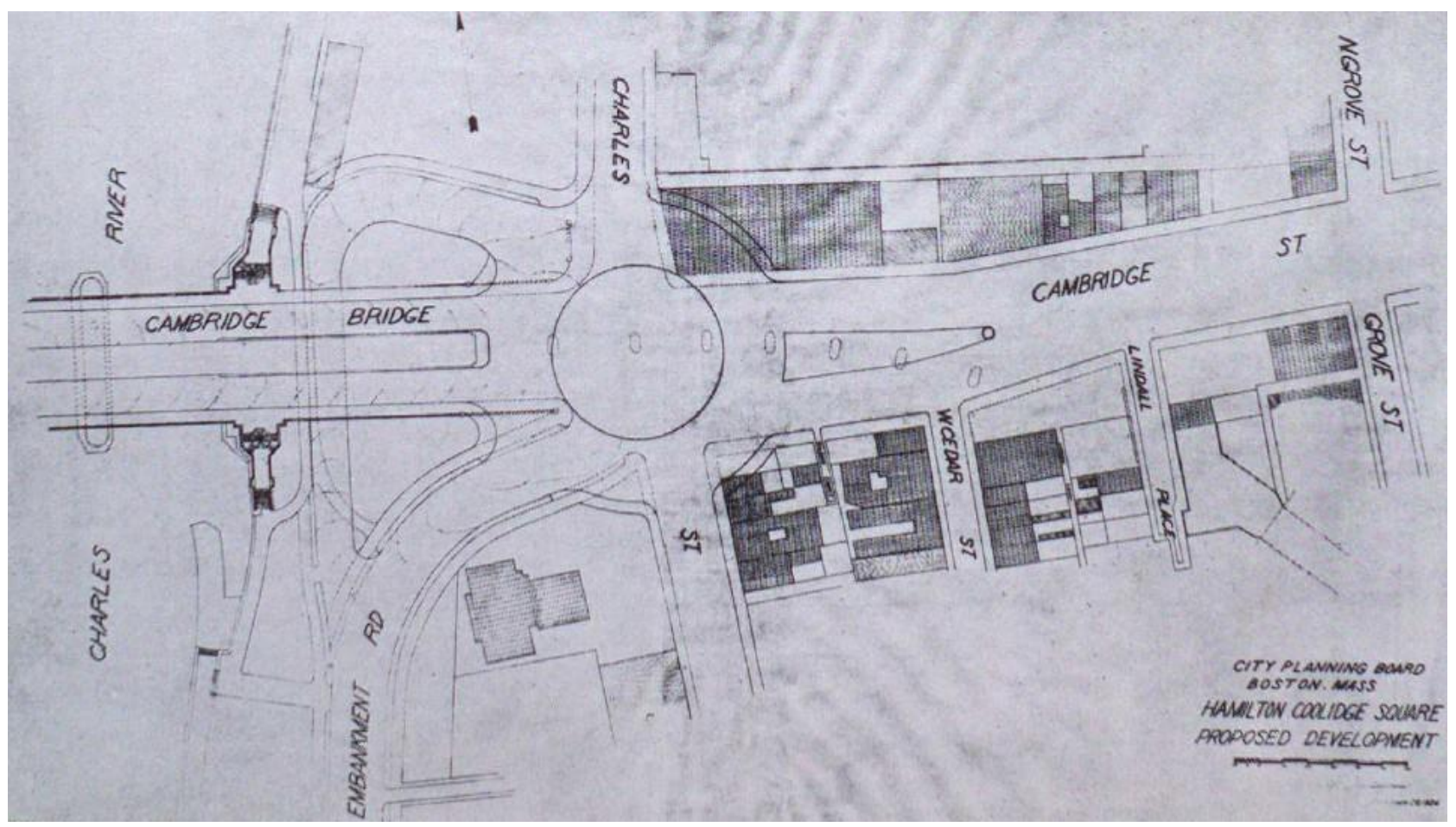

Figure 4-14. Plan for a rotary at the intersection of Charles and Cambridge Street, 1926. Boston City Planning Board, Thirteenth Annual Report, 29. 


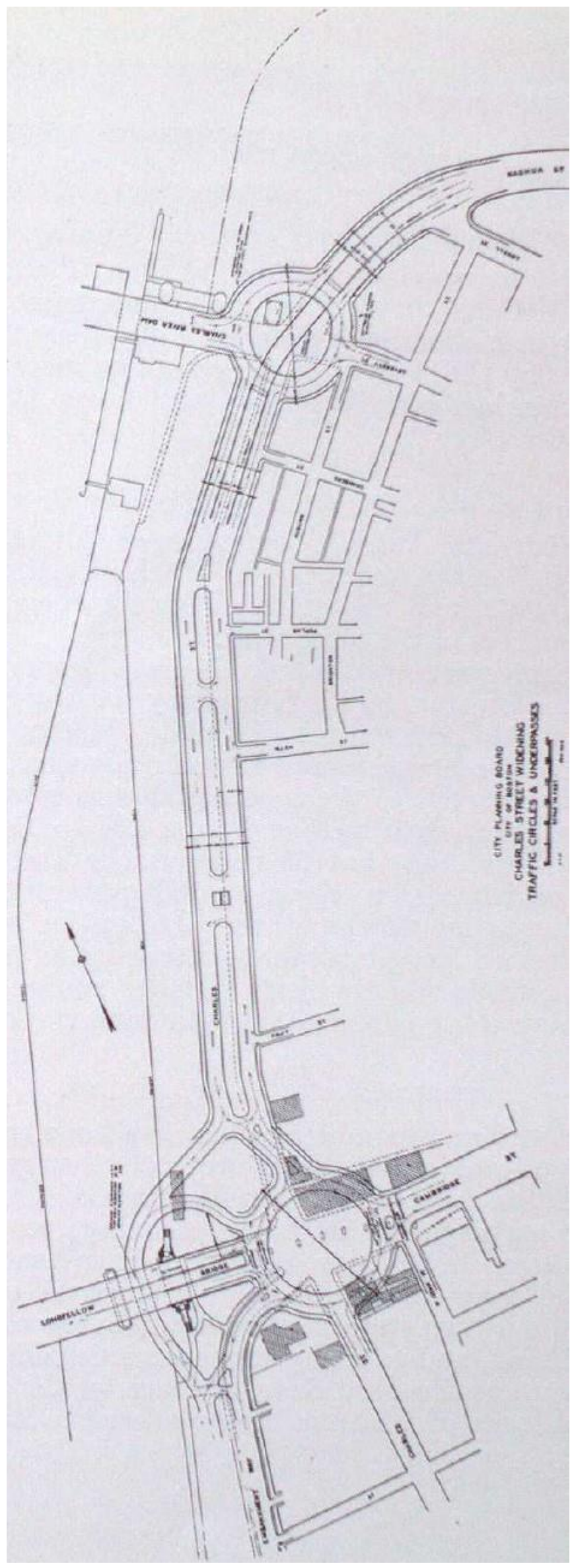

Figure 4-15. Plan for the widening of Charles Street north of Cambridge Street and the creation of traffic rotaries, 1929. Boston City Planning Board, Sixteenth Annual Report, 11. 


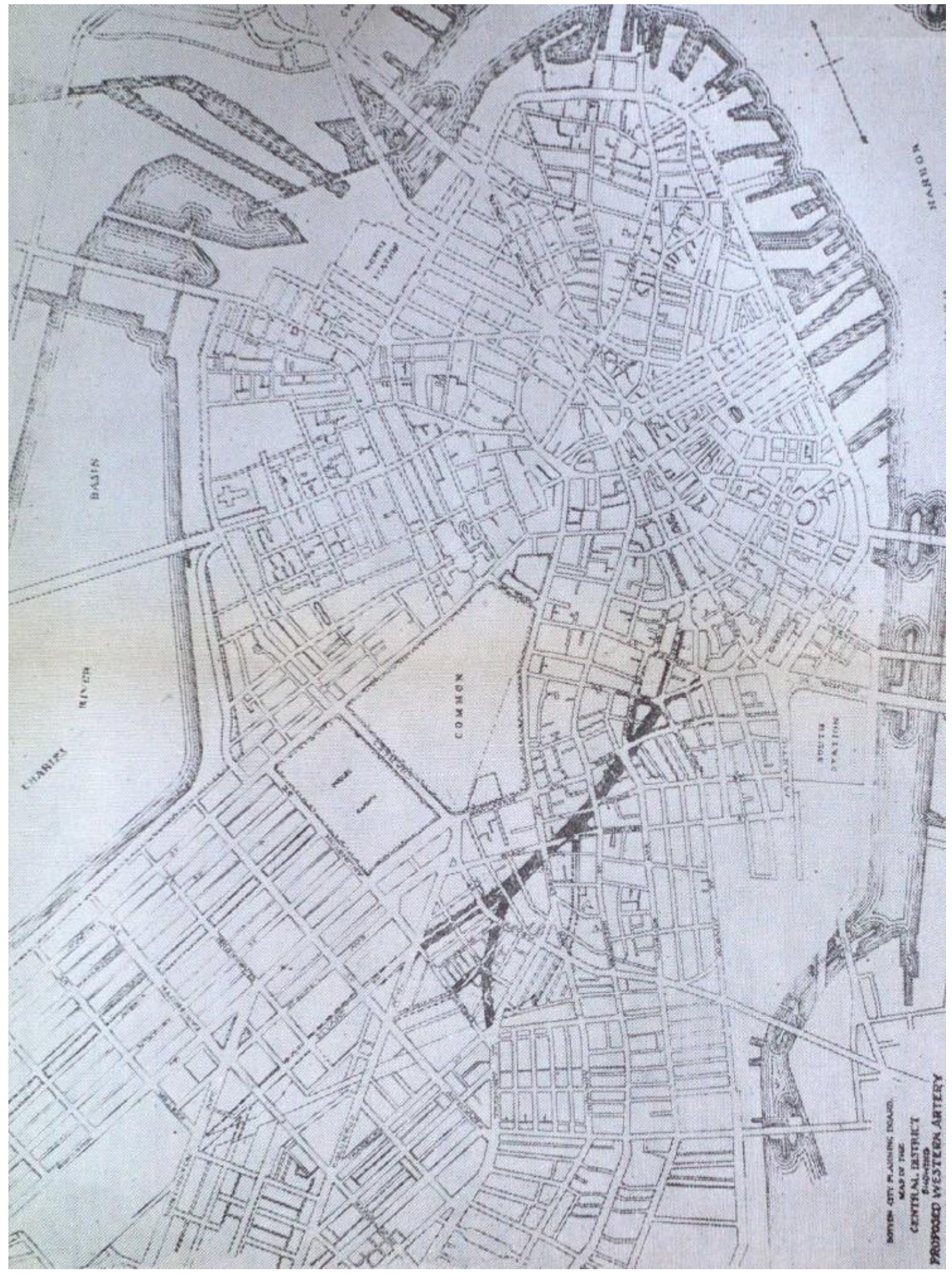

Figure 4-16. Original Western Artery proposal. Boston City Planning Board, Third Annual Report, map opposite page 22. 


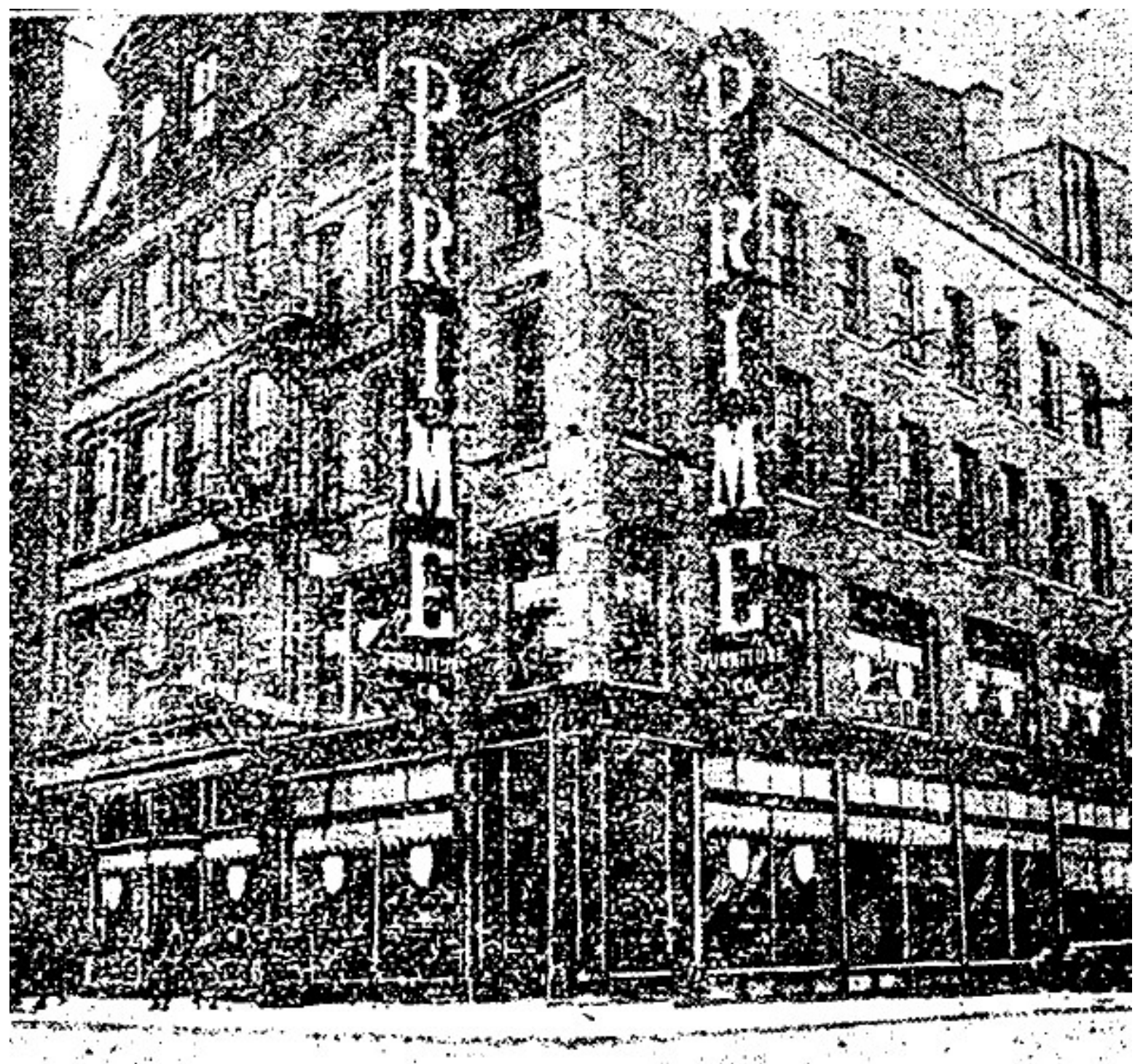

Figure 4-17. The Prime Furniture Company's new corner location at the intersection of Stuart Street and Washington Street. "Remodeled Store of the Prime Furniture Co Opened," Boston Globe, April 17, 1923, 5. 


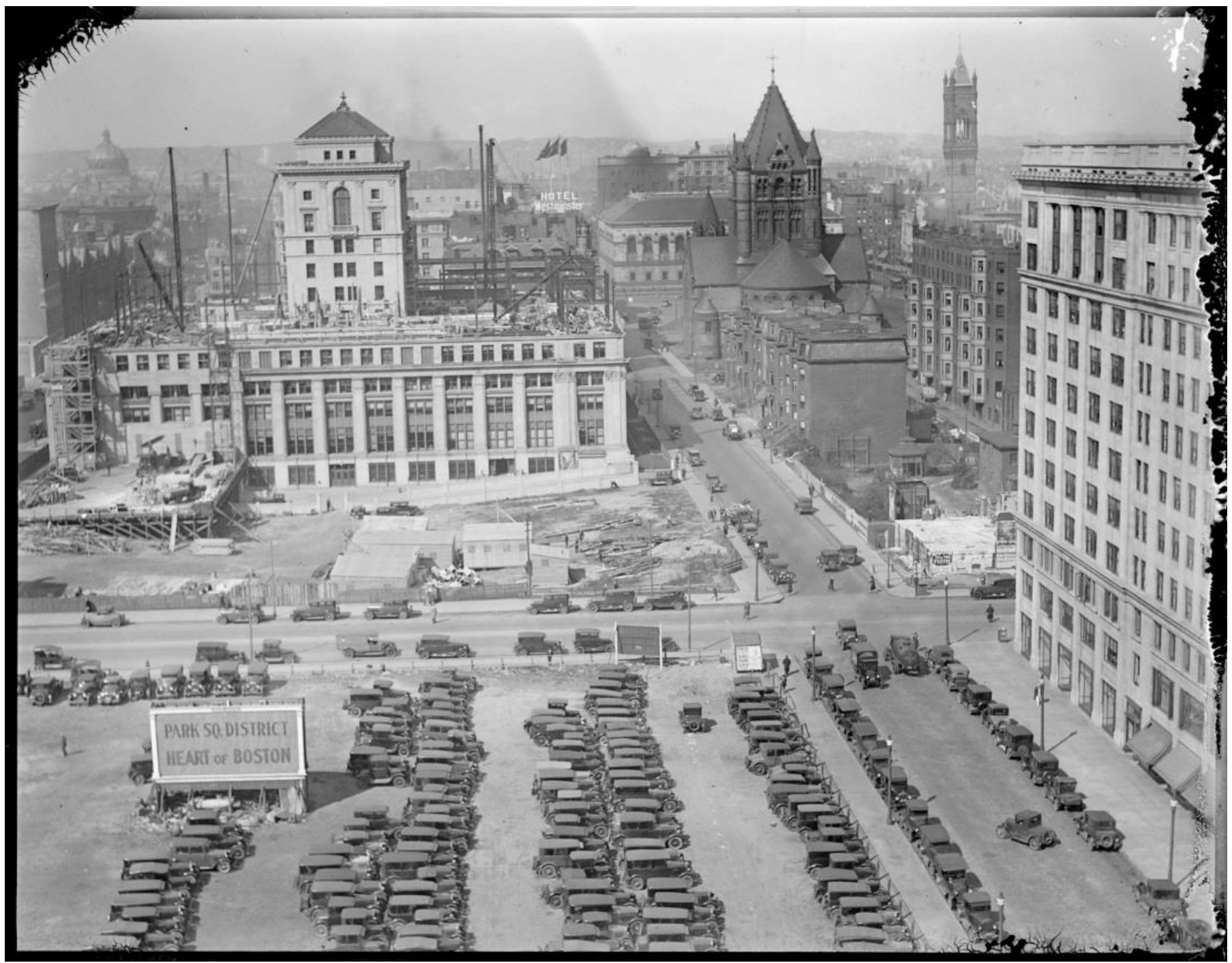

Figure 4-18. The John Hancock Building is in the left middle ground. Stuart Street runs along its left side and St. James Avenue runs along its right. Trinity Church and the Boston Public Library, both at Copley Square, are visible in the background. Photograph by Leslie Jones, 1920s. Courtesy of the Boston Public Library. 


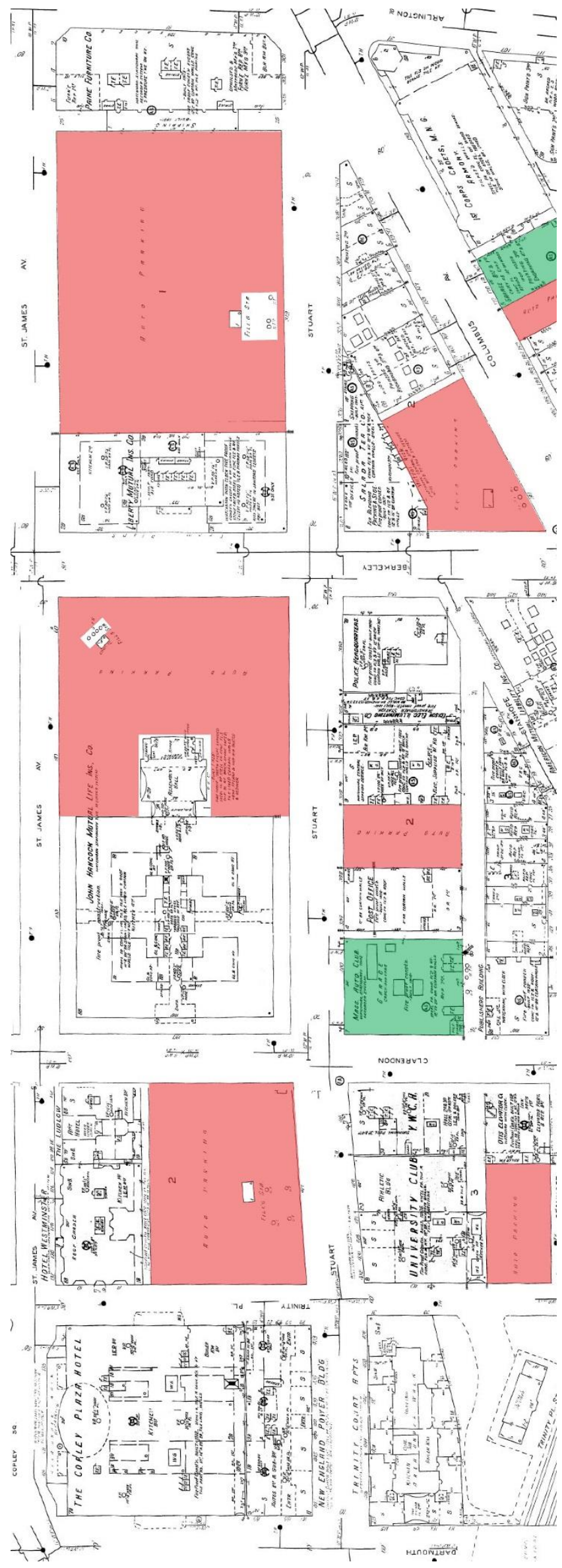

Figure 4-19. Composite image taken from plates 214, 215 and 216 of the 1936 Sanborn Atlas showing Stuart Street from Arlington to Dartmouth Street in the Back Bay. Open-air parking lots are shown in red, while parking garages are shown in green. 


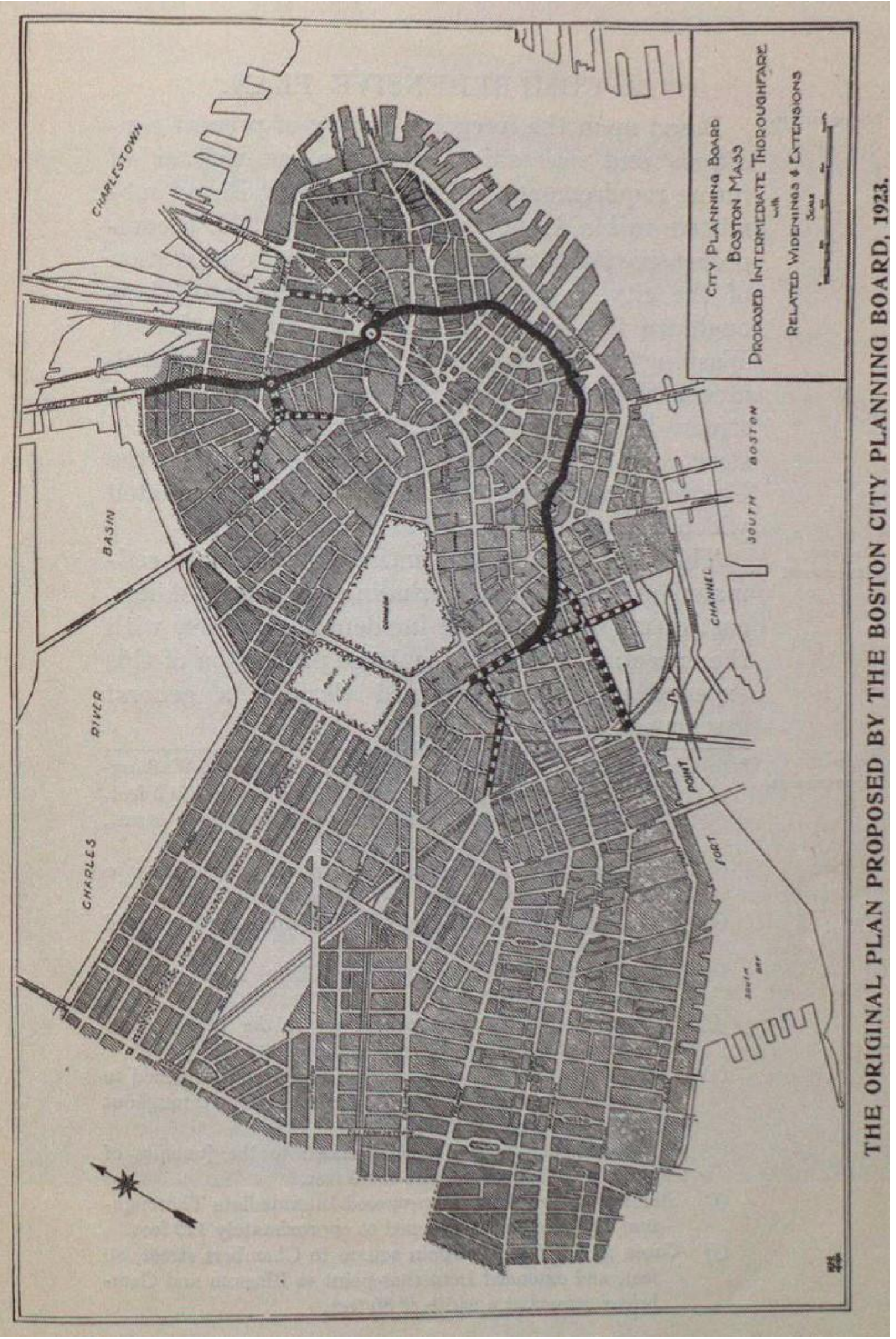

Figure 4-20. The Intermediate Thoroughfare Plan from 1923. Reproduced in Progress Report on Proposed Intermediate Thoroughfare, 9. 


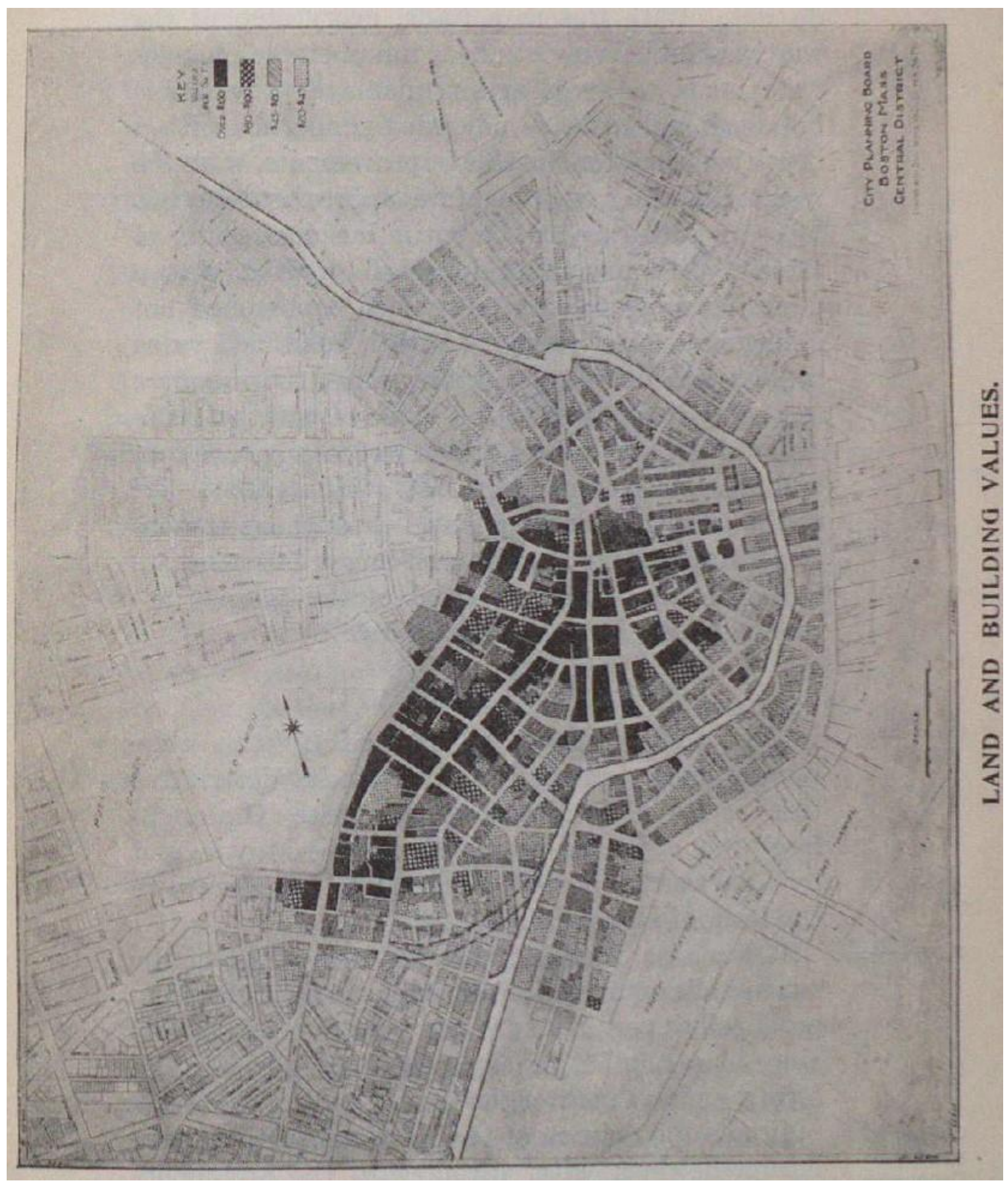

Figure 4- 21. Map prepared by the City Planning Board showing property values. The darker fills represented the most expensive property. Progress Report on Proposed Intermediate Thoroughfare, 11. 


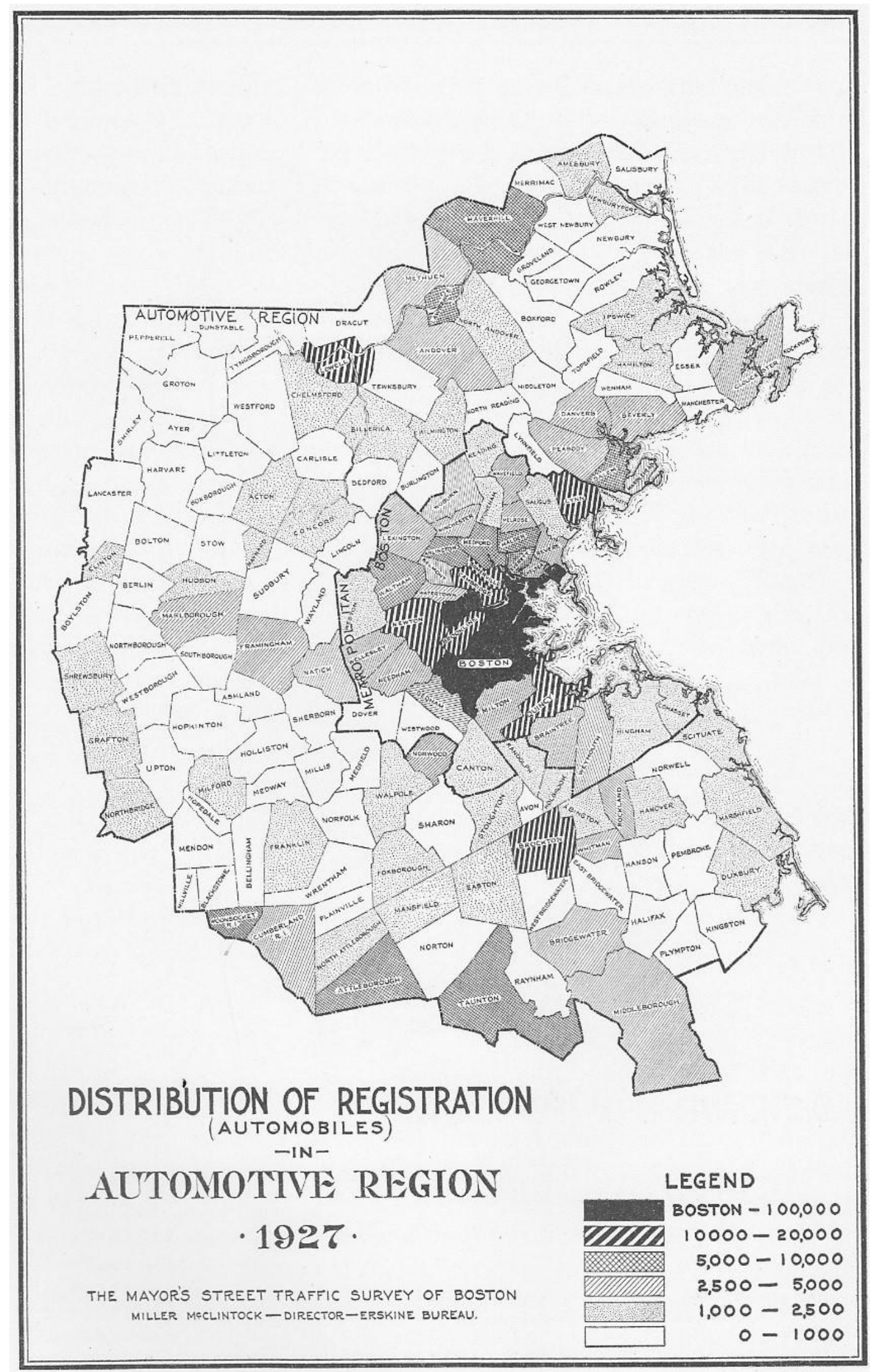

Figure 4-22. The automotive and metropolitan regions of Boston. McClintock, Street Traffic Control Problem, 42. 


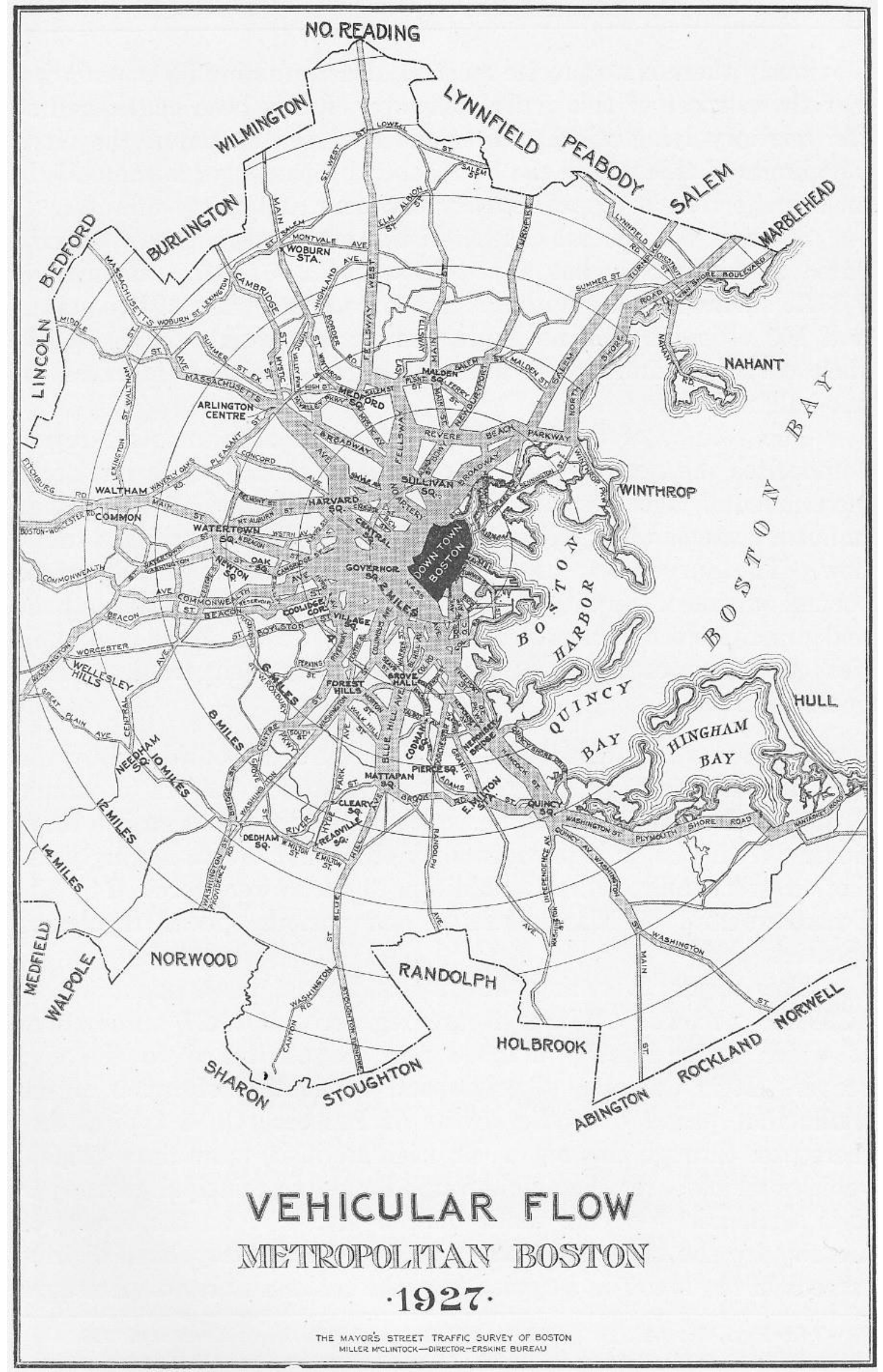

Figure 4-23. Assessment of regional traffic patterns. McClintock, Street Traffic Control Problem, 44. 


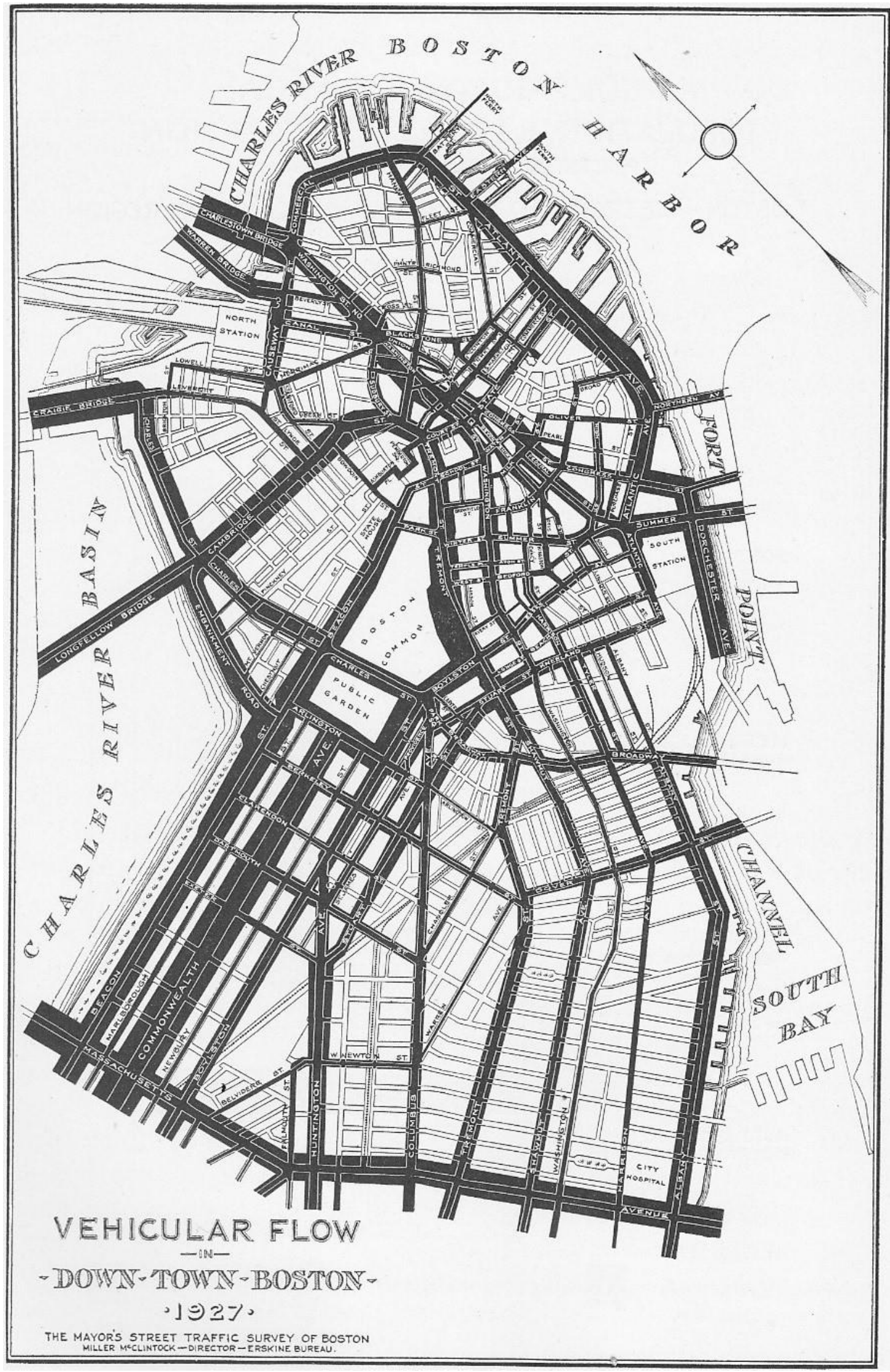

Figure 4-24. Map showing distribution of traffic in downtown Boston. McClintock, Street Traffic Control Problem, 68. 


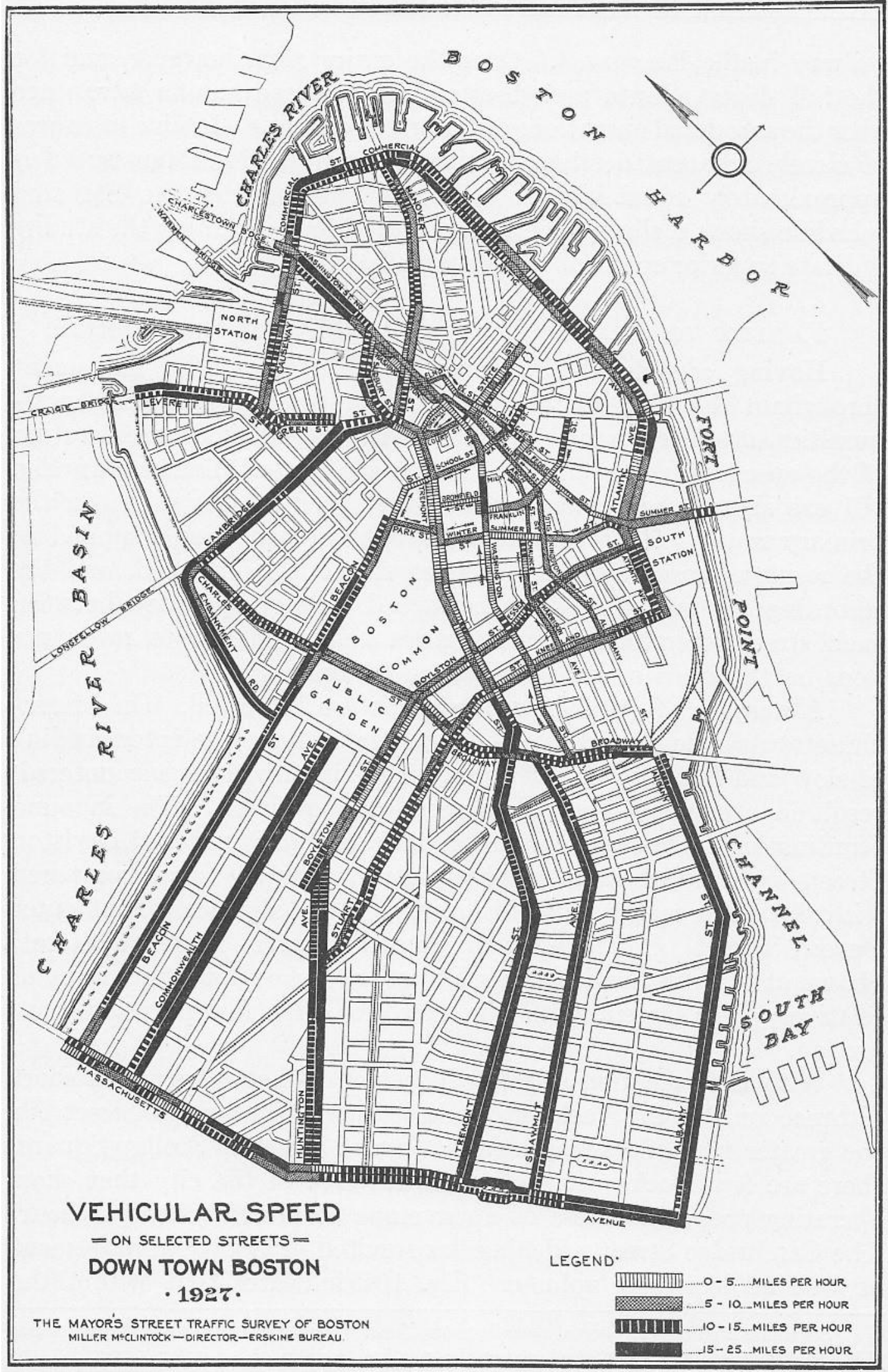

Figure 4-25. Map showing speeds of vehicular traffic on select streets. McClintock, Street Traffic Control Problem, 101. 


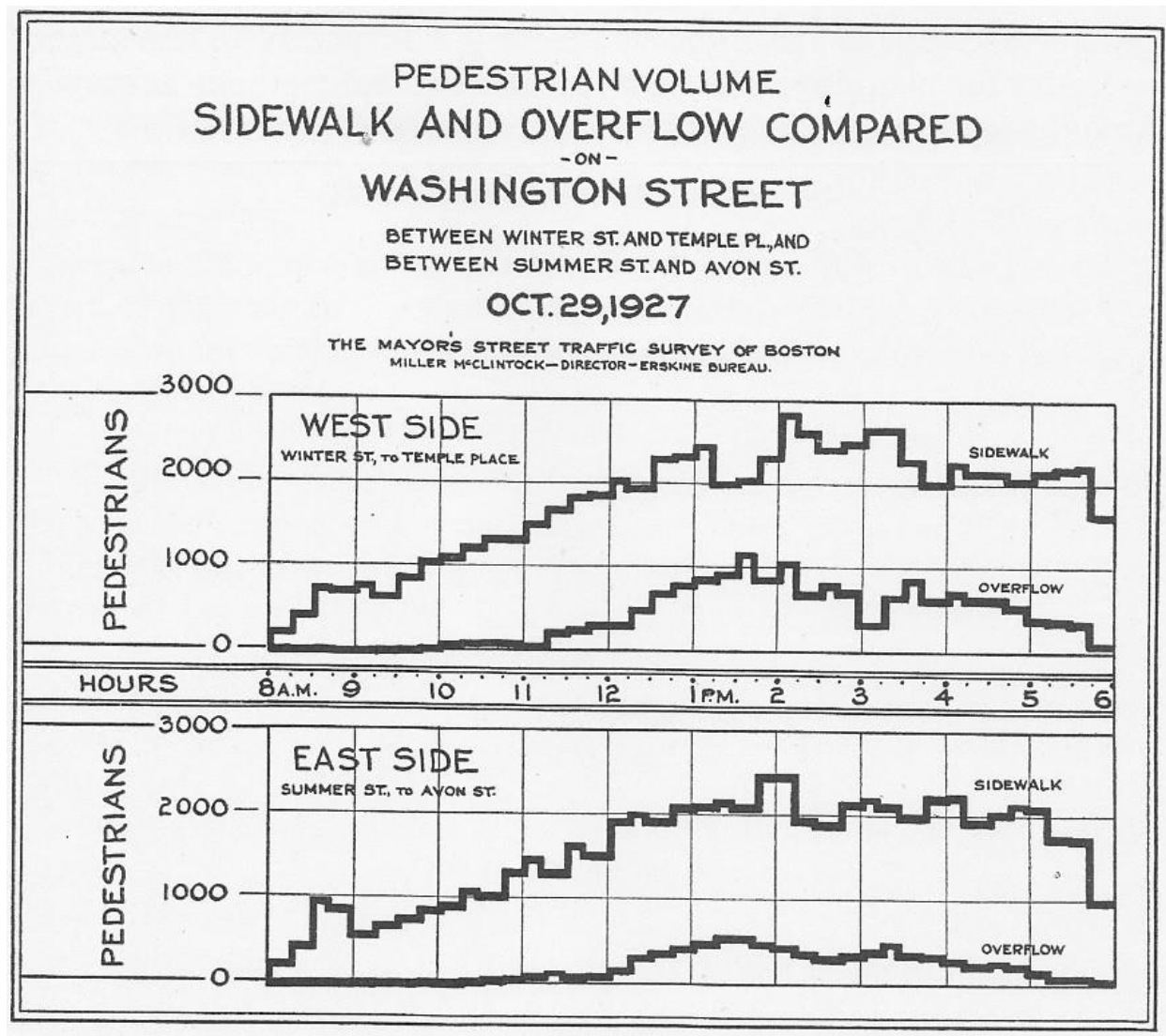

Figure 4-26. Diagram of pedestrian volume on Washington Street. McClintock, Street Traffic Control Problem, 107.

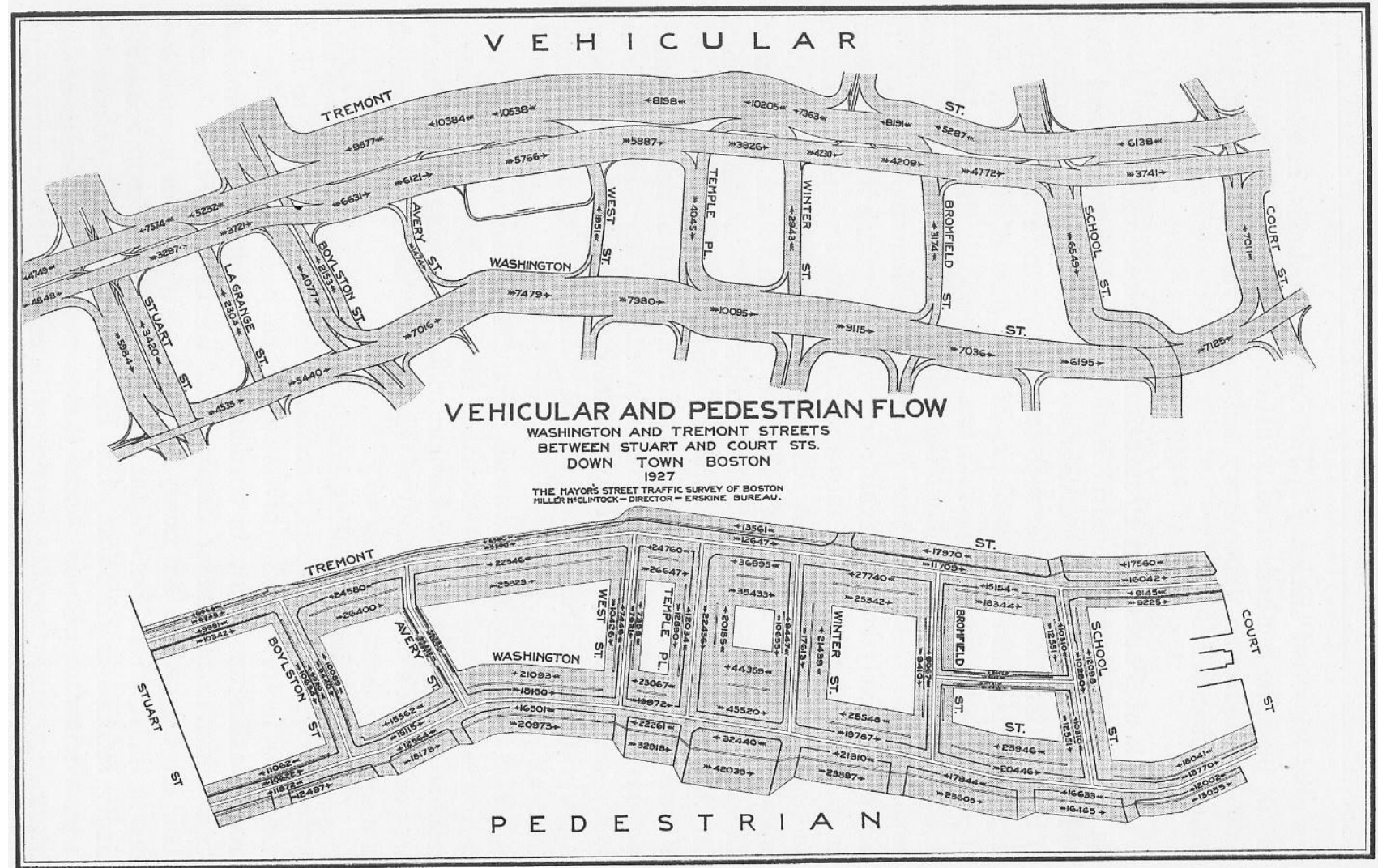

Figure 4-27. Diagram of vehicular and pedestrian traffic in the retail district. McClintock, Street Traffic Control Problem, 200. 


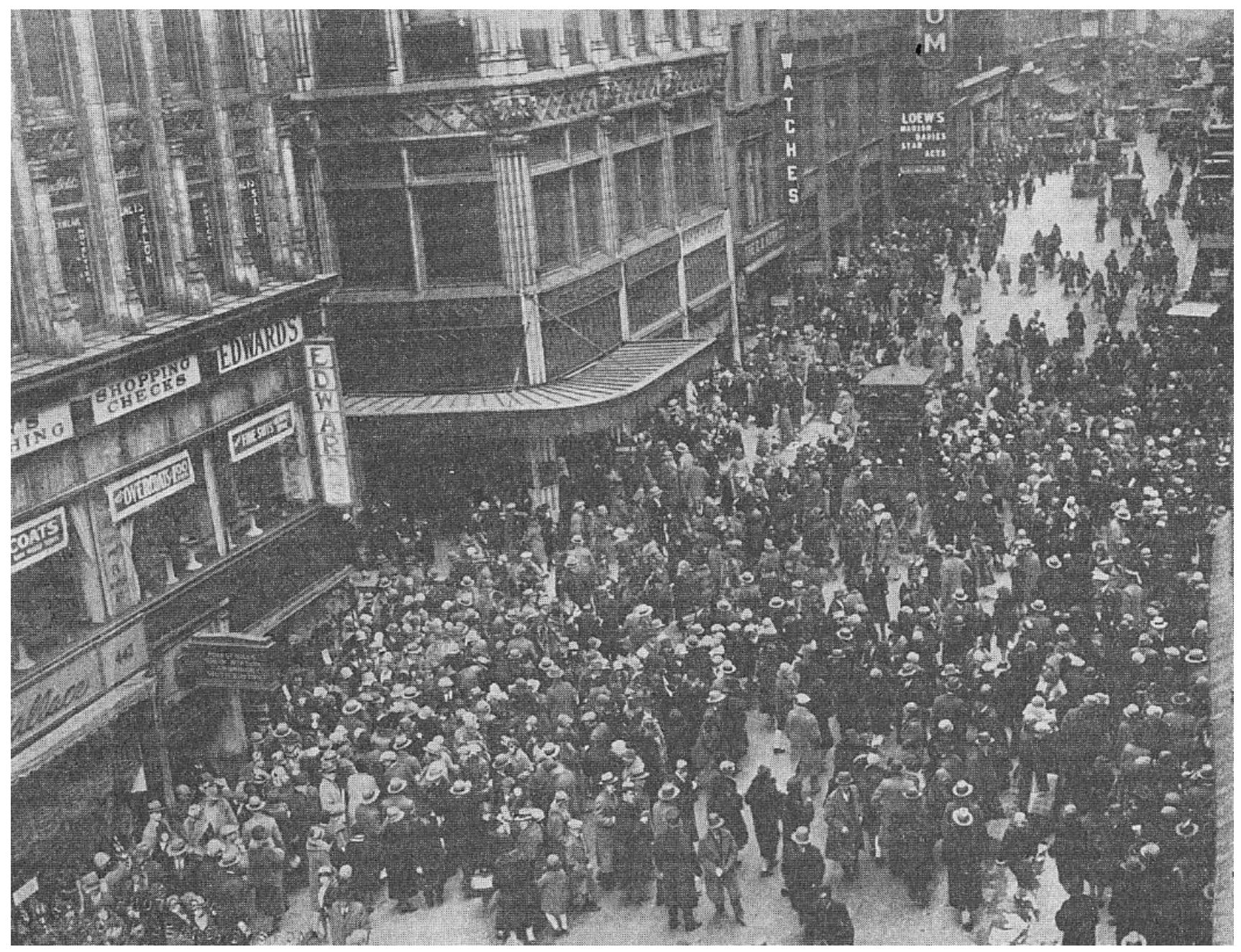

Figure 4-28. Pedestrian crowds in the retail district. Note the traffic tower in the midst of the intersection. McClintock, Street Traffic Control Problem, 205. 


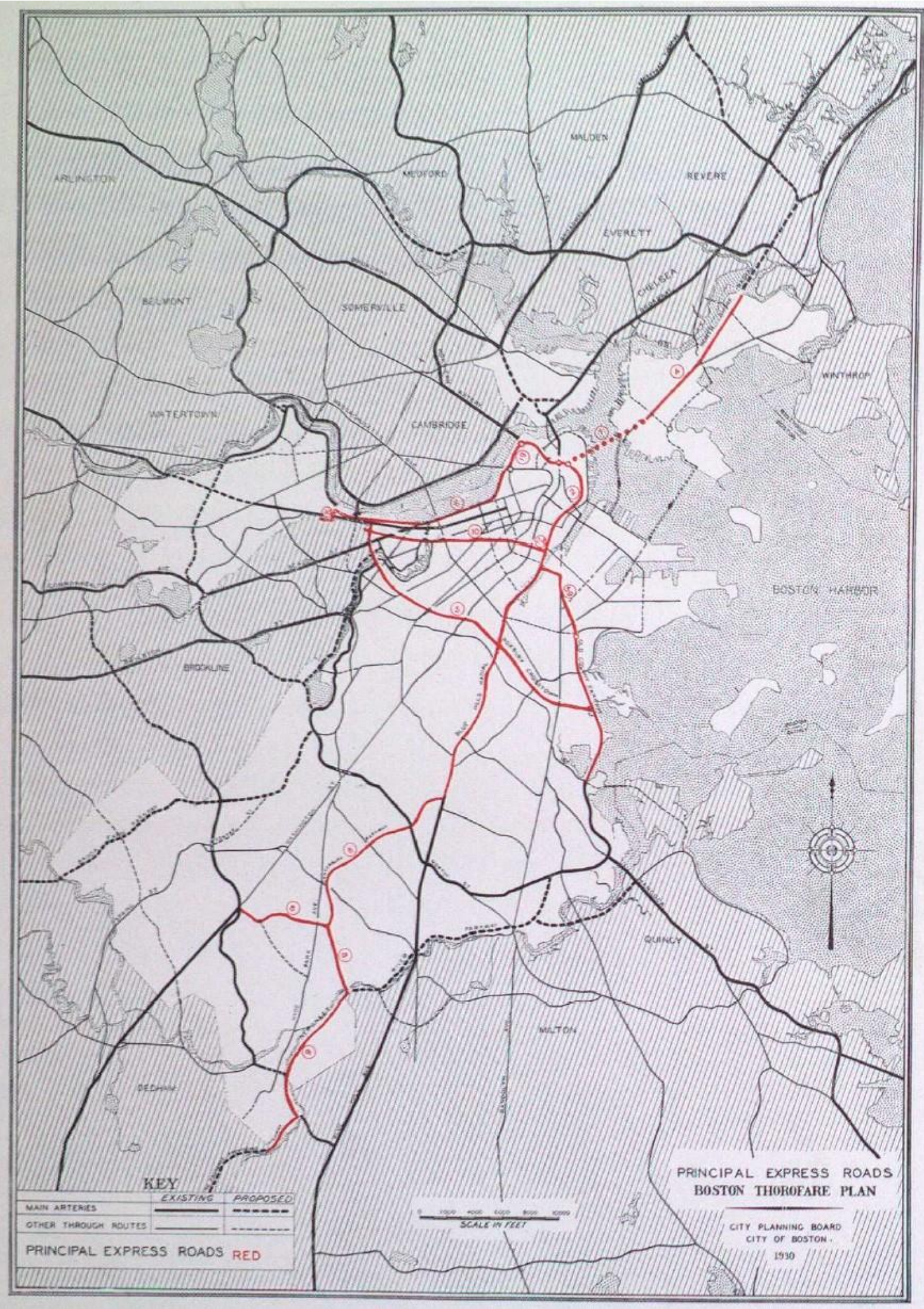

Figure 4-29. Thoroughfare plan for Boston, 1930. Whitten and the Boston City Planning Board, Report on a Thoroughfare Plan for Boston, 14. 


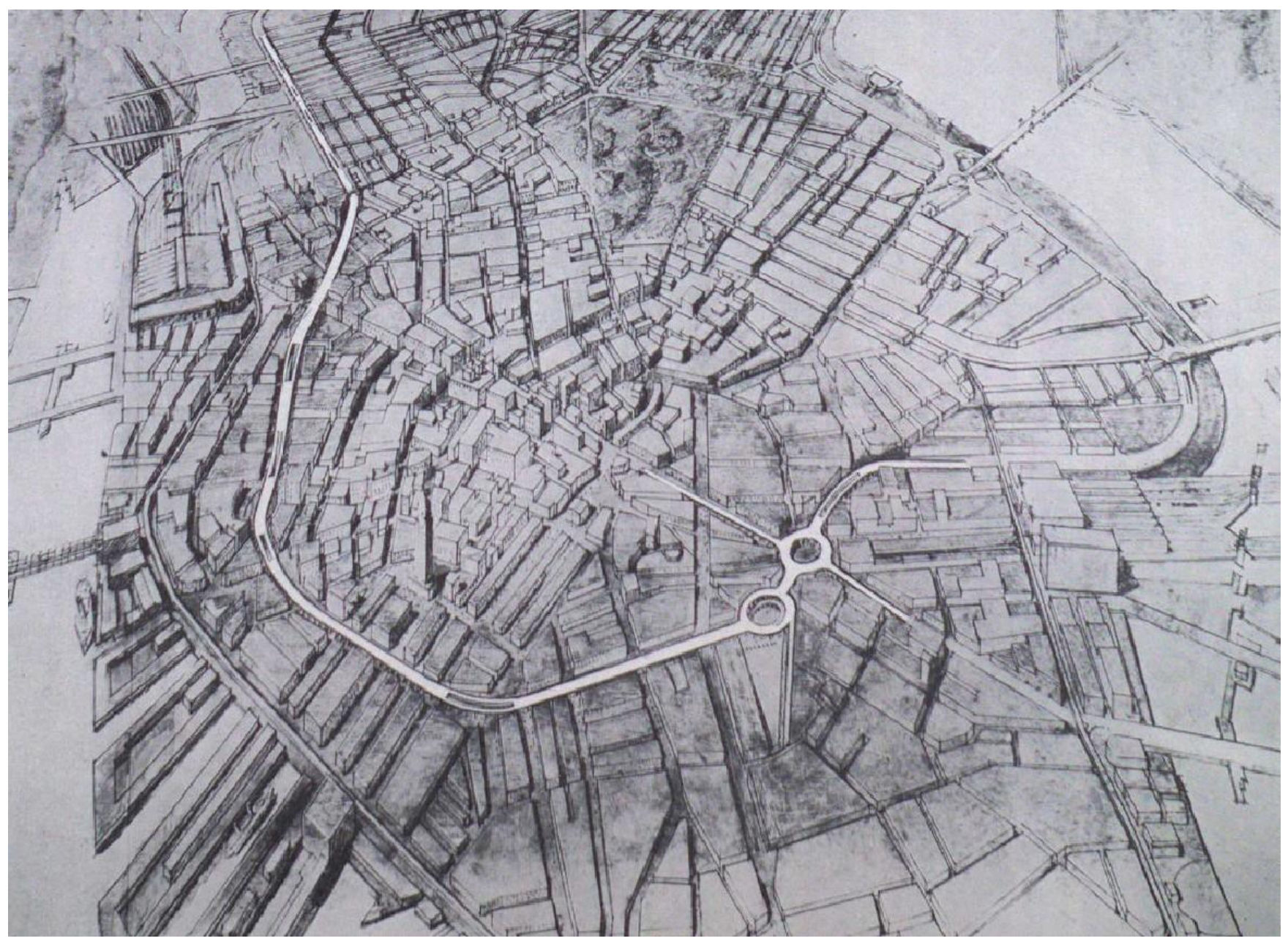

Figure 4-30. Route of the Central Artery, bird's-eye from the north. Whitten and the Boston City Planning Board, Report on a Thoroughfare Plan for Boston, 81. 


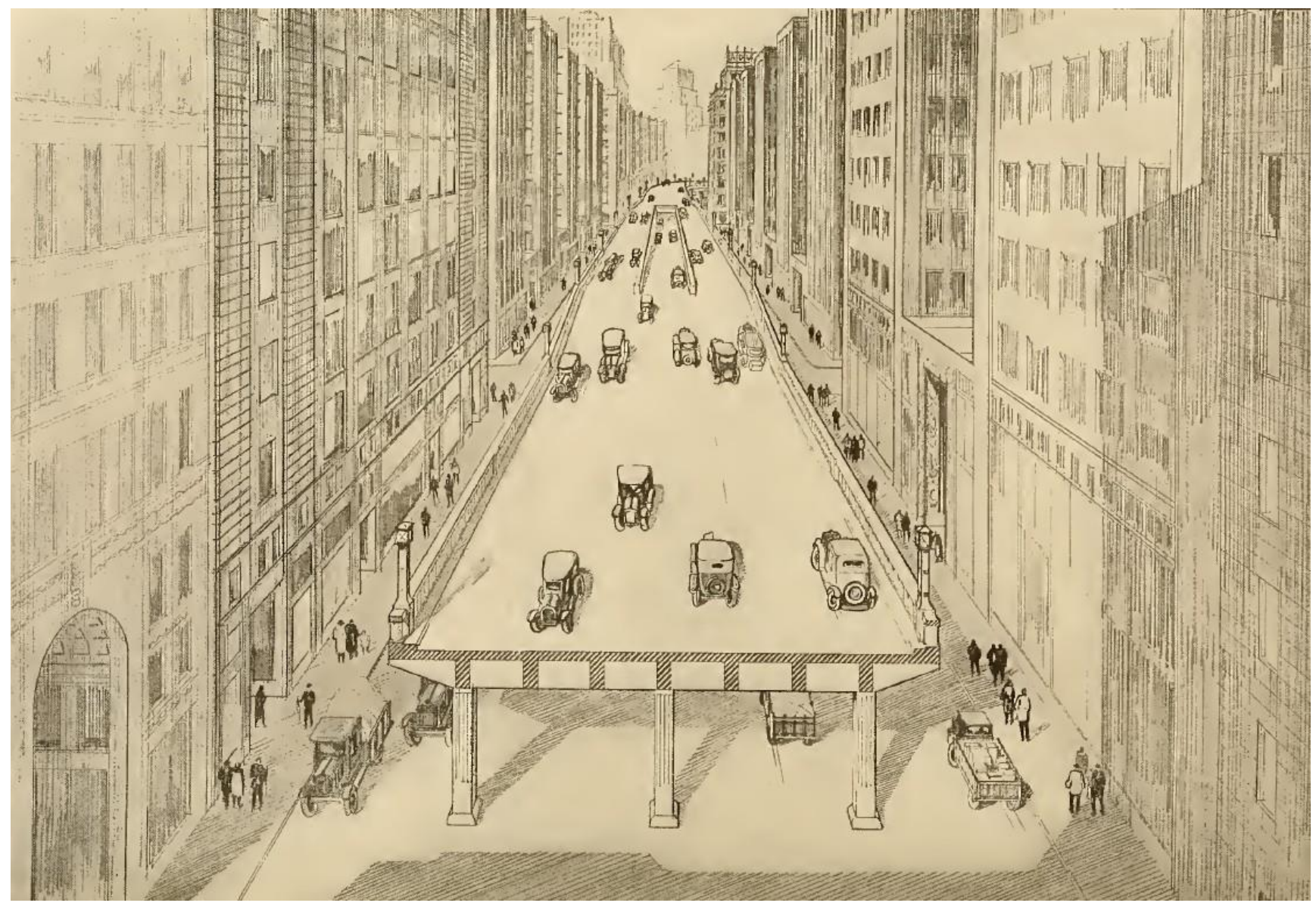

Figure 4-31. Rendering of the raised central artery, 1930. Whitten and the Boston City Planning Board, Report on a Thoroughfare Plan for Boston, 84. 


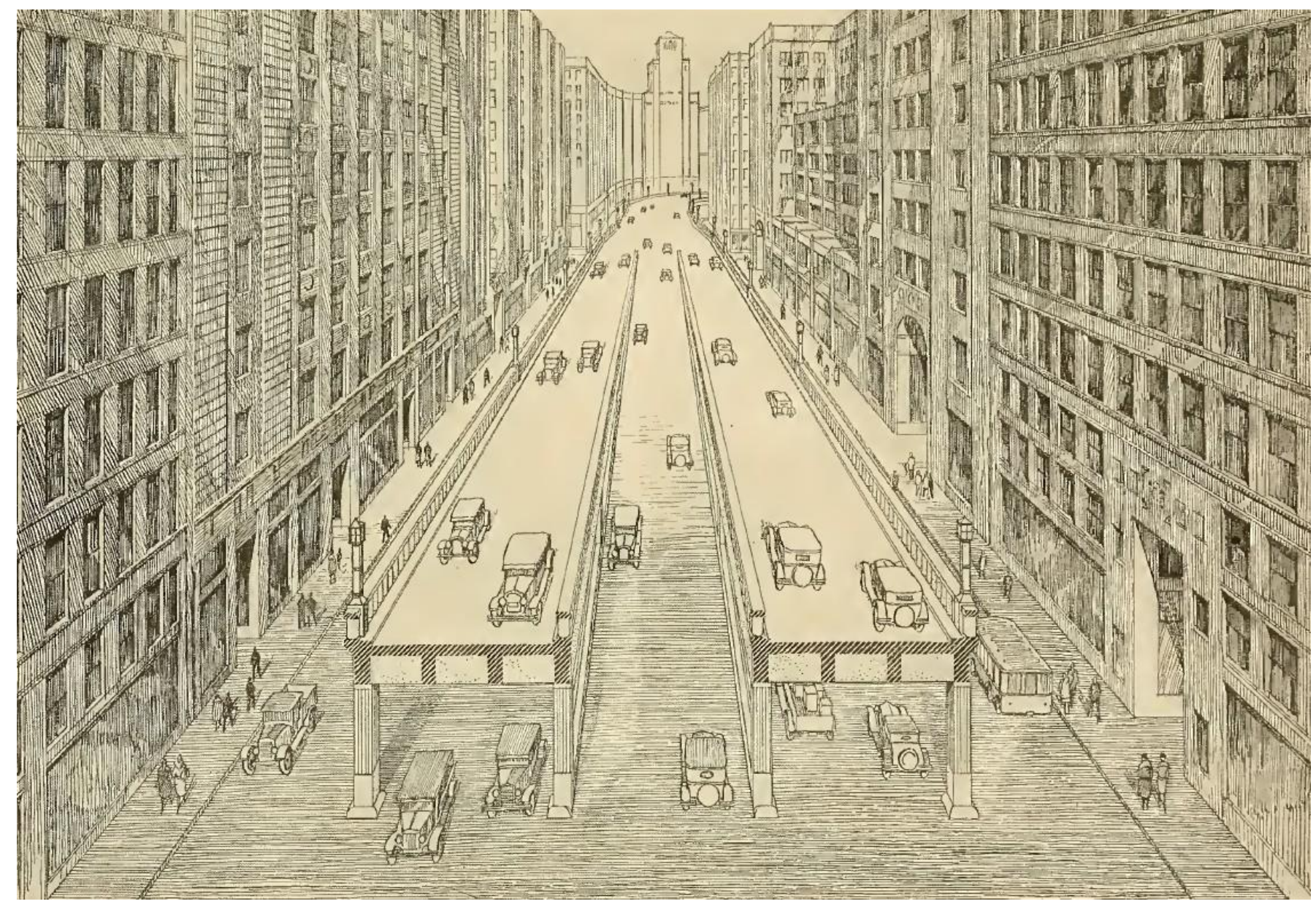

Figure 4-32. Rendering of the raised central artery, 1930. Whitten and the Boston City Planning Board, Report on $a$ Thoroughfare Plan for Boston, 85. 


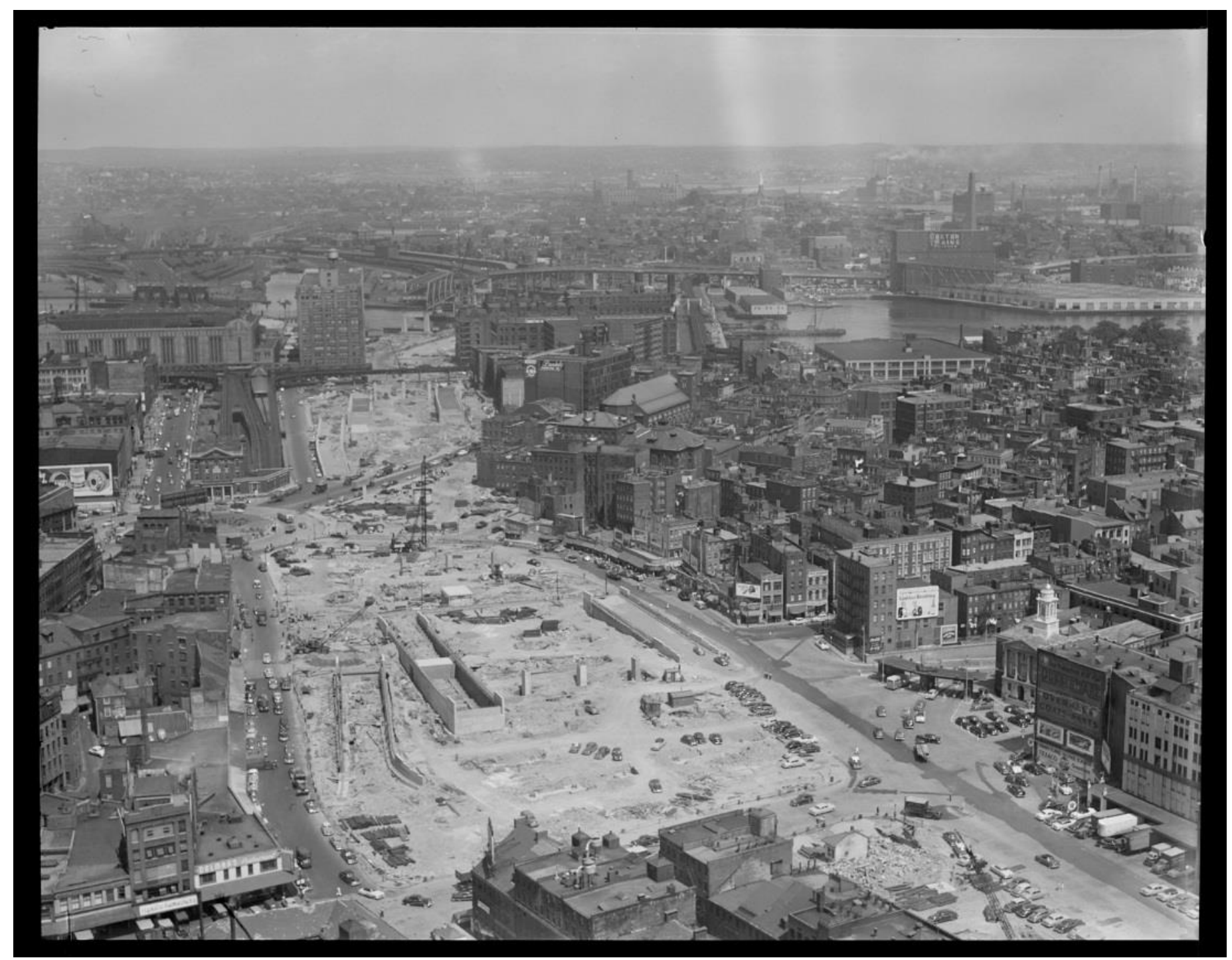

Figure E-1. The Central Artery under construction in the 1950s. Photograph by Leslie Jones. Courtesy of the Boston Public Library. 


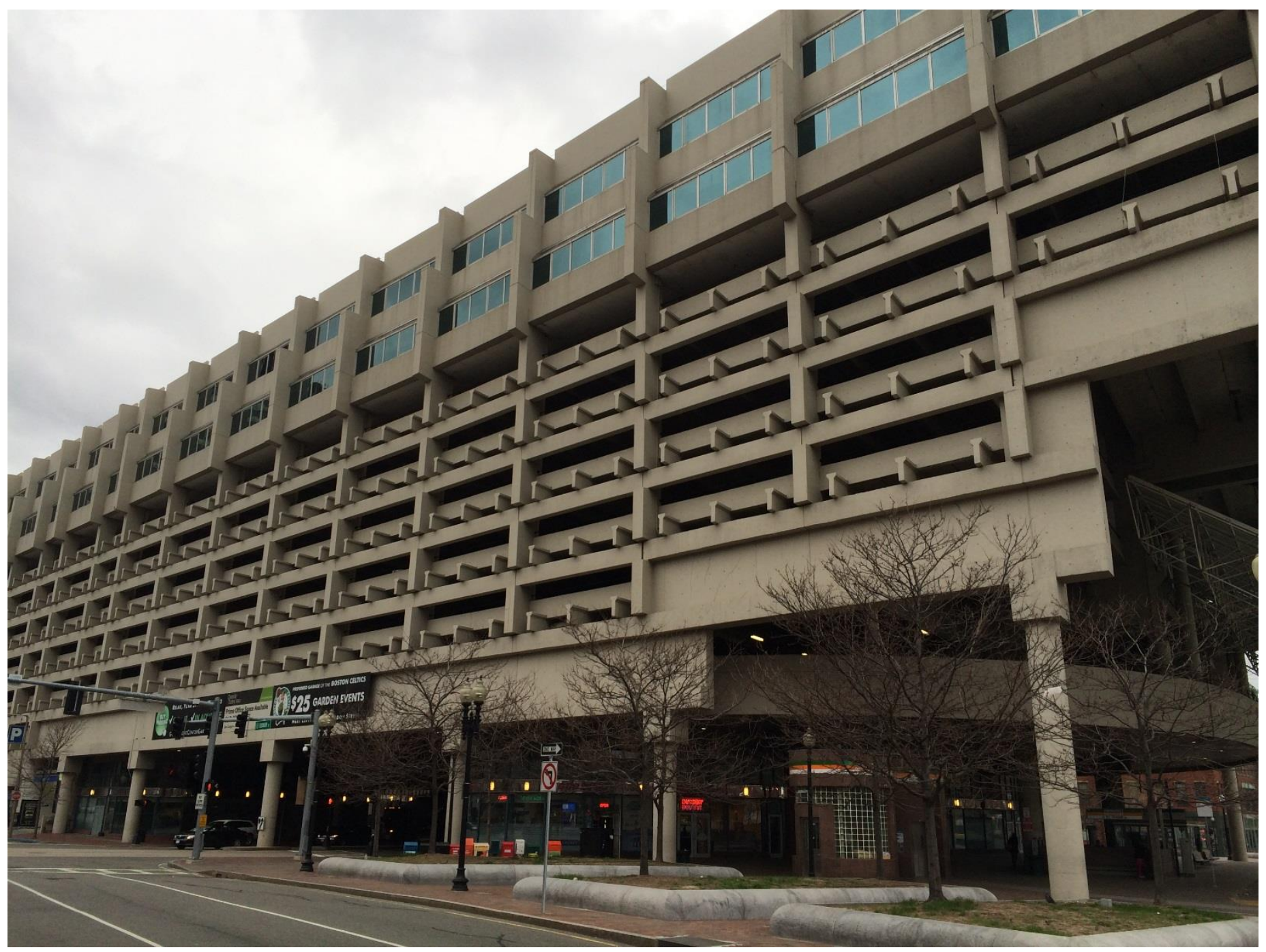

Figure E-3. The Government Center Garage as viewed from New Sudbury Street. Designed by Kallmann, McKinnell \& Knowles, 1970. Photograph by George Gilpatrick. 